
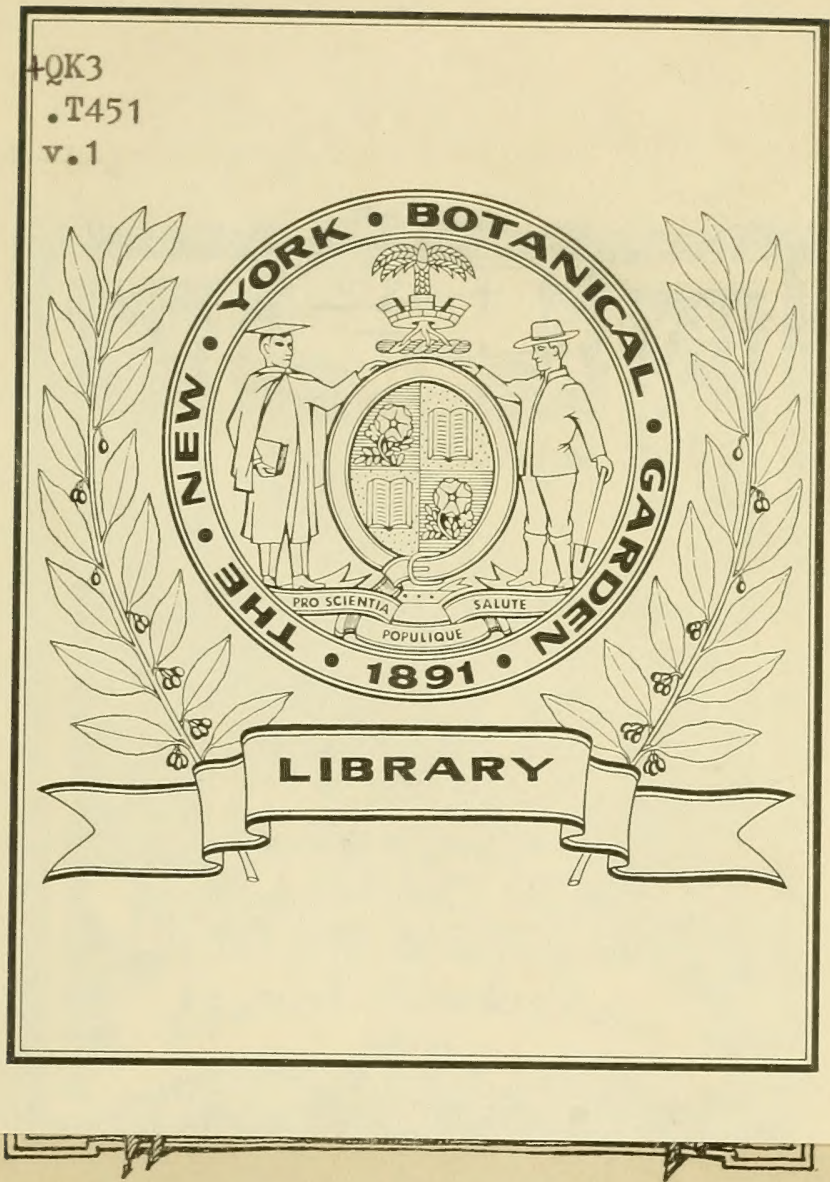




\section{TABII OF CONYENTSS.}

1. De Gardenia.

2. De Protea.

3. Oxalis

$\checkmark$ 4. Nova genera plantarum.

5. Iris.

6. Ixia.

7. Gladiolus.

8. De Aloë.

9. De medicina Africanorum.

10. De Erica.

11. Ficus genus.

12. De Moraea.

13. Restio.

14. Arbor toxicaria macassariensis.

15. De Myristica.

16. De Caryophyllis aromaticis.

14. De Moxae atque ignis in medicina rationaly 
T T451

$v_{1} 1$ 


\section{DISSERTATIO BOTANICA}

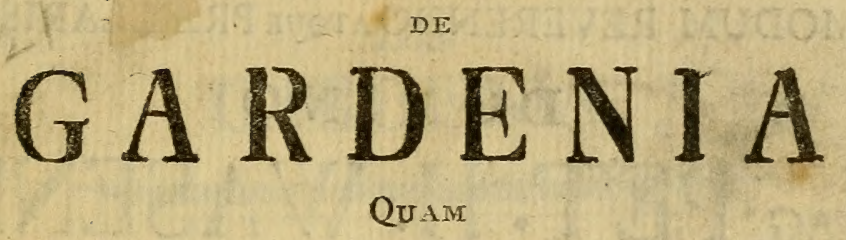

CONSENSU EXPERIENT. FAC. MED. UPSAL.

PUBLICE VENTILANDAM EXHIBENT.

\section{P R E S E S}

\section{CAROL.P. THUNBERG,}

MED. DOCT. BOTAN. DEMONSTR. ACAD. REG. SCIENT. HOLMIENS. CASAR, NAT. CUR. SOCIET, SCIENT. UPSAL. LUNDIN, AMSTELD, ET NIDKOSIENS. MEMBRUM.

\section{ET \\ RES PONDEN S}

Stipendiarius Regius

\section{PETRUS DJUPEDIUS,} MGDELPADO-JENTLANDUS.

In Aud. Gustay, Maj. Die xvi Dec. mdcclxxx. Horis Solitis

$$
\text { UPS A LI } \mathbb{E} \text {, }
$$

TYPIS JOHAN. EDM.AN, DIRECT. ET REG. ACAD, TYPOGR. 


\section{DOM I N O}

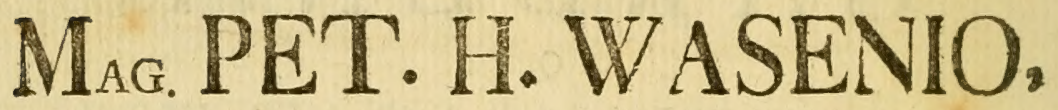

PASTORI in Torp et Borgsjó Vigilantissimo et Adjacentium Ecclesiarum PR RePOSITO LAUBATISSIMO!

\section{Parenti Atatem Colendo!}

unm voto diu expetii, letiflimus arripio occafionem, ut immenfum debitum Parenti optinso, ita et gratifiname mentem pectore calenti reconditam palam faciendi. Tua vero. in me, vel inde $a b$ eo tempore, quo naturali Paire orbato, Te amore filiali complecti contigit, promerita non recenfebo. Memorice enim lempiterne infixa potius fancte ferventur, guam inficeta oratione celebrentur. Sciant vero omnes me non vitam Tibi, led quod omnino celfuss, educationems et ad bonos imbibendos mores manuductionem Tuis curis debere, quin etiam $T e$ auctore dulci bocce Miffarum, quo delector conjortio frui mibi liceat. Ut igitur tanquams pignus pietatis pulcberrimam banc, quam Tibi offerre fuftineo, Plantam accipias, eft, quod ppero, me measque Tuo fingulari non minus, quam optimo patrocinio commendans fortunas. 0 . misium bonorum Renunerator fore perpetuo tuam exornet, exbilaret cetatem, fenilemque canitiem ferena et curarumb vacua cum mente conjungat, $f i c$, ut indulgentifamum devene: qari Patrems polfit ad extremum ufque balitum

Parentis Optimi

flius obedientiffimus:

PeTRus DJuredius. 


\section{DISSERTATIO BOTANICA}

DE

GARDENIA.

\section{I. $\oint$.}

b eo imprimis tempore, quo ordinem qualemcunque in difpefcenda multitudine plantarum fequi coeperunt Artis Amatores, eft, quod infigniora incrementa ceperit Scientia Botanica. Fundamentum primus jecit Caspards Bauhinus, dividendo omnes fuo tempore notas plantas in majores familias. Vacillans, tamen et fpurium adhuc erat hoc ipfum Scientix fundamentum, donec vere magnus Gallorum TOURNEFORTIUS a flore et fructu Syfrema fuum condere concinneque elaborare coepit; genuinum autem et optimum Ariadnæum filum Botanicorum Principi inveniendum relictum erat. Fovebat Suecia noftra in finu fuo, gelidis quamuis pruinis horrido, virum maximo in Floram amore accenfum, Generofam Equit. Arch. a LINNE, qui indefeffo labore adyta naturæ penetrando Syftema fuum confcripfit, prioribus antea datis longe melius atque perfectius. Hinc Scientia hxcce ampliffima longe facilior et amoenior reddita, plurimis guftari coepit, tantumque amari, ut circa medium hujus feculi nemo fere non effet, qui Botanicus evadere fuumque ad hoc Sexcuale Syftema perficiendum et 
augendum calculum addere non difcuperet. Ardentiffimo itaque Florx amore flagrantes Botanici non Europæ modo omnes latebras et cryptas fcrutari, fed remotifimas quoque utriusque Indix, Africx et novi nuper detecti mundi regiones lynceis oculis certatim frequentare inceperunt, gizls et numero ftupendo et utilitate infigni fecum reportantes. Adierunt KaLm Americam borealem, JaQvin Americam calidiorem, RolANDER Surinamum, Loefling Americam auftralem: Osseck Chinam, Hasselqvist Palæfinam, Pallas, Gmelin et Falk Ruffiam Siberiamque, Prafes Japoniam, Javam et Ceilonam: ForskoHL IEgyptum, Rothman Regnum Tripolitanum, Berlin et Smeatman Guineam Africes, Caput bonæ fpei Sparrman, Pra'es, Masson et Paterson: Terras Auftrales Commerson et SonNerat, Banks et Solander, Forster uterque et Sparrman. Et in Floræ campo, fub firio ardente adhucdum defudant Floræ amore fafcinati Viri præftantes, Mutis in America auftrali, Masson in Jamaica, Lib. Baro v. Wurmb in Java, Bladh in China, Sonnerat in Coromandelia, Koenig in Ma. labaria.

\section{II. $\int$.}

Virorum tot tantorumque induftria non potierunt non quam plurimæ antea nobis incognitx Floræ divicix e tenebris fuis erutæ in lucem produci ac nudo egentique generi humano in ufus defideratos verti. Mirati fumus collectiones plantarum 
nitidas Prof. Pallas, fmgulares paucas, quas ex multis mifit Dn. Mutss, raras Prof. ForsKohl et D:ris Rothman, rariffmas Prof. Forsteri et Doet. Sparrman, fed non fine admiratione Exp. Dn. Prazfidem exaudire potui commemorantem et numerum ftupendum, ultra mille, et indolem fingularem faciemque propriam plantarum, quas in terris aufralibus, ad promontorium Horn, in nova Guinea et præprimis in nova Hollandia collegerunt Viri excellentiffimi Dn. Banks et Solander. Nec minori latitia perfufus fui, dum aliquando mihi contigit oculis illos fubjicere Florz pulcherrimos thefauros, antea nedum vifos multo minus defcriptos, quibus e longinquo et diuturniori itinere reportatis ditare $\mathrm{Pa}$ triam fuam voluit Exp. Dn. Praefes. Numerum harum novarum fpecierum e promontorio bonæ fpei, Japonia, Java et Ceilona adductarum, tam et infignem inveni et plantas non paucas tam fingularis Itructuræ et indolis, ut fxpe adftupuerim. Inter multa alia pulcherrimis floribus fuis luperbiens Genus Gardenice præ aliis ita mihi placuit, ut de Differtationis materie cogitans intermittere non potuerim, quin Exp. Dn. Prefidern rogarem, wellet benigne mihi permittere, circa hujus parum antea cogniti generis et fpecierum novarum nuperrime deteetarum defcriptionem et delineationem vires meas periclitari. Sifto itaque Tibi, B. L. Gardeniæ genus emendatum ac feptem novis, intra decennium proxime praterlapfum vel nuperrime detectis fpeciebus adauctum.

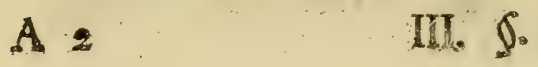




\section{III. $\int$}

GARDENIA $e$ ft planta, e Contortarum ordine glaturali, pentandra, calyce quinquicfudo, Corolla guinquepartita, antiberis Jeffilibus, Sylo clavato et fructu baccato.

Ordo Contortarun a corolla fua ante explicationem contorta nomen adeptus variis ab alis planrarum ordinibus fefe diftinguit criteriis: etenim

CaLYx in hoc ordine femper eft Perimtibiun mono. phyllum, apice in quinque, plus vel minus profundas lacinias divifum atque fic vel quinquedentatum, quinquefidum vel quinquepartitum.

Corolla femper adeft, florem efficiens completum, eaaue monoperala, aliis vero campanulata, aliis infunđ̈ibuliformis, Linzbo quinquepartito, ante explicationem inprimis in fpiram ita torto, ut altera lacinia alteri imbricatim incumbat, fupra Tubun fepius cylindricum fenfimque verfus fuperiora ampliatum, rarius campanulatum, rariffime olobofum et brevem.

Nectarium figura et fitu diverfum in quibusdan generibus prefens.

Stamrna numero naturali quinque, aliquando at rarius plura.

Pistillum in hifce variat, uti ct fructus: quibusdain enim piftillum unicum cum germine fimplici vel bifido; quibusdam ftyli funt duo.

Pertcarpium licet valde variet, ut paucis fit drupa, paucioribus bacca; plerisque tamen folliculi funt gemini. Semina omnibus numerofa funt, illis tantum exceptis, qquorua fructus drupa, 


\section{de Gardenia.}

Lacteschentes plurime, fi non omnes, funt plante con. torte, fic ut e caulibus et ramis vulneratis vel abfote fis album majori vel minori copia lac exftiller.

$V$ is fingularum, uti omnium lactefcentium, venenata eft, et id quidem eo magis, quo lątis uberiori copia profluunt. Quædam ex hifce adeo venenatæ funt, ut a Lupo, Vulpe vel pecoribus comeftr mortem frepe inevitabilem inferant. Medica autem harum vis, pro diverfa qualitate adftringente vel anodyna duplicis naturæ eft. Illæ enim, quibus adftringentes particula plurimæ infunt, in corticale corporeum inprimis agunt ac Hæmorrhagiis variis aliisque fluoribus fiftendis i. doneæ funt; quæ vero anodyno magis imprægnatæ funt, in medullare vim fuam exferentes, evacuationes facile omnes promovent et interne ficca vel cocta forma propinatæe fudores lotiumque pellunt, vomitum excitant imo et evacuationes alvinas fortiter cient. Radicem Periploce indice, quæ in Infulæ Ceilonæ fabulofis maritimis fponte crefcit, Exp. Dn. Præfes fiepius in pulverem redactam Egris, fcopo emetico dedit eamque et dofi eadem et rque facile Vomitum excitare invenit, atque ipfa Ipecacuahna Americana.

Usum idcirco in Medicina quarundam eximium effe $\mathrm{Me}$ dici experti funt, ut in Hydrope, Oedematibus, Dy. fenteria, Chlorofi, Scabie, Strumis, Menftruis, Hæ. moptyfi, Hæmorrhoidibus et Febribus variis.

In mumerum plantarum Contortarum referuntur Genera fequentia, fcilicet: Genipa, Cerbera, Rauvolfia, Macrocnemum, Vinca, Nerium, Echites, Plumieria, Tabernæmontana, Cameraria, Periploca, Apocynum, Cynanchum, Ceropegia, Afclepias, Stapelia, Pædexia, Cariffa, Allamanda, Pergularia, Cinchona, Gardenia. 


\section{IV. $\int$.}

Inventionis tempus, a quo innotuit primum Gaidenix genus non longe adhinc petendum. KÆঙ PFERUS quidem Gardeninm foridam uti et radicanreml in Japonia circa finem exeuntis feculi vidit, earumque mentionem fub nomine Mefpili injecit; fed ex Ejus defcriptione nobis relieta Gardenias has effe nemo divinaflet, nifi Exp. Dn. Prafes, vifis his in Japonia, e nomine Taponico illas recognoviffet. Et licet Rumphus priori quoque feculo defcriptionem qualemcinque figuramque flore pleno dederit Gardenice florida, quam nomine, e lingua malaica mutuato, Catfiopiri dixit, Botanicis Europxis nihilo tamen minus incognita manfit planta, quam nondum viderant. Circa medium vero feculi hujus accidit, ut Anglus quidam navis Præfeêus Dn. Hutchinfon in regione quadam Capitis bonæ fpei arbufculam quandam floribus magnis, plenis, odoratis, albifinis, pulcherrimifque onuftam offenderet. $\mathrm{Ea}$ huius fruticis amoenitate totus ftatim adeo fuit captus, ut prudenter eradicatum inque olla majori plantatum in Angliam fecum portaverit. Speciofisfimum hoc et novum Horti ornamentum, dono datum Dn. Richard Warner, femper tamen flores plenos producere continuavit, femina nulla omnino proferens, fic ut et de genere diu hafitarent Botanici et coacti effent Floriftæ propagines hujus, folutis pro fingulo aureis circiter decem fibi acquirere. Primus omnium Dn.Gordon, Hortulanus expertiffimus, fuit, qui propagines hujus primum duas, dein tempore a- 
liquo interjecto, adhuc totidem accepit, quas adeo ufque multiplicavit, ut aliis divendere aureosque plus mille hollandicos fibi acquirere potuerit. Adhuc vero, quoad Genus, ignotus erat nofter frutex. Miller eximius ille et doctus Hortulanus, primus tandem illum defcripfit dixitque Jafminum, foliis lanceolaris oppofitis integerrimis, calycibus acutioribus. Poft illum defcriptionem dedit aliam Dn. Ebret et appellavit Jafminum? ramo unifloro pleno, petalis coriaceis. Eis vero fefe oppoluit Dn. Ellis, contendens, non effe Jafmini, fed novum quoddam genus, inque Actis Anglicanis fub nomine Gardenix jafminoides defcriptionem inferuit meliorem. Cum autem e flore pleno genus verum detegere diu fruftra conaretur, tandem florem ficcatum Nobilisf. Dn. Arch. et Equ. a LINNE mifit, qui fruticis ramulum flore fimplici e China dudum miffum in Herbario fuo ficco fervabat propriumque inde genus Gardenix confituens Characterem in Generibus plantarum, Holm. 1764. p. 1 I 6 dabat fequentem:

Cac. Perianthium monophyllum, laciniis erectis, ftrictis, enfiformibus, verticalibus, diftantibus, perfiftentibus.

Cor. Monopetala, hypocrateriformis: Tubus cylindricus, calyce longior: Limbus quinquepartitus, planus: Laciniis obovatis longitudine tubi: margine folari rectiori. StAm. filamenta nulla: Antheræ quinque, lineares, ori faucis infertx, fupra fuam bafin, longitudine dimidii limbi, intra faucem elongatæ deorfum.

Pist. Germen inferum, Stylus filiformis, longitudine tubi, dein clavatus, definens Stigmate exferto, bilobo, ovato, obtufo, magno. 
Peric: Bacca ficca, bilocularis? Ellis..

SEMINA plurima.

\section{V. $\delta$.}

Species fic unica deteeta et Florida in Specie. bus Flantarum adpellata fuit. Hæc deinde pulcherrime ab Ehretio vivis coloribus depicta fuit, at floribus plenis, quales frutices omnes per totam Europam, Africam et Afiam poftea propagati adhuc proferunt. Præter hanc duæ aliæ innotuerunt fpecies, quas anno $\mathbf{1} 772$ in Capite bonæ fpei detexit Exp. Dn. Pre/es. Altera harum ab Exp. Dno. Doct. Laur. Montin defcripta fuit Anno I 773 , fub nomime Thunbergice capeniss: alterius defcriptionem Exp. Dn. Praess dedit anno 1776 fub nomine Rothmannice capenfis. Utraque hæc fpecies, quarum prior jam viva abundat in Hortis Europxis e feminibus, quæ mifit Inventor, quxque erit intra paucos annos, dum flores fuos fpeciofos producere valet, inter ornamenta hortorum minime fecunda, ad Gardeniæ genus migrare debet, æque ac Muffenda for . mova, poftquam e pluribus fpeciebus et florefcentia et fructus Generis Gardenix nobis innotuerint melius. Alia nova fpecies ab Exp. Dn. Prafide Anno 1776 , fub commoratione fua in regno Japonico le\&ta fuit, præter antea notam flomdan floribus fimplicibus. Speciem quoque novam e Ceilona miffam nobis communicare placuit Nob. Dno. Profeffori a Linné. Tres reliquas fpecies, in China lectas ad Exp. Dn. Pirefidern anno elapfo mifit Dn. P. J. 
P. J. BLADH, fic ut jam novem hujus generis fpecies numerentur, quarum characteres genericum et fpecificos in fequentibus dare nobis propofuimus.

\section{$\therefore \quad$ VI. 5 . \\ CHARACTER GENERICUS.}

Cac. Periantbiunz monophyllum, quinquepartitum: laciniis erectis, perfiftentibus.

Corolla monoperala, infundibuliformis: Tubus cylindricus, calyce longior. Limbus quinquepartitus, planus. STAm. Filamenta nulla:

Anthere quinque, ori tubi infertæ, lineares, ftriatæ, longitudine dimidia limbi.

Stignn exfertum, ovatum, obtufum, bilobum. Peric. Bacca.

Semina plurima, depreffa, per feries imbricatim impofita.

Numerus partium naturaliflimus eft quinarius; in quibusdam vero fpeciebus variat ufque ad novem, fcilicer antherarum, lacinianum calycis et linubi corollæ.

Essentia Generis: Antberce feffiles medio fui in ore tu. bi corollæ?

Stigina clavatum.

Bacca feminibus imbricatis.

Nomen Gardeniæ dedit D. Elurs, in honorem Amicì fui, D. Garden Med. et Hift. Nat. Carol. Americ.

$$
\text { VI. } \int \text {. }
$$

\section{SPECIES Jequentes funt.}

\section{* Inermes:}

radicans. I. G. inermis corollis obtufis, calyce angulato, foliis ellipticis, caule radicante. 
florida. 2. G. inermis corollis obtufis, calyce angulato; foliis ovatis acutis.

Tbwabergin. 3. G. inermis corollis obtufis, calyce tereti, foliis ovatis acutis.

gummifera. 4. G. inermis corollis obtufis, calyce hirto, foliis oblongis obtufis.

Muffende. 5. G. inermis corollis acutis, calyce hirto, foliis ovatis acuris.

Rotbmannia. 6. G. inermis corollis acutis, fubcampanulatis, calyce glabro, foliis oblongis acuris.

** Spinofe:

Ppinofa. 7. G. fpinofa floribus feffilibus hirfutis. micrantbus 8. G. fpinofa floribus feffilibus glabris. Jcandens. 9. G, fpinora, fcandens floribus pedunculatis.

\section{VIII. $\int_{0}$}

\section{Descriptio Specierunth.}

Omnes Gardenix frutefcunt et perennes funt.

I. G. Radicans. Caulis decumbens, radicans, glaber, craffitie calami, circiter pedalis.

Rami oppofiti, rudimentis foliorum tuberculati, flexuofi, erecti.

Folia in apicibus ramorum confluentia, oppofita, fubfeffilia, elliptica, integra, parallelo-nervofa, glabra, erecta, pollicaria ufque bipollicaria.

Stipulce intrafoliacer, avatæ, obtufx, vaginantes, mem. branacex.

Flores in ramis terminales, folitarii, fubfeffiles.

CALYX angulatus, glaber, 5.6 partitus; laciniis lan. ceolatis, verticalibus, erectis, perfiftentibus, tubo di. midio brevioribus. 


\section{de Gardenia.}

Corolla repius plena, alba, coriacea: limbi laciniæ oblongæ, obtufe, planæ.

Differt hæc a. G. florida eo, quod multoties minor caule tenui, frutefcente, decumbente, radicante foliisque anguftis ellipticis.

2. G. Florida: Caulis arborefcens, erectus, totus glaber, orgyalis.

Rami et ramuli oppofiti, erecti.

Folin oppofita, fubfeffilia, ovata, acuminata, integra, glabra, venofa, patentia, pollicem lata, bipollicaria. Stipule intrafoliaceæ, vaginantes, ovatæ, obtufæ, membranacex.

Flores in ramulis terminales, folitarii, fubfeffiles.

Calyx angulatus, glaber, 5.6 partitus: laciniis lanceolatis, verticalibus, erectis, decurrentibus, perfiften: tibus, tubo duplo brevioribus:

Corolla nivea, coriacea: tubus cylindricus, pollicaris. Limbus 5.6 partitus: laciniis ovatis, obtufis, planis, pollicaribus.

Bacca oblonga, calyce perfiftente coronata et angulata, glabra, 5.6 valvis, unilocularis, pollicaris. Pulpa lutea.

Raro corolla fimplex, fæe plena antheris plerumque fex, calyce fexpartito, limbo fexpartito et bacca hexagona.

3. G. ThUnbergia: Caulis arboreus, glaber, ramofiffi. mus, biorgyalis.

Rami alcerni, teretes, rudimentis foliorum annulati, cinerei, glabri, erekt, ramulofi.

Folin verticillata, terna vel quaterna, petiolata, utrinque acuminata, integra, concava, fubundulata, parallelo nervofa, glabra, norata glandulis pilofis in axillis nervorum paginæ inferioris, patentia, inæqualia, internodiis longiora, bipollicaria vel ultra. 
Petioli breves, fenfim dilatati in folium; fubtus calloî, glabri, unciales.

Stipule intrafolizcex, vaginantes, obtufie, membranaccx. Flores in ranulis terminales, folitarii, feffiles, erecti. Calyx cylinciricus, fuperne ampliatus, glaber, apice 0 . blique dehifiens, coronatus foliolis $4 \cdot 6$ petiolatis, cucullatis; intus villofus melleque madidus, tubo triplo brevior:

Corolla alba, coriacea. Tubus cylindricus, parum in. curvarus, obfolete ftriatus, fenfim paulo ampliatus, glaberrimus, palmaris. Limbus 7-9 partitus: lacinixe ovatæ, obtufiflimæ, margine reflexæ, integerrimæ, imbricatæ, patentiffimæ, pollicares. Os tubi villofum, fulcatum.

Rarius limbus corollæ 8 vel ro-partitus cum antheris totidem.

Antbere 7,8 vel Io, fxpiffime vero 9 .

Germen planum, coronatum tuberculis rotundatis, melliferis, glabrum. Stylus inferne filiformis, glaber; fuperne clavatus, villofus, tubo corollre longior. Stigma oblique truncatum, fulcarum, fulcorum marginibus reflexis, raro 4 -fulcatum.

Bacca ovata, fubrugofa, glabra, virefcens, dein alba, I.locularis, 5-valvis, polyfperma, magnitudine ovi gallinacei, per annos perfiftens nec decidua neque dehifcens, cortice lignofo, duro. Pulpa vix ulla.

Semina lenticularia, imbricata, in fingula plica folitaria. 4. G. Gummifera. Folia oblonga, obtula, hirta. Calyx hirtus; 5-dentatus.

Corolla infundibuliformis. Tulus longior quam in G. florida, magis filiformis et pilis tenuioribus tectus. Limbus obtufus, planus, 5-9-partitus.

Stigma incraffatum, bipartitum.

Bacca ficca, 2-4 locularis. 
Semina depreffo-plana, impofita ferie duplici.

Refert. Gardeniam floridam magnitudine et figura lim. bi corollæ:

5. G. Mussander: Frutex ramis teretibus, hirtis.

Foiza oppofita, brevifíme petiolata, ovata, acuta, glabra, ; pollicaria.

Stipule intrafoliaceæ, folitariæ, bafi dilatatæ, fubulatæ. Flores axillares et terminales breviffimorum ramulorum, folitarii, feffrles.

Calyx campanulatus, hirtus, 5-parritus: lacinix compreflæ finubus roindatis, fibulatæ, erectæ.

Corolla alba. Tubus filiformis, bafi furfum curvus, dein rectus, hirtus. Linubus planus, tubo dimidio brevior, 5 -partitus: laciniss ovatis, acuminatis, carnofis. Antberce quinque.

Stylus filiformis. Stigna crafiufculum, bipartitum: laciniis revolutis.

Bacca ovalis cortice lignofo, bilocularis. Pulpa ni. gra, lubrica, acida.

Semina ovalia, depreffo plana, quovis toculamento per binas feries impofita.

6. G. Rothmanna: Contis arboreus, erectus, ramofiffmus, féfquiorgyalis.

Rami et ramuli oppofiti, fubangulati, ftriati, fcabri, erecti, ferruginei.

Fulia oppofita, brevilfime petiolara, oblonga, acuta, integra, nervofa, glabra, fupra lete viridia, fubrus pallidiora, fempervirentia, notata fubtus glandulis. pilofis in axillis nervorum, digitalia. Stipulde intrafoliacex, fubulatæ, breves.

Floves in ramulis terminales, folitarii, feffiles.

Calyx cylindricus, obfolete 5-angulatus, extus glaber, intus pilofus, corolla triplo brevior, 5 partitus: lacinix filiformes, acutæ, ercetæ, femiunguictulares. 
Corolia fubcampanulata, extus albido-flavefeens, intus trifte flava maculis purpureis. Limhus 5-partitus; lacinix ovatie, acuminatæ, reflexæ, unguiculares. Antbera quinque, rarius fex cum Calyce 6.fido et Corolla 6-fida.

Germeis convexiufculum, inæquale, angulatum, glabrum.

Stylus filiformis, fenfim incraffatus, albus, longitudine fere corolla.

Bacca ovata, carnofa", lineis circiter 12 , obfoletis an. gulata, glabra, bivalvis, unilocularis, polyfperma, pulpofa, magnitudine pyri parvi, immatura viridis, matura nigra, ficcata altero latere dehifcens deque arbore decidens. Pulpa fufca, molli inftar pulpæ Tamarindorum.

Semlna lentiformia, imbricata, brunnea, in fingula plica folitaria.

Flos et tota planta fub exficcatione nigrefcunt.

7. G. Spinosa: Coulis fruticofus, ramofus.

Rawi teretes, glabri, fpinofi, rigidi.

Spince fupra-axillares, frpius oppofitx, rarius alternæ, decuffatx, patentes, pollicares.

Folia e gemmis fub fpinis plura, fubleffilia, ovata, obtufa, integra, glabra, patentia, inæqualia, pollicaria.

Stipule fetacer, minura.

Flores axillares, folitarii, feffiles.

Calyx campanulatus, extus hirfutus, corolla paulo brevior, 5-partitus: laciniæ ovatæ obtufæ, patentes. Corolla infundibuliformis, alba, cxtus hirfuta, 5-partita: laciniæ ovatæ, obtufæ, integræ, patentes. Antbere quinque. Stylus filiformis, longitudine tubi. Stigur clavatum. 


\section{de Gardenia.}

8. G. Micranthus: Canlis fruticolus, ramolus. Rami-teretes, villofi, parum ramulofi, fpinofi. Ramuli capillares, hirti, fpinofi.

Spinie fuprafoliacer, oppofitæ, acutæ, erecto patentes, femiunguiculares.

Folia e gemmis infra fpinas oppofita, petiolata, 0 vara, acuta, integra, glabra, nervola, patentia, unguicularia.

Petioli lineam longi.

Flores axillares, duo vel tres, feffiles, magnitudine feminis oryzx, ante explicationem médio angufati. Calyx truncatus, 5-dentatus, glaber, corolla multo brevior.

Corill. fubcampanulata, 5 partita: lacinix ovate, acuræ, reflexæ.

Antberce quinque.

Stylus capillaris, albus, longitudine corolle. Stigma globofum.

9. G. Scandens: Caulis fruticofus.

Rami reretes, glabri, cinerei, fpinofi, fcandentes.

Spine fupra-foliacex, decuftatim oppofitæ, femiungviculares.

Folia e gemmis infra fpinas aggregata, petiolata, ovata, obtuliurcula, integra, glabia, patentia, inequa-

lia, unguicularia.

Fetioli brevifimi.

Stipule retacer.

Flores axillares, folitarii, pedunculaci.

Pedunculus filiformis, uniforus, giaber, feminnguicularis.

Calyx fubcampanularus, glaber, tubo corolla quadruplo brevior, 5-partinus: lacinix lancovlatx, erefce. Corolla infundibulicormis, alba, glabra: Tubus cylin. dricus 
dricus, rectus, unguicularis. Limbus 5-partitus: Laciniæ lanceolatæ, patentes. Antherce quinque. Stylus filiformis, longitudine tubi. Stigma clavatum.

\section{IX. $\int$. SYNONYMA.}

1. G. Radicans: Sanfifi it. Mifuk tjinafi it. Kutjjinas Japonenfibus appellatur.

Kutfjunas altera. Kxmpf. Amoen. exot. fafc. V. p. 808.

2. G. Florida. S $/ 2$, vulgo Kutjjinas. Kæmpf. Amoen. exot. fafc. V. p. 808.

Catsjopiri, Rumph. Herb. Amb. T. 7. p. 26. t. I4. f. 2. Fafminum Ceilanicum folio oblongo, flore albo, pleno, odoratiflimo. Burman. Thefaur. Ceylanic. p. s29. t. 59. Fafminum foliis lanceolatis, oppolitis, integerrimis, calycibus acutioribus. Miller. Icon. tab. 180.

Fafminum? ramo unifloro, pleno, petalis coriaceis. Ehret. Nova Aćtá Phyfico-Medica Acad. Nat. Curiol. tom. 2. 176x. Obr. 34. pag. 333. tab. 8.

Ebret Tabul. pict. 15.

Cape Fafmine et Gardenia Fafminoides. Ellis Acta Angl. . Philofoph. Tranfact. Vol. 51. p. 932. tab. 23.

Gardenia florida. Linné Gener. plant. pag. in 6. Ejusd. Spec, pl. I764. pag. 305. Ej. Syft. Nat, 1774. pag. I 47, 208- Ej. Mantiff. 2. p. 346.

Gardenin forida, inermis foliis ovatis utrinque acutis, ftipulis obtufis, laciniis calycinis verticalibus, tubo recto Linn. Suppl. Syrt, N. Ed. XIII.

Hollandis in Africa et Indiis degentibus ubique communi nomine appellatur Catsjopiri vel Katjepiring. Elegantifimam hujus figuram floribus fimplicibus expectamus in deftinato opere botanico, D. Banks. 3. G. 


\section{de Gardenia.}

3. G. Thunbergia: Tbunbergia capenfis." Montin. Act. Holmienf. 1773. pag. 288. tab. Ir.

Bergkias. Sonnerat Voyage à la nouvelle Guiné pag. 47. tab. 17,18 .

Gardenia Tbunbergia, - inermis foliis ovatis utrinque acutis, ttipulis obtufis, calyce infundibuliformi appendiculato, laciniis cucullatis petiolatis. Linn. Suppl. Hollandis Caput bonæe fpei incolentibus dicitur WildeKatje-Pirisg.

4. G. Gummifera: Gardenia gummifera, inermis foliis oblongis obrufis hirtis, ftipulis fubulatis', laciniis calycinis ovaris breviffimis, tubo recto. Linn. Suppl.

5. G. Mussende. Muffenda formofa. Jacq. Plant. Amer. pag. 70. tab. 48.

Mufferzda formofa. Linné Mantiff. r. pag. 45. Ej. Syit. Nat, 1774. Tom. 2. pag. $18 z$.

Gardenin Muffendee: inermis foliis ovatis acutis, ftipu. lis mucronatis, laciniis calycinis fubulatis compreflis, tubo incurvato hirto. Linn. Supplem. Syft. Nat. Edit, XIII.

6. G. Rothmannia. Rotbmannia capen/is. Thunberg Act. Holmienf. 1776. pag. 65. tab. 2.

Gardenia Rotbmannia, inermis foliis oblongis, ftipulis fubulatis, laciniis fubulatis terretibus longitudine tubi, tubo glabro ampliato brevi. Linn. Supplem. Syft. Nat. Edit. XIII.

Follandis promontarii bonæ fpei incolis Swart $Y_{z e r-}$ bout audit.

7. G. Sprnosa Gardenia Spinofa, fpinis binis oppofitis fuprarameis rectis patentibus, foliis obovatis, laciniis calycinis foliaceis, tubo breviffumo. Linn. Supplem. S.yen. Nat. Edit: KIU.

X. S. 


\section{5 .}

\section{LOCUS.}

Ubi fponte crefcunt Gardeniæ fpecies, funt Afiæ inprimis et Africx regiones tam calidiores, quam temperatæ, adeoque vel intra vel etiam extra ipfos tropicos fitæ, ut in infula Amboina, Ceilona, Perfia, Coromandelia, Japonia, China, Capite bonæ fpei et America. Sic Gardenia flurida fponte crefcit in Japonia, China, Surattis, Amboina, Promontorio bonæ fpei; radicarzs in Japonia; Thunbergia et Roth. mannia in Africes capite auftrali, bonæ fpei dieto, illa in fylvis prope van Stades fluvium, hæc in Groot.Vaders bo/ch et fylvis juxta fluvium Zonder End; gummifera in Ceilona; Musfanda in fylvis Carthagenæ Americx autralis; Spino/a in China prope Macao et Madrafs Coromandelix; Micrantbus in China et Ceilona; Jcandens prope Macao in China. Coluntur vero fimul plures harum fpecies in plurimis regionibus, ut G. florida in hortis japonicis, capenfibus et plurimis Europxis botanicis aliisque; radicans in hortis Japonenfum; Thunbergia in horto capenfi "et multis Europæis botanicis. Rotbronniia adhuc tantum in horto capenfi focietatis commerciorum Hollandicx.

\section{6 . \\ USUS.}

Omnes Gardeniæ fpecies apud nos cultæ ornamenta prabent hortis noftris admiranda fpeciofifmis 
fuis floribus et foliis fempervirentibus, inprimis vero pulcherrimæ fpecies inermes, quas inter excellunt florida et Thuzabergia. Dolendum autem eft, quod per hyemem apud nos in frigidario fint fervandæ, intenfiffimi frigoris boreas noftratis impatientes, dum in auftraliori Europa ut in Gallia, Anglia et Hollandia fub diu vigent fimul cum Magnolia grandifora et glauca, Thea et aliis. E Florida fepes hinc inde vivæ in Japonia formantur, certe elegantifimæ eamque ob rationem a Japonenfibus in hortis prope domos et in ambulacris curiofe colitur. Fructus quoque hujus et Chinenfibus et Japonenfibus multum in ufu funt pro tingendo luteo et venales in fingulis eorum tabernis exfant ficcati. Thunbergu reliquas omnes elegantia florum fuperat. In Capite bonæ fpei florere incipit verfus finem Januarii, hoc eft mediam ibi EEftatem floretque ufque in Martium, dum arbor tota adeo obtecta eft floribus, ut nihil pulchrius. Flores finguli non diu perfintunt, fed abfoluta intra paucos dies horum florefcentia, alii fenfim de die in diem proveniunt et multiplicantur. Tondere fe quoque patitur hæc arbor, fed lente crefcit. Odor corollæ parum ingratus, Daturæ quodammodo fimilis, fed debilior. Lignum trunci valde durum eft; utuntur itaque hoc ruftici et inprimis clavas ligneas exinde fabricant. Gummifera e rimis corticis et foliorum gummi-refinam exfudat, Gummi Elemi haud abfimilem. Rotbrnannia floret in Capite bonæ fpei menfibus Januarii et Februarii odore florum fragranti, vefperi et nocte inprimis forti, 
odori florum Cheiranthi triftis valde fimili. Duriffi. mum eft ipfum lignum et rufticis multum pro axibus currorum conficiendis expetitum.

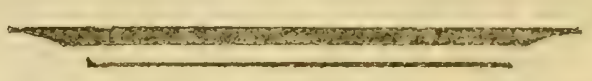

\section{Explicatio Tabularum.}

Tab. I. Fig. I. GARDENIA Radicans.

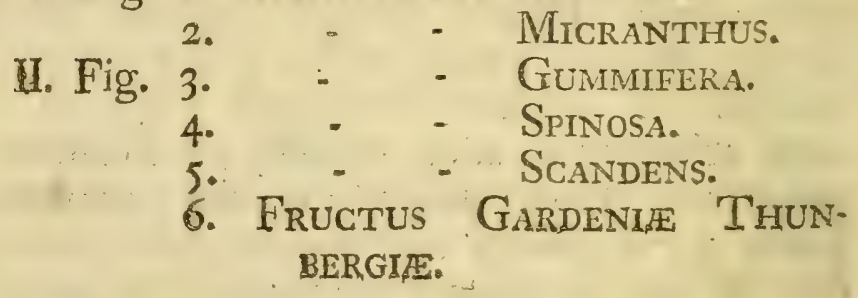




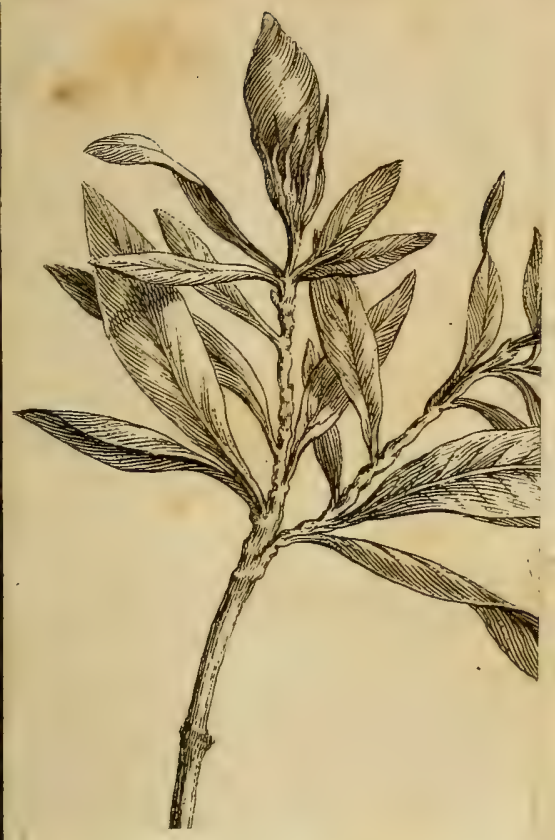

TheCCasprom 


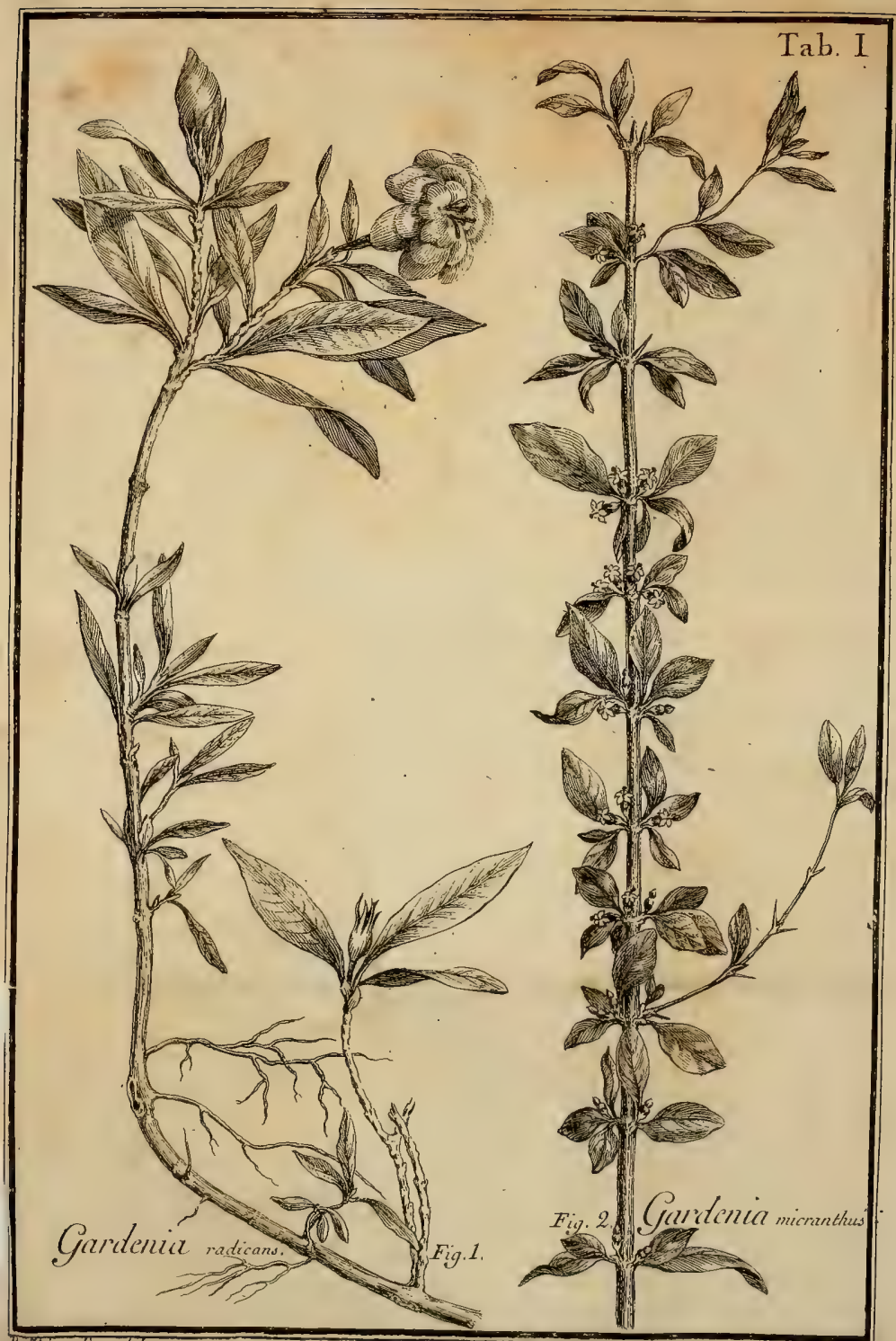




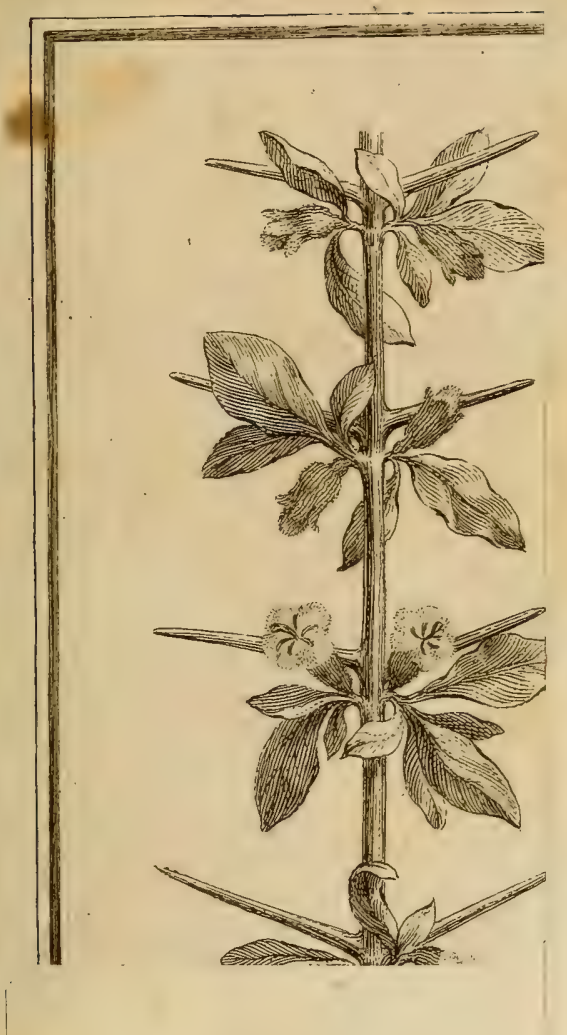

Frchasm? 


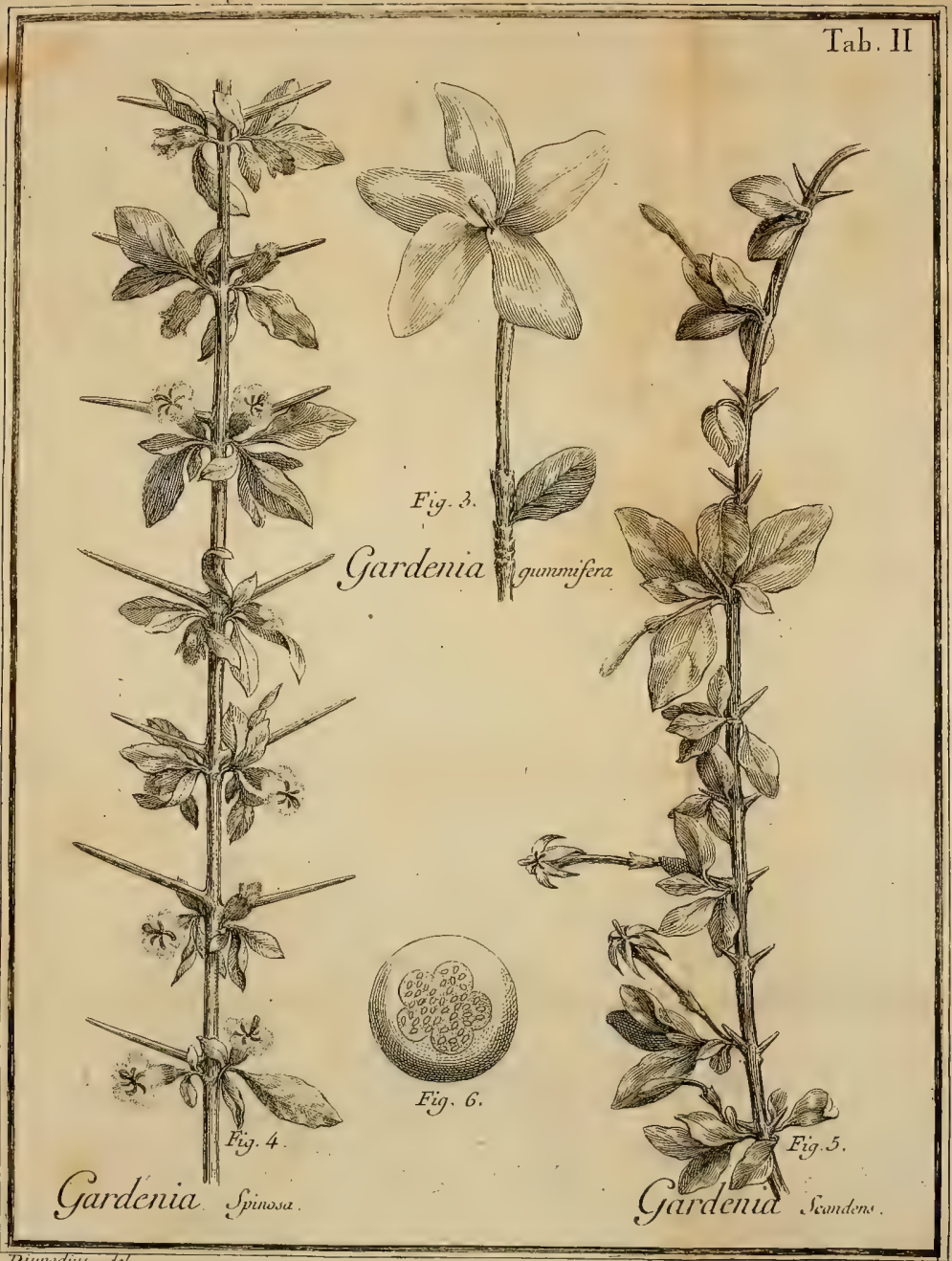

Doupidius atel.

- तhrel $J_{4}$ 
DISSERTATIO BOTANICA (2)

$\mathrm{DE}$
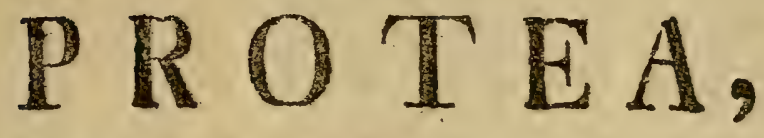

QUAM

COVSENSU EXPERIENT. FAC. MED. UPSAL。 PUBLICE VRNTILANDAM EXHIBENT

\section{PRAESES}

CAROL.P.THUNBERG, Med. Doct, Botan. Demonstr., Acad. Reg. Scient. Holmiens. Ciesar. Nat. Cur. Societ. Scient. Upsal. Lundin. Amst. et Nidros. Membrum,

\section{ET}

RESPONDENS

\section{JOHANNES ERICUS GEVALIN, VESTROĠTHUS.}

IN AUDIT, GUSTAY. MAJ. D.X/X JUNI, ANNO MDCCLXXXI, H. A. M. S.

\section{UPSALI E,}

Afud JOH. EDMAN, Derect. et Reg. Acad. Typogr. 
VIRO,

GENEROSO ATQUE EXPERIENTISSIMO DOMINO DOCTORI,

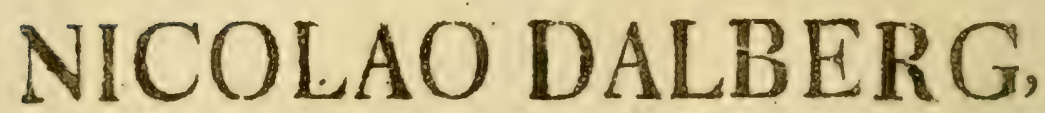

Sacre Regi⿸ Majestatis Medico Ordinario, Reg. Coll. Med. vic. Priesidi et Adsessori, Reg. Acad. Scient. Holm. et Reg. Acad. Mied. Paris. Membro,

\section{DAT, DICAT, DEDICAT}

RESPONDENS. 


\section{DISSERTATIO BOTANICA}

\section{DE \\ PROTEA.}

\section{S. I.}

Ther ea plantarum Genera, qua prafenti faculo plurimis novis fpeciebus ditata fune, merico nu- meratur Protea. Primá enim ejus incunabula $a b$ eo tempore perenda erunt, quo HERMANNUS, faculo praterito, fub innere in Ceilonam infrituen. do, Promontorium bone fpei Africes autralis, primus omnium Botanicorum falutavit. Botanicus ille non minus folide doctus, quam medicus expertus ingentem, päucos intra dies, plantarum cumulum collectum, in Europam amicis fuis transmifit. Has inter Generis noftri fedecim quoque fpecies repertæ fuerunt. Pof HERMANNUM decem indefefus PLUKENETIUS, verfus finem fæculi exeuntis, fibi adquiftas Proteas operibus fuis fenfim inferuit, quas inter fex eo tempore novx erant. Tres tantum exque his unicam novam, vidit PETIVER. Belgii vero Profefforibus, BOERHAVIO, ROYENO \& BURMANNO longe plures adhuc Pirotearum fpecies, tam ab HERMANNO ipfo leetas, quam ab aliis Africanis amicis fibi miffas, videre cumque orbe erudito communicare contigit. BOERHAVIUS enumerat oztodecin fpecies, quarum duz tunc temporis omnino erant nova, quibus, e tribus recenfitis ROYENT, duæ adhuc novæ accedebant, uti \& una BURMANNI, e quatuor ab eo defcriptis. Paucas licet A 2

Pro- 
Protens recenfeat JOH. BURMANNUS in decadibus plantarum Africanarum, plurimas tamen fpecies vir inclytus notas fibi habuit inque Mufro fuo jamdum adfervat xque inclytus filius, Paterni muneris non minus quam virtutis, eruditionis, Bibliothecr \& $\mathrm{Na}$ turalium Thefauri ditifimi hareditarius \& fucceffor, NICOL. LAUR. BURMANNUS. Portea, reformata Botanice inventisque nominibus trivialibus, fenfim plures fpecies antea incognitæ defcriptæ fuerunt, ut a Profeffore BERGIO quatuor, ab Arch. LINNZEO duæ \& a Doctore SPARRMAN una, quibus NOS cenfuræ Tux, B. L., hodie fubjiciendas, viginti quinque a nemine ante vel commemoratas vel defcriptas adjungimus.

\section{II.}

Species illæ Protearum, qux fic fucceflive detectx fuerunt, fequentes funt, filice:

HeRnANi: fphrocephala, conocarpa, hypophylla, cucullata, pinifolia, bracteata, mellifera, conifera, frobilina, argentea, acauris, grandiflora, fpeciofa, hirta, divaricata, cynaroides.

Elukesetii: cyanoides, ferraria, racemola, fcolymus, levifanus, faligna.

PetiveriI: nana.

Boerhavir: repens, pallens.

RorenI : crinita, purpurea.

Buminani: glomerata.

Bergn: phylicoides, fpicata, corymbofa, pubera. LinNeI: parviflora, totta.

SparRalanin: Sceptrum. 
Nostre: decumbens, florida, patula, tritcmata, lagopus, elliptica, tomentofa, heterophylla, incurva, caudata, comofa, prolifera, lanata, torta, alba, aulacea, umbellata, linearis, obliqua, imbricata, fericea, myrtifolia, glabra, fpathulata, cordata.

Ar illam antem, fi animum advertere velis feriem, qua certis fub nominibus propriis \& characteribus fpecificis, poft reformationem circa medium hujus frculi Botanices, fenfim innotuerunt fpecies Protex, mirum forfan obveniet, quod nemini nifi Svecix, paucis quidem illis, Botanicis fors illa obtigerit, Generis hujus fpecies in ordinem redigere orbigue Botanico clariori fub luce décriptas proponere. Hoc modo fenfrm publici juris factr funt: $20 \mathrm{ab}$ Arch. LINN $\mathrm{EO}$ : P. racemofa, glomerata, ferraria, cyanoides, hirta, cucullata, mellifera, cynaroides, fpeciofa, hypophylla, frobilina, conifera, pallens, argentea, parvillora, totta, conocarpa, purpurea, fcolymus, acaulis.

10. a Prof. BERGIO: P. pinifolia, Ipicata, fphærocephala, nana, pubera, levifanus, divaricata, phylicoides, crinita, corymbofa.

I a D:re SPARRMANNO: P, feptrum.

29 a NOBIS: P. decumbens, ficida, patula, triternata, lagopus, elliptica, tomentofa, heterophylla, incurva, caudata, bracteata, comofa, prolifera, lanata, torta, alba, aulacea, umbellata, linearis, repens, obliqua, imbricata, fericea, faligna, myrtifolia, grandifiora, glabra, fpathulata, cordata.

$$
\text { A } 3 \text {. S. ILI. }
$$




\section{S. III.}

Breviter lic data Generis hujus hiftoria licteramia, origo etjam nominum diverforum, tam a veteribus quam reventioribus Auctaribus illi concefforum, paulisper explicanda. Nomen caim huic generi varum varii Auctores impofuerunt.

Anetholnus trutex, bui folis planta \&s Silysioceptalus, adpellatum fuit ab HLRNANNO.

Cy:mi Lithiopici, Abrotanoites, Tiymelae, Chys. anthemigue nomina variis fpeciebus adignavic PLCKENETIUS.

Cononboror, Cinarordes \& Leviganum vocarme PETIVER \& RAJUS.

Argyrodendros COMMELINO \& RAJO audit. dicitur.

Conifera in Actis Londinenlibus feecies quadum

Fratcx Fethiopicus \& Silix conophora a BREYNIO vocatur.

Globulariam africanam TURNEFORTIUS, Ser. rarian vero \& brun an BURMANNUS dixit.

Aulax BERGIO Ipecies quadum dieta fuit, quam tamen deteftx poftea plures nova fpecies cum Froteis reliquis confuere jubent.

Leidadendron nomen PLLKENETIUS, PETIVER \& RAJUS Generis hujus quibusdam rpeciebus impofuerunt,quod poftea retinuerunt WOER HAVIUS, WACHENDOREFIUS, à LINNE DERGIUS.

Conocarpodendron, Hyponlyllonarnotendroil Leridocarprdendron. nomina tam in fcicntia noftra tadiofa, quam polycyllabica dofte concinnavit DOERHAVIUS. 
Protec nomen ROYENO debetur, quod afumfe. runt quoque WACHENDORFIIUS \& recentiores plurimi ut à LINNE', SPARRMAN', NOS.

Nomina generica convenientia, quo breviora fuerint, eo meliora ea numquam non reputamu, evitantes femper, dum commode tieri pureft, ea, qux nimis compofita \& polyfyllabica evadunt. Frotex itaque nomen, præ ceteris omnibus fynonymis nobis arrifit, idque eo magis, quod genus hocce no. ftrum Proteo fere fit inconftantius; alins enim fpeciebus fores nudi absque calyce communi \& cono; aliis perianthium commune imbricatum; alizs conus eft, intra cujus fquamas corollæ folitarix; aliis palex, flores diftingventes, funt; aliis quatuor, quinque vel plures corollæ intra perianthium commune; anis corolla bifida, alizs trifida; alis quadrifida; alus te. trapetala, fic ut in calyce, receptaculo, corolla certa nulla nota charaeteriftica quærenda fit.

\section{S. IV. \\ Cbaracter Genericus:}

caLYx. Periantbium commune imbricatum: fquamis , inæqualibus, perfiftentibus.

- . - proprizm nullum.

corouta tetraperala. Petala frpe cohærentia, frpius 1 divifa, lineari-oblonga: Unguibus erectis, Limn. bo patenti.

stam. Flamenta nulla. Antber quatuor, lineares vel oblongx, fub apice limbi corollæ infertx.

PIST. 
rнs. Germen fuperum, oblongum.

Stylus filiformis, corolla longior.

Sitgra fimplex, clavarum.

perrc. nullum. Calys patens, induratus.

sexist folitaria, inferne attentma, oblonga, compres- fiufcula, obtufa.

RECEPT. commune nudum, villofum, paleaceun vel conus.

- Fonentia Generis confiftit in corolla s-petala; ftaminibus limbo infertis! germine fipero; fominibus nudis. Variant variz fpecies \& $\mathrm{ab}$ invicem varis in circumftantiis differunt, e. g.

pinifolia \& aulacea flores gerunt racemofos absque ullo calycis rudimento, cujus loco pedicelli finguli brakea minuta muniunur.

bracteata \& umbellata flores quidem in capitulum colligunt fupra receptaculum commune, fed calyx communis nullus omnino verus adeft, ejus vero loco braktex alternæ, aggregatæ, fif $x$ flores $o b$. vallant.

racennofa pedunculis racemofis unifloris gaudet, adeoque perianthio fuo proprio inftruitur, dum re. liquis omnibus Proteis calyz proprius omnino fit nullus.

sigenten, conifera \& quxdam alix perianthium quidem haberit commune, at fimul inter fquamas has imbricatas flores colleeti perfpiciuntur, fic ut conus yerus exinde formetur. 


\section{de Proten.}

In omnibus ftruetura naturalifima Corollæ ea eft, ut in quatuor petala dividatur, ficut in pinifolia, aulacea \& mulcis aliis videre licet; attamen in aliis hæ laciniæ cohærent mulciplici modo: in quibusdam petala cohærent infma bafi, in nonnullis fub apice limbi patentis, in aliis utrinque nimirum \& infima bafi \& fub limbo, ut corollam monopetalam mentiantur. In quibusdam tria petala cohærent limbo tamen trifido, omnino diftineta a quarto, ut corollam dipetalam referant. In quibusdam petalorum ungves inferne omnino feparati perfpiciuntur, licet cohæreant fub limbo. In paucis cohærent ung. ves petalorum, limbo omnino patenti. In fingulis autem cafibus, ubi plura vel pauciora petala, vel inferne vel fuperne adglutinantur, cohæfio tamen hæc, imprimis florefcentia adulta, adeo levis eft, ut fecundum angulos acutiores, vel acicula vel compreffione, nec raro elaftica quadam vi, petala ab invicem fecedant \& diffiliant.

Stamina in hoc prolixo genere omnium minime variant. Confanter petalis infident \& in plurimis quidem proxime fub apice limbi, antheris communiffime oblongis vel linearibus, limbo fxpifime longitudinaliter adpreffis.

Pifillum notas femper conftantes fervat, germen fuperum, fylum longum, interdum longiffimum, \& ftigma clavatum fine ulla exceptione. 


\section{§. V.}

\section{SPECIES Protearum Sequentes funt.}

I:mo Pinnate: foliis pinnatis, filiformibus. decunbens. I. P. foliis trifidis filiformibus, caule decumbente.

florida. 2. P. foliis trifidis filiformibus, caule erecto, capitulis folitarịs bracteis obvallatis. cyanoides. 3. P. foliis trifido-pinnatis filiformibus, caule ereeto, capitulis folitariis nudis. patula. 4. P. foliis trifido-pinnatis filiformibus, caule erecto, capitulis aggregatis.

Jpharoce- 5. P. foliis bipinnatis filiformibus, pedunphala. culis capitulis brevioribus, fquamis ca. lycinis ovatis bafi villofis.

Jerraria. 6. P. foliis bipinnatis filiformibus hirtis, pedunculis capitulis longioribus, fquamis calycinis ovato-lanceolatis hirtis. triternata. 7. P. foliis bipinnatis filiformibus glabris, pedunculis capitulis longioribus, fquamis calycinis lanceolatis hirtis.

glomerata. 8. P. foliis bipinnatis filiformibus, peduncuio communi elongato nudo, pediceilis capitulis longioribus.

phylicoides. 9. P. foliis bipinnatis filiformibus, capiunlis terminalibus folienriis lmatis.

lagapus. 10. P. foliis bipinnatis filiformibus, capitulis fpicatis aggregatis.

Jpicata. II. P. foliis bipinnatis filiformibus, capitulis fpicatis diftinctis. 


\section{de Proten.}

sceptrum. r2. P. foliis inferioribus bipinnatis, fuperioribus trifidis integrisque.

2:do DENTATE: foliis dentatis, callofis.

crinita. I3. P. foliis quinque-dentatis glabris, caule ereeto, capitulis fubternis terminalibus. conocarpa. 14. P. foliis quinque-dentatis glabris, caule ereeto, capitulo terminali.

elliptica. I5. P. foliis ellipticis tridentatis glabris, caule ereeto, capitulo terminali.

bypopbylla. I 6. P. toliis tridentatis glabris fecundis, caule decumbente, capitulo terminali.

cucullata. 17. P. foliis tridentatis glabris, capitulis lateralibus.

tomentofa.18. P. foliis tridentatis tomentofis.

betero-

pbylla.

19. P. foliis tridentatis integrisque, caule decumbente.

3:tí ACEROSæ: foliis filiformibus, fubulatis.

pinifolia. 20. P. foliis filiformibus, floribus "racemofis ecalyculatis glabris.

racemofa. 2r. P. foliis filiformibus, floribus racemofis calyculatis tomentofis.

incurva. 22. P. foliis filiformibus incurvis glabris, capitulis racemofo-fpicatis tomentofis.

caudata. 23. P. foliis filiformibus hirtis, capitulis fubfeffilibus fpicaris.

bracteata. 24. P. foliis filiformi - canaliculatis, capitulo terminali, bracteis multifidis.

comofa. 25. P. foliis inferioribus filiformibus, fuperioribus lanceolatis, capitulo terminali.

$$
\text { B } 2
$$


furpured. 26. P. foliis linearibus recurvis, capitulis terminalibus cornuis, caule decumbente. prolifera. $2 \%$. P. foliis fubulatis adpreffis, caule prolifero.

corymbofa.28. P. foliis lineari-fubulatis adpreffis, ramulis verticillatis fubfantigiatis.

gnama. 29. P. foliis lineari-fubulatis, capitulo terminali, calyce colorato.

lanata. 30. P. foliis triquetris adpreffis, capitulo terminali lanato.

\section{4:to Lineares: foliis linearibus.}

torta. $\quad 3$ I. P. foliis linearibus obliquis callofis.

alba. 32. P. foliis linearibus fericeo-tomentofis.

5:to LANCEOLATæ: foliis ellipticis \& lanceolatis.

aulace.3. 33. P. foliis ellipticis, floribus racemofis ecalyculatis.

ambelista.34. P. foliis ellipticis, capitulis terminalibus, bracteis multifidis.

linearis. 35. P. foliis ellipticis, capitulo terminali tomentofo.

Scolymus. 36. P. foliis lanceolatis acutis capituloque terminali rotundo glabris.

mellifera. 37. P. foliis lanceolato-ellipticis capituloque rerminali oblongo glabris.

repens. 38. P. foliis lanceolato-cllipticis capitulogne ovato glabris, caule decumbente breviffimo.

obligua. 39. P. foliis ellipticis glabris callofis obliquis, capitulo caulino terminali. ... 
arvifora. 40. P. folis ellipticis obtufis callofis obliquis, capitulis terminalibus ramulorum glabris.

pallens, 47. P. folis ellipticis glabris acutis callofis, capitulo terminali involucrato, involucro longo acuto pallido.

conifera. 42. P. foliis ellipticis glabris actitis callofis, capitulo terminali involucrato, involucro longo acuto concolore.

levifanus. 43. P. foliis ellipticis glabris obtufis, capitulo terminali involucrato, involucro brevi obtulo.

frobilina. 44. P. foliis elliptico-oblongis retufo-callofis capituloque terminali glabris.

imbricata. 45. P. foliis lanceolatis glabris ftriatis imbricatis, capiculo terminali.

sericea. 46. P. foliis lanceclatis fericeis, ramis filformibus, caule decumbente.

faligna. 47. P. foliis lanceolatis fericeis, caule fruticofo, capitulis oblongis involucratis. argentea. 48. P. foliis lanceolatis argenteo-tomentofis ciliatis, caule arbareo, capitulis globofis.

6:to OBLONG E: foliis oblongis, ovatis.

acnzllis. 49. P. foliis oblongis capituloque globofo glabris, caule decumbente breviffimo. myrif olia. 50 . P. foliis oblongis glabris, capitulis terminalibus aggregatis.

grandifora.51.P. follis oblongis venofis capituloque hemif́phærico glabris, caule arboreo.

$$
\mathrm{B}_{3}
$$

glabri. 
glabra. 52. P. foliis oblongis aveniis capituloque hemifphærico glabris, caule fruticofo.

Speciosa. 53. P. foliis oblongis glabris, capitulo oblongo, fquamis calycinis apice barbatis. totta. 54. P. foliis ovatis glabris callofis, capitulo ovato, corollis cylindricis hireis.

birta. 55 . P. foliis ovatis, glabris, floribus lateralibus.

pubera. 56. P. foliis ovatis capitulisque terminalibus tomentofis.

divaricata.57. P. foliis ovatis hirtis, capitulis terminalibus, ramis divaricatis.

7:mo ROTUNDATE: foliis fubrotundis.

Spatbulata.58. P. foliis fpathulatis fubcucullatis glabris. cynaroides.59. P. foliis fubrotundis petiolatis glabris. cordata. 60. P. foliis cordatis.

\section{\$. VI.}

\section{DESCRIPTIO SPECIERUM.}

Protec Species omnes caulibus arborefcunt vel frutefcunt \& perennant.

Radix perennis, fxpius craffa.

Rami fæpius verticillati \& proliferi.

Folis omnibus alterna, fempervirentia.

1. P. Decumbens. Caulis filiformis, angulatus, decumbens, parum ramofus, glaber, fangvino. lentus, pedalis.

Rami, in apice caulis, circiter quatuor, alterni, cauli fimiles. 
Folia filiformia, fimpliciter trifida, fecunda, erecta, glabra, remota, digitalia, internodiis longiora; pinaze in medio folii oppofitæ, folio fimiles, lobo medio paulo breviores.

Florum capitulum in apicibus caulis \& ra- morum terminale, magnitudine pifi majoris. Periantbiatn commune imbricatum, glabrum; Squamis ovatis, acutis.

Corolla fericea.

2. P. Florida. Tota, excepto calyce, glabra.

Caulis teres, erectus, purpureus, pedalis \& ultra.

Folia filiformia, fparfa, apice glandulofa, inferiora pinnata, fuperiora trifida, erecta, palmaria: pinnse oppofitæ, fubtrijugæ, polliçares, fenfim breviores.

Flortun capitula terminalia, pedunculata.

Pedunizuli plures, alterni, erecto-patuli, braEteati, uniflori, inæquales, pollicares usque palmares.

Bractea in pedunculis inferne Sparfe, lanceolatæ; fuperne aggregatæ, flores obvallantes, majores, oblongx, omnes acutx, integræ, membranacex, purpuraícentes, pollicares.

Perianthium imbricatum; fquanse lanceolatæ, membranacex; glabræ, ciliatæ ciliis flavefcentibus longis, imprimis verfus apices.

3. P. Cranoides. Coulis teres, erectus, fimplex vel ramofus, glaber.

Rami fubverticilati, cauli fimiles, inæquales. Folia 
Folia filiformia, fimpliciter trifida, rarius bis trifida, acuta, glabra, frequentia, ereeta, pollicaria \& ultra; pinzze oppofitx, confimiles.

Flonth capitulum in apicibus caulis \& ramorum terminale, folitarium, magnitudine cireiter nucis avellanæ.

Periantbiztn commune imbricatum, ferrugineum, glabrum: fquamis lanceolatis, fuperioribus ciliatis ciliis albis.

Corolla intus purpurafcens, extus tota la. nata pilis longis denfisque albis.

4. P. PATUlA. Coulis filiformis, erectus, ruber, glaber, ramofus, pedalis.

Rami umbellati, glabri vel pubercentes, inæquales, patentes, ramulofi ramulis filiformibus.

Folia filiformia, trifido-pinnata, rarifime bipinnata, callofo-acuta, frequentia, glabra, patula, pollicaria.

Florurn capitula in ramis \& ramulis termi. nalia, aggregata, fubfeffilia, fenfim florentia, magnitudine pifi.

Periantbium commune imbricatum: Squame ovatæ, acuminatx, glabræ.

Corolla niveo-tomentofr.

5. P. Sph mis, radiculis fibrofis.

Caulis teres, flexuofus, erectus, rigidus, fufco. purpureus, fimplex, fuperne totus tectus foliis, inferne nudus, pedalis, craffitie calami anferini.

Folia 


\section{de Proter.}

Folz filiformia, bipinnata, flexuora, ereeta, glabra, frequentia, pollicaria; punne circiter 4 , oppofitx; pinnule alternx, fubfaftigiatx, apice acutx, rufelcenti-glandulofi.

Flor zzn capitula in apice caulis terminalia, pedunculata, aggregata, magnicudine nucis ifere avellanx.

Pedzuculi rufefcentes, hirti, uniflori, inferiores horizontales, fuperiores erecti, capittlis duplo breviores.

Pernanthum commune imbricatum; Squt mis latis, ovacis, acuminatis, bafi villofis, rufefcentibus.

Corollo argentea, pilis longis imbricatis.

6. P. Serraria. Caulis teretufculus, flexuofus, eredus, ramofus, purpureus, glaber, bipedalis \& ultra, craffitie vix calami columbini.

Rami alterni, flexuofi, filiformes, fubfartgiati, ceterum cauli fimiles, rarius ramulofi. erecto - patuli.

Folia filiformia, bipinnata, erecto-patula, frequentia, internodiis longiora, pollicaria; pinne circiter tres, oppofitx; pinnule alternæ, glandulolo-acutæ.

Florum capitula in ramis terminalia, pedun. culata, faftigiata, aggregata, magnitudine pifi.

Pedunculi filiformes, alterni, laxi, villofi, capitulis longiores, fuperiores fenfim breviores。

Perianthizun commune polyphyllum, hirtum, brevifimum; fquamis lanceolatis.

Corolle 


\section{Corolla extus hirta.}

$V$ on iat r:o foliis omnibus glabris.

2:0 foliis inferioribus glabris, fuperioribus hirtis.

3:0 folis inferioribus hirtis \& fuperioribus hirfutifimis.

7. P. Triternata. Caulis fubangulatus, fuperne flexuofus, fimplex,' glaber, fesquipedalis \& ultra.

Folia filiformia, triternata, verfus apicem caulis frequentia, erecta, glabra, fpithamæa; pinne oppofitx, acutæ, apice glandulofx; pinnule alternæ.

Flortum capitula terminalia, pedunculata, aggregata, magnitudine pifi majoris.

Pedunculi alterni, tomentof, fexuofi, cernui, unifori \& biflori, capitulo longiores, pollicares.

Bractea ad bafin pedunculi fubulata, glabra.

Periantbium commune polyphyllum; fqua me uti \& palex flores diftingventes lanceolatx, hirta.

Corolla lanata pilis argenteis.

8. P. Gloirerata. Caulis teres, erectus, purpureus, glaber.

Folza in apice caulis aggregata, fliformia, bipinnata, glabra, fesquidigitalia; pinnue circiter 4 , alternæ, confimiles, apicibus callóoxufef́centibus; pinnula circiter bina, alternx, pinnis fimiles. 
Peduncultus communis ex apice caulis continuatus, elongatus, nudus, teres, purpurafcens, glaber, fpithamæus; interdum pedunculi plures ex apice caulis.

Pedinculi proprii verfus apicem pedunculi cummunis alterni, uniftori vel bifori.

Bračte fub pedunculis lubulaiæ, glabræ. Flormu capitula magnitudine pifi majoris. Pevianthium commune polyphyllum, glabrum; Jutumis ovatis, acuminatis.

Palew flores diftingrentes fquamis calycinis fimiles.

Corolla extus hirfuta.

9. P. Phylicoines. Caulis teres, ereßtus, fuccus, glaber, inferne a calu foliorum tuberculatus, fuperne ramofus, pedalis \& ultra, craffitie calami fcriptorii.

Rami fubumbellati, fubfaftigiati, hirti.

Folia filiformia, bipinnata, inferiora glabra, fuperiora hirta, frequentia, erecta, pollicaria; punze circiter 3, oppofite; pinuzula alternæ, fubulatæ, apice rufeicentes.

Florzun capitulum in ramis terminale, folitarium, ovacum, nuce avellana majus.

Periantbium commune polyphyllum; fquamis lanceolatis, extus hirtis, intus glabris.

Corolla lanata pilis denfis grifeis.

10. P. Lagopus. Cazilis teres, ereetus, inæqualis, cinereus, inferne nudus, glaber, fuperne ramofus. 


\section{Ramni fubverticillati, ereeti, hirti.}

Folia filiformia, bipinnata, inferiora glabra, fuperiora villofa, pollicaria; pinne tres, op. pofitx; pinzule alternx, acutx, apice glandu. lofix, rufefcentes, faftigiatx.

Floratin capitula in ramis terminalia, fpicata; fpice folitarix, fefliles, oblongre, acuter, villofx villo denfiffmo albo, erectre digitales; capitulis aggregatis, quadriforis.

Diverfa omnino eft a P. Spicata capieulis fuis aggregatis \& fpica conica, feffili, hirfu. tiffima.

I1. P. Spicata. Caulis teres, erectus, ramofus, purpureus, tenuiffime tomentofus, bipedalis \& ultra, craffitie calami fcriptorii.

Rnzbi verticillati, quaterni, fmiles cauli.

Folia filiformia, bipinnata, glabra, fuprema fericea, frequentia, bipollicaria; pinne tres, oppofitx; pinnula alternx, acutx, apicis glandula oblonga flavefcenté.

Flon zim capicula fpicata; fpicse verfus apicem caulis \& ramorum plures, pedunculate, virgatx, ereftx, digitales; capinulis fparfis, remotis, quadrifioris:

Pedunzali fpica fparfi, tomentofi, multiflori, pollicares \& ultra.

Perintoinu comsune 4-phyllum, tomentofum, credum, abfolnta forefcentia patentifimum; Jazanis ovatis, acutis, concavis, corolla brevioribus. 
Corolle quatuor, extus tenuifime tomentofæ, fub apice barbatæ.

12, P. Sceptrum. Caulis teres, ereetus, glaber, ramofus, bipedalis \& ultra, craffitie calami anferini.

Rami fubvercicillati, ereâ, ghabri.

Folia inferiora filiformia, bipinnata, pinnis \& pinnulis alternis, faftigiatis, fulcatis, apice glandulofis, tripollicaria. Intermedia inferne attenuata, obovato-oblonga, trifida, apice glandulofa, bipollicaria. Suprema petiolata, obovato-oblonga, apice glandulofa, poliicaria. Ommia frequentia, imbricata, avenia, glabra.

Florum capitula in ramorum apicibus fpicata; fpice ferfiles, oblongx, argenteo-alba, tripollicares, capitulis aggregatis.

Periantisiun commune quadriforum, tomentofum; fquanis ovatis.

Corolla argenten, fere pollicaris.

I3. P. Crinita. Coulis teres, ereetus, villofus, bipedalis \& ultra.

Folia lefilia, ovata, obtufiffima, integra, apice 5-dentata, rarius indivifa \& 3 -dentata, dentibus callofis, glabra, bafi villofa, venofa, ereeto-patentia, pollicaria vel panlo ultra.

Florum capitula terminalia, breviffime pedunculata, duo vel tria, aggregata, magnitudine fere juglandis.

$$
\text { C } 3 \text {. }
$$


Periantliqun commune imbricatum; futu. mis lanceolatis, intus glabris, extus tenuiffime villofis, apice barbatis.

Corolla cylindrica, villofa, purpurafeens, ungvicularis.

Differt a Conocarpa: forum capitulis pluribus \& minoribus; Siluamis calycinis lan. ceolatis, longis; corollis brevioribus plis brevibus.

I4. P. CONOCARPA. Coullis teres, erectus, ramofus, tripedalis \& ultra, ciallite calami. Rami pauci, alterni.

Folia fefflia, oblonga, oburfa, integra; apice dentata, dentibus callofis quinque, rarius feptem, tribus vel nullis, ereeto-patcn. tia, gabra, bafi villofa, bipollicaria.

Florunn capitulum terminale, folitarium, magnitudine pyri.

Periantbium commune imbricatum; fqua. me ovatæ, acuminatæ, glabræ, ciliatæ.

Corolla filiformis, hirfuta pilis longis flavis, pollicaris.

Variat 1:0 caule glabro \& villofo.

2:0 foliis 7-dentatis, 5 -dentatis, 3 -dentatis

\& indivifis in diverfis arboribus, fxpe in eodem ramo.

15. Elliptica. Carulis flexuofus, ereetus, villofus.

Folia elliptica, 3-dentata, raro 4-dentata, glabra, erecto-patula, digitalia.

Flortum 
Flortum capitulum terminale, folitarium, magnitudine pyri.

Periantbium commune imbricatum, tomentofum.

Corolle longx, hirfutx.

16. P. Hypophylla. Caulis teretiufculus, purpurafcens, glaber, decumbens, fimplex, pedalis \& ultra, craffitie calami columbini.

Folia elliptico-lanceolata, obtufa cum acumine, indivifa, apice 3 -dentata dentibus callofis, inferne integra, fecunda, erecta, glabra, avenia, palmaria.

Florum capitulum terminale, folitarium, magnitudine juglandis.

Periantbiuth commune imbricatum, tomentofum; Squamis ovatis, acutis.

Corolla filiformis, villofa, pollicaris.

Differt facile $a b$ aliis caule decumbente foliisque fecundis.

17. P. Cucullata. Caulis teretiufculus, nodulofus, tomentofus, fimplex, erectus, craffitie calami anferini.

Folia feffilia; infra medium latiora, ovata, integra; fupra anguftiora, linearia, tridentata dentibus callofis, avenia, glabra, frequentia, imbricata, fesquipollicaria.

Florum capitula in axillis foliorum fuperiorum lateralia, feffilia, 5 -flora.

Perian- 
Ferisatbins? commune imbricatum, parum villofum; fulamie inferiores ovati, acuta, duplo breviores; fiperiores oblonga, acuminata, corolla duplo breviores.

Corolle filiformes, inferne pubefcentes, fuperne denfe villofa, pollicares.

Dignofcitur facile capitulis fuis latcralibus, anguftis.

I8. P. Tomentosa. Tota planta incano-tomentofa. Cazlis teres, erectus, fimplex, bipedalis \& ultra.

Folia linearia, integra, apice 3-dentata, rariffime 5 -dentata dentibus callofis, frequentia, ereeta, pollicaria \& fefquipollicaria.

Florzın capitulum folitarium, terminale, vel duo, magnitudine fere juglandis.

Periantbium commune imbricatum; fintumis ovatis, acutis.

Corolla tenuiffime pubef́centes, ungviculares. Dignofcitur facile eo, quod tota tomentofa fit. Variat foliis anguntioribus \& latioribus.

19. P. HeterophytuA. Caulis teretiufculus, inæqualis, fufcus, glaber, decumbens, apice ramofus, pedalis.

Rami alterni, pubef́centes, divaricati.

Folia oblonga, inferne attenuata, acuta, integra, bidentata \& 3 -dentata dentibus callofis, glabra, frequentia, incumbenttia, ungvicularia. 
Flor un capitulum in ramis terminale, fo. litarium, magnitudine nucis avellanæ majoris. Perinatbiuzb commune imbricatum, tomen. tofum; Jquamis lanceolatis, intus glabris.

Corolla villofa, ungvicularis.

20. P. Pinifolia. Tota planta glabra.

Caulis teres, erectus, ramofus, bipedalis \&r ultra.

Rami verticillati, cauli fimiles.

Folia filiformia, fubcanaliculata, acuta, apice glandulofa, frequentia, erecto-incurva, bipollicaria.

Florum racemi fafciculati, terminales, faftigiati.

Bracte fubulatx.

Pedunculi angulati, breviffimi.

Corolla exacte 4-petala. Petala linearia.

Anther ce corolla medio infertx, lineares, circumflexæ.

21. P. Racemosa. Caulis teres, erectus, ferrugineus, glaber, ramofus, tripedalis, craffitie vix calami columbini.

Rami bini, terni, quaterni, flliformes, ereBi, cauli fimiles.

Folia filiformia, acuta, frequentia, ereeta, inferiora glabra, fuprema fericea, pollicaria.

Flores in ramis terminales, racemofi. Racenni digitales.

Pedunculi capillares, breves, glabri, tniflori. 
Calyx uniflorus, triphyllus; foliis ovatis, acutis, villofis.

1.:- Corolla tota hirfuta lana denfa, lineam longa. Hac unica eft fpecies omnium notarum Protearum, quæ unicum rantum habet florem intra caly$\mathrm{cem}$, dum reliquis duo, quatuor vel plures flores intra calycem funt.

Hac nota characteriftica optime difingvitur a P. caudata \& incurva, quibus primo intuitu alias fimillima. 22. P. Incunva. Cautis teres, ereetus, rufefcens, glaber, luperne ramofus, bipedalis \& ultra.

lanki verticillati, inæquales, cauli fimiles. Folia fparfa, filiformia, incurva, glabra, pollicaria.

Fiorum capitula racemofo-fpicata, fubfesfilia, tomentofo-incana.

Heriantbuzu commune 4-phyllum, 3-forum vel 4 -florum.

3. P. CAUD A TA. Caulis teres, ercetus, rufefcens, glaber, fuperne ramofus, circiter tripedalis.

Rum ereeti, cauli fimiles.

Folia filiformia, erecta, inferiora apice glandulofa, hirta; fuperiora hirfuta; imbricata, ungvicularia.

Flortwn capitula fubfeffilia, fpicata; Spica cylindricx, ereetx, digitales.

Periantbium commune 4-phyllum, rarius uniforum, raro triflorum, frepius biflorum; lacime ovatæ, acuminatx, viliofx, inæquales.

Corolla hirfuta. 
Valde fimiles \& affines funt hæ tres fpecies, racemofit, incurva \& caudata, ut obiter intuenti varietates tantum appareant. Differunt vero incurva $1: 0$ a racemofa: $\alpha$. calycibus quadriflcris nec unitloris.

$\beta$. foliis magis incurvis.

2:0 a cauđata: a. foliis multo longioribus \& incurvis.

b. capitulis florum racemofis magisque remotis.

caudata a racemofa: $\%$ capitulis feffilibus.

$\beta$. calycibus 4-phyllis, bifloris \& 3 -floris.

$\gamma$. fpica florum frobiliformi, longa.

$\delta$. foliis brevioribus, fubfecundis, apice patulis.

24. P. Bracteata. Tota glabra.

Radix fufformis, defcendens, radiculis fibrofis.

Caulis teres, rugofus, erectus, fimplex, ra. rius bifidus, fufcus, pedalis:

Folia filiformia, fubcanaliculata, acuta, fubfecunda, frequentia, tripollicaria.

Florum capitulum terminale, folitarium, magnitudine juglandis.

Periantbizm nullum, fed receptaculum commune obvallatum foliis triquetris \& bracteis alternis, integris, pinnatifidis. 
Corolla coharens inferne, fubtetragona, $\pi$ pice 4 -fida; limbo patenti, glabro, intus fareto. pappo denfo, albo, corolla breviore.

Hre convenit cum P. pinifolia \& aulacea calyce nullo; cum urmbellata braeteis multifidis.

25. P. Comosa. Tota glabra.

Carilis teres, a cafu foliorum nodulofus, crectus, fufcus, glaber, ramofus, pedalis \& ultra, craffitie pennx anferinx.

Rsmi verticillato-quaterni, faftigiati, erecti, cauli fimiles.

Folia inferiora filiformia, obcufa, incurvatoereeta; fiperiora elliptico-lanceolata, obtufa cum acumine, avenia, comofa, omnia frequentia, resquipollicaria.

Fiores in cono terminali f́litario, magnitu. dine juglandis.

26. P. Punpurea. Tota glabra.

Cantis teres, fubfiliformis, rugofus, brunneus, ramofiffimus, decumbens, bipedalis.

Rami fpari, fubrmbellati, pubefcentes, ranulofi, cauli fimiles.

Ramuli fupremi faftigiati.

Folic lineari-fubulata, fupra fu!cata, fubtus convexa, mutica, integra, frequencia, imbricata, pacenti-recurva, lemiunggvicularia.

Flonzin capitula terminalia, in ramis \& ramulis folitaria, cernua, magnitudine pifi. 


\section{de Proteit.}

Periantbizan commune polyphyllum, im. bricatum, tomentolum; fquanh ex exteriores minutæ, ovatæ, breviffima; inferiores lanceola. tæa, capitulo longiores.

Corolloe ferruginex, minute:

27. P. Prolifera. Caulis erebus, tenuis, glaber, proliferus, bipedalis.

Ranni ereeti, foliis teeti, cauli fimiles.

Folia fubulata, frequentia, fubimbricata glabra, ungvicularia.

Flormun capitula in divaricatione \& apicibus ramorum terminalia, magnitudine pifi.

28. P. Corymbosa. Tota glabra.

Canlis teres, ereeus, ramofus, quadripeda. lis \& ultra.

Rami aggregato-fubvericillati, plurimi, breves, fubtartigiati, ereeto-patuli, digitales, internodiis breviores.

Folia linearia, fupra plana, fubtus convexa, acutiufcula, frequentia, imbricata, ungvicularia.

Flor zun capitula in ramis \& ramulis terminalia, folitaria, magnitudine pifi minoris.

Periantbizm commune polyphyllum, corolla brevius.

Corolle luter, minuti:

Serzen obovatum, compreffum, margine actito, infra attenuatum, apice obtufum, villofum, cavum nucleo albo, non dehifcens.

Vàrietas ef perianthio tomentolo.

$\mathrm{D}_{3}$ 
ina sin.29. P. NANA. Tota planta, exceptís corollis, glabra.

Caulis teres, erectus, ramofus, bipedalis, craffitie pennæ.

Ranni fubterni, erecto-patentes, apice filiformes, cernui.

Folir lineari-triquetra, acuta, frequentia, fub-imbricata, remipollicaria.

Flortun capitulum in ramis terminale, folitarium, cernuum, magnitudine pruni.

Perianthium commune imbricatum; fquama exteriores ovatx, virefcentes, ungviculares, interiores oblongæ, acutæ, purpureocoloratæ, patentes, pollicares.

Corolle lana aurea extus tętx, ungviculares.

Rofam referentibus floribus fatim nofcitur.

30. P. Lanata. Canlis filiformis, erectus, debilis, glaber, foliis tętus, ramofus, bipedalis.

Rami bini, inæquales, cauli fimiles.

Folia linearia, fupra plana, fubtus convexa, acutiufcula, imbricata, glabra, ungvicularia.

Florum capitulum in ramis terminale, fericeum, magnitudine fere juglandis.

Periantbium commune polyphyllum; fquasnis lanceolatis.

Corrolle extus pilis argenteis totæ lanatæ \& barbatæ, ungviculares. 
3I P. Torta. Tota planta, exceptis corollis, glabra. Caulis teres, fuberectus, lævis, ramofus, bipedalis \& ultra.

Rami verticillato-quaterni, incurvati, inxquales, cauli fimiles.

Raznuli in apicibus verticillati, brevifimi. Folia linearia, obtufufcula, callofa, integra, obliqua, erecto-patula, frequentia, femipollicaria.

Florum capitula in ramulis terminalia, magnitudine pifi.

Periantbizsm commune imbricatum, breviffimum, tomentofum.

Corolle argentex.

32. P. ALBA. Tota argenteo-tomentofa.

Caulis teres, erectus, ramofus, parum to. mentofus.

Rami umbellaci, circiter fex, filiformes, erecti, inæquales.

Foliz linearia, obtufa, ereeto-imbricata, pollicaria.

Florum capitula in divaricatione ramorum \& apicibus terminalia, tota argenteo-lanata, foliis obvallata, magnirudine pifi.

33. P. Aulacea. Tota planta glabra.

Caulis teres, erecus, parum ramofus, proliferus, 3 vel 4-pedalis, craffitie calami.

Rami fubverticillati, friati, ereeto-patentes. 
Folia feflilia, elliptica five inferne attentuat, obtufa cum acumine, integra, avenia, nervo medio folitario, ereeta, caulem ramofum tegentia, approximata, internodiis multo longiora, digitalia.

Florzm racemi terminalcs, fubumbellati, far Rigiati, oblongi, cernui, fenfim florentes, poillicares.

Pedunculi rugofi, vix lineam longi.

Braftee fub fingulo pedunculo lanceolate, canaliculatæ, alba, ereeta, longitudine pedunculi \& dimidii floris.

Periantbium nullum omnino.

Corolla tetrapetala. Petala linearia, actita, canaliculata, xqualia, ereeta, glabra, alba, ungvicularia.

Antberce medio petali inferta, lineares, Ipirales, alba.

34. P. Umbellata. Tota planta glabra.

Caulis teres, ereEtus, ramofus, bipedalis \& ultra: Rami inferius in caule rariores, verfus apicem frequentes, umbellati, faftigiati.

Folia ut in P. aulacea.

Florum capitula in ramis terminalia, folitaria, obvallata foliis \& bracteis, magnitudine nucis avellanæ majoris.

Perinntbium rullum, fed brąiex in receptaculo communi alternx, pinnatifidx.

Corolla ut in bradeata. 
35. P. Linearis. Caulis teres, ereetus, ramofus, purpureus, quadripedalis.

Kami teretes, longi, fimplices, friati, foliofi, glabri.

Folia fefflia, linearia, inferne fenfim atte. nuata, bafi fubtus callofa, obtufa, apice callo rufefcenti, integra, margine parum reflexo, fupra convexiufcula, fubrugofa, fubtus concava, frequentia, erecta, digitalia \& ultra.

Floruan capitulum terminale, fubfolitarium, conicum, magnitudine pomi mediocris.

Periantbizin commune polyphyllum, imbricatum; futuane latr, ovatx, acutx, intus totæ glabre, extus pubef́centes, bafi tomento denfo albo.

Receptacuizun villofum villo albo denfo.

Corolle tubus compreffus; Limbus 2-par titus, laciniis linearibus; altera latior apice 3-fida, cujus laciniis ftamina inferuntur, \& ftigma reflexum ante explicationem; alter $a$ triplo anguftior, integra; utraque villofa, Rylo dimidio brevior.

Hæc convenit cum conocarpa, totta, lineari \& aliis calyce imbricato \& piftillis longiffimis. 36. P. Scolymus. Totus frutex glaber.

Caulis erectus, rugofus, ramofus, tripedalis. Rumi fubverticillati, ereeti, cauli fimiles.

Folia inferne attenuata, lanceolata, acuta, glandula terminali, integra, erecto-patula, frequentia, digitalia. 
Floran capitula in ramis terminalia, folitaria, ovat, foliis obvallata, magnicudine pruni.

l'erialibiun commune imbricatum; finame extcriores ovatæ, interiores oblongx, concavæ, obtufx.

Corolla purpurafcens.

Receptaculuts ferrugineo-tomentofum.

37. P. Mellimera. Tota arbufcula glabra.

Caulis arboreus, erectus, ramofus, orgyalis vel paulo ultra.

Ram fparfi, ereeti, ramulofi.

Folia inferne attenuata, lanceolata, obtufiufcula, integra, avenia, frequentia, patula, digitalia.

Florltin capitulum terminale, ovato-oblongum, ferrugineum, vifcofum, magnitudine ovi anferini.

Pernantbium commune inbricatum; fquame infimæ minutæ ovatx; fuperiores oblongx; fupremæ lanceolatæ, ereetæ, concavæ, digitales. Cum fequenti hæc confufa fuit, licet diftinctifima caule arboreo, ramolo, multifloro; foliis planis; cono oblongo, bituminofo, glabro, nitido.

33. P. REpens. Tota glabra exceptis corollis.

Caulis flexuofus, brevifimus, decumbens, vix palmaris, fubramofus rathis binis vel tribus.

Folia in apice caulis \& ramorum conferew, feffilia, elliptica, fæpe convoluta, integra, margine cartilaginea, fcabra, ereda, fpichamæa. 
Flortın capitulum terminale, folitarium, rotundum, foliis obvallatum, magnitudine pruni.

Perianbum commune imbricatum; fquance evteriores minutx, ovata, obtufa; inferiores lanceolata.

Corolla villofa villo albo.

Hæc longe a priore diverfifima, radice repente, caule brevifimo, fubfimplici, unifloro; foliis linearibus, marginatis; capitulo ovato minori, minime vifcofo.

39. P. OвLIсUA. Coulis teres, erectus, glaber, bipedalis \& ultra.

Rami filiformes, creeti, fparfi, inæquales, pubefcentes.

Folia fefflia, lanceolata, acuta, glandula terminali, integra, obliqua, erecto-patula, frequentia, glabra vel tenuiffme tomentofa, fe mipollicaria.

Florum capitulum terminale, folitarium, magnitudine pruni.

Perianthium commune imbricatum; fuame exteriores ovatæ, acutæ, glabræ, interiores oblongæ, pilofæ.

40. P. PARvifiora. Caulis teres, erectus, ramofiffimus, tripedalis.

Rami fparfi, filiformes, flexuofi, virgati, ramulofi.

Ramuli verfus fummitates ramorum, alterni, frequentes.

E 2

Folia 
Folia lunceolata, inferne anguftata, glenduIa obtuia terminata, integra, obliqua, ereeta, ungvicularia.

Flomin capitula in apicibus ramulorum tubtetragona, glabra, magnitudine piperis.

Peduacusuli nulli nifi ramuli apice floriferi.

Periantbium commune imbricatum; Squanue quadrifariam poficx, ovate, cbufæ, concavr, glabræ.

Variat caule \& foliis glabris \& incano-fubtomentofis. 4. P. Pallens. Caulis fruticofus, erectiufculus, fubangulatus, glaber, ramofus, pedalis vel paulo viltra.

Rami fparfi, divaricati, fimplices, cauli fimiles, xquales, ereeti.

Folia caulina \& ramea fparfa, feflilia, lanccolata, inflexa, fubdecurrentia, inferne parum attenuata, integra, obtufiuicula, apice callofa, glabra, pollicaria vel ultra.

Rractere florum conum obvallantes foliis fublimiles, concavre, ereetx, apice patulo \& callofo, albici, cono triplo longiores.

Flortim conus in ramis terminalis, ovatus, glaber, fefrilis.

Perianthit communis fquame imbricatre, ovatæ, acutiufcula, concavæ; inferiores majores glabra, fuperiores fericeo-tomentofx.

Receptaczulum nudum. 


\section{de Proten.}

Corolla 4-petala; Petala linearia, obtufa, lineam longa; ungves albæ, villofa; lamina patentia, flavefcentia.

Filanenta nulla. Antbere 4 , infra apicem petalorum feffiles, ovatx, didymæ, flavæ.

Germen fuperum, bilobum, glabrum.

Stylus filiformis, incraffacus, Havefcens, lon. gitudine corollæ.

Stigya clavatum, obtufum, fiavicans.

42. P. Conifera. Caulis fruticofus, erectus, ramofus, tripedalis vel paulo ultra.

Rami verticillati, Alexuofo-ereeti, foliofi, ramulofi.

Folia elliptico-Ianceolata, acuta glandula terminali, integra, concava, glabra, fubrugo$\mathrm{fa}$, frequentia, erecta, pollicaria.

Florum conus in ramis terminalis, folitarius, tomentolus, ovarus, magnitudine pifi.

Valde afines funt P. pallens coniferaque \& difficile $a b$ invicem diffingvuntur plures earum varietates, nifi notis, qux fequuntur, foilicet: I:O quod in pallemi rami fparfi \& fimplices, fo-

lia magis lanceolata, conus florum glaber \& bractex coloratx.

2:0 quod in conifera rami verticillati iterumque ramulofi, folia elliptica, conus florum tomentofus \& folia floralia concolora.

43. P. Levisanus. Tota planta, exceptis capitulis, glabra. 
Conlis ereatiufulus, ranofus, pedalis.

Rami verticillato-proliferi, fex circitcr vel piuciores, inæquales, ereeti, apice nutantes, iterum ramulofi.

Folia fpathulata feu inferne attenunta, fuperne latiora, obtufa cum acumine, integra, avenia, ere̊to-patula, ungvicularia.

Flortum capitula in ramulis terminalia, folitaria, lanata, foliis obvallata, magnitudine pifi. Periantbizu commune, tomentofum.

44. P. Strobilina. Caulis ereeus, ferugineus, pubefcens.

Folia feffilia, ovata, fubretufa, glandula terminata, concaviufcula, integra, glabra patentia, reflexa, fesquipollicaria.

Flormin conus terminalis, folitarius, glaber, magnitudine pruni.

45. P. Imbricata. Tota planta, exceptis ramis \& corollis, glabra.

Caulis erectus, ramofus, tripedalis \& ultra. Rami bini vel terni, filiformes, erecti, inæquales, pubefcentes.

Folia feffilia, lanceolata vel oblonga, glandula terminata, integra, rugofa, imbricata, bafi adpreffa, apice patula, ramos tegentia, femiungvicularia.

Florum capitula in ramis terminalia, foiltaria, rarius bina, oblonga, magnitudine juglandis minoris.

Perian. 


\section{de Proten.}

Perianthizu commune imbricatum; futuma lanceolatæ, acuto-glandulofx, ungviculares.

Corolía extus lana flaveícente tota tecta.

46. P. Sericea. Caulis teres, decumbens, ramofus, glaber.

Rami filiformes, curvati, credtufculi, fparfi, inæquales, glabri.

F́lia lanceolata, integra, erecta, tota fericeotomentofa, ungvicularia.

Flortun capitula in ramis terminalia, folitaria, rarius aggregata, fubcernua, magnitudine pifi minoris.

Periantbizm commune imbricatum, glabrum; Squatnis lanceolatis.

Corolla luteo-tomentofa, vix ungvicularis.

47. P. Saligna. Caulis teres, erectus, friatus, purpurafcens, inferne nudus, glaber, fuperne ramofus, quadripedalis.

Rami alterni, conferti, breves, virgati, cauli fimiles.

Folia lanceolata, acuta, apice glandulofa, integra, tenuiffime argenteo-tomentofa, erecta,. vix pollicaria.

Florum capitula in ramis terminalia, oblonga, foliis obvallata; folitaria, magnitudine pifi.

Folia argentea funt, fed longe tamen difineta a P. argentea; hæc enim frutex, illa arbor, prater cetera; differt quoque a conifera. 
48. P. Argentea. Tota tomentofa.

Caulis arboreus, craficie femoris, nudus, ramofinmus, orgyalis \& ultra.

Rami \& ramuli teretes, rugofi, a cafu foliorum tuberculati, flexuof, creeto-patentes. Folia feffilia, lanceolata, acuta, apice glandulofa, integra, argenteo-tomentofa, nitentia, ciliata, patula, frequentiffma, digitaliạ.

Florturn conus terminalis, rotundus, magnitudine pruni, fenfim increfcens in magnitudinem pomi majoris.

Perianthii communis \& coni fquamæ ovatx, obtufx, tomentofx.

Corollce argenteo-tomentofx, vix ungviculares.

49. P. Acaulis. Tota planta glabra.

Caulis breviffimus, decumbens, raro ramofus, fufcus, bipollicaris.

Rami fubverticillati, diffufi, nodulofi, rugofi, inæquales, palmares.

Folin fparfa, decidua, terminalia, perfiftentia, inferne attenuata, oblonga, venofa, in. tegra, marginata, inæqualia, pollicaria usque palmaria.

Florums capitulum terminale, folitarium, magnitudine juglandis.

Periantbiutn commune imbricatum; Squamee exteriores ovatx; interiores oblongx, obtulx.

Corolle hirfutx. 


\section{de Proter.}

50. P. Myrtifolia. Tota planta, exceptis corollis, glabra.

Caulis reres, ereotus, purpureus, ramofus, tripedalis.

Rimm alterni vel terni, fliformes, laxi, flexuofi, patuli, alternatim ramofi, inrquales, purpurafcentes, apicibus parum villofis. Folia ferfilia, oblonga, obtufa, apice glandulofa, bafi obliqua, integra, patula, ungvicularia.

Flortim capitula in ramis \& ramulis terminalia, folitaria, magnitudine pifi.

Periantbizm commune imbricatum; /quane exteriores minores, lanceolatx, apice nigræ, interiores majores, ovatæ, obtufr, fubciliatx.

Corolle extus albo-hirfute.

5I. P. Granditiora. Tota arbor glabra.

Caulis arboreus, ereetus, ramofus, orgyalis vel ultra.

Folia fefflia, oblonga, obtufa, integra, venofa, patentia, digitalia.

Flortzin capitulum terminale, fclitarium, faftigiatum, magnitudine pugni.

Perianthinin commune imbricatum; fquanne exteriores ovatæ, fenfim majores; interiores oblongæ, obtuir.

Corolle tomentofo-albx.

Hac \& P. Cynaroides fpeciofx funt capitulis maximis; diftingvuntur invicem 
grandiflor a r:o foliis lanceolatis, fefflitus.

2:0 caule arboreo, ramofo, alto.

cynaroides $1: 0$ foliis fubrotundis, petiolatis.

2:0 caulc frutefcente, vix ramolo, humili.

52. P. Glabra. Cazulis fruticofus, totus glaber.

Folia feffilin, oblonga, apice glandulofa, integra, craffa, avenia, erecta, pollicaria.

Florzum capitulum terminale, folitarium, glabrum, magnitudine pomi.

53. P. Speciosa. Cazulis arborefcens, teres, villofus, ereetus, ramofus, orgyalis.

Folia fubpedunculata, oblongya, acuta apice nigro, insegra, marginata, nervora, coriacea, patula, glabra, palmaria.

Florum capitulum terminale, ovatum, miagnitudine ovi anferini.

Perianthinu commune imbricatum; fquame ommes glabrx; exteriores ovatx; intermedix oblongx; interiores lineari-oblongx; inferne anguftiores, extus apice villo longo nigro vel ferrugineo ciliatx.

Corolle filiformes, hirfutx.

V ariat foliis anguntioribus \& latioribus; calycibus apice barba ferruginea \& nigra.

54. Р. Тотта. Caulis teres, erectus, villofus.

Folia feffilia, ovato-oblonga, obtufa, glandula rubra terminata, integra, raro 3-dentata, erecto-patula, glabra, pollicaria. 
Florunn capitulum terminale, folitarium, ovatum, magnitudine pyri.

Periantbium commune imbricatum, glabrum; Jquance ovatæ, acutæ, ciliatæ, corolla multoties breviores.

Corolle filiformes, villorx, pollicares.

55. P. Hirta. Caulis teres, erectus, villofus, tripedalis \& ultra.

Folia feffilia, ovata, glandula obtufa terminata, integra, rarius ciliata, tenuiffime nervofa, glabra, imbricata, pollicaria.

Florum capitula infra apicem lateralia, in axillis foliorum folitaria, circiter 8-flora.

Perianthium commune imbricatum; $\int q u a m e$ fenfim longiores, oblongæ, acutæ, luteo-fangvinex, fpiendences, fubpollicares.

Corollw filiformes, villofx, perianthio paulo breviores.

Piftilla corolla duplo longiora, curva, glabra.

56. P. Pubera. Caulis ereetus, villofus, apice ramolus, bipedalis.

Rami verfus apicem fubverticillati, inæquales, patuli, cauli fimiles.

Folia feffilia, ovata, glandula obtufa, integra, tomentofa, imbricata, ungvicularia.

Florum capitula terminalia, raro folitaria, fxpe plura aggregata, magnitudine nucis avellanæ majoris.

$$
\mathrm{F} 2 \text { perinn- }
$$


P'eriantbium commune hirfutum; fquam! lanceolatr.

Corolla villis lanata, ungvicularis.

Varint foliis ovatis \& oblongis.

57. P. Diviricata. Carulis teres, flexuofus, prbefcens, ramofus, pedalis \& ultra.

Risini verticillati, terni vel quaterni, filiformes, divaricati, ramulofi, pubefcentes.

Folia feffilia, ovato-fubrotunda, integra, villora, rugofa, imbricata, inferiora reflexa, lineam longa.

Florun capitulum in ramulis terminale, folitarium, cernuum, magnitudine pifi.

Corollee argentex.

58. P. Spathulata. Caulis ereetus, glaber, ramofus, bipedalis \& ultra.

Rami bini vel terni, flexuofo-ereeti, glabri purpurafcentes.

Folic petiolata, fpathulata, obtufa, marginata, integra, obfolete ftriata, fubcucullata, glabra, imbricata, ungvicularia.

Patiolus teres, folio dimidio brevior.

Floram capitula in apicibus ramorum aggregata.

Perianthizm commune fubtetraphyllum, tomentolum, 4-florum.

Corolla lanatæ, vix ungviculares.

59. P. Cynaroides. Cazulis teres, erectus, rugofus, fimplex, vix pedalis. 
Folia petiolata, fubrotunda, integra, marginata, venofa, glabra, patentia, digitalia.

Petiolus femiteres, rugofus, glaber, pollicaris.

Florum capitulum terminale, ovatum, fafigiatum, ereetum, magnicudine fere capitis infantis.

Peruatbium commune imbricatum; fquame fenfim majores, oblongx, acutx, tomentolx. Corolla albo-tomentofa.

60. P. Cordata. Tola planta glabra.

Caulis decumbens, fimplex, teres, ftriatus, fpithamæus.

Folia alterna, feffilia, cordata, fubrotunda, integra, marginata, 9-nervia, ereहta; inferiora majora, palmaria; fuperiora fenfim breviora. Capitulum floris fubradicale, ovacum, truncatum.

Periantbiam commune imbricatum; Squa mis ovatis, fenfim majoribus, oblongis, ereetis, obtufis.

Pappus femen obvallans purpurafcens.

\section{f. VII. \\ SYNONYMA.}

1. P. Decumbens. Differt. Noftræ Tabula I.

2. P. Fiorida. Tab. Diff. I.

3. P. Cyanoides, Protea folis linemibus ramolis. Royen. Lugd. Bat. I 86. Wachend. Ultraj. 202.

$$
\text { F } 3
$$

Cyamus 
Cyanzes æhiopicus rigidis, capillaceis, tenuisfimis foliis tritidis ex promont. bonx fpei. Plak. mant. 61. Tab. 345. f. 6. Hill. Eden. p. 630. Tab. 53. f. 6. e Plukenetio mutuata. Levcadendron cyanoides Lin. Sp. Pl. p. 137. Berg. Act. Stockholm. I 766. p. 326. Pl. Cap. 27. Protea cyanoides Lin. Syf. Nar. Tom. 2. p. I I 8. Mant. I 88 .

5. P. Glomerata. Serraria foliis temuifime divifis, capitulis tomentofis. Burm. Afr. p. 265. t. 99. f. 2 .

Levcidendron glomeratum Lin. Sp. Pl. p 137. Berg. Act. Stockh. 1766. p. 328.

Levcadendron elongatum Berg. pl. Cap. p. 27. Protea glomerata Lin. Syft. Nat. t. 2. p. I 17 . Mant. p. I87.

6. P. Serraria. Abrotanoides arboreum monomotapenfe, floribus in ramulorum cymis. Pluk. Mant. I. t. 329. f. I.

Anetbifolius frutex africanus, flore fericeo. Seb. thef. 2. tab. 63. f. 6.

Serraria foliis tenuiffime divifis, floribus rubris apetalis. Burm. Afr. p. 264. t. 99. f. I.

Levcadendron ferraria, Lin. Sp. Pl. p. 137. Berg. Act. Stockh. 1766. p. 327. Plant. Cap. p. 28.

Protea ferraria. Lin. Mant. p. I88. Syft. Nat. t. 2. p. II 7 . 
8. P. Sphriocephala. Anethifolizus frutex africanus minor, capite tomentofo. Herm. Afr. 3. Levcadeadron fphærocephalum. Act. Stockh. 3766. p. 327. Pl. Cap. p. 26.

Protea fphærocephala. Lin. Mant. p. I88. Syft. Nat. t. 2. p. 118.

9. P. Phylicoides. Levcadendron phylicoides. Berg. AEt. Stockh. I; 66. p. 328. Pl. Cap. p. 29. IO. P. LAGOPUS \&

II. P. Spicata. Levcadendrou fpicatum Berg. Act. Stockh. 1766. p. 327. Pl. Cap. p. 25.

Prosea f́picata. Lin. Mant. p. 187. Syft. Nat. t. 2. p. 117 .

I2. P. Sceptrum. Protea feeptrum Guftavianum. D:r Sparrman A\&t. Stockh. I777. p. 53. t. T. 13. P. CRinita. Protea foliis lanceolatis, obtufis, apice tridentato-callofis, capitulis terminatricibus, foliofis. Roy. Lugd. Bat. I 84. Wachend. Ultraj. 20 I.

Levcadendron olexfolium Berg. Act. Stockh. I 766. p. 320. Pl. Cap. p. I 5.

14. P. Con OCARPa. Scolymocephalus africanus latifolius lanuginofis foliis in fummitate crenatis. Herm. Afr. 20. Ray. Dendr. 9.

Conopboros, capitis bonæ lpei folio in fummo dentato. Raj. App. 240. Petiv. Mur. 240. Levcadendron africana arbor argentea, fummo folio crenato. Pluk. Alm. 212. t. 200. f. 2. Folii tantum figura datur.

Cono- 
Conocarpodendron folio craflo, nervo laniinofo fupra crenato ibique limbo rubro, ficre aneo, cono facile diciduo. Boerh. Lugd. Bat. T. 2, p. 196. t. 196.

Levcadendron folis ovatis, obrerfis, oblongis; margine callofo-fimbriats; ad apicem crenatis. Wachend. Ultraj. 203.

Protea foliis oblongo-ovacis, apice quinquedentato-callofis Roy. Ligd. Bat. I 4 .

Levcadendron conocarpodendrum. Lin. Sp. P1. p. 135. Berg. Aer. Stockh. 1766. p. 32 r. Evanuit deinde in Syfemate Natura.

Africanis: Kreupelboom, Goudboom, Brandhoutboom vulgo appellatul.

16. P. Hypophyla. Scolynocepbaios foliis anguftis, in fummitate tridentatis. Raj. Dendr. 9.

Tbymelea capitata rapunculoides, Nerii crasfioribus foliis, fummo apice tridentatis, xthiopica, coniformi calyce fquamato. Pluk Mant. I8I. tab. 440. f. 3 .

Levcadendros africana feu foolymocephalus folio auguftiori; apicibus tridentatis. Pluk. Alm. p. 2I2.

Conocarpodendron folio rigido, angufto, apice tridentato, rubro, flore aureo. Boerh. Lugd. Bat. T. 2. p. 198. t. 198.

Yrotea foliis lanceolatis, linearibus, apice rridentato-callofis; capiculis aphyllis. Roy. Litgd. Bat. I\$4. Wachend. Ultraj. 202. 


\section{de Protea.}

Protea foliis lanceolato-linearibus; apice tridentato-callofis. Lin. Hort. Cliffort. 29.

Levcadendron hypophyllocarpodendron. Lin. Sp. Pl. p. 1 36. Berg. Act. Stockh. 1766. p. 321. Pl. Cap. p. 16.

Protea hypophyilocarpodendrum.Lin. Mant. p. 191. Sylt. Nat. T. 2. p. I 18 .

17. P. Cuculdata. Scolymocepbalos africana, foliis anguntis brevioribus, tribus in fummitate denticulis capitulis foliofis interceptis. Herm.Afr.20.

Levcadendros africana feu fcolymocephalos, anguftiori folio, apicibus tridentatis. Pluk. Alm. 212. tab. 304. f. 6.

Hypopbylbocarpodendron foliis inferioribus apice trifido, rubro, fuperioribus penitus rubris, glabris. Boerh. Lugd. Bat. T..2. p. 206. t. p. 206.

Levcrdendron foliis cuneiformibus, apice tridentato-callofis, fummis ultra florem protruifs. Wachend. Ultraj. 203.

Protea foliis lanceolatis obtufis flores involventibus, apice tridentato-callofis. Roy. Lugd. Bat: 184 .

Levcadendron cucullatum. Lin. Sp. Pl. p. 136. Berg. AEt. Stockh. 1766. p. 320. Pl. Cap. p. 14.

Protea cucullata Lin. Mant. I8o. Syft. Nat. T. 2. P. I I8. 
20. P. Prnifolia. Pini foliis planta africaria, cyperi capitulis. Herm. Afr. 18. Burm. Dec. Afr. p. 193. t. 70. f. 3 .

Pini folio planta capenfis, floribus fpicatis. Petiv. Scill. 47.

Pini facie frutex africanus, cyperi capitulis umbellatis. D. Scherard. Raj. Dendrol. 130. Aulax pinifolia Berg. P1. Cap. p. 33.

Levcadendron pinifolium. Lin. Mant. p. $3 \sigma$. Protea pinifolia. Lin. Mant. p; 187. Syft. Nat. T. 2. p. II7.

21. P. Racemosa. Tbymelcea fruticofa, pinaftri brevioribus foliis, floribus villofis, ex promont. bonæ fpei. Pluk. Mant. 180.

Protea foliis fetaceis, horibus racemofis. Lin. Hort. Cliffort. 496.

Levcadendron racemofum. Lin. Sp. Pl. p. 134. Berg. AEt. Stockh. 1766. p. 325. Pl. Cap. p. 23. Protea racemofa Lin. Mant. 187. Syft. Nat. T. 2. p. 117 .

22. P. Incurva. Tab. noftr. III.

23. P. CaUdata. Tab. noftr. II.

24. P. Bracteata. Scolymocepbalus africanus, foliis Rofmarini acutis. Herm. Afr. 20. Raj. Dendrol. 10.

Lepidocarpoderdron foliis anguftiffimis gramineis, fructu cancellato, femine coronato. Boerh. Lugd. Bat. tom. 2. p. 193. tab. p. 193. 
Levcadendron cancellatum. Lin. Sp. Pl. p. 134. Berg. Act. Stockh. 1766. p. 326. Syftematis Linnæani editioni Lütimæ infertum non fuit.

Protea Bracteata. Tab. noftr. I.

26. P. PuRPuRea. Protea foliis linearibus fimpliciffimis, ramis determinatis, floribus terminatricibus. Roy. Lugd. Bat. 186.

Levcadendron proteoides. Lin. Sp. Pl. p. I34. Berg. AEt. Stockh. I766. p. 326. Pl. Cap. p. 24. Protea purpurea. Lin. Mant. 195. Syft. Nat. T. 2. p. II 9 .

27. P. PROLIFERA. Tab. noftr. IV.

28. P. Corymbosa. Levcaciendron corymbofum. Berg. Act. Stockh. I 766.p. 325. Pl. Cap. p. 2 I. P'rotea corymbofa. Tab. noftr. II.

29. P. NANA. Tbymelea xthiopica, abietiformis, floribus phoeniceis. Pluk. Mant. 180.

Conopboros capenfis, pini folio. Raj. Suppl. app p. 243. 63. Petiv. Gazoph. p. 40. t. 25 . f. 7. Levcadendron nanum. Berg. Act. Stockh. 1766. p. 325. Plant. Cap. p. 22.

Protea rofacea. Lin. Mant. I89. Syft. Nat. T. 2. p. II 8 .

30. P. LANATA. Tab. noftr. III.

33. P. Aulacea. Tab. noftr. II.

35. P. Linearis. Tab. noftr. IV.

36. P. Scolymus. Scolymocepbalus africanus, fruticis xthiopici coniferi Breinii foliis, capite majori fquamato. Raj. St. III. Io. 
Levcadendron acaulon, ramis numerofis e terra excrefcens, calyce floris immaturo extus ex rubro \& flavo variegato, intus flavo. Boerh. Lugd. Bat. T. 2. p. 192. t. p. 192.

Levcadendron fcolymocephalum. Lin. Sp. Pl. p. I35. Berg. Act. Stockh. 1766. p. 323. Evanuit poftea in Syftemate Naturæ.

37. P. Mellifera. Scolymocepbalus africana; foliis anguftis, villofis, cono mellifero. Raj. St. I. III. 9.

Lepidocarpodendron foliis anguftis brevioribus falignis, calycis fquamis elegantiffime ex rofeo, aureo, albo, atro-rubro, variegatis, florum plumis albis. Boerh. Lugd. Bat. T. 2. p. I 87. t. p. I $8 \%$.

Protea caule multifloro, calycibus oblongis, foliis lanceolatis integerrimis. Roy. Lugd..Bat. 185 .

Levcadendron repens. a. Lin. Sp. P1. p. 135. Berg. Act. Stockh. 1766. p. 322.

Protea repens. Lin. Mant. p. I 19. Syft. Nat. T. 2. p. 118 .

Africanis incolis: Zuykerbofches \& Tulpboom vocat.

38. P. Repens. Lepidocarpodendron foliis longiffimis angurtiffimis, fructum elegantiffime ex rubro, flavo \& albo variegatum, fuccingentibus, radice repente. Boerh. Lugd Bat. T. 2. p. 190. tab. p. 190. 
Levcadendron foliis longiffimis obtufe trigonis, longitudine florem fuperantibus. Wachend. Ultraj. 204:

Protea caule unifloro, calyce oblongo, foliis linearibus longifimis. Roy. Lugd. Bat. 185 .

Levcadendron repens. $\beta$. Lin. Sp.PI. p. 135. 40. P. Parviflora. Lin. Mant. p. 195. Syrt. Nat. T. 2: p. I I g. Tab. noftr. IV.

41. P. PALLENS. Conocarpodenaron folio rigido, craffo, angufto, cono laniis parvo. Boerh. Hort. Lugd. Bat. T. 2. p. 197. 1. p. I97.

Conocarpodendron folio angurto rigido brevi, cono parvo, aureo, corona foliacea fuccincto. Boerh. Lugd. Bat. T. 2. p. 200. t. p. 200.

Conocarpodendron folio tenuiffimo, anguftisfimo, faligno, cono calyculato. Boerh. Hort. Lugd. Bat. T. 2. p. 203. t. p. 203.

Conocarpodendron folio tenui, angufto, faligno, cono calyculato, corona foliacea fuccincto. Eoerh. Lugd. Bat. T. 2. p. 204. t. p. 204.

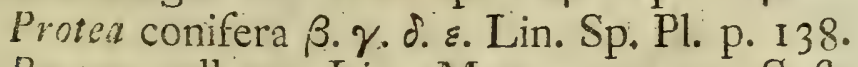
Protea pallens. Lin. Mant. p. I93. Syft. Nat. T. 2. p. I I 8 .

42. P. ConIFERA. Scolymocepbalos africana foliis brevioribus, in tubercula definentibus. Herm. . Afr: 20 .

Thymela capitata . Julifera angufo falicis folio. Promontor bonæ fpei. Pluk. Mant. I81.t. 229, f. 6 .

$$
\text { G } 3
$$

Frutex 
Frutex xthiopicus conifer, foliis cneori, falici xmulus. Breyn. Cent. 2I, t. 9.

Levcadendrum falignum. Berg. A Et. Stockh. 1766. p. 323. PI. Cap. p. I7.

Protea conifera. Lin. Sp. Pl. p. 133. a.

Protea faligna. Lin. Mant. p. 194.

43. P. Levisanus, Levifanus capenfis, ferpilli folio. Petiv. Gazoph. 9. tab. 5. f. 7 .

Cbryfantbemusn conyzoides xthiopicum, capitulo aphyllo, Thirymali paralii foliis fubrotundis, hiulculis in fuperficie confpicuis. Pluk. Mant. 47. t. 343. f. 9.

Brumia foliis oblongis incanis, florum capitulo ramulum terminante. Burm. Afr. 267. t. 1 co f. 2.

Conocarpodendron foliis fubrotundis brevisfimis; capituli immaturi, globofi, parte inferiori fufca, media aurea, fuprema viridi. Boerh. Lugd. Bat. T. 2. p. 202 . t. p. 202.

Protea foliis oblongis, ovatis, lana obvolutis. Roy. Lugd. Bat. 187.

Protea fulca. Lin. Sp. P1. ed. r. p. 95.

Brunia levifanus. Lin. Sp. Pl, ed. 2. p. 289.

Levcadendron levifanus. Berg. AEt. Stockh. -66. p. 324. Pl. Cap. p. 20.

Protea levifanus. Lin. Mant. p. 194. Synt. Nat. T. 2. p. I19.

44. P. Strobilina. Conocarpodendror acaulon; folio rigidi, nervofo, oblongo, latiori, cono fnfco; 
fulco; femine oblongo in medio quafi excavato. Boerh. Lugd. Bat. T. 2. p. 20s, t. p. 20 I. Protea Atrobilina. Lin. Mant p. 192. Syft. Nat, 'T. 2. p. 118 .

45. P. IMBRICATA. Tab. noftr. V.

47. P. Saligna. Tbymelea capenfis, fericeis longioribus \& acutis foliis, caule geniculato, pilofo. Pluk. Mant. 181. t. 229. t. 4 .

48. P. Argentea. Conocarpodendron foliis argenteis fericeis latiffimis. Boerh. Lugd. Bat. T. 2. p. 195. t. p. 195.

Levcadendros africana arbor tota argentea fericea, foliis integris. Pluk. Alm. 21 2. t.200. f. I.

Argyrodendros africana, foliis fericeis \& argenteis: Commel. Hort. T. 2. p. 5I. t. 26 . Raj. Dendr. 9.

Frutex xhiopicus conifer, foliis cneori lanuginofis falici æmulis. Breyn Prodr. 2. p. 49. Arbor ferens folia argentea. Zanon. Hiftor.24. Globularia africana frutefcens; thymelæa folio lannginofo. Tournef. Inftit. $46 \%$.

Conifera falicis facie, folio \& fructu tomentofericeo candicante obductis, femine pennato.

Protea foliis lanceolatis integerrimis hirfutis nitid. Lin. Hort. Cliff. 29.

Protea argentea Lin. Sp. PI. 137. Mant. p. I94. Syft. Nat. T. 2. p. I 19.

Africanis incolis: Silverboom \& Witteboom. 
49. P. AcA ULis. Scolymocephalus africanus, hauni folio \& procumbens Raj. H. 3. 9.

Lepidocarpodendron acaulon, foliis paucis latis, nervo \& marginibus rubris ornatis, fruatu parvo. Boerh. Lugd Bat. T. 2. p. I91.t. p. I9.1.

Levcadendron acaulon. Wachend. Ultraj. 204. Protea caule unifloro, foliis lanceolatis. Roy. Lugd. Bat. 186.

Lepidocarpodendron acaulon. Lin. Sp. P1. p. 135. Berg. AEt. Stockh. 1766. p. 322. evanuit deinde in Syftematis Naturx ultima editione.

5r. P. GRANDiflora. Lepidocarpodendron folio faligno, lato, caule purpurafcente. Boerh. Lugd. Bat. T. 2. p. 183. tab. p. 183.

protea foliis lanceolatis, integerrimis, flore patente glabro, ftylis longiffimis. Roy. Lugd. Bat. I86.

Africanis incolis: Waageboom \& Waagenboom.

53. P. Speciosa. Scolymocephalus africana foliis longis, glabris, cono fericeo, fquamis rubiginea, villofa, crifta ornatis. Raj. H. T. III. 9. Lepidocarpodendron folio oblongo, viridi, limbo rubro ornato, fquamarum apice \& margine lanuginofis. Boerh. Lugd. Bat. T. 2. p. 185 . t. p. 185 .

Lepidocarpodendron foliis anguftis longis, falignis, nervo rubro, florum plumis violaceo. purpureis. Boerh. Lugd. Bat.T.2.p.186.t. p. 186. 
Lepidocaipoldezdron foliis angatis, longis, falignis, calycis fquamis elegantifime ex flavo, fufco, albo, nigro variegatis, florum plumis atro-purpureis. Boerh. Lugd. Bat. T. 2. p. 188. t. p. 188 .

Lepidocarpodendron folio faligno viridi, nervo \& margine flavo, cono longo, fuperiore parte maxime claufo. Boerh. Hort. Lugd. Bat. T. 2. p. 189 . t. p. I 89.

Protea foliis lanceolatis integerrimis glabris, calycibus fuperne villofis. Roy.Lugd. Bat.p. I 86. Levcadendron lepidocarpodendron. Lin. Sp. Pl. p. 134. Berg. Act. Stockh. 1766. p. 322. Levcadenitron ipeciofum. Lin. Mant. p. 36 . Protea Lepidocarpodendron. Lin. Mant. p. 190. Syft. Nat. T. 2. p. Ir8.

Proter fpeciof. Lin. Mant. p. I9r. Syft. Nat, p. I: 8 .

Hollandis Africam incolentibus: Kreupelbofches vocatur.

if. P. Totтa. Lin.Mant.p. igr.Syft. Nat.T.2.p. I Is. 55. P. Hirt A. Lepidocarpodendrumi foliis fericeis brevioribus, confertiflmis, cono gracili longo. Boerh. Lugd. Bat. T. 2. p. I94. t. p. 194.

Hypopbyllocarpodendron, foliis lanuginolis, in apice 3 -fido, rubro, quafi florefcens. Boerh. Lugd. Bat. T. 2. p. 205. t. p. 205.

Salix conophora africana angufto, obtufo, folio lanuginofo. P. Breyn. Prodr. p. 372. 
Levcadendron hirtum. Lin. Amoen. Acad. 6. Afr. 3. Spec. Plant p. 136. Berg. Adt Stockh. 1766. p. 324

Protea hirta. Lin. Mant. p: r88. Syft. Nat. p. I 18.

Afranis: Kreupelboom.

56: P. Pubera. Levcudendron thymelaoides. Berg. Act. Stockh. I766. p. 324. Pl. Cap. p. I9. Protea pubera. Lin. Mant. p. 192. Syft. Nat. T. 2. p. 118 :

57: P. Divaricata. Scolymocepbalos africanus, argenteus, foliis brevioribus myrtiformibus, capitulis rarioribus. Herm. Afr. 20 :

Levcadendron divaricatum. Berg. $\Lambda$ ct. Stockh. I766. p: 324. Pl. Cap. p. I9.

Protea divaricara. Lin. Mant. p 194. Sy?t. Nat. T. 2. p. I Is.

58. P. Spathulata. Tab. noftr. V.

59. P. Cynaroides. Cinaroides frutex, folio fub. rotundo, rigido, e monte tabulari. Petiv. Muf 374 .

Scolymocepbialos africana, lato, rotundo, glabro folio; cono maximo, fericeo, candido. Raj. H 'T. III. 9 .

Lepidocarpodendron, folio fubrotundo, rigido in pedunculo longo, craffo, flore maximo, purpureo. Boerh. Lugd. Bat. T. 2. p. 184. t. $\mathrm{p} .184$.

Cono- 
Conocnrpode"dron, folio fubrotundo, crasfo, rigido, valde nervofo, cono longo, variegato, ex rubro \& flavo; flore aureo. Boerh. Lugd. Bat. 'T. 2. p. 199. t. p. 199.

Salix conophora, africana, rigido, craffo folio. P. Breyn. Prodr. p. 373.

Levcadendron foliis fubrotundis patentiffimis, petiolatis, foliolis calycinis carinatis. Wachend. Uitraj. 204.

Levcadendron cinaroides. Lin. Sp. Pl. p. 135. Berg. AEt. Stockh. 1766. p. 319.

Protea cynaroides. Lin. Mant. p. I90. Syft. Nat. T. 2. p. I I 8. 6o. P. Cordata. Tab, noftr. V.

$$
\begin{gathered}
\text { 5. VIII. } \\
\text { L OCUS. }
\end{gathered}
$$

Omnes fpecies Protex crefcunt in magno illo promontorio auftrali Africes quod Bonæ Spei cognomen accepit, nec unica fpecies nobis nota fuit, alibi crefcens, antequam Dom. Banks in Novæ Hollandix regionibus auftralioribus P. Serrariam inveneric, uti etjam Genus Bankfix, eadem facie \& habitu cum Proteis. Amant vero aliæ fpecies Protearum loca depreffa \& fabulofa; aliæ loca magis elevata \& colles; alix jterum fumma cacumina montium, vehementisfimis expofita ventibus \& nubibus.

Sic crefcit fponte.

Florida in montibus Franfche Hoek. 
Serraria in collibus infra latus orienmie Taffclberg inque fummis montium cacuminibus inter Cap \& Bay Falfo, aliorumque.

Sccptrum, Prolifera, Cordata, Spicata \& Pabera in fummis montibus Hottentotts-Holland.

Hypophylla, Purpurea, Lezifanus \& Repens, in campis arenofis extra Cap inter frutices.

Pinifolia in montibus prope Platte-kloof, Hottentotts-Hollands-berg \& alibi.

Corymbofa in campis fabulofis prope fuvium Breede Rivier diEtum.

$N_{n n a}$ in montibus Roode-fand.

Aulacea in montibus Platte-liloof.

Umbellata in fummo Taffelberg.

Linearis in regionibus Farl \& Drakentein, locis arenofis.

Mellifera in collibus \& campis infra Taffelberg prope Cap \& infra Conftantian copiofifrma.

f'allens in collibus montium prope Cap vulgaris.

Argentea ad latera Taffelberg, Confantiam, Witteboom, Paradys, Kerftenbofches, alibique; etjam in hifce locis frpius plantatur \& elegantes fylvas format.

Acratis in collium planitie infra Taffelberg \& alibi.

Grandiflor in Duyvelsberg infra Taffelberg \& Steenberg, prope viam ad Houtbay, in montibus Koude Bockefeldt, alibique communis.

Specio/a in collibus infra Taffelberg fub fronte \& lateralibus, vulgaris. 
Hirta in campis infra Taffelberg, prope villas fubjacentes.

Cynaroides in fummitatibus montium variorum ut in Taffelberg, in montibus prope Roode-fand \& Platte-kloof, alibique.

Cordats in montibus Hottentotts-Holland \& in montibus prope fluvium Rivier Zonder End dictum.

$$
\text { \$. IX. }
$$

\section{FLORENDI TEMPUS.}

Floret Aprili, Majo, J̈znio, P. Serraria, Repens, Speciofa, Grandiflora, Hirta, Cynaroides, Sceptrum, Prolifera.

Funzio, Fulio \& feqq. menfibus, P. Hypophylla, Linearis, Pallens, Acaulis.

Septembri, Octobri, Novembri \& Decembri, Levifanus, Corymbofa, Nana, Argentea, Acaulis, Cordata, Spicata, Crinita.

Decembri, Fanuario \& Februario, Pinifolia, Aulacea, Umbellata.

$$
\begin{gathered}
\text { S. X. } \\
\text { U.S U S. }
\end{gathered}
$$

Mellifere florum capita frpe ad dimidium, tempore florelcentix, replentur fucco melleo, qui $\mathrm{ab}$ infeetis fltratione purificatus \& leni igne infpisfatus, Syrupum eximium prebet, propinandum in Tuff, Raucedine \& morbis aliis pectoris. 
Speciofe flores fuccum melleum fuppeditant, eadem fere copia ac bonitate atque mellifera.

Ex Argentea fylvæ fæpe curiofe plantantur, pro concilianda umbra, pulcherrimæ certe omnium ob argenteum foliorum nitorem fplendidifimum.

Grandiflor ce cortex adftringens curandæ Diarrhoex infervit.

In patria Protearum, ubi lignum rarum \& valde carum, plurium fpecierum vel ligna, dum arbor vel frutex fatis procera \& craffa, vel radices ad focum alendum adhibentur, eumque in finem diligenter a fervis collecti fafces humeris impofiti domum quotidie portantur ut Conocarpx, Speciofx,

Hirtæ, Grandifloræ, Melliferæ, Argenteæ \& aliarum quarumdam.

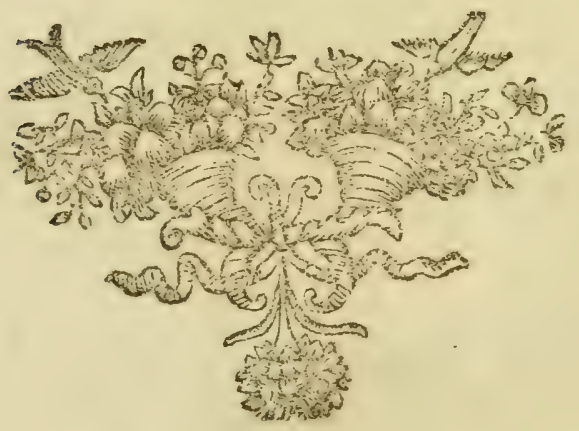



Tab. I

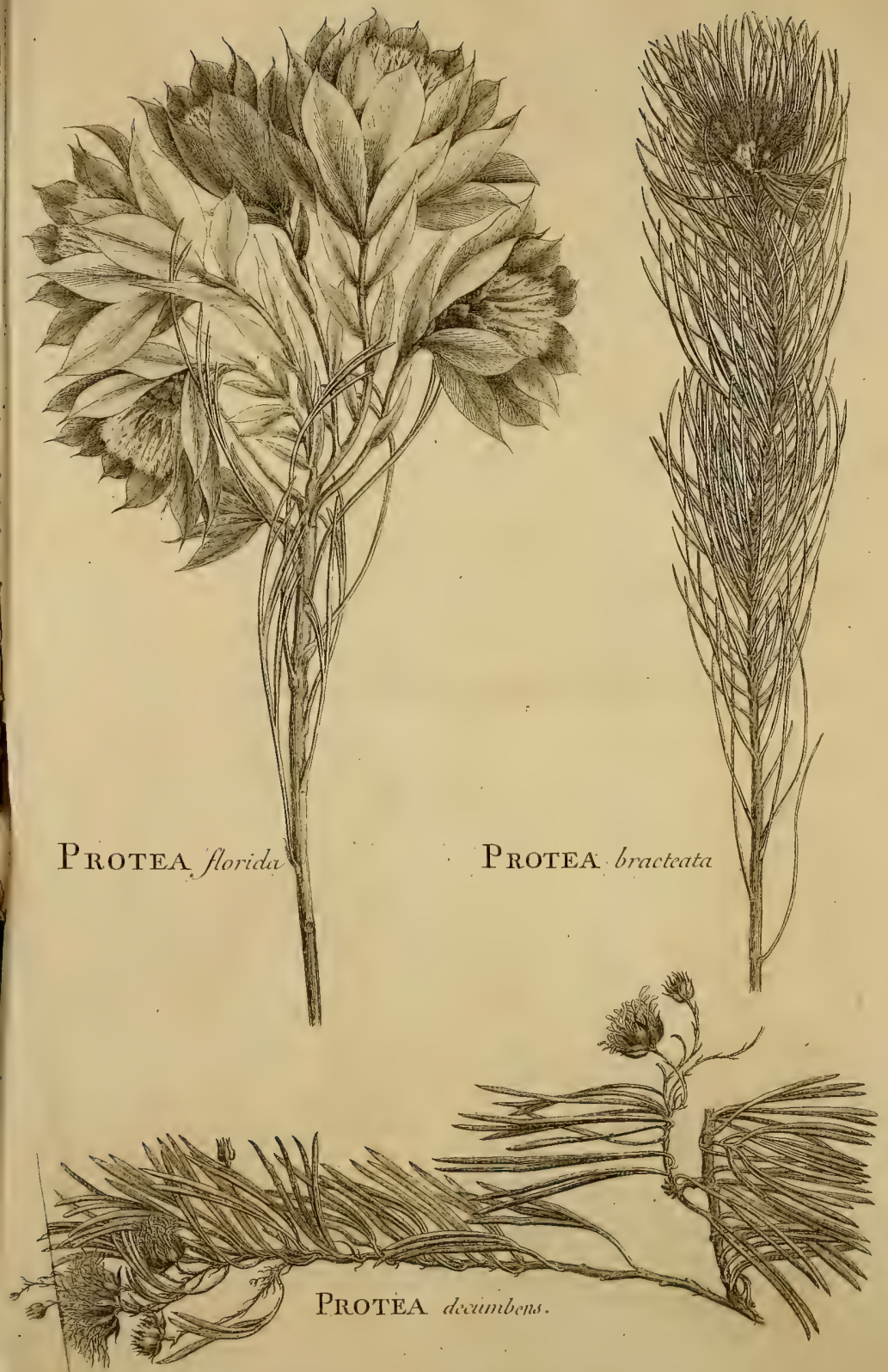




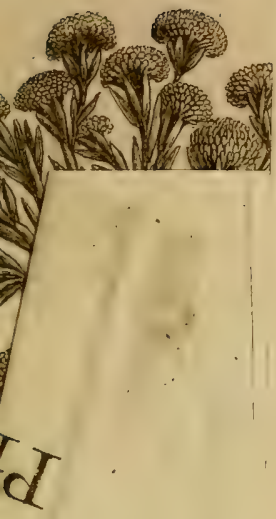




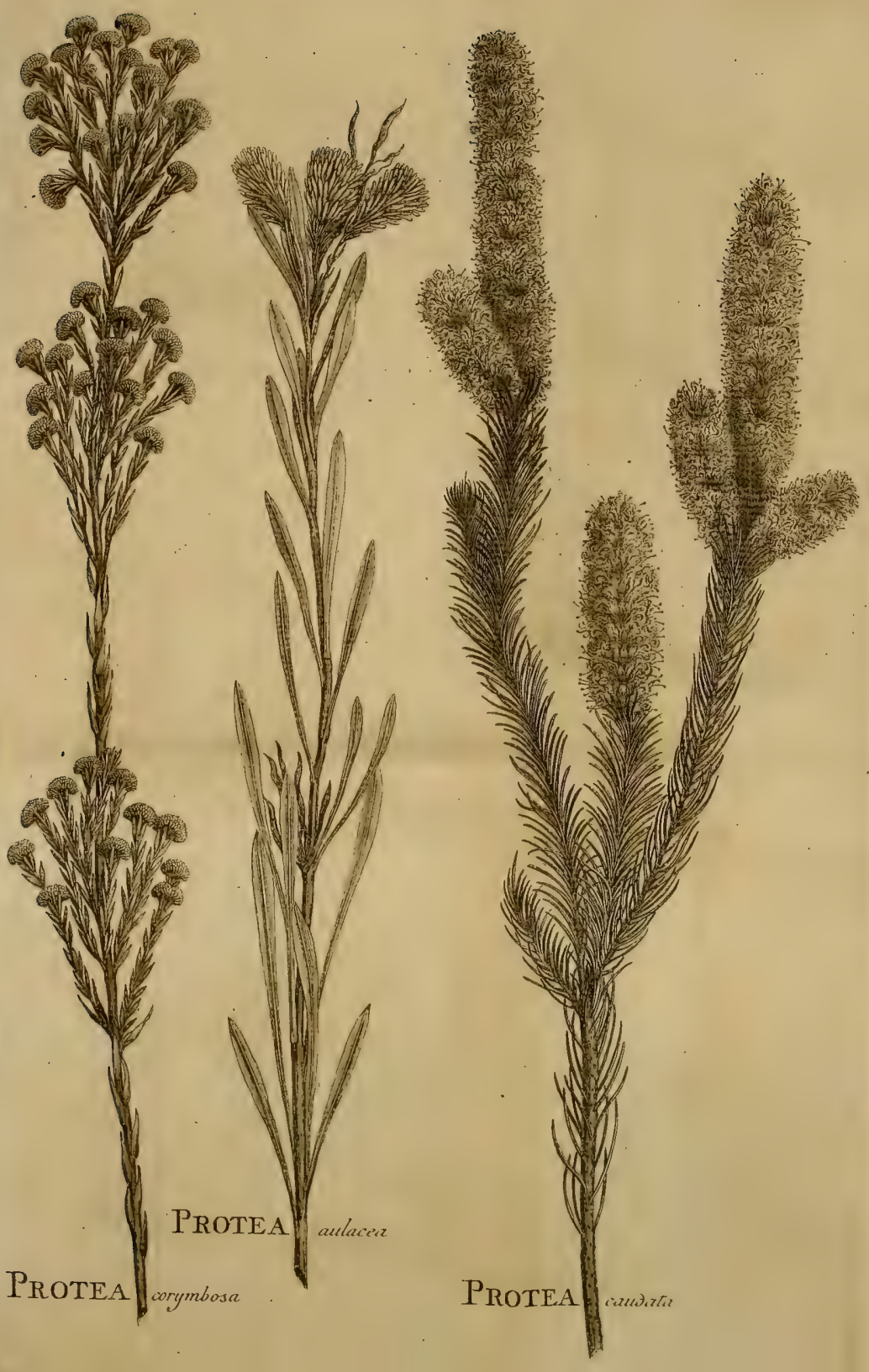


2 


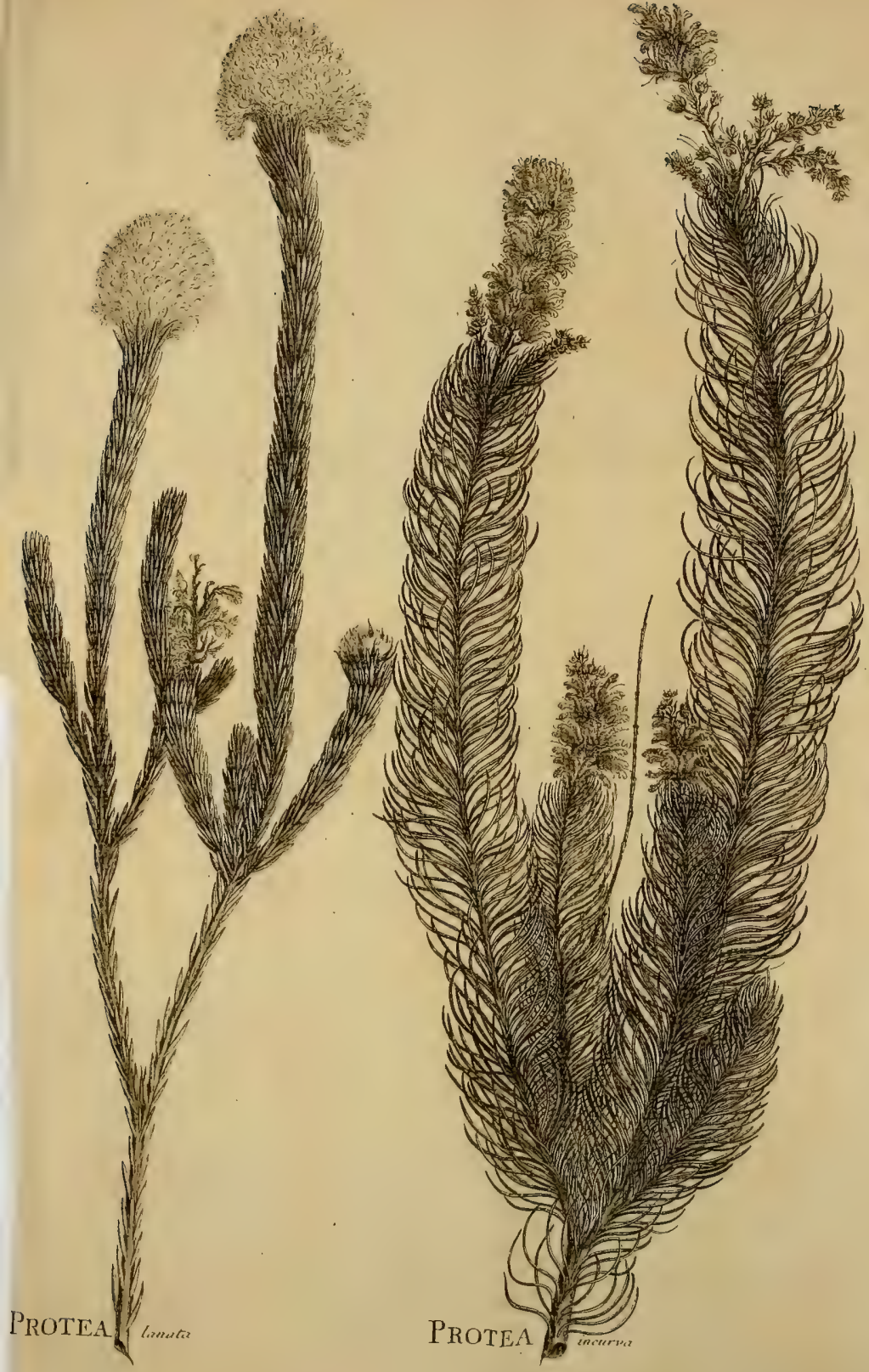





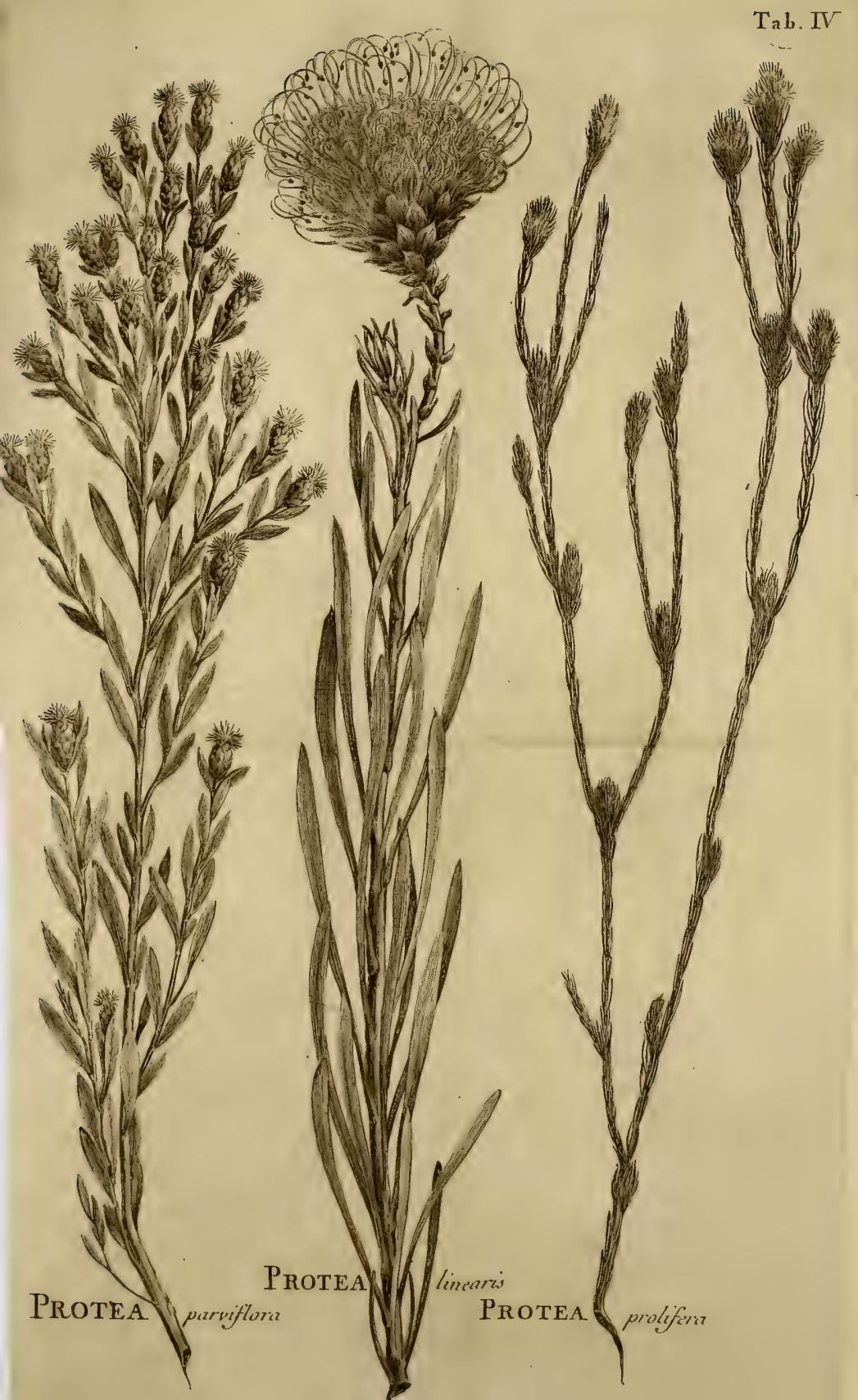





\section{Tab. $T^{\top}$.}

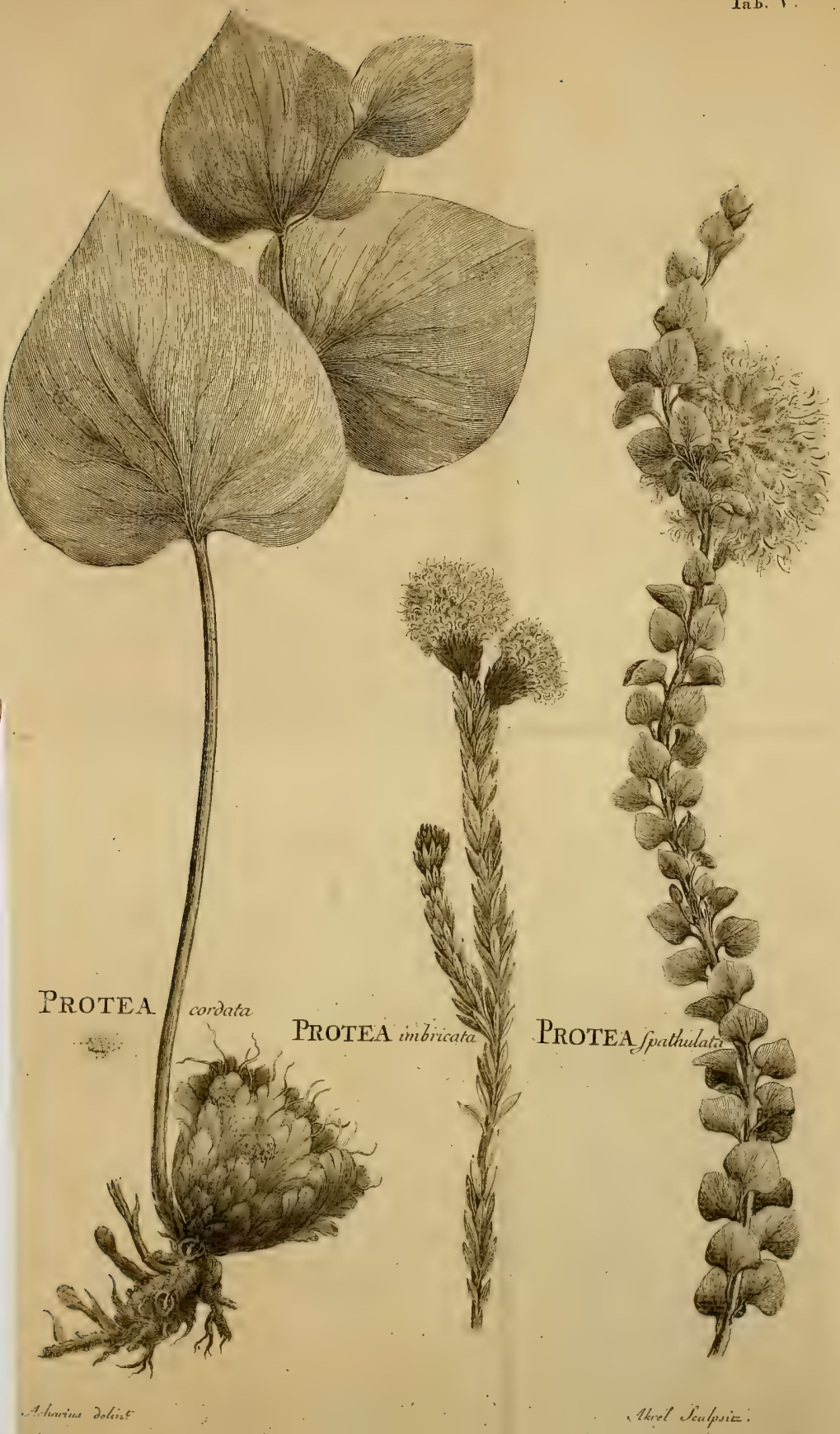




\section{D. $D$.}

\section{OXAIIS}

\section{QUAMI}

DISSERTATIONE BOTANICA, CONSENSU EXPERIENT. FAC. MED. UPSAL. PUBLICE VENTILANDAM EXHIBENT

\section{PRAESES}

CAROL.P.THUNBERG, Med. Doct, Botan. Demonstr., Acad. Reg, Scient. Holmiens, Cersar. Nat. Cur. Sociét. Scient. Upsal. Lundin. Amst. et Nidros. Membrum, ET RESPONDENS HERMAN RUDOLPH HAST, OSTROBOTHNIENSIS.

IN AUCIT, GUSTAV. MAJ. D. VII JUL. ANNO MDCCLXXXI, H. A. M. S.

\section{UPSALIE,}

Arud JOH. EDMAN, Dikect, et Reg. Acad. Trpogr. 


\section{B. $^{\prime}$}

Q pecimen-Academicum editurus, talem inprimis eliges A re volui differtationis materiam, quæ artis amatoribus utilis mihique gratiffma foret, præfertim cum ab ipfa pueritia, jucundifrmi Floræ Campi plurimum mihi attulerint delectamenti. Hujus cupiditatis mere explendæe, ampla mihi data eft occafio ab Experimentisfimo Domino Prxfide; qui ex Africa \& india Orientali infignes fpendidiffmosque Floræ Thefauros in $\mathrm{Pa}$ triam nuperrime fecum duxit, quorum e numero, ut ego quidem arbitror, Oxalidis Genus non ultimum tenet locum. Ingratum ego non fore fperavi, fi Oxalidum pleniorem defriptionem exhiberem, tam fpecierum ante cognitarum quam undecim novarum, in Syfematibus hodiernis non adhuc introductarum. . Robur enim fcien. tiæe botanicæ confiftit in fpecierum folida definitione, certitudini generum innixa. Nullæ fpecies certo diftingvi poffunt, nifi antea confituta fuerint genera, his vero determinatis, facillime. Species hæ novæ omnes in. defeffo Experientiffimi Domini Præfidis, fudio \& labori debentur, quas benigniori tuæ L. B. cenfuræ hodie fubjicio rquum tuum \& favens expetens mihi ju. dicium. 


\section{DISSERTATIO BOTANICA}

\section{DE \\ OXALIDE.}

\section{S. I.}

XALIS eft planta decandra, pentagyna, cognofcenda periantbio quinque-partito, corolla fubcampanulata, gernine fupero, capfula oblonga quinque loculari; relata ad

CEESALPINi Herbas pluribus folliculis.

Morisoni Siliquofas Papilionaceas bivalves.

RAJI vafculiferas monopetalas.

KNAUTII unicapfulares pentapetalas.

HERManni Quinquevafculares polyfpermas.

BoERHAVII Siliquofas quinque capfulares.

Rivini \& Ludvigir Regulares monopetalas.

Ruppir Regulares pentapetalas.

TOURNEFORTII campaniformes.

Magnolir Monopetalos calyce interno \& externo.

LiNNEI Decandriam Pentagyniam.

is. II.

NOMEN GENERICUM.

Trifolium veterum plures, illud autem acetófum DODONÆUS, BAUHINUS, BARRELIERUS, \& BOCCO, corniculatum DALECHAMPIUS, luteumque IMORISONUS appellarunt.

Oxalidis affinis plantam BREYNIUS vocavit. A 2 
Oxys plurimis veteribus dißta fuit, ut PLUKFNETIO, RAJO, CI USIO, PLUMIERIO, COMMELINO, SEBE, TOURNEFORTIO.

Oxalis recentiorum botanicorum nomen eft, quod retinuerunt v. ROYEN, GRONOVIUS, BURMANNUS, FEVILLEUS, MILLER, à LINNE, EHRET, NOS.

\section{S. III.
Charater Genericus.}

CaLYX. Perianthium monophyllum profunde quinque partitum, breve, perfiftens; lacinice erectx:

corolla. Monopetala, tubulofa, fubcampanulata, calyce longior. Tubus fenfim ampliatus, bafi quinque dentatus, dentibus acutis. Limbus quinque partitus, patens; lacinice xquales, obovatx, ante explicationem \& fub fomno contortx:

staM. Filamenta decem, lateribus germinis inferta, capillaria, fxpius libera, rarius connata. in cylindrum, erecta, inæqualia: quinque breviora, fimplicia, quinque longiora, externe dente erecto armata.

Antber e incumbentes, didymx.

PISTILL. Germen fuperum, quinquangulare, glabrum. Styli quinque, filiformes.

Stigmata obtufa, villofa.

PERIC. Capfiila oblonga, quinquangularis, glabra, quinque valvis, quinquelocularis. Semina plura, globofa, glabra. 


\section{De Oralide.}

Filamenta fape infima bafi connatá quidem in cylindrum, in pluribus fpeciebus inveniuntur, ficuti in plantis monadelphis; hæc vero non conftans eft nota vel toti generi communis; fed quibusdam tantum fpeciebus in Capite bonæ fpei crefcentibus propria. Neque raro in plantis Capenfibus inveniuntur vel filamenta connata, qux libe ra efle debent, ut in MORFiS, IXIIS, IRIDIBUS, vel filamenta connata, dum antheræ coalitæ effe deberent, ut lin LOBELIIS; vel filamenta libera, dum naturaliter connata forent, ut in HER. MANNIIS, MONSONIIS, aliis.

\section{S. IV.}

SPECIES Oxalidis funt, qux fequuntur:

r. Foliis SIMPLICIBUS.

monopbylla $\mathrm{r}$. foliis ovatis indivifis.

2. Foliis TERNATIS.

* ACAULES.

a. Scapis unifloris.

minuta. 2. fcapis unifloris, foliis ternatis: foliolis oblongis glabris.

punctata. 3. fcapis unifloris, folits ternatis: foliolis obcordatis punctatis.

naians. 4. fcapis uniforis, foliis ternatis: foliolis obcordatis glaucis.

acetofella.5. fcapis unifloris, foliis ternatis: folio. lis obcordatis pilofis.

$$
\text { A } 3
$$

Lana- 
lanata. 6. feapis uniforis, foliis ternatis: foliolis obcordatis hirfutis.

comprefsa. 7. Capis uniforis, foliis ternatis: fo. liolis obcordatis ciliatis, petiolis compreffis.

purpurea. 8. fapis uniforis, foliis ternatis : foliolis fubroundis ciliatis.

longiflora.9. fcapis unifloris, follis tematis: folio. lis femibifidis.

b. Seapis umbelliferis.

violacea. ro. f́apis umbelliferis, follis ternatis mhbris, calycibus callofis.

caprina. I I. fapis umbelliferis, foliis ternatis glabris, floribus erectis.

crman. I2. fcapis umbelliferis, foliis ternatis glabris, forbus plerisque clanfis cernuis. fericea. 13. fcapis umbelliferis, foliis ternatis tomentofis.

** CAULESCENTES.

a. pedunculis unifloris.

repens. I4. caule repente, pedunculis uniforis, foliis ternatis: foliolis obcordatis hirtis. incarnata.15. caule bulbifero, pedunculis unifloris, foliis ternatis: foliolis obcordatis glabris.

bifida. I6. caule erecto glabro, pedunculis unifloris, foliis ternatis: foliolis fenibifidis.

glabra. I7. caule erecto glabro, pedunculis u- 
nifloris, foliis ternatis: foliolis oblongis emarginatis glabris.

birta: I8. caule erecto hirto, pedunculis unifloris, foliis ternatis fubfeffilibus: foliolis oblongis emarginatis glabris.

verficolor. 19. caule erecto hirto, pedunculis unifloris, foliis ternatis: foliolis linearibus callofis.

b. pedunculis umbelliferis.

cornicula-20. caule decumbente herbaceo; peta.. dunculis umbelliferis,

fricta. 2r. caule erecto herbaceo, pedunculis umbelliferis.

frutefcens.22. caule erecto fruticofo, pedunculis umbelliferis,

c. pedunculis racemiferis.

barrelieri.23. cáule erecto, pedunculis racemiferis.

3:0 Foliis DIGITATIS:

flava. 24. foliis multifidis glabris.

tomentofa.25. foliis multifidis hirtis.

4:0 Foliis PINNATIS.

Senfitiva. 26. foliis pinnatis.

\section{Defriptio Specierum.}

Radix plerisque bulbofa eft, bulbo vel lana involuto, vel cortice duriori tecto.

Folia omnibus petiolata, uni fpeciei fimplicia, duabus multifida, uni pinnata, reliquis, quotquot funt, ternata. 
Flores vel folitarii, petiolati vel umbellati, nunquam feffiles.

I. O. Mnsopirylla. Radix bulbofa, parum profunde inidens. Bulbus globolus, lanugine denfa molli ferruginea obductus: bulballi corniculati, albi, plures.

Folia radicalia, fimplicia, ovata, emarginata, morgine carinaque dorfali ciliata.

Petzoli hirti, fcapis triplo breviores.

Scapi circiter tres vel quatuor, unilori, hi:ti, digitạles vel paullo longiores.

Periantbitum hirtum; lacinice lanceolata, acutæ.

Corolla calyce quadruplo longior. Tubus flavefcens. Limbus dilute purpurafcens; lacinia obtufx.

Filainerta capillaria, alba, exteriora quinque brevifima, interiora quinque calyce paullo longiora,

Antbere fubrotundx, fulcatx, flavx.

Styli ftaminibus interioribus breviores, inter Filamenta patentes, albi.

2. O. Minuta. Folia radicalia, ternata. Foliola integra, glabra.

FETIOLI filiformes, glabri, fcapo breviores.

Scapus filiformis, erectus glaber, uniflorus, ungvicularis.

Corolla calyce multoties longior. Tubus flavefcens. Limbus albus.

Differt, a purpurea foliis neque margine zze. 


\section{De Oxilide.}

que apice ciliatis; a Punctata foliolis ovatis, integris, nec obcordatis.

3. O. Punctata. Radix bulbofa, parum profunda.

Bulbus durus, acute triangularis, lateribus duobus ftriis elevatis reticulatis rogofus.

Folia radicalia, fubcainofa, obcordata, in:tegra, glabra, pundtatiffima callis elevatis; pagina fuperior viridis, inferior læte purpuiralcens punctis aureo-micantibus.

Petioli fcapo breviores.

Scapi plures, nudi, unifori, pollicares.

Periantbium breviffimum.

Corolla calyce quadruplo longior. Tribus Alavus. Limbi lacinix obtufx, ereeto-patulx, velperi uti ante Alorefcentiam convolutæ, albicantes.

4. O. Natans. Radix filiformis, fimplex, longitune indeterminata.

Folia in fuperficie aquæ umbellata, ternata: foliola curvata, emarginata, glabra, fupra viridia, fubtus glauca, patula, natantia

Petioli foliis breviores.

Pedunculi unicus, duo wel tres, uniflori, vix pollicares.

Corolla alba.

5. O. Acetocella. Radix dentata

Folia radicalia, ternata: Foliola obcordata, tenuiffime pilofa pilis adpreffis, fupra lxtius viridia, fubtus pallidiora, reflexa. 
Petioli teretes, frriati, pilofi, erecti, debiles, bipollicares.

Scapus unicus vel duo, fimplex, ftriatus, pilofus, erectus, debilis, uniflorus, longitudine periolorum.

Bractce in medio fcapi, oppofica, fubula. tæe, breves. .

\section{Crolla alba.}

6. O. Lanata. Radix bulboĺa, profunde infidens. Bulbus ovatus, angulatus, profunde rugofus, durus, glaber.

Folia radicalia, umbellata, ternata: Foliola obcordata, pubefcencia; interdum in radice elevata, fub umbella foliofa, duo alia folia oppofita.

Petioli pubefcentes, ungviculares.

Scapi fimplices, teretes, villofi, 'digitales, interdum ungviculares.

Braciece paullo infra forem dux, oppofitx, lanceolatæ, concavæ, acutæ, pubefcentes, erectx, lineam longæ.

Perianthium ad bafin fere quinque-partitum, erectum, intus glabrum, extus villofum, lineam longum. Lacinice ovatæ, obtufx, virides, apicibus rufefcentes.

Corolla calyce quadruplo longior, fubcampanulata, bafi quinque-dentata. Tubus inflatus, fenfim ampliatus, flavefcens. Linzbi laciniæ obovatæ, obtufx, patulæ.

Filamenia erecta, filiformia, bafi coalita in 
cylindrum, alba; quinque calyce breviora; quinque longitudine calycis; latere externe dentata.

Anthere ovatx, flava.

Styli ftaminibus longiores, erecti, filiformes, flavi, villofi.

Stigmata obtufa, villora.

Capfula cylindrica, obfolete quinque-angularis, decem - ftriata, obtufa.

Semnina orbiculata, plurima.

Varietates: a) Limbo purpureo, foliolis minoribus. In hac folia pubefcentia, corollx tubus flavus, \& limbus purpureus, vel purpureo-variegatus.

ß) Limbo albo, foliolis majoribus magisque tomentofis. Foliola huic patilo majora, villofo-tomentofa, uti \& petioli \& calys, Corolla tota alba.

Differt ab O. tomeniofa, cui foliis fimilis, fcapo unifloro. a Punctata, quod multoties major \& pubefcens.

7. O. Compressa. Folia radicalia, diffufa, ternata: Foliols, ob-cordata, ciliata; fupra glabra, viridia; fubtus hirfuta, albida.

Petioli lineares, compreffo-alati, ciliati, inxquales, pollicares vel paullo ultra.

Scapi aliquot teretes, hirfuti, ereeti, uniflo. ri, bipollicares.

Peristitbium pilofum, corolla triplo brevius. Corolla lutea. 
Similis O. Cernua, a qua differt

a) pedunculis unifloris.

B) minori magnitudine.

\%) petiolis compreffis:

8. O. Purpurea. Radix bulbofa, parum profunda. Bulbus ovatus, durus, lævis, magnitudine avellanx.

Folia radicalia, plurima, diffufa, ternata: Foliola fubcuneata, fefflia, vix emarginata, integra, inæqualia, intermedio majori, glabriuscula, margine ciliata, pagina utraque punEtis pellucidis.

Petioli inæquåles; teretes, pubelcentes, pro-. ftrati, ungviculares, pollicares \& ultra.

Scapi ex umbella foliorum ereeti, teretes, glabriusculi, uniflori, petiolis æquales vel bre-viores.

Bractea dux; oppofiz in medio fcapi.

Periantbium ereetum, glabrum, lineam lon-gum. Lacinice ovatx, acutiusculæ, virides, glabræ.

Corolla calýce fexies longior.: Tübus inflátus; ampliatus, calyce triplo longior, fubquinquedentatus, flavefcens. Limbus patens; Lacimice rotundatx.

Filamenta erecta, filiformia, bafi connata, alba:

Antber e ovatæ; flàvæ.

Styli calycem æquantes, erecto-patuli, albi. . Stignata plumofa, obtufa, fliva. 


\section{De Oralide:}

Capfula fubcylindrica.

Semina plurima, ovata.

Varietates plurimæ funt.

I:o foliis totis viridibus:

a) Limbo rubro purpureo vel violaceo:

ß) Limbo albo.

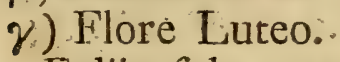

2:0. Foliis fubtus purpureis :

a) foliis fupra immaculatis, minor.

$\beta)$ foliis fupra bafi purpureis, major:

\%) pedunculis longiffimis, erectis.

9.- O. Longiflora: Folia in apice caulis umbellata. ternata; Foliola feffilia, infra medium bifid lỏbis lanceolatis:

Scapus fquamolus, fimplex:

Pedunculus ex umbella: foliorum unicus. uniflorus.

Bractea in medio pedunculi dux:

10.. O. Vrolacea. Radix bulbofa, fibrofa.

Folic radicalia, ternata: Foliola obcordata, reflexa.:

Petioli bipollicares:

Scapus fimplex, erectus; umbelliferus; palmaris.

Umbella circiter triflora:

Corolla violacea vel purpurea.

In O. Caprina. Radis bulbola. Bulbus ovato-tri-" angularis, lavis.

Scapus fimplex, glaber, palmaris.

$$
\text { B } 3
$$

Fo. 
Folia obcordata, refiexa; fupra canaliculata, viridia; fubtus carinata, læte purpurea. etioli canaliculat, glabri, fcapis duplo breviores.

Scapi ex umbella foliorum glabri, umbelliferi.

Pedicelli duo, tres vel quatuor, ungviculares, fupra partim dilatati, pilofi, unifori.

Periantlium glabrum, tubo triplo brevius: Lacinie lanceolata, pilofe, apice flavo-callofx, marginibus rubris.

Corolla purpurea, calyce plus duplo longior; Tubus ampliatus, femiungvicularis. Linubus coeruleus vel incarnatus, patens: Lacinice oblongx, obtufx, crenulatx, tubo longiores. Filamenta capillaria, bafi connata, quinque longitudine calycis, quinque duplo fere breviora, fimplicia.

Antbere orbiculate, complanatæ, flavæ.

Styli ftaminibus duplo longiores, corolla vero duplo breviores, filiformes, pallidi.

Stigrmata plumofa, Aavefcentia.

Hac longe minor eft. O. Cernua, floribus ereetis, purpureo-cæruleis, minoribus.

12. O. Cernua. Radix longa, filiformis, attenuata, fibrillofa, bulbofa.

Folia radicalia, ternata; Foliola femibifida, obcordata, glabra, fubtus pallida, fupra læce viridia, fubciliata, feffilia, bafi glandula purpurea : Lobi rotundati.

Petioli filiformes, erecti, debiles, glabri, fpithamai. 


\section{De Oxalide:}

Scapi lineares, longiffimil, petiolis duplo longiores, pedales vel ultra, umbelliferi.

Umbella multiflora, floribus quatuor ad viginti usque.

Flores pedunculati', duo vel tres, florentes eręti, reliqui claufi cernui.

Pedunculi glabri, ungviculares vel pollicares, villofi.

Periantbium ad bafin fere quinque-partitum: Lacinice lanceolatæ, acutæ, erectx, extus apice biglandulof $x$, villor $x$ vel glabræ, virides, corolla quadruplo breviores.

Corolla fubcampanulata, calycis bafi infertá dentibus. Tubus longitudine calycis, bafi quinque-dentatus: dentes acuti. Limbi lacinix obovatæ, rotundato-obtufæ, vefperi \& ante florefcentiam convoluti, erecto-patentes.

Color corollx Alavus.

Filanenta capillaria, bafi connata in cylin. drum; quinque longiora, calycem fuperantia, latere exteriori dente erecto adnato; 5 breviora, calyci æqualia.

Anthera ovatx, incumbentes, aurantiacx.

Styli breves, reflexo-patentiffimi.

Sitigmat obtufa, villofa.

Capfula oblonga, cylindrica, obfolete quinque-angularis.

Obr. Hxc pedunculis longiffimis corollisque Alavis, $\mathrm{ab}$ Ox. Caprine, cui fimilis \& proxima; differt. 
Folia fupra fxpe notantur mactilis fparfis purpureis.

13. O. SERICEA. Radix profunde infidens.

Folia fub-verticillata, petiolata, ternata; Foliola obcordata, fupra viridia circulo rubro, pilis albis hirta; fubtus tomentofa, purpurea vel argentea. Quædam folia fubtus magis purpuralcentia, quædam magis argentea, quædam purpureo - argentea.

Yetioli toti hirti, fcapis duplo breviores.

Scapi ex umbella foliorum plures, toti hirti, umbelliferi, digito longiores.

Pedicelli tres, quatuor vel quinque, uniflori, cernui, hirti, ungviculares, intermediis brevioribus.

Bracter ad fingulum pedicellum binæ, :vatæe, hirtæ.

Periantbii laciniæ lanceolatæ, acutæ, hirtæ, corolla duplo breviores.

Corolla flava.

Filamenta capillaria, alba; quinque longiora, calycis fere longitudine; quinque duplo breviora.

Antbere orbiculatx, compreffx, flavæ.

Styli ftaminibus longiores, filiformes, villofi.

Diftincta ab O. cernua, foliis tomentofis pracipue fubtus; a Linzata, floribus umbellatis.

14. O. Repens. Radices fibrofæ, tenues, ramofx.

Caules radicales, plures, herbacei, farmentofi, filiformes, foliofi, ramofi, villofi, purpurafcentes. 
Rami filiformes, foliofi, alterni, cauli fimiles, proftrati.

Folia ternata: Foliola obcordata, fefflia, glabra.

Petioli ungviculares, usque bipollicarès, femiteretes, pubefcentes, virides, laxi, erecti. usculi.

Flores axillares, pedunculati, parvi.

Pedunculi teretes, geniculati, villofi, unifri vel biflori, petiolo paullo breviores.

Bractea oppofitæ in genu, breviffimx, lanceolatx, villofr.

Periantbium ad bafin fere quinque-partitum; lacinice lanceolatæ, acutæ, erectx, pubefcentes., corolla breviores, lineam longæ, perfiftentes.

Corolla flava, campanulata. Tubus inflatus, bafi quinque-dentatus, pallidus. Limbi lacinix ovatx, obtufifimæ, integra.

Filannenta bafi connata, filiformia, erecta, alba, quinque longitudine calycis, quinque paullo breviora.

Antherce parve, ovatx, flavæ.

Styli filiformes, creet, longitudine ftaminum longiorum, villofi.

Stigmata fimplicia.

Capfula columnaris, acute quinquangularis, acuta, pubefcens.

Sernina parum comprefla. 
Pedunculi funt vel uniflori, vel biflori, vel umbellato - quadriflori.

Similis valde O. corniculate, dum peduncuculi uniflori; differt vero eo; quod omnibus partibus minor fit.

15. O. Incarnata. Caulis teres, debilis, erectus, glaber, purpureus, bulbiferus, ramofus, vix pedalis.

Bulbi axillares.

Folia caulina, ternata; Foliola obcordata, glabra, intra marginem purpureo-callofa, reflexa.

Petioli capillares, laxi, patuli, glabri, bipollicares.

Flores ex axillis pedunculati.

Pedunzculus petioli figura \& longitudine, uniflorus.

Bractea in medio pedunculi.

16. O. Bifida. Tota planta glabra, excepto calyce. Caulis raro fimplex, fæpiffime ramofus, filiformis, frriatus, laxus, diffufus, pedalis \& ultra.

Rumni alterni, fecundi, ftriati, erecti.

Folia in apicibus ramorum, umbellata, ternata: Foliola femibifida, reflexa, viridia.

$P$ ttioli ftriati, inæquales, pollicares.

Flores ex apicibus ramorum feu umbella foliorum umbellati, pedunculati.

Pedunculi plures, unifiori, pilofi, petiolis duplo longiores. 


\section{De Oxalide.}

Braftex in medio pedunculi dux, oppofitx, retacex, apice fulvo.

Periantbium hirtum. Lacinia ovatx, apice fulvæ, glandulofx, corolla triplo breviores.

Corolla tubus havefcens; Limbus violaceus.

Differt 1:mo ab O. Caprina caule ramofo \& lobis foliorum magis divaricatis \& acutioribus. 2:0 a Corniculata foliis bifidis.

Diftineta eft ramis fecundis a ceteris omnibus.

Variat caule fubfimplici \& ramofo.

7\% O. Glabra. Tota planta glabra. Radix bulbofa.

Caulis fimplexl, filiformis, fulcato-angulatus, erectus, paimaris.

Folia circiter tria, fubverticillata, ternata:

Foliola feffilia, obovata, emarginata, canaliculato - convoluta, lineam longa.

Petioli fubamplexicanles, bafi lati, longitudine foliorum, ftriati.

Flores axillares, pedunculati, erecti.

Pedunculi ex verticillo foliorum circiter tres, uniflori, digitales.

Bractea infra Horem duæ, 'oppofitæ, lanceolatæ, acutæe, ereEtæ, breviffimæ.

Periantbium albidum, corolla' quadruplo brevius; Lacinice lanceolatx, apice flavo glandulofx.

Corolla fubcampanulata, bafi calycis infer.ta; Tubus bafi fubquinque-dentatus, a bafi fenfim ampliatus, calyce longior, flavefcens. 
Limbi lacinix obovatx, rotundato-obtufx, patenti-erectæ, purpurex.

Falanenta capiliaria, alba; quinque longiora, extus dente ereeto, calyce paullo breviora; quinque breviora, ftylis omnia bafi connata. Antber ovatx, parva, flava.

Styli breviffimi, reflexo-patentiffimi.

Carfula oblonga, obfolete quinquangularis. Differt ab O. hirta, guod folia fint petiolata, emarginata \& uti tota planta glabra. a Verficolore foliis absque callo emarginatis, obovacis nec linearibus.

18. O. Hirta. Radix bulbofa, lavis.

Caulis junior fimplex, adultior fxpe ramofus. Rami indivifi, patentes, multiflori.

Folia ramorum vaginantia, ternata; foliols obovata, integerrima, convoluta, recurvata.

Flores axillares, pedunculati.

Pedunculi unifori, foliis paullo longiores. Brabter duæ infra calycem oppofitx, lineares.

Perianthium ad bafin fere quinque-partitum; Lacinice lanceolatæ, acutx, erectx.

Corolla campanulata, calyce duplo longior.

Dignofcitur hæc facile foliis feffilibus, integerrimis nec emarginatis, \& quod tota planta pubefcens.

Variat caule fimplici \& ramofo; breviffrmo \& longo; flore fimplici \& pleno cæruleo. 
12. O. Versicolor. Radix bulbofa; bulbus durus, ovatus, glaber, lævis.

Caulis fimplex, teres, glaber, erectiusculus; fquamis aliquot alternis, breviffimis, purpurefcentibus; flexuofus; viridis, digitalis.

Folia in apice caulis verticillata, ternata; fo. liola linearia, canaliculato-convoluta, emarginata, lupra glabra, fubtus carinata, pilofá, papulofa, margine utrinque \& apice punctis purpureis elevatis pellucentibus callofa, lineas duas longa. Interdum fub umbella foliorum tinum vel duplex par.

Petioli teretes, villofi, longitudine foliorum. Bracter duæ, oppofitx, calyci approximata, fubulatæ, virides apice rufefcente.

Periantbium profunde quinque-partitum, ereetum, lineam longum: Lacinice ovatx, acutæ, virides apice rubro, glabræ.

Corolla calyce fexies longior, campanulata. Tubus inflatus, flavefcens, longitudine calycis. Limbi laciniæ ovatæ, rotundatæ, albæ margine rubro.

Filanzenta filiformia, erecta, alba, bafi connata, quinque calyce duplo longiora, externe dente ereeto armata.

Antberce ovatæ, flavx.

Germen rubro ftriatum.

Styli calyce paullo breviores, albi, erecti, pilofi.

Stigmata villofo-albida.

$$
\text { C. } 3 \text { - }
$$


Cap $\int u l a$ ovata, fub-quinquangularis.

Variat caule fimplici, ramolo \& prolifero; floribus purpureis albisque.

Nofcitur optime foliolis linearibus, apice callofis.

20. O. Corniculata. Radix fibrofa.

Caulis herbaceus, angulatus, glaber, bafi decumbens, apice erectiufculu's, ramolus, fpithamæus.

Rarm pauci, alterni, breviffimi.

Folia ternata: Foliola obcordata, glabra, fubtus parum pallida, caulina majora, ramea minuta.

Petioli Ariati, glabri, patuli, bipollicares.

Peduasculi axillares, friati, glabri, erecti, petiolis longiores, umbelliferi.

Unbella fimplex, rarius compofita, triflora vel quadriflora.

- Corolla lutex.

21. O. Stricta. Radix fibrofa.

Caulis herbaceus, angulatus, fimplex, glaber, erectus, palmaris.

Folia ternata; foluola obcordata, glabra, margine tenuiffime ciliata.

Peduncul axillares, erecti, pilofi, umbelliferi, longicudine petiolorum, pollicares.

Unbella fimplex.

Corolla fiava.

22. O. Frutescens. Caulis fruticofus, erectus. 


\section{De Oxalide.}

Folia ternata; foliola lateralia fefflia; intermedium petiolatum, majus.

Pedunculi umbelliferi.

23. O. Barrelieri. Caulis ereetus, ramofus.

Folia ternata.

Pedunculi bifidi, racemiferi.

24. O. Flava. Radix bulbofa, profunde infidens.

Folia radicalia, multipartita, glabra. Foliola quinque ad novem usque, obovato-lanceolata, convoluta, apice recurva, vix ungvicularia. Petioli teretes, rubicundi, glabri, longitudine fere fcapi.

Scapus folitarius vel pauci, teretes, uniflori, digitales.

Periantbii laciniæ ovato-lanceolatæ, obtufx, glabrx, virides, corolla triplo breviores.

Corolla calyce triplo longior, flava.

Filanenta filiformia, erecta, alba, bafi in cylindrum connata, inæqualia; quinque longiora, longitudine calycis, externe fquama, al$\mathrm{ba}$, ereeta, acuta, inferius armata; quinque duplo breviora, fimplicia.

Autbere lunatx, fulcatæ, flavx.

Germen ovatum, acutum.

Styli fliformes, albi, longitudine filamentorum breviorum.

Capfula ovata.

Differt ab O. tomentofa foliolis longioribus, paucioribus, omnino glabris, viridibus. 
25. O. Tonmenosa. Radix buibofa, profinde infdens. Bulbus ovatus, levis, magnicudine vix avellanix.

Folza radicalia, peltata, multipartita, hirta pilis albis. Foliola ultra duodecim ad viginti usque, obovata, integra, convoluta, femiungvicularia.

l'etioli valde hirti, fcapis breviores, ungve longiores.

Scapi duo, tres vel plures, indivifi, valde pilofi, uniflori.

Perianthium ad bafin quinque-particum, corolla multoties brevius, albo-hirtum; Laci. nice lanceolatæ.

Corolla calyce fexies longior, alba.

26. O. Sensitiva. Radix fibrofa.

Caulis teres, decumbens, fimplex, glaber, pollicaris, palmaris usque pedalis.

Folia in apice caulis verticillata, pinnata, patentia, digitalia. Foliola multijuga, fefilia, ovata, glabra, parallelo-nervofa, fupra viridia, fubtus pallidiora, lineam lata, verfus apicem fenfim majora, vix ungvicularia.

Pedunculi e verticillo foliortim plures, ftriati, hirfuti, erecti, folia longitudine fuperantes, umbelliferi.

Umbella fimplex, multiflora.

Pedicelli uti \& calyces hirti, ungviculares.

Nocte complicando fe verfus inferiora folia dormiunt, diebus calidis erecta, ad tactum 
(Te contrahunt, quafi fentientia uti mimoja pudica \& jenjitiva.

$$
\begin{aligned}
& \text { S. VI. } \\
& \text { SYNONYMA. }
\end{aligned}
$$

I. O. Monophyzla. Lin mant, p. 24I. Tab. Differt. noftr. 1.

2. O. Minuta. Tab. Dif. I $I_{\text {。 }}$

3. O. Punctata. Tab. Diff. I.

4. O. Natans Tab: Diff. I.

5. O. Acetosella. Trifolium acetofum. Dodon. pempt. 578 .

Trifolium acetofum vilgare. Bauh. Pin. 330.

Oxys flore fubcæruleo. Tournef. initit. 88.

Oxys flore purpurafcente. Tournef. inftit. 88 .

Oxalis foliis ternatis, fcapo unifloro. Lin. flor. Lap.

194. Hort. Cliff. 175. Materia Medica 216 . Roy.

Hort. Lugd. Bat. p. 4.58.

Oxalis acetofella. Lin. fp. pl. p. 620. fyft. nat. t.

2. p. 360 .

Faponerzfibus Katabami.

8. O. Purpurea. Wxalidzs affinis planta bulbofa affricana, flore purpureo magno. Breyn. Centur. 102. p. 46. Oxys bulbofa africana rotundifolia, caulibus \& floribus purpureis amplis. Commel. Hort. i. Ip. 4t. Tab. 21.

Oxys Africana bulbofa trifolia, flore luteo magno. Seb. mul. I. p. 37. tab. 22, f. 10.

Oxalis bulbofa trifolia hirfuta, flore albo. Burm. Afr. 67. tab. 27. f. 3 .

Oxalis fcapo unifloro, foliis ternatis, radice bulbofa. 
Lin. Hort. Cliff. 175: Spec. PL. T. p. 433. Royen. Lugd. Bat. p. 458 . Ehree. pizt. tab. 10. f. 2.

Oxalis purpurea, Lin. Sp. P1. 2. p. 621. Syft. nat. t. 2. p. 360 .

9. O. Longiflora. Lin. Sp. Plant. 2: p. 62r. fyft。 nat. t: 2. p. 360 .

10. O. Violacea. Oxys purpurea, virginiana, radice lilii more nucleata. Pluk. Alm. p. 274. t. 102, f. 4 . Oxalis caule aphyllo, purpureo flore, radice tuberofa rotunda. Gron. Virg. I6ז.

Oxalis violacea.. Lin. Spec. Plant. p. 62 r. fyftem. natur. t. 2. . p. 360.

II! O. Caprina. Oxalis bulbofa; pentaphylla \& hexaphyllà, floribus magnis luteis \& copiofis. Burm. Afr. 80. tab. 29. \& t. 28. f. j. Miller ic. I95. f. r. Oxalis pes capræ. Lin. Sp. Pl. p. 622. Sylt. natur. t.. 2. p. $36 \mathrm{I}$.

12. O. Cernua. Tab. Difert. noftr. I I. Africanis wilde fyring:

I4: O. Repens. Tab. Diff. I.

I5. O. InCaRnata. Oxys bulbofa xthiopica minor; folio cordato, flore exalbido purpurafcente. Commel. Hort. I. p. 43 , t. 22 .

Oxalis caule bulbifero. Lin. Hort. Cliff. 175. Roy. Lugd. Bat. 458.

Oxalis incarnata. Lin. Sp. Pl. p. 622: fyit. nat. to 2. p. 360 .

16. O. Bifida. Oxalis biflora. Burm. Prodrom. Afr. Tab. Differt. noftr. I.

17\%. O. Glabra. Tab. Differt. noftr. II . 
II 8. O. Hreta. Oxys Africana hirfuta latioribus foliis, flore magno purpureo. Pluk. Amalth. 164. Oxys Africana bulbofa, dorycnii monfpelienfium parvis foliis, floribus purpureis amplis. Pluk. Amalth. 164. t. 434. f. 7 .

Oxys Africana bulbofa, flore purpureo, caule foliofo. Raj. Suppl. 599.

Oxys bulbofa Africana, flore purpureo, foliis pilofis, pedunculis parvis. Seb. Muf. I. p. 33. t. 22. f. II.

Oxalis caule ramofo, foliis lineari-lanceolatis fesfilibus, floribus lateralibus folitariis. Roy. Lugd。 Batav. 532.

Oxalis bulbofa foliis anguftis ternis hirtis, flore purpureo. Burm. Afr. 70. t. 28. f. I.

Oxalis radice longa fibrofa, caulibus ramofis, foliis ternis anguftis, florum petiolis longiffimis. Burm. Afr. 7.1. t. 28 . f. 2.

Oxalis hirta. Lin. Sp. pl. p. '623.

Oxalis feffifolia. Lin. Mant. 24I. Syft. Nat. t. 2. p. $36 \mathrm{r}$.

19. O. Versicolor. Oxys Africana, foliis tenuiffimis, flore amplo verficolore. Pluk. Amalth. 169. t. 434. f. 3 .

Oxys bulbofa africana angútifolia, flore rubro obfoleto amplo. Raj. Suppl. 548.

Oxys Africana, foliis tenuiffimis in fummitate caulis. Raj. fuppl. 598.

Oxalis bulbofa trifolia, foliis linearibus obtufis, flore externe rubro, intus albo. Burm. Afr. 65.t. 27. f. I. 
Oxalis bulbofa anguftifolia, caule fructicofo, flore rubro. Burm. Afr. 66. t. 27. f. 2.

Oxalis verficolor. Lin. Sp. pl. p. 622. Syft. Nat. t. 2. p. 360 .

20. O. Corniculata. Trifolium corniculatum. Bauh. pin. 330 .

Trifolnum! luteum minus repens, etiam procumbens. Morifon. Hift. 2. p. 183. f. 2. t. 1\%. f. 2.

Oxys flavo flore. Cluf. Hift. 2. p. 249.

Oxalis corniculata. Lin. Sp. pl. 628. fy?t. Nat. t. 2. p. 361. Hort. Cliff. 175. Roy. Lugd. Bat. I58. Sauvag. Monfp. 173. Gort. Gelric. 9r.

Safjo vulgo Katabani \& fimmogiefa. Kæmpf. Am. exot. falc. V. p. 888.

Faponenlibus. Sanfjo, Safjo, ficambo \& fimmoguna.

2i. O. Stricta. Trifolizin acetofum corniculatum luteum majus rectum indicum feu virgineum. Morif. Hift. 2. p. 184. .. 2. t. 17. f. 3.

Oxys americana elatior. Tournef. inftit. 80.

Oxalis Stricta. Lin. Sp. pl. p. 624. fyft. nat. p. 36r. Gron. Virg. I61. Brown. Jamaic. 231.

22. O. Frutescens. Oxys lutea frutefcens, trifolii bituminofi facie. Plum. fp. 2. ic. 213. f. I.

Oxalis caule erecto fruticofo, foliis ternatis, impari maximo. Mill. dict. 7 .

Oxalis frutefcens. Lin. Sp. pl. p. 624. fyft. nat. t. 2. p. $36 \mathrm{I}$.

2:3: O. Barrelieri. Trifolinan acetofum americanum, rubro flore. Barrel. rar. 64: tab. I I39. Boccon. muf, 2. p. 63.t. $5 \mathrm{I}$. 


\section{De Oxalide.}

Oxalis roleo flore, erectior. Fewill. peruv. 2. p. 173. t. 23.

Oxalis Barrelieri. Lin. Sp. pl. p. 624. fynt. nat. to 2. p. 36I.

24. O. Flava. Oxys Africana bulbofa, floribus amplis luteis, foliis minimis hirfutis. Raj. fuppl. 549. Qxalis bulbofa, anguftis digitatis foliis, flore folitario, luteo. Burm. Afr. 6. t. 27. f. 4 .

Oxalis Africana, bulbofa, foliis fimpliciter decaphyllis, flore flavo. Burm. Afr. 69. t. 27. f. 5.

Oxalis bulbofa, fimplici caule ad fummum foliofo, flore luteo. Burm. Afr. 81. t. 30. f. r. Oxalis flava. Lin. Sp. pl. p. 62r. Syft. Nat. t. 2 。 p. 360.

25. O. Tomentosa. Oxys parva africana, flore magno candicante, Lupini foliis argenteo-fericeis. Pluk. Amalth. p. I64. t. 350 . p. 3. 26. O. Sensitiva. Herba viva, foliis polypodii. Bauh. Pin. 259.

Todda vaddi. Rheed. Hort. Malabar. tom. 9. p. 30I. tab. I04. f. 2.

Herba viva. Cluf. exot. 290.

Herba mimofa malabarenfium.Zanon. Hift. 199. t.6r. Oxyoides Malabarica fenfitiva, caule viridi glabro, flore luteo majore. Garcin. Act. Angl. 1730. p. 379. t.: 2.

Oxalis Senfitiva. Lin. Sp. pl. p. 622. Flor. Zeyl. I80. Syft. Nat t. 2. p. 360 .

Ceilonenfibus : nidi combe.

Ternatis: Igo igo, cage cage. 
Favanis: tr jit trjit.

Maleis: Daun tacol Manufia, daun idop \& Curang curang.

\section{VII. \\ L O C US.}

Crefcunt quidem aliquot fpecies generis Oxàlidis in Europa, ut acetofella, corniculata; plures tamen in Afia vigent, ut Jen/itiva, acetafella, repens, \& corniculata; atque in America, ut punctata, longiflo. ra, violacea, Jtricta, fruteforns, barreliert;

Plurimæ vero in Africa ad promontorium bonæ fpei fedes fuas fixerunt, ut purpurea, flava, caprina, ver/icolor, incarnata, birta, monopbylla, minuta, punctata, natans, lanata, comprefja, cernua, Jericea, bifida, glabra, tomentola.

Pauciffimæ \& vix ulla fpecies præter fenfitivam, intra tropicos crefcunt, fed zonam fic dictam temperatam pleræque amant, \& paucæ regiones frigidiores, extra circulos tropicos.

Amant quxdam loca monto $\int a$, quxdam Jyluas, plurimæ vero loca aprica \& Solum argillaceum, vel argilla fabuloque mixturn.

Sic vivunt Monopbylla, mïnuta, punctata, lana$t a$, glabra, in collibus arenofis infra Taffelberg promontorii bonx fpei; punctata etiam in terra del fuego a D. Dire Sparrman inventa fuit; natans' in aquis prope fluvium Breede rivier infra Roode-Sand. lanata \& purpurea omnium vulgatiffima, in omni- 


\section{De Oxalide.}

bus collibus \& campis fabulofis prope \& extra Cap, inter Taffelberg \& montium feriem proximam; compre $\iint a$ in campis arenofis extra Cap, locis tamen femper aquofis; Caprina \& ferice in lateribus Leuwe: ftaart; inque folfa inter Montes tabularem \& leonis; Caprina vulgaris \& cernua copiofiffima prope Cap, in \& extra hortos; Repens prope Cap, locis aquofis, \& in hortis; in Madagafcaria inque Ceilona; Bifida juxta Cap urbem \& ad latera foffarum montis Diaboli; Verficoloris varietates in Collibus \& campis infra montes $\mathrm{Ca}$ penfes Drakenftein \& alibi vulgares. Flava ad pedem Leuweftaart inque collibus infra Duyvelsberg. Tomento fa in collibus inter Duyvelsberg \& littus maris æthiopici. Hirta flore pleno in Páarden eyland capitis bonx fpei. Acetofella in Svecix \& aliorum Europæ regnorum fylvis, inque regni Jáponici montis Fakonix regionibus.

Longiflora \& fricta in Virginia.

Violacea in virginia \& Canada.

Corniculata in Italia, Sicilia \& Japonia.

Barrelieri in America.

Frutefens in America Meridionali.

Senfitiva in Indiis; ut in Java, Ceilona, Amboina, Malabaria, Canaina, Decan, Sitoe alibique.

$$
\text { FLORENDI TEMPUS. }
$$

Floret Senfitiva ardente fub frio, toto fere anno, inprimis ficciffimo \& calidiffimo anni tempore, foliolis die : explicatis \& tactu : fe contrahentibus, nocte vero dormientibus.

Reliquæ vero Aliaticre \& Europeæ flores fuos producunt verfus folftitium vel paullo ante. 
Capenfes pleræque florent menfibus Maji, $\mathcal{F}_{n}$ nii \& $\mathcal{F}_{\text {uliz. }}$ Paucæ funt, quæ prius vel ferius florefcunt; fic florent Aprili, Majo: monophylla, punctata, bifida, purpurea, flava, tomentofa.

Maijo, Funio, Fulio: lanata, purpurea, caprina, hirta, verficolor.

Funio, Fulio: cernua, fericea, glabra.

$\exists u l i o$, Augufto; repens. Septembri, Octobri: Natans.

\section{U. IX.}

Ex omnibus Oxalidis fpeciebus tres folummodo in uft funt, nirnirum Acetocella, Cerina, \& Senfitiva.

Oxalis Acetosella, quam folum noftrum natale profert fpecicm, ab antiquioribus retro temporibus in officinis fuit recepta. Quod ad ejus qualitates attinet, nullo gaudet odore, fapore vero grate dulcefcenti-acido, quem, ut alia acida, vim habere aperientem \& refrigerantem concludimus, quod etiam experientia teftatur. Herl,a re. cens \& fal effentiale unica funt fimplicia, qux ex acetofclla in noftris Pharmacopolis obveniunt. Ex herba recenti obtineturtSuccus expreflus, qui defreatus \& lege artis tractatus dat falis effentialis uncias tres rol quatuor ex herba recentis libris viginti. Succris exprcffus vel Confcrua Acetocelle ex equali portione fucci recentis \& facchari albifini facta, in feorbuto adhiberi poteft, inprimis fi ad Confervam coclcarix fit junet. Sal acetocclla easdem habet vires ac Sal Tartari, corumque ufis idcm; fic omnium confenfu ob vim furm refrigerantcon in febribns inflammatoris, biliofis ac putridis, optatis Medicorum optime refpondct. Cum vero hacce remedia magni pretii fint, inprimis fal effentiale, a Medicis raro præfcribuntur.

OxA.LIS CERNUA fal effentiale xque Lonum, majori autem copin, quam acetofella producit. In loco itaque natali non femcl a Pharmacopeo per expreffionem fucci \& cryftallifationem optime preparatum fuit, îsdem atque fal acetoftlle inferviens ufibus.

OXALIS SENSITIVA apud gentes varits magis ad fuperfitionem ac incantamenta, quam ad medicumenta adhibetur. Practerea tamen Ternatenfes decocto totius plantæ contra Phthifin cum aftmate utuntar. Sapore gaudet amaricante. Decocto herbae cum melle, ad pituitam folven. dam, in morbis pectoris, utuntur Cingalli, \& fuccus radicis, contra morfuras fcorpionum, aliquando tam Cingallis, quam Malabaris, in ufu eft. 


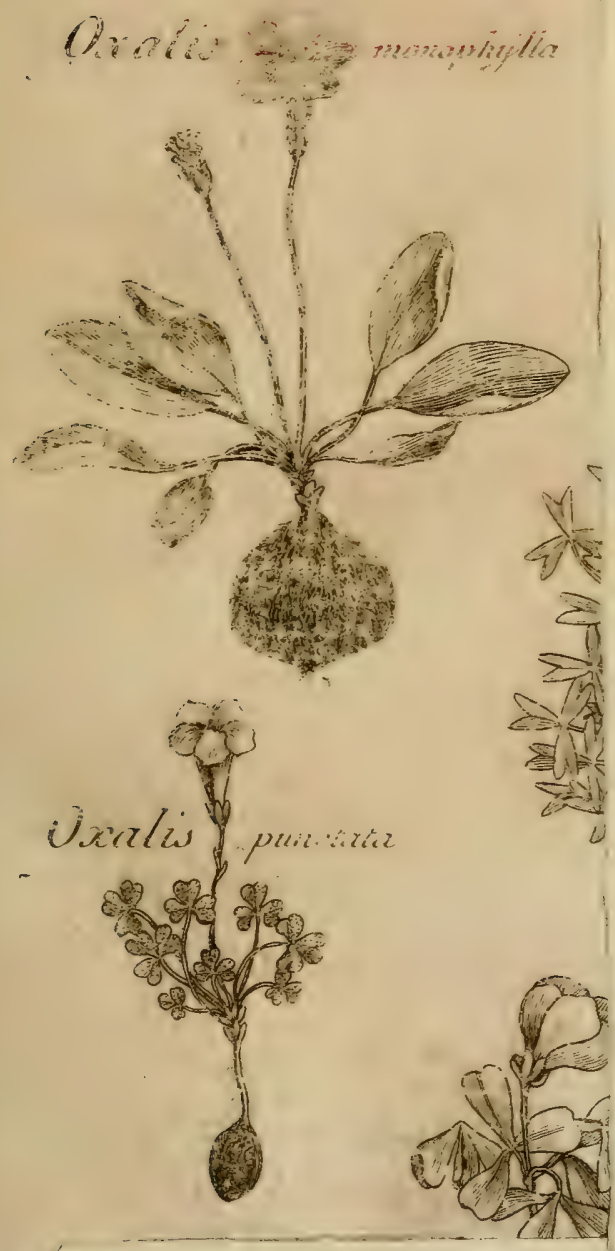




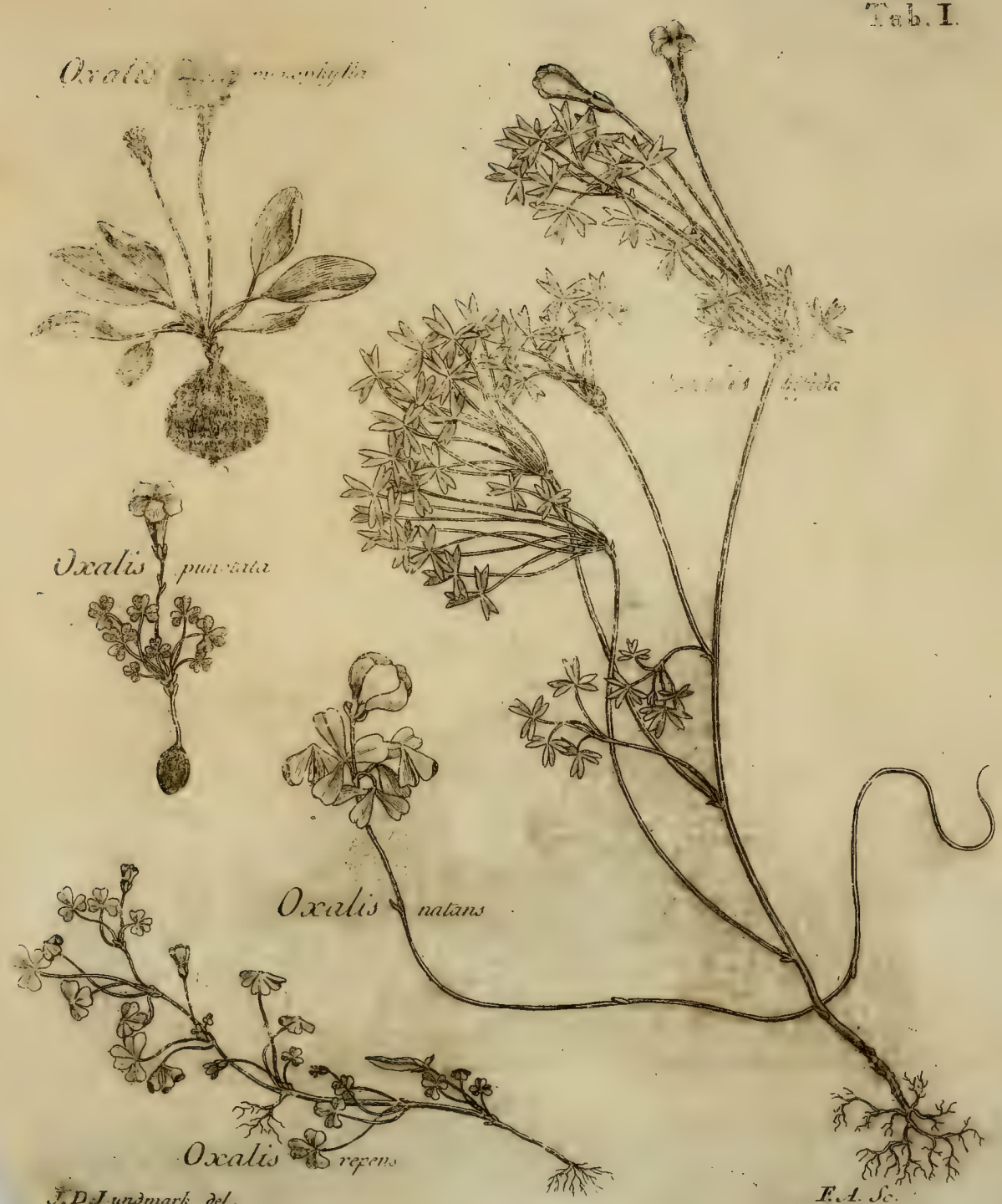




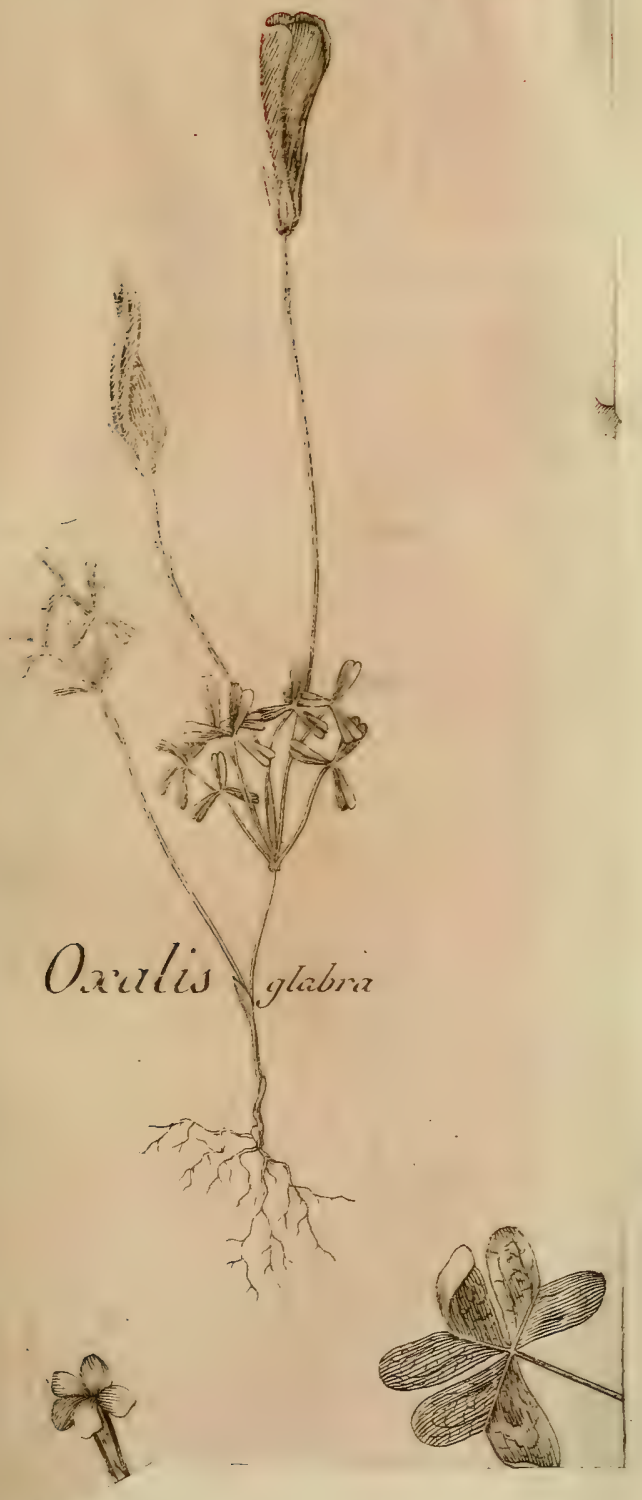




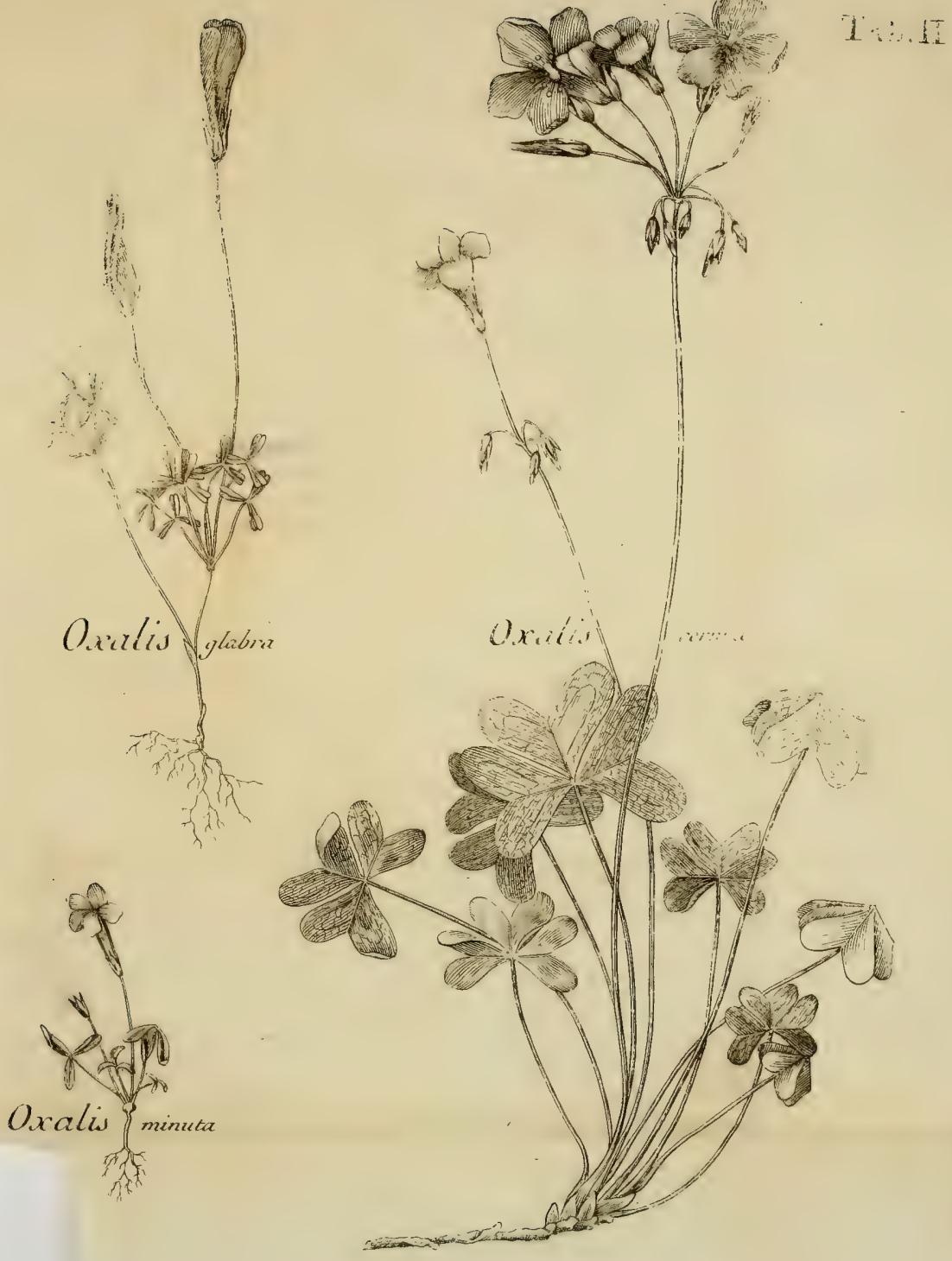


NOVA GENERA

\title{
PLANTARUM,
}

\author{
QUORUM \\ PARTEM PRIMAM,
}

SUFFRAC. EXPER. FACULT. IIED. UPSAL.

PUBLICE VENT TILANDAM EXHIBENT

PRAESES

\section{CAROL.P.THUNBRRCi,} Mind. Doct. Frofess. Fiec. nt Emtraord d Acad. Peg. Scient. Holmieæs. C.sar. Nat. CUm. Snc?ET. ECILNT. Upsal.

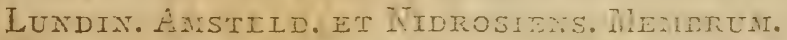

ET

- RESTONDENS Botmicán

EIBSAMY

Claudius Fr. Hornftedt,

O- Gothus.

IN AUDIT, GUST, D. NXIVi, NOV.

ANNOO MDCCLXXXI.

Horis Solitis.

UPSALIR,

Apud Joh. Edman, Direct. et Reg. Acad. Typogr. 
In Sacram Regtam Majestatem MagNe FideI Viro,

Cancellarie Regie CONSILIARio,

ORdinis REgII WaSEI EQUITI ET COMMENDATORI, Perillustri ac Generosissimo LIBERO BARO N I
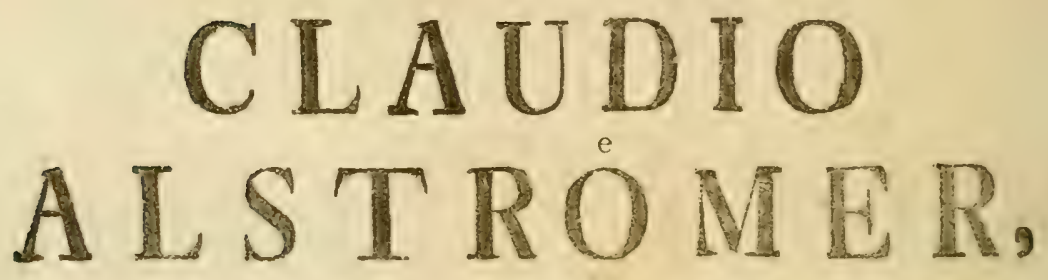

Historia Naturalis

$$
\text { PATRONO, }
$$

EJUSDEMQUE CULTORUM

MECENATI SUMMO,

\section{$S A C R U M$}




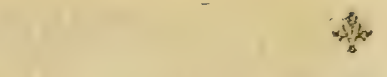

$+v^{*}$

Q

mperium Naturx fpatioffimum non alios, quam ipfus orbis terrarum limites agnofcit; cumque omnes, qua in globo hoc terraqueo exiftunt, regiones, nondum fint detectx, licet novæ quotannis fere per indufriam navigantium inveniantur terræ, nemo certe mirabitur, plantas, quas cognitus gignit orbis, univerfas \& fingulas nondum efre collectas, defcriptas. Omni quidem avo novi quidpiam in medium producere valuerunt indefeffi naturæ Scrutatores, hoc vero inprimis, quo vivimus, Seculum detedorum fuit feracifimum. Antea ingentes mun. di plagas peregrinatores detexerunt, fed magis ad ea, qux facræ auri fatisfacerent fami, quam quidem ad animalia \& vegetabilia, quibus terras illas provida exornaverat natura, adverterunt animum. Sic non multis ab hinc annis folertifimi Botanici, pericula quavis contemrentes, incognitas, argonautarum infar, adierunt terras, non ut loca quævis obvia fugitivis infpicerent oculis, neque ut mores tantum incolarum a nofris abhorrentes notarent; fed ut naturæ fimul miracula recondita, per xftum \& frigora, avide colligerent \& collecta adcuratis defcriptionibus curiofæ Europæ ante oculos quafi collocarent. Hoc animo BOUGAINVILL fuum, orbem A.

uni- 
univerfum circumnavigantem, COMMERSON cum amico SONNERAT eft comitatus, immortalemque virum Cap. COOK, pari itinere, fecutus eft ill. Dom. $B A N K S$ cum amico Doct. SOLANDER; atque alia, per Archipelagum aufralem, navigatione fodalem habuerunt D. SPARRMAN, Præftantes Viri, FORSTER nterque, pater \& filius, dum fuas, eum in finem, fufceperunt peregrinationes. Quantum horum virorum itinera humana genti adtulerint utilitatis, partim dudum novimus, partim fcripta, quæ benigne promifia impenfius exfpectamus, docebunt. Sed nec partes teiluris noftræ, quas ante hanc xtatem humana detexit induftria, nova peregrinantibus Botanicis denegarunt inventa. Quam plurima enim ill. JAQVIN ex America, PALLAS e Sibiria, KOENIG ex Afia, PRESES ex Africa aliique aliunde retulerunt, qux citius aut ferius in ufus humani generis vocata, commodis noftris profpicient. Ego vero Hiftoriæ naturalis percupidus \& his incitatus exemplis, longiora etiam itinera, fi velint fata, meditans, jam vero fpecimen Academicum editurus, ne cocta fæpius ante recoquerem, talem eligere potiffimum volui Differtationis materiem, qux novi quidpiam proponeres nec omni careret fructu. Genera igitur plantarum nova, non quidem omnia, quæ recentioris ævi Botanicis debemus, fed ea tantum, quæ in itineribus fuis detexit Exper. D. PR/ESES, colligere fum annixus, illorumque non nulla, botanice defcripta, Tuis. L. B. oculis fubjicio.

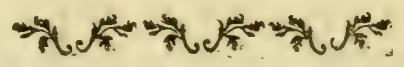




\section{GENERA NOVA PLANTARUM. \\ G A L O P IN A.}

ALYX nullus,

Corolla 4 - fida, fupera, revoluta, fufco - virefcens. Stam. Filannenta 4, capillaria, decidua, longa, receptaculo inferta.

Pist. Germen inferum.

Styli duo, filamentis paullo breviores, excrefentes, albi.

Stiginata fimplicia.

Pericarp. nullum.

Semina bina, nuda, lubglobofa, muricata.

Character generis: Cor. 4-fida. Calyx 0. Semina 2, nuda.

Locus: Tetrandria, Digynia ante Aphanem. Differt. 1:0 a Galio: a) Calyce nullo. b) Stylis duobus. 2:0 ab Aphane: a) Filamentis receptaculo infertis. B) Corolla Jupera.

Specres I. Galopina circæoides. Crefcit in Syleis Hautniquas, GrootVaders - bofcb, aliisques Floret Decembri, Fanuario.

Radix annua.

Caulis berbaceus, teves, ruber, glaber, fimplex, varius re: mofus, debilis, erectus, circiter bi-pedalis. Rami alterni, patentes, cauli fimiles. 
Folia oppofita, petiolata, oblonga, acuta, integra, glubras fultus pallida, policuria \& finallo ultra. In axis. lis folionum alias folia minora, finitia.

Flores terminales, paniculati. Panicula laxa, diffufa. Pedunctuli \& pedicelli oppofiti, capillares, gliubri, bracteriti. Bractere dus, oplofiter, Jetace.e.

\section{RETZIA。}

Cad. Perinatbium I-phyllum, ungviculare, 5-partitum. Lacinice lanceolate, inæquales, acutx, villcfx, longitudine dimidia calycis.

Corolla monopetala, infera, tubuilofa, cylindrica, intus extusque villofa, bipollicaris, parum curva, purpurea, apice 5 -fida: lacinice ovate, obtufx, concave, intus glabre, atropurpurex, extus apiceque valde hirfutæ, erectx, lineain longx.

Stam. Filamenta 5, fubulata, corolli inferta laciniisque duplo breviora.

Antberce compreffi, fagittatæ, fufcx. Pollen albidum.

PIST. Germen fuperum in fundo calycis.

Stylus filiformi - capillaris, corolla longior, pauls Iulum exfertus, purpureus.

Stigina bifidum.

Peric. Capfula oblonga, bivalvis, bilocularis, acuta, bifulca, glabra.

Semina plura, minuta. Character genevis: Capf. 2 -locularis. Corolla cylindricn. Stigma bifidum. 
Locus: Pentandria, Monogynia, pof Theophrafam. Nones domm fuit in honorem amici dignifimi JAH. RETZI, Prof. \& Demonftr. Ectan, in Acad. Lundenf.

Spzcies I. Reczia capenfis:

Keizin capenfs. Thunb. AEt. Lumient, Tom. I. pag. 55. tab. 1. fig. 2.

\section{WEIGELA。}

Cat. Feriantbian ;-phyllum, inferum; lacinis fubulatis, ereetis, xqualibus.

Corolla I-petala, infundibuliformis; thiobus longitudine calycis, intus villofus; Limbus campanulatus, femiquinquefidus, laciniis ovatis, obtufis, ereeto-patentibus.

Stam. Filemerita 5 , tubo inferta, filiformia, longitudine fere corollix, ereeta.

Antber ce ereetr, lineares, bafi bifidæ, apice obtura. PIsт. Germen fuperum, 4-gonum, truncaum, glä. brum.

Stylus e bafi germinis, fillformis, corolla paul. lo longior.

Stigna peltatum, planum.

Fructus adhuc ignotus eft. In forenti planta videtur effe:femen nudum.

Character generis: Sem. I. Stigma peltatum. Stylus e bafi germinis!

Locus: Pentandqia, Monogynia ante Plumbag inerr.

$$
\text { A. } \quad \text { No. }
$$


Nomes in memoriam Amici dileetifimi \& Botanici excellentifimi, WEIGEL, Prof. Botan. \& Chemix in Acad. Gryphica.

Specres I. Weigcla japonica.

Wergela japonica. Thunb. Act. Stockholm, 1780. p. $13 \%$ tab. 5 .

\section{B LAD HIA.}

CaL. Perianthizun I-phyllum, perfiftens, virefcens, glabrum, brevifimum, profunde 5-partitum: lacinice ovatz, concavæ, lacero fubferratæ, patentes.

Conolla i-petala, rotata, decidua, 5-partita: laci. nice ovatx, obtufa, patentes.

Stam. Flanent 5, breviffima, corollæ fupra faucem inferta, alba.

Antbere cordatx, acutæ, conniventes in conum, flavæ, corolla breviores.

Pist. Germen fuperum, convexum, glabrum, viride. Stylus filiformis, albus, corolla longior.

Stigma fimplex, acutum, virefcens.

Peric. Bacca globofa, calyce Atyloque perfiftentibus coronata, unilocularis, glabra, pifi minoris magnitudine.

SEMEN folitarium, globofum, membrana involutum. Character generis: Bacca I-fperma. Semen arillatum!

Locus: Pentandria, Monogynia poft Myrfinem. 


\section{Plantarum.}

Nomes in honorem \& memoriam Amici, D:ni P. J. BLADH, in Cantona Chinæ Mercatoris Celeb. \& Botanici indefeffi, inclyti.

Sfecies I. Bladhia japonica.

Zaponice: Quackitz it. Fabokofi, vulgo Fanna Tadfi banna. Fiempfo. Amo exoto fajc. V. pag. 766. it. Sjiro Tad. at barna.

Crefsit prope Nangafakt in montibus inter frutices, alibique, Floret fulio. lope culta in bortis.

Fructus nuaturus Decembri, Fanuario, Februario, Martio, Aprili.

Radix peremis, repens, fibrillofa.

Caulis frutefcens, flexuofus, erectus, rarifinte ramofus, pulmaris atque pedalis.

Folia verfus Jumnitaten frequentia, oppofita, petiolata, ovata, acuta, Jerrata, glabra, patentia, pollicaria funmis paullo najoribus.

Tetiolus linearis, lineann longus.

Fiores ex axillis folionum umbellato-racemofi, cermui. Pedunculus frintus, glaber erectus, mabelliferus, bipollicaris. Pedicelli teretes, rubri, glabri, cernui, ungviculares. Corolla alba Jvavens odoven Jpaygit.

Varietas duplex occurrit:

a) Fructu rubro, Fanna tadfi banna dila.

ß) Fruciu albo, Sjiro tadfi banna.

\section{HOVENIA.}

CAL. Periantbium I-phyllum, 5-partitum, perfiftens: dentibus deciduis, bafi intus pilofum: laci. 
mive orate, rencra, fupra linea modia clevata, deciduix.

Corouta 5-pectia. Petala inter lacinias calycis infera, obovata, obtufifma, patula, convoluta, namina obvolventia, aba, longitudine dentium calycis.

Stan. Filnmena 5, bafi calycis inferta, calyce paullo breviora.

Anther fubrotundie, intra petaia reconditx. Prst. Germer fuperum, convexum, glabrum. Sigluts unicus, crecus, calyce multo brevior. Stigmata tria, patula, reflexa, obtura.

Peric. Carfula ovato-globola, trifulca, glabra, ma. gritudine piperis, trivalvis, trilocularis.

Semen in fingulo loculamento unicum, lenticulare, glaberrimum, rubrum.

Character generis: Capfula 3-locuhris, 3-valvis. Petala convoluta.

Stigma 3-fidum.

Locus: Pentandria, Monogynia poft Diofmam.

Nomen dedi in Memorian fempiternam Macenatis optimi, Domini David ten HOVEN, Ecabin. \& Commifar. urbis Amfteldamenfis.

Species I. Hovenia dulcis.

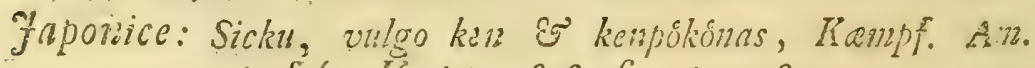
exot. fajc. V. pag. 808. fig. pag. 809.

Crefict prope Nangafaki.

Floret Funio, fulio, Augufto.

Fructus maturus Novenilur, Decenbri.

Radix perennis.

Caulis: arbor craffa, excelfa. 
Ranni terates, glabri.

Folia alterna, petinlata, fubcordata, ovata, acuminata, ferrata, dependentia, nervofa, glabra, palmaria.

Petiolus femiteres, reflexus, glaber, pollicaris.

Flores axilares of terminales, paniculati.

Panicula compreffa, dicbotonna.

Pédunculi fubteretes, dichotomi, poft florefcentiom incraffati, carnofi, carne dulci rubente; Pedicelli divarie cati, flexi retroplexique, glabri, ungviculares, lie meam. longi.

Flores facile decidui.

Raro calyx 4-partitus faminibus quatuor.

Pedunculi carnofi. eduntur a Faponcnflbus, funtque fapore dulci, fere pyri.

\section{CHENOLEA.}

CaL. Periantbinm i - phyllum, globofum, conca. vum, fubcarnofum, 5 - - irtitum laciniis arcte inflexis; extus argenteo-tomentofum, intus glabrum.

Corolla nuda.

Stan. Filamento 5, bafi calycis inferta, filiformia, erecta, fecundum marginem capfulz flexa, longitudine calycis。

Antberce minuta.

Pist. Germen fuperum.

Stylus filiformis, breviffimus, vix lineam dimidiam longus.

Stigmata duo, fimplicia, fubulata, acuta, patenti - reflexa, ftylo paullo longiora. B 
Peric. Capfula rotunda, fubdepreffa, umbilicata, glabra, unilocúlaris.

Semen Subrotundum, apice bifidum, glabrum, maturitate nigrum.

Character generis: Capfula r-fperma, I-valvis. Calyx 5 -fidus.

Locus: Pentandria, Monogynia, floribus incompletis inferis poft Celofiam.

Specres I. Chenolea diffúa.

Cressit prope Cap, locis depreffis, marittimis, in faldabnabay, alibique.

Floret Martio, Aprili.

Caules plures, radicales, fliformes, herbacei, diffuls, fimplices \& ramoofi, foliis tafi, purpurei, inferne glaliri, Juperne fubtomentofi, insequales, apicibus erectis, palmaves \& ultra.

Rami alterni, Iparfi, rari, cauli fmmiles, breviffini.

Folia faftigiatimascspofita, feffilia, ovato-lanceolata, obtufa cum ocumine, carmofa, integra, fupra tiana, fubtus convexa, frequentia, fusprema magis approximata \& imbricata, evecto-patentia, argenteo. tomentofa, internodiis longiora, feniunguicularia. Flores axillares, folitarii vel bini, felfiles in omni axilla foliorum, verfus apices ramorim.

\section{CUSSD NIA.}

CaL. Periantbium I-phyllum, truncatum, fubdentatum, corolla brevius.

Corolla. Petala 5, oblonga, acuta. Stam. Filamenta 5, breviffima. Antber o ovatæ. 
Pist. Germien inferum.

Styli duo, filiformes, patuli.

Peric. Fruetus didymus, angulatus, calyce ftylisque coronacus, bivalvis, bilocularis.

Character genericus: Involucrum nullum.

Perianthium I - phyllum, cre-

natum. Semina bilocularia.

Locus: Pentandria, Digynia poft Pimpinellam.

NOMEN huic generi impofitum fuit in memoriam bene meritam Celeb. Viri, in Acad, Monfpelienfi Profeff. Medic. D:ni Petri Cusson.

Species 1. Cuffonia thyrfoidea: foliis quinatis; foliolis funplicibus, cuneatis ternatisque apice dentatis. CufJonia thyrfoidea. Thunb. Act. Nov. Upfal. Tom. 3. p. I 20. tab. XII.

Species 2. Cuffonia fpicata: foliis reptenis; foliolis fin . plicibus lanceolatis ternatisque apice ferratis.

CuJjonia fpicata. Thunb. Adt. nov. Upfal. Tom. 3. pag. I 20. Tab. XIII.

\section{POLLIA.}

CAL. Perianthium nullum, fi non bracteam velis. Corolla hexapetala, nivea. Petala tria exteriora, ovata, concava, majora, obtufa, cum exterioribus alternantia, linearia, apice latiora; tria interiora inflexa, nervofa, tenuiffima, bractea paullo breviora.

StaM. Filamenta 6, receptaculo inferta, capillaria, apice incurva.

Antberce rotundx, didymx, flavx.

B 2

PIST. 
Pist. Germen fuperum, glabofum.

Stylus filiformi - fubulatus, incurvatus, albus,

bractea vix longior.

Stigna fimplex, obtufum.

Peric. Bacca globofa, bractea corollaque reflexa perfiftente cincta, glaberrima, magnitudine piperis, albida immatura, cxrulea matura. Semrna angulata, plurima, usque viginti, fufca. Character generis: Corolla infera, 6-petala. Bacca polyfperma:

Locus: Hexandria, Monogynia, ante Afparagum.

Nomen in honorem Patroni Summi, Domini J. van der POLL, Confulis Amfeldamenfium me. ritifimi.

Differt a Dracena et Afparago, Bacca Polyfperma. Species I. Pollia japonica.

Faponice: Famma Mioga.

Crefcit prope Nangafaki; in fava guoque inverita: Floret Septernlwi.

Caulis ungulatus, evectus, srticulatus, partin ransofus, vils info-afperatus, bipedalis.

Rani alterni, breves, fenfmi florentes, cauli fimiles. Folia in infinso caule approximata, in fipreno valde remo. ta, alterna, monlexicaulia, en ilormia, longitu. dinaliter nervola, integza, glalia Jed tamen vetrorfum afpera, fulbtus albida, patula, peduliu fibo perioribus brevioribus, pollice latiora.

Flores verticillata - corymbo $/ 2$.

Pedunculi verticillati, $4=\sigma$, villofi, virides, albidi, finters. tes., pollicares, biflori vel triflori. 
Pedicelli breses, nivei.

Brociea Jub janjulo peduniulo lanceolato, convesto, alba.

\section{GETHYLLIS.}

CaLYX nullus, nifi vagina oblique truncata. Corolla 1 -petala, 6 partita: Tubus longus, filiformis, radicalis; Limbi laciniz plano-patentes, oblongx, ungviculares.

Stam. Filamerita 6, ori tubi inferta, limbo dimidio breviora.

Antborre fpiraliter inflexæ, lineares.

Pollen luteum.

Pist. Germen inferum.

Stylus fimplex, ftaminibus longior.

Stigma capitatum.

Peric. Bacca fubcarnofa, radicalis, ex ipfo bulbo feffilis prodiens, clavata, obtufa, digitalis, inferne alba, medio flava, apice purpurea maculis rubris.

Semrna nidulantia, 3-5, triplici ferie impofita, glo: bofa, glabra.

Character genevis: Corolla fupera, 6 partita, fila mentis longior.

NoMEN olim uni fpeciei imfofuit Nob. Arch. à LINNE eamque ad Dodecandriam retulit e ficco fpecimine feductus. Nomen idem nos quoque retinuimus, licet fpecies noftras inter nova genera numeremus, cum vix prater nomen, cum Linnæana defcriptione B. 3 
generica quidquam noftræ commune habeant. E cliaractere ergo in Generibus plantarum \& Syftemate naturx minime genus hocee cognofci poteft, nec unquam Gethyllis afra Linnæi Botanicis innotuiffet, nifi cafu in Herbario ficco Linnæano, plantam male ficcatam, \& incompletam videre con tigiffet:

Locus: Hexandria, Monogynia poft Alftroemeriam. In quibusdam floribus filamenta fupra bafin, præcipue in fpecie 2:a, divifa, cum totidem antheris. Raro antheræ duæ in unico filamen. to indivifo. Hinc videtur quandoque antheræ 8, ro vel plures.

SpEcies I. Gethyllis fpiralis: foliis linearibus spiralibus glabris; limbir laciniis nvato - oblongis.

Papiria fpiralis. Thunb. Adt. Lund P. I. feet. 2. p. Im. SpECIES 2. Gethyllis ciliaris: foliis lineavibus ppiralibus ciliatis, limbi laciniis ovato-ablmingis.

Papiria ciliaris. Thunb. A\&t. Lund.P. r. feet. 2. pag. IIr. SPECIEs 3. Gethyllis villofa: folizs lineari-filiformibus Ipiralibus villofis, limzli laciniis ovato-oblongis.

Papiriavillofa. Thunb. Act. Lund. P. I. fect. 2. pag. III. Species 4. Gethyllis lanceolata: folins lanceolatis planis, limbi laciniis lanceolatis.

Papiria lanceolata: Thunb. Act. Lund.P. I. feet. 2. p. II 2.

\section{N A N D IN A.}

CAL. Perianthium polyphyllum, fexfariam imbricatum fquamis circiter fex fingula ferie, ovatis acutis, glabris, albo-incarnatis, caducis. 
Corolla 6 - petala, a'ba, membranacea, caduca, Petala oblonga, concava, acuta, calyce longiora, fefquilineam longa.

Stam, Filamenta 6, breviffima.

Antbere oblongx, ereetx, flavæ linea atra, lon. gitudine corolls.

Pist. Germen fuperum, ovatum, brunneum, glabrum. Stylus triqueter, breviffimus.

Stigma trigonum.

Peric. Bacca exfucca, globola, glabra, extus rubra, intus alba, difperma, magnitudine pifi. Semina hemifphærica, glabra.

RECEPTACÚLUM globofum, album, glabrum, impresfopunctatum.

Character genleris: Corolla 6 petala.

Calyx polyphyllus, imbricatus.

Locus: Hexandria, Monogynia poft Canaripam.

Species I. Nandina domeltica.

Japcnice: Nandfokf, vulgo Natten vel Nandin. Kempf, Asn. Exat. fajc. $V$. pag. 776.

Crefcit vilique, onbium vulgatifina, in onni villa: Culta. Fioret funio.

Radix perennis, plures caules emittens.

Caulis: Frutex evectus, laxus, fuperne ramofus, orgyalis, craffitie digiti vel pollicis.

Rami vaginis folionum vefitit, flexuof, apice foliofi.

Folia petiolata, fupra decompofita, ternata.

Foliola fubfefrlia, ounta, fetaceo-acuminata, integerrime margine reflexo, glabra.

Petioli fulcatz, glabri. 
Flores ternitinales, paniculati.

Panzicula fupradecomiofita.

Pedunculi \& Pedicelli angalati.

\section{EHRHARTA.}

CAL. Gluma bivalvis, ovata, concava, patula, altera paullo majore, membranacea.

Corolla duplex: exterior bivalvis; valvulæ oblon$g x$, complicatæ, carinatæ, retufx, transverfe rugofæ; calyce triplo longiores, bafi extus villofx. Interior paullo brevior, carinata, lrvis.

Nectarium patheriforme, hinc truncatum, inde lacerum, album, breviffimum.

Stam. Filamenta fex, brevia, capillaria, alba. Antbere erectx, lineares, emarginatx, corolla breviores.

Pist. Germien fuperum.

Stylus compreffus, villofus, ftaminibus brevior. Stigma fimplex, villofum.

Character gencris: Corolla infera, glumacea, duplex! Neetarium patheriforme.

Loces: Hexandria, Monogynia polt Hypoxin.

NoMEN: Domino FREDERICO EHRHART, Botanico maxime oculato \& diligentiffimo, ob merita in hocce ftudium non pauca, confecratum fuit rovum hoc e gramimum familia, genus.

Species I. Ehrharta capenfis. Ebrbarta capenfis, Thunb. Act. Stockh. I779. p.
216. tab. 8. 


\section{FAI C KIA.}

CaL. Periantbium 2 -phyllum, fubinflatum, 5 - angtalatum, corolla duplo brevius, viride, 5 -partitum; anguli medio dilatati, comprefir, exfantes; Lacinis ovata, acutæ.

Corolla $\mathbb{I}$-petala, campanulata, crenato - decempartita, albida vel albo -incarnata, limbo patenti, ungvicularis.

Stam. Filamenta 6, filiformia, tubo corolla inferta eique longitudinaliter parum adnata, erecta, alba, inæqualia, corolla paullo breviora. Anthere ovatx, compreffx, albidx.

Prst. Germina 4, fupera, glabra.

Styli duo, capillares, albi, divaricati, longitudine corollx.

Stigmata capitata, obtufa, alba, fimplicia. Semina in fundo calycis 4 , globofa. RECEPTACULUM purpureum. Character generis: Calyx i - phyllus. Corolla I - petala.

Semina 4.

Locus: Hexandria, Digynia, ante Atraphaxin. Nomen huic plantæ impofitum fuit in memeriam benemeritam Botanici folidiffimi, Dom. JOH PETR. FALCK, in Academia Scient. Petropolitana Profeffor celeberrimi.

Species I. Falckia repens.

Falckia repens. Thunb. Act. Lund. 
I8

\section{Gencra nova}

\section{WURM B E A.}

CaLyx monophyllus, tubulofus, 6 -angulatus, gla. ber, femi-fexpartitus; Lacinins lanceolatis . acutis, erectis, patentibus.

Corolla nulla.

Pist. Germen fuperum, triquetrum, fulcatum, glabrum. Styli tres, triquetri, fubulati, longitudine fta. minum.

Stigmata obtufa.

Peric. Capfula oblonga, triquetra, trifulca, glabra, trilocularis, a medio tripartita, e ftylis tribus: coalita.

Semina rotunda, plurima.

Character generis: Calyx 6-partitus.

Corolla. o.

Capf: 3 locul: polyfperma:.

Locus: Hexandria, Trigynia, flor. inf. poft Scheutzeriam.

Nomen dedimus in honorem Dini FR. v. WURMBS, Lib. Baronis \& hodie in Batavia Societat. ind. orient. Mercator. celebr. Societ. Scientiar. Batav. Secretar: Hiftor: naturalis uti \& aliarum fcientiarum peritiff. eorumque Culto.. rum Patroni faventifimi.

Species: I. Wurmbea capenfis.

Crefcit ad Cap. infra colles, in Groene Kloof E alibi, 10.. cis: arenofis.

Floret Fulio, Augufto, Septembri \& Octobri. Radix globofa, glabra, profunda. 
Cublis finplex, foliatus, vaginatus, frintus, Alexuofus, ere. Etus, glaber, digitalis vel palmaris.

Folia tria; Cusulina alteina, waginantia, bafi lationa, cancuva, Jenfinn nngufiata, apice fetacea, dificha, putentia, integerrina, glabra, longitudine caulis vel paullo longiorn; fuperiora breviora.

Flores spicuti, felfiles, fpurfi, alterni.

Racbis flixuofa, angulata, friata, pollicaris vel digitalis. Varietas triplex bujus datur:

a) bunnilior, calycibus albis: Iacinianum mavgini. bus maculaque fupra os tubi purpureis; fananinibus albis; Jpica 3 feu 4 -flora vel ultra:

B) calycibus totis purpureis; marginibus nigris; /taminubus purpureis; fpica ovata.

2.) Crlycihus albis; marginibus fufcis; fpica longiort.

d) calycibus totis allis, elongatis; fpica longa.

Wurmber fine onni dubio e Melantbio ciliato progenita eft, cui adeo finilis, ut minime, ab eo, ppecie diftingub poffet, nifi corolla effet 1 -petala: tabus tamen loco divifurarun petalorum friatus eft.

\section{DEUTZIA.}

CaL. Periant tizum $\mathrm{I}$ - phyllum, fubcampanulatum, $\mathrm{co}$ rolla triplo brevius, tomentofum, 5 -fidum, rarius 6-fidum; laciniis ovatis, obtufis, erectis.

Corolla 5-petala, raro 6-petala. Petala extra marginem germinis inferta, oblonga, obtula, integra, alba, femi-ungvicularia.

StAM. Filamenta 10, extra marginem germinis inferta, linearia, apice filiformia, fub apice e- 
20

\section{Genera nova}

marginata, bifida, alba, longitudine corol$l x$, alternis paullo brevioribus. Anthere globolx, didymæ.

PIst. Germen fuperum, fertiforme, medio concavum. Styli tres, rarius quatuor, filiformes, corolla paullo longiores.

Stigrnata fimplicia, clavata.

PerIc. Capfula globofa, truncata, perforata, fubtriangularis, callofa, fcabra, piftillorum bafi* bus perfiftentibus triariftata, trivalvis, trilocularis, rarius quadrilocularis, magnitudine piperis, cinerea, bafi dehifcens.

Semina plura in fingulo loculamento. Character genzeris: Capfula 3 -locularis.

Filamenta 3 -cufpidata.

Locus: Decandria, Trigynia poft Cherleriam.

Nomen huic arbori facrum voluimus, debuinus HiAtoriæ naturalis Cultori Cultorumque ejus Patrono maximo \& faventifimo, J. DEUTZ, Scabino urbis Amfteldamenfis longe meri. tiffimo pluriumque Collegiorum Præfidi di. gniffimo.

Species I. Deutzia fcabra.

Faponice: Foro Utfugi vel Famma utugi. Kampf. Ams. exotic. fafc. V.p. 854 .

Crefcit in montibus Fakonice et regionibus adjacentibus. Floret Mnjo, $F_{u n z i o .}$

Caulis arboreus.

Rami alterni, teretes, leves, purpurafcentes.

Ramuli villo/, Jcabri, patuli, ramis finniles. 
Folia oppofita, petiolata, ovata, acuminata, frrata, weno. fo-rugofa, pilis fiellatis jabra, pacenta, pollicaria vel uitra.

Petioli villofo- fabri, lineann longi. Flores in ultimis ranulis paniculati. Panicula comi $\mathcal{f}$ a pedicellis alevnis. Peduzculi atque pedicelli angulati, tonzentojo- foabri.

Ujas: Folia jcabra pro levigrandis E poliendis inrits e ligno confectis rebus a Fabris lignariis adbibentur.

\section{THUNBERGIA.}

CaL. Pevianthin I I-phyllum, ad bafin fere multipartitum: laciniis circiter I2, fubulatis, ereẼo-paculis, glabris, bracteis triplo brevioribus.

Corolla I-petala, campanulata; Tubus fenfim ampliatus, ungvicularis; Limbus 5 -fidus. Stam. Fllament 4, tubo fupra bafin inferta, inæqualia; duobus inferioribus brevioribus; duobus fuperioribus; tubo breviora.

Antber c ovatx, adnatz.

PIsT. Germen fuperum.

Stylus filiformis, tubo paullo brevior, ereहtus. Stigma bilobum.

Capsula globofa, roftrata, glabra, bilocularis, longitudinaliter dehifcens, bracteis longior; Ro. ftrum compreffum, fulcatum, lineare, obtufum; Diffepimentzwn obovatum, emarginatum, fub apice foramine perforatum, lateribus membranaceum, perfifens. 


\section{Generey}

SEMra in fingulo loculamento bina, reniformia, rugora, convexa latcre externo; interno concava, tulco longitudinali; ferruginea, magnitudine milii.

Character generis: Capfula bilocularis.

Cor. campanulata.

Cal. multipartitus.

Locus: Didynamia, Angiofpermia poft Cymbariam. Nones datum fuit a Prof. RETZIO, in memor am CAROL. PETR. THUNBERG, Med. DoEtoris \& in Horto Acad. Upr. Demontratoris Botanices, ob longinqua fufcepta periculofa itinera inque Botanicis \& $\mathrm{Z}$ Zoologicis detecta non pauca.

Species 1. Thunbergia capenfis.

Tbumbergia capenfis. Retzius Act. Lund. T. I. p. 16з. cum figura.

\section{H Y D N ORA.}

CALYX carnofus, lubteres, palmaris, primum claufus, dein apice dehifcens; ante aperturam apice triqueter, fupra bafin parum dilatacus; extus rimofus lacunis pubefcentibus, rufefcens tuberculis elevatis, obtufis, fubfufcis: poft dehifcentiam fuperne in tres limbos divifus, inferne infundibuliformis.

Lacinice limbi fublanceolatæ, obtufæ, fungo dimidio breviores, divaricatæ apicibus infle. xis; margines externi parum extrorfum fle- 


\section{Plantarum.}

xi, interni dilatati, oblique inflexi, bafi in dentes tres coeuntes ciliis muricatis. Cilia inftar Hydni imbricata, albo-incarnata, exteriora longiora, interiora fenfim breviora. Corolla tripetala. Petalum fingulum intra margines inflexos limbi adnatum; cordato-oblongum, carnofum, niveum, pollicare.

Stam. Filanenta tria, tubo medio calycis inferta, lata, in unum corpus coalita; extus antheris fere ad bafin teeta; intus nuda, concava, alba; femiungvicularia.

Antbere tres, cordatx; Atriatx, carnofx, glabræ; albo- incarnatæ; bafi connatæ; apice liberæ, obtula, conniventes.

Pollen tenuifimum, fulcis antherarum infidens, album:

Pist. Germen infra famina, convexum, carnofun, glabrum, album.

Stylus craffifimus, brevifimus, fubnullus. Stigma trigonum, convexo-planum, trifulcatum fulcis e centro ad angulos exenntibus, transverfe tenuifime friatum, album. Peric: Bacce bafi fungi inclua, carnofa, alba, trigona, multifulcata.

Semrna: Corpufululs ovato - cylindrica, plurima; imsghatura verticalia, totam fere capfulam re. plentia, fuperne affixa, petiolata, inferne \& lateribus libera; intus carnea, folida, carno: fa; extus globulis minimis, fubpellucidis, niveis obfita. Peizoli breves, fubfafciculati. 
Mntzra libera, nidulantia in pulpa tenuisfima, minuta, fenfim magis \& magis fufca, glabra.

Conarater generis: Fungi Calyx tripartitus.

Corolla 3-pctala, calyci adnata. Stamina 3. Piftillum!

Locus: Monadelphia, Monogynia ante Waltheriam. Species I. Hydnora africana.

Hydnora africana. Thunb. AR. Stockholm. I775. p. 69. tab. 2. f. I. 2. 3. \& 1777 . p. I 44. tab. 4. fig. 1. 2.

Apbytein hydnora Bif̂. Acad. Er. Acharii 1775. cum tabula.

\section{RADER M A HIA. Flores nasculini:}

CaLyx nullus. Amentum cylindricum, fuperne fenfim incraffatum, fpichamæum, floribus totum tectum.

Corolla. Petala duo, oblonga, concava, obtufa, villofa, alba, filamentum includentia.

Stan. Filamentzm unicum intra fingulam corollam, filiforme, diaphanum, album, corollæ longitudine.

Anthera pyramidalis, Alava.

Flores feminei in eadern arlore:

CaLyx nullus. Pericarpizun ovatum, germinibus tętum.

Corolda nulla. 
Pist. Germinn convexa, fexangulata, frequentifima. Stylus filiformis, perfiltens.

Stigma unicum vel fxpius duo, capillaria, revoluta, lineam longa.

Peric. Pomum ovatum, muricatum, carnofum, multiloculare.

Semina multiplici ferie imbricata, oblique triquetra, carne pulpofa obducta, magnitudine juglandis: Nucleus albus, cortice tenui brunneo obduetus.

Character generis: M.Cal. o. Cor. 2 -petala. F. Cal. o. Cor. o. Styl. I. Pomum multiloculare.

Locus: Monoecia, Monandria poft Ceratocarpum. Nomen: in Honorem Mæcenatis Summi \& Hiftoriæ naturalis imprimis Patroni \& Fautoris maxi$\mathrm{mi}$, in fummo Confilio Batavino - Indico Confliarii \&c. Societatis fcientiarum Batavinæ illuftris Præfidis, Joach. Cornel. Math. RADERMACHER.

Species 1. Radermachia incifa: foliis incifis.

Radermacbia incifa, Thunb. A\&t. Stockh. 1776. p. 253. Specres 2. Radermachia incegra: foliis indivifis.

Radermacbia integra. Thunb. Act. Stockh. 1776. p. 254.

\section{KEURA.}

Flores mafculi \& feminei terminales, di. fincti in diver $\int a$ arbore.

M. CalyX et Corolla nulla. 
Stam. Filannenta fparfa, folitaria in panicula ramofiffima, brunnea, vix lineam longa. Antberce lineares, acutx, erectx, flavx.

F.Calyx et Corolla nulla, nifi bractex germina diftingventes.

BRACTEF inter germina lineari-lanceolatæ, germine breviores, albidx:

PIst. Germina aggregata, feffilia, 5 - angulata, convexa, viridia, glabra.

Stylus nullus.

Stigmata duo, raro unicum, cordata, marginata', alba.

Peric. Nuces obovatæ; inferne attenuatæ, 5-angu* laté, glabræ.

Character generis: M. Cal. o. Cor. o. Filamenta folitaria. F. Nuces aggretatx.

Locus: Dioecia, Monandria ante Najadem. Species I. Keura odora.

Keura odorifera. Forskåhl. Flora Egypt. Arab. p. 172. Zavanis: Pudia.

Radix perennis.

Zunior acaulis eft folics plirimis; adulta caulefcit; adultior arborefcit, caudice craffitie dupla femoris, biorgya. lis, tota tuberculis frequentillimis afperata, apice ramofi.

Rami alterni, cauli fimiles, bracbio crafiores, patentes. Folia in juniori planta radicalia, in adulta Jemper terminalia, trifarian inbricata, enfffornia, inferne ereEta, a medio dependentia, fefrilia, ferrato - Jpinofa, jpinis allis erectis, tri-vel quadri-pedilia, cannliculata, carina dorfali Jpinofa Jpinis albis recurvis. 
Flores utriusque fexus terminales; ina calli nudi, antberis folitariis, fpar/is, ravo Jubumbellatis in parzicula ramofiffima peducellis capillaribus, tomentofo - brun. neis, ferninei Seffles, aggregati in Spica ovata. Uterque fexus in Ceylona occurrit; in Fava tantum mascus lus, uti $\sigma^{\circ}$ in Arabia bucusique inventus fute. Eructus magnitudine Bromelia Ananas aliquando.

\section{MONTINIA.}

M. Calyx 4 -dentatus, breviffumus, glaber: dentes erecti.

Conolla 4-petala, fupera. Petala ovata, obtufiffima, inter calycis dentes inferta, patentia, alba. Stam: Filamenta 4, raro 5 cum petalis 5. RECÉPTACULUM inferum, concavo-planum, glabrum. F.CALYX 4-dentatus, capfulam veftiens, glaber: dentes erecti, breviffimi. Raro calyx 5 -den. tatus cum petalis \& filamentis 5 .

Corolla ut in mare

Stam. Filamenta 4, intra dentes calycis breviffima, caftrata absque antheris, alba.

Pist. Germen inferum, concavo-planum, glabrum. Stylus corolla brevior, craffus, fupra bipartitus. Stignnata dio, reniformia:

Peric. Capfula ovato - oblonga, glabra, lineis elevatis, bilocularis, longitudinaliter dehifcens. Septutn craffum, didymum.

Semina plurima, imbricata, ovata, compreffa, margine omni alata.

CHA- 
Character generis: M. Cal. 4 part. Cor. 4 petala. F. Cal. 4 part. Cor. 4 petala. Stigma 2. Capf. 2 locul.

Locus: Dicecid, Tetrandria, poft Vifcum.

Nomen in honorem Laurent. Montin, Med. Doet.

Botan. eximii, Patroni \& Amici dilectiffimi.

Specres I. Montinia caryophyllacea.

Montinia caryophyllacea.Thunb. Act.Lund.T.I. p. Ios.

In Tabula cernuntur magnitudine naturali.

Bladhia japonica.

Wurmbee capenfis varietates $\alpha . \beta . \gamma$.

Deutzia fcabra. 



\title{
NOVA GENERA PLANTARUM,
}

\author{
QUORUM, \\ PARTEM SECUNDAM,
}

SUFFRAG. EXPER. FACULT. MED. UPSAL.

PURLICE VENTILANDAM EXHIBENT

$$
\text { PR止 SES }
$$

\section{CAROL.P.THUNBERG,} Med. Doct. Prof. Reg. et Extraord. Acad. Cesar. N. c. Reg. Seient. Holmens. Socift. Scient Upsal. Patr. Holmiens. Berolin. N. Sctent. Lundin. Harlem. Amstel. et NidRosiens. Membrum.

ET

RESPONDENS

CAROLUS HENR. SALBERG, STOCKHOLMTENSIS.

IN AUDIT. GUST. D. X JULII

ANNO MDCCLXXXII,

HORIS SOLITIS.

\section{UPS A LI $Æ$,}

TYPIS JOHA N. EDMAN, DIRECT. ET REG, ACAD, TYYOGR, 
IN SACRAM REGIAM MAJESTATEM

$$
M A G N \text { EIDEI VIRO, }
$$

DIRECTORI GENERALI NOSOCOM. REGN. SVECI E ETC. ETC.

\section{EQUITI AURATO ORD. REG.VASÆI}

GENEROSISSIMO ATQUE NOBILISSIMO

\section{DOMINO DOCT.}

OLAO AF ACRELL,

\section{MECENATI MAXIMO,}

Hanc pir reverentix qualemcunque tefferam confecratam voluit, 


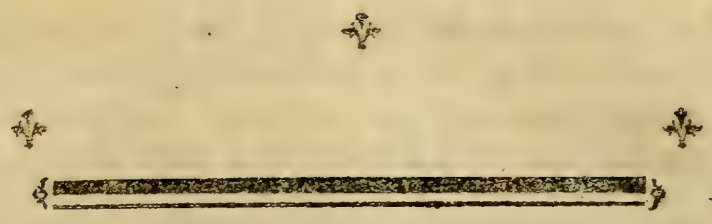

A co usque tempore, quo in phalanges diftribuere, 2. \& \& ad genera referre plantas incceperunt Botanici, Scientia vegetabilium citius increvit \& longe facilior reddita eft. Genera fixa primus omnium conitruxit immorralis TOURNEFORTIUS, eorumque numerum po. ftea fenfim adauxerunt omnes feculi hujus Botanici, ut ultra mille \& quingenta hodie numerentur. Multa tamen adhuc, Scienriæ Amatoribus detegenda reftant, quæ vel omnino non, vel qua folum barbarum nomen nota funt. Sic adhuc nefcimus, quænam fit illa arbor, quæ in Java \& Ceilona fponte crefcens, ab omnibus fere incolis commemoratur, dicta lignum fercoris, ob fingularem ipfius ligni, prafertim recentis, tetrum \& abominandum odorem, odori ftercoris humani adeo fimilem, ut fimilius nihil. Decerptos ramos \& foliz tantum hujus, nullos vero fiores, Cel. Præf. videre contigit. Vidit tamen decocto hujus exanthemata curis chronica fæpe \& optime profligata. Malabariæ \& infulæ Ceilonæ incolæ quotidie li. gnorum fuorum amaritie infigni imbutorum, magna cum laude mentionem faciunt, fummoque cum frubtu contra morfuras ferpentum venenatas, atque febres ardentes adhibent, licet a Curiofis Europreis vix unicum horum Bo. tanice adhuc notum fit. Attulit Cel. Prær. ex hifce regionibus pocula ex hifce lignis tornata, quæ vinum fibi infufum ea inficiunt, intra pauca momenta, amaritie, ut absque naufea vixque bibi poffit. Neque adhuc detegere valuerunt Chinam frequentantes Mercatores noftri, radicem illam amarifimam Schynlyn, quam ad fuxus al. E 
vinos fiftendos roburque ftomachi amiffum reftituendum, tantum decantant Chinenfes. Notius eft, quam quod notiflmum, Camphoram contra plurimos morbos remedium effe præftantifimum. Communiter hec camphora e Japonia ad nos adfertur, e Lauri Camphoræ radicibus \& jignis coctione \& fublimarione extracta. Exftat vero alia Camphoræ fpecies, Camphora Baros dicta, ex urbe $\mathrm{Ba}$ ros infulæ Sumatræ oriunda, qua tantum priorem Camphoram noftram virture fuperat, ut pro hujus unica libra lubentiffime centum libras folvant Japones. Hujus vero Camphoræ, tam carx, tam aftimata, tamque fortis origines adhue ignoramus, licet id certo fciamus, quod hxe ipfa naturalis fit, quod pelluciditate virrum xmuletur, quodque arbor longe diverfiffima fit a Lauro camphorifera. Hec vero \& plura alia obfcura, ventura, line dubio, dereger acas. Mihi vero fpecimen Academicum edituro, jam contingit, tibi B. L. Generum Plantarum novorum partem fiftere fecundam, ea certisfime fpe, ut, xque ac primam, hanc benigne excipias. Continet hæc inter alia, tria Genera, qux antea quidem. dudum defcripta funt a Cel. Prof. FORSTERO, in defcriptionibus novorum Generum; fed cum eodem circiter tempore, Cel. Præfes etiam hxc iṕa Genera detexcrit aliterque atque fufius defcripferit, hanc illorum defcriprionem heic communicare volui. Nomina quidem alia hifce $a b$ initio impofita fuerunt a Cel. Præfide, ea vero cum nominibus Forfterianis, typis dudum divulgatis, potius commutari voluimus, quam inurile \& tædiofe numerum fynonymorum nimis adangere. Et hac eft ratio, cur, inprima Difertationis parte, duorum Generum fervata fint nomina, prius illis impofita fcilicet: $\mathrm{Ra}$ dermachia a Cel. Præfide in actis Holmienfibus \& Keura FORSKOHLEI in recenfione Generum FORSKOHLEI defcripia, licet a Celeb. FORSTERO recenfita \& depicta fub nominibus Artocarpi \& Athrodactyli, fuerint.

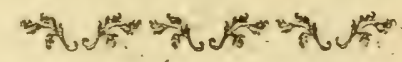




\section{GENERA NOVA PLANTARUM.}

\section{W I T SENA.}

ALYX, præter bracteas, nullus.

Conolla I - petala, tubulofa, erecta, bracteis longior. Tubus cylindricus, fenfim ampliatus, bafi luteus, apice nigro-cæruleus. Limbus 6-partitus, erecto-patens: Lacinix oblongx, obtufx, tomentofæ, luteæ, ungviculares.

Stam. Filamenta tria, tubo fuperne inferta, lineam longa.

Antberce oblongx, erętx, flavx.

PIsT. Germen fuperum.

Stylus unicus, filiformis, erectus, apice cernuus, corolla paullo longior.

Character generis: Cor. 6-partita, cylindrica. Stigma emarginatum.

Locus: Triandria, monogynia ante Ixiam.

Nomen in memoriam dedi D:ni WITSE'N, Confulis Amfteldamenfium Confult; \& Scientiarum in genere Patroni \& Promot. fummi.

Differt. I:O ab Ixia: Corolla Cylindrica.

Stigmate emarginato.

2:0 ab Antholyza: Corolla regulari, aquali. E 2

SPE- 
Species 1. W. Maura.

Antbolyza maura. Lin. Syft. Ed. 13. Tom. 2. p. 78. Mant. p. 175 .

Crefcit in montium latcribus ad Nordbak E* Baijfals. Floret Aprili, Majo.

Radix lignofa.

Caulis anceps, inforne tantum mudus, a eafu foliorum articulatus, glaber, fuperne totus foliis veftitus, fepius fimplex, rarius bifidus, erectus, bipedalis.

Folia alterna, feffilia, equitantia, enfiformin, fubfalcata, acuminata, lineata, marginuta, erects, imbricnta, glabra, palmaria usque jpitbanza.

Flores termzinales, capitnti.

Capitula duo, tria vel quatuar, alterna, Squansola, fubbiflora. Squama feu brictex alterne, oblonga, acuta, concave, ferruginece, glaura; exteriores breviores, ungviculares; interiores longiores, pollicares.

\section{FAGRAEA.}

CAL. Periantiram I-phyllum, campanulatum, 5-partitum; lacinia obtulæ, incumbentes, apice membranacex.

Corotla -petala, infundibuliformis: Tubus teres, apice fenfim dilatatus, palmaris: Limbus contortus, 5-partitus: Lacinia oblongx, obliqux, obtufx, integræ, patulæ.

Sтxм. Filomenta 5, tubo inferta, filiformia, xqualia, corolla breviora.

Anthere didymæ, ovatæ, verticales, extus convexi, 4 -fulcatx, intus planx, facile btpartibiles.

Pist. 


\section{Plantarum.}

PIST. Germen fuperum.

Styizus filiformis, longitudine corollx.

Strgina peltatum, orbiculatum, planum.

Peric. Bacca ovata, carnofa, glabra, epidermide teEta, bilocularis, magnitudine Pyri minoris. Character generis: Bacca 2-locularis, carnofa. Semina globofa. Stigma peltatum.

Locus: Pentandria, I-gynia, polt Randiam. NOMEN in honorem JON. THEOD. FAGRAEI, Med. Doct. \& Botan, meritiffimi. Differt. I:O a Portlandia: Culyce coroliaque infera. Titbo fubcylindrico. Stigmate peltato.

2:0 a Brunsfelfia: Stigmate peltuto. Bacca ovata, glabra, carnofa. Bacca carnofa, biloculario

3:0 a Strychno: Periantbio perfffesite. Stigmate peltato. Bacen carnofa.

SpeCIes I. F. ceilanica。 Seminibus orbiculatis, glabris.

Habitat in Ceilona.

Floret Decembri, Fanuario.

Caulis frutefcens, evechus, fuldetragonus, craffitie digiti bipedalis.

Folia faftigiatim oppofita, petiolata, frequentia, obovato o oblonga, obtufiffima, integra, coriacea, palmamb lata, Jpitbaman.

Petioli Jemiteretes, pollicares.

Flores terminales, fibumbellati, peduncalnti: 
Umbella circiter triforn. Peduarculi uation, oracteati, ainguiculares. Brofted oppofits, ovate, obtulae.

\section{A H L I A.}

CAL. Perianibitim 5-phyllum: Foliola lanceolata, acuta, concava, patentia, lineam longa.

Conolia 5 - pecala, lutea. Petala ovata, concava, patentia, calyce duplo breviora.

Starr. Filamenta 5, filiformia, inter petala inferta, ereeta, longitudine calycis, flava. Antherce oblongæ, quadrifulcatæ, flavæ.

PIST. Germen inferum.

Styli duo, filiformes, erecto-patuli, lutei, ftaminibus longiores.

Stignata fimplicia, obtufa.

Penrc. Copfula ovata, truncata, lineis 5 elevatis exarata, calyce perfiftente coronata, bivalvis, unilocularis.

Semina plurima, minuta.

Character generis: Flores calyculati fparfi.

\section{Capfula.}

Locus: Pentandria, 2-gynia ante Phyllidem.

NUiris dedimus in honorem D:ni VAHL, in horto Hafnienfi Botan. Demonftrat, meritiff.

Species I. V. capenfis.

Crefcist prope, Verkeerde Valleij fubulofis locis.

Floret Decembri.

Tota plante villoja, vifcosa. 


\section{Plantarum.}

Radix perennis.

Caules fubredicales, plures, berbacei, erecit, fintolices vel ramofi, teretes, fpitbamaei.

Rami oppofiti, faftigiati, cauli finiles.

Folia oppofita, fefrilia, lanceolata, acuta, integra, concava, erecta, longitudine internodionum, pollicaria.

Axille onufe fodis minoribus.

Flores axillares, pedunculati.

Pedunculus teres, erectus, biflorus bracten in medio lanceolata. Eacies: Airoi.

\section{CAROXYLON.}

CaL. Periantbizm diphyllum, fuborbiculatum, rude, intus concavum, extus carinatum, margine tenuiffimum, erectum corolla brevius.

Corolla I-petala, 5-partita fere ad bafin: Tubus nullus. Limbi lacinix obtufx, latx, fubrotundæ, concavo-crifpæ, membranaceæ, patentes, flavefcentes vel parum obfcure purpurafcentes.

Nectarium: fquamæ 5, corollæ mediæ infertæ, corolla paullo anguftiores \& breviores, cumque ea inferne connatx; frudui conniventi impofitæ, ovatæ, acutiufculæ, concavæ, membranaceæ, flavefcentes bafi virefcente.

STAM. Filamenta 5, lateri germinis inferta, corolla breviora, alba, capillaria.

Antber ce minima.

Pist. Germen fuperum, conicum, glabrum. 
Stylus fimplex, corolla brevior, erectus, albus. Strgmata duo, revoluta, albida; raro Atigma

Peric. nullum. fimplex.

SEMEN I, depreffum, rotundum, viride, fpirale, membrana tenuiffima veftitum, filamentis nectarioque perfiftentibus teetum.

Cefaracter generis: Semen tunica vertitum.

Corolla 5 -petala.

Nectar. 5.phyllum, conivens, corollæ infertum!

Locus Pentandria, I-gynia polt Sauyagefiam. Differt. I:o a Salfola: Figlo manifege urico. Fruktu angiospermo. Celyce dipbyllo. Nectario.

2:0 ab Anabafi: Nectario!

Specres 1. C. fallola. Calyce dipbyllo.

Africanis: Canna bofch.

Crefcit in omini Carro.

Floret OEtobri.

Radix perennis.

Candis arborefeens, erectus, vamofifinus, nudus. Rami Spar/i, rigidi, flexuofi, patuli, ransulofi.

Ramuli ultimi $\mathrm{Jparfi}$, teretes, flexiles, tomentofo-albi, foliofi, floriferi, pollicares E ultra.

Eolia is ultimis ramis frequentifina, imbricata, feValia, Jubglobofo-ovata; intus concaviufcula, glabra; extus gibba, cinero-tomentofa, obtufa, minutifinia, adpreffa. Axille aliis foliis onufa. 


\section{Plantarum.}

Anasafs proxime accedit.

Ujus: Ex coneribus brijus, cum pinguedine ovisa fapo Africorus cincrafens proparatur a Ruficis.

\section{MASSONIA.}

Calyx nullus.

Corolza 6-petala. Petala neEtario extus impofita, lanceolata, patentia, femiungvicularia, erecta. NECTARIUM inferum, cylindricum, 6-ftriatum, membranaceum, 6-dentatum.

Stam. Filamezzta 6, neetarii dentibus inferta, filiformia, declinata, petalis paullo longiora, purpurafcentia.

Antherce ovatx; eredtx, flave.

PIst. Germen fuperum relpeetu nectarii.

Siylus fubulatus, declinatus, longitudine fami-

num.

Stignna fimplex, acutum. Peric. Capjula triquetra, fuperne incraffata, obtufa, glabra, ungvicularis, trilocularis, trivalvis, angulis dehifcens.

Semina plurima, angulato-globofa, glabra, atra, magnitudine feminum finapios.

Character generis: Nectarium inferum.

Corolla 6-petala, Nectario inferta.

Locus: Hexandria, I-gynia poft Pancratium.

Nomen impofitum fuit huic generi a Cel. Præfide in honorem amici \& olim in intarioribus 
Africx regionibus, fub bienni itinere comitis amantiffimi, D:ni FRANCISC. MASSON, Hortulani Regii \& Botanici plurimis etiam poftea itineribus \& novis detectis inclyti \& bene meriti.

Differt. 1:0 ab Afphodelo a) Nectario cylindrico. B) Capfula triquetra.

2:0 Pancratio: 1. germine Jupero.

2. Nectario 6-dentato.

3:0 Narciffo: a) germine fupero.

b) Nectario dentato, apice ftaminisfero.

Species I. M. latifolia: foliis rotundato-ovatis glabris.

Crefcit in Roggefeldt.

Floret Septembri, OEtabri.

Radix bulbofa. Bulbus rotundus, fibrofus, magnitudine Rapbani.

Scapus fubnullus.

Folia vadicalia, bina, fuborliculata, integra, craffa, planas depreffa; Jupra viridia maculis margineque purpus. reis; fubtus pallida, imnaculata, glabra.

Flores radicales inter folia., pedunculati, glomerati, braEteis sincti.

Pedunculi fenfin incrajfati, allidi, glabri, Jeniungvicuo lares, uniflori.

Bractea unica ad bafin finguli pedunculi ovata, acuta, concava, membranacea, longitudine fere foris, perfiftens, erecta.

SPEC. 2. M. Ianceolata: foliis lanceolatis integris giabris. Crefcit in fummo monte Onderfte Roggefeldt. Floret Auguftio. 
Folia Radicalia, pauca, lanceoluta, fubenfformia, integra, glabra, tripollicari.s.

Siapus filiformis, erectus, glabor, inferne allus, fuperne purpurafcens, bipollicaris.

Flores pedunculatr, fulfaftigiati.

Pedunculi lparfi, filiformes, aniflori.

SPEC. 3. M. undulata: foliis lanceolatis undulatis glabris. Crefcit in interioribus Africe nuftralis regionibus.

Bulbus magnitudine nucis avsllanse, flivofus.

Folua radicalia, tria, quatuor vel quinque, inferne valde angufata, enfiformi-lanceolata, undulata, evecta, glabra, digitalia.

Scapus evectus, Fenfim incraffatus, glaber, pollicaris.

Flores ter minales, umbellati, pedrunculati.

Pedunculi brevilfini, unifori.

SPEC. 4. M. echinata: foliis ovatis muricatis pilo/is.

Cre/cit juxta margines montis, dicte Bocklands Berg, in interioribus Capitis bonce Jpei regionibus.

Bulbus magnitudine vix nucis avellance.

Folia radicalia, duo, ovata, obtula cum acumine, integra, plana, depreffa, tota fupra tuberculis muricata, pilofa pilis Jparfis albis, pollicaria.

Scapus nulus vel brevifimus.

Flores glomerati inter folia.

\section{A L ODENDRUM.}

CaL. Periantbium monophyllum, perfiftens, 5-partitum: laciniæ ovatæ, acutæ, craffiufculæ; intus glabræ, albidx; extus villofo-muricatæ marginibus fubrevolutis; corolla multoties breviores. 
Corolla ante explicationem s-angularis, longitudi ne calycis; explicata s-pecala.

Petala lanceolata, obtufa, patentia, intus canuiculata, extus carinata, undulata, villola, cilyce triplo longiora, ungvicularia, incamata. NeCTARIa 5, petaliformia, intra petala receptaculo inferta, lineari-lanceolata, apice fubulata, glandula terminata, corolla anguntiora, ejusdem vero longinudine, glabra, argenteoglandulofa.

Stam. Filamenta 5, æqualia, longitudine corollæ, alba; quatuor antheriferis unoque fterili. Antbere ovatx, fulcata, cordatx, brunnex, dorfo infertæ.

Pist. Gernen fuperum, pedicellatum, capitatum, muricatum, fufcum.

Stylus lateri altero germinis infertus, filiformis,

longitudine filamentorum.

Signa fimplex, obtufum.

Preic. C.pfula ovaca, 5 -angularis angulis obtufis, 5-fulca, muricata, pedunculata, 5-valvis,

5-locularis, magnitudine Pruni.

Semina bina in fingulo loculamento, fubtriangularia, dorfo convexa, glabra, brunnea, magnitudine Pifi.

Character generis: Capf. 5-locularis. Neetarium 5-phyllum.

Locus: Pentandria, I-gynia poft Cedrelam. Differt. a Cedrela: nectario.

a Sauvagefia: Cappula $j$ :locularia 
Variat mumerus partinn corrolle, nectarii Es faninum:

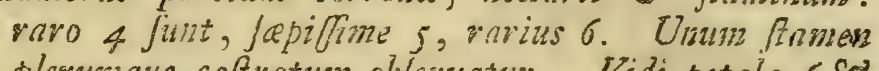
plerumgue caftratum objervatur. Vidi petala $68^{\circ}$ zectaria 6 cum finminibus 4.

Capfula pedunculo brevi fupra calycem goudet, Loculamenta quedan capfula Jape fierilia.

Species 1. C. Capenfe.

Africanis: Wilde Caftanien.

Crefcit in Groot Vaders bofcb.

Floret Decembri, Fanunio.

Radix perennis.

Caulis: arbor excelfa, valde crafla.

Rami oppofiti vel terni, cicntricibus folionum fcabri, fruoti, teretes, divaricati, fufci.

Folia fofrigiatim ofpofita, periolita, ovata, obtufa, imteger. rima, lirienta scrvis parallelis, Jenjiervircntia, fupro viridia, fubtus pallidiora, palmaria.

Petioli crnfi, breves, Jupra plani, fubtus convesi, linenns longi.

Flores paniculati, pedunculati, terminales.

Pedunculi breves, villofi, oppofiti cun impari, uniflori.

\section{EKEBER GIA.}

CaL. Periantbium I-phyllum, campanulatum, tomentofum, 4-partitum: Lacinia ovatæ, obtufr. Corolla 4-petala, calyce paullo longior. Petala oblonga, obtufa, alba, extus tomentofa.

NECTARIUM: annulus bafin germinis cingens. STAM. Filamenta IO, breviffima, pubefcentia. 
Antbere ovatx, acutx, ereetx, flavx lineis duabus nigris.

PIST. Germen fuperum.

Stylus cylindricus, breviffimus.

Sighna capitatum.

Peric. Bacca globofa, 5-fperma, magnitudine nucis avellanæ.

Semina oblonga.

Bacca variat feminibus $2 \cdot 5$.

Character genzeris: Nedtarium fertiforme, cingens germen.

Bacca 5 -fperma, feminibus oblongis.

Locus: Decandria, I-gynia poft Swieteniam.

Nomen impofuit huic generi Cel. Prof. And. SparkMAN in fempiternam memoriam meritorum in fcientias Celebris Capit. \& Ord. Wafæi Equ.D:n CAROLI GUSTAVI EKEBERG. Differt. a Swietenia \& Melia: Bacca. Nectario integro. SPECIES I. E. capenfis.

Ekebergia capenfis. Sparrman Act. Holm. 1779 p. 282. tab. 9.

Africanis: Effenbout \& Effenboom, item Hauteniquas EfJen,

i. e. Afk-trád ob fimilitudinem foliorum cum Fraxino.

Crefcit in fylvis Hauteniquas, ingue Jylva EfJenboch dicta infra Langekloof.

Floret Novembri \& fequentibus mengibus.

Caulis: arbor procera cortice cinerafcente.

Rami E Ramuli alterni, a cafu foliorum sodofi, rugofi, pa: tentes, cinerafcentes, glabri. 


\section{Plantarum.}

Folia in extrennitatibus ramulorums aggregata, fparfa, petion lata, pinnata cum impari. Foliola opposita, Jeffilia, trijuga, oblonga, acuminata, integra, margine revoluta, lateri interiori ad bafin anguffata, parallelo nervofa, glalira, fubtus pallidiora, infe. viora pollicaria, Juperior a jenflm majora, bipollicaria; Petiolus univerfalis, fenuiteres, glaber, inferne apbyllus, /pi. ibaniezls.

Flores axillures \& terminales, paniculati.

Panicula ex ala folii folitaria, erecta.

Pedunculus univerfalis compreffus, Ariatus, glaber, jalma.

ris; Pedicelli cernui, ghabri, lineam longi.

Ufus: Lignum durun variis rebus fubricandis infervit.

\section{IN O CA R P US.}

CaL. Periantbium I-phyllum, campanulatum, glabrum, bifidum; lacinix rotundæ, fubxquales. Corolla I-petala, tubulora. Tubus cylindricus, ca lyce brevior. Limbus 5 -partitus: lacinia lineares, acutæ, undulatæ, fæpe reflexæ, caIyce duplo longiores.

STAM. Filamenta decem, breviffima, tubo inferta, 5 fuperiora, 5 inferiora. Antbera ovatx, didymæ, erecta. PIsT. Germen fuperum, oblongum, villofum. Stylus nallus.

Strgmatis loco punctum excavatum. Peric. Drupa ovata, compreffa, obtufa, I-fperma. $N u x$ fibris lignofis intertexta. Nucleus ovalis, compreffus. 
Character generis: Corolla tubulofí.

Drupa I-fperma.

Locus: Decandria, monozynia por Arbutum.

SpEc. I. I. edulis.

Gajan, gajanus. Rumph. Herb. Amb. Tom. I. p. 170 tab. 65.

Inocarpus edulis. Forf. Gen. Plant. p. 6; Tab. 33.

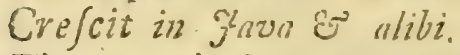

Filoret majo \& Jequ. snenalibus.

Caulis arboreus.

Rami alterni, rugofi, flexuofl, brunnei, glabit.

Folia alterna, petiolata, oblonga, nbtufia, integra, fibundulata, nevooia, glabra, fubtus pallidiora, Jpitbannoa. Petiolus teres, vix lineanu longus.

Flores fpicati.

Spice axillares, fexusfo-erecte, digitales, usque Ppitbanee, foribus approximatis.

\section{BARRINGTONA.}

CaL. Periantbiuniz fuperum, perfiftens, viride, glabrum, diphylium: foliola ovata, concava, perfiftentia, pollicaria.

Corolr a 4-petala, alba. Petala ovato-oblonga, integra, caduca, calyce duplo longiora.

NECTARIUM conicum, tubulofum, bafin ftyli veftiens, apice dentatum denticulis pluribus, inæqgualibus.

STAM. Filamentí plurima, receptaculo inferta, capillaria, corolla longiora, incarnata, caduca. Ans. 


\section{Plontarum.}

Antbere fubrotundr, minutx, flavæ lineis atris. Pist. Gerrnen inferum, marginatum, planum. Stylus filiformis, longitudine ftaminum.

Stigrna fimplex.

PERIC. Drupa ovata, conico-quadrangularis, apice attenuata, calyce coronata.

Nux ovata, offea, extus rugofo-fibrofa, 4-lo. cularis.

Nuclei folitarii, ovati, rugofi.

Character generis: Calyx diphyllus, perfiftens. Drupa nuce 4-loculari.

Locus: Polyandria, Monogynia poft Mammeam. Nomen impofuit Cel. Prof. FORSTER in honorem D):ni BARRINGTON e Juảicibus Regiis Princ. Walliz.

Differt. I:० ab Eugenia, cui valde fimilis:

I. Staninibus receptaculo injertis.

2. Calyce dipbyllo.

3. Nectario.

2:0 a Mammea, cui valde affinis:

1. Nectario.

2. Nuce 4-loculari.

3. Calyce dipbyllo, perfiftente.

4. Stigmate acuto.

SpEC. I. B. fpeciofa. Barringtonia. Forfter Gen. Plant. p. 75. Tab. 38, 38 . a 38 b.

Butonica. Rumph. Herb. Amb. Tom. 3. p. 172. Tab. II 4 .

Mamme Afiatica. Lin. Sp. Plant. p. 73 i.

Crefcit in Fava \& Ceilona ad littora maris. 
Floret Fumio Ev Jequentibus mengluus.

Arbor excella, debilis.

Rami angulati, glabri.

Folia in apicibus ramorum, frequentia, [parfa, fubjefilia, obovato-oblonga, inferne attenuata, obtula, emarginata, integra, glabra, patentia, palmam lata, pedalia.

Flores pedunculnti, Joliterii.

Pedunculus digitalis, usque fpitbamaus, glaber, cernuus. Flores ommium maximi \& pulcberrimi, fed facillime corolla E fanninibus deciduis.

\section{CHA M I R A.}

Cax. Periantbium 4-phyllum, erectum, claufum, ungvibus corollæ paullo brevius; foliola lanceolata, extus convexiufcula: duo ftaminibus longioribus oppofita, bafi producta in nectarium cornutum, rectum, albidum, ca. lyce duplo brevius.

Corolla 4-petala, cruciata: ungves lineares, ereeti, lineam longi. Larninn ovata, obtufa, patentia, longitudine ungvium.

Cozor corollæ albus.

Nectarium: glandula globofa, virefcens, glabra, fesfilis extra ftamina breviora, utrinque unica. STAM. Filamenta 4, receptaculo inferta, lineari-fubulata; calyce paullo breviora, erecta, alba; 4 longiora, duobus oppofitis duplo brevioribus. 


\section{Plantorum.}

Antbere ovatx, 'flavx: filamentorum Iongiorum quatuor conniventes.

PIs̄T. Germen fuperum, ovatum, glabrum. Stylus breviffimus, viridis.

Stigma obtufum.

Peric. Siliqua oblonga, dorfo recta, ventre convexa, fubarticulata, bivalvis, bilocularis, pollicaris. Semina plura, ovata. Character generis: Calyx bafi cornutus!

Glandula extra ftamina breviora.

Locus: Tetradynamia filiquofa, ante Cheiranthum. Affinis quidem eft Heliopbile, fed re ver a diftinetunz genus. Differt. 1:0 ab Heliophila: a) Cornu calycis producto.

b) Nectarii glandula globofa.

c) Calyce perfiffente.

2:0 ab Hefperide: a) Glandula nectarea fimplici.

b) Cornu calycis.

Cheirantbo convenit, fed differt:
a) Glandula fimplici nectarea.
b) Cornu calycis.
c) Calyce claufo, perfiftente.

Species I. C. cornuta.

Crefcit in fifsuris rupis Vitteklipp dicte, in Svartland. Floret Septembri.

Tota planta fucculenta, debilis, glabra.

Ridix fibrofa, annua.

Caulis unus vel plures procumbentes vel fubfcandentes, inzRamuli ferne fubangulati, fuperne teretes, glabri, Folia alterna, petiolata, cordato-Jubrotunda, acuminata, dentato-angulata; inferiora majora; fuperiora Jenfim minora, nervo/a. $P_{e-}$ 
Petioli femitevetes, Jupra canaliculati, folic breviores, polli. cares, patentes.

Flores alterni, remotifrnis: terminalibus approxinatis peciuno culatis.

Pedunculi florentes erecti, linean longi, unifori, fruetiferi reflexi.

\section{GALA XIA.}

CAL. Spatba univalvis membranacea, glabra, tenuiffima, connivens.

Corolla I-petala; fupera. Tubus filiformis vel capillaris, longus, erectus, glaber, pollicaris, apice paullulum ampliatus. Limbus 6.partitus: Losinice obovatæ, obtufx, patentes; tribus exterioribus bafi fovea neetarifera.

STam. Germen inferum, obtufe triangulare, glabrum.

Stylus centro germinis infertus, filiformis, ftaminibus paullo longior.

Stigmata tria, filiformi-multipartita, patentia. Peric. Capfula oblonga, glabra, trivalvis, trilocularis, fubcylindria, trifulca.

Semina plurima, globofa, minima. Character generis: Cor. I-petala, 6-fida. Locus: Monadelphia, Triandria ante Lercheam. Difjert. a Moræa: x. Stigmatibus multipartitis nec bilabiatis. 2. Corolla 1-petala: tubo longo; limbo Sexpurtito cquali.

ab Ixis: 1. Strminibus comnatis.

2. Sticnatibus multipartitis.

3. Sp.ritsa univalvi. 


\section{Plantarum.}

Species I. G. ovata: foliis ovatis.

Crefcit copiofe circa urbene Cop, in collibus.

Floret a Funio ad Septembris menfem.

Radix filiformis, defcendens, bulbo affixa: bulbus ovatus, reticulatus. Bulbilli frepe conglomerati, plures.

Scapus vel caulis mullis.

Folia radicalia, congefta, vaginantia, ounto-oblonga, obtuJa, fupra fulco longitudinali fubvenofa, plana, mar. gine fulcartilaginea, glabra, pollicaria.

Corolla valde fatua uariat colore flavo, purpureo, violaceo, veperi le claudit uti \& G. graminea corolla fatifcendo involuta, ante boram quartam.

Variat a) corollis totis flavis, , repiffime.

B) corollis violaceis,

Specres 2. G. graminea: foliis lineari filiformibus.

Crefcit in collibus inter Cap \& tafelberg, copiofe, E alibi circa urbem.

Floret Funio, Fulio, Anguffo.

Radix ut in $G$, ovatn.

Folia radicalis, fafciculats, ad fingulam forenn bina, bafi latiora, inde linearin, apice fetacea, integra, canaliculata, glabra, pollicaria vel bipollicaria.

Flores raticales inter folia vaginantio, fafciculati, feffiles, tubo longo capillari.

Tubas corollde longitudine foliorum.

Color corolle Japius flavus; a frigore vejpertino circa borams guartam fatifcit, contrabitur, vixque aperit iterum florem., nifi calidis a Jplendente fole diebus.

Variat a) corollis totis favis.

B) tubo flavo, limbo violaceo.

Difficile ficcantur bre Jpesies, ctm a frigore vel minimo bu- 


\section{Genera nova}

mide evadunt \& corolle apicems primo, deirs limsbuns totum contrabunt crifpando. Non confervantur \& exficcantur, nifi in libro bene incluje tene. nntur, usque dum fenificcaice fuevint; tum lepn. rande evunt, alias cbarte ita adglutinantur ut feparari fine laceratione nequeant.

\section{A I T O N I A.}

CaL. Periantbium I - phyllum, corolla multo brevius, erectum, 4-partitum: lacinix ovatx, acutæ. Conolla 4-petala, erecta. Petala lato-ovata, convexa, obtufiffima, ungvicularia, albo-purpurea vel incarnata.

Stam. Filamenta fæpiffime 8 , raro 9 vel 10 , a bafi fere ad medium in unum corpus coalita, inde libera, lineari-fubulata, fulcata, corolla longiora, exferta, pallida, virefcentia. Anthere ovatx, fulcatx, flavæ ftria fufcefcente. PisT. Stylus filiformis, longitudine filamentorum. Stigma fimplex, obtufum.

PERIC. Bacca ovata, exfucca, membranacea, fragilis, inflata, 4-angularis angulis productis acutis, glabra, magnitudine Pruni.

Semina Columnæ affixa, globofa, glabra, folitaria. Character generis: Corolla 4-petala. Bacca exfucca inflata!

Locus: Monadelphia, Octandria.

Nomen in honorem Dom. AITON, Hortulani in Horto Regio Kewenfi.

Species I. A. capenfis. Thunb. Act. Lund. Tom. I. p. I66. cum figura. 


\section{Plantarum. \\ C A S UARINA.}

Mas. Calyx nullus, fed amentum filiforme, imbricatum; fquamis minutis, ovatis, acutis, ciliatis, unifloris, circiter oeto verticillatis.

Corolla nulla.

Stam. Filamentum unicum intra fingulum foliolum infertum, capillare, foliolo paullo longius. Femina. Strobilus ovatus, fquamis ovatis, acutis, carinatis, ciliatis.

Corolla nulla.

PIST. Germen minutum.

Stylus filiformis, bifidus, exfertus, ftrobilo Iongior.

Stigmata bifida.

PERIC. Strobilus oblongus. Capfulæ conicx, bivalves, valvulis perpendiculariter dehifcentibus. SEMEN folitarium, conicum, margine apiceque membranaceum.

Character generis: M. amenti fquama uniflora. Cor. 0 . F. Strobilus. Cor. o. Atigmata 2, bifida. Capfula 2-locularis, I-Iperma.

Locus: Moncecia, Monandria poft Cynomorium. Ohf. Stamina oeto funt, ad fingulum articulun, fed unicum tantum intra finguli folioli amenti apicens. Specres 1.C. equifetifolia: Verticillis Aaminum approximatis.

Cafuarina littorea. Rumph. Herb. Amb. Tom, 3.p. 86. tab. 57. 
Cafuarima. Forit. Gen. Plant. p. 104. tab. 52. Malaice : Kajo Tjansmara.

Crefcit in $\mathcal{F}_{a v a} \mathrm{E}^{\mathrm{a}}$ aliis Indie orientalis infulis. Floret Mario \& Sequentibus meñabus. Arbor omnium facile maxima $\xi^{N}$ vaftifima, varnofifima. Ramuli [parfi, teretes, cinerei, verticillato-nodo 13 ex folits deciduis; ultinui bifpidi ex foliolis exaridis recurvis; longi, laxi, iterum ramulofi.

Ultimi ramuli Jpar/2, aggregati, filiforni -capillares, laxi, foliis decurrentibus tecti, articulati, friai, apice florentes, digitales.

Folia ( $(j$ vera) verticillata, octona, longe decurrentia, ins. ferne fubconnata, erecta, apice patula, fubulata. Flores in ultinis ramulis verticillato-picati, mafculi $E^{\circ}$ feminei diftincti in eadem arbore.

Spica mafcula filiformis, ramulo crafior, fubclavata, pollicaris. Strobilus femineus oblongus, obtufus, folitarius in ramulis infra mares, pedunculatus pedunculo vix lineave longo, evectus, nagnitudiue nucis.

SPECIES 2. C. nodiflora: verticillis ftaminum Yyemotis: Arbor excelfa.

Rami छे ramuli, ut in priori, fed magis profunde ftriati. Flores mascali in ultimis ranmulis verticillati verticillis resnotis, diftinEtis. 
Mitfer

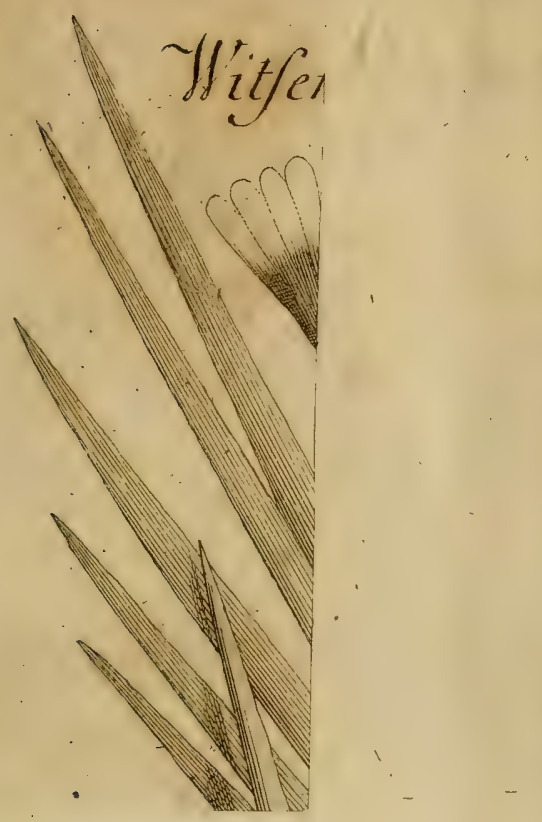





\title{
NOVA GENERA P LAN T AR UM,
}

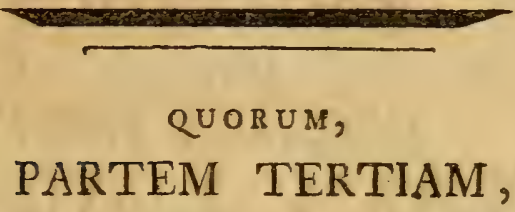

SUFFRAG. EXPER. FACULT. MED. UPSAL., IUBLICE VENTILANIAM EXHIBENT PR. IS ES

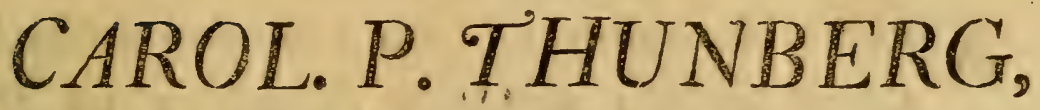
Med. Doct. Prof. Reg. ex Extraord., Acad. Cesar, n. c. Reg. Scient, Holmiens, Societ. Scient. Ups. PAatr. Holmens. Berol, n. Scrut. Lund. Harreks. Amstel. et Nidrosiens. Memerum.

Kaingane

\section{ET}

- Wisw vogk

\section{RESPONDENS \\ mond in \\ JOHANNES Gust. LOdin,}

\author{
SUDERIANNUS.
}

IN AUDIT. GUST, MAJ.D. XVIII JUNII ANND MECCIXXXIIE. FORIS SOEITIS.

\section{UPS A L I $Æ$ E,}

TYPIS JOHA N. EDMAN, DIRECT. ET REG. ACAD. TYPOGR. 


\section{BRUKS.PATRON, \\ HÓG Á DLE HERREN,}

\section{HERR JOH. ABRAHAM GRILL ABRAHAMSSON,}

\section{SAMT}

\section{HO̊GÅDLA FRUN,}

\section{FRU ULRICA FÓD D LÜNING, \\ GRILL}

HÓGGUNSTIGE VÁLGÓRARE !

Konglige Academien i U'pfala byfer fere vedermálen of Grillifka Familliens àdelnodiga nit for nyttige Vetenfkaper och i fynnerbet fór Natural.Hi. ftorien: och jag, fom nu vid detta Lirdoms fátet fortfátter mina ftudier, forvarar $i$ vordfant minne E.ter bogt berömliga ynneft ocb mainga viallgárningar, ocb upoffrar fajom et ringa vedermále deraf denna Botanifka Afhandling, med trogna biner til den $\mathrm{Na}$. dige Almagten fór Edert beftándiga vail.

Med oupborlig vórdnad bar aran frambirda MINE HÓGGUNSTIGE VÅLGÓRARES 


\section{GENERA NOVA PLANTARUM.}

\section{GONDCARPUS.}

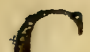

JALYX nullus.

Corolisa 4 -fida, perfirtens.

Stam. Filanhenta 4 , corolla inferta.

Drupa infera, fubglobofa, corolla perfifente coronata, 8-gona, glabra, I-locularis, Ifperma.

Character gezlevis: Corolla 4 -fida.

Drupa 8-gona, I-fperma.

Locus: Tetrandria, Monogynia poft Elæagnum.

Species I. G. micranthus.

Fuponice: Faro Gufo.

Crescit juxta Nagajaki in Faponia.

Floret Augufo.

Rudix fibrofa, anmuas

Caulis tetragonus, folitarius vel plures, baji decumbens, apice erectiufculus, Juperne ramofus, vix jpitbiamisus.

Folia oppofita, brevifine petiolata, nvata, acuta, ferrata, glabra, patentia, lineam longa.

Flores in ramsis fpicati, remoti, fublecundi, cernui, minutio 


\section{O.THERA.}

Cax. Perianthizm I-phylium, glabrum, 4-partitum, perfiftens: lactnise ovatæ.

Corolla 4-petala, alba. Yetala ovata, obtufa.

Stam. Filamenta 4 , bafi infima petalorum inferta, corolla duplo breviora.

Antbere didymx, 4-fulcatæ.

PIsT. Germen fuperum, glabrum.

Stylus nullus, fed ftigma unicum, feffile.

Fructus ignotus.

Character generis: Petala ovaza, plana. Cal. 4-partitus. Stigma feffile. Capfula?

Locus: Tetrandria, 1-gynia, poft Rhacomam.

SPECIES I. O. japonica.

Faponice Mikade ko i. e. millepeda plinta.

Crefcit in Faponia.

Caulis fruticofus.

Rawi teretes, friati, purpurei.

Folia alterna, petiolata, ovata, obtula r integra, coriacea, slabra, patentin, Jefouipollicasia.

Petioli jemiteretes, glabri, linean longi.

Flores axillares, aggregati, pedunculati.

l'edunculi Jemilinean longi.

\section{O R IX A.}

CAL. Perianthium I-phyllum, 4-partitum, brevisfimum.

Conolla 4-petala, virefcens. Petala lanceolata, patemria, lineam longa.

Stam. 
Stam. Filamenta 4 , petalis breviora. Antbere globolx.

Pist. Germen fuperum

Stylus unicus, ereetus, petalis brevior.

Stigma capitatum, obtufum.

Peric. Capiularis videcur efle fruetus.

Locus Tetrandria, l-gynia poft Rhacomam.

Character generis: Petala lanceolata, plana.

\section{Cal. 4-partitus.}

Stigma capitatum. Capfula ?

Species I. O. Japonica.

\section{Crefcit in Faponia.}

Caulis frutefcens, flexuofus, glaber, erectus, ramofus, orgyalis. Rami alterni, glabri, ultinsi villofio

Fola aiterna, petiolata, ounta, integra, Jupra viridia, fubtus pallida, villofa imprimis juniora, patentia, jemipollicaria.

Flores racemofi, racemis alternis pollicaribus.

Bractere ful pedicellis concave, oblonge, glabra.

Pedunculi et pedicelli villofi.

\section{S K I M M I A.}

CaL. Periantbium $\mathbf{I}$-phyllum, viride, minimum, perfiftens, ad bafin fere 4-partitum: lacinice ovatæ; acutæ.

Corolla 4-petala, alba. Petala ovata, minuta, concava.

STam. Filamenta 4 , breviffima.

Prst. Germen fuperum.

Stylus unicus. 
Prercarp. Baccat ovata, umbilicata, glabra, rubra, obfolete 4 -fulcata, magnitudine pifi, intus farinaceo-pulpofa, alba, fubquadrivalvis.

Sempa quatuor, fubrigona feu externe convexa, oblonga, alba.

Cimaracter gerieris: Pet. 4, concava. Cal. 4. part. Bacca 4. fperma.

Locus: ante Rhacomam.

Species I. S. japonica.

Faponzce: Portugal no thi, Sir San, vulgo Mijama Skinmi, Krazzlf. Am. exotic. fajc. $Y$. pag. 779.

Crefcit prope Nangalaki, urlem Faponia.

Caulis fruticofus, erectus, glaber.

Rami alterni, fubtetragani.

Folia in apicibus ramorum, aiterna, petiolinta, frequentifima (ut fere verticillata), oblonga, undulata, integra, apicem verfils obfolete crenata, evecta, acus minuta, margine reflexa, digitalia; Jupra fatura. tius viridin, rugofa; fubtus pallidiora, punctata; craja, fomperviresitia, Japore aromatico.

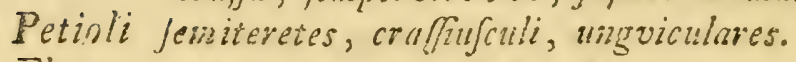

Flores in apice ramorum, paniculati.

Pedunculi teretes, incraffuti, unguiculares.

Fructus maturus Decembri.

Periantbium raro sppartitun.

\section{NIGRINA.}

Cat. nullus.

Corolla 4 -petala, infera.

Stam, Filumenta 4, brevifima. 
Fructus forfan capfula.

Character generis: Cor. 4-petala. Capfula?

Locus: Tetrandria, Monogynia ante Elæagnum. SpEcIES I. N. fpicata.

Crefcit in Faponia.

Caulis berbaceus, Jubfucculentus, teres, glaber, crectiufcus lus, folminis vel ulira.

Folia oppofita, petiolata, ovato.oblonga, obtufa, Jerrata, gla bra, fupra viridia, fubtus pallida , fefquipollicaria

Petioli ungviculares,

Flores axillares, /picati.

Spica compofita: Ipiculis alternis, flofculis oppofitis,

Bractea ful fingulo flosculo ovata, acuta.

Planta ficcatione nigrescit.

\section{DORANA.}

Cat. Periontbizun I-phyllum, 5-fidum, corollas brevius :

lacinice ovatæ, concavæ, glabræ, corolla breviores.

Corolta 1 -petala, fubcylindrico-rotata, 5 -fida: limbi lacinix ovatx, obtufx, erectæ.

Star, Filamenta 5 , tubo corollæ inferta, brevifima ut fere nulla.

Anthere oblongx, fubtetragonæ, inclufx.

Pist. Germen fuperum, conicum, glabrum. Stylus I, filiformis, corollæ longitudine.

Stigma truncatum, emarginatum.

Peric. Capfula ovata, acuta, glabra, I-valvis, I-locularis, polyfperma, magnitudine piperis.

$$
\text { A } 3
$$

CHA- 
Character generis: Caplula x-locularis. Corolla 5 - fida. Stigına emarginatum.

Jocus: Pentandria, Morogynia, poft Menyanthem. Species I. D. japonica.

Crefcit in Faponia. Grponzice: Tufukaki. item Fitatif et Senrjo.

Caulis arboreus, orgyalis, ramo/us. Rami alterni, teretes, glabri, cinerci, divaricati. Falia alierna, petiolata, oblonga, acuminata, vemote ei ob. folete lerrata, nervofa, glabra, patentia, digitalia. Petioli lemiteretes, fupra fulcati, glabri, unguiculares. Flores raccmofi, allsi, minuti. Racemi axillares, vix unguiculares.

\section{DR Y A N D RA.}

Cal. Periantbium 2-phyllum: lacinice ovatæ, acutæ, corolla breviores.

Corolla 5-petala, flava. Petala obovato-oblonga, reflexo-patula, ungvicularia.

StaM. Filamenta novem, inferius in unum corpus coalita, inæqualia, corolla dimidio breviora. Antbere minutæ.

Pistillum in flore mafculo nullum adfuit in tota panicula, unde flores dioicos efre conjicio. Locus: Monadelphia, Enneandria. SPECIES I. D. cordata.

Faponice: Dodicku et Abrafin. Kompf. Am. exot. fafc. V.pag. 789. 
Crefcit in infula Nipon, in regionibus Fakonia et alibia Floret Majo, Funio.

Caulis arboreus, orgyalis et ultra.

Ranni teretes cortice ratgo/o, functati, glaliri.

Folia in ramalorum "picilus approximatn, altcrn?, petioliata, cordata, acuta, integra, guinqueverio nervis ramofis, glabra, fultus pallidiora, patentia, pal. mam lata et longa.

Petioll longitudine fere folii, teretes.

Flores terminales, paniculati.

Panicule rami dicbotoni et tricbotomi, patuli.

E jenvinibrss oleum exprimitur pro lucernis, abralin gøras dictum.

\section{AUCUBA}

Flores mafculi:

CaL Perianthium I - phyllum, truncatum, obfolete 4-dentatum, viride, villofum, brevifimum, perfiftens.

Corolla 4 -petala. Petala ovata, acuta, patentia fubtus concava, viridia, pilofa, frupra convexa, purpurea; lineam longa, decidua.

Staм. Fulimienta 4, receptaculo inter petala infertas, craffa, erecta, breviffima, alba, bafi purpurafcente.

Antbere ovati, didymæ, 4-fulcatæ, purpurafcentes.

Receptaculum convexo-plamum, viride, glabrum, foramine medio quadrato impreffo.

Flores 
Flores feminei in eadem arbore.

PIsT. Germen inferum.

Stylus craflus, brevis.

Stigma fimplex, capitatum.

PEric. Nux ovata, I - locularis.

Character generis : Mas. Cal. 4-dentat Cor. 4-petala. Fem. Nectar. O. Nux I-locularis,

Locus: Monoecia, Tetrandria poft Serpiculam. Aifsnis valde Serpiculæ; fed diftincta:

a) receptaculo maris perforato.

ß) Nectario nullo.

Species 1. A. japonica.

Gaponice: Aukuba Kontef. Am. exot. fafc. V preg. 775.

Crefit in Kokora Faponice alebique, culta vulgaris.

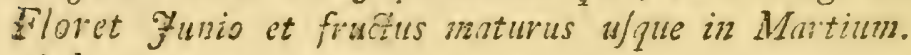

Arbor migna, rainosa.

Rami dicbotoni, teretes, glabri, fubcarnofi, divaricati. Folia in apicibus ramulorum aggregata, petiolata, oblonga, acuta, remote ferrata, glabra, Jubtus pallidiora, palmaria, pollicers lata ov ultra.

Petioli ungviculares.

Flores terminales, paniculati.

Pedunculi et pedicelli villosi.

Gariat a) foliis fufco-viridibus, immaculatis.

b) foliis late viridibus, albo-variegatis.

Floret etiam pufilla.

Exficiatione tota nigrefcit.

\section{BUMA L D A.}

CaL. Periantbium $\mathbf{x}$-phyllum, ad bafin fere 5 -partitum: 
tum: lacinice crata, obtufa, concara, ferrugineo-albs, corolla paullo breviores.

Cororia 5-petala, aba. Petala lineari-obovata. germine inferta.

STAx. Fllatidi 5, ungibus petalorum inferta, fifformia, ereda, hirta, longitudine fere corollix.

Antbire dorfo inferte, ovatx, didjmæ. Pist. Gemmon fuperum, conicum, villofum. Styli cuo, ereeti, villofi, longitudine filamentorum. Sizgzata fimplicia, capitata, truncata.

PERICARPIUM non vidi maturum, fed videtur effe Capíula bilocularis.

Character generis: Capfula 2-locularis, biroftris. Corolla 5-petala. Styli villofi.

Locus: Pentandria, 2-gynia ante Phyllidem. Species I. B. trifolia.

Crefcit in montibus Fakonise.

Floret Majo, Funio.

Coulis fratiofus, denfe ramofus, omnilus partibus glaber. Rami ierces, obfolete angulati, geniculati, purpurei. Ramis!i oprojite, filiformes, ranis fimiles, patentifimi, folinfi.

Folia oppolita, fectiolata, termata. Foliola ovata, acuminata, tenniffme ferrata, fulbtus pallida, brevifine petiolulata, wingvicularia.

Petioli capillares, patentiffini vel reflexi.

Flores in ramis termizales, racemofi pedunculis capilavibus. 


\section{I N DERA.}

Calyx nullus.

Corolla 6-petala. Petala ovata, obtufa, Aavefcentia, femilineam longa.

Stam. Fil:s7hezta fex, germini inferta, corolla multoties breviora.

Anthere minutæ.

Pist. Germen fuperum, ovatum, glabrum.

Stylus unicus, ereetus, corolla paullo brevior. Stigmata duo, rellexa.

Peric. Copfula bilocularis.

Character gezzeris: Corolla 6-petala, Capfula.

Locus Hexandria, r-gynia ante Orontium. Species I. L. umbellata.

Faponice: Kuro Nofji, kuro Miji, it. kuro Ganni Motji. IKturo Nofji. kemintf. Anz. ex. Fafc. V. p. ans.

Crefcit in Fakna, monte Faponise.

Floret Aprili, Majo.

Caulis fruticofus, laxus.

Rarni ct ramuli alterni, flexuofi, glabri, patentiffmi.

Fulua in ulitinis apicilus ramulorum aggregata, petiolatu, oblonga, acuta, integra; fupra viridia, glabra; Jubtus pallida villofa; pollicaria.

Petioli vix linean longi, hupra villofin,

Flores terminales, umbellati.

Uinbella fimplex, multiflora.

Pedunculi parum filofi, ungviculares.

Pedicelli tomento/h, dublo fere breviores. 
Ufus: e ligno conficiunt Faponenfes pericillos nuolles pro purificandis dentibus.

\section{TOMEX.}

CaL. Involucrum univerlale 5-phyllum, raro 6-phyllum, 5-florum, rarius 6-florum, perfiftens: folia ovata, extus tomentofa, obtufiffima, inæqualia, imbricata, valde concava, exterioribus minoribus.

Periantbium proprium (vix corolla) 5-phyllum, perfiftens: foliola lanceolata, extus villofa, ereeto - patula.

Corolza nulla, nifi Perianthium proprium. STAM. Filamenta I 2 ; filiformia, inæqualia; exteriora 5 , longitudine involucelli; interiora 7 , alba, breviora.

Antberce ovate, didymæ, flavæ.

Nectariumi: Squamæ 5, inter ftamina interiora fitx, plicatæ, crenatæ, virides, glabræ, longitudine filamentorum.

$\mathrm{Pis}_{\mathrm{T}}$. Gerinen fuperum, triquetrum, viride, glabrum, inter nectari fquamas medium.

Stylizs nullus.

Stigma fubulatum, virefcens, abortiens.

Character generis : Corolla O. Cal. duplex: involuc. 5 -phyllum.

Perianch. .5 - phyllim.

Locus: Dodecandria, I-gynia poft Afarum. Species I. T. japonica.

Faponice: Firoa. 
Crefcit in Rofido, fatis vulgoris. Floret OAdori, Novembri.

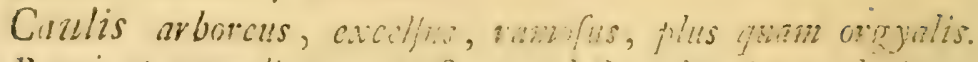

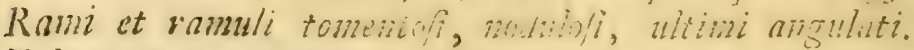

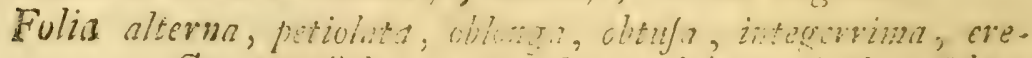

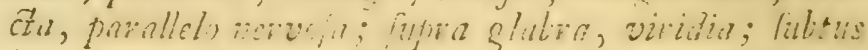

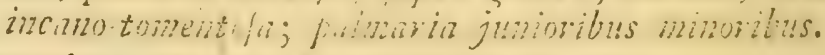

Petioli angullati, friati, ionemito/s, prollicares. Flores axillares, in capitulum collesti, pedicellati. Peduncasli angulaci, friati, folitarii, tonacinofl, bracteari, Seminngviculaves.

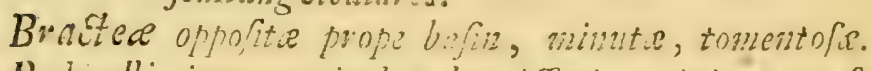
Pedicelli iatm capitulun buevifimi, quini, raro fax, wssijo. vi, tonzentofi, funilinasun longi.

Fruthes numquan vidio.

\section{APACTIS.}

Calyx nullus.

Corolla 4-petala. Petala fubrotunda, crenata, concava, inaqualia, oppoficis lationibus.

STAn. Filumertat circier 16 ufque ad 20. Pist. Germen fuperum Stylus unicuis.

Character genems: Corolla 4-petala. Cal. O. Locus: Dodecandria, I-gynia poft Rhizophominz SPECIES I. A. japonica.

Canlis arboreus, crectus, ramofifninuts. Ranni alterni, terctes, functuto-fcabri, eredti. Ranuzeli ramis fimiles, ulitimi frequentes. 
Folia in minulis nlterna, petiolata, orita, acilty, frata,

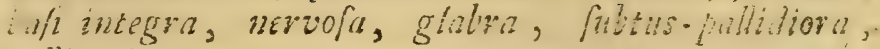
pallicaria.

Potio't junteretes, fulcati, Seminuguiculares.

Flores in ultimis romulis racenzof.

Rucomi rape oututi, exerefcentes magis oblongi.

Pedunculus ei pedicelli villofo-fabri.

\section{EURYA.}

Cai. Perianthnum 5 -phyllum, calyculatum: calyculus diphyllus, calyci fimilis, triplo minor. Foliola calycis ovata, concava, obtufa, extus fuifa vel viridia, glabra, intus viridia femilineam longa.

Corouta 5-petala. Petala fubrotundo-ovata, concava, alba, magnitudine calycis.

Nócturinz: puncta vel margo purpuresis ad bafin filamentorum.

Stma. Filamenta 13 , brevifima ut fere nulla, alba. Anterce erecte, 4-gonx, àlbidx, longitudine fere corollx.

Prst. Gemberl fuperum, convexum, glabrum. Siglus fubulatus, viridis, antheris brevior. Sizgmata tria, reflexa.

Peric. Capfula globofa, fylo perfiftente acuta, glabra, 5-valvis, 5 locularis, magnitudine vix: piperis.

Semina fubtrigona, punctata, brunnea, glabra. Cuaracter generis: Cor. 5-petala. Cal, s-phyllus, calyculatus.

Caplu: 


\section{Capfula 5-locularis. Stan I3.} Locus: Dodecandria, i-gynia polt Triumfertam.

Srecris I. E. japonica.

Japonles: Fifakiki, it. Silna

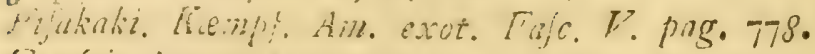
Cirefcit juxta Vargaliki an montibus, vulgaris. Ploret Septemiliri, OEtobri.

Caulis fiuticolus, uti onnes ej:s partes, glaber. Rami et ramuli altuni, laxi, evecto-incurvi, cinevei.

Folia in ranulis altern, freatentia, potiolata, elliptica fen obhența utrinque atienuita, lemata margine parum ref?io, laji integri, glabivina, crafliufcula, fennpowirenta, dificha, eresta, acumine emarginato, navolin: liupra veridia; fubtus favefcentia; pollicavia et ultira.

Petioli decurrentes, Semitivetes, fupra fulcati, glabri, lineam longi.

Flores axillaves, l'ini, fedinculati, cernui, raro folitarii st ternit.

Peduncull fliformes, uriffori, glabri, cernui, petiolis vix longiores. Dioici videntur fores locpizus elde.

\section{CLEYER A.}

CaL. Periantbium I-phyllum, coriaceum, glabrun, perfiftens, corolla brevius, 5-partitum: incinice ovatæ, rotundatæ.

Corolla 5-petala. Petala ovata, acuta, flavefcentia. Stam. Filamenta circiter 30 , germinis lateribus inferta, capillaria, inæqualia, bafi interdum laviffime coharentia, corolla multo breviora. 
Autber fubulatx, didymx, hirtx, fulcx. Pist: Germen fuperum, convexum, glabrum.

Stylus unicus, fimplex, fliformis, ftaminibus longior.

Stignna emarginatum.

Peric. Coplula ovata, acuta, glabra, calyce perfiftente reflexo cincta, bivalvis, bilocularis, magnitudine pifi minoris.

Character geheris: Capfula 2 locularis. Cor. 5-petala. Nomen in memoriam Medici olim et Botanic. Jap. Dom. Cleyeri.

Locus: Polyandria, r-gynia port Tiliam.

Species I. C. japonica.

Faponice: Mokokf wel Mukakf. Kampf. Ans. ex. Fafc. V. p. 873. fig. pag. 774.

Crefit prope Nangufaki.

Fioret mentibus atutumalibus.

Caulis arboveus, vamulolus, onnin parte glaber.

Ranni et ramuli fulverticillati, terni, quaterni vel quini, cinerei, rugofi, lecundi, erecti.

Folia in ultimominn ramulorum ultimo apice fubverticillata, quaterna, quina vel fena, inceqalia, petiolata oblongooovata, obtufa, apice tenuiffime Jerrata, crafa, fempervirentia, pupra lote viridin, Jubtus pallidio$r a$, plana, felquipolicaria.

Petioli lemiteretes, fupra Julcati, rubri, lineanz longi. Flores axillares, unus, duo vel tres, pedunculati. Pedunculi cernui, uniflori, femipolicares. Differt "Vateria indica, cui finilis videtur: 


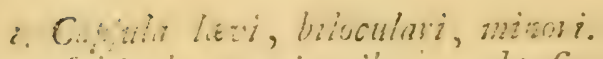

2. fuhis longe miznibus et obtufuritis.

3. foribus ariularibus an pedunculis atifloris.

\section{LICUA $\mathrm{LA}$.}

Cat. Perbanthing tripartitum, extus pilofum. Corozla ad bafin fere j-partita: Lachnze ovace, acutre concava.-

Nectarma, fertifume, truncatum, corolla duplo brevius.

STans. Fhamenta fex, neftario inferta, ereeta, brevifima, alba.

Antbere oblongx, didymx, flave.

PIsT. Gerian fiperum, convexum, tripartitum, ful. catum, glabrum.

Stylus unicus, fimplex.

Stıgmąa duo.

P. nic. Drufa globofa, magnitudine Pifi.

Nhx dura.

Chimacter gemoris: Cor. 3-partita.

\section{Cal. 3-partitus.}

NeAarim fertiforme. Drupa.

Inows: Hexandria, I-gynia ante Bromclim.

Sncies I. L. fpinof.

Licuala finofa. Bar. Wumb. A\&. Banv. P 2.

p. 469. Thunb. ad. Stockhom, 782 pag. 284 


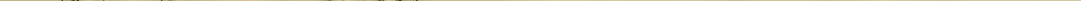





\section{PLANTARUM,}

QVORUM

PARTEM QVARTAM,

CONS. EXPER. FACULT. MED. UPSAL;

PUBLICE VENTILANDAM EXHIBENT

\section{PRÆSES \\ CAROL.P. THUNBERG} Med. Doct. Prof. Reg. et Extraord., Acad. Cefsar. N. c, Reg. Scient. Holmiens, Societ. Scient. Ups. Patr.

Holmens. Berol. N. Scrut. Lund. Harlem. Amstel. et Nidrosiens. Membrum.

\section{RESPONDENS \\ Petrus U1r. Berg.}

U P I A N D US.

Stipendiatius Regius.

IN AUDIT. GUST. MAJ. D. III. JUNII ANNO MDCCLXXXIV.

HORIS SOLITIS.

UPSALI Æ,

APUD JOHAN. EDMAN,DIRECT. ET REG. ACAD. TYPOGR. 



\section{GENERA NOVA PLANTARUM.}

\section{TECTONA.}

CAL: Periantbium I-phyllum, 6-partitum, perfiftens, extus tomentofum, intus glabrum: la. cinice ovatæ, erecto-patulæ.

Corolla I-petala, rotata, 6-partita: lacinice ovatx, patula, extus tomentol $x$, intus glabræ, longitudine laciniarum calycis.

Stam. Filamenta 6 , ori tubi corollæ inferta, brevisfima. Antherce rotundx, didymæ, fubexfertæ, altero latere brunnex, altero flavæ.

PIst. Germen fuperum, ovatum, cinereo-villofum, calyce tectum.

Stylus filiformis, erętus, calyce paulc longior. Sizgmata duo, revoluta, obtufa.

PERrc. Drafa ovata, calyce tecta, cinereo-villofa, 4-valvis, 4-locularis, magnitudine avellanx.

Semina minuta.

Character generis: Corolla 6-partita. Cal. 6-particus, inferus.

Bacca 4-locularis.

Locus: Hexandria, Monogynia poft Prinos.

Flores exiam in Figura Rhediana fxpifime Hexandri func.

$$
\mathrm{C}_{2} \cdots \text { Sp. } t \text {. }
$$


Sp. 1. T. grandis.

Tektona. Linn. Suppl. Syft. p. 20.

Malaice: Cajo Fatu.

Hollandis: Cojaten bout.

Crefcit in fyluis infularum Fave \& Ceilone in MallabaArbor maxima.

via, Coromandelia E alibi. Sape culta.

Folia oppolita, Feffilia, ovato-oblonga, utringae attenunta, integra, nervofa, fubtus cinerea, fupraglabra, punEtisque frequentibus adprer $\Gamma_{a}$, patentio, palmanu. la. ta, Jpitbaumea E ultra.

Flores painiculiti:

Panicula fupradecompofite tripartita, patens, tota tomento/s. Pedunculi E pedicelli decufjati, tetragoni, quadrilulcati, to. mentofis.

Bractece ful fingulo pedicello duce, oppofite, linceolate, integre, deciduce, linean longa.

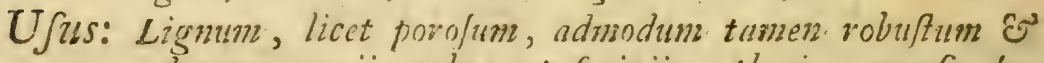
durum, variis relus ut foriziis, thecis, menfis fabricandis, imprimis vero pro trabihus domorums infervit, hancque obvationems etjams ad Caput bona. fpei advedtum care divenditur.

\section{APONOGETON.}

Aponogeton Linn. fupplem. Syftem. p. 32 .

Calyx \& Corolla nulla, nifi fquama fpathacea exter. num floris latus cingens, fimplex, feffilis, ovata, obtufa, integra, erecta, glabra, alba.

STAM. 
Stram. Filminenta I I-19, fuperioribus foribus pauciora, inter capfulas \& 1patham inferta, fubulata, glabra, alba, fpatha multoties breviora. Antberce furcx.

PIST. Gerrising plerumque 4, raro 3, 5. Stylus nullus.

Stigrnata fubulata, incurvata.

Peric. Capfule 4, rarius 3, 5, ovatæ, fubulato-acutæ, exteriori latere gibbæ, interiori planæ, glabræ, r-loculares.

Semina in qualibet capfula tria, bafi capfulæ affixa, fefilia, obovata, obtufifima, fubcompreffa, gla. bra, rubra.

\section{Character generis: Cal. O.}

\section{Bractea. Capf. 4.}

Locus: 12-Andria, 4-Gynia.

SP.I. A. monoftacbyon: fpica fimplici, foliis cordato - ovalibus.

Aponogeton monoftachyon. Linn. Suppl. p. 24.

Crefcit in inundatis Coromandelive, Ceilonce.

Scapi \& Petioli radicales.

Folia cordata, ovato.oblonga, acuta, integra, glabra.

Flores ppicati brakteis breviffimis.

Sp. 2. A. crifpum: Spica fimplici, foliis enfformibus crippis.

Habitat locis depreffis infule Ceilona.

Floret Novenibri, Decembri.

Radix fibrillofa.

Scapi lineares, foliis triplo longiores, flexuof, erecti, glabri. $\mathrm{C} 3$

Fo. 
Folia petiolata, calformia, acuminata, cripa, glabra, petiolis longiora, Spitbamea.

Flores fpicuti Spica interrupta, pollicari.

Sp. 3. A. diftachyon: fpica bifida, foliis eiliptico-lan. ceolatis.

Aponogeton diftachyon. Linn. Suppl. p. 215. Incolis: Water Uyntjes $i$. e. Bulbi aquatici.

Habitat in vivulis ad Cop:tt Bonce Ipei juxta Paurl E alivi. Radix globofa, carnofa, fibrofa, glabra.

Caulis nullus, fed petioli \& fcapi radicales, longi provivuli profunditate, lineares, connpredis, frinti, glabri, fimplicifrmi, molles.

Folia in junioribus petiolis mulla, in adultis oblongo-ovata, acuta, integerrima, glabra, natantia, digitalia $\mathrm{E}^{\circ}$

ultra. Ommino referunt folia Potannogetonis natan. tis.

Pedunculus ine duas racbides divifus. Racbis Jemiteres, pa tens, glabra, multiflora, alba.

Flores picati, alterni, Jecundi.

Folia adulta viridia, juniora rufefcunt.

Flores linven odorem spargunt.

Bractea Jub florefcentia albee, etate vire/cunt.

Facies Potamogetonis respectu foliorum.

\section{HEMIMERIS.}

CaL. Perinnthium I-phyllum, ad bafin fere 5-partitum, corolla multo brevius: Lacinice inæquales, ovati, perfiftentes.

Corolza 1-petala, rotata, ringens. Tubus brevifimus, vix ullas, intrufus, albus: Labium furerius fillum 
fifum, bafi faccatum foflulis nectareis, inferius concavum, obtufum.

Stam. Fllamenta 2-4, filiformia, bafi labii inferioris inferta, circumflexa.

Antbere minimæ, cordatæ, cohærentes, flavæ.

Pist. Germen fuperum, acutum, glabrum.

Stylus filiformis, longitudine \& fitu ftaminum. Strgma fimplex, acutiufculum.

Peric. Capfula ovata, acuta, didyma, bafi altero latere gibba, bivalvis, bilocularis.

Semina plurima, glabra.

Character Generis: Capfula 2-locularis, loculo altero gibbofiore.

Corolla rotata foffula nectarea.

Stamina circumflexa.

Locus: Didynamia, angiofpermia ante Antirrhinum.

Affinis Antirrhino \& Columnex; differt vero:

I:0 Ab Antirrbino cap/ula longiori, teretiori, latere attero gibbofa; corolla rotata, faccata, non cornuts.

Staminibus circunflexis.

2:0 a Columnea: corolla rotata. Staminibus circumflexis.

Hemineris. Linn. Suppl. p. 45

Filamenta 2 ut in Diandria; anthera connata ut ins Synge: nefia.

Sp. I. H. montana: diandra foliis oppofitis ovatis crenatis.

Hemimeris montana. Linn. Suppl, p. 280.

Crefcit in collibus montizan Capenfiums.

Floret Fulio, Augufto.

Radix Flurofa, anma: 
Caulis fimplex vel prope radicem ranofus, tetraronus, fexuolo erectus, pubefcens, purpurafcens, palmairis.

Ranni oppofiti, fimplices, cunili fimniles.

Folia oppofita, petiolata, lato-nvata, obtufa, crenata, glabra, nervofa, internodiis breviora, patentia, fupra viridia, fubtus purfurafcentia, ungvicularia.

Petioli longitudine fuliorum, leminngviculares, decurrentes, lineares, fupra fulco longitudinali, purpura/centes, birti; axille foliis onufte.

Flores axillares, pedunculati, vel terminales.

Pedunculi oppofiti, uniflori, lineares, comprefie, apice latere externo Jenzicirculo elevato purpureo, longitudine foliorun.

Calycis lacinice obtufas: duce inferiores magis lineares, transverla; tres fuperiores proxinniores; intermedia magis ovata, viridis, margine faturatiore.

Corolla temuifine villofa, tota flava: lacinia media circulo utvingue puncforum purpureorum. Labium fuperius inflexun, profunde tripartituin: laciniæ laterales callo obtulo bajeos, ovate, obtufe, breviores; inter. media latior, emarginata. L. inferius media lacisia labii fuperioris latius, obtuff(finumn, longius, emarginatum, concavo-planum, patens; , baji dente duplici genitalia cingente, evecto.

Filamenta 2, bafi circumflexa, labio inferiori adpreffa, e. jusque dentibus inclufa, brevifima.

Sp. 2. H. macropbylla: tetrandra foliis oppofitis cordato - ovatis dentatis.

Crefcit inter Bockland E Hantunz prope rivun, in Capite Bonce lpei,

Radix anmua, fibroja.

Caulis bafi flexus, jatin a radice ramofus. 
Rami oppinfit, teiragoni, glabri, fimpliciter vanulofi, ranulis confinzilibus, laxi, evecti, inter arbufcula adfcerzdentes, virides, purpureo-variegati, pedales. Folis oppofita, petiolata, cordato ovata, obtufiufcula, dentata, patentia, glabra; fupra viridin, concaviufcula, fulco longizudinali venisque impreffs; fubtus pallida, carina vemisque elevatis; inferiora majora, ungvicitlivia, Juperiora fensim minora.

Flores alterni, pedunculati.

Pedunculi capillares, erecti, apice curvi, pilofi, purpurei, ungriculares.

Bractece jub ba/t pedunculi, leffiles, cordato-ovate, obtufins. fculde, concave, integre, reflexa, lineann longe. Periantbium Subbilabiatum; labium fuperius tripartitum, ereEtum; inferius bipartitum, laciniis lanceolatis, acutis, glabris, viridibus, corolla multoties brevioribus, intus concavis, extus fubcarinatis.

Corolla violacea: labium fuperius minus, erectum, fornicatum; intus bafi lacuna transverja magna, medio li. neis duabus purpureis, extus bafi bicallofum callis exftantibus, obtufis, lutefcentibus; apice emarginatum lobis rotundatis, integris, labio inferiori triplo mimus. Labium inferius maximunn, tripartitum, bicomnutum: lacinice laterales expanfe, oblonge, obtuif/fince, bafí concave, intermedia confinnilis, fed pailo major. Cornua antica, Jenfim attenuata, Jubulata, Jurfum curvata, fubungviculavia.

Filamenta 4, inequalia: duo longiora, baf labii fuberioris inferta, erecta; duo brevinva, bafi labii inferioris in. Jerta, bafi circumiflexa, erecta.

Capjula fublineavis, calyce perfiftente coronata, parum curvata, utvinque Julco exarata, glabra, fylo perffetente, ungvicularis. 
Sp. 3. H. zunilabiata: tetrandra foliis oppofitis pinnatifidis.

Antirrhinum unilabiatum. Linn. Suppl. p. 279. Crefict in Capitis bonce Jpei fabulofis, prope verloren vallej. Floret OEtobri.

Radix fufformis, fibrillo/a, anmua.

Caulls tetrigomus, filofus, purpurafcens, fatim a radice ra.mo/us, brevilfimus.

Rami decufeti, tetragoni, glabri, fomplices vel ramulofi, ere. cto $\cdot$ diffu/i, longifrini, Jpbitannci.

Ramuli ramis fimiles.

Folia fub ranis \& ramulis oppofita, petiolata, pinnatifida, pollicaria. Lacinne alterne, lineares, obtufe, integerrime.

Petiolus linearis, lateribus decurrens, fubtus convexus, fistwis conuliculutus, glaber, folio bruvior.

Flores alterni, pedunculati.

Bractea fub fingulo pedimculo linearis, outufa, glabra, patens, peduiculo brevior.

Pedunculus tetragonus, fubplofus, evectus, cernuus, uniflorus, ungvicularis.

Periantbuum viride, pilolum: lacinice lanceolate, obtule, prtulie, corolla multoties breviores, lineam longa, bine poffice reflexa.

Corolle labium Juperius maximiym, bafi violaceum, bicormu. tum, tripartitum; laciniae fubrequales, orbiculatoovite, undulute, integre: intermedice erecte; laterales fulluerticales, fingevinece verlus bafin ftriis ja. turatiorilus. Cormua bina, dependentia, conica, obeufa, brevifina, calyce panlo brevinva, intus extusque fluza. Labiun infermus (Jubnullunn) respectue Juperi- 
Juferioris minimum, lateraliter oblongun, Jeu dilatatum, lankvineum, fuperiori media piate evecta, inferiori revoluta.

Filamenta 4 ; duo fuperiora longiora \& majora, bafi clavata, dcin fliformia, arcuato-inflexa; duo breviosa. Anthere inflex, mininu; bah virides; azedio flave; apice villofe, serulea.

Cayfula ovatn, fubtetragona, bifulca, apice comprefJa, emarginata, fubzill fa, calyce foyloque perffftentibus coronata. SP. 4. H. fabulo/a: diandra foliis oppofitis pinnatifidis.

Hemimeris fabulofa. Linn. Suppl. p. 280.

Crefcut in colibus fabulo/is capenjibus.

Floret Fulio, Aligufto.

Radix capillaris, fibrofa, ammua.

Caulis tetragonus, luberectus, gluber, digitalis.

Rami decuJati, patentifimi, diffufi, tetraconi, glabri, foli. of , ranulofi, purpurafcentes; inferiores longiores, digitales; fuporiores breves.

Folia ofpo/ita, petiolata, incilo-pinnatifida, patentia, glabra: lacinice obtufe, oppofitce, integrae.

Petioli longitudine foliorum, fubtus convexi, Jupra fulcati, glabri, leminngviculares.

Flores nxillares, pedunculati.

Pedunculi uniflori, glabri, lulcati, longitudine foliorum.

Calycis larinice brevioves, virides margine purpurafcente; duabus inferioribus paulo latioribus, patent?bus, tribus /uperioribus erectis.

Corolla fluva lobo medio utrinque purpuren-punctato.

Labium fuperius trifidum, reflexum: lobi laterales obtufi, intus lacuna, extus buli atrinque callo, minimo, vix objervando; internedius latior, emarginatus.

$$
D_{2} \text { L. in. }
$$


L. inferius concrovm, furfunz inflexum, integrams, pilofum. Palatuss utvinque gibbere intus pro. minaulo.

Filamenta duo, labio inferinvi adireffa, eopue breviona. Converaunt $H$. wontana, diffula E Cabulofa:

क) conolla non becaudata, jed callis duobus, prominentibus.

B) copfuln ovntn, acutri.

Caulis E Folia, pralertine tenella, fubtus purpurafcunt. SP. 5. H. diffufa: tetrandra foliis alternis oppofitis. que pinnatifidis.

Hemimeris diffula. Linn. Suppl. p. 280.

Crefcit in collibus arenolis juxta Cap in arena mobili littoris infra Leuveftart.

Floret Fulio, Augufo.

Radix fibrofa, ammua.

Caulis unicus vel plures rndicales, fimplices, angulati, decunbentes, glabri vix jpitbamai.

Folia oppofita alternaque, petiolata, glabra, pinnatifida; fupra fulco, fubtus racbide longitudisali, ungviculavia: pinzce ovate, obtulee, fepe dente unico notate vel integre.

Petioli lineares, Jupra fulco longitudinali, decurrentes, unguiculares.

Flores ex axillis foliovum folitdrii, pedunculati.

Pedunculus filiformis, uniflorus, glaber, foliis longior, npice incurvus.

Calycis lacinice acutce, tres proximiores evecte, duce reflexe, Ariate linea elevatn, lanean longe, corolla auplo breviores, margine tenurffine ciliate.

Corolla extus allida intus purpureo-vilacea. Labiuns fuperius bifidurn, lobis obtuls, corscavo-inflexis; bah bio callowum, 
callofum, collis luteis. L. inferius trifidum, lobis concavis, obtufis, cequalibus, mitermedto emarginato. Filamenta 4 , corolla breviora, recurva, apice connato-coberentia; duo minnara, furfun flexa \& lape in medio membrana fubrotunda aucta, lupra majora ins. ferta, fed infexa; dun paulo miljora, infra minora

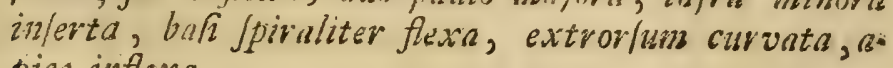
pice inflexa.

\section{ALECTRA.}

CAL. Periantbium I-phyllum, bilabiatum: Labium fuperius bifidum, inferius trifidum: lacinie ovatx, obtufx, tubo breviores.

Corolia I - petala, tubulofa: Tubus fenfim parum ampliatus, ungvicularis. Limbus patens, 5 -partitus: Lactnice lato-lanceolatæ, obtufæ, fubtus purpureo-ftriatæ, ungviculares.

Stam. Filamenta 4, tubo inferta, quorum duo paulo breviora, filiformia, flava, barbata villo Alavo, longitudine tubi.

Antbere ovatæ, didymæ, dorfo infertæ, flavæ. PIsT. Germen fuperum.

Stylus filiformis, longitudine filamentorum. Stigma incurvum, ftylo paulo craffius ejusque longitudine, utrinque friatum.

Peric. Capfula ovata, obtufa, didyma, glabra, bivalvis, bilocularis.

Sernen in fingulo loculamento unicum, ovatum.

Cbaracter generis: Capfula bilocularis.

Corolla campanulata,

Filamenta barbata,

Locus: 
Locus: Didynamia, Angiofpermia poft Acanthum. SP. I. A. capenfis.

Crefit prope fluvius Zeeko, Sóndags \& Cablienus revier dictos, locis guaminzofis Capitis bona jpei.

Floret Novembri, Decembri.

Radix annua.

Caulis fimplex, teres, friatus, erectus, villofus, inanis, spi. tbanceus. E pedalis.

Folia Jparfa, lefflia, ovata, obtufa, erestll, villofa; inferiora minora; fuperiora Jenfine majora, unguvcularia. Flores terminales, lpicnti, lutei, purpureo-Ariati. Spica foliuta, lenfim glorens.

Pl nta ficcatione nigrefcit.

Habitus Orobancbis. 



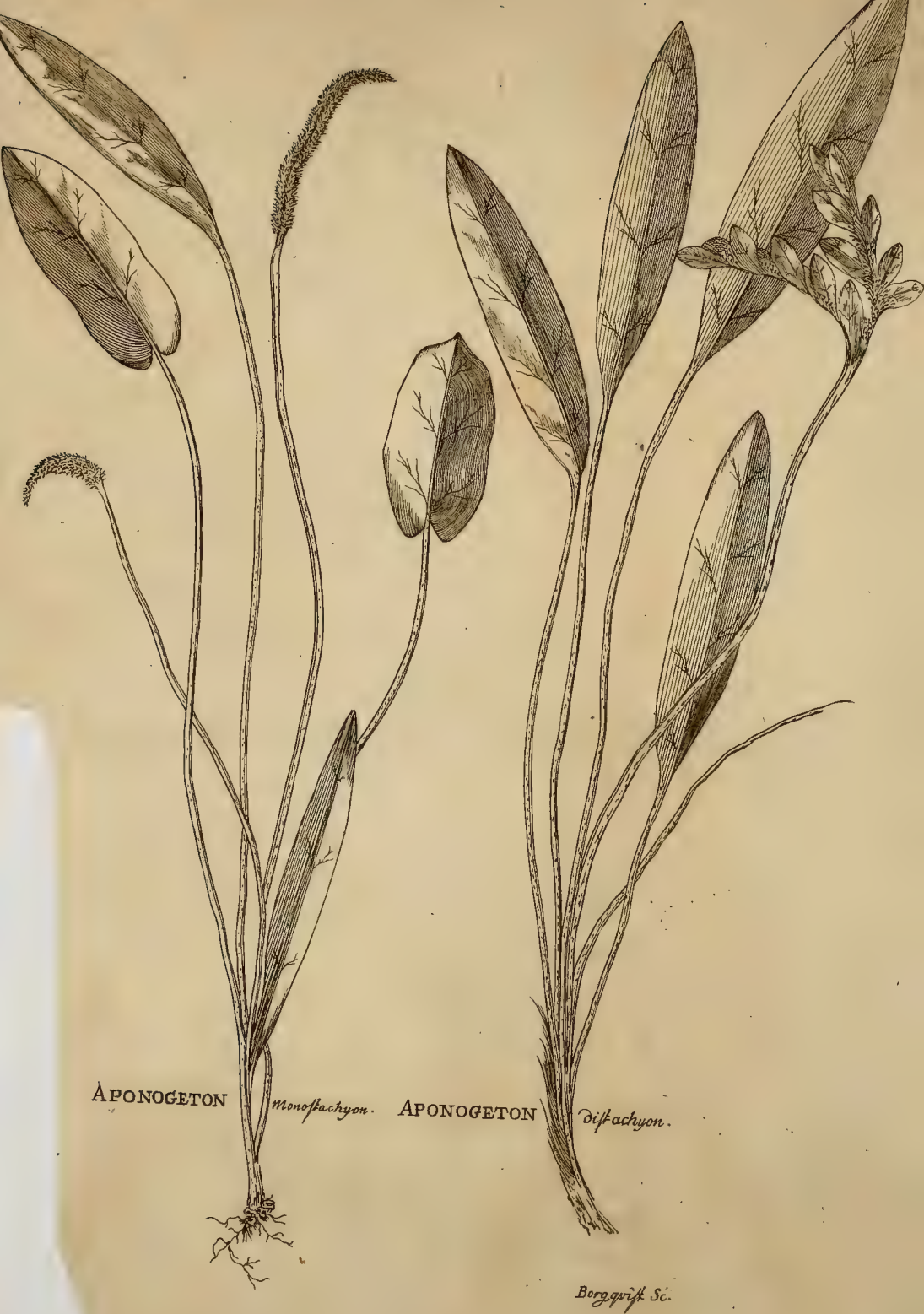





\section{NOVA GENERA \\ PLANTARUM.}

\section{MYRISTICA.}

E

lores mafculi:

CaLyx. Periantbium ovatum, glabrum, trifidum: la. cinice erecto - patulx.

CoRolla nulla, nifi calycem pro corolla fumere velis.

Stam. Filamentum unicum, cylindricum, obtufum. An bera unica fub apice filamento circumcinEa, ftriata, albida.

Flores Feminei:

CaL. Perianthium ut in mare, fed inferne dehifcens, deciduum.

Corolla nulla.

PisT. Germen fuperum, ventricolum, longitudine calycis.

Stylus unicus, didymus, breviffimus.

Strgmata duo, acuta, brevifinaa.

Peric. Drupa carnofa, carne apice dehifcente. Nux ovata, mace reticulata cineta, glabra.

Nucleus ovatus, lacunofus, cinereus, glaber. Character generis: Cal. 3 - fidus.

Cor. O. Drupa. 
Locus: Moncecia, Monandria ante Charam tecundum Syftema Linnæanum.

Sp. 1. M. mofchata: fructibus glabris.

Sp. 2. M. tomentofa: fruktibus tomentofis.

Myrific Thunb. AC:. Stockh. 1782. p. 46.

\section{EUCIEA:}

Flores mafculi:

CaL. Peranthium I - phyllum, corolla multoties brevius, fubangulatum, glabrum, viride, 5dentatum; dentibus breviffimis, erectis.

Corolla I-petala, patula, alba, 5-parcita: lacinice ovatx, obtufx, concavæ, nivex, femilineam longæ.

Calyx \& Corolla fxpe 4-fidi, fxpius vero 5-fidi, rariffime 6 -fidi.

Stam. Filamenta 13 , 8 in circumferentia, 5 in cen tro, bafi corollx inferta, breviffima, longitudine calycis, albida. Raro filamenta 15. Antberce tetragono-fubulatæ, fulcatx, erectx, albidx, apice latere utroque perforatæ.

Flores feminei:

CaL. Periontbium I- phyll $\mathrm{Im}$, raro 5-dentatum, frpius 4-dentatum, perfiftens: lacinze ereEtx, corolla triplo breviores.

Corolla raro 5 fida, frpius \& fida: lacinia ovatæ, obtufx, concavæ, ereetx, albæ.

Pist. Germen fuperum, ovatum, fubvillofum. Styli duo, longitudine corollæ, virides, crasfiufculi. 
Stigmata emarginata feu bifida, obtufa.

PERIC. Bacca globofa puncto umbilicali, glabra, viridis, matura rubra, carnofa, magnitudine pifi. Sernen unicum, globofum, glabrum, brunneum.

Character generis: Mal. Cal. 5-fidus. Coroll. 5 - fida.

Fem. Cal. 4- fidus.

Coroll. 4- fida.

Bacca I - fperma.

Locus: Dioecia, Dodecandria fecundum Syftema Linnæanum.

Sp. 1. E. racemofa: foliis planis.

Euclea racemofa: Linn. Supplem. fyft. Nat. p. 67. \& 428 .

Padus foliis fubrotundis, fructu racemolo. Burm. Afr. p. 238 tab. 84. f. I. femina.

Crefit in Paarden-Eyland dunis E infra Taffelberg Cho pitis bone Jpei.

Eloret Majo, Funio, Fulio.

Radix pereminis.

Caulis fruticofus, evectus, orgyalis.

Rami Jubumbellato-terni, ramulof, erecii, cineren-rufeo fcentes.

Ramuli ramis finiles, mifefcentes, glabri.

Folia alterna, petiolata, ovata, olitufifima, cralfa, fempervirentia, glabra, Jupra viridia, fubtus pallidiora, integerrima marginibus parim refexis, evecta, internodiis longiora, unguicularia.

Petioli craffi, breviflini, puppurei.

Flores racemofi, masculi \& feminei in difincto individuo. 
L'edunculi axillares, folitorii, angulati, glabri, vefieri.

Pedicclll opponiti altevilque, uniflori, reflexi, linean longi. Gu:minis rudinsentun in fundo calycis floris mafculini ova. tum, "cutum, fubviliofunz cum fylo Jterili.

Sp. 2. E. undulata: foliis undulatis.

Africanis: Gvarri-bofches.

Crefcut in krum - rivier \& alibi, in promontorio bona fpei. Radix perennis.

Caulis fruticojus, vix orgyalis, ramofiffmus.

Rami ramulique ofpofiti, alterni \& fubumbellati, ieretes, erecti, fcabridi, cinerei.

Folia oppofita alternaque, fubpetiolata, ovata, obtufifima, integra, undulata, fupra viridia; Jubius pallida, linea elevatn longitudinali; erecta, Sempervirentio.

Petioli crafi, brevifimi.

Flores axilluves, rracmef, mafuli ov feminei diftincti in diverfo individun.

Racemi erectiufculi, raro reflexi.

Pedicelli oppofiti, uniflori.

Filamenta circiter $X I$.

Antbere tetragone, latere utroque perforato-debifcentes.

Ujus: Bacce mivice eduntur ab Hottentottis.

\section{HARTOGIA.}

Hartogia Linn. Supplem. Syft. p. I 6.

CaL. Periantbium 5-fidum, perfiftens, glabrum: lacinice acutæ, breviffimi.

Corolia 4-petala. Petala ovata, cbtufa, patentia, albida. 
StAM, Filanenta 4, bafi germinis iníerta, breviffma. Antber o ovatæ, fulcatæ.

Pist. Germen fuperum, ovatum, glabrum. Siylus fimplex, fubulatus.

Stigina acutum.

Peric. Drupa exfucca, ovata, Icabriufcula, glabra, magnitudine vix nucis avellanæ.

Nux difperma, fubcarnofa.

Character generis: Petala 4, patentia. Cal. 5 -fidus. Drupa ovata, difperma.

Locus: Tetrandria, Monogynia poit Struthiolam.

Nomen in memoriam Hartogii, Peregrinatoris in Sp. 1. H. capenfis. promontorio bonæ fpei celebris.

Hartogia capenfis Linn. fuppl. p. 128.

Crefcit in Capitis bone Spei Jyluis.

Arbufcula orgyalis, ramofiffma, glabra.

Rami decufati, teretes, cinerei, patuli. Ramuli fimiles, fenfim filiformes, lisxi, erecto-patuli.

Folia oppofita, elliptica, obtuf, emarginata, ferrata, inzferne integra, attenuats in petiolum, evecta, gla. bra, digitalia.

Flores axillares, paniculati, cernui, minuti.

Adeo fimilis Schreberce fcinoidis, ut diu eanden crediderin, fed differt al Hartogia in non paucis Scbrebera.

r: 0 ramis alternis, tomento/is.

2:0 foliis alternis, pilofis vel tomeentofis, Serraturis pauciovibus.

3:0 Petiolis tomentofis.

4:0 Pedunculis longioribus.

5:0 Nectario.

6:0. Sty. 
6:0 Stylis dinobus.

7:0 Crapjula depreffa, 2. partita.

\section{SPARRMANNIA.}

CaL. Periantbium 4-phyllum, inferum: Folia lanceolata, integra, reflexa, villola.

Cor. 4- petala, Hava. Petala cuneiformia, integra, plana, calyce duplo longiora.

NeCTARIa propria, difformia, filiformia, torulofa, ftaminibus breviora, lutea: tornli inflati, turbinati.

Stam. Filatnenta plurima, germini inferta, filiformia, exteriora nectariis fimilia fed longiora, corolla breviora.

Antbere cordato - ovatx, infidentes.

PIST. Germic fuperum, fubglobofum, quinquangulare, hifpidum.

Stylus filiformis, rectus, dependens inter ftamina, ftaminibus multoties longior.

Stig ma truncatum, papillis elongatis terminatum. Peric. Capfula 5-gona, 5-locularis, fufca, echinata: Sct reetz, rigidæ, pilofr, f́pina terminatæ, in angulis majores patentes; Spina pellucida, reeta, pungens.

Semina in quovis loculamento bina, oblonga, gla. bra, altero latere carinata, nigra.

Habitus Triumfettæ refpectu herbæ, Geranii refpectu floris, Hibilci refpectu fructus \& Gei refpeetu cápfulæ echinatz. 
Character genericus: Cal. 4 phyllis. Caplula angulata, 5 -locularis, echinata. Nectaria plura, torulora.

Locus: Polyandria, Monogynia poft Calophyyllum. In memoriam D:ni Doet. And. Sparrman, Profesf. Regii \& plurium Acad. Scient. Membri, amici \& popularis Noltri, itineribus in Chinam, Promontorium bonæ fpei \& Terras auftrales celebris, Genus hoc novum Capenfe dixit D:nus Prof. à Linnè.

Sp. I. S. Africana.

Sparrmannia Africana. Linn. fuppl. p. 41. \& 265. Crefcit in capite bone Jpei Africes, zuter arbores, in Jylvis Efebojsh \&o Hautniquas dictis, inque lateribus montium inter Hautniquas \& Lange Kloof.

Floret Octobri, Novembri, Decenebri \& Fanuario.

Tota planta villoja.

Caulis frutefcens, erectus, bipedalis vel ultra.

Rami alterni, teretes, eresti.

Folia alterna, longe petiolata, cordata, ovata, lobata, ackminata, Serrata, novem-nervia, dependentia.

Petioli teretes.

Stipule laterales, fubulate, erecte.

Flores umbellati pedunculis ante flovefcentiam deflexis. Pedunculi oppofitifolii, erecti, pilofi, umbelliferi, petiolis longiores.

Pedicelli fimplices.

Involucrum polyphyllum, fubulatum, brevifintum. 


\section{NIPA.}

Flores monoici: feminei terminales; mafculi laterales inferiores.

Mafculi :

CaL. Spatbe oblongæ, concava, acuminatæ, coriaceæ; exteriores majores, interiores lenfim includentes.

Periantbiuzn proprium nullum.

Corolla hexapetala. l'etala linearia, xqualia, pa. tenti - reflexa, lineam longa.

Stam. Filanentum unicum, filiforme, erectum, longitudine petalorum.

Anthera apice filamenti perforata, I2-fulca. ta, oblonga, flava.

Feminei:

Cal. Spatbe uti in mare.

Corolla nulla.

Pist. Germen angulatum, fæpe quinquangulare, oblique truncatum, glabrum.

Stylus \& Stigma nullum; fed eorum loco fulcus in alterutro latere.

Peric. Drupre plurimæ, aggregatæ in capitulum magnitudine capitis, angulatæ angulis inæqualibus acutis vel obtufis, inferne attenuatx, fuperne obtufatæ, glabræ, magnitudine nucis caftanex.

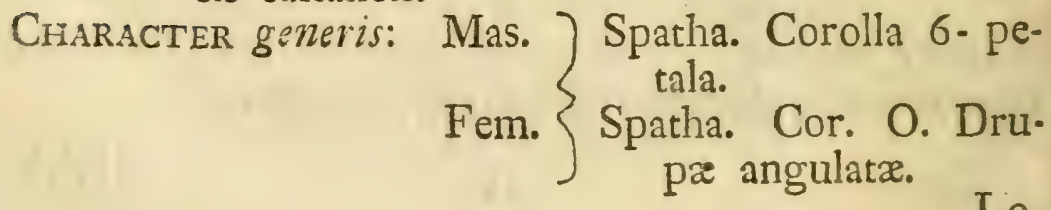


Locus. Monoecia, Monandria poft Cynomorium in Syftemate Linnæano.

SP. I. N. fruticans.

Nipa fruticans, Thunb. AEt. Stockholm 1782 p. 231 . Nipa Rumph. Herb. Amboin T. I. p. 72. Tab. XVI. Habitat in Infula Fava $E^{*}$ aliis Indiee orientalis infulis. Caudex in juniori palma nullus, in adultiori ultitudine aliquot pedum.

Folia pinnata: Pinne friate, marginate, acumisate, glabra.

Flores mafculi $\&$ feninei in endem palma, fed diffineti in diverfis pedunculis; Mafculi plures, laterales, inferiores, pedunculis dichotomis infidentes, Jpica. ti; Feminei terminales, aggregati in capitulum globofum, Jefrles.

Pedunculi \& Podicelli paniculati, dicbotomi.

Ujus: Folia domibus tegendis $\&$ Aoreis conftruendis inferriunt. Fructus edules, tam crudi guanz faccbaro conditi In. colis Indice orientalis.

\section{PHELYPAEA.}

Flores mafculi:

CAL. nullus, nifi bractex foliaceæ, oppofitæ.

Corolla 6-partita, connivens. Lacinice fubrotundæ, obtufifimæ, concavæ; extus dorfo fubpilo$\mathfrak{f x}$, intus glabræ, bafi barbatæ, margine ciliato-crenulatæ, tenues, tres exteriores, tres interiores, ungviculares.

Stam. Filamentum unicum, ereetum, crafffimum, 
corolla brevius, ftylo fimile, medio recep. taculo infertum.

Anthera ovata, clavata, Atigmati fimilis, pollinifera.

Pollen pallidum.

Receptaculum barbatum, poris 6 a corollæ laciniis decurrentibus neetareis pertufum, fterile.

Obf. Corolla \& Bractece interdum ciliato-ferratx; Corolle lacinix quandoque inæquales.

Flores feminei :

Cal. nullus.

Corolla I - petala, capfulam vertiens, 6 -partita: Tubus breviffimus. Limbi lacinix fupra germen parum connatæ, oblongæ, obtufæ, concavæ, erectx, ungviculares, intus bafi fovea neEtarea decurrente pertufx, barbatz.

Pist. Germen fuperum feu corollix fundo inclufum, barbatum.

Sty'us craffifimus, purpureus, glaber, lineam. longus.

Stigma capitatum, fubumbilicatum, ftriatum? parum oblique truncatum.

Peric Capínla columnaris, craffa, fubcompreffa, obtufa, fulcata, glabra, fere pollicaris, 7-valvis, 7 -locularis.

Columna craffa medio ftellula oblonga.

Semma plurima.

Character generis: Cal. nullus. Cor, 6 -partita. Pift. I.

Locus: Dircia, Monandria poft Najam fecundum fyftema Linnxanum.

Valde. 
Valde fimilis eft Hyobanchi \& Orobanchi; differt:

1:0 ab Hyobanche: floribus longe diverfis, uti \& fructu.

2:0 ab Orobanche: calyce nullo.

Corollæ figura, fexu \& capfula.

Sp. 1. Ph. fanguinea.

Africanis: Aardroos.

Crefcit in sampis demer/ss fubulofis inter Cap. EO Jerienn montium fub fruticibus, parafitica.

Floret Fulio, Augufto, Septembri, OEtobri.

Caulis finplex, totus tectus fquamis inubricatis, evectus, fenfin parum incraffatus, pollicaris usque digitalis. Folia mulla, fed potius fquance oblongee, obtufiffime, glabra: intus concave, extus convexe; fparfe, pollicares, adpreffe, floribus quoque inftar bractearum inter/parfa, inferiores jenfim minores; omnes profertinn apice incarnatio.

Flores foliturii vel fepius aggremati, carno/z, fangvinei, mefculini Eo feminei deffincti in difincto individuo. Bractea bina, fuboppofite, oblonga, obtufe, concave, fango vinea, ungviculares, corolla breviores, capfulde. inferte, glabra.

\section{PHORMIUM.}

Phormium Forft. Nov. Gener. N:o 24. Linn. Suppl. p. 28 .

CaL. nullus.

Corolla monopetala, profunde 6-partita, fubcylindrica: lunbi lacinice tres exteriores brevio. res; tres interiores longiores, patula.

STAM. Filamenia lex, filiformia. Aluberw incumbentes, ovatz.

PIST:

G 3 
Pist. Germen fuperum, trigonum, glabrum. Pori melliferi nulli.

Stylus filiformis, corolla paulo longior.

Stigma fimplex, obtufum.

Peric. Capílala oblonga, trigona anoulis fulcatis, trifulca, glabra, trivalvis, trilocularis.

Semina plurima.

Character generis: Corolla fexpartita laciniis tribus exterioribus brevioribus.

Locus: Fiexandria, Monogynia poft Hyacinthum. Nomen Generis impofuit Celeb. Prof. Forfter fpeciei cuidam a fe inventæ in Nova Zelandia; quod \& nos retinere voluimus fpecies no-

vas capenfes ejudem generis defcripturi.

Nimis affine Hyacintbo, differt vero facile: coilla irregulari, laciniis tribus exterioribus multo brevioribus E calycis vices fungentibus.

- Sp. I. Ph. tenax: fcapo polyftachyo angulato, foliis enfiformibus canaliculatis.

Pbormium tenax. Linn. fuppl. p. 204.

Crelcit in Nova Zelandia. Forfter.

Folia radicalia, enfiformia, canaliculata, integra, firiata, ri. gida, glabra, pedulia \& ultra.

Scapus angulatus, polyftacbyus, ramis alternis, floriferis.

Flores racemofi, fubfecundi.

In noftro Jpecimine ficcato corolla profunde quidem, non tamen usque ad bafin partita eft.

USus: Aoreas e folionum fibris pro veftimentis variis plectunt mulieres nove Zelandice.

Sp. 2. Ph. alooides: fcapo fimplici, floribus cernuis cylindricis, foliis fubenfiformibus glabris 
Phornium alooides. Linn. fuppl. p. 205.

Crefcit in capitis bonze spei campis deprefis arenzo/is, in Paar. den eyland, in Suartiand, Nordbuk, in monte Ri. beck Caffel dicto, collibus arbis, Pandeberg, alibi. Floret Majo, Funio, Fulio, Augufto.

Bulbus globofus, carnofus, fibrofus, albus.

Folia radicalia, bina, vaginantia, lanceolato enfiformia, concava, Jubundulaía, integra, glabra, fcapo brevio. $r a$, patentia, fupra purpureo-maculata.

Scapus fimplex, teres, carnofus, glaber, erectus, purpureo. maculitus.

Flores racemofi, cernui. Racbis angulata.

Bractea fub pedunculo lata, acuta, membranacea, brevifima. Pedunculus teres, erecto-patens, glaber, Jemiungvicularis. Corolla cylindrica: Lacinia tres interiores longiores, lato-lineares, obtufifima, emarginatie, concave, pollicares, aquales, invicem minimze colsarentes; tres exteriores duplo breviores, bafi invicem \& cum intcrioribus parum connate, ovate, concave; fuperior retufa.

Filamenta baji luciniarum inferta, alba, longitudine corolla. Vurzetates: (oc) Cornllis totis croceis; fcapo purparafcente, immaculato, Spitbameco.

( $\beta$ ) corollis luteis: Laciniis exteriovibus apice virentibus, interiobus apice purpureir; fcapo foliisque fupra-maculatis; fcapo /pitbamseo.

$(\gamma)$ corollis purpureis.

Sp. 3. $\mathrm{Ph}$. orchioides: fcapo fimplici, floribus cernuis ovatis, foliis lanceolatis glabris.

Hyacinthus orchioides. Linn. fp. Pl. pag. 455. Syft. Veg. p. 277 .

Pbormizun hyacinthoides Linn. fuppl. p. 204.

Cre- 


\section{Crefcit in Capite bonæe fpei, ad pedem Leuveftart, Duyvelsberg, deprefís Svartand \& a. libi.}

Flovet Fulin, Augufto.

Euibus glohofus, carsofus, mngnitudine nvellnne, albus, fihrillofits.

Folus raro unicum, Sape duo radicalin, vaginantis, lato-linceolnta, convoluto-concava, acremin ita, fishundulata, integerrimn, revoluta, ylabra, digitalia vel ultra, altero breviore, pollicem lata.

Scapus fimplex, foliis vaginatus, teres, glither.

Flores racemoí, ovati, patuli. Rachis flexuofa angulata.

Bractea ad bafin floris vitta, acuta, membranacea, brevifjima, alba.

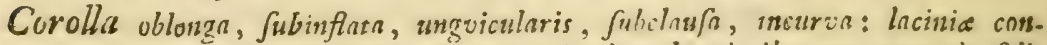
cava, obsufa: trihus extericribus brevioribus, quaram dorfalis apice incraifata, fulfornicnta, obtuia: trilus interioriribus longiorihus, quarum infimo paulo brevior.

Filamenta filifurmi-fuhulata, tulo corolle inferta do ad medium longitudinaliter adnata.

Antherce parve, fupra fluva, fubtus fufca.

Varietates: $\alpha$. corollis finvis, ovato-ol.loniris; Jcapo fubiracluso, brevidimo fe. re inllo Supra terram;

B. corollis fluvis, fcapo foliis longiore.

$\gamma$. corollis apice purpureis, bafi carulefcentihus; fcapo palmari, purpureo-macslato; foliis extus purpureo maculatis.

d. corollis alhis apice virentzhus; Icapo /pitbamao, albo, fuperne purpureo punctaro; foliis fupro purpureo - maculatis.

E. corollis alhis, apicibus purpurafcentihus; Scapus fpitbamalis, iviridis, purpureo-variegatus; Folin decumhentin, carnofa, caroliculatn, lineari-astenunta, glahra, immaculata, fpithaman.

Sp. 4. Ph. hirtum: fcapo fimplici, floribus cernuis ovatis, foliis hirfutis.

Crefcit in copitis bonce fpei aquofis.

Flnret Augufto do fequertihus menfibus:

Scapus fimplex, flexuofo-erectus, glaher, porpureo-suaculatus, fpithomaus.

Folium unicum, bafi lata vaginans, lineare, birfutumb.

Flores racemofi, cernsi, ounti, albo-carulefcentes. 

GENERA NOVA

\section{PLAN T A UM.}

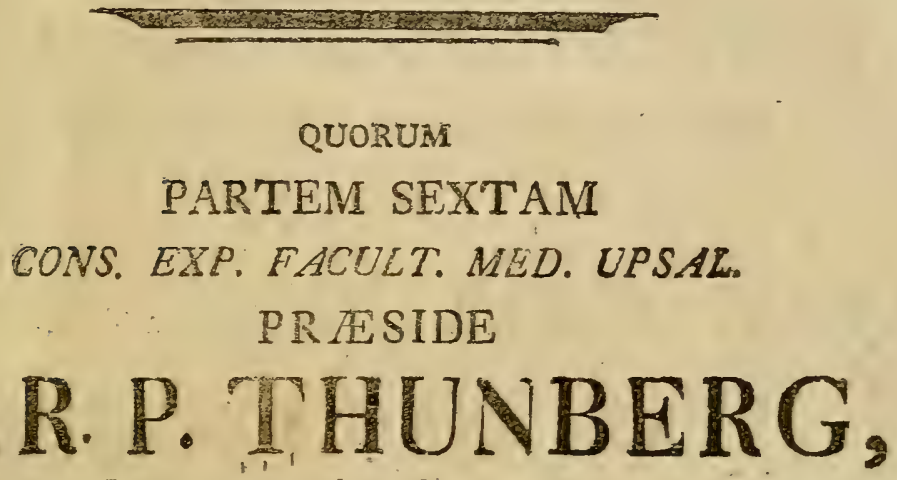

Equite Aurit. Beg. Ord. de Vasa,

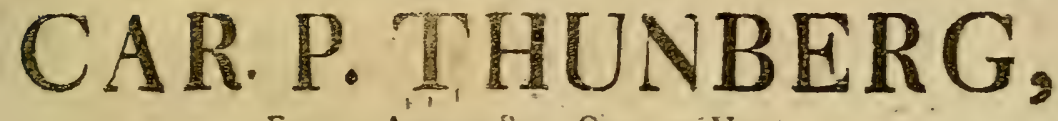

Medic. Doct. Frotess. Med. et Botan. Reg. et Ord. Acad. Cämar. Nat. Curyos, Reg, Scientr. Londinens. Holmiens. Socret, Sciznt. Upsar. Puitacelar. Patr. Holm. Bezol. Nat. Scrut. Lundens. Harlem. Amstelu. Zeiand. Nidrosiens. Hairens, Nat. Scrut. Line. Londin. Medic. Edim. zurg.et Nat.Studios. Tbid. Memero;nec non a cad Scignt. Paris. Monspelizns.

Agricult. Paris. Medic. Londin. Florentin. et Batavin. Ind.

Or. Correspomd.

\section{PUBLICO EXAMINI SUBMITTIT}

\section{Gabriel Tobias Stro̊m, JUNECOPIA - SMOLANDUS.}

Th Audit, Gust. Maj. D. Xxvi. Maji Mdecxeir. F. A. M. $S$.

\section{UPSALI E,}

IITTERIS VIOUE DIRECT, JOH. EDMAR. 


\section{IN}

SACRAM REGIAM MAJESTATEM MAGNAE FIDEI VIRO, REGII DICASTERII GOTHICI CONSILIARIO, GENEROSO ATQUE CONSULTISSIMO

\section{DOMINO}

FOH. GABR. BILDENSKO̊LD,

\section{MÆCENATI SUMMO!}

Ob collata beneficia, in piam gratisfmæ mentis tesferam

\section{S A C R A.}




\section{GENERA NOVA \\ PLANTARUM.}

\section{IS A.}

Cat. Spatba.

Corolla 6-petala, bilabiata. Labiurn fuperius tripetalum: Petala duo confimilia, æqualia; tertium angultius. Labizun inferius tripetalum: Petaluin unum faccatum, cornutum, patens; duo confimilia, intra cornu indufa. Cormi neetareum anticum.

Stam. Filamenta nulla, fed

Anthera fesfiles in lobis exterioribus ttigmatis.

I'ollen flavum.

PIST. Germen inferum, trilobum.

Stylus brevis.

Stigma trilobum.

Peric. Capfisla infera, fexfriata, glabra, r-locularis. Semina numerofa, parva.

Character Generis: Cor. ringens. Cornu anticum. Petalum unum faccacum petala duo includens!

Iuocus: Gynandria, Diandria.

Nomen Difz olim impofuit Celeb. Prof. BERGIUS Plantæ, qux ad Satyrium amandari debet; $\mathrm{H}_{2}$ no- 
nomen igitur Dilæ adoptavit huicqgve Generi impoluit Cel. Præres.

Sp. r. D. Lonuicomsz: cornu cylindrico longiori. Difa longicornis. Linn. Suppl. Syft. p. 406. Synt veg. xiv. p. 817 .

Crefcit in Taffelberg, in praruptis montis, promontorii Alrices, bonæ fpei dieci.

Floret Januario, Februario.

Fulia radicalia, fapum inferne vaginantia, circiter quinque, lanceolata, inferne fenfin attenuata, actra, integra, nervofa, recurvato-patenria, fupra viridia, fobus pallidiora, fcapo breviora, digtalia vel polnaria.

Scapus teres, ereetus, glaber, vaginis membranaceis teßus, uniforus, fpithamxus.

Flos terminalis, foltarius, nutens, carruleus.

Spatba dimidian caplutam a latere infurion amplexans: lanceolata, acuta, concava, mentura. nacea, capfula brevior.

Sp. 2. D. mactelatit: cornu brevisfimo Icrociformi. Difa maculata. Linn. Euppl. Sylt. p. 407. Syft. veg. XIV. p. 817.

Crefcit in Capite bonæ fpei, in montium lateribus proFlore Oetobri.

pe Winterhoek juxta Rode Sand.

Folia radicalia, circiter fex, oblongo-ovata, acuta, utrinque attenuata, integra, glabra, patencia, fubeus pallidiora, femipollicaria.

Scapus filiformis, flexuofo-erectus totus fere vaginatus, palmaris, usque f́pithamæus. 


\section{Plantarum.}

Magine ties vel quatuor, alterna, membranaceæ, rufo-maculatz.

Brafter vaginis fimiles, capfula brevior. Flos folitarius, nutans, cæruleus.

\section{MONETIA.}

CaL. Periantbiunn I.phyllum, 4-partitum: lachis ovatz, patentes.

Cororla 4-petala, receptaculo inferta.

Petala ovata, acuta, albida.

STAM. Fiamenta quatuor, receptaculo iníera.

Antberice oblonga, lutex.

Prst. Germen fuperum, fubtetragonum, definens in Siylzin conicum, crasfuiculum. Stigna acutum.

Peric. Breca globofa.

Character Generis: Cal, 4-fidus. Petal. 4.

Germ. fuperum. Bacca.

Locus: Tetrandria, Monogynia.

Nones, quod in loco natali impoluit Cel. Præles, pof reditum in Europan mutavit, dum refiverat hoc Genus novum ab III. Hereti$\mathrm{ER}$, uti \& alia Genera ab aliis, interim fuisfe delcripta.

Sp. I. M. barlerioides.

Monetia barlerioides. L'Heretier Nov. Stirp. fafc. I. p. I. tab. I. Hort Kewenf. I. p. I60.

Crefcit in ylvis promontorii bonæ pei ariis, ut in Musfelbay, trans Camtous rivier \& alibi, rarior. 
Floret Novembri, Decembri, Januario. Frutex glaber, erectus, tri-vel quadripedalis. Rami \& ramuli oppofiti, tetragoni, cinerei, divarica. ti, fpinofi.

Spina quaternæ, verticillatæ, teret-fubulatæ, pungentes, horizontaliter patentes, pollicares fuperioribus tenerioribus \& brevioribus.

Folia oppofita fub fpinis, petiolata, ovata, acuta, mucronata mucrone pungente, integra, glabra, horizontaliter patentia vel refiexa, petiolis pluries longiora, pollicaria.

Flores axillares, glomerati, breviter pedunculati.

\section{CURTISIA.}

CaL. Periantbium s-phyllam, tomentofum, 4-fidum: lacinice ovatæ, acutx, erectx.

Conolla 4-petala; Petala oblonga.

Stam. Filamenta quatuor, capillaria, longitudine corollx.

Anthere globolæ, didyma, flava.

Pist. Germen inferum, tomentolum.

Stylus fimplex, filiformis, longitudine corolli.

Stigmata duo, fimplicia, revoluta.

Peric. Bacca globola, flavelcens, I-fperma. Character Generis: Cal. 4-fidus. Pet. 4. Germen inferum. Bacca I-lperma.

Locus: Tetrandria, Monogynia.

S. P. 1. C. faginea.

Curtifia faginea. D. Dryander Phil. Transact. \& Hort. Kew. I. p. 162. IN- 
Incolis africanis : Asfagay-hout.

Crefcit in Capitis bonæ pei fylvis variis ut in fylva prope Paradys, in Grootvaders bolch, juxta Buffeljagts rivier, van Stades rivier copiofe \& alibi fatis vulgaris.

Floret Decembri \& Januario.

Arbor excella, ramofisfima.

Rami decusfati, teretes, cinerei, glabri, erecti.

Ramuli fimiles, purpurafcentes, ultimi tomentofi. Folia oppofita, petiolata, ovato-oblonga, acuta, bafi integra, a medio ad apicem ferrata, nervofa, lupra viridia, fubtus pallidiora, glabra, patentia \& reflexa, pollicaria usque palmaria.

Petioli ungviculares uti \& venæ foliorum fubtus ferrugineo-tomentofi.

Flores paniculati, minimi.

Panicula trichotoma, Iupradecompofita, tota cinereo. tomentola.

Pedunculi \& Pedicelli oppofiti.

Bractea oppofitz, lanceolatx.

Ujus: lignum flavefcens, durum, compa\&um Hottentottis pro manubriis lancearum, Asfagai diktarum infervic.

\section{ELEGIA.}

Flores mafculi \& feminei in diftincto individuo: o. CaLyX 6-glumis, inæqualis: Cluma tres exterio es minimæ, ovatæ; interiores duplo majores, ovatz, concava. 
Corolla nulla.

Stam. Filamenta tria, brevisfima.

Antber ovatz, didymx, fulcx.

*. CaLyx 6.glumis, inæqualis, maris tamen calyce major.

Glume ovatre, concavi, acutæ, glabræ, tres interiores longitudine Capfulæ, tres exteriores duplo minores.

PIst. Germen fuperum.

Stylus fimplex, brevisfimus.

Stigmata tria, divaricata, plumola.

Perrc. Capfula ovata, Pigmatibus coronata, trigona, trifulca, trivalvis, trilocularis, lateribus dehilcens.

Character Generis: \$. Cal. 6-glumis, inæqualis.Cor.o.

Locus: Dioecia, Triandria.

9. Capfula 3-locularis.

Nomen olim dedit III. LINNé Elegie; poftea vero hoc genus ad Reftionem reculit.

Sp. I. E. juncer.

Elegia juncea. Linn. Mant. p. 162. 297.

Reftio elegia. Lin. Sylt. veg. xIIv. p. 882.

Crefcit in collibus montium promontorii bonæ fpei prope urbem; in fummo Taffelberg \& ali. bi juxta rivulos, frequens.

Floret Januario \& lequentibus menfibus.

Culmus fimplex, rarisfime ramofus, articulatus, aphyllus, ftipulacus, reres, glaber, erectus, pedalis, bipedalis \& ultra.

Stipuls articulos vaginantes, magnæ, ovatæ, rigidæ, ereetæ, glabræ, flavæ margine membranaceo, decidua, pollicares.

Flo- 
Fiorum fpicx paniculatx, alterne, bracteatx, erectx, plurimx, a medio frepe culmo ad ejus apicem.

Bractea univerfales fesflies, ovato-oblongx, acuta, concavo-planæ, ere£æx, rigidæ, glabræ, flavæ margine membranaceo, fpicis longiores, decidux; inferiores remotiores \& majores; fuperiores frequentiores \& mino. res;

partiales in paniculis lanceolatie, acutr, minimx.

Spiculie ovatr.

\section{WILDENOWIA.}

Flores dioici, in diftinetis culmis diftinet;

Calyx muleiglumis. Glume imbricatæ, acuminatæ, perfiftentes, drupa longiores.

Corolla 6-petala, bafin fruetus cingens.

Petala rotundato-ovata, membranacea, ad. presfa, æqualia, perfiftentia.

Stam. Filansenta tria.

Pist. Germen fuperum.

Stylus unicus, brevisfimus.

Stigmata duo vel tria, plumofa.

Peric. Nux ovata, obtufa, glabra, dura, I-locularis. Character Gezzeris: Cal. multiglumis. Cor. 6-petala. Nux 1 -locularis.

Locus: Dioecia, Triandria poft Elegiam. Wildenowia Thunb. A ct. Holmenf. 1790 .p.26.feqq.tab.2. Sp. I. W. Striata: culmo tereti ftriato. 
2. W. teres: culmo ramisque tereibus levibus. 3. W. compresfia culmo foliofo levi, ramis compresiss.

\section{LAUROPHYLLUS.}

CAL. Perianibium fubietraphyllum:

Folia lanceolata, concava, glabra, minutisfima.

Corolla nulla.

STAM. Filanienta quatuor, filiformia, calyce longiora. Ansberce globolo-tetragonz.

Pisr. Germen fuperum.

Styli fimplicis rudimentum.

Character Geinevis: Cal. fubterraphyilus. Cor. o. Germen fuperum.

Locus: Tetrandria, Monogynia inter Nigrinam sa Salva. doram.

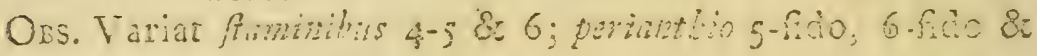
4-partito.

Sp. i. L: capen/is.

Crejot in Capitis bone fpei fylvis, prope Hautriquas. Kloof \& alibi.

Floret Januario.

Arbor erceta, tota glab:a, fefcuiorgyalis.

Rami teretes, rugoî, brunnei.

Ramusli angulati.

Folia alternatin fparfa, petiolata, oblongुa, acutiufula, ferrate, bafi \& apice integra, fupra viridia, fubtus pallida, parallelo-nervora nervis ramofis, margine revoluta, fempervirentia, erecta, digitalia.

Perioli trigoni, vix pollicares.

Flurs paniculati, minuti.

Panicula ampla, fupradecompofita.

Pedunculi \& Pedicelli compresfi, fenfim breviores.

Bratee folitariæ vel binx, calyci fubjectre, lanceolatæ, con-

cave, glabira, cinereo-flavefcentes. 


\section{CANCELLIERÁDINNAN}

\section{VÄLBORNA FRUN}
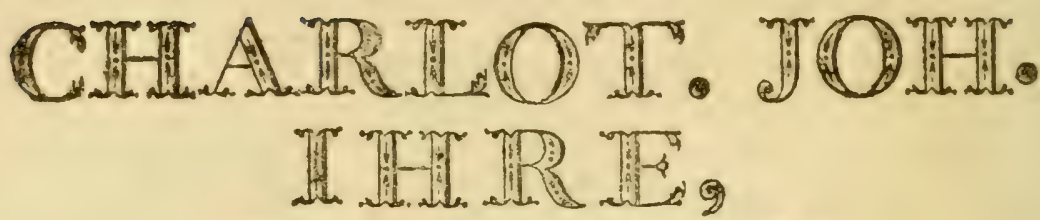

FODD GIE

\section{SAMT}

FRIHERRINNAN

HÖGVÄLBORNA FRÖKEN

ANINA TUDITIHI

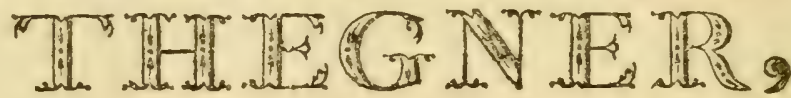

Min Huldafte Mofter!

Tillegnas desfe blad $i$ djupafle ödmiukhet, 


\section{$V I R O$}

AMPLISSIMO ATQUE CELEBERRIMO

\section{DOTHFTO DOGJORH,}

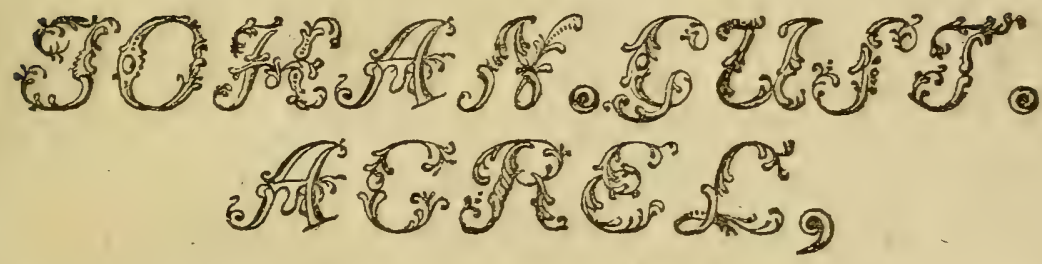

MEDICINE THEORET. ET PRACT. PROF. REG. ET ORD. REG. ACAD. SCIENT, HOLM. ATQUE SOC, REG. SCIENT. UPS. AEEMBRO.

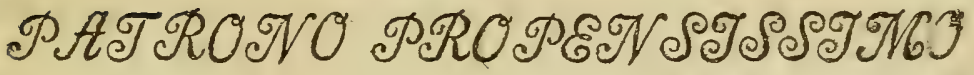

\section{S A CRUM.}




\section{MONGL. MAGG:TS}

\section{TROTJENARE OCH CAPITAINE, $V A ̈ L B O R N E$ HERR}

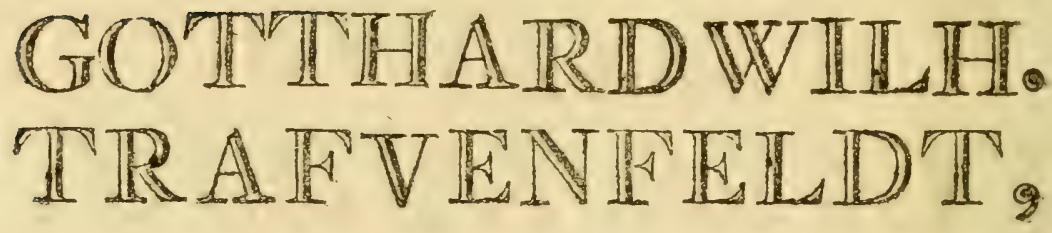

\section{MIN HULDASTE FADER!}

Hett breft, som andas izel tackfamhet för EDER FADERLIGA omvairdnad, tillegnar EDER desfa blad, under gladafte tillfredsfällelfe, at hafva nadt ett tillfiblle, ati ehuru ofullkomligen, ytira den vordnad, med hvilken jag fidje framinardur at vara

\section{MIN HULDASTE FADERS}




\section{NOVA GENERA PLANTARUM. - a w CAVANILLA.}

19.

今. CaL. Perinntbium 4-phyllum, rude, extus hirtum, perfiftens: Foliola ovata, patentia, vix lineam longa.

Corolla nulla.

STAM. Filannente quatuor, capillaria, calyce breviora. Antbere ovatx, didymx, albidz.

9. CaL. ut in mare.

Corolla nulla,

PIST. Germen inferum, oblongurn, hirtum.

Sitylus in apice germinis radiatus, perfiftens. Peric. Nux anceps, ovata, rugofa, hirta, I-locula: ris, magnitudine pir.

Character generis: $\{$ Cat. 4-phyllus. Cor. O. of Styl. radiatus. Nux.

Locus: Diœcia, Tetrandria ante Hippophaërn.

Nomek: in honorem Dom. Dottor. Jos. ANron, Cavanilles, hípani, Botan. Celeberr.

Sp. I. C. Jcandiens.

Crefcit in fylva Grootvaders Bofch dicta, in pramontorio bonæ Spei Africes. 
Floret Januario.

Tota Planta birfuta.

Caulis frutefcens, teres, inferne glaber, cinereus; fuperne punctato-fcaber, fcandens, flexuolus. Rami alterni, cauli fimiles, fenfim filiformes. Folia alterna, petiolata, oblonga, obtufa, fubfinuata, denticulata, fupra viridia, fubtus ferruginea, patentia, bipollicaria.

Petioli ungviculares.

\section{DAHLIA.}

Flores dioici, in ramis \& ramulis terminales, capitati, in receptaculo communi aggregati.

A. CaLYx nullus, nifí f́qama flofculos difingventes, paleacer, intus glabræ, extus hirfutx, breves. Corolla. Petalum unicum prope fingulum Stamen filiforme leu enfacum, covolucum; albidum, ungviculare.

Stam. Filanentum unicum juxta fingulam calycis fquamam \& petalum, brevisfimum, ereßum, petalis triplo brevius.

Anthera bafi cum filamento connata, ovata, didymo-bilocularis.

9. CaLYX ut in Mare.

Corolla nuilla.

Pist. Germen villofum, fingulum prope fquamam fingulam calycinam.

Stylus unicus, filiformis. Stigma fimplex. 
Perrant. Capfula ovata, extus villofa, 4 -vaivin, $4 \cdot 0$. cularis.

Sertast ovatum, glabrum, bivalve, dehicurs, inane.

Locus: Monandria, Monogynia poft Phyllachne; vel fecundum

L. Dicecia, Monandria poft Pandanum. Character: Cal fquama. Cor. 3-phylla. Capf. I-locul. Sp. D. crinita.

Dahlia crinita. Aat. Societ. Hif. Nat. Hafnienf.

\section{LIGTHFOOTIA.}

CAL. Periantbiums 4-phyllum, cinereum, villofum, brevisfimum, perfiftens: Foliola ovata, obtufa, patulo reflexa.

Corolta nulla.

STam. Fulamenta plurima, germinis bafi inferta, filiformia, calyce longiora. Antbera globofie, minima.

PIst. Germen fuperum, ovatum, glabrum.

Styli 5 , rarius 4 vel 6 , reflexi.

Strgstata capitaca, crifpa.

Peric. Fruetus ovatus, glaber, ftigmatibus coronatus, calyce cinetus.

Character generis: Cal. 4 . phyllus. Cor. O.

Locus: Polyandria, Pentagynia, inter Nigellam \& Reaumuriam.

Sp. I. Ligthfootis indica.

Crefcit in fylvis infula Javæ, prope Bataviam \& alibi. Favanis: Roccum. 
Arbor excella.

Romi Kannulique alterni, teretes, cinerei, punEtatofcabridi, erecti.

Folia alterna, petiolata, ovata, fubculpidata, ferrata ferraturis obtufis, utringqe glabra, nervola, fpichamaa.

Petioli brevisfimi, crasfi.

Flores in ramis \& ramulis aggregati, pedunculati. Pedunculi filiformes, fimplices \& ramof, reflexi, cinereo-tomentofr, ungviculares.

Genzs nominavit in Prodromo fuo Celeb. Dn. Prof. SWARtz ejusque unam nominat in Montfer. rat crefcentem fpeciem.

$$
\text { STAVIA. }
$$

Cax. Perionthizss comonzue hemifphricum: foliola plurima, linearia, imbricata;

Proprium monophyllum, 5-partitum: lacinix lineari-\{ubulat:, erę̃

Corolra 5-petala. Petula oblonga, obtufa, erecto. patentia.

STAM. Filamizentra 5, bafi perianthii inferta, fubulata. Antbera fubrotundx.

Pist. Girmen inferum, turbinatum.

Stylus unicus, fisfus in Stigma didrmum. PERIC. nullum; fed receptaculun commune, planum, paleaceum vel pilofim

Semina folitaria, ovata.

Character Generis: Co . fupera, 5-pecala. Stam. calyci inferta. Sty'us bifidus. 
Locus: Pentandria, Monogynia prope Bruniam. Differt a Brustia germine infero. Genus e fpeciminibus capenfibus, a Celeb. Præfide communicatis, nominavit Botanicus excellens, præmatura morte ereptus, Dn. D. AND. DAHL. SPEC. I. S. radiata: foliis lanceolato-trigonis patulis, calycis radio colorato capitulo breviore. Staavia radiata. Dahl obf. botan. p. 15. Brunia radiata. Lin. Spec. Plant. p. 283. Syft. veg. XIV. p. 240 . Hort. kewenfis. 1. p 277.

crefcit in campis arenofis inter urbem cap. bonæ lpei \& montium feries; in fummo etiam TAFFELBERG vulgaris.

Floret Majo \& leqventibus menfibus.

Caulis fruticofus, inferne fimplex, fuperne magis magisque ramofus, erectus, bipedalis \& ultra. Rami trichotomi, fufco-cinerei, fcabri, glabri. Ramuli trichotomi, fuperne dichotomi, filiformes, laxi, inferne glabri, fuperne villofi, erecti, fubfantigiati.

Folia fparfa, petiolata, lanceolato-trigona, acuta apice fufco, lubimbricato approximata, apice patula, inferiora glabra, fuprema villofa, lineam longa. Flores terminales in fupremis ramulis, pifo minores. Calycis radius albus: apice foliolis paculis, deuftis, capitulo brevioribus.

Ujus: pro foco alendo lignum infervit. SPEC. 2. S. glutinofa: foliis lineari lanceolatis trigonis patulis, radio calycis colorato capitulo longiore. Staavia glutinofa. Dahl obl. botan. p. 17. 
Brunia glutinofa. Linn. Syf. veg. XIV. p. 2470. Mantif. p. 210.

Crefor in fummo Taffebrerg cap. bonz fpei fat Floret Majo. copiole cum priori.

Cuzlis fruticofus, erectus, glaber, tripedalis \& ultra. Ram \& Ramzli fubverticillaci, teretes, fulco-purpura. fcentes, incurvato-ertedi, fubfaftigiati, glabri. Folia fparfa, in ramulis frequentiora, petiolata, linearilanceolata, trigona, interra, acuta apice fapius fufco, patentia, inferiora glabra, fuperiora villola, ungvicularia.

Pitiol flavefcentes, foliis multo breviores.

Tlores teminales in ramulis, magnicudine fere corgl? kiabias caly cis color arus: foliola trigona, patulo-reflexa, flavefcentia, apico dentha, capiculo longiora.

\section{MAUHLIA.}

CAz. Spatha diphylla: folia obsonga, acuta.

Corolla 1-perala, infundibuliformis: Tubus fenuin ampliaus, brevis. Liwhias 6-particus: lacmle oblongx, obture, rqvales, erecto-patentes.

STAR. Finmena fex, filfomia, apici tubi intera, iacinis oppofita, limbo breviora.

Artherse incumbentes.

Pist. Gertzen fuperum.

Siyhus filiformis, longitudine faminum.

Stigma fimplex.

Peric, Crelula ovata, trigona, trivalvis, trilocularisa Semba plurima. 
Character Generis: Cor infera, 6- partita: limbo aqvali. Locus; Hexandria, Monogynia port Pontederiam. Generz quogve huic nomen impofuic Cel. Dn. D. DAHL. Sp. I. M. linearis: foliis linearibus fcapo brevioribus. Mauhlia africana, Dahl obr. botan. p. 26.

Agapanthus umbellatus. Hortus kewenfis. vol. r. p. 4 I4. Crejcit in Capitis bonæ ipei campis inundatis. Floret OEtobri \& feqventibus menfibus. Scapus teres, ereetus, glaber, pedalis \& ultra. Folia radicalia, plurima, linearia, acuta, integra, glabra, erecta, fcapo duplo breviora.

Fiores umbellati, plurimi, cærulei. Y'edancule geniculati, pollicares.

Sp. 2. Mo en/folia: follis lanceolato-enfiformibus fcapo longioribus.

CFejcit in Capicis Dona fpeinterioribus provinciis, inter Scendags \& Vifch-rivier,

Floret Decembri, Jantario. Scapus fillformis, pollicaris.

Folia radicalia, bina, lanceolata feu enfiformia, attenuaco acuminata, integra, Striata, glabra, ereEta, pollicem fere lata, palmaria,

Fiores umbellati.

Pedunczli capillares, ungviculares.

Curolls infe:a, tubulofa, apice campa nulata, pollicaris,

\section{STRELIT'ZIA。}

$C_{A L}$, Spath.z univerfalis horizonealis, connivens, continens f́pathas, fiores fruetusque, multiflora, glabra. Spatbe partiales flores \& tructus 
cingentes, concavæ, lanceolatæ, acutæ, gelatina vilcidx, brunnex.

Gelatina albida vel fubflava.

Corolla tripetala. Petala duo fuperiora approximata; inferius remotum, infra nectarium ficum; omnia ovato-lanceolata, acuminata, concava, integra, confimilia \& rqualia, digitalia.

NeCTARIUM diphyllum, inter petala fitum: folium Juperius minimum, alterum amplexans, apice obtulum, carinatum, crasfiufculum, emarginatum, ungviculare. Inferius petalis paulo brevius, genitalia includens; Carina dorfalis fulcata fulcis qvatuor; a medio ad apicem haftatum; alx fuperne marginibus elevatis, intra qvas ftamina \& piftillum.

Stam. Fulamenta 5 , filiformia, longitudine dimidia hafte, alba.

Anthere lineares, longitudine haftæ, cumque ea longitudinaliter imprimis.apice cohærentes, alba.

Pollen a latere antico album, vifcidum.

PIsT. Germen infra receptaculum floris.

Stylus longirudine hattx, filiformis, albus.

Stigma cylindricum, vifcofum, ungviculare, trifidum, extra apicem haftæ exfertum, fufcum. Peric, Capfula fesfilis in fundo fpathæ, ovata, glabra, trigona, trivalvis, trilocularis.

Semina fubglobola, columnæ affixa, alba, plurima, bafi barba cincta.

Character Generis: Cor. 3-petala. Cap. 3-locula. ris. Neetarium haftatum! 
Locus: Pentandria, Monogynia prope Heliconiam. Sp. I. S. augufta: foliis fimpliciter nervolisHeliconia alba. Linn. Supl. p. 157. Syft. veg. XIV.p. 245. Europeis incolis: Witte Pifang.

Crefcit in Africa Aufrali, in Capitis bonæ fpei interioribus regionibus, nempe in humidis umbrofis fylvis Hauteniquas prope rivulum Pifang rivier dittum.

Floret OEtobri, Novembri.

Radix fibrofa.

Scapus fimplex, vaginatus, crasfitie brachii \& ultra; alcitudine ciriciter 18 pedum.

Folia petiolata, erecta, vaginata, lato-ovata, obtufa, tenuisfime \& fimpliciter nervora, integra, glabra, pedalia \& ultra.

Petioli teretes, ftriati.

Flores intra fpatham plures, circiter duodecim, ereEti, florentes, primum bafi, continuata fenfim florefcentia verfum apicem, fesfiles inter fingulas fpathas.

Corolli tota alba, uti etiam nectarium.

Sp. 2. S. regina. Hort. kewenl. Vol. I. p. 285. tab. 2. Europeis incolis: Geele Pifang.

Crefcit in Capite bonx fpei prope montes juxta fluvium kamtou.

Floret OEtobri, Novembri.

Radix fibrofa.

Scapus fimplex, vaginatus, bipedalis, longitudine foliorum.

Folia plura, radicalia, petiolata, erecta, oblonga, obK 3

túfa, 
II4 Nova Genera Plantarum.

tufa, coriacea, tenuisfime nervola \& reticulata, inferne undara, integra, glabra. Racbis crasfa. Petioli teretes, Atriaci, inanes; glabri, digitum crasfi. Corolla aurantiaca. Nectarium cæruleum.

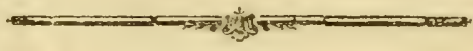

\section{THESES.}

I.

Non foli Medicina fed Uesunombia etjan maximopere infervat jisentia Botanica.

II.

In Theologia Hermeneutica, etjan Botanices non exiguuin esfe ujumb, pizrisua docest Jcripta evriditorum Hierobotanica.

\section{III.}

Quanvis non omnitum berbintun atilitas aut no. xa detecta lit; maxtmopere tamen expedit, fi herbas utules ab inutulibus $\because$ noxiis tuto dijcernere difcinas.

\section{IV.}

Nulla tamen planta in oeconomia naturce prorfus eft innutilis.

$$
\mathrm{V} \text {. }
$$

Defectum Herbariorum vivoratn ars delineandi quodornmodo Jupplet. 


\section{GENERA NOVA PLANTARUM}

-

QUORUM,

PAR'TEM OCTAVAM

VENIA EXP. FACULT. MED. UPSAL.

PR AESIDE
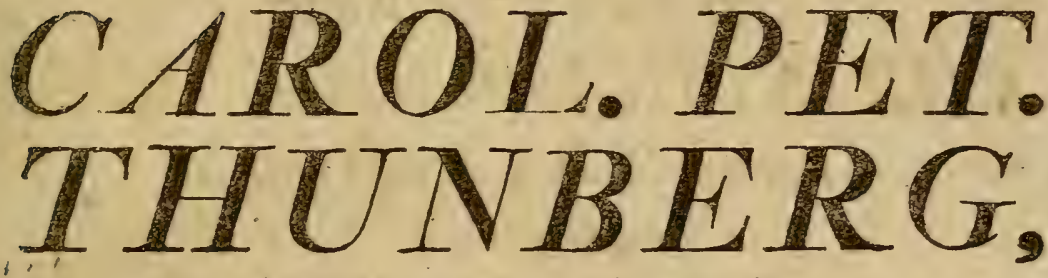

Equite Aurat. Reg. Ord. de Vasa,

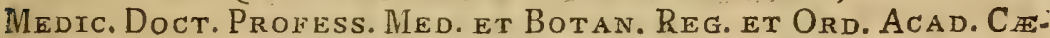
Sar. Nat. Curios. Reg. Scient. Londin. Holm. Societ. Scient. Upsal. Philad. Patr. Holm. Berol. Nat. Scrut. Paris. Hafni. Ens.etthalens. Hist. Nat. Jund. Harlem. Amsteld. Zeland. Nidrosiens. Ticinens. Tenens. Linn. Londin. Phys. Góttingens. Medic. et Nat. Studios. Edimburg. Membro; nec non Acad. Scient. Paris. Monspeliens. Agricult. Paris. Medic. Londen. Scandinay. Florentin. et Batayin. Ind.

Or, CORREŚPOND.

PUBLICO SUBMITTIT EXAMINI

CONRADWALLENIUS,

UPLANDUS.

IN ÁUDIT. GUST. MAJ. D. 20 JUNII I798.

H, A. M. S.

\section{U'P S A L I Æ,}

LITTERIS JOH, FR, EDMAN, REg. ACAD, TYPOGR. 


\section{KPRKOHERDEN}

ÓFVER

FRÖSUNDA OCH KORSTA FÖRSAMLINGAR HÖGÄREVÖRDIGE OCH HÖGLÄRDZ्

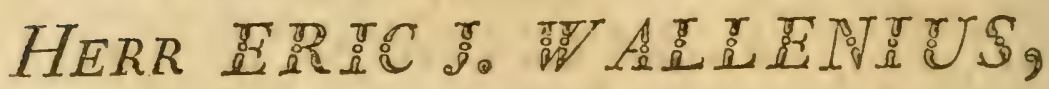
S A M T

\section{HÖG ÄDLA FRU}

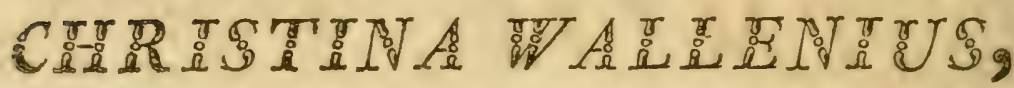

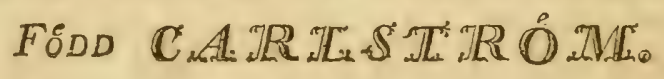

\section{MIN FAR OCH MOR!}

F्वृ

§illàten mig nyttja detta tilfålle, att offenteligen betyga EDER min tackfamket, fo̊r den o̊mma omvărdnad och mångåriga omkoftningar J haft ofparde for mitt Vål -

- Min fơrbindelfe ókes med EDERT Vâlgjörande Jag kånner den - men kănner dărjâmte min ofórmógenhet att uppfylla denfamma. Upptagen dock HULDASTE FO̊RÁLDRAR! med vanlig ynnelt, detta fvaga Offer, med vơrdnad helgat af

\section{EDER}

lydigfte Sore

Convad Wallenius: 


\section{NOVA GENERA \\ PLANTARUM}

ANCISTRUM.

C

AL.Perianthium 5-phyllum, patens, fuperum, perfifens: foliola ovata, obtufa, integra, intus glabra; extus villofa.

Corolla nulla.

Stam. Filamenta duo.

Antheræ globof $x$, didymæ.

Pist. Germen inferum.

Stylus unicus, brevisfimus.

Stigma multipartito-penicilliforme.

PERIc, Nux ovata, albo tomentofa, glochidibus tota cincta, magnitudine Piperis. Sublato tomento nux tegitur bafibus glochidum, implicatis, albidis.

Semen unicum.

3p. I. A. decumbens: foliis pinnatis hirfutis, fructibus tomentofis glochidibus armatis.

Anciftrum decumbens. Prodr. Flor. cap. I. p. 6. Crefcit in Roggeveld.

Floret Novembri, Decembri.

Coules plures, radicales, decumbentes, flexuofo-ereEti, ftriati, villofi : palmares.

Folia radicalia, plurima, pinnata, hirfuta, diffura, L... 
digitalia: pinne impares, æquales, dentatæ, obovatæ; caulina alterna, vaginantia, remora, fimilia, minora.

Flores in fummitate caulium fpicati.

\section{ACHARIA.}

Flores Monoici.

3 Cal. Perianthium diphyllum, minutum.

Corolla Monopetala, villofa.

Stam. Filamenta tria, corollæ laciniis inferta, bre.

visfima.

Antherce dorfo affixx, didymx.

\& Calyx ut in Mare.

Corolla ut in Mare: Lacinice ovatæ, acutæ.

PIsT. Germen fuperum.

Stylus unicus.

Stigmata tria.

Peric. Capfula oblonga, acuta, glabra, tripartibilis, 1- locularis.

Semen rugofum, globolum, fquamofum cortice duro femen includente.

Sp. I. A. Prodrom. Fl. Cap. I. p. 14. c. fig.

Crefcit prope van Stades rivier alibique.

Floret Decembri, Januario.

Caulis herbaceus, mox ramofus, glaber, palmaris usque pedalis.

Rami alterni, aggregati, angulati, flexuofo-erecti, virgati, ramulofi.

Folia alterna, petiolata, incifo-trifida, tenuisfime pu- 
befcentis, pollicaria. -

Lebi obovati, incifo-dentati.

Flores pedunculati, axillares, reflexi, mafculi fupe. riores, feminei inferiores.

Pedanculi folitarii, uniflori, brevisfimi

\section{CHLORIS.}

CALYX brakteiformis, biflorus, biglumis, corolla bre vior: Gluma exterior ovata, obtufa, bifida, carinata, ariftata, integra, glabra, brunnea, flore brevior; Arifta ifetacea, flexa, patens, longitudine floris; interior gluma concava, obtufa, mutica, ceterum fimilis.

Corolla floris inferioris \& Majoris major, ovata, obtufa, concava, margine membranaceo-albibida, 'brunnea, cenuisfime ciliata.

STAM, Filamenta tria, capillaria. Antherce lineares, bifurcatx.

Rist, Germen ovatum, glabrum.

Styli duo.

Stigmata villora.

IPERIC. Semen folitarium, oblongum.

I. Spec. C. petra: fpizis digitatis fenis, floribus fecundis, corolla ciliata.

Chloris petræa. S.WARtz Prodr. Flor. ind occid. p. Thunb. Prodr. Flor. Capenl. p. 20.

(Crefcit in collibus Hautniquas.

Floret Novembri.

Radix perennis, cafpitofa. 
Culmi fxpius plures, fimplices, inferne fubcompresfi, fuperne filiformes, friati, glabri, erecti, pedales.

Folia prope radicem aggregata, diticha, linearia, patentia, digitalia; in culmo vaginantia, adpresfa, brevia.

Spica terminales, digitatx, plerumque fex, raro 7 vel 5, lineares, compresæ floribus unilateralibus, falcatæ, fefquipollicares.

Sp. 2. C. Falcata: fpica falcata, floribus fecundis, corolla ciliata.

Cynofurus falcatus. Prodr. Flor. Cap. I. p.

Melica falx. Linn. Syrt, veg, XIV. p. 113. Suppl。 p. 109.

Crescit in collibus Hautniquas, in Langekloof \& alibi。 Floret Novembri, Decembri.

Culmus fimplex, erectus, glaber, pedalis \& ultra. Folia convoluto filiformia, glabra, fpiralia, erecta, breviora.

Spica folitaria vel binata, compresfa, falcata, pollicarisa

\section{ARDISIA.}

CAL. Perianthium monophyllum, perfifens, quin. quefidum: lacinice lanceolatx, erectæ.

Corolla monopetala, 5-partita. Tubus brevis, longitudine calycis. Limbi laciniæ lanceolatæ, acutæ, patentes, tandem reflexæ.

Stam. Filamenia 5, fubulata, ereeta. Anthera acutx, bafi bifidæ, erektx, apice conniventes. PIST. 
Pist. Germen fuperum, ovatum, minutum.

Stylus fubulatus, erectus, ftaminibus longior.

Stigmâ acutum.

PERIC. Niux fubrotunda, monofperma.

Semen fubrotundum, cortice duro fragili ob. ductum.

Sp. I. A. ovata: foliis ovatis, caule compresfo fulcato,

Habitat in India orientali.

Caulis -fimplex, compresfus, fulcatus, glaber, fpithameus.

Folia in apice, duo vel tria, petiolata, ovata, coriacea, integra margine reflexo, glabra, palmaria.

Flores paniculati.

Sp. 2. A. elliptica: foliis sllipticis, caule tereti rugo-

fo, paniculis lateralibus glabris.

Ceilonenfibus: Balludan.

Crefcit in Ceitona.

Coulis arboreus, glaber, rugofus, ramis angulatis.

Folia fparfa, elliptica, petiolata, glabra, integra, pal. maria.

Flores axillares, paniculati.

\section{BOSCIA.}

CAL. Perianthium monophyllum, viride, brevislimum, 4 \& 5 -dentatum.

Corolla pentapetala. Petala linearia, obtufa, conca. viufcula, patentia, lineam longa.

Stam. Filamenta 4 \& 5 , bafi germinis inferta, filiformia, alba, erecta, petalis breviora.

$$
\text { L } 3
$$


Antherce oblongx, dorfo affixæ, virefcentes.

PIsT. Germen fuperum, ovatum, glabrum. Styli tres, longitudine filamentorum.

Stigmata fimplicia.

PERIC. Capfula fubglobofa, umbilicata, 4-fulcata, 4valvis, 4-locularis, glabra, pifi magnitudinẹ. Semina folitaria.

Ob5. Variat numerus 4 narius \& 5-narius Calycis, corollæ \& Ataminum.

¥. Sp. Bofcia undulata. Prodr. Fl. Capenf. p. 32. Africanis: Witte Peerhout.

Crescit prope Buffeljagts rivier.

Floret Januario.

Arbor tota glabra.

Rami alterni, teretes, cinerei, rugofi, erecto-patentes. Ramuli fimiles, fenfim tenuiores.

Folia fparfa, petiolata, ternata, raro binata, rarius fimplicia inferne in ramulis. Foliola elliprica, fesfilia, acuta, raro obtufa vel excifa, integra, undulata, tenuisfime parallelo-nervofa, nerwo medio crasfo fubtus notata, utrinque lævia i glabra, digitalia inferioribus minoribus.

Petiolus filiformis, fupra fulcatus, longitudine folioli. Flores in ramulorum apicibus paniculati, cinerei, minutisfimi.

\section{LANARIA.}

Calyx nullus.

CoRolla I-petala, fubcampanulata, extus plumófolanata. Tubus brevis. Limbus 6-partitus: lacinice lineari-lanceolatæ, patula.

STAM。 
Sram. Filamenta fex, filiformia, bafi laciniarum limbi inferta, corolla brevior.

Anthere ovatæ, fubincumbentes.

PIst. Germen inferum, turbinatum, extus lanatum. Stylus filiformis; erectus, longitudine ftaminum. Stigma trifidum.

Peric. Capfula ovata, trilocularis.

Semina pauca.

Sp. I. L. plumofa. Prodr. Flor. cap. p. 63.

Hyacinthus lanatus. LINN. - Syrt. veg. XIV. p. 336 . Sp. Pl. p. 455.

Africanis Paarde Kapock.

Crefcit in collibus trans Swellendam, prope Rietvalley, in Lange Kloof \& alibi.

Floret Novembri, Decembri.

Caulis fimplex vel fuperne in plures ramos divifus, fubtrigonus, inferne villolus, fuperne plumofo-lanatus, pedalis \& ultra.

Folia radicalia, enfiformia, canaliculata, carinata, venofa, glabra, ferrato-fcabra, longirudine caulis; caulina alterna, fesfilia, lanceolata, acuta, conniventia, glabra, ferrato fcabra, internodiis breviora, pollicaria: Juperiora magis approximata \& breviora.

Flores paniculati; panicula compofita, denfa, pilis albis plumofis denfe tecta.

\section{TOXICODENDRUM.}

Flores dioici.

o Caid. Perianthium 5-7 phyllum: foliola ovata, acus ta, hirta, parva.

Co. 
Corolla nulla.

Stam. Filamenta ro usque 20, bafi contigua, brevisfima, ut fere nulla.

Antherc fublesfiles, ovatx, fulcatx, biloculares.

of Cal. Perianthium 7 vel 8 phyllum: foliola quatuor exteriora, ovata, acuta, concava, erecta, piftillum cingentia, extus fericea.

Corolla nulla.

PIsT. Germen inferum, ovatum.

Stylus brevis, trigonus.

Stigmata tria.

PERIC. Capfula fubglobofa, fexfulca, cinerea, glabra, fexvalvis, trilocularis feu tricocca.

Semina oblonga, atrorubentia bina in fingulo loculamento.

Toxicodendrum Capenfe. Acta Scient. Acad. Holmenf. 1796. p. 188. tab. 7 . 


\section{THESES.}

I.

Omnia fere, quevis fingulis individuis in $570 b 0$ terraqueo, ad vitam degendam falutiferam fint neces. faria, vicisfim e tribus Nature regnis ditisjime nancifcuntur.

II.

Regnum tamen Vegetabile \& in Medicina $\mathcal{E}^{\circ}$ in Oeconomia, utilitate ceteris, Separatim Jumtis, pre. cellere contendimus.

\section{III.}

Hiftoria Naturalis tum illiteratis tum litteratis fuis cultoribus amæenitatem adducit Jvavisfimam.

IV.

Sed tamen quisque, eo altiore Sese jactabit voluptate, quo majore Hiftoria Naturalis pollet induftria.

V.

Non convenit Naturam accufare, ficubi exiguun quoddom incommodum Sexcentis commodis admiscuerit. 




\section{HO̊GADLA FRUN}

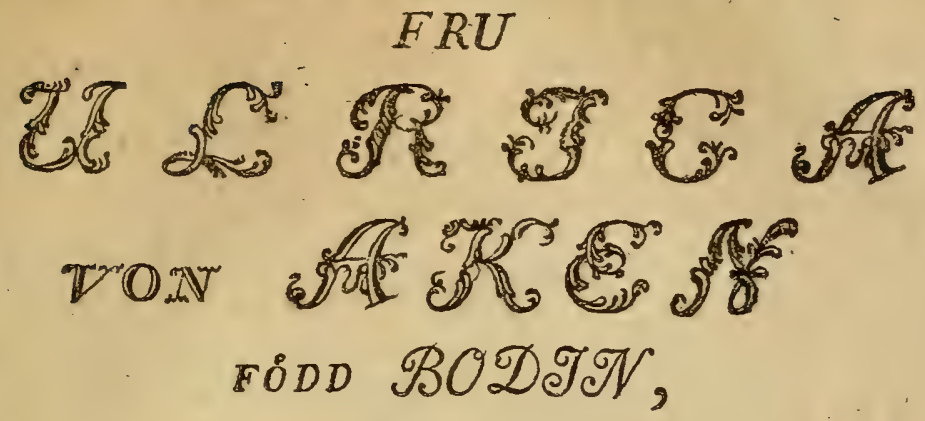

\section{MIN VO̊RDADE FASTER!}

$\mathrm{D}$

jag har den lyckan, att uti EDER, MIN FASTER, ega icke allenaft en nåra Slågringe, utan :fven cn ådelmodig Válgỏrarinna, fom altid lamnat de foorfta vedernålen af ómbet och omforg fỏr mitt vål, och til d: fs befordran oj fpart någon koftnad; hvilket åfven mitt hjerta lifligare kånner och erkănner, ån jag med ord fỏrmår uttrycka; fă år vifst ingen, fom méd mera tkal fkulle forura af mig den vỏdnadsfullafte erkånfla. Jag fkulle ock ingen ting hogre onfka, ån att kunna på ett EDRA våigårningar nog vårdigt fåtr bevifa denna lkyldiga tackfamhet: men berófvad alla andra medel hårtil, tager jag mig nu friheten, att med EDERT vòrdade Namn pryda desfa blad, och för en Allmånhet betyga buru hỏgt jag år EDER förbunden. Emottag med valbehag, och EDER vanliga godhet detta ringa Offer af min vödnad och tackfambet, och tillat mig att framgent for vara innefluten i EDER yoneft. Måtte Fo̊rfynen gèra EDER lefnad falll! - Mătte den dagen fent intråffa, pả hvilken jag fkulle fakna ett få fåkert Stỏd, och en få ảdelmodig Vålgórarinna! Under trognafte onflkningar hårom tił det Hỏgfta Våfendet, frambårdar jag med fullkomligaite kårlek oç vordnad till mit filta

\section{MIN VO̊RDADE FASTERS}

odmjukafte tjenare NILS GUST. BODIN. 
SACRAM REGIAM MAFESTATEM

$$
\begin{gathered}
\text { SPECTATE FIDEI VIRIS, } \\
\text { ASSESSORI MERITISSIMO, } \\
\text { ARTIS MACHAONIE DOCTORI }
\end{gathered}
$$

\section{EXPERIENTISSIMO,}

AMPLISSIMO ATQUE P:R ECLARISSIMO

DOM. GUST

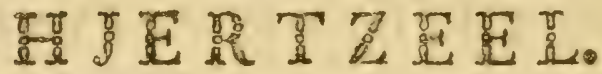

\section{NEC NON}

GRIINASII CAROLSTADIENSIS L. L. O. O.

$$
\text { LECTORI CELEBERRIMO, }
$$

STNEDRII ECCLESIASTICI ASSESSORI, MAXIME REVERENDO ATQUE PR RECLARISSIMO DOMINO

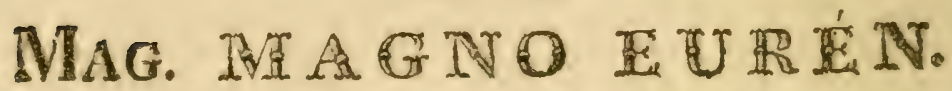
FAUTORIBUS OPTIMIS

\section{$S A C R U M$}

voluit, debrit NICOL, GUST: BODIN. 


\section{NOVA GENERA \\ PLANTARUM.}

\section{ROHRIA.}

ALYX communis, polyphyllus, imbricatus: foliola interiora longiora.

CoRolla compofita, radiata. Corollule hermaphroditz plures in difco; mafculz in radio. Cor. propria hermaphroditi floris infundibuliformis, quinquefida laciniis linearibus; Mafcula ligulata, lanceolata, tridentata.

STAM. Hermaphroditis filamenta 5 , brevia. Anthera cylindrica, tubulofa. Mafculis Antherce 5, in fauce tubi. PIsT. Hermaphroditis Germen obovatum, hirfutum. Stylus flitormis, longitudine corolla. Stigma bifidum. Mafculis nullum.

PERIC. Semen hermaphroditis turbinatum, angulatum. Pappus polyrihyllus: foliola linearia, inæqualia, cuspidata, eiliata, corolla breviora. Receptaculum favofum.

Sp. I. Julcota: foliis lanceolatis ciliato-fpimofis imbricatis fubeus unifulcatis glabris. 2. R. bifulca: folis inceolaris ciliato fpinofis imbricatis fubius bifulcatis glabris. M 3. $R$. 
Epinofis fubtus tomentofis, caulinis oblongis calyceque ciliatis. Vahl. AEt. Hafn. Hitt. Nat. Vol.2. S. 2. p. 39. t. 6.

Rhoria Carthamoides. Thunb. I. c. Vol. 3. S. I. p. 103 . t. 8.

19. R. cynaroides: foliis radicalibus integris inermi bus, calycibus ovaris integris. Vahl. Aet. Harn Hift Nar. Vol. I. S. 2. p. 6. tab. 8 .

20. R. grandiflora: foliis oblongis dentato-fpinolis, fubtus tomentofis, flore folitario. Thunb. AEt. Hafn. Hift. Nat. Vol. 3. S. 1. P. 10\% tab, 7. Rhoria ilicifolia. Vahl. 1. c. Vol. 2. S. 2. p.

2I. R. cruciata: foliis cordaco oratis glabris fpinofodentatis. Thunb. ABt. Hurn. Hint. Nat. Vol. 3: S, r. p. 104.

22. R. decurrens: foliis decurrentibus runcinatis Ipinofo-ciliatis fubtus comentofis. Thunb، Aet. Hafin. Hilt. Nat. Vol. 3. 5. r. $p$ ic4. $f .9$.

23.R. palmata: folis palmato pinnaritidis fubrus tomentofis fpinofis, calse lanaco. Thung, AB. Hafn. Hitt Nocur。 Vol. 3. Sed. I. pag. Ios, fig. 13. 


\section{ZUCCANGNIA.}

CaLYX nullus.

CóRolla monopetala, cylindrica, unguicularis, fexfida: lacinice tres, exteriores duplo longiores, lanceolntu-fetacex, frpe reflexæ.

Stamin. Fildmenta 6.

Anthere ovatio.

PIst. Germen fuperum. Stylus unicuss.

Peric. Caphla fupera, ovata, trilocularis.

Sp. I. Z. viridis: Phormium viride. Disfert. Nov. Gener. Plant, P.5 Lachemalia viridis. Prodr F: Cap. p. 64. Hort. Keventir. Vol. I. p. 452.

Hyacinthus viridis. Linn Syrt. Veg. XIV. p. 335. perGmelin p. 560.Spec. Plant. p. 454 Jacq. Plant. Rar. vol, I. fig, color.

\section{SANSEVIERIA.}

CaLyx nullus.

CoRolla monopetala, infundibuliformis, perfiftens, hexagona, rexpartita: limbi laciniz lanceolatz, ereetz, patentes.

Stamin. Filamenta 6 , fobuha, bafi laciniarum limbi inferta, longitudine corollis. Antieve oblonga, eresta. 
Pistill. Germen ovatum.

Stylus fubulatus, longitudine ftaminum.

Stigma trifidum.

Pericarp. Bacca globola, pulpora.

Seminc plura.

Differt ab Alechride fructu.

Sp. I. S. thyrgijfora: acaulis foliis lanceolatis carnofis, floribus geminatis Prodr. Flor. Cap. 1. p. 65. Alethris hyacinthoides: guineenfis: Linn. Sytt. veg. XlV. p. 336.

Sp. 2. S. athiopica: acaulis foliis linguæformibus convolutis, racemolo-oblongo, floribus ereetis. Prodr. Flor. Cap. I. p. 65.

Alethris hyacinthoides: Zeylanica: LinN. Syrt. Veg. XIV. p. 336.

\section{EUCOMIS.}

CALyx nullus.

Corolla monopetala, campanulata, fexpartita: limbi lacinize oblongr, obtufx.

Stair. Filamenta fex, fubulata, bafi dilatata \&r coalita in Nectarium concavum fundo corolla adnatum, corolla breviora.

Antherce ovatæ.

PIST. Germen fuperum, ovatum, trigonum. Stylus fubulatus. Stigma fimplex. 
Peric. Capfula ovata, obtufa, glabra, trigona, trilocularis, trivalvis.

Semina plurima, ovata, parva.

Nimis affine genus Ornithogalo.

Sp. r. E. nana: foliis ovato ollongis, racemo enicato. Fritillaria nana. Linn. Sy?t. Veg. XIV. p. 325. Ornichogalum nanum. Prodr. Fior. Cap I. p. 62.

Sp. 2. E. Undutate: follis enfiformibus undulatis, racemo fpicato.

Ornithogalum undulatum. Prodi: Flor. Cap. I. p.69. Sp.3. E. punctata: foliis enfformibus undulatis, $\mathrm{Ca}^{-}$ naliculatis, racemo longisfimo.

Ornithogalum punctatum. Prodr. Flor. Cap. I. p. 62.

\section{SCOTIA.}

Calyx Perianthium monophyllum, 5-fidum. Tubus turbinatus, fubcompresfus, perfiftens. Limbi laciniæ ovatæ, obtufx, concavæ, æquales, erekt.

Corolia 5-petala. Petala tubo calycis inferta, oblonga, concava, obtufa, zqualia, eręta, lateribus mutuo incumbentia, laciniis calycis duplo longiora.

Stam. Filamenta 10 , fubulata, tubo calycis inferta, ereeta, petalis paullo longiora. Anthera oblongx, incumbentes.

Pistill, Germen fuperum, oblongum, compresfim, pedicellatum.

Sty. 
Styius filiformis, longitudine ftaminum. Stigma fimplex, obtufum.

PERIC. Legumen compresfum, oblongum, glabrum, digitale.

Semen folitarium vel bina.

Semina cocta Horcentottis edulia.

Sp. r. S. afra. Prodr. Flor. Cap. p. 79.

Guajacum afrum. Linn. Sylt. veg. XiV. p. 396.

\section{ROEMERIA.}

Calyx Perianthium 5-phyllum, obfolete 5-gonum: foliola ovata, acuta, concava, extus hirfuta, perfítentia.

Corolla pentapetala. Petala ovata, obtufa, concava, erecta.

Stam. Filampizá 5, brevia.

Antherce ovata.

Pist. Germen fuperum, ovatim, vertice depresfum. Styltis crasfus, erectus, longitudine ftaminum, Stignato tria, fubrotunda.

PERic. Nux rotundafa, rugofo-ftriata, unilocularis, in embryone srifperma.

Semen unicum ad maturitatem perveniens oblongum, rubrum, lateri pedicelli affixum.

Differt a Sideroxylo:

1. Calyce 5-phylla, nee I-phyllo;

2. Corolla 5 -petala, nec rotata;

3. Stigmatibus tribus, nec fimplici. 
Sp. 1. R. argentea: foliis ovatis retufis tomentofis, 2. R. inermis: foliis ovatis retufis glabris.

3. R. melanophlea : foliis elliptico-oblongis glabris. Sideroxylon argenteum, inerme \& melanophleum. Prafid. Prodrom. flor. capent. p. 36.

\section{SERISSA.}

Calyx Perionthium 1.phyllnm, inferum, glabrum, minimum, 5 dentatum.

Corolla tubulola glabra, virefcens, 5 partita. Lainice vvata, refexr. Tubus fauce barba claufus.

Stamin. Filaminte 5 breviffima, ori tubi inter la. cinias iníerta.

Anthere ovatx, didymx, fluvo nigra.

Pistill. Gimen fuperum, convexum, glabrum. Stylus filiormis, exfertus, tubo paullo longior.

Stigma globolo-capitatum.

Peric. Capfula didyma, comprisa, emarginata, bilocularis.

Sp. I. S. cipenfis: foliis ovatis glabris, ramis flexuofis, floribus paniculatis.

Lycium barbatum. Prodr. Flor. Cap. p. 37. Linn. Sylt. veg. XIV. p. 228, Sup.l. p. I 50. Crefcit in collibus infra montes urbis Cap \& alibi. Floret Augufto \& fequentibus menfibus. Frutex glaber, bipedalis \& ultra. Rami alterni, divaricati, Aexuofi, rugofi, cinerei, ramulofi. 
Folia oppofita, petiolata, ovata, obtufufcula, fxpe acuminata, integra, glabra, fupra viridia, fubc:s pallida, pollicaria \& ultra.

Petioli ungviculares.

Flores axiliares, paniculati.

Pedunculi capillares.

Stipula \& Bracteæ albo-ciliatæ.

S. p. 2. S. Faponica:

Lycium japonicum. Flor. Japon. p. 93.

\section{AUGEA.}

Calyx Perianthium I-phyllum, canalicutatum, perfiftens, 5 partitum.

Lacinice ovatæ, obtufæ cum acumine, con-

Corolla nulla.

caval, flavefcentes, erectæ, lineam longæ.

NeCTARIUm I phyllum, bafi calycis infertum, germen cingens, 10-dentatum, brevisfimum.

Stam: Filamenta dec $\mathrm{m}$, dentibusNectarii inferta, capillaria, erecta, breviffima.

Antherce fubulatx, fulcatæ, erectx, flavæ, calyce breviores.

Pistill. Germen fuperum.

Stylus filiformis, erectus, flavus, brevifimus.

Stigma fimplex, obtufum, flavum.

PERIC, Capfula baccata, tereti-oblonga, obtufa, glabra, decemftriata, pulpofa, decemvalvis, decemlocularis, pollicaris. 
Semina tunica propria cincta alba, plurima, lenticularia, glabra, viridia.

Charact.generis: Cal. 5 partit. Cor. nulla. Neetarium decemdentatum Capfula 10.valvis, 10locularis.

Locus: Decandria, Monogynia poft Samydam.

Sp. A. Capenfis.

Crefcit in Carro juxta Bockland.

Floret Oetobri.

Radix annua, fufiformis, fibrola.

Caulis ftatim a radice in ramos divifus, herbaceus, glaber, erectiusculus.

Rami alterni, fimplices \& ramulofi, teretes, glabri, erectiufculi, pedales.

Folia oppofita, connata, teretia, fupra plana, obtua a, ereeta, glabra, fefquipollicaria.

Flores laterales inter folia, folitarii, bini vel tres, pedunculati, ereeti.

Pedunculus uniflorus, ungvicularis.

Tota planta, fucculenta, glabra, debilis.

\section{PLECTRANTHUS.}

Calyx Perianthium I phyllum, bilabiatum: Labium fuperius ovatum, latius, adfcendens; Inferius quadrifidum, acutum: Lacinice dur infima paullo longiores.

Corolla I-petala, ringens, refupinata:

Tubus compresfus, calyce longior:

Labium fuperius trifidum: lacinia media

$$
\text { N } 2
$$

ex. 



\section{GENERA NOVA}

\section{PLANTARUM,}

$\Rightarrow$

QUORUM

PARTEM DECIMAM

VENIA EXPERIENT. FACULT. MED. UPS.

\section{PR $Æ S I D E$}
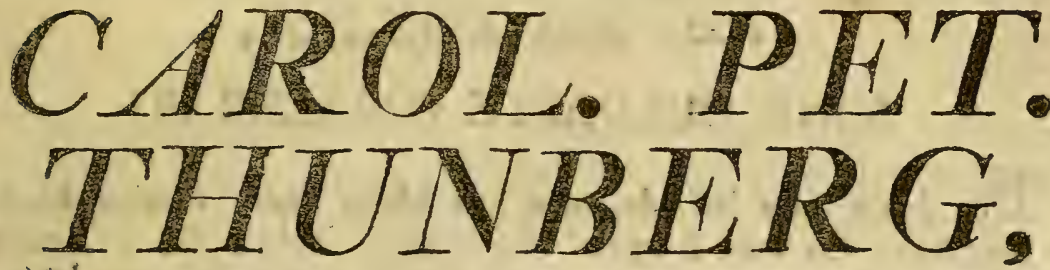

Equite Aurat. Reg. Ordo. de Vasa, Medic. Doct. Profess. Med. et Botan. Reg. et Ord. Acad. Ceasar. Naz, Curies. Reg. Scient. Londin Holm. Societ. Scient. Upsat, Philad. Patr. Holm. Berol. Nat. Scrut. Paris. Hafniens. et Halens. Hist. Nat, Lund. Harlem. Amsterd. Zeland. Nidrosieng. Ticinens. Ienens, Linn, Lonnin. Phys, Gótringens. Med.

Mataitens. Medic. et Nat. Studros. Edimburg. Membro; mec non Acad. Scient. Paris. Monspeliens. Agricult.

Paims. Medic. Lonidin. Scandinav. Flórentin. et Batavin. InN, Or. Correspond.

\section{PUBLICO EXAMINI SUBMITTIT}

WBRARE

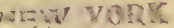
SPTESAL

\section{PETRUS BRANTSTRÓM, Stip. RFG. Helsingus,}

IN AUDIT. BOTAN. D. ॐ JUNII MDCCC.

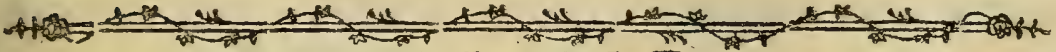
U P S A L I EE. Litteris Johr Fredr, Edman, Reg. Acad。Typogr。 


\section{RI RKOHERDEN}

ขтะ MO OCH REGNSJO FÖRSAMLINGAR, VALAREVORDIGE OCH HÓGLARDE,

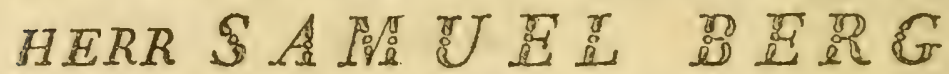

\section{SAMT \\ Ho̊GÁDLA FRU}

C要A

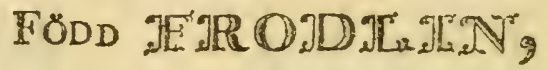

\section{MINE HULDASTE FÓRÁLDRAR!}

F or den mindre Jyfande, men kan hánda mera nyttige Medborgaren, den fom àt tyfa vâlgjerningar helgar fitt lif, tefe fällan Åreftoden. - Den lrulpnas ômma och tackfumma blick, den egna ådla tillfredsfaillelfen, fom dygden allena inger, fe dår! defs hela belóning. - Să, Mine Vơrdade Fo̊råldrar, e. ger, vid kảnlan af mina furbindelfer och min ofơrmoggenhet, jag åt EDRA vålgjerningar ej annat offer at låmna, ån ett hjerta, fom utgjuter fig i tyfta vålfignelfer.. - Bildade under $\mathrm{E}$ DER o̊mma upfigt, må det go̊ra mig vårdig, att fândigt få nåmnas EDER,

\section{MINE HULDASTE FO์RÅLDRAR。}




\section{GENERA NOVA PLANTARUM.}

SARCOPHYLLUS.

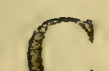

AL. Perianthium I:-phyllum, campanulatum, fucculentum, glabrum, s-partitum; Lacinice ova. tæ, obtuґx, margine revolutæ, æquales, ereetæ.

Corolla papilionacea. Vexillum obovatum, calyce triplo longius. Ala fubnaviculari. lanceolatæ, vexillo paulo breviores. Carina navicularis, vexillo æqualis.

STAM. Filamenta 10, diadelpha, longitudine corollæ. Anthere minimæ, oblongæ, incumbentes.

Pist. Germen fuperum, glabrum. Stylus unicus.

PeRIC. Legumen oblongum, acinaciforme, frpe attenuatum, femipollicare.

Characer Generis: Calyx regularis, 5-partitus. Legumen acinaciforme, acutum.

Locus: Diadelphia, Decandria poft Aspalathum. Sp. I S. carnofus.

Crefcit in Montibus prope Bayfalfo, in Cap-b. Ip. Floret Martio.

Frutex toius glaber, erectus, ramofisfimus, peda. lis \& ultra. 
Rami \& Ramuli fparfi, divaricati, incurvo-erecti, virggati, teretes, fubftriati, cinerei cortice molli. Folia fafuiculato terna, fesfilia, linearia, acuta, integra, glabra, carnofa, rugofa, patenti-incurva, ungvicularia.

Flores in ramulis terminales, folitarii, erecti, tan. dem reflexi.

\section{OEDMANNIÁ.}

Cal. Perianthium I-phyllum, tubulofo-campanulatum, lave, bilabiatum, glabrum, corolla duplo brevius. Lab. Superius maximum, bifidum; inferius fimplex, filiformi-fetaceim. Corolla papilionacea. Vcxillum maximum, pedicellatum, cordatum, ovatum, excifum cum mucrone obtufo, integrum, concavum, glabrum. Ale binz, pedicellatæ, dimidiatocordatz. oblongz, obtufisfima, integra, vexillo duplo anguftiores ejusdumque longitudinis. Carina dipetala; petala navicularia, pedicellata, femicordata, acuta, longitudine alarum.

Stam. Filamenta 10, connata in corpus compres. fum, apice libera, arcuata, longitudine corolla, antherce lineares.

PIsT. Germen fuperum. Stylus filiformis, arcuatus.

Stigma fimplex, ftaminibus paulo longius.

PERIC. Legumen ellipticum, glabrum. 


\section{Genera Nova Plantarum.}

Charafier Genericus: Cal. bilabiatus: Lab. fuperius bifidum, inferius fetaceum.

Nomen: in memoriam Rev. Viri, Dom. Sam. OEd. Man Theol, Prof. Upf. \& in Hiftoriam Na. turalem non minus quam plurimas alias Scientias optime meriti.

Locas. Diadelphia, Decandria, poft Borboniam. Sp. 1. Oedm. lancea. Acta Stockh, 1800.

\section{WIBORGIA.}

Calrx turbinato - campanulatus, lavis, quinquedentatus, finubus inter dentes rotundatis; lacinice acurx: dente infimo acuto, longiori. Corolla papilionacea. Vexillum obcordatum. Ale oblongx.

STAm. filamenta Io, diadelpha.

PIsT Germen fuperum.

Stylus unicus.

Peric. Legumen ovatum, turgidum, pedicellatum, transverfe fulcarum, altero margine membranaceo-alatum.

Characier Generis: Cal. Campanulatus, 5-dentatus: finubus rotundatis. Dens infimus acutus, longior. Legumen transverfe fulcatum, membranaceo - alatum.

Nomen: in honorem Botanic. Celeb. Dn. Wiborg, Hafn. Prof. meritisfimi.

Locus: Diadelphia, Decandria poft Spartium. Sp. 1. W. obcordata: foliolis glabris obtufis, ramis elongatis laxis. 
Crefcit in arenofis regionibus prope Picketberg. Floret Septembri, OEtobri.

Caulis fruticetcens, glaber, ramofus, tripedalis \& ultra.

Rami \& Ramuli alterni, elongati, Itriati, cinerei, laxisfimi, pubefcentes.

Folid alterna, breviter peciolata, glabra, ternata. Foiiola obovata, obtufa, fape excifa, brevisfime petiolulata, lineam longa.

Flores racemofi, lutei.

Racemi longisfimi, fubfecundi.

Pedunculi capillares, retroflexi, pubefcentes, vix lineam longi.

Calyx tenuisfime pubefcens.

Sp. 2. W. Fufca: foliolis glabris mucronatis, ramis virgatis ereetis.

Crescit in arenofis Swartlandia.

Floret Septembri.

Frutex rigidus, erekus, glaber, cinereus, ramofifismus, bipedalis \& ultra.

Rami \& Ramalli fparfi, flexuof, ftriati, iterum ramulofi.

Folia alterna, petiolata, ternata, glabra: Foliola petiolata, ovata, obtufa cum mucrone, integra, glabra, femiungvicularia.

Petioli capillares, fulcaci, folio breviores, petiolulis brevisfimis.

Racemi digitales floribus reflexs, lureis.

Pedunculi brevisfimi.

Planta ficcatione tota nigrelcit. 


\section{Genera Nova Plantarum.}

Sp. 3. W. Sericea: foliolis ramisque virgatis pubefcentibus.

Frutex ereetus, rigidus, ramofisfimus, totus glaber, bipedalis \& ultra.

Rami \& Ramuli alcerni, erecto-patentes, ftriati, flexuofi, virgati.

Folia alterna, petiolata, tota fericeo-pubefcentia, ternata: Foliola fesfilia, obovata, obeufa, lxpe retula, raro oblolete mucronata, lineam longa. Flores racemofi, lutei, cernui.

Racemi longi.

Pedunculibrevisfimi, pubelcentes, refexi. Voriat foliis magis \& minus fericeis.

\section{LEBECKIA.}

Cal. Perianthium turbinato - campanulatum, 5-parcitum: lacinice acutz, finubus rotundatis.

Corolla papilionacea. Vexillum obcordatum. Ale oblonga. Carina oblonga.

Stam. Filamenta 10, connata.

Pist. Germen fuperum:

Stylus unicus.

PERIC. Legumen cylindricum, fubcompresfum, polylpermum, glabrum.

Obf. Spartiis facie affinis, eisque ante adnumerata, differt præcipue Calyce diverfo \& Legumine.

Chara aer Generis: Calyx campanulatus: lacinizacuta, 
finubus rotundatis. Legumen cylindricum, fubcompresfum.

Nomen: in honorem D. LEBECr apud Societ. Ind. Commercior. Holland. in Java Officiar. Ce. leb. Præfidis olim Difcipuli omnium carisfimi. Locus: Diadedphia, Decandria, poft Sparcium. Sp. 1. L. Aphylla: ramis filiformibus virgatis laxis. Linn. Syft. veg. per Gmelin. p. 1088

Sp. 2. L. Contaminata: foliis fimplicibus lineari.filiformibus glabris, floribus umbellatis.

Spartium contaminatum. Linn. Syt. vegetab. per Gmelin p. ro88. Mantisf. p. 268.

Caulis frutelcens, angulatus, glaber, ereetus, parum ramolus, pedalis \& ultra.

Rami alterni, incurvi, fimiles.

Folia fparla, Cesfiiia bafi flavelcente, lineari-filiformia, mucronata, glabra, bafi villora, parula, bipollicaria, rarius aggregata.

Flores terminales, fubumbellati vel racemofi, rarius folitarii.

5p. 3. L. Sepiaria: foliis fimplicibus filiformibus glabris, foribus racemofis.

spartium fepiarium. Linn. Sylt. veg. per Gmelin p. I088. Spec. Plant. p. 995.

Crefcit in littore infra latus occidentale Leuweberg \& alibi in Cap. b. Ip.

Floret auguito.

Caules e radice fape plures, fimplices vel fuper- 
ne parum ramofi, teretes, glabriulculi, pedales.

Folia fpaŕa, fesfilia. fimplicia, fliformia, glabra, xa, patula, fuperne aggregata, bipollicaria.

Flores racemofi, lutei.

Racemus cernusus, digitalis \& ulera.

Legumen lineare, glabrum, bipollicare.

Sp. 4. L. Pungens: foliis fimplicibus obovatis, ramis ramulisque f́pinefcentibus tomentofis, floribus folitariis.

Crejcit juxta Olyfants rivier, inque Cannaland. Floret Novembri, Decembri, Januario.

Frutex erectus, tenuisfime tomentolus, ramofisfimus, pedalis \& ultra.

Rumi \& Ramuli alcerni, fubreticulati, teretes, obfo lete ftriati, cinereo-tomentofi, fpinefcentes. Folia alterna, brevisfime petiolata, obovita, obtufis fima, integra, tenuisfime pubefcentia, vir ungvicularia.

Flores in ramis [parfi, folitarii, lutei.

Legumen oblongum, falcatum, tomentofum, pollicare. Sp.5. L. Scorpizs. Linn. Syrt. Veg. per Gmelin p. 1089. Sp. 6 L. armata: foliis ternatis, ramis fpinefcentibus teretibus cinereis, floribus racemofis. Crefcit in Carro juxta Hexrivier Cap.b. fp. Floret Oetobri.

Frutex erectus, ramofisfimus, bipedalis \& ultra. Rami fparfi, fubfecundi, teretes, obfolete ftriati cinereo-albi, elongati, fpinefcentes, ramulofi ra. mulis brevibus fpinefcentibus. 
Folia ternata, peticlata, glabra. Foliola oblonga, ob. tufa, integra.

Flores in ramis racemofn, racemis longis.

Rp. 7. L. denfa: foliis ternatis villofis, foliolis con. volutis oblongis, floribus racemofis remotis.

Frutex ereetus, glaber, ramofus, bipedalis. Rami fparfi, aggregati, teretes, elongati, parum ramulofi, ereeti apice incurvo, glabri, (pitha. mæi \& ultra.

Folia alterna, petiolata, tenuisfime pubefcentia, ternata. Foliola Sesfilia, ovato-oblonga, convoluta, lineam longa.

Petiolus brevisfimus. Flores racemofi, remoti.

Sp. 8. L. Humilis: foliis ternatis villofis, foliolis lineari-oblongis, fioribus racemolis reflexis rarus incurvis.

Crefcit in Bockland Cap.b. Cp.

Floret Novembri, Decembri.

Caulis fruticofus, mox ramofus, glaber, vix pol. licaris.

Rami (parfi, plurimi, iterum ranulofi, decumbentes, incurvi, vix fpithamai.

Ramali filiformes, fimiles.

Foli:a alterna, breviter petiolata, tenuisfime pube. fcentia. Foliola fesfilia, oblonga, vix line. am longa.

Racemi incurvi, pollieares floribus reflexis. 
Sp. 9. L. Sericea: foliis ternatis fericeis: follolis linearibus, floribus racemofis.

Spartium fericeum. Linn. Syft. veg. per Gmel. p. 1089. Caulis fruteícens, ereetus, totus fericeus, bipedalis \& ultra.

Folia alterna, petiolata: foliola lineari-oblonga, obtufa, integra, ungvicularia, intermedio longiori.

Petiolus folio paulo brevior.

Flores racemofi, lutei, racemo longo terminali.

Sp. 10. L. Cytifoides: foliis ternatis villofis: foliolis oblongis, floribus racemofis.

Spartium cytifoides. Linn. Syrt. veg. per Gmelin. p. 1089. Suppl. p. 320.

Ebenus capenfis. Linn. mant. p. 264.

Caulis fruticofus, erectus, villofus, ramofus, bipe. dalis \& ultra.

Rami alterni, fimiles.

Folia alterna, petiolata, ternata, tenuisfime pubefcentia: Foliola oblonga, inferne attenuata, obtufa cum acumine, integra, fubtus carinata, fupra canaliculata, ungvicularia.

Petioli filiformes, folii longitudine. Flores racemofi, fubfecundi, lutei. Pedunculi femiungviculares.

Legumen lanceolatum, acutum acumine curvo, glabrum, fefquipollicare. 


\section{RAFNIA.}

CAL. Perianthium ringens, bilabiatum: labium fuperius bifidum ; inferius divaricatum, triffdum:dente medio anguftiori,filiformi-fubulato. Corolda papilionacea. Vexillum cordatum; Ala ova. זæ. Carina oblonga, acuta.

Stam. Filamenta 10 , connata.

Pist. Germen fuperum.

Stylus unicus.

PERIC, Legumen lanceolatum, compresfum, glabrum. $\mathrm{ObJ}$.

Rafnix genus optime nofcitur Calyce a Crotalaria:

Charager generis. Cal. bilabiatus: inferioris labii dente medio filiformi-fubulato.

Nomen: in honorem D RAFN, Asfesf. \& Botanic. inclytisfimi.

Locus: Diadelphia, Decandria ante Crotalariam. Sp. I R. amplexicaulis: foliis amplexicaulibus orbiculatis: caulinis alternis, flora. libus oppofitis coloratis.

Cratalaria amplexicaulis. Linn. Syft. veg. per Gmelin. p. 1094. Spec. plant, p. I003.

Frutex ereetus, glaber, ramolus.

Rami alterni, breves, fubfimplices, teretes, eręti.

Folia caulina inferiora alterna, cordata, orbiculata, excifa, integra, glabra, venofa, pollicaria; fuprema bracteiformia, fimilia, fed oppofita \& colorata, flavelcentia.

Flores verfus apicem axillares, folitarii, peduncula. ti, lutej. 
Sp. 2. R. elliptica: foliis ovato-ellipticis acutis, cau. linis alternis, floralibus opporitis. Frutex erectus, totus glaber, ramofus. Rami alterni, angulati, ereeti. Folia caulina inferiora alterna, fesfilia, elliptica feu ovata, utrinque attenuata, acuta, integra, glabra, fefquipollicaria; floralia anguftiora \& minora, oppofita, vix colorata

Flores axillares, lutei.

Legumina glabra, cernua.

Sp. 3. R. cuneifolia: foliis cuneiformi-obovatis, ramis angulatis, floribus terminalibus.

Spartium ovatum. Berg. Cap. p. 197.

Caulis fruticofus, erectus, bipedalis, ftriatus, glaber, fufcus, ramolus.

Rami \& Ramuli alterni, angulati, fubancipites, glabri, incurvato:erecti.

Folia alterna, fesfilia, obovata, acuminata, integerrima, crasfiufcula, erecta, approximata, internodiis longiora, ungvicularia; inferiora majora, magis fubrotunda; fuperiora minora, anguftiora. Flores terminales, pedunculati. Pedunculus uniflorus, vix lineam longus. Sp. 4. R. triflora: foliis ovatis glabris, ramis angulatis, pedunculis ternis unifloris.

Crotalaria triflora, Linn. Syft. veg. per Gmelin. p. I095. mant. p. 440.

Crefcit in fummis lateribus Taffelberg. Floret Februario', Martio. Frutex erectus, glaber, totus ramolus. 
Rami angulati, fufci, ereeti, fubfimplices.

Folia alterna, fesfilia, ovata, mucronata, integra, glabra, nervofa; inferiora majora, fefquipollicaria, usque palmaria; fuperiora minora.

Pedunculi tres, uniflori, folio breviores.

Legumina oblonga, inflata, glabra, pendula.

Sigcatione nigrelcit.

S. 5. R. oppofita: foliis lanceolatis alternis, pedunculis lateralibus.

Liparia oppofita. Linn. Suppl. Synt. veg. p. 554.

Crotalaria oppofita. Linn. Syft. veg. per Gmel. p. 1094. Cytifus Capenfis. Berg. Pl. cap. p. 217.

Caulis fuffruticofus, fubfimplex vel fummo apice ra. mofus, flexuofo-erectus, teres, totus glaber, bipedalis.

Rani capillares, brevisfimi.

Folia caulina alterna, fesfilia, oblonga, acutiufcula, integra, glabra. imbricato-erecta, pollicaria; ramea \& floralia oppofita, minora.

Flores axillares, pedunculati, folitari, lutei. Pedunculi folio muitoties breviores.

Sp. G. R. axillaris: foliis lanceolatis alternis oppofitisque. floribus terminalibus.

Caulis fuffruticofus, erectus, fummo apice ramofus, totus glaber, erectus, compresio-angulatus, bipedalis.

Rami alterni, fimiles, breves, raro divifi.

Folia caulina alterna, fesfilia, elliptico-ovata, acu-

ta, integra, glabra, erecta, pollicaria. Ramea \& foralia oppofita, fimilia. 
Flores axillares inter folia oppofita, pedunculuti, lu. tei, ereeti.

Leguinina lanceolata, cernua.

Sp. 7. R. angulata: foliis lanceolatis alternis, pedunculis lateralibus, caule angulato.

Caulis fuffruticofus, fimplex, ereetus, trigonus, totus glaber, pedalis \& ultra.

Folia alterna, fesfilia, oblonga, obtufa cum mucrone, integra, glabra, imbricato-ereeta, pollicaria.

Florés axillares, colitarii, pedunculati.

Pedunculi trigoni, folio vix breviores, fruktiferi refiexi. Legumina lanceolata, compresfa, pollicaria.

Calycis finus in hac \& oppofita acuti, nec adeo divaricati ac in ceteris.

S. 8. R. Spicata: foliis lanceolatis alternis, floribus axillari-racemofis.

Caulis fubherbaceus, incurvato-erętus, fubfimplex, totus glaber, pedalis.

Folia alterna, fesfilia, lanceolata feu ellipticolanceolata, acuta, integra, glabra, pollicaria.

Flores in apice caulis axillares, racemofi racemo foliofo, lutei.

Variat foliis anguftioribus \& latioribus, tamen femper lanceolatis.

Differt a Crotalaria juncea: florum 1pica foliofa. Sp. 9. $K$. anguftifolia: foliis lanceolatis alternis, pedunculis lateralibus, caule tereti.

Caulis frutefcens, teres, purpurafcens, ereetus, gla. ber, ramofus, pedalis. 
Rami alterni, divaricati, glabri, virgati.

Folio alterna, fesfilia, inferne anguetata, lanceolata, integra, glabra, eręto patentia, pollicaria.

Flores in fummitate ramorum axillares, unifori.

Sp. 10. R. filifolia. foliis lineari-lanceolatis alternis, floribus axillaribus.

Crefcit in montibus Hottentots Holland C. B. S. Floret Decembri, Januario.

Caulis frutefcens, teres, ftriatus, totus glaber, ramofus, pedalis \& ultra.

Rami fparfi, patentes, teretes, friati, fubfimplices. Folia alterna, fesfilia, lineari lanceolata, acuta, integra, glabra, ereeta, pollicaria.

Flores fparfi, imprimis verfus apicem ramorum plus vel minus frequentes, pedunculati, lutei. Pedunculi longitudine folii vel paulo longiores. Legumina oblonga, ftylo longo curva, acuminata, gtabra.

Variat r. ramis magis diffufis \& ereetis.

2. floribus paucioribus vel copiofioribus.

3. foliis anguftioribus \& latioribus.

Sp. II. R. Retroflexa: foliis obovatis, ramis reflexis retroflexisque.

Caulis fruticolus, totus glaber, erectus, ramofisfimus, bipedalis:

Rami\&Ramulialterni,Hexuofi, reflexi \& retroflexi nodofi. Folia fesfilia, oppofita, obovata, obtufa, integra, glabra, ungvicularia.

Flores in fummis apicibus axillares, brevisfime pedunculati, lutei. 


\section{Genera Nova Plantarum.}

Siccatione nigrefcit.

Sp. 12. $R$. erecta: foliis oblongis, floribus lareralibus, caule erecto.

Caulis fruticofus, teres, totus glaber, erectus, ra. mofus, pedalis \& ultra.

Rami alterni, fimiles.

Folia alterna, fesfilia, ovata, integra, glabra, ungvicularia.

Flores axillares, pedunculati.

Sp. 13. R. diffufa: foliis ovatis glabris, caule decumbence.

Radix fuffiformis, alte defcendens.

Caules e radice plures, herbacei, teretes, glabri, de cumbentes, ramofi, inæquales, usque pedales. Rami \& ramuli alterni, fecundi, filiformes, diffuf: Folia alterna, fesfilia, fimplicia, ovata, acuta, integra, glabra, patentia, ungvicularia.

Flores axillares, brevisfime pedunculati, folitatii, lutei.

Legumen pedicellatum, oblongum, ftylo recurvo coronatum, glabrum, femipollicare. 


\section{THESE: \\ I.}

Admirandus, qui inter fingula naturce regna conjpicitur nexus, Jummam Creatoris Sapentiam luculentisfime teftatur.

II.

Per hunc nexum credere non fas eft, Creatorems Syftema nature, in formatione rerum, condere voluisfe.

\section{III.}

Inter ommes Hifiorice Naturalis partes, ea om. nino primum locum obtinet, quce Regni Vegetabilis incolas familiares nobis reddit.

IV.

Quo plura inveniuntur nova Genera Plantarum, eo major difficultas oritur, diffinctiones corum rite determinandi.

\section{V.}

Clasfis Pentandria E quod ad numerum civium छ quod ad ufum Medicum, pre reliquis maximam noftram attentionem meretur.

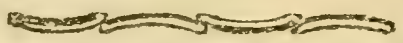




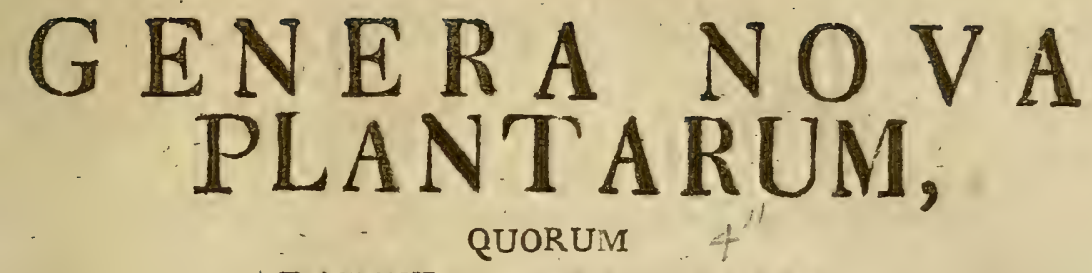

PARTEM UNDECIMAM

CONSENSU EXPERIENT. FACULT. MED. UPS.

\section{PR $Æ S I D E$}
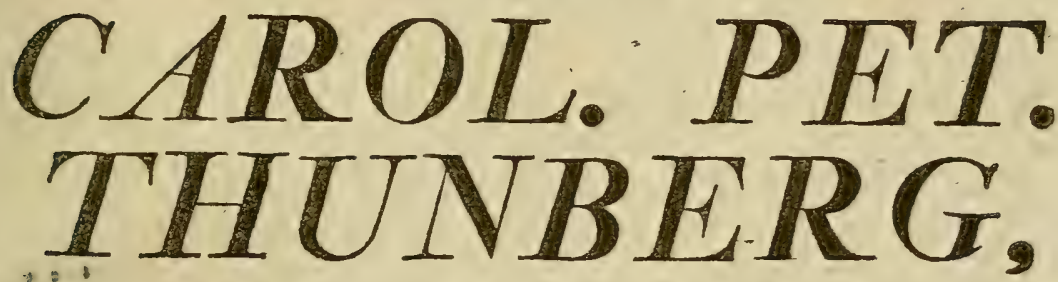

Equite Aurat. Reg, Ord, de Vása, Medic. Doct. Profess. Med. et Botan. Reg. et Ord. Acad. Cefsar. Nat; Curios. Reg. Scient. londin. Holm. Societ. Scient, Upsal. Puilad. Patr, Holm. et Civ. Berol. Nat. Scrut, Paris. Hafn. et Haleng. Hist. Nat, lund, Harlem, Amsteld. Zeland. Nidrosiens. Ticinens. Imnens. Linn. Londin. Pays. Góttingens. Med. Matritens. Medic. et Nat. Studios, Edimburg. Membroji nec non Acad. Scient. Paris. Monspeliens. Agricult.

Pakis. Medic, Londin. Scandinav. Florentin. et Batavin. Ind. Or. Correspond.

PUBLICÆE CENSURÆ SUBMITTIT Samuel Wallner

Stip. Gutherítut UPLANDUS.

IN AUDIT. BOTAN. D. IV JUNII MDCCC.

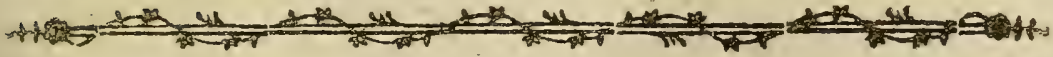
U P S A L I $\mathrm{FE}$.

Litgeris Joh. Fredr. Edman, Reg. Acad. Trpogr. 
Pedunculus uniflorus, teres, tomentofus, brunneus, pollicaris.

Calyx brunneo-tomentofus, apice ante explicationem floris audus calyptra, calyci fimili, caduca.

Corolla incarnata.

Sp. 2. H. pedunculatus : foliis ovatis tomentofis, floribus axillaribus, pedunculis folio longioribus. Caulis frutefcens, ereetus, cocus tomentofus. Folia fimplicia, brevisfime petiolata, ovata, mucro. nata, comentofa villo ferrugineo nitenti, inie. gra, patentia, ungvicularia.

Filores axillares, pedunculaci.

Fedunculi filiformes, ferrugineo-tomentoli, ereet, fubbifori, interiores digitales, fuperiores fenfim breviores, folio femper longiores. Calyx tomentofus, ferrugineus.

Corolla incarnata.

Sp. 3. H. Sericetus: foliis obovatis fericeis, floribus axillaribus, pedunculis longitudine folit. Caulis fruticofus, fulcus, teres, glaber, erectus, pe. dialis \& ultra.

$\mathbb{R} a m s i$ fparfi, frequentes, ramulis filiformibus; flexuofis, aggregatis, virgatis, tenuisfime tomentofis.

Folia fimplicia, fparfa, fesflia, obovata, mucronata, integra, tenuisfime albo fericea, ereEto-pacula, ungvicularia:

Flores axillares, pedunculati, albi.

Pedunculi uni \& calyx tomentofi, longitudine folii. Sp. 4. H. yloucus: foliis fimplicibus ovatis fubtus co. men. 
mentofis, floribus axillaribus, pedunculis folio longioribus.

Frutex erectus, ramofisfimus.

Rami alterni, teretes, nodulof, fuperne angulati, glabri, erecti.

Folin alterna, brevisfime petiolata, ovata, obtufa, integra margine revoluto; fupra fulcata, glabra; fubtus coftaca, fericeo-tomentofa, imbricato-erecta, ungvicularia \& vitra.

Flores axillares, folitarii, pedunculari, purpurei. Pedunculi filiformes, villofi, folio longiores, pollicares.

Calyx tomentofus.

$s_{p}, j$. H. cane fens: foliis ovatis tomentufis marginatis, Aoribus axillaribus, pedunculis folio duplo brevioribus.

Crefcit: in Hantum.

Floret Oetobri \& lequentibus menfibus.

Frutes ereetus, cinereo.fufcus, ramofus.

Rami \& ramuli teretes, nodulof, fubtomentofi, divaricato-erecti.

Folia alterna, fimplicia, fubfesflia, ovato-elliptica, acuta, integra, marginata, incano-tomentora, un. gricularia.

Flores axillares, pedunculati, Colitarii vel bini. Peduncali teretes, folio duplo breviores, unifor: Calyo incanus, tenuisfime tomentofus. Legumen lanceolatum, fylo longo perfiftente acu. minatum, compresfum, tomentofum, pollicare.

$$
\text { P. }
$$


Sp. $\%$.H. cordatus: foliis ovatis hirfutis.

Caulis fruticofus, tocus hirfutus, ereetus.

Rarni fimiles.

Folia alterna, fesfilia vel brevisfime petiolata, fubcordata, ovata, acuta, integra, nervofa, tota utrinque hirfuta, imbricata, ungvicularia. Flores axillares, fubfolicarii, breviter pedunculati. Calyx valde hirfutus.

Sp. 7· H. obcordatus: foliis ternatis: foliolis obcordatis. Spartium Sophoroides. Berg. Plant. Cap. p. 198. Cazlis fruricofus, totus glaber, erectus, ramofus, bipedalis \& ultra.

Rami \& ramuli alterni, fulcati, erecti, fubfaftigiati. Folia alterna, petiolata, glabra, ternata: foliola fub. fesfilia, obovata, truncato-obtufisfima cum nu. crone, integra, nervofa, convoluta, ungvicularia.

Petiolus femiungvicularis.

Flores racemofi, in apice ramulorum.

Pedsncull ungviculares.

Calyx glaber.

Corolla incarnata.

Legusidina linearia, compresfa, glabra, polyfperma, digitalia.

Sp. 8. H. Capenfis: foliis pinnatis: pinnis lanceolatis tomentofis.

Sophora capenfis: Linn: Syft. veg. XIV. p. 392. Sophora oroboides. Berg. Plant. Capenf. p. 42 . 
Africanis: keureboom, wilde keur.

Crefcit ad foslas rivorum vulgaris, prope Cap, ad keurebooms rivier, in Hautniquas copiofis: fime.

Floret Novembri \& fequentibus menfibus ad Junium usque.

Arbor orygalis \& ultra. Rami teretes, tomentofi, erecti. Ramuli fparfi, fimiles, virgati. Folia fparfa, petiolata, pinnata cum impari: pinne octojugz vel ultra, brevisfime petiolulatx, lanceolatæ, mucronatæ, integræ, utrinque to. mentofx, fubtus pallidiores, patentes, ungviculares.

Petiolas filiformis, fubpollicaris; Petioluli brevisfimi, impar longior, omnes tomentofi. Flores in ultimis ramulis fubterminales, axillares, pedunculati, pedunculis vix ungvicularibus.

Calyx tomentofus.

Corollse incarnatx, glabræ.

Legumina enfiformia, compresfa, tomentofa, digitalia.

\section{HALLIA.}

CaL. Periontibium 5-paritum: lacinlia æquales, lan. ceolatæ, ereetz.

Corolla papilionacea. Vexillum ovatum, obtufum. Ale oblongx. Corina compresโa, navicularis, obovata. 


\section{I56}

Stam. Filamenta io, quorum g connata in cylindrum. Antherx fubrotundx.

Pust. Geribes fuperum, ovatum, glabrum.

Stylits fubulatus.

Stigna fimplex.

Penic. Legumes ovatum, monofpermum.

Ob. Genus Hedyfaro proximum, medium inter Onobrychides \& Alhagi Tounnesortr.

Character Generis: Calyx 5.partitus, regularis. Legumen monofpermum.

NOMEN, in honorem D. Birg. Hall Hiftor. Na. tur. Cultoris indefels. Med. Doet. \& Praet. feliciss.

Locus: Diadelphia, Decandria, ante Hedyfarum. sp. I. H. alsta: foliis oblongis glabris, ftipulis decur. rentibus, caule alato.

Crefoit in collibus extra urbem Cap. Fioret Martio, Aprili.

Castis herbaceus, fæpe plures e radice, quorum quidam patuli, cotus glaber, ramofus, compresfus, alatus, laxus, incurvo.e. rectus, fefquipedalis.

Rami alterni, fimiles, virgati, elongati, fubfimplices. Folra alterna, brevisfme petiolata, filsuræ ripula.

rum inferca, lanceolaco-ovata, acuta, integra, oblique lineata, glabra, ungricularia.

Stipule fesfiles, convolutz, apice bifidr, folio paulo breviores.

Flores in apice ramorum, racemol, folitarii. 
Pedunculus fore brevior.

Sp. 2. H. virgat : foliis lanceolatis mucronatis glabris, pedunculis uniforis folio brevioribus.

Caulis herbaceus, teres, ftriatus, totus glaber, bipedalis, ramofus.

Rami inferne prope radicem tres vel guatuor, elongati, fimplices \& bifidi, cauli fimiles.

Folia alterna, breviter petiolata, lanceolara, acuminaro-mucronata, incegra, nervola, glabra, pollicaria.

Stipule dux, lanceolatæ, acuminatæ, integræ, gla. bra, erecta, longitudine petioli, lineam lon. ga.

Flores axillares, pedunculati, folitarii.

Peduncali Atipulis duplo foliisque multokies brevi. ores.

$S_{p}$. 3. H. flaccida: foliis lanceolatis mucronatis glabris, pedunculis unifloris longitudine folioram.

Comlis herbaceus, decumbens, fliformis, fuperne trigonus, ftriatus, totus glaber, fexuofus, pecalis \& viltra, ramofus.

Rami alterni, fimiles, patentes, fimplices.

Folica alterna, brevicer petiolata, lanceolata, mu.

cronata, integia, glabra, ungvicularia.

Stipulc binæ, ovatæ, mucronatæ, patenti.reflesæ, longitudine petioli feu femilineam longr.

Flores ex axillis foliorum, pedunculati, folitarii. Pedunculi capillares, unifori, flexuofi, folio vir longiores.

Brneter binx, oppofita, minutisfimæ in pedunculo fub flore. 
Corolla purpurea.

Sp. 4. H. cordata: foliis cordatis oblongis acutis glabris, pedunaulis longitudire folioram. Glycine monophylla. Linn. Syf. veg, per Gmel. p. IIO5. mant. p. IOI.

Hedyfarum cordatum. Azt. Nov. Upfal. Vol. 6. p. 41. Tab. I.

Sp. 5. H: afarina: foliis cordatis fubrotundis mucronatis villofis, pedunculis longitu. dine foliorum.

Crotalaria Afarina. Berg. Plant. Capenf. p. 194. Folia alterna, brevisfime petiolata, cordata, ovato-fibrotunda, mucronata, integra, villofa, venofo-reticulata, inzqualia, ungvicularia.

Stipule binæ, ovatæ, acuræ, reiexæ, femilineam longæ. Plores axillares, pedunculati.

Pedunculi capillares, unifori, longitudine folii.

Bractex oppofita, minutisfima in pedunculo fub flore. Sp. 6. H. imbricata: foliis cordato-ovatis convolutis imbricaris, floribus axillaribus fesfilibus.

Hedyfarum imbricatum. Aet. Nov. Upr. Vol. 6. p. 42. Hedyfarum imbricatum. Linn. Supplem. Syft. p. 330, 33\%. Syft. Veget. per Gmel. p. I1 22.

\section{OLINIA.}

Car Periantbizm tubulofum, fubcampanulatum, glabrum, lineam longum, 5.dentatum: dentes rotundati, brevisfimi. 
Corolla 5-petala. Petala apici calycis inferta, linearia, obtufa, alba, intus fupra bafin fubvil. lofa, patentia, lineam dimidiam longa.

NeCtaria: fquamulae 5, raro 6, obtufx, bafi petalorum infertæ, antheris fuperimpofitæ, fubconcavæ,

fupra convexiufcula, pallide flavefcentes. Stam. Filamentic 5, raro 6, brevisfima, fere nulla, calyci lub nectariis inferta.

Authere parvæ, globorx, didymæ, Alavæ. Pist. Germen fuperum, concavum, glabrum. Stylus brevisfimus.

Stigma incrasfatum, obtufum, bifidum. Peric. Capfula calyce perfiftente coronata, oblonga, obfolete pentagona, 5 -fperma.

Sp. 1. O. cymofa. Sideroxylon cymofum. Prodr. Flor. Cap. p. 36. Linn. Sylt. Veg. per Gmel. p. 39\%. Character Generis: Capful. 5-gona, 5-fperma.

Nect. fquam. 5 , ancheris fuperimpofitz! Nomen: in honorem Dn. DoEt. Joh. Henr. Olin, Botan. celebr. ad Muf. Nat. Acad. Upf. Ama. nuenf.

Locus: Pentandria, Monogynia poft Sideroxylon. 


\section{THESES,}

I.

Cujuscumque homines fuerint ftatus \& conditionis, Botanices ftudio non fine fruktu \& fe dicare posfunt \& debent.

\section{II.}

Cognitionem Plantarum cultumque non minus rei cujuslibet familiaris ufui, quam publico bono inServire contendimus.

\section{III.}

Clasfis Icofandria fruktus continet fucculentos, eosque boni faporis atque ad viktum utilisfimos.

\section{IV.}

Quamdiu homines venatui fuere dediti, tamdiu etiam Botanices ftudium flocci fecerunt.

$\mathrm{V}$.

Pauca Infeeta ad homines alendos, multa ad cxtera animantia conferunt.

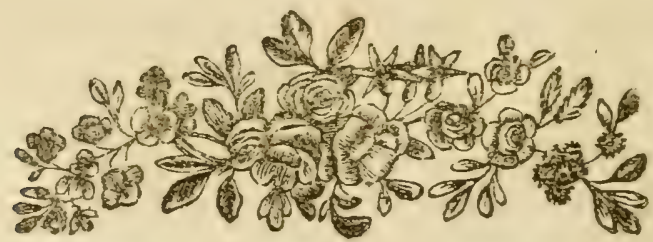




\section{GENERA NOVA PLAN T.A R U}

\section{QUORUM \\ PARTEM DUODECIMAM.}

CONSENSU EXPERIENT. FACULT: IIED. UPS.

\section{PR SIDE}
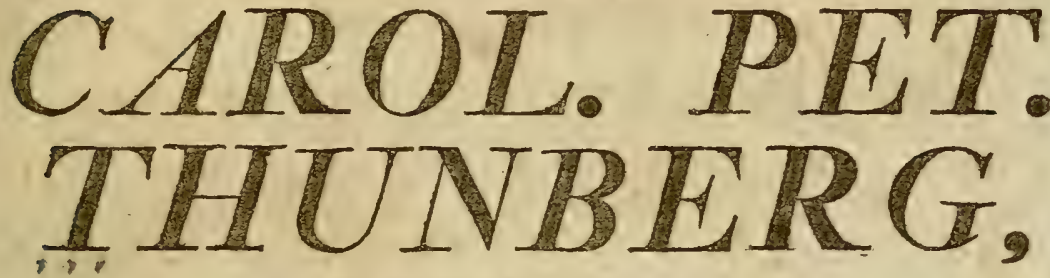

Equite Aupat. Reg. Ord, de Vasa,

Misatc. Doct. Profess. Med. et Botan, Reg. et Ord. Acad. Casar. Nat. Curios. Reg. Scient. Londin. Holls. Societ. Scient. Upsal. Puilad. Patr. Horm.jet Civ, Orcon. Find. Ezrol. Nat. Scrut, Paris. Hafn. et Halent.

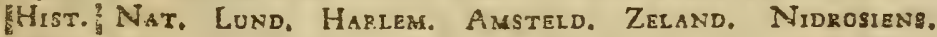
Ticiners, Iznens. Linn. Londin. Prys. Góttingens. Med. iMatritens. Mrdic. et Nat. Srudios. Fdimburg. Membro;

fage non Acad, Scient. Paris. Monsteilens. Agricult.

Paris. Medic. Londin. Scandinav. Florantin. ex Batavin, IND. OR. CORRESFOND.

PUBLICE CENSURR SUBMITTIT ANDR. GUST. SALMENIUS. Stipend. Victorin. VESTROG.

IN AUDIT. BNTAN. D. IS DECEMB. MDCCC.

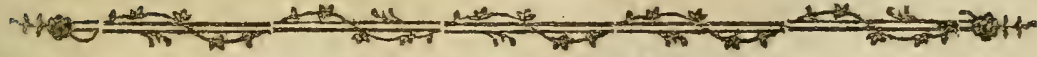
U P S L I I S ,

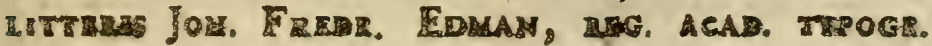




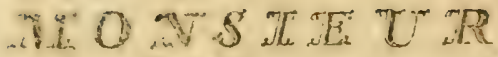

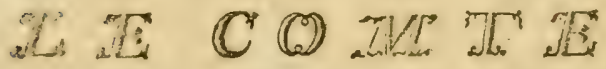

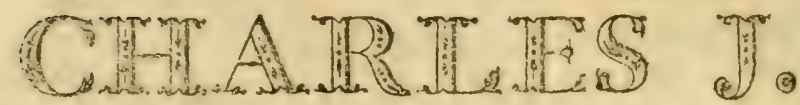

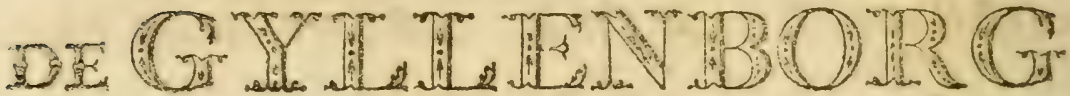

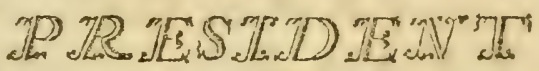

ET

CHET ALTER DE LORDRE DE L'ETOTLE POLAIRE DE SA IIAYESTE' LE

ROI DE SVEDE.

$\mathscr{R}$

egardez je TrOLis fapplie, d"un opil gracicux, que j'ofe mettre di uos pieds le peiti ourrage Acadenique, que j'ainhonnen de VOUS offirir. Les boines graces dont il VOUS a plit combler les objets / 5 pliar clers ì mons coster; difsipent toute crainte de VOUS déplaire, en mettint VOTRE illujose non d̀ la tête de ces feuilles, qui font le pienzier fruit de anes eludes Accileniques. Permetiz qu'elles mar. rquent, ¿̀ quicongue los voutra binis lire, les refpectueux jentimens de

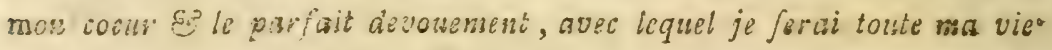

\author{
MTONSW TUR \\ VOTRE \\ $\sim$ \\ tres lumbie Eo trps \\ oheifsaut ferviteur. \\ ANDRE GUST. SAL.VENIUS.
}




\section{DOMINO}

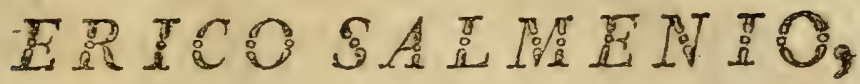

MERCATORI ESTUIIATISSIMO

$$
\text { PRECLARISSIMO DOMINO }
$$

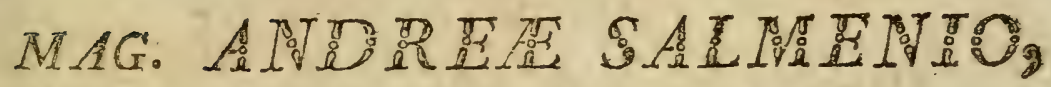
RECTORI SCH. MERITISSIMO. ADIIODUII REVERENDO

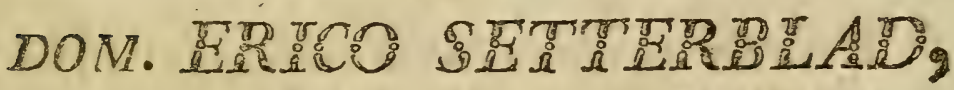
PASTORI XN EKBY VIGILANTISSIMO,

$$
\text { DI I N N ISS IIMO. }
$$

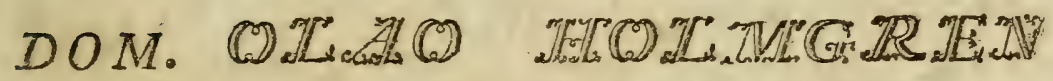
PATRONO OL. PROPENSISSTMO. $P A T R U I S$ ATQUE CONSANGVINEIS DILECTISSIMIS.

Primitias Sndzorm 


\section{THESES.}

I.

Maximam certe Scientia Botanicæ utilitarem attulerunt defcriptiones Generum ita diez Sciagraphicæ.

II.

Motus in plantis fic diEtis fenfitivis obfervatus, irritabilitatem arguit, „non Senfationem.

III.

Naturam nunquam Saltus facere, fed aucta fenfim affinitate disfimilia inter fi invicem conjungere; plurima in omnibus regnis natura obvia teitantur exempla.

$$
\text { IV. }
$$

Sua agricultura incrementa cafibus Expius debet ipf faventibus isdemque fortuitis.

V.

Sola nominum in memoris eongefta feries aque parum in Botanica, ac in aliis difciplinis, verum fciem. iæ cultorem probat.

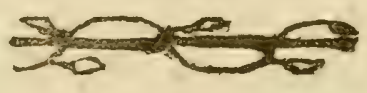




\section{GENERA NOVA \\ PLA T A R U M}

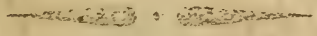 \\ ROSENIA.}

CATYx polyphyllus, imbricarus: Folioli orata, obtefa, integra, glabra, hyulino lcariola: linea longitadinali brunnea opaca.

Corolda radii ligulata, convoluta, fornicara; Difa tabulofa, s.fidn, hermaphrodita.

STAM. Filmernta quinque, brevisfima. Antbere in Cylindrum coaliz:

Pistiz. Stylus filiformis.

Stigma bifidum.

PER. Receptacubum paleaceum. Polece lanceolate, membranacex.

Sermen angulatum, glabrum.

Pappus capillari-paleaceus, duplex: radii plerumque duo interiors, fetacei, longiores; exteriores capillares, in plures phalanges bafi connati.

CHARACTRR Generis: Receptaculum paleaceum. Pappus duplex, paleaceus: Corolls radiata.

Locus: Syngenefia , Polygamia Superflua, poft Cotulam. NOMEN: in Honorem Virorum, fraternitate, nomine \& meritis illuftrium D. Nicol. Rosèn à RQ- 
senster:y, Deimum Botanices, dem Medi. cinze Praeticze in hus Actemia Rrofosforis ac S. R. Meveftat. Archigrei \& Isquic de Stella polari; Nec non I., Wherh. Rosme. nuar, Medigin, pract. In Acadomia Catol. Dundonfi Proresforis a Equltis de Stella polari.

SP. M. R. glandulofa.

Crefoit in interioribus Cupit b. Crei regionlbus. Gadis finticofus, teres, glaber, Aloxnotus, eredus, mamofistinaus, bipedilis \& ulara.

Rami \&o Romole altorni, terni \& umbellato-quaromi. divaricato pacentes, Ariuti, filligiati.

Ramali lacerales, brevisfini, Lolis recti.

Folen fublatciculato-epproximatn, Cesnlia, ovasa, obtus

fa, intogr: , concaviufoula, marrine imprimis glan.

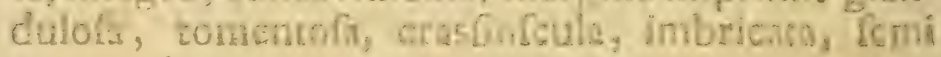
unguicularia.

Gopicule teminalin in ulcinis ramulis, folicaris.

\section{DORIA}

Carym polypiyllus, fumplen: follola aqualis.

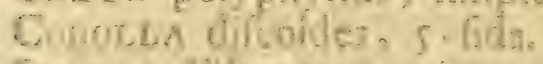
SIA:S. WWwnthe quinque, filiformia. Andiene connaca in cylindrum.

Dr:1, singis fillfownis. Simping bifiliane

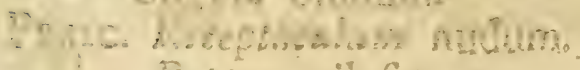

$$
\text { Pesposs pilofis. }
$$


ChapaCter generis: Receptaculums nudum. Pappus pilofus. Calyx rqualis fimplex. Corolla difcoidea.

Locus: Syngenefia, Polygamia fuperflua, port $\mathrm{Ci}$ nerariam.

$\mathrm{Ob}$. Vix alia nota, quam abfentia radii differt a $\mathrm{Ci}$. nerarin; hac vero nota, fi vel unica esfer, fatis videtur fufficiens ad feparanda duo Genera fatis ampla.

SP. I. D. nives: foliis linearibus tomentofis, capiculis pendulis.

Caulis frucelcens, totus niveo lanatus, ereetus, ramofus, pedalis \& ultra.

Rami \& Ramusli fparfi, filiformes, elongati, cau-

li fimiles.

Folia fparfa, fesfilia, linearia, integra, niveo to. mentofa, erecto patentia, unguicularia.

Capitula terminalia, folitaria vel bina, niveo-tomentofa.

Sp. 2. D. undulata: foliis ellipticis undulatis glabris, capitulo folitario.

Crefcit in Bockland.

Floret Novembri, Decembri.

Radix fibrofa, annua.

Foliu radicalia, plurima, petiolata feu ellipti$\mathrm{ca}$, inferne in petiolos attenuata, crifpa margine revoluto, glabra, erecta, digitalia. Petioli folio longiores, feu fubpalmares, lineares, friati, fubvillofi.

$$
\text { Q } 2
$$

Scts- 
Cantis folinarius vel duo, teres, glaber, finplex, erectus, fesquipedalis.

Bractee aliquot fparfa in caule, fenfim minores. Capitulazu terminale folitarium.

SP. 3. D. alatn: foliis ovatis decurrentibus glabris; capitulis paniculatis.

Cineraria alata. Linn. Syst. veg. per Gmelin p. rz39 Suppl. p. 3 I4.

Coulis fruticofus, totus glaber, a foliis alatus. eretus, ramofus, pedalis \& ultra.

Rami \& Ramuli alterni, flexuofo-erecti fimiles. Folia fparfa, fesfilia, decurrentia. ovata, obtu. fisfima, lacero-fubdenticulata, glabra, erecto.patentia, unguicularia.

Capitula pariculata, glabra. Panicula terminalis, fimplex. Pedunculi capillares, glabri.

Sp. 4. D. perfoliata: foliis amplexicaulibus cordato.o vatis glabris, capitulis folitariis.

Cineraria perfoliata. Linn. Syft. veg. per Gme. lin p. 1240. Suppl. p. 375 :

Caulis herbaceus, angulatus, glaber, erectus, ramofus, pedalis \& ultra.

Rami \& Rawuli alterni, fimiles, faftigiati. Folia amplexicaulia in ramificationibus, alcerna, cordata, ovata, acuminata, undulata, gla. bra, infima fesquipollicaria, fuperiora fenfim breviora.

Copitula in ultimis ramulis elongatis terminalia; folitaria. 
SP. 5 D. denticulata: foliis lanceolatis denticulatis glabris, capitulis paniculatis.

Cineraria denticulata. Linn. Sylt. veg. per Gmelin p. 1230 Suppl. p. 275.

Caulis herbaceus, totus glaber, ceres, ftriatus. erectus, ramofus, pedalis.

Rami \& Ranuli dichotomi, teretes \& filiformes, erecti, glabri faftigiati.

Folia radicalia \& in infimo caule approximata, plurima, fesfilia, elliptico-lanceolata, acuminata, denticulata, margine denticulato crifpo revoluto glabra, ereeta palmaria; caulina in ramificationibus lanceolata, pollicaria fenfim minora.

Capitula in ultimis ramulis paniculatis terminalia.

SP. 6. D. Serrata: foliis obovato-oblongis ferratis fubtus tomentofis, capitulis ter. minalibus.

Caulis herbaceus, angulatus, ftriatus glaber, flexuofo-ereetus, fuperne ramofus, podalis.

Rami alterni, filiformes, cauli fimiles, fubfa. Atigiati.

Folia radicalia, petiolata, obovato-oblon ferrata, fupra glabra, fubtus tomento. $\mathrm{fa}$, ereeta, digitalia, in petiolos attenuata; Caulina alterna, fenfim minora.

capitull in ramulis terminalia, Solitaria. 
Sp. 7. D. eiongata: foliis cordatis ovatis incifis dentatis glebris, capitulo folitario.

Cineraria elongata Linn. Syrt. veg. per Gmelin p. 1238. Suppl p. 374 .

Coalis herbaceus, teres, ftriatus, interne ramofus, erectus, pedalis vel paulo ultra.

Rami in caulis infima bafi, alcerni, pauci, elongati, teretes \&x filiformes, friati, glabri, flexuofo-eręt, uniflori.

Folia fubradicalia vel in cauli inferiori fita, petolata, cordata, ovata, incifa, dentata, utrinque glabra, fubtus interdum purpurea, fubpollicaria. Catune fguama alternæ, filiformi-fetaceæ, vix unguiculares. Capitula terminalia, folitaria.

Variat. a caule \& foliis glabris \& . $\beta$. caule inferiori foliisque fubtus albo tomentofis.

Sp. 8. D. erofa: foliis lyratis incifis dentatis fcabris, capitulis paniculatis.

Crefcit juxta Ribek Cafteel, Paardeberg \& alibi. Floret Novembri, Decembri.

Caulis herbaceus, bafi decumbens, dein ereEtus, teres, ftriarus, flexuofus, villofus, pedalis, apice tantum paniculato ramofus.

Folia alterna, petiolata, lyrata, tota fcabra pa. pillis minutisfrmis eminentibus, fubtus pubefcentia; Lobi laterales inæquales: plures, fimplices $\&$ dentati, patentes, lineam longi usque unguiculares; ultimus lobus ma- 


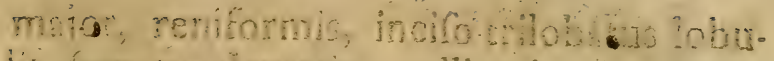
lis fimatu-deuratio, bollicaris.

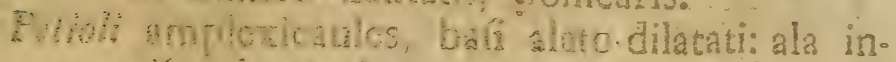
cile, denticulata.

Chpiria paniculats panicula cogrctata.

SF, 9. I) Sonchifotia : Coltis smplexicaulibus anuats Gibois cupitulie cerminabian, caule her.
biceo.

Gineruna fonchislia. Lim. Syl. veg. per Gme. In e t239. Spes. Plane. p. 1243

- Crentis herbacous, debilis, giaber, ereatulcu.

lus, pedalis.

Folig atrerra, ramder, anplexicaulia inforiore rinuato dontara, miora : fuperiora bali den. tata, lancenlatu, fuperuc incegra; pollicaria. Cupitula terminalis; panca.

En, ro. D. incipa: Colin oblongis glebrisincins slenta: tis, capintis ceminalibus.

Carblis herbicens, Aexuofo creans, fimplex, teres, friatus, pubefcens. pdalis; apice in pedunctos circiter ces samofus.

Folie rudicalia, pluca, majora; canina alcencs mninora: radicalie pecolata, oblonge, incils, dencata, glabra, rorius fubus pubofcencias nervofa, digitalia; caumb feblitia, hoterig.

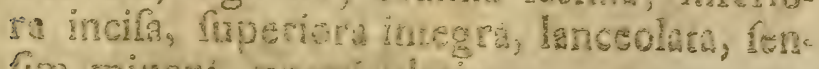

frm minord, unguinularis.

Caphole termindia, Coliraria

Q. 3

Sp: 


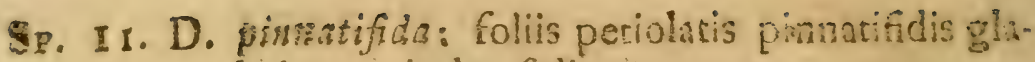
bris, capitulo rolitario.

Caulis herbacens, teres, Aexuolo-creenus, ra. mofus: pedalis.

Rami aiterni, filiformes, elongaci, fuperne aphylli.

Eolia fparfa, petiolata, pinnatifida, tota glabra, ereeta, digicalia. Pinnae fuboppofica, ovatæ, dentata, vix lineam longæ. In foliis quibusdam inferioritus lobus extimus major Capitulusn terminale, folitarium. Squame foliacex, lanceolato-fetacex.

Sp. 12. D. bipinnata: foliis bipinnatis, glabris, pinnis linearibus, capitulis paniculatis.

Crefcit in Hantum.

Floret Decembri.

Caulis herbaceus, teres, ereaus, totus glaber,

fuperne paniculatus, bipedalis.

Rami alterni, fliformes, fubfaftigiati.

Folia bipinnata, tota glabra, erecta, digitalia. Pinna lineares, fulcatæ, fecundx, inflexæ,

fimplices vel divifæ in pinnulas breves.

Capitula in ramulis terminalia.

Semina Atriata.

Pappros capillaris fubpillofus. 


\section{THESES. \\ I.}

Morbos exanthematicos animalculis vivis fuam debere originem, verofimile videtur.

II.

Adcuratiores Generum \& fpecierum defcriptiones multum adferre lucri Scienciz botanicx licet fateamur; tantum tamen abeft, ut cum illis faciamus, qui præter necesfitatem nova Genera novasque Species fingunt, ut potius credamus, in is tantum modo cafibus, ubi graviora fvadent argumenta, a receptis nominibus esfe difcedendum.

\section{Lucani effatum:}

III.

Servare modum, finemque tenere,

Naturamgue Jequi

in medicorum alte infixum esfe oportet mentibus.

IV.

Inter res arduas fane eft determinare, utrum venx featio committi debeat ignaris \& cognitione Anatomia omnino deftitutis hominibus.

\section{V.}

Haud inter minimas difficultates botanices, faltem tironibus, difcendæ referendam esfe variam a variis pro lubitu receptam divsionem clasfum, tu; to poftulumus.

VI.

Hiftoria naturalis utilisfima omnino en Secerdoti, fijuidem inde Creatoris majeftatem \& bonitatera probandi, argumenta defumuntur plurima \& vali. disfima. 


\section{NOVA GENERA \\ PLA N T R U M \\ JACOBEA.}

CaLYX calyculatus: Squannis fubulatis.

Corolla discoidea.

Stam. Fulamenta 5, capillaria.

Antbera connatz in Cylindrum.

PrST. Siylus filiformis

Stigma bifidum.

PERIC. Receptaculum nudum.

Pappis Capillaris.

Character Generis: Receptaculum nudum.

Pappus pilofus.

Calyx calyculatus.

Corolla discoidea.

Locus: Syngenefia, Polygamia Superflua, ante Senecionem, a quo differt abfentia radii. Sp. I I. reclimats: foliis linearibus, capiculis pedunculatis.

Senecio reclinatus. Linn. Syft. Veg. per Gme-

lin pag. 1226. Supplem. pag. 369.

Carblis frutefcens, ceres, ftriatus, -totus glaber,

Alexuofus, erektus, apice in pedunculos

paniculatos ramofus, bipedalis \& ultra. 
Folia rparfa, linearia, utrinque parum attenuata, acuta, integra margine revoluto, glabra, patentia, Iæpe reflexa, bipollicaria , fuperioribus brevioribus.

Redunculi filiformes, flexuofi, foliolis aliquo: brevibus linearibus fquamofi, fubfaftigiati, fimplices, uniflori.

Calyx fub apice vel nigro. maculatus vel im. maculatus.

Sp. 2 I, anguffifolis: foliis linearibus glabris, Capitulis paniculatis.

Caulis frutefcens, totus glaber, ftriatus, ereEtus, ramofus, pedalis \& ultra.

Rami alterni, filiformes, flexuofi, ereeti, fimplices, fubfaftigiati.

Folia alterna, fesfilia, linearia, integra margine revoluco, patentia apice retlexo, pollicaria.

Capitula paniculata panicula terminali. Calyx fquamis fub apice non viftulatis.

SP. 3 I. perficifolia: foliis amplexicaulibus linearibus fubtus tomentofis, capitulis paniculatis. Senecio perficifolius. Linn. Syft. Veg. per Gmelin pag. 1225. Spec. Plant. pag. I215. Caulis fubherbaceus, vix fruticefcens, teres, itriatus, inferne glabriufulus, ramofus, erectus, pedalis \& ultra.

Rami alterni, patulo-ereeti, faftigiati, filiformes, fubtomentofi, iterum in paniculam ramulofi. 


\section{Plantarum.}

Folia alterna, bafi aurita, femi amplexicaulia, linearia, integra margine reviluto, fupra glabra, fubtus niveo-tomentofa, patencia, pollicaria.

Panicule terminales, faftigiatz.

Calyx bafi albo - lanatus, apice non uftulatus. Sp. 4 I. mucronata : foliis linearibus mucronatis fubtus tomentofis, capitulis paniculatis.

CEulis fruticofus, teres, cinereo tomentolus,

ramolus, ereetus, pedalis \& ultra.

Rami in caule inferiori aggregati, alterni, e-

longati, inferne foliis teeti, tomentofi, fuperne glabriufculi, aphylli, in paniculam ramuloli.

Folin fparfa, fesfilia, linearia, mucronata, integra margine revoluto, fupra tomentofa, viridia, fubtus niveo-tomentofa, patentiereeta, pollicaria.

Paniculce terminales, effufx. Calyx fquamis minime uftulatis.

Sp. 5 I. nivea: foliis linearibus lanatis, capitulis fo. litariis.

Caulis fruticelcens, totus lana nivea obductus, ramulofus, ereetus, pedalis.

Rami alterni, filiformes, elongati, fuperne ramulofi, lanati, flexuofo-ereeti, fantigiati. Folia alterna, fesfilia, linearia, cbufuufcula, integra margine revoluto, utrinque inprimis vero fubeus niveo-lanata, patentia, pollicaria. $\quad R_{2}$ 
Capitula in ultimis ramis terminalia.

Calyx extus inprimis bafi tomentofus, non uftulatus.

Sp. 6. I. paniculatt : foliis linearibus denticulatis glabris, capitulis folitariis.

Senecio paniculatus. Berg. PI. Cap. pag. 277. Senecio longifolius? Linn. Syft. Veg. per Gmelin pag. I 229. Mant. pag. $47^{\circ}$.

Coulis fruticécens, teres, erectus, totus glaber, fimplex, fuperne divifus in panicu. lam floriferam, pedalis vel paulo ultra. Folia alterna, fesifilia, linearia, margine revoluto-denticulata, glabra, patula, fesquipollicaria; fuperiora minora, bafi dentatopinnata.

Parbicula patens, fubfattigiata, capitulis folitariis. Pedunculi filiformes \& pedicelli capillares, elongati, fenfim breviores, fpithamæi \& ultimi pollicares.

Calyx non uftulatus.

Sp. 7. I. bidentata : foliis lineari-ellipticis dentatis comentolis, capiculis fesfilibus.

Carsles fruticefcens, teres, Orriatus, inferne tomentofus, erectus, flexuolus, rarius ramo. fus, fuperne in paniculam ramulofus, pedalis \& ultra.

Folia fparfa, fesfilia, elliptico-linesria, acuta, tomentofa \& glabriufcula, quadam latiora, dente majori uno alterove in medio nota- 
ta; reliqua margine revoluto - denticulata; patentia, flexuora, digitalia fuperioribus fenfin minoribus.

Copitsla terminalia, folitaria in pedunculis. Pedinculi iexuof, filiformes, infuriores digitales, fupremi ungriculares.

Calyos glaber. parum untulatus.

Sp. 8 1. Fabra: foliis oblongis ferratis fcabris, paniculis compofitis.

Creftit in regionibus Hexrivier, Cap bona ipei. Fiorer Deecmbri, Januario.

Castis herbaceus, teres, ftriarus, tenuisime pubefens, flexuolus, erectus, fiftulofus, ramofus, bipedalis.

Rami alcerni, cauli frmiles, inferiores longiores, fuperiores breviores, in paniculam ra. mulofi, virgati, nec faftigiati, erecto-patentes.

Folia cazslina alterna, fesfilia, obovato-oblon. ga, obtufa, feriata margine incrasfato revoluto, venofa utrinque inprinis vero fub. rus fcabra, pubefcentia, patentia, digitalia: anara amplexicaulia, lanceolata, ferrata, yix ungvicularia.

Copitzlo in ramis terminalia, paniculara: pombcisla hemifpharica, compofita.

Calyx fquamis apice non uftulatis.

Sp. 9 I. vefits: follis ovatis ferratis glabris, panicula compofits. 
Senecio veftitus. Berg. Plant, Cap. pag. 292. Cre/cit juxta Paarduberg in Cap. b. Spei. Floret Novembri, Decembri.

Caulis fruticolus, icres, totus glaber, erectus, ramofus, pedilis \& ultra.

Rambi alcerni, fumiles, fimplices, eręti, apice in paniculam ramulofi.

Folia alterna, approximata, fesfilia, ovato.ob. longa, acura, ferrata, dentibus argutis fubmucronatis, utringue glabra, imbricata, pollicaria, fuperioribus minoribus.

Panicula terminalis, compofiza.

Pedunculi filiformes, fquamofi, fartigiati. Squame foliacez, lineam longr.

Calyx non uftulatus.

Sp. Io I. putpurea: foliis inferioribus lyratis hirtis, fuperioribus lanceolatis dentatis, capitulis folitariis.

Senecio purpureus. Linn. Syft. Veg. per Gmelin pag. 1 226. Sp. plant. pag. 1215. An Senecio erubelcens? Ait. Hort. Kewenf. Vol. III pag. 190.

Crefcit in campis graminofis Cap. bon. Spei. Caulis herbaceus, bafi decumbens, ereetiufculus, debilis, tosus hirtus, fufcus, frm. plex \& ramofus, fpithamæus usque pedalis. Folia inferiora obovato. oblonga, incifo lyrata, obtufe dentata, hirfuta, inferne anguta. ta, tripollicaria: couliza fuperiora fagitta- 
ta, lanceolata, dentata, pollicaria, fenfim minora, ceterum reliquis fimilia.

Flormm capicula paniculata, laxa, incurvo.e. reeta.

Pedunczali \& Calyx toti hirfuti fquamis non uftulatis.

Sp. I I I. peucedanifolia: foliis pinnatis glabris : pina nis linearibus.

Senecio peucedanifolius Linn. Syft. Veg. per

Gmelin pag I 225. Suppl. pag. 372.

Caulis fruticefcens, teres, ereetus, fuperne ramofo-paniculatus, bipedalis vel ultra, vix maniferte pubefcens.

Ramb filiformes, fimiles, fubfantigiati, patuli. Foha inferne approximata, pinnata, glabra vel vix manifefte \& rarisfime pubigera, erenta, palmaria. Pimsce lineares, integrz, pollicares, impari longiori ; fuperiora minora.

Paniculd in ramis terminales.

Calyx non ufulatus.

Sp. 12 I. tomentioja: foliis pinnatis lanatis, pinnis lanceolatis.

Senecio virgatus? Linn Synt. Veg. per Gmelin pag. 12:6. Sp. plant, pag. 1215 .

Caulis vix frutefcens inanis, fublanatus, ftriatus, ramolus, fexuofus, erectus, pedalis \& ultra.

Rami alterni, nanci, elongat, fuperne in pedunculo ramulofi. 
Folia pinnata, lanata, alba, erecta, palmaria fuperioribus minoribus. Ptnne fuboppofite, lineari-lanceolatæ, integræ margine revoluto, patentes, ungviculares.

Capitula in ramis \& ramulis terminalia, folitaria. Squame foliacer, lineari-fetacer, flexuofr, vix lineam longæ.

Calyx tomentofus, non uftulatus.

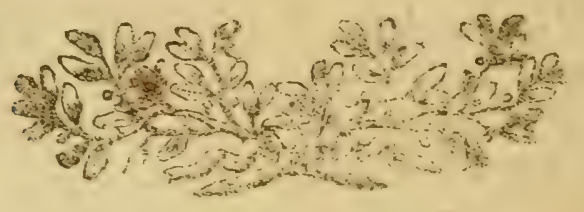




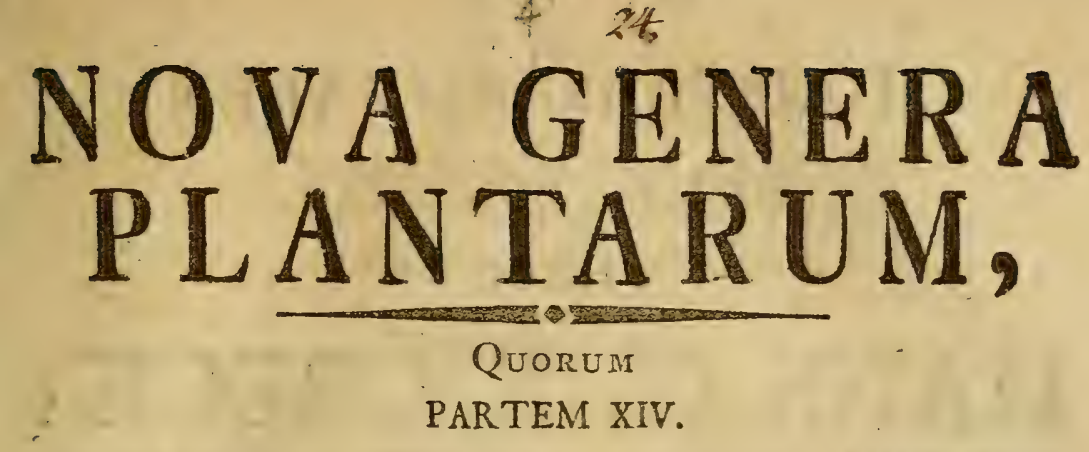

CONSENSU EXPERIENT. FACULT. MED. UPS.

\section{P R $邓 S I D E$}
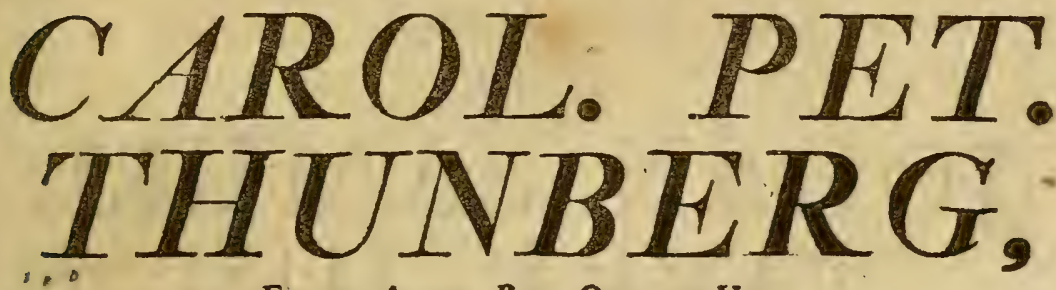

Equite Aurat. Rgg. Ord. de Vasa,

Med. Doct. Prof. Med. ex Bot. Reg. et Ord. Acad. Casar. Petzoror. et Nat. Cursas. Reg. Scient, Lond. Holm. Socint. Scirat, Uss. Philad, Patr, Holm, et Civ. Orcon. Fint. Beror, Nat. Scrut, Paris, Hafn. et Halmes. Hist. Nat. Lund, Harlem. Amsteld. Zeland. Nidrosiens. Ticinens, Ienens. Linn. Londin. Phys, Góttingens. Mrd. Matritene. Medic. ext Nat. Studios. Edimburg. Megbro; anc non Acad, Scient. Paris. Mongfelizss. Agricult.

Par18. Medic. Londin. Scandinav. Florentin. et Batayin, Ind, Or, Correspond.

PUBLICE CENSURA SUBMITTIT

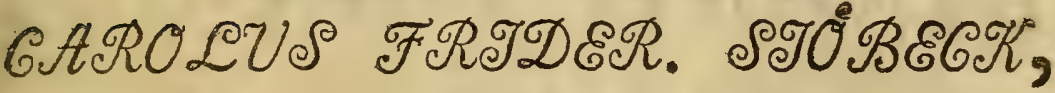
SMOLANDUS.

- IN AUDIT. BOTAN. D. III JUNII MDCCCT.

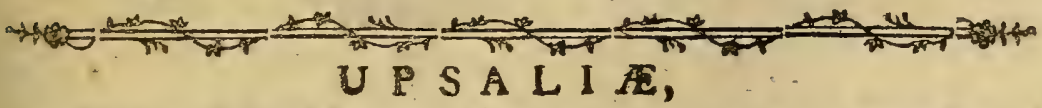

M.TTERES JOH. FREDR, EDNAN, RBG. ACAD. TKROGR 


\section{MÓNSTERSKRIFVAREN}

ÅDEL OCH HÓGAGTAD

\section{HER R}

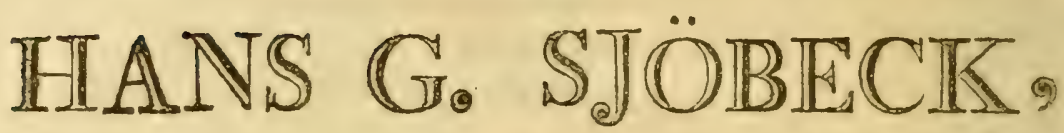

$$
\begin{gathered}
\text { POST - INSPECTOREN } \\
\text { HÓGÅDLE }
\end{gathered}
$$

HERR

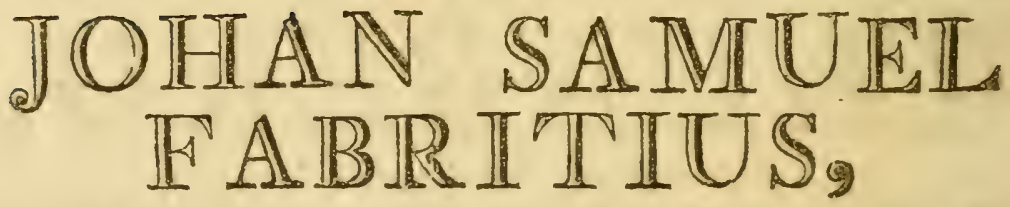

$\mathbb{R} \AA D$ - OCH HANDELSMANNEN ÁDEL OCH HO̊GAGTAD

\section{HERR}

\section{ADOLPH}

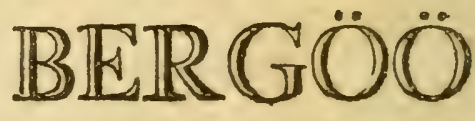

Med vo̊rdgad och tackfamhet tilågnade

af DERAS 


\section{NOVA GENERA \\ P L A N T A R U \\ DENEKIA.}

Calyx Polyphyllus imbricatus: Squama exteriores angulatr, pubefcentes, virides; interiores fcariofx.

COROLLI Radii feminex, bilabiatæ.

Difi hermaphroditx, quinquefidx.

STAm, fizhnenta quinque.

Antbere in cylindrum connarx.

Pist. Germen nudum.

Stylus filiformis.

Peric. Receptaculum nudum.

Serrina oblonga.

Pappus: foliola obtufa, nivea.

Character Generis; Recept. nudum.

Pappus nullus.

Corolla Radii bilabiatæ; Difci quinquefidæ.

Locus: Syngenefia, polygamia fuperflus.

Nomnen: In honorem Celebris Botanici, Dom. Affeff. Deneke, ad Cohort. Stralfundenf. Chirurg. primar.

SP. I. D. Capentis.

Crefcit in aquis Lange Kloof Cap, b. fpei. Floret Januario.

Caulis reres, friatus, tomentolus, ramolus, ereEtiufrulus, fpithameus vel ultra. Rams alterni, fimiles, apice nutantes.

$$
\text { A } 2
$$


Falia alcerne, femiamplexicaulia, oblongo Ianceolata, obtufa cum mucrone, integra, undulata, lupra glabra, fubtus tomentofa; in. feriora digitalia, fuperiora fenfim breviora. Capitulo terminalia, paniculata. Faniculs coardactô.

\section{LAPEIROUSIA.}

Caryx polyphyllus, imbricatus, tomentolus: Jquama lanceolatæ, apice \& margine fcariofæ.

Cororla discoidea.

Stam. Filamenta s, capillaria, brevia. Antbere in tubum connatz.

Pist. Receptaculum convexum, papillofo-fcabruma Semins ovata, compreffa, coftata, glabra. Pappus nullus nifi margo tenuis. Character Generis: Receptaculum fcabrum. Pappus nullus.

Calyx margine fcariofus.

Locus: Syngenefin, polygamia fruftranea, prope Osmitem.

Nomen in demeritum honorem celebris inter Botanicos viri \& floræ Pyrenaicæ pulcherrimæ AuEtoris, Dom. Picot de Lapeirouse.

S8. 1. L. Calycina.

Ofmites Calycina, Linn. Syft. Veg. per Gme. lin. p. 1261. Suppl. p. 380.

Crefcit juxta margines fylvarum hauteniquas C. P. S.

Floret Novembri. 
Caulis fruticofus, teres, inferne pubefcens, fimplex fuperne hirfuto-tomentofus, ramofus, erectus, pedalis \& ultra.

Rami per intervalla aggregato - fubverticillati, cauli fimiles, erecti.

Folia fparfa, approximata, feffilia, lanceolata, mucronata, integra; tota utrinque hirfuta, to. mentofo-fericea; imbricato-erecta, pollicaria. Florums capitula in ramis terminalia, folitaria, rocundata, parum convexa, magnitudine fere fabz.

\section{CHORISTEA.}

CaLYX Duplex: exterior 4 phyllus, interdum 5 phyl. lus; Foliola ovata, obcufa, patentia, margine punctato - ferrata, carnofa, unguem lata, fe. mipollicaria; Interior 12 phyllus: Foliola lanceolata, alterna, anguftiora, acuta, mucrona. ta, ferrato-ciliata, erecto-patentia, longitudine exteriorum.

Cororla radiata; Radii ligularis; difci tubulofa. STAM. Filamenta quinque, capillaria. Antbere connatz.

Pist. Stylus filiformis. Sitgma bifidum.

Peric. Receptaculurn planiufculum, hifpidum fpinis ereetis, fubulatis, femiungvicularibus. Pappus fetaceus vel paleaceus, ferrato plumofus. Character Generis: Receptaculum fpinofo-hifpidum. Pappus ferato-plumofus. Calyx duplex, polyphyllus. 
Locus: Syngenefia, polygamia neceffaria, juxta Po. lymniam.

Sr. I. C. Carnofa: foliis alternis oblongis, calyce ferrato. Polymnia carnola. Linı. Sylt. veg. per gme. lin. p. I $\approx 0$. fupplem. p 344.

Crelcit in arenofis maritimis prope ganfe kraal, in verlooren valleij \& alibi in Cap. b. fpei. Floret Sepremiri, Octobri。 Radix defcendens, perennis.

Cantis frucicofus, fuperme parum ramofus, bafi decumbens, dein ereetus, glaber, fpithameus. $\mathbb{R} a m i$ alterni, fulcati, fimiles.

Folia alterna, feffilia, oblonga, obtufa; carnolá, integra, ereeta; fupra convexa fulco a bafi ad medium exarata, fubtus concava marginibus reflexis, tenuiffira lana veftica, pollicaria.

Capituia terminalia, folitaria.

Sp. 2. C. Spinofa: foliis oppofitis ovatis, aculeis fupraaxillaribus.

Polymnia fpinofa Linn. Syft. Veg. per gmelin. p. 270. Suppl. p. $38 \div$.

Crejcit juxta olyfants rivier in Carro Cap. b. fpei. Floret OEtobri.

Crulis fruteícens, teres, totus glaber, lavis, ereetus, fuperner in pedunculos ramofus, bi. pedalis.

Folla oppofita, feffilia, cordata, ovata, mucronaca, nervola, integra \& dertibus fpinofis armata, margine fubrevoluto incraflata, gla. bra, pollicaria.

Eaphata terminalia, folitaria. 


\section{CENOPTERIS.}

Frondis Capfrels in lineolis fubmarginalibus, membrana exterius dehifcente tectis.

Sp 1. C. flacida; pinnis lanceolatis fubdentatis.

SP. 2. C auriculata: pinnis oblongis incifo-pinnatifidis. Sp. 3. C. odontites: pinnis enfiformibus incifo pinnatifrdis: pinnulis bafeos bifidis.

SP. 4. rutcefolna: pinnulis incifis: laciniis lanceolatis integris bifidisque.

Cænopteris rutæfolia \& furcata. Berg, Act. Pe. trop. 1782. p. 248. t. 7. f. 1. 2.

Crefcit in Cap. b. fpei.

SP. 5. C. rbizopbylla: pinnullis incifis; laciniis lanceo. latis integris.

SP. 6. C. myriopbylla : pinnulis pinnatis : laciniis obeufis. Crefcit in America meridionali Prof. Svartz.

Sr. 7. C. japonica: pinnulis bipinnatis: laciniis acutis. Trichomanes japonica, Flor. Jap.

Sp. 8. C. Vivipara: pinnulis filiformibus.

Acrofticum viviparum; Linn. Suppl. P. 444.

Crefcit in infula mauritii.

Sp. 9. C. cicutaria; pinnulis incifis: laciniis dentato. augulatis.

Afplenium cicutarium. Linn. Syft. Veget, per Gmel. p. 1304.

Crefcit in Jamaica. 
Rerum naturalium cognitio, neglecto earum ufu, merito parvi æeftimatur. Hic tamen fine illa vagus, incertus, fallax fæpe, periculofus interdum.

II.

Cur ufus rerum naturalium tardiores fecerit progresSus, atque etiannum vix ex ephebis exciiffe videatur, cauffam effe putamus, quod feculorum prifcorum experientia, incerta nomenclatura innixa, ante noftram periesit ætatem.

\section{III.}

Summi Creatoris fapientiam non minus veneramur in ea Naturæ Oeconomia, ad cujus leges res naturales deftruuntur, quam in provida illa cura, qua omnia productione continua perennant.

\section{IV.}

Lichenum in arte tinctoria ufus eximius dudum derectus, Hiftorix Naturalis Contemtores moderate judicare docebit de iis, qua adhuc Naturæ fcrutatorum fe fubsraxerint indagini.

$$
\text { V. }
$$

In regno Vegetabili varietates fpecierum ex foli \& cceli diverfa natura fapius pendent, quam ex generatiose hybrida. In regno animali contra.

\section{VI.}

Ut indies crefcit fpecierum novarum numerus, ite \& geners haud raro novos expolcunt limites. At vero, ut Reformatoris eft profpicere, ne mole fua corruant genera, ita \& cavere oportet, ne caractere nimis exquilito genera facile coalefcant. 


\section{THE S E S.}

l.

Plures funt Plantæ, quæ linteis Fabricandis infervitunt.

II.

Nec pauca funt illa vegetabilia, e quibus charta ido. nea parari poteft.

III.

Flores plerumque e Caule \& Ramis, rarius e Radice, rarisfime e foliis proveniunt.

$$
\text { IV. }
$$

Vires Plantæ non raro tam a folo, quam climate \& culture pendent;

$$
\text { V. }
$$

Uti \& plures ejus partes exinde mutari, augeri vel diminui posfint.

VI.

Folia diver fo gaudent qualitate Medica, pro diverfa fus xtate. 


\section{NOVA GENERA \\ P L A N T A R U M}

\section{STOBÆA.}

Calyx Polyphyllus, imbricatus: foliolis lanceolatis, fpinofis.

CoROLLæ uniformes, monopetalæ, profunde quinque. partitx.

STAM. Filamenta quinque.

Aritber ce connatz.

Pist. Germen rugofum.

Stylus bifidus.

Receptac. favofum, hispidum.

Sernina oblonga, truncata, hirfuta.

Character Generis: Corolla uniformis, quinque partita. Calyx in bricatus, fpinofus. Receptaculum favofum, fetaceo-hispidum.

Locus: Syngenefia æqualis, juxca Atractylidem.

Nomen dedi in memoriam Celeberrimi olim Botanices in Acad. Lundenf. Profesfor. ac Archiat. Reg. Dom. Kil. Sтов вi.

Sp. II. S. glabrata: foliis cordatis, amplexicaulibus, glabris, oblongis.

Caulis herbaceus, crasfiusculus, angulatus, glaber, flexuofo-erectus, inanis, bipedalis vel ultra, fuperne ramofus.

Folia alterna, femiamplexicaulia, cordata, oblonga, indivifa, acuminata fpina producta, den. tato-f́pinofa, utrinque glabra, reticulata, patentia, digitalia fuperioribus minoribus. 
Flores in ramis terminales, majusculi, lutei. Calyx polyphyllus: Foliola fpinofo-acuminata, nervofa, ciliato-fpinofa.

$\mathrm{SP}_{0}$ 2. S. carlinoides: foliis cordato oblongis, glabris, dentato-runcinatis, fpinofis.

Crefit in Roggeveld \& Hantum. Floret Decembri.

Caulis herbaceus, angulatus, totus glaber, erectus, fupene ramofus, bipedalis.

Rami alterni, filiformes, er Eto patentes. Folia alterna, fesfilia, cordata, oblongo-lanceolata, Cpinolo acuminata, dentato fubpinnatifida, lobis fpinofo-fubpalmatis, utrinque glabra, ereCo-patentia, digicalia luperioribus minoribus. Flores in ramis terminales, lutei, magnitudiae avellanx.

Calyx polyphyllus: foliola fpinofo-acuminata, ciliato.rpinofa, flofculis longiora.

Sp. 3. S. atraftyloides: foliis infimis petiolatis, fuperioribus fesfilibus, dentato-pinnatifidis.

Carlina atractyloides. Linn. Syft. veg. per Gme. lin p. 1191. Spec. Plant. p. 1161 .

Caulis herbaceus, ftriatus, pubefcens, ereetus, apice parum ramofus, pedalis.

Folia radicalia petiolata, fubtus tomentofa; caulina fesfilia, cordata, acuta fpina acuminata, glabra, omnia incifo-pinnatifida: lacinbiis acutis fpinofis ; digitalia fuperioribus fenfim minoribus. SP. 4. S. decurrens: foliis decurrentibus, glabris, incifo-pinnatifidis, fpinofis. 
Crefcit in montibus Hautniquas, \& in Krumrivier. Floret Novembri, Decembri.

Caulis herbaceus, ereftus, angulatus, alatus, totus glaber, ramolus, pedalis.

Ramii a'terni, elongati, flexuofo erecti.

Folia alterna, decurrentia, oblonga, incifo-pinnatifida lobis rhombeis, glabra, ciliato fpinofa, unguicularia usque palmaria,

Flores terminales, folitarii \& terni, magnitudine avellanx.

Involucrun follaceum fub flore, polyphyllum: foliola pinnato-fpinulofa, tomentofa. Sp. 5. S. larata: foliis cordatis, ovatis, fpinofis, tomentolis.

Cartis herbaceus, bafi fublignofus, angulatus, flexuofus, tomentofus, ereetiufculus, ramofus, pedalis \& ulira.

Rami alterni, fimiles, fenfim breviores.

Folia alterna, fesfilia, cordata, ovata, acuta cum fpina, dentato-fpinofa, utrinque incano-tomentofa, pollicaria.

Flores in ramis terminales, magnitudine fabæ. Calycis polyphylli foliola oblonga fpinofo-acuminata, fpinofo-ciliata, tomentofa.

Sp.6. S. Rigida: foliis cordatis, pinnatifidis, fpinofis, tomentofis.

Crefcit in campis extra urbem Cap \& fupra littus maris, pone Duyvels kopp \& alibi. Floret Martio, Aprili.

$$
\text { A } 3
$$


Caulis herbaceus, teretiufculus, rufefcens, glaber, Hexuofo erectus, apice ramolus, pidalis. Rami brevisfimi, fattigiari.

Folia fesfilia, cordata, inciro-pinnutifida, fpinofoacuminata, dentato-fpinota, lúurus comentola, pollicaria.

Flores in ramis terminales, lutei, magnitudine vix avellanz.

Folioli Calycis ovata, rigida, fpinola, acuta \& fpinis fubdivifis l.teralicer armata.

Sp. 7. S. beterophyll.?: foliis tomencofs : infrmis indivifis, fuperioribus ly ratis.

Radıx alte defcendens.

Caulis bafi decumbens, dein erectiufculus, ramolus, tomentolus, vix fpithamæus.

Rami pauci, elongati, fimiles.

Folia inferiora peciolata, oblonga, indivifa, ciliato-fpinofa; fupra glabra, fubtus tomentofa, digitalia; fuperiora alterna, femiamplexicaulia, bafi attenuata, lyrato pinnatifida, fpinola, fabtus denfisfime albo-tomentola, pollicaria vel ulrra fuperioribus minoribus.

Flores terminales, lutei, magnitudine avellanæ. Calycis foliola fpinofa lateribus \& apice.

SP.8. S. pinmatifida: foliis tomentoris, p nnatifidis: laciniis ovatis; fupra \& apice fpinofis.

Caulis herbaceus, teres, pubelcens, flexuofo-areetus, fuperne ramolus, pedalis.

Rami fimiles, fubfartigiati. 
Folia fesfilia, pinnatifida, pollicaria: pinna ovatæ, fpinofo-mucronatæ, fubcus imprimis inca. no-tomentola, pagina luperiori \& margine fpinis tenuisfimis, echinatis.

Capitula florum in ramis fubfpicata.

Calycis foliola oblonga, fpina terminata, ciliato. fpinof́a ́pinis minimis.

Sp. 9. S. pinnata: foliis tomentofis pinnatifidis: pinnis linearibus fpina terminatis.

Crefcit in Bockland.

Floret Novembri.

Caulis fuffruticofus, totus tomentofus vel albo. lanatus, teres, fuperne ramofus, Spithamæus. Rami breves, faftigiati.

Folia fesfilia, linearia, pinnatifida, imprimis fubtus lanato-tomentofa, palmaria: pimne lineari-lanceo. latæ, fpina terminatæ, integræ margine reflexo. Flores terminales.

Calycis foliola fpina terminata, integra, unguicularia.

\section{PENTZIA.}

CALYx polyphyllus; imbricatus : Jquame fapremæ fcariolix.

Corole e difcoidex.

Stam. Filanewa quinque.

Antberce connatz.

Pist. Gervisen planum, nudum.

Stylus filiformis.

PERIC. Recept. nudum.

Pappus paleaceus, foliolis niveis fubangulatus. Ssmina cylindrica, glabra.

CHA- 
Character Generis : Recept. nudum. Pappus paleaceo-angulacus. Calyx apice fariofus.

Locus. Syngenelia, Polygamia fuperfua, poit Xe. ranthemum.

Nonnen impofrum in honorem Celehris inter Srecos Hiftoriz Naturalis, imprinus Entonolog. \& Botan. Culcoris, Dom. Confuliar. Pentz.

Sr. 1. P. crenara: Gnaphalium dentatum Linn Syn. vager. per Gmelin p. 12:4. Sp. Plant. p. 1:9 \% Tanacerum Aabelliform: Heret. Seri. An_l. p. 21 t. 27

Crefent in Carro \& Cannaland.

Floret Novembri, Decembri.

Caulis fruticolus, teres, Alexuofo ereatus: romofus, pedalis \& ulera.

Rani alterni \& fubumbellato-aggregati, filiformes, romencoli, flexuolo-ereeti, Lubstigiati, ramulis fimilibus.

Folia fparfa, petiolata, cuneata, apice crenata, lateribus integra, quinque-rervia, utrinque alho tomentora, ereeta, lineam longa.

Petioli lineares, tomentofo albi, longicudine folii. Flores terminales, racenolo-fubumbellat, tantointi. Pedun wi capillares, tomencofi, unguiculares, fu. perioribus brevioribus.

Calyx ovacus, imbricatus, glaber, luteus, apice fcariofus

Corolle dilcoidex, lutea.

Ufus. Herba amara adhibetur ab Hotteneotis in Ungventis,

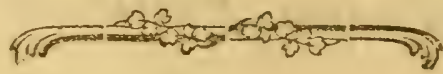



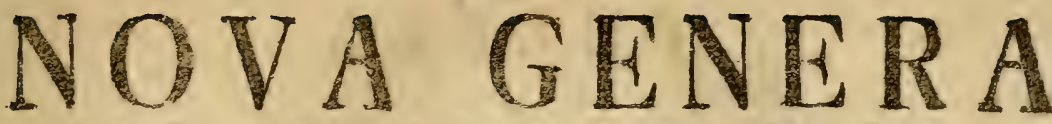

$\mathrm{P}$
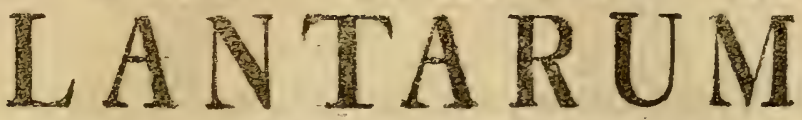

\author{
QUORUM \\ PARTEMI XVI.
}

CONSENSU EXPERIENT. FACULT. MED. ITPS.

\title{
PRASIDE
}
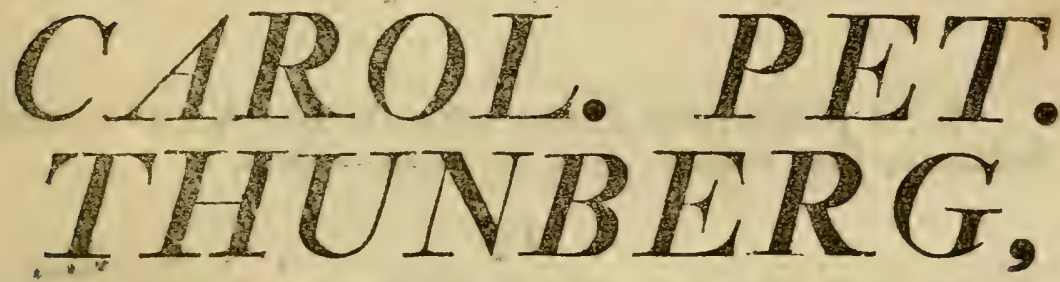

Equita: Aura t. Reg. Ord, de Vasa,

Med. Doct, Prof, Med, ex Bot, Reg. et Ord, Acad, Cesar, Petzozol. et Nat, Curios. Reg. Scient, Lond. Holm. Societ. Scient. Ups. Philad. Patr, Holm. ex Civ. Oscon. Fint. Berol. Nat. Scrut. Paris. Hafn, et Halens.

Hist. Nat. Lund. Harlem. Amsteld. Zeland. Nidrosiens.: Ticinens. Ienens. Linn. Londin. Peys. Góttingens. Mad, Matritens. Medic. et Nat. Studios. Edimburg. Meabro; hec non Acad. Scient. Paris. Monszeliens. Agricult.

Paris. Medic. Londin. Scandinay. Florentin. et Batayin, Ind, Or. Correspond.

PUBLICE CENSURA SUBMITTIT

\section{GUSTAVUS ERICUS SO̊RLING,}

Stip, Possieth. StOCKHOLMIENSIS.

IN AUDIT. BOTAN, D. XV DEC. MDCCCI.

H. P. M. 's.

U P S A L I $\mathbb{E}$,

Litteris Jou, Fr. EDMAN, Reg. Acad. Typogr. 


\section{THESES。}

I.

Succi Vegerabilium, confreatia, colcre aliisque proprie. atibus, in diverfas valde difcrepare inveniuatur.

II.

Plante licet nonnulla fint omnino aphylla, plurime ramen absque manifeita noxa foliis fuis fpoliari non posfunt.

III.

Licet plurimarum Plantarum qaalitates Vires optime indicast, funt tamen, quæ interdum fallunt.

IV.

In radicibus non omni anni tempore virtus medica quærenda erit;

V.

Verum igitur femper obfervandum eft Medico pru. denti momentum, quo cum maximo fructu colligi debens.

VI.

Color viridis, in foliis communisfimas, in flovibus ragior occurrit. 


\section{NOVA GENERA \\ P L A T A R U M. \\ ronoturnon \\ RELHANIA.}

Caryx Polyphyilus, imbricatus: fazamis oblongis, apice fcariofis.

Corolla radiata. Corollula hermaphroditz numerof in difco: feminex plurimx in radio.

Stam, Franenia hermaphroditis quinque. Anibera tubulora.

PIST. Germen oblongiulculum. Stylus unicus. Stigmata 2 , revoluta.

Peric. Saterlat glindrica, glabra. Pappus membranacs: hacerus. Recepteculutn paleaceum.

Character Gesal : Receptaculum paleaceum.

Pepuus membranaceus, lacerus.

Corolla radiara.

Locus: Syngenefá, polygamia fuperfua, prope Tánacetum.

Sp. I. R. Squarrofa: foliis ovatis acutis reflexis gla* bris, urnhellis terminalibus.

Ahanafia fquarrofa. Lim. Syft. veg. per Gme. lin p. 1207 . Sp. Plans. p. 1180.

Crejcit in Carro.

Floret Novembri.

Caulis fruticofus, totus glaber, cinereus, ereetus,

ramofus, tripedalis vel ultra.

Rani fubverticillati, flexuofo-erecti, fartigiati. $\mathrm{B} 2$ 
Folia fparfa, approximata, fesfilia, ovata, acuta, inegra, glabra, reflexa, lineam longa vel paullo ultra.

Flores terminales, aggregato fubumbellati, ereeti. Peduncull fiore breviores.

Calyx cylindricus.

Sp. 2. R. genifififoliu: foliis lanceolatis glabris, umbellis terminalibus.

Athanafia geniftifolia. Linn. Syft. veg. per Gme。 lin p. 1207 . Sp. Plant. p. 404.

Crefcit in Carro prope Cap.

Floret Auguito.

Coulis fruticofus, flexuofus, totus glaber, ramo. fus, bipedalis \& ultra.

Rami \& Ramuli Cparfi . frequentes, flexuofi, virgati. Fola fparfa, frequentia, fesfilia, lanceolata, acuta, integra, imbricato patula, unguicularia. Unibella terminales, 3 -usque 5 -floræ.

S. 3. R. pumilo: foliis linearibns villofis, pedunculis terminalibus folitariis.

Athanafia pumila. Linn. Syst. veg. per Gmelin p. 1207. Suppl. p. 562 .

Crefcit in depresfis prope Brandvalley. Floret Oetobri.

Radix fibrola.

Caulis herbacens, teres, inferne glaber, decumbens, fuberectus, ramofus, palmaris.

R. mi ramulique alterni, filiformes, fubfaftigiati. Folia fparfa, fesfilia, linearia, glandulofo-villofa, parentia, integra, unguicularia. 
Capitula in ramulis terminalia, folitaria, pecun. culata.

Pedunculi unguiculares.

SP. 4. R. fesfilifiora: folitis linearibus villofis, capitulis fesfil bus.

Athanafia fesflifora. Linn. Syft. veg. per Gme. lin p. 1207. Suppl. p. 36.

Crefcit in arenofis Svartand.

Floret OEtobri.

Radix fibrofa.

Carlis herbaceus vel plures e radice, apice ra. mulofi, villof, Rexuofo erecti, palmares.

Rami \& ramuli faltigiati.

Folia fesfilia, frequentia, linearia, glandulofo villofa, curvata, vix unguicularia.

Capitula fesfilia, parva.

SP. 5. R. cuneata: foliis obovatis convolutis glabris, capiculis terminalibus fesfilibus.

Athanafia uniflora. Linn. Syft. veg. per Gme. lin p. 1208 Suppl. p. 362.

Caulis frucicolus, teres, cinereus, totus glaber, erectus, ramofus, bipedalis \& ultra.

Ramu \& ramul, per intervalla fubverticillati, fa. Ptigiati.

Folıa in ramis \& ramulis frequentia, fesfilia, obovata, convoluto trigona, apice recurvo fubtrifida, imbricata, lineam longa.

Capitula in ranulis terminalia, folitaria, fesfilia. SP. 6. R. paleacea: foliis linearibus fupra niveis, capitulis terminalibus folitariis. 
Leyfera palcacea. Linn. Syn. veg. per Gmelin p. 1245.

Leyfera ericoides. Berg. Plant. Cap. p. 204.

caulis fruticofus, Alexuoforectus, ramoinslimus; fufcus, pedalis.

Rami \& ramuli terni \& verticillati, flexuofi, fubfartigiati.

Folin in ramulis fesfilia, frequentia, linearia, obtufa, convoluta, fupra niveo-tomentofa, fub¿us pubefcentia, imbricata apice patulo, lineam longa.

Capitula terminalia in ramulis, folitaria, breviter pedunculata.

SP. 8- $R$, tomentofa: foliis linearibus tomentofis, capitulis terminalibus fefislibus.

Caules e radice plures cefpirofi, filiformes, laxi, erecti, inferne glabri, ftricti, ramofi, fpithamæi. Raziz alcerni, capillares, fubromentofi.

Folia e gemmis alternis fesfilia, linearifiliformia, obeufa, fulcata, tomentofa, unguicularia.

Capitala florum terminalia, bina, tria vel plura fesfilia.

Calyx oblongus, fubcylindricus; fquane inferiores fab apice tomentofx, fuperiores purpurea. S. 9. R. reflexa : foliis linearibus tomentofis, fquamis calycinis fetaceis reflexis.

Crefoit in campis arenofis Piketberg.

Flaret Oetobri.

Radix fibrillofa.

Catuis frutefens, teres, fimplex vel ramofus, eredus, fpithamzus vel paullo ulıra. 
Rami Sparfi, fimiles, erecti, faftigiati.

Folia alterna, fesfilia, linearia, obcufa, integra, tomentofa, erecto-patentia, unguicularia.

Capitula terminalia, cylindrica.

Calycis fautima lanceolata, acuminatx, reflexæ. Bapprs: corona foliacea, nivea, foliolis ovatis, obtufis, brevisfimis.

Sp. IO. $R$, pungera: : foliis lanceolatis fubulatis glabris fubeus firiatis, capiculis fesfilibus.

Relhania nungens Heret. Sert. Anglican. Caulis fruticofus, nodulofus, teres, erectus, ramofus, pedalis vel ultrs.

Rami dichotomi, fimplices vel iterum bifidi, fo. liis tecti, erecti.

Folia fesfilia, frequentia, imbricata, lanceolatoacuminata, mucronata, rigida, pungentia, fupra concava, fubtus nervofa, integra, glabra, fubpollicaria.

Captula in ramis \& ramulis fesfilia, terminalia, folitaria.

SP. II. R. trinervis: foliis lanceolatis glabris, fub-

tus trinervibus, capiu ulis cerminalibus fesfilibus. Caulis fruticofus, erectus, ramofus, pedalis. Rami \& ramuli alterni, incurvato-erecti. Folia fparfa, approximata, imbricata, fesfilia, ellipticoslanceolata, acuta, integra, glabra, concaviuscula, fubtus coftis tribus elevatis, unguicularia.

Capitulum fingulum in apice ramulorum terminale, fesfile, folitarium. 
Sp. I2. R. quinquenervis: follis lanceolatis villofis fubtus quinquenervibus, capitulo fesfili.

Cosulis fruticolus, teres, pubercens, fuperne ramolus, ercetus, pedalis \& ultro.

Rami dichotomi, erecti, fimplices.

Folia forá, fesfilia, ellipticolanceolata intera,

villofa, fubtus quinquenervia, imbricaca, un. guicularia.

Copitulum terminale, folitarium, resfile.

SP. 13. R. pinnata: foliis pinnatis, foliolis linearibus. Crefcit in Bockland. Floret Novembri.

Caulis frutefcens, teres, frriatus, erectus, ramofus, pedalis \& ultra.

Rami alterni, filiformes, elongati, lnxi, eredti. Folia pinnata, fubquinata: folıoia linearia, mucronata, unguicularia.

Capitula in ramis \& ramulis terminalia. 


\section{D.}

$(1,5,5)$

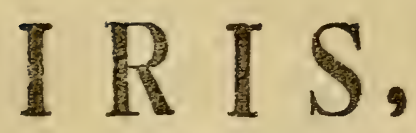

QUAM

DISSERTATIONE BOTANICA

DELINEATAM,

CONS. EXPERIENT. FAC. MED. UPSAL.

\section{PRAESIDE}

\section{CAROL.P. THUNBERG,}

Med. Doct., Prof. Reg. ext Extraord., Acad. Cresar. N. C. Reg. Scient. Holmiens. Societ. Scient. Upsal. Patr. Holmiens. Berolin. N. Scrutat. Lundin. Harlem. Amstel. et Nidrosiens. Membro.

PUBLICO EXAMINI SUBJICIT, Stipendiar. Bjelikian.

\section{OLAUS JACOB. EKMAN,}

SUDERMANNUS.

IN AUDIT, GUSTAY. MAJ, D. XVI DEC. ANNO MDCCLXXXIT. H. A. M. S.

\section{UPSALIAE,}

APUd JOH. EDMAN, DIRECT, ET REg. ACAD. TYPOGR, 

SACRAM REGIAM MAJESTATEM

\section{SUMM FEDEI VIR。}

ReGis Regnique SvIogothicI SENATOR, Reginde Augustissime SUMME MARESCHALLE,

Regil Collegir Metallici PR ESES,
OMNIUM S:R R:IE M:Tis ORDINum
EQUES ET COMMENDATOR,

ILLUSTRISSIME EXCELLENTISSIMEQWE COMES AC DOMINE,

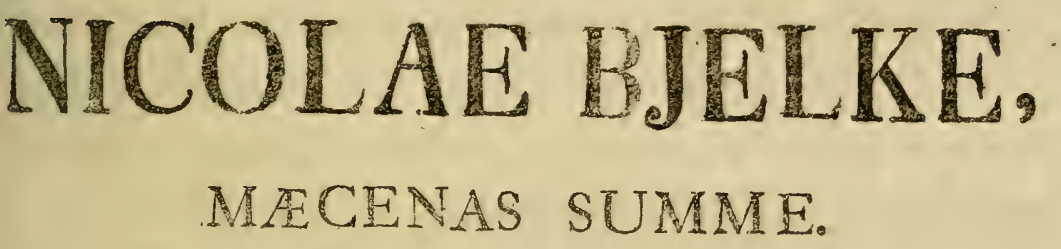

Qur paternum avum meum, ante bos quatuen annos pie defunctum, Excridentissime Heros, benevolentifinai amoris adfectusque pignoribus adeo profequi dignatus es, wt ipfum gloriantem andiverim fe numquam ullum $\mathrm{T}$ U I in $f_{s}$ 


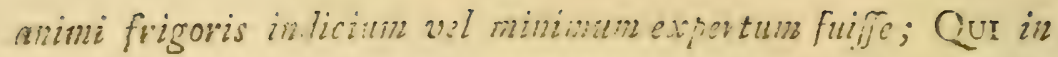

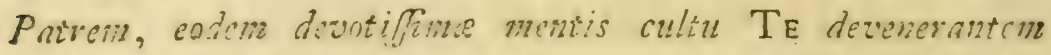

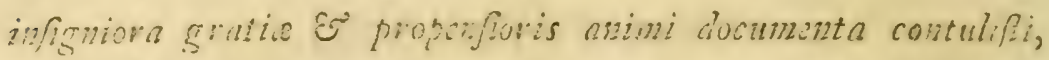
patiaris etjoin, que TuA ef proliva gratiu, Filium publice de co fibi gratulari, guod nova generofu $\mathrm{T}$ U $\mathrm{x}$ in le quoque voluntatis fignificatione auifus fit $\mathcal{E}$ exbilaratus." Hac fpe G fingulizi, quo litteras litterarumque cultores, quormm eso

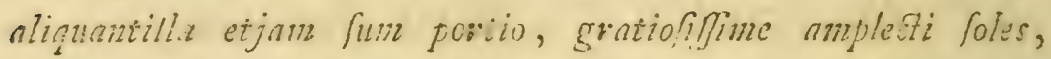
favore fretus, prinitias las TUO NOMIN I coisecribe non fun verecundatus, mean pictatem fuljeciffimo animo teftificuturus: bunillinis finul precibus contendens, velis Tanto in

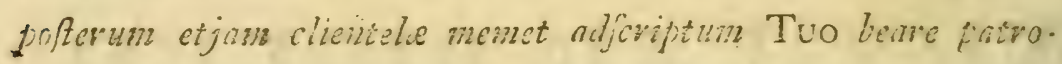
cinio. Supplices preces intis, que pro TUA incolunnitate fulit funditaue patria TE inter fua prafidia E dulcia decora nuanerans, zumanuan ridjungeye dejuzet

II.LUSTRISSIMI EXCELLENTISSIMIQUE MOMINIS TUI

Cultor devotifimins

OLAUS JACOB. EKAMN. 


\section{IR I D E.}

\section{§. I.} Quid ad certam plantarum cognitionem faciant
defcriptiones generum \& fpecierum adcuratiores, illum non fugere poteft, qui vel tantillum ftudio botanico operam dedit. Inficias quidem ire neminem mihi perfvadeo, Botanicen multum cepife incrementi, poftquam in Sciencix formam redacta fuerit \& ordines fyrtematici plures fuerint inventi. Facile autem ut inveniatur nomen plantz \& eo ipfo ut innotefcat tota ejus hiftoria, requiritur: Ut optima ejus exhibeatur figura, æneis infculpta laminis, eaque vel fine coloribus impreffa vel coloribus vivis illuftrata; ut optime, fuccinete \& perfeete fit omnibus fuis partibus defcripta, terminis technicis optimis, diftinetis \& notis; ut bene, artificiofe \& ftudio elaboratum fit Syftema, utque determinetur Claffis \& Ordo; ut genus certum fit, character ejus brevis \& optimus atque charaeter fpecificus fimul erutus; ut Synonyma Auctorum examinentur follicite \& vera certaque citentur; ut denique varietates a folo \& climate obferventur, defcribantur. Hæc ego mecum confiderans, dum Differtationis materiam eligerem, prolixum Irịdum genus melius nofre, accuratius examinare \& perfechius defcribere mihi propofui, eo animo, ut octoA

decim 
decin novarum fpecierum africanarum, quas in Promontorio bonæ fpei detexit Celeb. Dn. Præles, defcriptionibus \& quinque earum figuris non nullam apud $T e, B$. L. inirem gratiam.

$$
\text { 5. II. }
$$

IRIS, planta triandra, monogyna, dignofcenda corolla fupera, hexapetala, inxquali, petalis alternis geniculato - patentibus \& ftigmatibus cucullato - bilabiatis, pertinet ad

CæEAlpini Herbaceas, triplici principio, bulbofas. Morisoni Hexapetalas Tricapfulares.

Rajı Graminifolias Floriferas vafculo tricapfulari. Chriftophor. KNaUtir Unicapfulares hexapetalas. Chriftian. Knautif Monopetalas difformes.

Hermanini Tricaplulares.

Boerhavir Monocotyledones bracteatas.

Ruppir Regulares monopetalas.

Ludvigir Regulares hexapetalas.

TOURNEFORTII Liliaceas.

Magnolir Calice folum interno, bulbofas.

LinNæI Triandras, Monogynas.

Ordinem naturalem Enfatarum.

\section{§. III. \\ DESCRIPTIO GENERIS.}

Calyx. Spatbo bivalves, perfiftentes.

corolla 6 -petala, inæqualis, fupera. Petala tria majora, geniculata: Ungues lineares, intus concavi, extus convexi, parum fuperne dilatati, erecti; Lamnıı oblongx, patentes. 


$$
\text { De Iride. }
$$

Genu barbatum vel imberbe. Petala tria alterna minora, erecto-patula.

NECTAR. Linea longitudinalis in unguibus \& genu petalorum majorum fæpe villola.

stam. Fulamenta tria, germini inferta, lineari fubulata, corolla breviora.

Anthera oblongx, ftigmatibus tectx.

Pistill. Germen inferum, glabrum.

Stylus breviffimus.

Stignata tria, petaliformia, lineari-oblonga, intus carinata, extus fulcata, erecta, ftaminibus incumbentia, bilabiata. Labinm exteruus minus, emarginatum; interius majus, bifidum, fubinflexum.

PERIC. Capfula infera, oblonga, angulata, glabra, trivalvis, trilocularis.

Sernina plurima, ovata, glabra.

Cbaracter Genericus: Corolla 6-petala, inæqualis. Petala alterna geniculato - patentia. Stigmata tria, cucullato-bilabiata.

Differt r:o ab Ixia, Croco, Gladiolo, Antbolyza: corolla hexapetala.

2:0 a Morca, cui proxime accedit:

I. Petalis alternis geniculato-patentibus, alternis erectis.

2. Stigmatibus cucullato-bilabiatis.

Corolla quidem frpius 6-petala invenitur, petalis ad infimam usque bafin divifis; interdum tamen A 2

bafi 
bafn leviter coherent unguibus, non tamen totis ut in monopetalis \& tubulofis corollis.

Filawnenta in africanis prælertim fpeciebus fape plus minus cohrrent monadelpha, dum in aliis perfecte libera funt.

Capfula aliis \& quidem fxpius trigona, aliis, rarius tamen, hexagona.

$$
\text { S. IV. }
$$

Characteres Specierum.

\section{* BARBAT E.}

a. foliis enfiformibus.

ciliata. 1. I. barbata folis enfiformibus ciliatis. minata. 2. I. barbata foliis enfiformibus glabris, fapo unifloro, petalis oblongis acutis.

pzanila. 3. I. barbata foliis enfiformibus glabris, fcapo unifloro, petalis oblongis obufis.

frefinne. 4. I. barbata foliis enfiformibus glabris, fcapo uniforo, petalis rocundacis.

florenztina. 5. I. barbata foliis enfiformibus glabris brevioribus fcapo fubbifloro.

biflora. 6. I. barbara folis enfiformibus glabris brevioribus fcapo fubtrifloro.

apbylla 7. İ. barbata foliis enfiformibus glabris aquantibus, fapo mulifioro fubnudo. variegata. 8. I. barbata folis enfiformibus glabris $x$ quantibus, fapo multifloro.

germanca. s. I. barbata folis enfiformibus glabris falcatis brevioribus fcapo multifioro. 


\section{De. Iride.}

Sambucina. IO.I. bartata foliis enfiformibus glabris erectis brevioribus fcapo multifloro, petalis deflexis planis:

Squalens, in. I. barbata foliis enfiformibus glabris ereetis brevioribus fcapo multifloro, peralis deflexis replicatis.

comprefJa. 12. I. barbata foliis enfiformitus glabris, fcapo paniculato compreffo.

dichotoma. 13. I. barbata foliis enfiformibus glabris, caule paniculato tereti.

b. foliis linearibus.

tripetala. I4. I. barbata folio lineari longiori fcapo unifloro, petalis alternis fubulatis.

iricuspis. I5. I. barbata folio lineari longiore fcapo fubbifloro, petalis alternis trifidis. plumaria. 16. I. barbata foliis linearibus, fcapo multifloro, ftigmatibus fetaceo-multifidis.

\section{* * IMBERBES. \\ a. foliis en/iformibus:}

xipbium. I7. I. imberbis foliis enfiformibus canalicula* to-fubulatis brevioribus fcapo bifloro. p. feudacorus. 18.1.imberbis foliis enfiformibus, petalis alternis tigmate minoribus.

fretida. I9. I. imberbis foliis enfiformibus, fcapo unangulato.

virginica. 20. I. imberbis foliis enfiformibus, fcapo ancipiti.

werficolor. 2 I. I. imberbis foliis enfiformibus, fcapo tereti flexuofo, germinibus fubtrigonis.

$$
\text { A } 3 \text { ocbro- }
$$


ocbroleuca. 22. I. imberbis foliis enliformibus, fapo fubtereti, germinibus hexagnonis.

spatbacea. 23. I. imberbis foliis enfiformibus rigidis, fcapo tereti bifloro, fpathis longiffimis. ramnofa. 24. I. imberbis foliis enfiformibus, caule paniculato multifloro.

\section{b. foliis linearihus.}

fifyrincbium. 25. I. imberbis foliis linearibus undulatis reflexis, fcapo unifloro.

verna. 26. I. imberbis foliis linearibus planis, fcapo unifioro, petalis alternis æquantibus. perfica. $\quad 27$. I. imberbis foliis linearibus planis, fcapo unifloro, petalis alternis brevioribus. angufta. 28. I. imberbis folio filiformi-lineari erecto glabro, fcapo glabro fubunifloro, rpathis obtufis.

Setacea. 29. I. imberbis folio filiformi-lineari ereeto glabro, fcapo glabro unifloro, fpathis acutis membranaceis.

tenuifolia. 30. I. imberbis foliis filiformi-linearibus, fcapo billoro.

graminea. 31. I. imberbis foliis linearibus, fcapo fubbifloro ancipiti, germinibus hexagonis.

Spuria. 32. I. imberbis foliis linearibns, fcapo fubtrifloro tereti, germinibus hexagonis. fibirica. 33. I. imberbis foliis linearibus, fcapo fubtrifloro tereti, germinibus trigonis. martinicen/2s.34.I. imberbis foliis linearibus, petalis baf foveolis glandulofis, germinibus tri. gonis. 
pavonia. 35. I. imberbis folio lineari glabro, fcapo fubunifloro.

crispa. 36. I. imberbis foliis linearibus crifpis. papilionacea.37. I. imberbis foliis linearibus reflexis hirtis.

edulis. 38. I. imberbis folio lineari pendulo glabro, fcapo glabro multifloro.

triftis. $\quad 39$. I. imberbis foliis linearibus glabris, fca-" po hirto ramofo.

polyfacbya. 40. I. imberbis foliis linearibus planis, fcapo glabro ramofo.

vifaria. 4I. I. imberbis foliis linearibus planis, fcapo vifcofo.

bituminof 17. 42. I. imberbis foliis linearibus fpiralibus, fcapo vifcofo.

c. foliis tetragonis.

tuberofa. 43. I. imberbis foliis tetragonis.

$$
\text { 5. } \mathrm{V} \text {. }
$$

DESCRIPTIO SPECIERUM.

Radix plerisque bulbofa eft vel carnofa, paucis tuberofa \& fibrofa.

Scapus teres, angulatus vel compreffus; fimplex vel divifus; uniforus, paucifiorus vel multiflorus; foliis brevior, xqualis vel longior.

Folia vaginantia, equitantia; nuda, rarius hirta; integra, quandoque undulata, crifpa vel fpiralia; enfiformia, lineari-enffformia, linearia, linearifiliformia \& rarius tetragona; caule longiora, breviora vel æqualia. 
Flores, unus, duo, tres, plures; numerus inconftans; fenfim florentes; colore infinite variantes: albi, lutei, purpurei, cærulei \& frepius variegati.

1. Cillata: I. barbata foliis enfiformibus ciliatis. Bulbus ovatus, fibrofus, reticulatus, magnitudine avellanæ.

Scapi plures, quorum plurimi vaginis foliorum reconduntur \& unicus floret; hic foliis vaginatus totus, fimplex, compreffus, debilis, albus, glaber, erectus, uniforus, palmaris.

Folia radicalia circiter fena, bafi convoluta, fcapum ad fummum apicem alternatim vaginantia, enfiformia, acuminata, erecto - patentia vel recurva, nervofa, glabra, integra, margine ciliata, fcapo fubæqualia, interioribus fenfim brevioribus magisque convolutis.

Corolla lutea. Petala minora obovata.

Stignthatis labium interius bifidum: lacinice fetacex, longitudine ftigmatis.

Capfula trigona, trifulca.

2. Minuta. I. barbata foliis enfiformibus glabris, fcapo uniforo, petalis oblongis acutis.

Bulbus ovatus, reticulacus, magnitudine pifi majoris.

Scaptzs fimplex, foliis vaginatus, ereetus, uniflorus, palmaris.

Folia circiter quatuor, alternatim vaginantia, enfiformia, fubfalcato-reflexa, integra, glabra, fcapum æquantia, fuperiora fenfim breviora. Corolla lutea. Petala minora lanceolata. 
3. Pumila. I. barbata foliis enfiformibus glabris, fcapo unifloro, petalis oblongis obtufis. I

Scapzus foliis vaginatus, fimplex, uniflorus, palmaris.

Folia circiter quinque, alternatim vaginantia, enfiformia, ftriata, glabra, fcapum xquantia.

Variat fcapo foliis longiori \& breviori.

4. Susiana. I. barbata foliis enfiformibus glabris,

rcapo unifloro, petalis rotundatis.

Scapus fimplex, teres, fulcatus, unifforus, fpithamæus.

Folia alterna, vaginantia, enfiformia, erecta, tenuifime friata, obfolete undulata.

Corolla omnium congenerum maxima, tenuisfima, albo nigroque variegata, palmaris vel ultra.

Ũngzes petalorum majortum extus purpurei, intus purpureo-punetati \& ftriati, unguiculares. Lamince fuborbiculatx, undulatx, apice inflexo, ere\&tx. Genu atrum. Pet. minorum lanine ovatæ, deflexæ, margine frpe retroflexo, obtufx, majoribus concolores, breviores \& anguftiores. Ungries intus a genu ad bafin ciliis flavo-fufcis barbaci.

Stigmata petalis concolora. Labizum interius obtufiffimum; exteyizus bifidum: lacinice ovatæ, crenulatx, retroflexx.

Capfula obfolete trigona, acumine longo, apice amplo, lineis tribus purpureis.

5. Florentina. I. barbata foliis enffformibus glabris brevioribus fapo fubbifloro. $_{B}$ 
Scapus teres, ftriatus, fimplex, erectus, fubtriflorus, pedalis \& ultra.

Folia enfiformia, nervofa, fubfalcata, margine externo obfolete crifpa.

Petala infima bafi connata. Unggues majorum craffiufculi margine alari tenui, pollicares, extus virides, intus barbati ciliis albis, apice flavis. Genu barbatum. Lamince obtufx, emarginatx, pollicem latx, pollice paullo longiores, dependentes, albx, prope genu ftriatx. P. qmz:ora oblonga, erecto-inflexa margine reflexo, obtufa, emarginata, alba, bipollicaria; ungues craffufculi, attenuati, virefcentes, unguiculares.

Antbere albr, unguiculares.

Stigmata nivea, longitudine unguium peralo. rum majorum, unguem lata; loburum interius obtufiffimum, externus bifidum: lacinice acutx, crenulatx, ereetr.

Capfula acumine pollicari fubcomprefro bifulco obfolete trigono, trifulca, unguicularis.

Simillima I. Germanicx, differt vero:

I. petalis albis integris.

2. P. minorum marginibus bafi reflexis.

3. majoribus magis ereetis.

4. Stigmatis labio crenato \& magis erekto.

6. BIFLORA I. barbata foliis enfiformibus glabris brevioribus fcapo fubtrifloro.

Scapus fimplex, ftriatus, biflorus vel triflorus, foliis longior, fpithamaus. 
Folia equitancia, enfiformia, fubfalcata, acuta, friaca, erecto-patula.

Prtali violacea, integra.

Capjula teres, triftriata.

7. Aphylla. I. barbata foliis enfiformibus glabris

quantibus, fcapo multifloro fubnudo.

8. Variegata. I. barbata foliis enfformibus glabris xquantibus, fcapo multifloro.

Scapus ftriatus, foliis vix longior, pedalis \& ultra. Folia equitantia, enfiformia, acuta, ftriata, ereata; inferiora fcapi longitudine, Juperiora fenfim breviora,

Fiores in fummitate fcapi divifi, alterni, fenfim florentes, fpeciofi, flavi, nigro reticulati.

9. GERMANiCA. I. barbata foliis enfiformibus glabris

falcatis brevioribus fcapo multifloro.

Scapus fuperne divifus, multillorus, foliis longior.

Folia enfformia, refexo-falcata, nervofa, pollicem lata.

Flores cærulei. Petala minora integerrima. 10. Sambucina. I, barbata foliis enfiformibus glabris erectis brevioribus fcapo multifloro, petalis dellexis planis.

Scapus fuperne divifus, multiflorus, foliis longior, bipedalis.

Folia enfiformia, apice inflexo-falcata, ftriata, fuperiora fenfim breviora.

Similis I. germanicx, differt autem:

a. petalis majoribus faturatius violaceis \& fubemarginatis. 


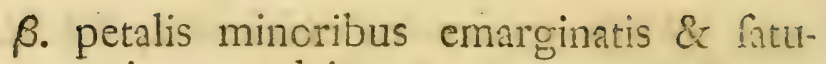
ratius cærtuleis.

\%. Rtigmatibus acutis, ferratis, carina corulefcente.

\1. SQualens. I. barbata foliis enfiformibus glabris erectis brevioribus fcapo multifloro, petalis deflexis replicatis.

Scapus apice divifus, hoc ent, foribus inferiobus pedunculatis, ftriatus, mulifiorts, folis longior, bipedalis.

Folia alterna, enfformia, acuta, norvofa.

Flores albi vel cxrulei.

Difjert a Germanica, cui quodamrnodo funlis:

t. petalis majoribus medio replicatis, fatumatus violaceis venis albis, flavefcentibus \& $\mathrm{in}$ modio cærulefcentibus.

2. petalis ninoribus \& ftigmatibus fquolide favis \& emarginatis.

13. Compressa I. barbata follis enfformibus glanis, fcapo paniculato compreffo.

Caulis frutefcens, compreffus, glaber, dichocome rnmofus, articulatus, decumbens, apice ereeturculus, bracteatus, pedalis \& ultra.

Rami alterni, elongati, fcapo fmiles, unifori.

Bractex feu Spatbx in caule \& ramis alternx, compreffe, carina acuta, glabræ, apice membranacex, pollicares, internodiis breviores.

Folia alterna, enfiformia, acuta, nervofa, glabra, caule breviora, pedalia. 
Corollo alba. Ungues petalorum majorum parum dilatati, intus barbati, flavo-punctati. Gerut macula flava. Lawine obtulx. $P$. mumorims unuuses duplo anguftiores, immaculati. Lamm oblongæ, obtufæ, erectæ.

Filamenta bafi infima connata, fubulata, alba. Stignata albido-cxrulefcentia: labium externts crenulatum; interius bifidum; lacinice lanceolatx, erectx, petalis breviores.

I3. Dichotoma. I. barbata foliis enfformibus glabris, caule paniculato tereti.

Caulis teres, glaber, ramofus.

Rami fimplices, elongati, nudi, patentifimi, circiter triflori.

Folia radicalia fex vel feptem, alternantia, amplexicaulia, enfiformia, difticha, brevia; caulina ad ramificationem fingulam breviffima.

Flores longe pedunculati, dilute purpurafcen. tes, omnium congenerum ninimi.

I4. Tripetala. I. barbata folio lineari longiori, feapo unifloro, petalis alternis fubulatis.

Bulbus ftriatus, globofus, fibrillofus.

Folizun unicum, vaginans, lineare, canalicula. tum, glabrum, nervofum, laxum, dependens, fcapo duplo longius.

Scapus fimplex, erectus, teres, geniculatus, fubuniflorus, glaber, pedalis. Gericula brakteis fpathis fimilibus amplexata.

Elos terminalis, folitarius.

$$
\text { B } 3
$$

$\operatorname{Spg}$ 
Spatha bivalvis, pedunculum amplexans: infirior brevior, acuta, glabra, unguicularis vel ultra. Intra latet flos inexplicatus cum braeteis duabus tenuiffimis, lineari-oblongis.

Corolla cxrulea genu flavefcente. Ungues petalorum majorum latiores, lineares, intus cæruleoprnerati, barbati, bafi fovea neetarea: lamin.e ovatx, acute, caruleo-albx, genz barbato. $P$. minorum ungues anguntifimi, extus convexi, infra genu frpe dentibus duobus oppofitis; larnince geniculato - patentes, lineari - fubulatix. Ungzues omnes bafi connati, germini inferti.

Filanenta longitudine dimidia tubi, bafi connata.

Antbere flavefcentes.

Germeil ovatum, fexfulcatum.

Stylus trigonus, incraffatus, glaber.

Stiginata linearia; labiun exterius obtufum; interizus longifimum, acutum, longitudine fere laminarum.

15. Tricuspis. I. barbata folio lineari longiori fcapo fubbiforo, petalis alternis trifidis,

Bulbus magnitudine avellanx.

Scapus implex, teres, geniculatus, erectus, uniflorus vel biflorus, fefquipedalis.

Folium unicum, lineare, nervofum, erectum, apice dependens, fcapo longius, bipedale.

Lamine petalorun majorum albæ, fuborbiculatæ cum acumine, pollicares. Ungues extus virides, intus Alavi, nigro punetati. $P$. minora multoties breviora \& minora. Unglues extus convexi, 
vexi, virides, intus concavi, fulco punctati, longicudine majorum, fed anguftiores. Lawitzice trifidx: Lacinie lanceolatex, divaricatw, lineam longx, intermedia paullo longiori, albæ fuico punetatx.

Stigmatis labum interius bifidum; hamue o. vatæ, obtufx, laminis majorum petalorum duplo breviores, albæ, erectx.

1. Variat a: lacinis pet. majorum, fubrotundis. $\beta$ - - ovatis, pollicaribus, flavis. a. Genu macula magna cærulea, circulo violaceo.

ß. - - - crocea, læpe obfoleta.

2. Variat a. corolla purpurea.

$$
\begin{aligned}
& \text { b. - - flava. } \\
& \text { c. - - alba. } \\
& \text { d. - violicea. }
\end{aligned}
$$

16. Plumaria. I. barbata foliis linearibus, fapo multifloro, ftigmatibus fetaceo-multifidis.

Scapus geniculatus, flexuolus, erectufculus, apice ramofus, bracteatus, palmaris usque fpithamaus. Folium lineare, reflexo-pacens, fcapo brevius. Petala bafi connata: untuges major uzn obovaci, extus virefcentes margine tenuiori cxruleo; intus dilute cærulei. Genu macula flava tridentata, linea duplici barbata. Lamine obufe, violaceæ, unguiculares; alternæ paullo anguitiores \& breviores.

Antbera antice crocex, apice \& dorfo nigre. Stigmata dilute cærulea, laminis petalorum breviora, cucullato-bilabiata. Labium exterius 
linen:- apice fetazeo-arinato fecis quingue rel fer brevilus, incurvum; interus brevius, fetaccomultidun, infar petaloum Dianthi plumarii. Rarinme fcapus occurrit uniHorus; fiepius ramolus eft, ramis unifionis atque trifuris.

17. Xiprium. I. imberbis foliis enfiformibus canaliculato-fubulatis brevioribus fapo bifioro.

Folia enfiformia, non baf folum, ut in ceteris, fed tota longitudinaliter canaliculato-convoluta, apice fubulata, fcapo breviora.

Flores carulei pealis emarginatis.

18. PsEUDACORUS. I. imberbis foliis enfformibus, petalis alternis ftigmate minoribus.

Radix carnofa.

Sonpus multiflorus, floribas pedunculatis.

Eulia radicalia \& carlina alternantia, enfiformia, plana, nervofa, caulem xquantia.

Petala lutea; majora utrinque unidenảata.

r9. Foetid.A. I. imuerbis foliis enfiformitus, fcapo unangulato.

Scaprss fimplex, femiceres vel unangulatus, articulatus, folits fpathaceis alternis vaginatus, multiflorus, bipedalis.

Folia enfiformia, acuta, nervofa, fcapo breviora, fcetida.

Petala cærulefcenti-triftia, magnitudine mediocria. Ungrses majorum fubtus plicis rugofi; minora ereeto-patula, ftigmatibus majora. 20. VIrginica. I. imberbis foliis enfiformibus, fapo ancipiti. 
Scapres anceps, articulatus, foliis alternis vaginatus, multiflorus, foliorum longitudine, pedalis. Folias enfformia, anguftiora, apice incurva, nervofa; fuperiora fenfim breviora.

branacex.

Spatb e margine \& apice tenuifima, mem. 2r. Versicolor. I. imberbis foliis enfiformibus, fapo tere: hexuofo, germinibus fubtrigonis.

Scapus teres, articulatus, apice bifidus vel fimplex, multiflorus, foliis longior, bipedalis.

Folia alterna, vaginantia; Juperiora fenfim breviora.

Flores cærulei, magni.

22. Ochrolevca. I. imberbis foliis enfformibus, fapo fubtereti, germinibus hexagonis.

Scapus teres, foliorum vaginis tectus, multforus, foliis longior, pedalis.

Folia enfiformia, falcata, acuta, ftriara, nervofa. Spatbe marginibus membranacea.

Petala majora bafi dilatata venis obfcuris; minor nivea bafi venis flavefcentibus.

Stigmata nivea.

Capjula hexagona angulis obtufis.

23. Spathacea. I. imberbis foliis enfiformibus rigidis, fcapo tereti bifloro, fpathis longiffimis. Scapus fimplex, multiflorus, pedalis.

Folia duo vel unicum, enfiformia, a medio ad apicem lenfim valde attenuata, marginata, nervo$f_{2}$, Atriata, rigida, glabra. 
Spatbe foliis fimiles, fed latiores, apice membranacex, fpithamix.

Flores lutei.

24. Ranosa. I. imberbis foliis enfiformibus, cuule paniculato multifloro.

Caulis inferne teres, digitum craffus, fuperne ramofifimus, muliflorus.

Rumi fubrichotomi, paniculat, comprefioangulati, fiexuofi, glabri.

Folac radicalia enfiformia, longe vaginantia, nervofa, apice attenuata, glabra, longitudine circiter caulis. Caulina fenfim breviora \& in Spathas abeuntia.

Flores lutei, minuti.

Broffec ad ramificationes ovatx, acutx, membranacex, ramis \& pedunculis breviores.

25. Sisyrinchium. I. imberbis foliis linearibus undulatis reflexis, fcapo unifloro.

Bulbe duo, alter alteri impoficus.

Scapus brevifimus, fimplex, foliis vaginatus totus, uniflorus, digitalis.

Folia plura, linearia, apice attenuata, reflexa, undulata, fcapo longiora.

Petala purpurea, genne macula lutea.

26. Verna. I. imberbis foliis linearibus planis, fcapo unifioro, petalis alternis xquantibus. Radix fibrofa. florus.

Scapus fpathis alternis tectus, fimplex, uni-

Folia linearia, nervofa. 


\section{De lride.}

27. PERsica. I. imberbis foliis linearibus planis, fcapo unifloro, petalis alternis brevioribus.

siapus fimplex, uniforus, palmaris.

Folia linearia, plana, friato-nervofa, inæqualia, fcapo longiora, fpithamæa.

Petala majora oblonga, obtufa, undulata, fubemarginata, convoluta; medio linea flava punctis violaceis, apice maculis violaceis. Minora linearioblonga, patula, alba, convoluta, unguicularia.

Stigmatis labıuzn utrumque ereetum, albo cærulefcens. Interius bifidum: lacinice lanceolatæ̇, femi- unguiculares.

28. Angusta. I. imberbis folio filiformi-lineari erecto glabro, feapo glabro fubunifloro, fpathis obtufis.

Bulbus ovatus, tunicatus, glaber, fibrofus, magnitudine avellanæ.

Scapus teres, erectus, fubfimplex, glaber, vaginatus, articulatus, fpithamrus vel paullo ultra.

Folizm fcapum inferne longe vaginans, filiformi-teres, acuminatum, friatum, glabrum, ereEturn, fcapo longius.

Flores terminales, unicus vel duo, erecti, fenfim florentes.

Spatba exterior glabra, viridis apice rubro, pollicaris; interiores tenuiffimæ, albx.

Ungues petalorum majorum flavi margine albido, utrinque purpureo-punctati. Genu lave, croceum circulo purpureo. Lamine ovatæ, obtufx, patentes, pollicares, intus flavæ, extus pur-

$$
\mathrm{C}_{2}
$$

pureo- 
pureo-nervofa. P. mingera lanccolata, ofturn, Hava, extus fufco-purpurco-ftriata, fenfin in ungres attenuata. Unigues omnes bafi connati.

Stigmatum labiun interizes bifidum: lacinice oblongæ, acutæ, interiori latere rectx, exterioni productx, erectx, flava.

Capfula acute trigona, obtufa.

29. Setacea. I. imberbis folio filifom ineari ereato glabro, fcapo giabro unifloro, pathis acutis membranaceis.

Screus filformis, fxpius fimplex, unilorus; maro divifus, triforus; ereens, palmaris usque fpithamaitus:

Folizm fapius unicum, rarius duo, filifomilineare, ereetum, apice cernuum, fcapo duplo longius.

Hlores cærulei, minuti.

3o. Tenutania. I. imberbis foliis flifomi-linearibus, fcapo bifloro.

Scopizs fimplex, foliorum vaginis tectus, biflorus.

Folia pauca, lineari-filiformia, vaginis latis decurrentia.

Flores bini, terminales, pallide cxrulei.

Capfela filiformis, corolla longior.

Stignatis labiann exterizs brevifimum, obtufum; interizs bifidum: lacinice oblongx, multo. ties longiores.

31. Gramines. I. imberbis foliis linearibus, fcapo iubtrifloro ancipiti, germinibus hexagonis. 
Scopus compreffus, fubdiphyllus, uniforus vel billortis, fpithamatis.

Folia linearia, ftriata, fcapo longiora.

Flores cxrulei \& lutei.

Capfula ventricofa, hexagona.

32. Spuria. I. imberbis foliis linearibus, fcapo fubtrifloro tereti, germinibus hexagonis.

Scatus teres, fuperne divifus, fubtriflorus. Folia linearia, acuta, plana.

Flores cxrulei.

33. Simirica. I. imberbis foliis linearibus, fcapo fub-

trifloro tereci, gुerminibus trigotris.

Scofus teres, fuperne divifus, trifiorus vel mutifiorus, follis longior, pedalis \& ultra.

Folia linearia, nervofa, plana.

Flores cxrulei.

Spatbe brunnex, fcariofi.

34. Mratingerss. I. imberbis foliis linearibus, pe talis bafi foveolis glandulofis, germinibus trigonis.

35. Pavonia. I. imberbis folio lineari glabro, fcapo fubunifioro.

Scapus teres, articulatus, villofus, fimplex, fubbiflorus, pedalis.

Foliun unicum, lineare, fubcanaliculatum, ftriatum, villofum, fcapi longitudine.

Spatbe acutæ, ftriatæ, glabræ, bipollicares.

Pedunculi fubancipites, uniflori, glabri.

I'etala omnia bafi coalita; tria exteriora multo. ries majora, ovata, obtula, integra; iria interiora

$$
\text { C } 3 \text {. }
$$


nuteo anguftiora \& dimidio breviora, "lanceolata, acuta.

Nedaria tria intra petala majora: fingulum foliolurn ovatum, obtulum, petaliforme ad bafin.

Filamenta ultra medium connata in cylindrum, lincari-fubulata, corolla multoties breviora, purpurafcentia.

Aintbere ftigmatibus adpreffre, aurantiacx, lineis duabus fufcis.

Strgmata longitudine faminum.

Capjula trigona.

Pulcherrimus fane flos Corolla aurantiaca:

bafi maculis punctisque nigris \& fupra bafin macula cordata carulea, cujus bafis eft tomentofo- nigra.

36. Crispa. I. imberbis foliis linearibus crifpis.

Scapus fulcatus, fiexuofus, fuperne divifus, palmaris vel ultra.

Folia radicalia, alterna, lineari-attenuata, crifpa, rellexa, fcapo xqualia vel longiora.

Flores terminales, alterni, inferiores pedunculati, tres vel quatuor.

Corolia 6-petala.

Petala alterna majora; Inmine ovatx obtulx, venofx, unguiculares. Genu imberbe, luteum, tenuiffime punctatum. Alterna minora, paullo anguntiora, majoribus vix breviora, confimilia, patentia.

Antbere ovatx, nigræ. Pollen a latere exteriori fulvum. 


\section{De Iride.}

Stignatis labiun exterius breviffimum, luteum; interius bifium, luteum: lecinas lanceolate, acuta, longitudine petalorum.

Varietates a) petalis luteis, venis fanguineis.

$\beta$ ) .. - cæruleis.

$\gamma$ ) - incarnatis.

37. Papilionacea. I. imberbis foliis linearibus reflexis: hirtis.

Bullus ovacus, tunicatus, magnitudine pifi. palmaris.

Scapus ereetus, pilolus, divifus, multiflorus,

Folic alternantia, enfformia, convoluta, flexuolorecurvata; extus lineata, pilofa; intus pubefcentia; longitudine fcapi vel paullo longiora; fuperiora breviora, fuprema fpathæformia.

Spathe binæ vaginantes, folis fimiles, pilofx. l'edunculi trigoni, ex eodem centro bini, tres vel quinque, incraffati, glabri, inæquales, fenfim florentes.

Ungues petalorum majorzm latiores, bafi fovea neetarifera, viridi-variegati. Lamine ovatæ, acutæ. Genu imberbe circulo viridi. Minorum zingues lineares; lanince ovato-oblongæ, acutæ. Ungues omnes bafi connati.

Stigmatum labium interius bifdum: lacinia oblongx, acutx.

$V$ arietates funt plures:

a) Corolla tota flava: genu circulo viridi.

ß) petalis \& piftillis intus rubris; genu macula flava: circulo fufco. 
$\gamma)$ pecalis tribus majoribus totis flavis: genu circulo viridi; petalorum trium minorum laminis piftllorumque labiis internis fanguineis.

Differt hæc ab. I, ciliata.

I. foliis totis hirtis.

2. laminis alternis ovatis.

38. Exutrs. I. imberbis folio lineari pendulo glabro, fapo glabro multiloro.

Scapus profunde radicatus, reres, Alexuofus, fisperne divifus, multiflorus, pedalis.

Folium fcapum inferne longe vaginans, lineare, ereßum, apice dependens, fcapo triplo long:

Flores folitarii vel plures, alterni, fubfecundi. Petals bafi connata.

Frlamenta fubulata, alba, bafi, uti corolla, connata.

Anthere antice fulcate, flavæ vel albr.

Stigmatis labnum exterizs obtufum, integerrimum; interias bifdum; lasinice lanceolate, acutæ, latere altero producto crenulatæ, erectoinflexx, longitudine petal. minorum.

Variai 1:0 Corolla cxrulea, in qua ungues petalorum majorum intus fufco-friati; grenu imberbe, fufco-ftriatum; laminæ crenulate, pollicares. Petala minora lineari-lanceolata, obtufa, emarginata, unguibus majorum paullo longiora, majoribus duplo anguftiora.

2:0 Corolla alba. 
3:0 Coiolla lutea, in qua ungues petalorum majorum obovati, extrs virefcentes, lateribus flavis; intus flavi maculis flavo-virentibus, villofi. Lamine oblongæ obtufæ, flavæ, pollicares. Genu imberbe, croceum macula flava. Petala minora Iutea.

39. 'Tristis. I. imberbis follis linearibus glabris, fcapo hirto ramofo. thamæus.

Scapus divifus, ereetiufculus, multiflorus, fpi-

Rami feu pedunculi flexuof, patentifimi, hir: futi, uniflori usque triflori.

Folia alcerna, enfiformi-linearia, undulata, nervofa, apice dependentia, fcapo longiora.

Petala minora dimidio anguftiora, ovato-lanceolata. Tulyus virefcens, bafi connatus.

Latizivace omnes triftes feu trifte-rufefcentes, carina rubra. Genu imberbe, late luteum.

Antberce carulex.

Stigmatis labiun interius bifidum: lacinie lanceolatæ, carina intus cæruleæ, laminis paullo breviores.

40. Polystachya. I. imberbis foliis linearibus planis, fcapo glabro ramofo.

Scapzzs teres, fuperne divifus, articulatus, gla. ber, multiflorus, pedalis vel ultra.

Folia alternantia, linearia, apice fetaceo-attenuata, nervofa, erecta, Scapum xquantia.

Flores magni, fpeciofi, cærulei genubus luteis. Spatbr apice fcariofx, laceræ. 
Differt ab I. ramola: Ccapo ramolo, pedunculis fimplicibus.

4i. VISCARIA. I. imberbis folis linearibus planis, fopo vif́ofo.

Scapus teres, glaber, articulatus, flexuofoerectus, fupeine divifis, glurinofus, purpuriIcens, pedalis.

Nednhali nlemi, flexuor, ghtmof, mitor.

Folia panca, alrema, linearia, crecta, ícapo longiora.

Lnmina pequlum mojormm ovate, obtuiufculæ, unguiculares. Gum imberbe, albidum.

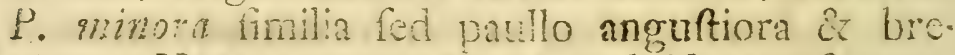
viora. Lizgue extus of intus aluido vircécentes.

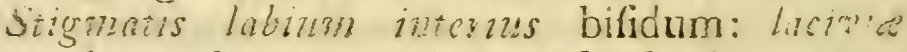
lanceolatx, laminis majorum duplo bieviores; exterius bifidum, duplo brevius.

42. Bitumirosa. 1. imberbis foliis linearibus fpiralibus, fcapo vifcofo.

Scopus articulatus, fexuofo-ereetus, fuperne divifus, glutinofus, multiforus pedalis \& ultra.

Foliurn unicum, lineare, apice attenuatum, fpirale, friatum, glabrum, fcapo brevius.

Spatbe articulos vaginantes, friatx, glabræ. Flores in pedunculis folitarii.

Peduaculi e vaginis cum fcapo duo, filiformes, flexuof, patentes, vifcof, pollicares \& ultra.

Corolla tota unicolor, flava, reflexa.

Petala tria majora obtufa. Genu imberbe, rubro-punctatum. 
Stigmata lutea: Labium exterius minimuni; interius bifidum: lacinice lanceolata, acutz, longitudine petalorum minorum vel unguiculares.

43. Tuberosa. I. imberbis foliis tetragonis.

Folia terragona.

\section{S. VI. \\ SYNONYMA.}

Synonyma Auctorum in prolixo hoc genere plurima funt; ea vero omnia \& fingula heic enumerare, neque neceffe neque utile duximus. Sic ne nimis Differtationis adaugeremus molem, pauciffima \& ea primaria allegare voluimus:

1. ciliata. Linn. Supplem. p. 98 .

1. minzita. Ibid. p. 98.

I. pumila. Linn, Sp. Plant, p. 56. Syrt. Nat. Tom. 2. p. 78 .

I. fufann. Linn. Spec. Plant. p. 55.

I. florequtina. Ibid. p. 55 .

1. biflora. Linn. Spec. Plant. p. 56. Syt. Nat. Tom.2. p. 78 .

1. aphyllia. Linn. Spec. Plant. p. 56.

I. variegatr. Linn. Spec. Plant. p. 56 . Sytt. Nat. Tom. 2. p. 78 .

1 permanica. Linn. Spec. Plant. p. 55.

I Jambucina.Linn. Sp. Pl.p. 55. Syt. Nat. Tom. 2. p. 78. I. Squalenzs. Linn. Spec. Plant. p. 56. Thunberg. Flor. Japon. mfer.

I. compreffi. Linn. Supplem. p. 98. 
I. dicbotoma. Pallas itin. Vol. 3. p. 7I t. 'T. A. f. 2. Linn. Suppl. p. 97 .

1. tripetala. Linn. Supplem. p. 97.

I. tricufpis. Iris tricufpidata. Ibid. p. 98.

I. plannaria. Moræa juncea. Linn. Spec. p1. p. 59. Syft. Nat. 'Tom. 2. p. 79.

Moræa vegeta. ibid.

Morxa iriopetala. Linn. Suppl. p. 100.

1. xipbium. Linn. Sp H. p. 58.

1. peudaconus.ibid. p. 56. Syf. Nat. Tom. 2. p. 79.

I. fretida. Iris feetidiffma. Linn. Sp. Pl. p. $5 \%$

1. verficolor. ibid. p. 57. Thunb. Flor, Japon. mícr.

I. virginica. Linn. Sp. Pl. p. 58.

1. ochrolezca. Linn. Syft. Nat.Tom.2.p.79. Mantifing.

1. Spatbacea. Iris fpathulata. Linn. Supplem. p. 99.

1. ramofa. Iris ramofiffima. ibid, p. 99.

I. fifyriacbiram.Linn. Sp. Pl. p. 59.

1. verua. ibid. p. 58 .

1. perfica. Linn.Sp.Pl. p. 5 .Syft. Nat.Ton. 2. p.79.

1. Setacer. Iris fetifolia. Linn. Suppl. p 99 .

1. tenzurfolia. Pallas Itin. Vol. 3. p. 7 I4. Tab. C. fig. 2. Linn. Supplem. p. 97.

1. graminea. Linn. Sp.P1.p. 58. Syf. Nat.Tom.2.p.79. Thunb. Flor. Japon mfci.

1. Spura. Linn. Sp.Pl.p.58.Syft. Nat.Tom.2.p.79.

I. Jibirica. Linn.Sp.Pl. p.57.Syf. Nat.Tom.2.p.79. Thunb. Flor. Japon. mfer.

I.martinicenfis. Linn. Sp. Pl. p. 5s.Syft. Nat. Tom. 2. p.79.

I. pavonia. Linn. Sripplem, p. 98.

1. crifpa ibid. p. 98. 


\section{Di İride.}

T.papilionacenibid. p. 98 .

T. ecinlis.

ibid. p. 98. Hollandis: Uyenţes.

1. trifics.

ibid. p. 97 .

1. vifertia.

ibid. p. 98.

1. biuzminofa. ibid. p. 98.

1. tuberofa. Linn. Sp. p. 58.

\section{S. VII. \\ LOCUS.}

Inveniuntur Irides fponte crefcentes in omnibus noti orbis partibus; paucifimas tamen alit America borealis, mulas proferunt frigidiores Afin regiones, plures adhuc Europa, tam borealis, quam auftralis; plurimas autem verfus promontorium bonæ fpei calidiffma progignit Africa. Sic crefcunt:

\section{Americane:}

Veyfoculur in Virginia, Marilandia, Penfylvania.

Verma in Virginia

Martinzicenfis in Martinica.

Agnater:

faflan in oriente. Conftantinopoli in Belgiura venitigns. jqualuzs in Japonia.

dicbotona in Dauria rupeltrbus apricis viggris. ocbrolensa in oriente.

perfica in Perfia.

tenziffolin in arenofis Dauriæ \& prope Wolgam. graminea in Japonia.

Marica in Japoniz \& Sibiriz pratis. tuberola in Arabia \& Oriente. 


\section{EUROPRE:}

fumila in collibus apricis Auftrix, Pannonix. jiorentina in Carniola \& Italia. biflora in Lufitanix rupibus. viatugata in Hungaria. germanzea in Germania. fambucina in Europa Auftrali. fiqualezs in Enopa auntrali. xipbium in Hifpania.

pfeudacorus in aquis palucium \& foftrum Svecia, aliarumque Europæ regionum.

feetida in Gallia, Anglia, Hetruria.

fifyrincbizsn in Hifpania, Lufitania.

granimea in Aufria ad radices montium.

Jpuria in Germanix pratis.

fibirica in Aufria \& Helvetix pratis.

AFRICANR:

cilina in collbus prope urbem Cap.

minazta in proclivis nonds Lewweftart didei prope

Cap urbem.

comproth interioribus regionibus Hotentottorum, in fylva propezeckorivier juxta villam incolx hock. irfictaia in collbus prope Cap urbem, juxta Picketberg \& alibi rarius.

trictepis in collibus infra Duyvelsberg copiofe, in

Swartand \& prope Bergrivier.

plumaria infra Duyvelsberg, juxta urbem in colliuus. Spatbare in Hanteniquas regionibus prope Wolfwekranl ingue Lungelloof prope Keurbooms rivier. ramofa in Swartland arenofis. 


\section{De Iride.}

argafa in collibus infra Duyvelsberg \& Leuwekopr. fetace in cullibus hinc inde rarior.

paom in Swartanc collbus \& alibinter fitices rarior. cr) fou prope urbem Cap in collibus.

prophonace in collibus prope urbem Cap, vulgaris. edulis in arenofis Grcenekloof, Swartiand, campis de. preffis exra Cap urtem, in collibus Duyvelsberg \& alibi vulgatifima.

twitis infra Duyvelsberg prope urbem Cap. polylacha inter Sondagsrivier \& Víchrivier. vifcura in arenofis Saldahna bay prope villam incole Lolper.

lituminf prope Dergivier, Vierentvintgrivieren \& alibi. aphylh in horts culta ignotæ achuc patrix eft.

\section{VIII. \\ FLORENDI TEMPUS}

Iridum incidit in illas menfes, qua in illis orbis re ronibus, ubi fponce crefcunt, vernales funt; hx enim, uti phrime alix enfate, bubufe \& frathacex plante primo vere germinant, forefcentia vel breviori vol in alkatem usque protracta. Americanæ itaque, Afiaticx \& Europxæ menfibus Martio, Aprili, Majo \& Zunio, pron patria earum a Borea remotior adeoque calidior fiteric, e terræ gremio primum folia fua protrudunt, mox forbus fpeciofininis fuberbiunt. Africes autem in terris auftralibus, tempora contraria obfervantibus, vernales menfes audiunt Augufuss, September, October, November, dum arenofi \& argillacei campi vafiffrni pulcherrimis Iridibus exornantur \& in æfatem naque fipe rara hxc ornamenta fervant.

5. IX. 


\section{S. IX. \\ US U.}

- Corollis fuis fpeciofirmis, coloribus mire ludentibus \& pulinerimis, füctura partium foris fere ominin fingulari, Irides quidem videntur illas inter plantas merito poffe referri, qux ornamentum globo noftro conciliant oculosque in primis oblectant. Sernper itaque \& omnibus, vel tantillum perpolitis gentibus in delicis habirx inque hortos ad exomandas areolas introduete fuerunt. Omnis tamen fridum in folo ornamento non confiftit virtus, fed inferviunt praterea tam efce, quam morbis tollendis. Plurima namque fpecies africanx, fpeciatim tamen edulis tam fimiis, quam hominibus nutimento funt. Bulbi harum cum fapis in fafciculos collecti ac levirer cocti \& fapiunt bene \& optime nutriunt.

In ufu medico fuere radices Iridum ab co inde tempore, quo vixit DLOSCORIDES. Tres ille ent. merat fpecies, itpote tunc temporis adhibitas, Mrcedonican foilicer \& lllyszom, tamquam melives, arque Africanm, quam non tanta gaudere virtuce, contendit. Preftantioris radicis figna adfert fequentia: Optimu, inquit, e/z, cui denfa eft radix, quafi decur. tata, frangenti contuniax, colore fubfulvo, perquann odorata, guftu amariove, odore fincero, quicque fitum non redolet ac inter iundendum ftermitanenta ciet. DIOSCOR. Cap. I. Hujusmodi radici vim adfcribit attenuantem \& contra Tuffes efficacem, fcilicet, ut humores excreabiles attenuet, faddit et,am vim ineffe pur- 
purgantem, Emmenagogam, Sarcoticam, ulcera detergentem offaque nudata carne operientem, emollientem frumas inveteratosque firrhos.

Inter Arabes virtutis medicæ ergo, maximi etiam radix fuit pretii. In primis uftata fuit in morbis inflammatoriis peetoris, in Tuffi \& Raucedine ad ejiciendam pituitam pulmonibus conclufam. Denique laudatur etjam ab AVICENNA in Hydrope.

Noftris in officinis hodie confervantur radices $I$. florentina, germanica \& peudacori.

I. Florentina. Pharmaco Iridis Florentine Radix.

Qualitates. Fragrantem habet odoren violarum, unde etjam nomen Svecicum: ViolRot. Sopor ejus leviter amaricans eft, faucibus diu adhærens. Manducata fumriam acrimoniam prodit, præcipue fi recens radix vel faltem non diu in Pharmacopoliis fervata. Sicca debilior.

Vires. Insiderzs vifcidum adeoque inter præftantiora expeetorantia numeratur. Eccoproticn, leniter inteftina convellens ftimulansque. Errbina, quam quidem virtutem cum permultis aliis vegetabilibus habet communem. Ob gratum odorem pulveribus Iternutatoriis addicur. Carbaretica, ulcera purgans. Urina infuper gratum odorem impertiri memorat LIEUTAUD Synopf. Med. 844.

Usus. In Tuffi Catarrbali: bafis itaque eft Trochifcor. Bechic. alb. \& flav. Pharm. Sv. In Tufji Peripneuwanicorum \& Pleuriticorum ufurpata fuit perææpe ut adjuvans idque in formulis pulverum antimonialium ad incidendam pituitam Peripneumonicorum. In Obftru- 
Atone Infantzm, nam lenite raperit \& tomina pellio, adeoque locum habet in Electianio e Manne. Pham. Svec. qux formula infantum ufui accommodata videtur.

Haud raro quoque pulveribus digeftivis Khabarbarinis admifcetur ut adiuvans, cuijus exemplum haber Pulv. digeftiv. Ph. SV. ed. I. 1;2, In zulcur. bus ${ }^{3}$ caite offum exteme jampridem a Chimmis

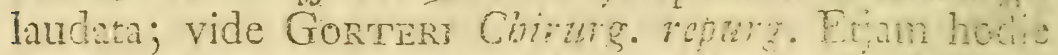
in ufu en ad purgonda uicora mali noris, nec non in carie offina ad exfoliationem accelerandan.

Dosis interne a groivad Scrup. bis vel tor quotidie. 1. Germanca. Phamac. Iridis nophratis hadin. $\mathrm{Le}$ pracedens veceribus mulum in ufu fuit.

RuAltates. OAor debilis violarum vel potius fidnaufeofus. Rece:ss faporem acerrimum habet. Sicual pracchenti deblior tam odore, quam fapore.

Vires. Purgans. Lewis Mat. Mcd. 386. Diunc. Hica, Enmucnagoga. Sicca insidenr.

Usus. Bydrops. Radix recens a flamentis purgate, in talcolos fect ot per nychemeron in vino vel cerevifa primaria infufa urinam pellere dicitur. Succus expreffus eundem in them propinatur.

Celeb. WERLHOFE feminam hydropicam fanavit fucco, ex rafura radicis recentis ad uncias quatuor in aqua foniculi uncis duabus macerata, expreflo, addito panxillo Sacchari. Vide Obererv. de Febribas p. 60.

SENNERTUS in Medic. Pract. L. III. P. VI. S. II. fuccum hujus inter valentiora diuretica enumerat fvâdetque, fuccum e radicibus recentibus exprefum dari 


\section{De Iride.}

ad uncias duis vel tres cum Manna, melle vel alio quodam mulciaginolo vehiculo, ne fauces irritet. Succum quoque cum vitello ovi fubactum, oportune dari ex ERASTo adfert.

Quantum quidem ex quibusdam experimentis; qux in Nofocomio Provinc. Upfalienfi inftiuta benigne nobiscum communicare voluit experientif. Dn. Doctor J. Gusr. ACREL, judicare licet, fuccus radicis huius recentis infigni modo inteftina nimulat \& convellit. Dofis dubia eft, nam interdum torminibus alvum duxit certa cius quantitas, dum alia vice fruftra ut Catharticum eadem quantitas data fuit. Eft etiam quxdam refpectu modi agendi differentia, fi nimirum fuccus affuif aqua exprefus, defxcatus propinatur, vel fi turbidu= \& faculis commixtus datur; huic enim major purgandi vis ineft, priori vero longe debilior.

Erf Cel. LIEUTAUD jure aliquo monuerit, $\mathrm{Hy}$. eragogum hoc caute ufurpari debere, quod pluries male confre, nemo nécit. Synopf. Meal. p. 864 . Medicum tamen ablterrere non debet, quin oblata occafione debitaque adhibita prudentia iterum experimenta inftituat, heroicum præfantiffmumque medicamen forfan indagaturus, modo dofin \& propinandi methodum fimul invenerit.

1. Pseudacorus Pharmac. Acori palufris Radix. Ph. Sv. edit. I.

Qualitates. Recens inodora. Sapor fubaditringens, acris.

VIRES. Recens purgans, cosmetica. Sicca Jubffyptica. 
Usus internzes in Hydrope. PLATER. RAMSAY. extemizs in Scabie, Herpete. LEWIS.

Dosis. Succus expreffus ad gt. Lxxx omni hora vel bihor. ut purgans, ubi alia purgantia fruftra tentara fuerint. RAMSAY apud LEWIS. 328. Id incommodi habere dicitur, ut dofis femper fere fit incerta. LEWIS 1. c. Ex noftris Pharmacopoliis exclufa hodieque non ufurpata, nif in curationibus dometticis.

I. Tuberosa. Pharmac. Hermodaetyli Radix. Olim inter Arabes in uitum recepta. Vim \& effeetum eundem fere cum pracedenti habet. Avicenva Canon. Med. L. II. Tretat. II. huic radici vin tribuit alvum ducendi fimul ac adfringendi; commendat ufum ejus in Podagra, quod fcilicer externe adplicata ftatim reprimar delores; fi vero fxpius ufitetur, tumorem faciut durum \& tophaccum. Olim in Arthritzde ufitata, nunc in defvetudinem abiit ob incertas ejus virtutes, forfan etjam, quoniam radices in noftris Pharmacopoliis diutius fueine Cervata adeoque inefficaces. In Germania adhuc adhibica, noftris vero ex officinis jure profuripta.

Dosis. In Subrantia a femidrachma ad drachm. In Decozto ad femiunciam.

I. Brflora. Pharmac. Iritis vio!acee flores.

Flores hujus Iridis in pharmacopoliis noftris nondum recepti funt, quum vero Syrupus eleganter coloratus variis ufibus aptus ex illis parari poffit, utiles videntur. Cel. BERGII Mat. Med. p. 42.

Quis Tab. I. \& II. monftrant, Irides: crifpa, fetacea, pavonia, papilionacea \& bituninofa magritudine funt naturali. 



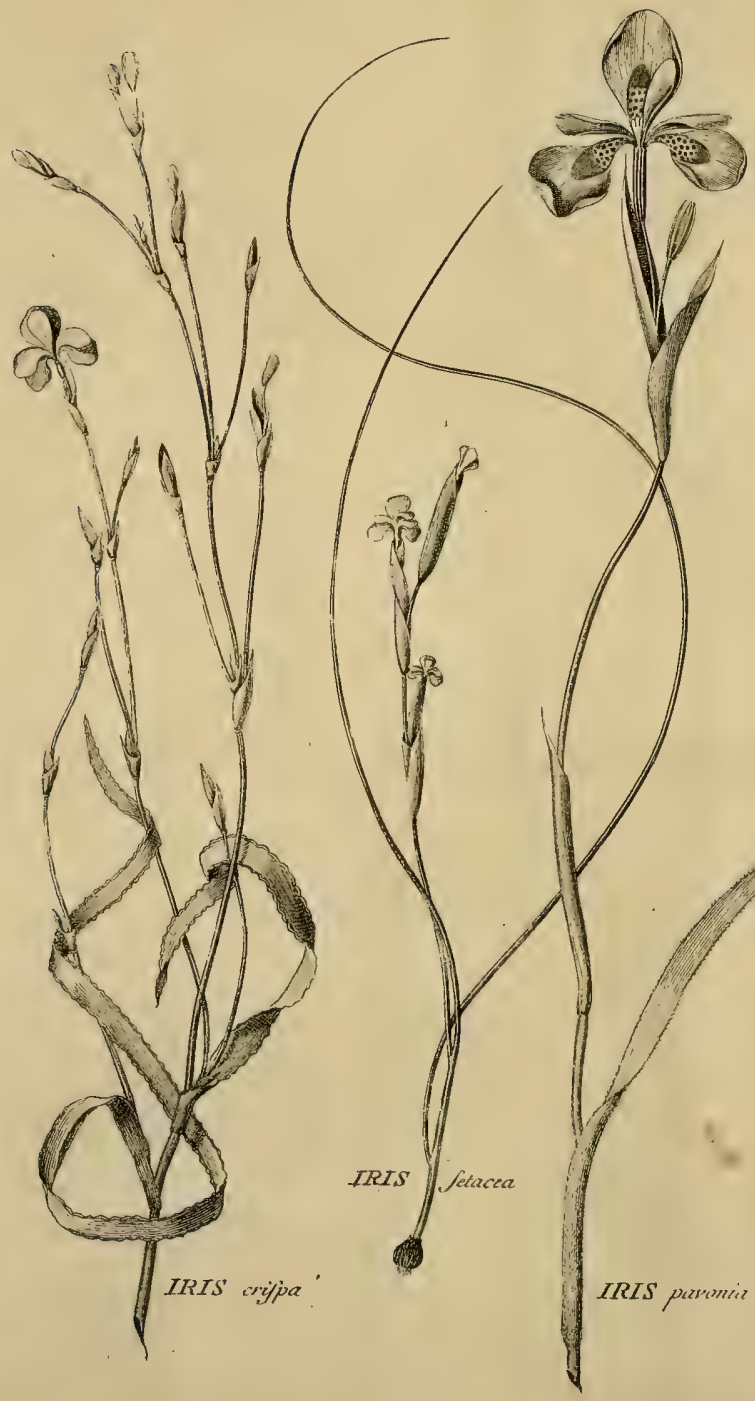


$+1$ 
TAB。 II.

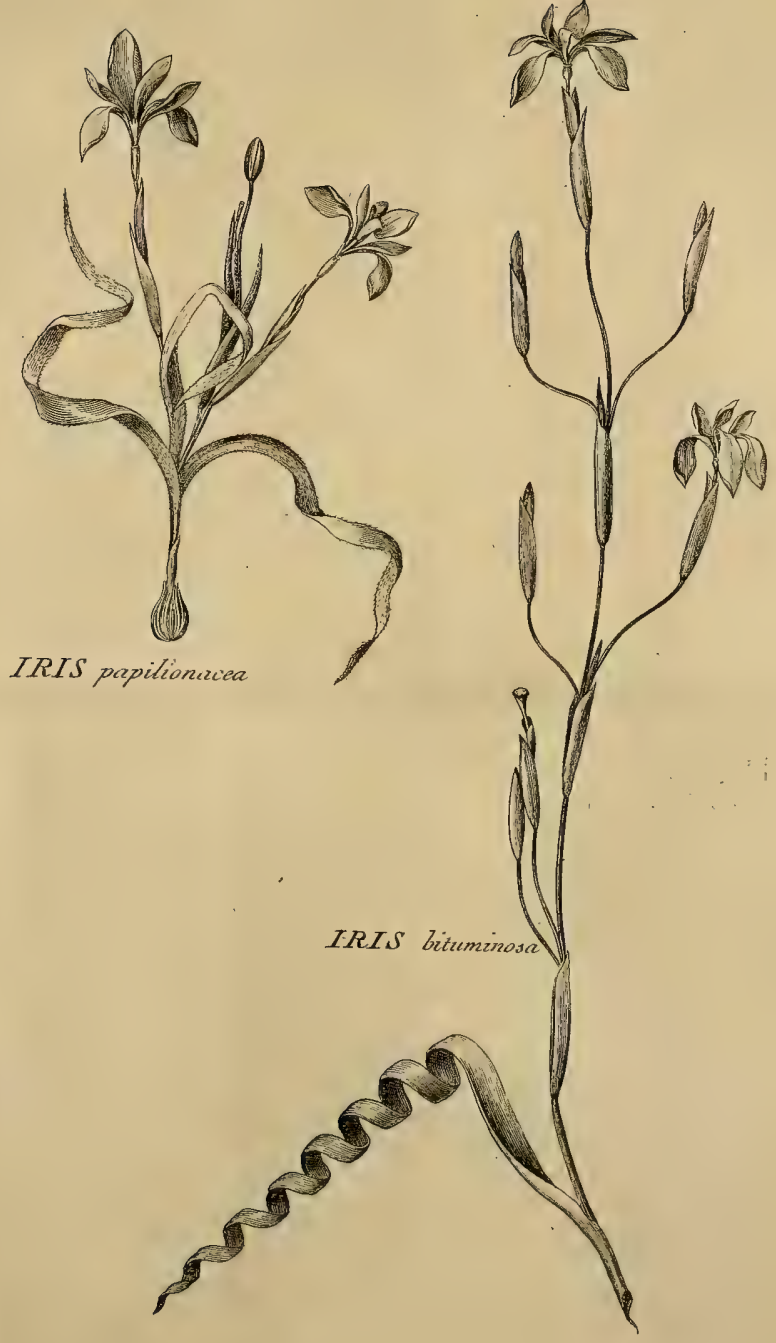




\section{D.}

\section{X I A,}

QUAM

DISSERTATIONE BOTANICA

DELINEATAM,

CONS. EXPERIENT. FAC. MED. UPSAL.

\section{PRÆSIDE}

CAROL.P.THUNBERG, Med, Doct, Prof. Reg. et Extraord., Acad, Cefar, N. C. Reg, Scient. Holmiens., Societ. Scient. Ups. Patr.

Holmens. Berol, n. Scrut. Lund. Harlem. Amstel. et Nidrosiens. Membrum.

\section{PUBLTCO EXAMINI SUBJTCIT , Johannes Dan. Rung, STOCKHOLNIENSIS.}

IN AUDIT. GUST, MAJ. D. XXI JUNI ANNO MDCCIXXYII. H. A. M. S.

\section{UPSALIAE,}

TYPIS JOHAN. EDMAN, DIRECT. ET REG. ACAD. TYPOGR, 
IN SACRAM REGIAM MAJESTATEM

$$
M A G N B E \text { FIDEIVIRO, }
$$

DIRECTORI GENERALI NOSOCOM. REGN.

S V ECI E: ETC. ETC.

\section{EQUITI AURATO ORD. REG. VASAEI}

GENER OSISSIMO ATQUE NOBILISSIMO

$$
\text { DOMINO DOCT. }
$$

OLAO ${ }_{\mathrm{AF}}$ ACRELL,

\section{MACENATI MAXIMO。}

\section{SACRUM.}




\section{DISSERTATIO BOTANICA}

\section{$\mathrm{DE}$ \\ IXI A.}

\$. I.

xia, ex ordine Naturali Enfatarum, Triandirn, 1 monlogyma, a ceteris congeneribus diftinguitur corolls monopetala, tubalofia; tabo secto, fitiforni; linho o-partito, equali. Diti licet, et veteribus quoque, quadam hujus fpecies fuerint notæ, pluri$m æ$ tamen recentiorum inventis funt adnumerandx. Paucæ illx, quæ huc ufque detectæ et defcriptæ fuerunt, plerumque ficcatæ in manus Botanicorum inciderunt, fic ut ex fpeciminibus ficcis characteres vel infufficientes vel omnino falfi confecti fint, unde neque ipfum Genus neque Species invicem dignofci potuerunt. Ob hafce rationes corolla generis frpiffime dicta fuit hexapetala. $\mathrm{Ob}$ easdem rationes ad hoc Genus, nullo tamen jure, relatæ funt fic dictæ Ixia chinenfis, gladiata et africana, quæ ad Moræas migrare omnino debent. Præterea et fponte crefcentes et imprimis in hortis cultæ ita variant $\mathrm{fca}$ po fimplici et ramofo, fapo brevi et altiori, floribus paucis et plurimis, rachide recta vel flexuofa, ut facile fallatur ille, cui non contingit in folo natali attentiori oculo omnes varietates infpicere et accuratiori fubjicere examini. Itaque cum Cel. Præfidi in Africa Auftrali, ubi omnes Ixiæ fponte cre: fcunt, vivas colligere et defcribere, mihi vero ex 
herbario ficco illas in ordinem redigere contigerit, non inutile fore duximus, amplum fatis hoc genus. accuratius determinare et fpecies melioribus atque: certioribus characteribus fpecificis infgnire, quam qui antea dati fuerunt, additis 15 novarum defcriptionibus et feptem figuris. Ita tamen facile non eft, in tanta fpecierum multitudine, qux infinite variant et: luxuriant, nec ullas fere notas conftantes fervant, optimos eruere charaeteres fpecificos, ac quisque fibi perfvaferit. Non mirum itaque, neque fecundum Syftema Linnæanum, neque fecundum Differtationem Domini de la Roche, Ixiarum fpecies certo inveftigari poffe. Si ergo neque noftri conatus omnibus tollendis difficultatibus: fuffecerint, ignofcas H. L. et hifce, donec meliora præftiterit alius, benigne: utaris.

\section{\$: II. \\ CHARACTER GENERICUS:}

CALYX. Spatba bivalvis, infera, corolla brevior: valvule oblongx, perfiftentes; exterior la-tior interiorem vaginans.

Corolla monopetala, tubulofa, regularis, fupera. Tubus filiformis, fenfim an plizus, reetus. Limbus campanulatus, regularis, 6-partitus: lacinice oblongx; obtufx; rquales, patentes.

Stan. Filamenta tria, filiformi-fubulata, tubo pro-pe os inferta, corolla breviora. Anthere. oblongx, fulcatx.

Rist: Germen inferum, triangulare, glabrum. 


\section{De Ixis.}

Stylus fimplex, filiformis, erectus.

Stigmata tria, filiformia.

PERIC. Capfula ovata, trigona, ftriata, obtufa, glabra, trivalvis, trilocularis.

Sernina plura, rotundata, glabra.

Ellcntia Generis: Corolla tubulofa: Tubus filiformis, rectus; Limbus 6-partitus, campanulatus, æqualis. Stigmata tria, fimplicia.

Obs. Corolla Ixiæ numquam 6-petala.

$$
\text { §. III. }
$$

\section{DIVISIO SPECIERUM.}

* caule ramiique folio/is.

fruticofa. I. I. caule ramofo, foliis imbricatis tecto. ** Jcapo foliis breviore:

minuta. 2. I. fcapis unifloris, foliis lævibus. bulbocodium.3. I. fcapo ramofo, floribus folitariis, foliis fulcatis reflexis.

burnilis. 4. I. fcapo ramolo, floribus fecundis, foliis fulcatis erectis.

*** fcapo foliis longiore :

a. birfute.

pilosa. 5. I. foliis linearibus pilofis, floribus alternis.

birta. 6. I. foliis enfiformibus hirtis, floribus fecundis.

fecunda. 7. I. foliis elliptico-enfiformibus, fcapo villofo-fcabro.

$$
\text { A 2 } \quad \text { b. gla }
$$


b. glatre:

a foliis crifpis:

erifpai 8. I. foliis linearibus crifpis, floribus. alternis.

ainnamomea. 9. I. foliis lanceolatis crifpis, floribus alternis.

corymbofn 10. I. foliis lanceolatis crifpis, fcapo ancipici.

B. toliis requalibus:

linearis II. I. foliis linearibus, fcapo fimplici erecto.

apillaris. I2. L foliis linearibus, fcapo polyftachyo, fpathis fcariofis.

Sciacer. I3. I. foliis linearibus, fcapo flexuolo glabro.

fcillaris.: I4. I: foliis linearibus, floribus fecundis, rachide flexuofa.

ariftata. $\mathbf{I} 5$. I. foliis linearibus, fpathis ariftatodentatis.

pendula. I6. I. foliis lineari-enfiformibus, fcapo pclyftachyo, fpicis pendulis.

bulbifera. I7.I. foliis enfiformibus, fpathis membranaceis fetacectaceris.

arectin. I8. I. folis enfiformitus, fapo polyftachyo, floribus titemis immonculis. maculata. 19. I. folis enfiformibus, fcapo polyftachyo, Horibus alcernis, corollis ba. fi maculatis.

5rocutan 2o. I. folis: enfiformibus, foribus fecundis, corollis bafi hyalino-iencítratis. 
Lencea. 2I. I. foliis enfiformibus, floribus fecundis, fcapo fimplici Alexuofo.

pentandra. 22. I. foliis enfiformibus, floribus pentandris.

falcata. 23. 1. foliis enfiformibus reflexo-falcatis. excuja. 24. I. foliis ovaris, floribus fecundis, fcapo flexuofo.

\section{§. IV. \\ DESCRIPTIONES SPECIERUM.}

Radix omnibus: bulbofa eff, bulbo extus a rudimentis foliorum priorum annorum reticulato, intus folido. In Ixia pendula bulbi plures impofiti, depreffi.

Folia vaginantia, equitantia, integra, fxpius glabra et fcapo breviora.

Scapus fimplex vel polyftachyus, fxpifime varians. Carulefiens unica eft fpecies fruticola:

Floref fentia fpicata, fpica fimplici vel divifa: nulli itaque: flores pedunculati, led qui quales videntur, terminales funt in Ixiis polyftachyis: ramis unilloris:

I. FRUTICOSA. I Cazíí fuffruticofus, ramofus, totus: glaber et foliis tectus, palmaris vel paullo; ultra.

Folia linearia, apice attenuata, fubfalcata, tenuifime ftriata, denfiffime imbricata, pollicaria nfque bipollicaria.

thoyes terminales, carulei. 
Spathice membranacex.

Tubus corollix flavus, femipollicaris.

2. Minuta. I. Bulbus globofus, reticulo teetus, magnitudine pifi.

Folia vagina inclufa, linearia, fupra concava, fubtus convexa, glahra, erecta, longitudine fcaporum, unum pro fingulo fcapo.

Scapus raro unicus, fxpius plures, $2-4 \mathrm{vel}$ ultra, fimplices, teretes, erecti, uniflori, glabri, pallide purpurafcentes, pollicares, bracteati.

Bratea paullo fupra medium dux, linearifiliformes, oppofitx, erectx, lineam vix longx.

Calyx nullus, nifi bractex.

Corolle tubus albus, ftriis purpureis. Limbi lacinize fupra concavæ, nivex, fubtus albæ, ftria duplici purpurea, longitudine tubi, lineam dimidiam longx.

Antberce ereetx, flavefcentes.

Capjula virefcens ftriis purpureis.

Facies tota adeo Fabriciz minutx, ut nifi infpiceres ftamina, ftigma et bulbum, eandem crederes

3. Bulbocodium. I. Bulbus ovatus, glaber, fubtruncatus, fibrillofus.

Scapus trigonus, inferne vaginatus, ramolius, pauciflorus, glaber, palmaris vel fpithamæus.

Folid linearia, acuta, fulcata, craffiufcula, glabra; infimum longiffimum fcapo longius fæpe duplo vel ultra, laxum, reflexum; reliqua, circiter duo vel tria longitudine fcapi erecta. 


\section{De Ixia.}

Flores in fcapi ramis terminales, majusculi, fenfim forentes.

Spatba exterior ovata, viridis; interior lanceolata, acuta, membranacea, capfulam vaginans.

Corolle tubus breviffimus: Limbi lactniá intus flavæ, ftriis tribus fuícis, extus flavo-vireficentes.

Filamenta pubefcentia.

Stigmata fex, reflexa.

Differt a reliquis Ixiis ftigmatibus fex.

Variat floribus 1:0 petalis 3 interioribus fla-

vis; 3 exterioribus viridibus.

2:0 petalis 3 interioribus albo-flavis;

3 exterioribus virefcentibus.

3:0 petalis 3 interioribus cæruleo-albis;

3 exterioribus virefcentibus.

4:0 corollis parvis, 3 interioribus albis,

3 exterioribus viridibus.

$5: 0$ corollis lureis.

6:0 corollis caruleis.

7:0 corollis rofeis fundo luteo.

Variat præterea floribus magnis et minoribus, omnium colorum; foliis linearibus et filiformibus.

Scapus vero multiflorus eft; rarius vero nifi unicum florem fimul aperit, reliqnis intra fpa-. tham reconditis, fic ut uniflorus videatur. Folia interdum filiformia, interdum linearia, in terdum enfiformia, fcapo plerumque longiara; et fxpiús reflexa. 
Bulbocodium et rofea ea dem oft fpecies, e plurimis varietaribus conitans: $a b$ aliis diftingvitur:

1. foliis reflexis, marginibus revolutis.

2. floribus remotis plus, quam in aliis. 4. Humils. 1. Buthar profunde infidens, glaber, magnitudine avellanx.

Scapu timplex vel ramolus, filiformis, ereEtus palmaris ufque fpithameus.

Folia duo vel tria, linearia, multi-fulcata, glabra erecta, fcapo longiora.

Flores racemofi, tres ufque octo in rachide Alexuofa.

Spatibe virides, truncatæ.

Variat a. corolla lutea.

$\beta$. corolla albido-rufefcens $f$. incarnata.

$\gamma$. fcapo indivifo, paucifloro.

$\delta$. fcapo ramofo, multifloro.

5. Pilosa. I. Bullus globofus, fibrofus, glaber, magnitudine vix pifi.

Folıa linearia, acuminata, fubterna, erecta, ftriata, pilofa, fcapo duplo breviora.

Scapus fimplex, teres, erectus, glaber, multiflorus, palmaris et ultra, fuperne obfcure purpurafcens.

Flores alterni, feffiles, fubnutantes.

Coroll.s extus rufefcens, intus alba. Limbi $l a$ einice concavx, tres inferiores albæ; tres exteriores intus albæ, extus purpureo-virefcentes, margine albo. 
Antbere lineares, bafi bifidx, dorfo fupra bafin inlertæ, flavæ.

Stigmata eręto-inflexa, hirta, alba.

Capsula 6-fulcata.

Vefperi ab hora quarta flores aperit.

6. Hirta. I. Folia enfiformia, Atriata, villofa, fcapo

breviora.

Scapus fimplex, inflexo-ereetus, glaber.

Flores fecundi, faturate cærulei.

Spathe integra.

Valde fimilis I. fecundex, fed differt: folijs valde villofis, pilis albidis.

7. Secunda. I. Bulbus deorfum imbricatus, durus, magnitudine pifi.

Folia enfiformia, inferne attenuata, glabra, nervofa, nervo medio craffiori, erecta, fcapo duplo breviora.

Scapus teres, flexuolus, erectus, villofo-fcaber, raro fimplex, frpius ramolus, ramis flexuofopatulis, fpithamæus ufque pedalis.

Flores fecundi, in rachide flexuofa, rarius panci, fæpius 4,5 vel 6 , erecti, cærulei.

Spathe bafi virides, apice brunnex, integra. Singularis planta non fcapo modo, fed rachide imprimis flexuofis dignofcitur ab aliis optime fcapo villofo-fcabro.

Variat. fcapo fimplici et ramó́.

8. Crispa. I. Bubzus reticulatus, ovatus,

Folia circiter quinque, lineari-lanceolata, acuta, marginibus pulcherrime crifpa, glabra, ner- 
vo longitudinali craffo, fcapo plus duplo brevióra.

Scapus fimplex vel ramofus, teres, glaber, flexuolus, ereहtus, multiflorus, fubpedalis.

Flores alterni, remoti.

Spatba exterior tridentata, nervis totidem ftriata; interior bidentata, nervis duobus.

Coroile tubus fubviridis; Limbi lacinie cxrulex.

Antber ex extremitate altera affixx, inflexæ.

Stigmata reflexo-patentia, apice clavata.

Variat: I. fcapo fimplici et ramolo.

2. corollis cæruleis et albis.

9. Cinnamomea. I. Bulbus conicus, deorfum imbricatus, truncatus, margine acuto fibrofo, glaber, magnitudine pif.

Scapiis fimplex, teres, flexuolo-erectus, viridi-purpureus, glaber, 1pithamæus.

Folıa radicalla duo, margine obverfo väginantia, lanceolata, obtula, fubfalcato-reflexa, nervo medio elevato, margine crifpo-undulata, fcapo triplo breviora, digitalia; cotyledonis unicum, amplexicaule, ovatum, obtufum, apice reflexum, integrum, glabrum, ungviculare; caulina duo, fpachæformia, remota: inferius convoluto-vaginans vagina longa, apice comprefum, obverfum : fæpe crifpum, glabrum, pollicare ufque tripollicare; fuperius ungviculare. Flores fecundi, erecti, a 3 ad 9 . Racbis fubflexuofa, glabra. 
Spatba exterior concava; obtufa cum acumine, glabra, viridis, apice purpurafcente, tubo panllo brevior, lineam longa; interior fubæqualis, apice tenuior, bifida.

Corolle tubus parum ampliatus, fubcurvatus, purpurafcens, fubungvicularis. Limbi lacinie tres interiores totæ albæ; tres exteriores intus albæ, extus purpurafcenti-ftriatæ.

Anthere erectæ, dorio fupra bafin infertx, lineari-fubulatæ, limbo breviores, flavæ.

Capfula fexftriata.

Florum fpica refert Gladiolum recurvum; fed differt corolla regulari.

Foliis crifpis fimilis eft Ixice Crifper; differt vero

Foliis lanceolatis, duas lineas latis.

10. Corymbosa. I. Bulbus ovatus, truncatus, reticulatus.

Folium radicale unicum, enfiforme, crifpum, ftriatum, recurvatum, glabrum, digitale, fcapo duplo brevius; caulina unum vel duo, fpathæformia, amplexicaulia, ftriata, decurrentia, minora.

Scapus inferne fimplex, fuperne paniculatus, anceps, ftriatus, glaber, flexuofus, erectus, $\mathrm{fpi}-$ thamæus.

Rami alterni, dichotomi, compresfi, faftigiati.

Flores in ramis fubumbellato-faftigiatis terminales. 
Spatba viridis apice obtufo rubicundo.

Corolle tubus fenfim ampliatus, longitudine fpathæ. Limbi lacima lanceolatx.

Stigmata apice globofa.

Viriat flore albo et cæruleo.

37. Linearis. I. Bulbus ovatus, fibrofus, lævis, magnirudine avellanx.

Scapus fimplex, teres, erectus, glaber, palmaris, fpithamzus et ultra.

Folia circirer tria; irfinnum longe vaginans, lineare, utrinque convexum, linea media elevata, angufififimum, vix lineam dimidiam latum, erectum, parum apice attenuatum, integrum, glabrum, fapo paullo brevius, raro $x$ quale. Superiora duo pathacea, breviffima.

Flures raro unicus, plerumque duo vel tres, fecundi.

Spatba convolute, lanceolata, acuta, friata, glabra; exterior major, longitudine corollx.

Corolla nubus albillus. Limbi lacinice obtufæ cum acumine, ungviculares.

Stigmata revoluto-patentia, purpurafcentia.

Capfula vix angulata, fexfriata.

12. Capillaris. In Bulhus reticulatus, fibrofus, magnitudine avellanæ.

Folia linearia, nervofa, glabra, 1capa dimidio breviora.

Scarus teres, apice divifus, capillaris, ereEtus, bipedalis, ramis pedicelliformibus uniforis. 
Flores in ramis terminales, vel in apice fcapi alterni, feffiles, ereeti, albidi, venofo-reticulati. Spatbo fcariofe venis tuicis, dentatæ.

Flores in hac fpecie videntur pedunculati, féd rami unitlori.

3. Setacea. I. Folia linearia, acuta, anguftiffima, fcapo breviora, linea media elevata, glabra, fubterna; in medio fcapo folium breve, fpathis fimile.

Scapus filiformis, flexuofus, erectus, pauciflorus, ruber, glaber, digitalis, fimplex, vel ramofus vel bifidus.

Spatba fubinflata, viridis, valde concava, ftriata, glabra, longitudine tubi femiungvicularis.

Corulle Limbi lacinix tres exteriores intus albæ, extus rubro ftriatæ, tres interiores totæ albæ.

Stylus ftaminibus longior ${ }_{\text {a }}$ corolla berevior, filiformis, albus.

Variat: I. a. flore virelcente, limbi apice albo.

$\beta$. flore luteo, limbi bafi fúca.

2. a. fcapo unifloro.

$\beta$. fcapo multifloro, fimplici.

$\gamma$. fcapo multifloro, ramofo.

Limbi bafi fufca fimilis eft maculatx, fed diftincta ab ea,

a. quod multoties minor

ß. quod ramofa.

$\gamma$. foliis lineari-anguftis.

14. ScIllaris. I. Scapus teres, erectus, glaber, vaginatus, ramofus, pedalis.

B 3

Rami 
forentes.

$R$ mi fliformes nudi, flexuofi, laxi, glabri,

Folia longe vaginantia, linearia, circiter tria, craffufcula, vix lineam dimidiam lata, ftria duplici profunda fcapo breviora, fpithamæa.

Flores fecundi, remoti.

Racbis flexuofa, multiflora, floribus fæpe decem.

Spatha exterior paullo major, glabra, ftriata, bafi viridis; apice cinerea, membranacea, integra; interior bali viridis; apice membranacea, bifida, cinerea.

Corolle tubus breviffimus, flavo-virefcens. Limbi lacinize concavæ, flavæ, tribus exterioribus dorfo purpurafcentibus.

Stigmata involuta, villofa, flavefcentia. Capfula obfolete trigona, fexfulcata. Semuna fubreniformia.

15. Aristata. I. Bulbus reticulatus, magnitudine avellanæ.

Scapus fimplex, teres, erectus, glaber, palmaris, ufque pedalis, vel paullo ultra.

Folza circiter quatuor vel quinque, linearia, quinque-nervia, nervo medio et marginibus craffioribus, acuta, ereeta, glabra, fcapo dimidio breviora.

Flores fecundi, rariffime unicus, ramis duo, fxpe a quinque ufque ad novem in rachide vix flexuofa.

Spatbe fubmembranacex, ariftato-dentatæ.

Corolla albo-incarnatæ. 


\section{De Ixin.}

16. Pendula. I. Radix moniliformi-articulata: articuli plurimi orbiculati, depreffi, approximati, carnofi, rufefcentes.

Folıa radicalia inferne fcapum vaginantia, lineari-enfiformia, acuta, friata, glabra, pedalia vel paullo ultra.

Scapus teres, glaber, erectus, inferne craffitie calami fcriptorii, fuperne divifus, ramis capillaribus nutantibus, flexuofis, orgyalis.

Spathe membranacex, laceræ.

Corolle in ramis alternæ, magnæ, incarnatæ, tubo brevi.

Omnium Ixiarium altifima, fpeciofa corollis magnis, cernuis.

87. Bulbifera. I. Scapus fimplex vel ramofus, fubcompreffus, ftriatus, glaber, inferne foliis vaginatus, palmaris ufque pedalis.

Folia enfiformia, nervofo-ftriata, difticha, erecta, glabra, fcapo breviora, fpithamæa.

Flores tres vel plures, magni, rachide inter flores flexuofa.

Spatha membranacea, nervofo-reticulata, grifea, apice fufca, lacera, filamentofo-ariftata.

Corulla tubus brevis, lineam longus: limbus ultra medium, non vero ad tubum ufque 6 partitus: lacınice magnæ, ovato-oblongæ, obtufiflimæ, patentes.

Antberce lineares, longx, intus convexx, extus lamellofx, albx.

Capjula fexftriata. 
Variat: a flore purpureo.

B. flore rubro alboque variegaro.

$\gamma$. flore flavo.

$\delta$. Capo brevifimo et fimplici.

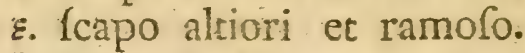

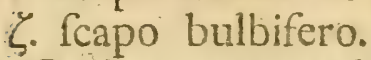

18. Erecta. I. Bulbus magnitndine avellanx.

Folia circiter 3 vel 4 , enfiformia, mulinervia, erecta, glabra, fcapo duplo breviora.

Scapus teres, glaber, erectus, polyftuchyus, pedalis ufque bipedalis.

Rami alcerni, capillares, erecti, digitales.

Flores in fcapo et ramis fpicati, in rachide flexuofa digitali.

Spatbe fubmembranacex, fubarifatx.

Variat corollis luteis et violaceis unicolo. ribus.

19. Maculata. I. Bulbus avellana nuce duplo major. Folia tria, quatuor vel quinque; enfiformia, multinervia, fapo duplo breviora.

Scapus fxpius fimplex, raro polyftachyus, teres, erętus, fpithamæus ufque pedalis et ultra.

Rami filiformes, erecti vel patentiffimi.

Florum fpicæ terminales, rachide flexuofa.

Spathe membranacex, bafi grifex, apice brunnex, fublaceræ.

Corolla fupra os tubi macula obfcura in bafi limbi.

Adeo fimilis I. erecte, ut vix quidquam aliud differat, præter maculam corollæ. 
Variat: $a$. corolla albida.

b. corolla flava.

c. corolla flava apicibus purpureis.

d. corolla albo-cærulefcente.

e. corolla cærulea.

f. corolla purpurea macula pallida, qux rariffima.

g. corolla viridi, qux pulcherrima, fpicis frpe pedalibus.

20. Crocata. I. Bulbus avellana paullo major.

Folia circiter quinque, enfiformia, reflexofubfalcata, multinervia, pollicaria ufque digitalia, fcapo duplo vel fæpe triplo breviora.

Scapus fimplex, teres vel ramofus, fubcompreffus; flexuofus, erectus, glaber, palmaris ufque fpithamæus.

Rami patentiffimi, nudi, fcapo fimiles.

Bractea bafi grifex, apice ferrugineæ, fubdentato-laceræ.

Flores fecundi, fpeciofi, campanulati, tubo brevi, aurantiaci macula fupra os tubi pallidiori hyalina; raro duo vel pauci, fxpius quinque vel feptem.

Variat: a. fcapo fimplici, brevi, paucifloro et macula atra fupra feneftratam. b. fcapo alto, polyftachyo, multifloro.

c. fcapo altiori, corollis rubicundis.

Hec omnium Ixiarum facile pulcherrima, uti ceteræ culta magis ramofa et fpeciofa evadit.

$$
\text { C 2I. LAN- }
$$


21. Lancea. 1. Bulbus rudimentis foliorum denfe involutus, avellana major.

Folia circiter tria vel quatuor, lanceolato-enfiformia, marginibus et nervo medio craflioribus, marginibus revolutis, tenuiffime ftriata, glabra, erecta, digitalia. Folia unum vel duo tpathæformia in fcapo.

Scapus fimplex, teres, hinc inde compreffus, flexuofus, erectus, glaber, foliis duplo longior.

Flores fecundi, circiter fex, albo-purpurafcentes.

Spatbe cinerex, apice ferruginex, obtufx, integræ.

22. Pentandra. I. Scapus ramofus vel fimplex, teres, flexuofus, glaber, pedalis.

Folia enfiformia, ftriata, glabra, fcapo multoties breviora.

Florum fpica longa, interrupta, flexuofa.

Spatba membranacea, fexlineata, longitudine tubi; exterior major, carinata, tridentata.

Corolle tubus virefcens, brevis; limbi laci. nice purpurea.

Filamenta fxpius tria, rarius 5 et 4 , ori tubi inferta, limbo duplo breviora, filiformia, albida. Antbere ovatæ, incumbentes feu horizontaliliter nutantes, lubcompreffæ, didymæ, flavæ.

Stigmata tria fxpius, rarius vero 5 et 4 , reflexo-patula, filamentis paullo breviora, obtufa, lineam longa, plumofa.

capfula trigona, fexfulcata. 
Obf. E filamentis 4, frpe bina connata inveni in unum corpus cum ftigmatibus 4 , antheris feparatis vel connatis.

Variat floribus triandris tribus ftigmatibus; tetrandis ftigmatibus 4; et pentandris ftigmatibus 5.

23. Falcata. I. Bulbus conicus, deorfum imbricatus, truncatus margine acuto fibrofo, magnitudine pifi.

Scapus fimplex et ramofus, glaber, fuperne purpurafcens, multiflorus.

Folia difticha, reflexo-falcata, ftriata, glabra, fcapo duplo breviora.

Flores alterni, unus, duo vel plures.

Corolle tubus ruber. Limbi lacinice tres interiores rotundatæ, albæ; exteriores intus albæ, extus rubrx.

Stigmata flexuofo-involuta, hirta.

$\checkmark$ ariat: fcapo fimplici et ramofo, palmari et fpithamæo; floribus alternis et fecundis; rachide vix flexuofa, et valde flexuofa.

24. Excisa. I. Bulbus globofus, fibrillofus, glaber, pifo minor.

Folia radicalia duo, ovata, obtufa, glabra, margine interiore amplexantia, ibique pro fcapo excifa, patentia, femipollicaria. Referunt folium unicum, bifidum. Folium infra medium fcapi fpathas referens, folitarium.

Scapus teres, flexuofus, erectus, glaber, uniflorus et multiflorus, digitalis \& palmaris. 
Spatha glabra, apice obtufo, fubcrenato; exterior viridis, tubo brevior.

Corolle tubus ruber. Limbi lacinice obtufisfimæ, patentes; extus rufefcentes, rubro-ftriatæ; intus albæ, rubro-ftriatæ.

Anthere brunnex, erectx.

Stigmata parva, revoluta, hirta.

Rariffime caulis medio cauliculum edit, unifiorum.

§. V.

\section{SYNONYMA.}

1. fruticosa.

2. minuta.

3. bulbocodium.
5. pilofa.

6. birta.

7. Secunita.
Linn. Supplem. Syft. Nat. p. 93. ibid. p. 92.

Ixia Bulbocodium. Linn. Syft. Nat. Tom. 2. p. 76 mantiff. p. 320 Sp. Pl. p. $5 \mathrm{I}$.

Ixia rofea? Linn. Syft. nat. T. 2. p. 75 .

Ixia quadrangula. de la Roche Difp. p. 16 .

Ixia bulbocodioides, ibid. p. 19. Linn. Suppl. Syft. Nat. p. 92. Ixia inflexa. dela Roche Difp. p. I5. Ixia flexuofa? Linn. Sp. Pl. p. 5 I. Ixia fcillaris? Linn. Syft. Natur. Tom. 2. p. 76. Sp. Pl. p. 52. Ixia fecunda. Berg. Pl. Cap. p. 6. de la Roche Difput. p. 17. 
8. crifpa. Linn. Supplem. Syft. Nat. p. 9 r. 9. cinnamornea. Linn. Supl. Syft. Nat. p. 92. Europxis. Caneelbloem et Avondbloem Caneelbloem.

Io. corymbofa. Caryophyllus Monomotapenfis, nervofis Buplevri foliis, intus cavis, flore cæruleo, cauliculis fecundum longitudinem alatis. Pluken. Alm. p. 87 . Tab. 275. fig. I.

Ixia corymbofa. Linn. Sp. Pl. p. 5 I. Ixia imbricata? de la Roche Difp. p. I 7. Ir. linearis. Linn. Supplem. Syft. p. 92. 12. capillaris. ibid. p. 92. 16. pendula. ibid. p. 9 r.

I7. bulbifera. Ixia bulbifera. Linn. Sp. Pl.! p. 5 I. Sylt. Nat. Tóm. 2. p. 76 .

Ixia monanthos. de la Roche Difp.

p. $2 \mathrm{I}$.

Europxis: Vluweelbloem.

18. erecta. Ixia polyftachya Linn. Sp. P1. p. 51. Syft. Nat. Tom. 2. p. 76. Ixia erecta. Berg. Plant. Cap. p. 5, Ixia thyrfiflora. de la Roche. Difp. p. 20.

19. maculata. Linn. Syft. Nat. Tomt. 2. p. 76. Mant. p. 320.

20. crocata. Ixia crocata. Linn. Syft. Nat. Tom. 2. p. 76. p. 320. Spéc. Pl. p. 52 . Ixia Milleri. Berg. Pl. Cap. p. 8. 
22. pentandra. Ixia fcillaris? Linn. Sp. Pl. p. 52. Syit. Nat. Tom. 2. p. $7^{6}$. Ixia pentandra. Linn. Supplem. p. 92.

23. filcata. Linn. Supplem. Syitem. p. 92. Europæis: Avondbloem.

24. excifa. Linn. Supplem. Syft. Nat. p. 92.

\section{§. VI. \\ LOCUS.}

In extremo angulo auftrali Africes omnes Ixix fedes fuas fixerunt et ex his paucx funt, quæ alibi fponte crefcant. Sic inveniuncur:

fruticosa in montibus Platte Kloof et Rivier Zonder End diEtis. Etjam inventa fuit in terra del fuego a Prof. Forter.

minuta prope Cap in collibus rarius et extra Zoutrivier locis arenofis inundatis.

bulbocodium in Leuweberg, in collibus infra Duywelsberg inter urbem et fortalitium copiofe et alibi, etiam in alpibus Italicis.

bumilis in Picketberg et collibus circum Cap. pilofa, fetacea, falcata, et excifa in collibus circum urbem Cap.

birta, capillaris et ariftata in arenofis humidis hine inde.

Secunda in collibus Grone Kloof et Roode Sand, atque in arenofis Swartland. crifpa in collibus Roode Sand ei juxta Picketberg. cinnamomea in collibus Leuweftaart. 
corymbofa in fabulofis et ipfis viis Swartlandix.

linearis in campis arenofis inter Cap et Stellenbofch. callaris in collibus Grcene Kloof, Duywelsberg, Leuwekop et alibi.

pendula in regione krumrivier prope ipfum fluvium ejusdem nominis et in locis adjacentibus humidis copiofe.

bulbifera in Roode Sand copiofiffime, in collibius Leuweftaart rarius, in arenofis Swartland et alibi.

evecta infra Duywelsberg, in collibus Grcene Kloof, arenofis Swartland et alibi fat vulgaris. maculata b. et c. prope Bergrivier; d. et e. in collibus prope Groene Kloof; a. b. et c. in are. nofis Swartland; f. in Saldahnabay; g. in Roode Sand; alibique vulgatiffima et maxime varians in diverfis locis.

crocata cis et trans. Swellendam ufque ad Vifchrivier. lancea infra Picketberg.

pentandra extra Cap, prope Grcene Kloof in colo. libus.

\section{§. VII. \\ FLORENDI TEMPUS.}

Plurimæ Ixix in capite bonæ fpei primo vere florere incipiunt; paucx vel hyeme: proveniunt vel in feram ufque xftatem perfiftunt. Quæ loca depreffa, arenofa et inundata amant, maturius hofce exornant campos; montes vero et colles qux inha. bitant. fpecies, ferius: florento, 
Menfibus Majo, Junio, Julio dudum floret minuta. Junio, Julio, Augufto: bulbocodium, pilo$\int_{a}$, fetacea falcata. Augufto, Septembri, Octobri: bumilis, birta, Jecunda, crifpa, cinnamornea, corymbofa, linearis, capillaris, fcillaris, ariftata, bul. bifera, erecta, inaculata, lancea, pentandra, falca. ta, excifa. Octobri, Novembri, Decembri: fruticojas, pendula, crocata.

\section{§. VIII. \\ US US.}

Edules quidem harum aliquot funt fpecies, imprimis animalibus fodiencibus; nullæ tamen vel Hottentottis vel Europæis valde expetitæ. Ob flores vero, qui et pulcherrimi et coloribus fæpe multum variantes funt, in Hortos Magnatum introductæ coluntur ibique fpeciofifimæ evadunt.

Odorem noctu et vefperi fvavem fpargunt cin. namomea, pilofa et falcata, vefperi flores fuos aperientes, ideoque hx, imprimis cinnamomea a pueris collectæ domibus in vitris aqua repletis fervantur.

Circa horam quartam fpecies hæ flores fuos aperiunt, et quidem adeo adcurate, ut horam vefpertinam inde concludere liceat, nifi inftet pluvia, quam tum foribus claufis præfagit. 


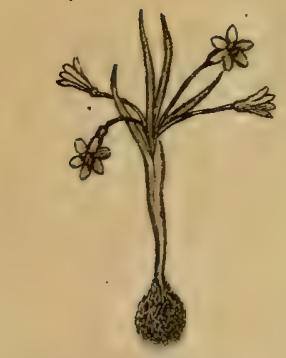

Tria minutu 

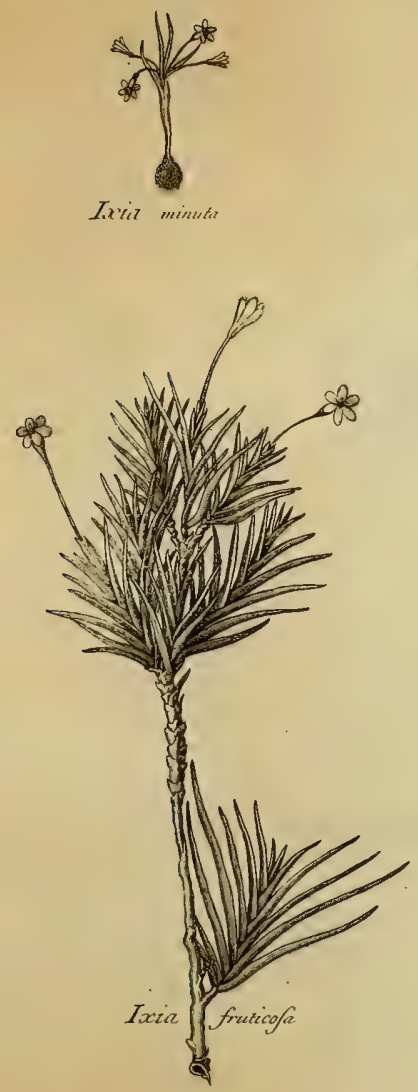
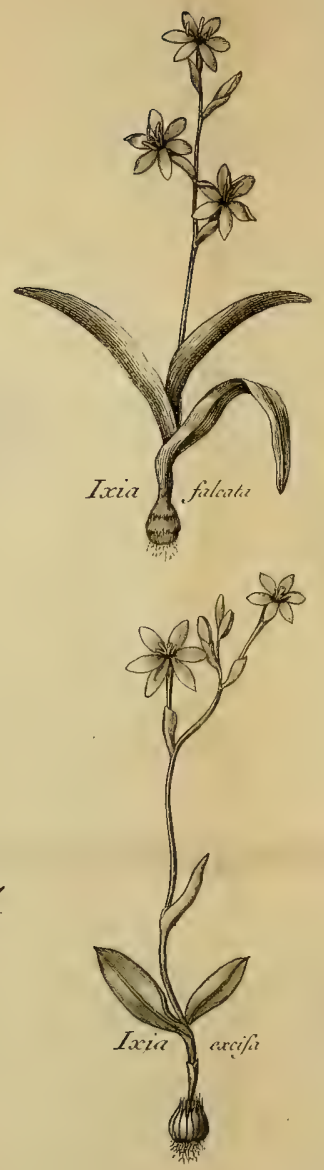
牲 


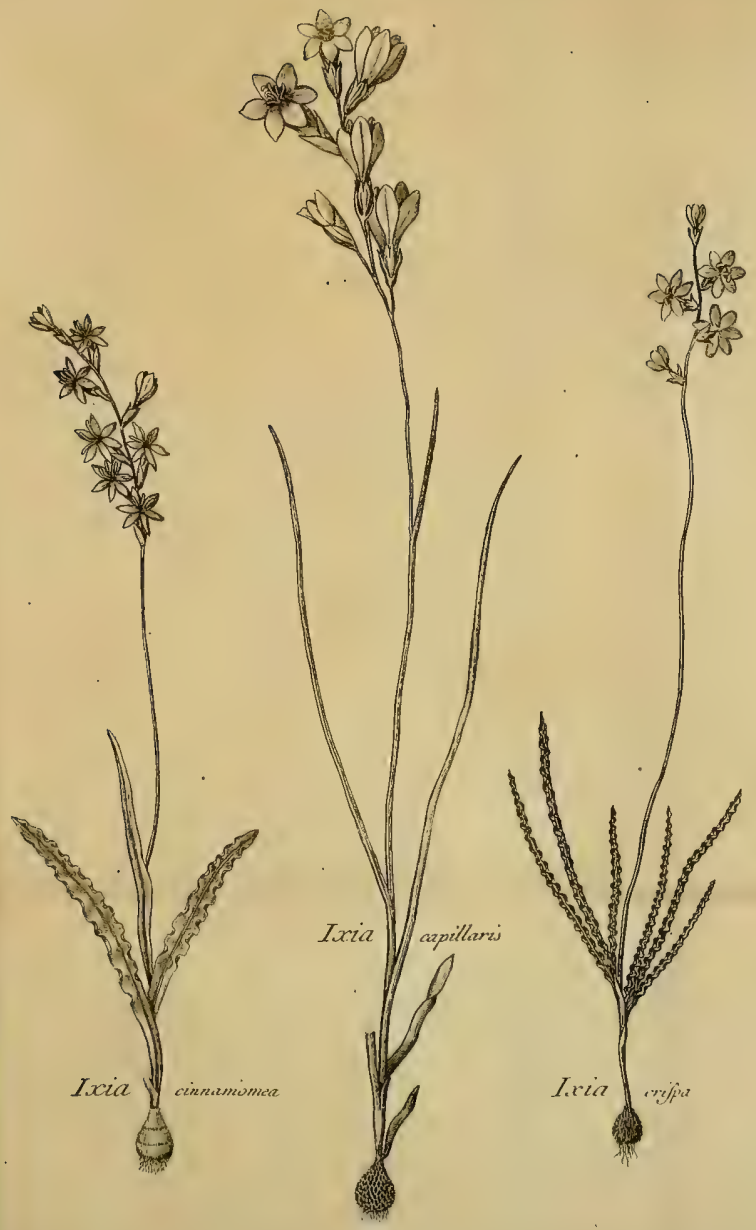





\section{GLADIOLO.}

\section{S. I.}

4 nfatarum ordinis Naturalis Genera, ob fimilitudinem nimiam, non fire difficultate infigni dignofcuntur, ut Crocus \& Galaxia ab IXIa, IXIa a Gladiolo, Gladiolus ab Antholyza, Iris a Mor.tea \& Sisyrinchio; Morea a Ferraria, Witsenia a Dilatride, Dilatris a Wachendorfia. Quo enim magis affinia fuerint Genera, \& quo plures fpecies Genus contineat, eo major femper furgit difficultas eas rite diftingvendi, fique hæ fpecies a loco \& cultura variantes fimul affumant formas, longe major evadit hæc ipfa difficultas.

Hæc eft ratio, cur plures harum, inprimis vero Ixize, Gladioli \& ANTHOLYZE, fpecies confuderint Auctores, quibus vivas hafce Enfatas examini accuratiori fubjicere non contigit. Gladiolum itaque ramofum dixerunt plantam, qux IxIA croca'a polyftachya flore luteo, Gladiolum imbricatum, qux ANTHOLYZE forfan eft fpecies; Gradiolum capitatzim, quz Morea ; Ixtam africanam, gladiatam \& cbinenJem, qux ad MoREas referendæ; I IxIam aiopecuroideam, quæ Gladiolus nobis audit fpicatus; Ixiam puniculatam \& longifloram, quæ GLadiolus longiflo- 
rus; Ixtam flabellifoliam \& iridifoliam, qua Gladrolo plicato adnumerandæ; IXIAM Fabricii, quæ GLADrolus anceps dici debet; Ixiam galaxiam \& fugacilfimam, qux Galaxies Genus conftituunt; ANthoLYZAM merianam \& merianellam, qux Gladiolus merianus \& mevianellus; IXIAM birfutam \& WaCHENDORFIAM umbellatagn, qux Dilatris corymbofa; ANTHOLYZAM mauram, quæ WiTsENIA erit, ut Veterum in his errores alto prateream filentio.

$\mathrm{Ob}$ variantes, quas induunt, a folo \& climate, formas, varietates non raro pro diverfis fpeciebus habuerunt Auktores, ut GLADIOLUM carneum pro communi, Gladrolum permeabilem pro trifti, GLADrolum undulatum pro augufio, IxiAm milleri pro crocata.

Si unquam fublatæ erunt, vel faltem diminutx in Botanicis obvenientes difficultates, Genera fingula, quam accurate fieri poteft, defcribenda, præfertim in plantis vivis, ut certi eruantur characteres, quibus unius ab altero differentia vera pateat.

Ut vero hoc non animo folum perpenderem, fed etiam huic obtinendo fini meam qualemcunque conferrem aleam, \& aliquam fimul apud Te, B. L. dum fpecimen edo academicum, inirem gratiam, ex. plicandum \& defcribendum mihi affumfi intricatum Gladioli Genus, proximis Ixie \& Antholyze generibus adeo in haud paucis fimile, ut in quibusdam examinandis fpeciebus dubius de Genere hreat attentifimus, nec imperitus alias Botanophilus. Sepa- 
ratur tamen Gladiolus Triandrus \& Monogynus fe. quenti charactere elfentiali : Corolla monopetala, tus bulofa: tubo curvato; limbo $\sigma$-partito: laciniis fupreana É influna extra vel intra laterales collocatis.

\section{S. II. \\ CHARACTER GENERICUS.}

CALXX. Spatha bivalvis, infera, corolla brevior: $V a l-$ vile oblongx, perfiftentes, exterior major interiorem includens.

Coror. monopetala, tubulofa, fupera. Tubus cylindricus, interdum bafi filiformis, curvatus. Linnbus 6-parritus, fubcampanulatus: lacinice firprema \& infima extra vel intra laterales, oblongx, erecto-patulx.

Stam. Filamenta tria, ori tubi inferta, filiformia, corolla breviora. Antbere incumbentes ovatz.

PIST. Gerwen inferum, triangulare, glabrum.

Stylus fliformis, longitudine filamentorum. Stigmata tria, revoluto-patentia, obtufa, villofa.

Peric. Cap fula ovata, trigona, obtufa, ftriata, trivalvis, trilocularis.

Semina plurima, glabra.

Differt ab Antrozyza: laciniis limbi fubæqualibus: ab. Ixis: tubo curvato \& fitu laciniarum limbi. Spatiha vel eft tubo corollæ brevior vel longior; obtufa vel acuta; integra vel lacera; glabra vel hirfuta. 
TUBUS COROLLE in hoc genere valde variat; eft enim ipatha brevior, æqualis vel longior; magis vel minus profunde partitus; ringens, cylindricus vel filiformis; fimplex i. e. fubæqualis vel duplex i. e. bafi filiformis, dein cylindricus; curvatus vel geniculatus.

LimBUS COROLLÆ 6-partitæ quoque variat, ut fit campanulatus frepius; reflexus, patens \& crifpus rarius; æqualis vel inæqualis.

\section{§. III. \\ DIVISIO SPECIERUM. \\ * Simplices facapo indivijo:}

a. ringentes; limbi laciniis divaricato-ringentibus. x. montanus: corolla ringentis tubo fpathæ obtufr æquali, foliis ellipticis nervofis.

2. Flexruofus :' corollz ringentis tubo fpatha acuta lon. giore; fcapo flexuofo.

B. reflexi; limbi laciniis reflexis:

3. recurvus: corollæ limbo reflexo, fpica fecunda, foliis linearibus.

$\gamma$. patentes; limbi laciniis perentibus: 4. falcatus: corolla limbo patenti, folio lanceolato falcato.

d. campanulati; limbo canpanulato: a. erecti ; floribus evếíts:

5. biflorus: corollx ereetx limbo campanulato, fcapo bifloro, foliis linearibus.

6. dicbotomus: corollæ ereetz limuo campanulato, fcapo bis dichotomo quadrifloro, foliis linearibus. 
7. crifpus. corollæ erectæ limbo campanulato, floribus fecundis, foliis crifpis.

b. nutantes; corollis cernuis:

8. triffis: corollis cernuis, tubo fimplici, foliis trinerviis bifulcis linearibus.

9. communis: corollis cernuis, tubo fimplici, foliis enfformibus multinerviis.

I0.Wat fonius: corollis cernuis, tubo duplici, limbi laciniis oblongis, foliis linearibus glabris. II. Merinnellus: coroilis cernuis, tubo duplici, limbi laciniis ovatis, foliis enfiformibus pilofis. 12. Merianus: corollis cernuis fubcylindricis, tubo duplici, limbi laciniis ovatis, foliis enfiformi bus glabris. c. imbricati; floribus imbricatis:

13. Spicatus: corollis erectis, fpica imbricata difticha, foliis linearibus. *** RAMOSI fcapo polyfachyo:

I4. alopecuroides: polyftachyus, /fpica imbricata difticha, foliis enfiformibus nervofis.

I5. alatus: polyftachyus, corolla laciniis lateralibus latiffimis, foliis enfiformibus glabris.

16. bicolor: polyftachyus, corolla ringente, fpathis la. cero-ariftatis, foliis enfiformibus glabris. 17. anceps: polyftachyus, fcapo ancipiti, fpathis crifpis. 18.junceus: polyftachyus, floribus fecundis, foliis lan. ceolatis.

19. Setifolizs: polyftachyus, foliis lineari-fetaceis. 20. marginatus: polyftachyus, fpica longifima, floribus alternis cernuis, foliis enfiformibus multinerviis marginatis.

$$
\text { A } 3 \text {. }
$$


21.augufLus: polyftachyus, foribus fecundis, fpathis acutis, foliis enfiformibus.

22. longiflorus: polyftachyus, tubo corollæ longiffimo, fpathis obtufis, foliisque enliformibus glabris.

23. tubfforus: polyfrachyus, tubo corolla longifimo, ipathis foliisque ellipticis plicatis, hirfutis. 24.plicatus: polyftachyus, floribus fecundis, Ipathis foliisque enfiformibus plicatis, hirfuris. 25. Spatbaceus: polyfachyus, [pathis membranacciz arifratis glabris, foliis enfiformibus plicatis hirfutis:

26. gramineus: polyftachyus fapo laxo, fpicis capillaribus flexuofis, foliis enfiformibus glabris.

\section{§. IV.}

\section{DESCRIPTIONES SPECIERUM.}

Radix bulbofa bulbo tunicato, carnofo, globofo. Scapus obvenit fimplex, divifus vel polyftachyus; brevis vel altus; erectus, flexuofus vel laxus; teres vel anceps; nudus vel bracteatus.

Folia polymorpha: fetacea, linearia, elliptica, lanceolata, enfitormia, equitantia; plana, nervofa, fulcata, plicata; glabra, pilofa.

Florefcentia omnibus fpicata, floribus paucis vel numerofis; fpica erecta, nutante, flexuofa, fecunda, imbricata, difticha vel dichotoma.

8. G. Montanus: corollæ ringentis tubo fpathæ obtufx æquali, foliis ellipticis nervofis. 
Scapus teres, flexuofo- erectus, virefcens, glaber, pedalis.

Folia elliptica, integra, trinervia, glabra, palmaria usque fpithamæa.

Florum tubus fpathis brevior, corollis Spatbisque obtufis.

Corolla limbus ringenti-bilabiatus; labium fuperius tripartitum macula purpurea; inferius profundius tripartitum.

2. G. Frexuosus: corolle ringentis tubo fpatha acuta longiore, fcapo flexuofo.

Scapus teres, flexuofus, erectus, glaber, pedalis. Folia nulla fub florefcentia.

Spat be oblongo-lanceolatæ, acuminatæ, glabræ, tubo corollæ breviores, pollicares.

Florums Spica ovata, 4-5-flora.

Corolla albido-incarnata : tubus fpatha duplo longior; limabus ringens.

3. G. Recurvus: corollæ limbo reflexo, fpica fecunda, foliis linearibus.

Scapus ftriatus, foliis fere totus vaginatus, curvatus, palmaris.

Folia tria vel quatuor, vaginantia, alternantia, linearia, friata, glabra, fcapo breviora.

Flores fecundi, tres vel quatuor, cernui, extus rubri, intus albi, limbi laciniis reflexis.

Corolla tubus filiformis, virefcens, fpatha brevior: limbi laciniæ lanceolatæ, concavæ, patentireflexæ.

IXıæ falcatæ nimis affinis. 
4. G. FalCatus: corollæ limbo patenti, folio lanceolato falcato.

Scapus compreffus, ftriatus, flexuofus, glaber, palmaris.

Folium unum vel duo, obverfe-amplexicaule, ovato-lanceolatum, falcatum, obtufiufculum, integrum, ftriatum, glabrum, pollicare vel paullo ultra. Folium fpathaceum in medio fcapo.

Spathe virides, obtufx, tubo multo breviores. Corolla carulea limbo patenti.

IxIæ excifæ affinis:

5. G. Biflorus: corollæ erectæ limbo campanulato, fca. po bifloro, foliis linearibus.

Scapus totus vaginis foliorum tectus, ereetus, pedalis. Folia circiter tria, longe vaginantia, linearia, glabra, infimo breviffimo, fupremo longitudine fcapi.

Flores terminales, bini, coloris trifis.

6. G. Dicнотомus: corollæ ereetæ limbo campanulato, fcapo bis dichotomo quadrifloro, foliis linearibus.

Scapus teres, ereetus, glaber, pedalis, apice: bifidus, brachio fingulo bifioro.

Folium bafi vaginans, lineare, glabrum, fcapo longius; fpathaceum folium lineare, acutum, lub dichotomiis.

Flores fecundi, erecti.

7. G. CRispus: corollæ ereetæ limbo campanulato, floribus fecundis, foliis crilpis. 
Scapus teres, flexuofo-erectus, glaber, fpithamæus usque pedalis.

Folia circiter quatuor, enfiformia, crifpa, glabra, fcapo breviora.

Flores fecundi, 4-9, fpathis breviffimis obtufis. Corolla albo-incarnatæ, erectæ, tubo fesquipollicari. 8. G. TRIsTIS : corollis cernuis, tubo fimplici, foliis trinerviis bifulcis linearibus.

Scapus fimplex, vaginatus, ereetus, glaber, craffitie culmi tritici, pedals \& ultra.

Folia alternatim vaginantia, linearia, acuta, ftriata, glabra, integerrima, fuperiora fenfim breviora, circiter tria vel duo.

Corolla cernua. Tubus cylindricus, fenfim ampliatus. Limbus fubinflatus: lacinice ovatæ, concavæ, acuminatæ, apice patulo; fuprema latiffima, intra proximas laterales, profundius divila, fubfornicata; infima anguftiffima extra laterales fibi proximas.

Color corolle triftis, varius in variis individuis.

\section{Varietates hujus quam plurimæ funt:}

a. odorzus: corolla hyalina, albido - flavefcente: limn. bo extus carina purpurea vel rufefcente, apice intusque rufefcenti-malculato, punctato.

b. inodorus: corolle tubo hyalino-albido; limbo ex viridi-flavefcente: Laciniis tribus fuperioribus intus extusque carinaris nervofisque purpurafcentibus, tribus inferioribus carina punctisque purpurafcentibus. 
c. grandis: corolla albido-trifti; laciniiis tribus fuperioribus intus linea duplici purpurea, extus purpureo-multiftriatis; inferioribus intus fulco medio flavelcente, apice purpurafcente; bipedalis, folio infimo fubxquante fcapum, profunde fulcato, tetragono.

d. inodorus: corollis albis, carinis externis ftria duplici purpurea; laciniis tribus inferioribus intus bafi lutefcentibus, ftriis aliquot purpurafcentibus; foliol infimo fubfiliformi, fcapo duplo longiore.

e. corollis parvis, virefcenti-albidis, plurimis.

$f$. bumilis: corollis una vel binis, albo-incarnatis, fpithamæus.

g.punctatus: odorus, coroila cærulefcente vel cærulefcenti-carnea: infimæ tres lacinice medio albæ lineis punctisque cxruleis. Flores alterni in fcapo flexuofo.

b. lutea: corolla viridi-lutefcenti, unica vel binis, fcapo Spithamæo.

i. apbyllus: corollis albido-incarnatis, quaternis, fecundis; Jcapo pedali.

k. ruber: corollis albo-incarnatis, fubfecundis, immaculatis; fcapo fubaphyllo, fubpedali.

l. purpureus: corollis albo-purpureis, fubternis, immaculatis; fcapo foliofo, pedali.

m. inflatus: corollis albo-purpureis, fubinflatis, fubternis, immaculatis; / capo foliofo, pedali.

n. violaceus: corollis violaceis fubinflatis, immaculatis, fubquaternis, tubo brevi; Sapo foliofo, pedali. 
o. haftatus: corollis albo incarnatis macula haftata. p. cordstus: corollis albo-incarnatis, macula cordata; folizs planioribus.

q. perineabulis: floribus fecundis plurimis; crefcit in fabulofis (infulæ Equorum) Parden Eyland, forens Junio, fcapo tripedali. Folia circiter 4 , longe vaginantia, ftriata, plana, utrinque in medio \& margine vena elevata pallida; inferiora longiora, pedalia ; fuperiora fenfim breviora. Corolle tubus ampliatus, vix lineam longus. Limbus inflatus, extus albus linea media"purpurea : Lacinia fuprema latior, concavo-fornicata, intus alba, intra duas laterales; laterales duæ fuperiores albæ, apice extus intusque purpurafcentes, intus medio flavæ Atriis purpureis ; infima extra laterales inferiores, alba, apice utrinque purpurafcens.

Singularis hæc fpecies folio infimo craffucculo, lineari, intra marginem utrinque fulco profundo exarato; reliquis foliis fpathæ fimilibus, convolutis, fed fpathis longioribus.

9. G. Communis: corollis cernuis, tubo fimplici, foliis enfiformibus, multinerviis.

Scapus teres, foliis ultra medium vaginatus, gla. ber, erectus, fesquipedalis.

Folia obverfa, alternatim vaginantia, enfiformia, novem-nervia, glabra inferiora fenfim breviora, fcapo multo breviora, pollicem lata. Flores alterni, cernui, purpurei, plures.

$$
{ }_{\mathrm{B}} 3 \text { IO G. }
$$


10. G. Watsonius: corollis cernuis, tubo duplici, limbi laciniis oblongis, toliis linearibus glabris. Scapus fimplex, teres, foliis vaginatus, erectus, pedalis \& ultra.

Folia circiter tria, longe vaginantia vaginis ftriatis, lineari-lanceolata, acuminata, ftriata, glabra, fcapo breviora, fuperioribus fenfim brevioribus.

Flores tres vel quinque, fublecundi, cernui, purpurei. Corcllce tubus duplex, bafi filiformis, dein cylindricus, fesquipollicaris, geniculatus, curvatus; Linnbr lacenice oblongx, acutæ.

II. G. Merianellus: corollis cernuis, tubo duplici, limbi laciniis ovatis, foliis enfiformibus pilofis.

Scapus fimplex, vaginatus, inferne rectus, fuperne flexuofus, fesquipedalis.

Folia unum vel duo, longe vaginantia vaginis Atriatis, pilofa, fcapo breviora.

Flores tres vel quatuor, fecundi, cernui, flavoincarnati.

Corolice tubus duplex, inferne filiformis, geniculatus, inde cylindricus, curvus. Limbi lacmice 1ubrotundx.

I2. G. Merianus: corollis cernuis cylindricis, tubo duplici, limbi laciniis ovatis, foliis enfiformibus glabris.

Scapus fimplex, teres, ftriatus, inferne foliis vaginatus, flexuofo-erectus, fpithamæus.

Folia plura usque 4 , obverfo margine vaginantia, 



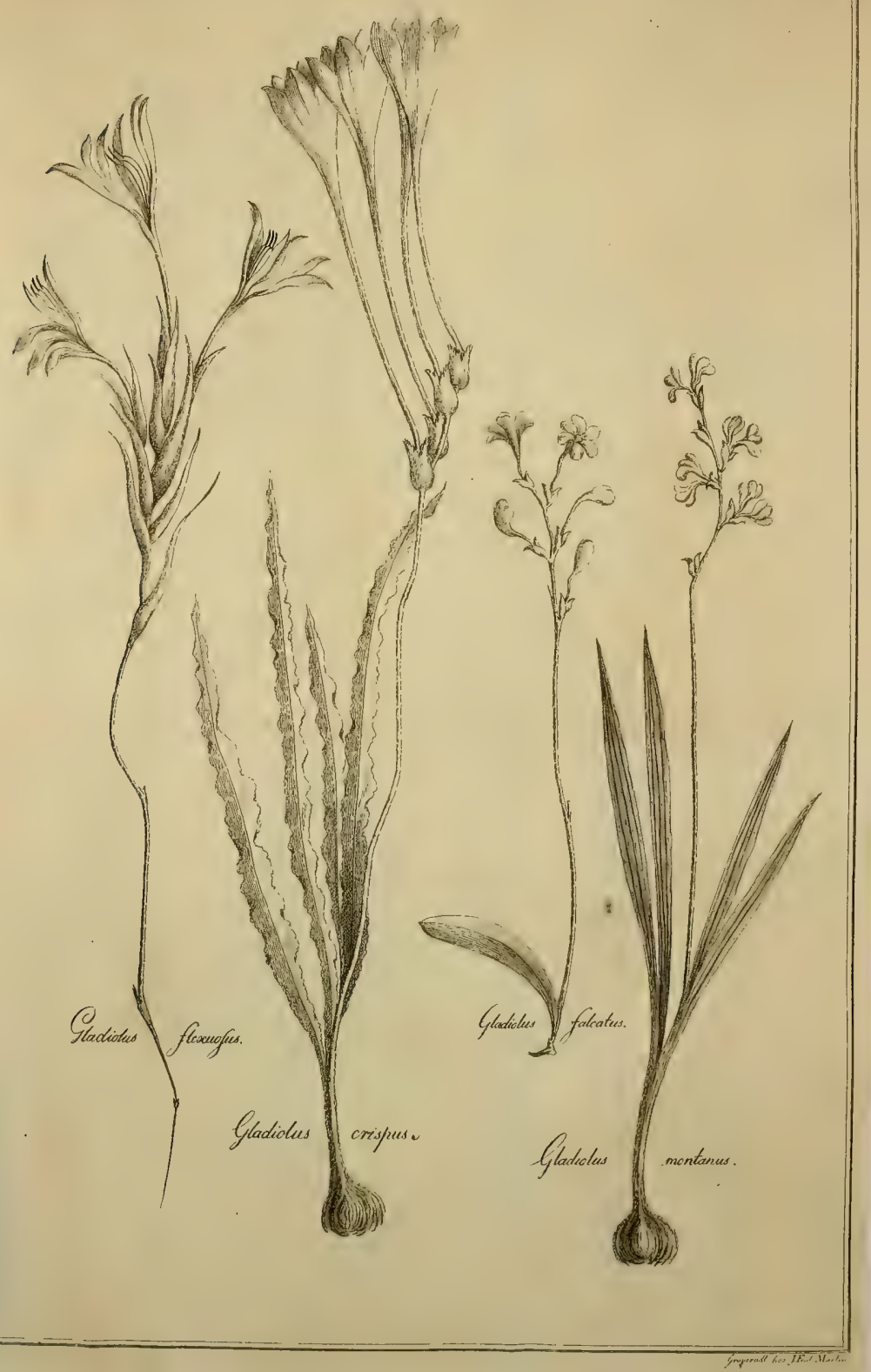




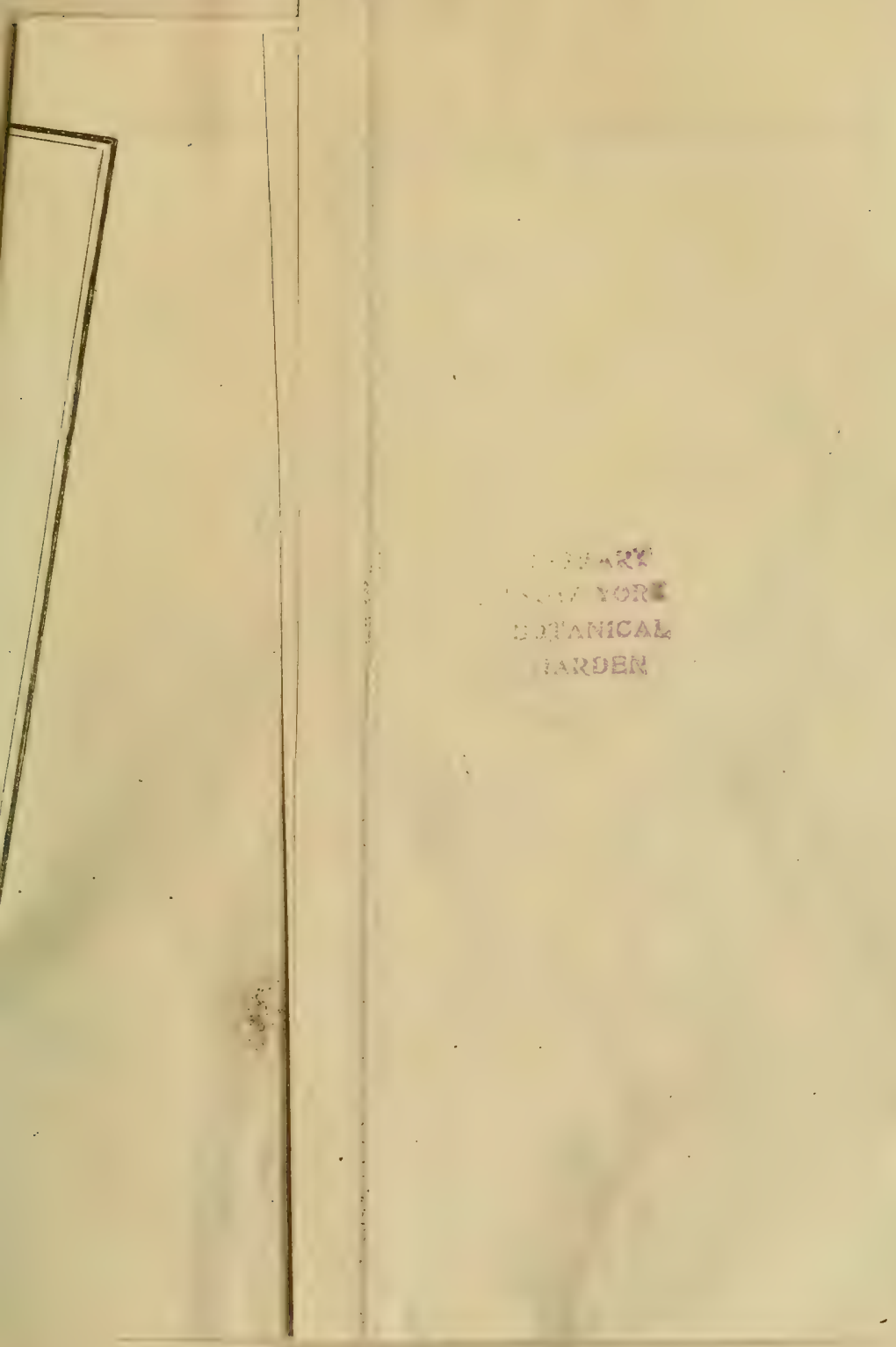


tia, enfiformia, obliqua, parum ftriata nervo medio utrinque elevato, integra, margi. nata, fcapo breviora.

Flores 4 usque 8 , alterni, cernui, purpurei. Corolle tubus bafi filiformis, friatus, fenfim ampliatus, geniculato-reflexus, inde inflato-cylindricus, lævis, nutans; a bafi ad genu ungvicularis, a genu ad limbum pollicaris. Limbus campanulatus: lacinice ovatæ, obtufiffimæ cum acumine, concavæ, xquales, femiungviculares: fuprema extra laterales proximas; infima intra laterales inferiores. 13. G. SpICATUS: corollis erectis, fpica imbricata difticha, foliis linearibus.

Scapus fimplex, terer, vaginatus, erectus, fpithamæus. Folia quatuor alternantia, longe vaginantia, linearia, glabra, infericra fenfim breviora.

Flores diftichi, imbricati, cærulei, circiter duodecim parium in ́́pica pollicari.

Differt a fequenti floribus majoribus; fpica brevio. ri, fed latiori ovata; fcapo fimplici. 4. G. Alopecuroides: polyftachyus, fpica imbricata difticha, foliis enfiformibus, nervofis.

Radix plurimis bulbillis contans.

Scapu foliis vaginatus, teres, flexuofo-erectus, apice polyftachyus, fpicis alternis virgatis, fpithamæus.

Folir duo vel tria, alternatim longe vaginantia, linearia, friata, glabra, fcapo breviora, fuperioribus fonfim brevioribus. 
Flores diftichi, imbricati, minimi. Spicx lineares, digitales, ereetx.

Spathe margine membranaceo, albo.

Corolle tubus vix fpathis longior.

Variat fcapo fimplici \& ramofo; corollis albis \& cxruleis.

15.G. Alatus: polyftachyus, corollæ laciniis lateralibus latifimis, foliis enfiformibus glabris. Scapus comprefius, flexuofus, erectus, ftriatus, fimplex \& ramofus, palmaris usque pedalis. Folia alternatim vaginantia, enfiformia, Atriata, glabra, fuperioribus fenfim brevioribus.

Rachis flexuofa, torta.

Flores alterni vel fubfecundi, 3-7, magni. Spatbe tubo corollæ longiores, integræ, virides. Lacinia dur limbi corollæ latiores.

Variat I:o floribus incarnatis, foliis brevioribus. 2:0 floribus triftibus reticulatis, foliis lon. gioribus.

3:0 floribus violaceis, foliis longioribus.

16. G. Bicolor: polyftachyus, corolla ringente, fpathis lacero-ariftatis, foliis enfiformibus glabris. Scapus fubramofus, angulatus, triatus, fulco utrinque profundo exaratus, bafi foliis vaginatus, glaber, flexuofo-erectus, fpithamæus.

Folia alternatim vaginantia, obverfa, enfiformia, obtufa cum acumine, integra, Atriata, fcapo duplo breviora.

Spice duæ; altera uniflora, tenuior; altera triflora craffior, longitudine dimidia fcapi. 
Racbis angulata, flexuofa, glabra.

Spatha membranacea, apice lacerato-partita laciniis acutis, venofa, bafi grifea, apice ferruginea. Corolle tubus filiformis, fenfim ampliatus, fuperne inflatus, fpatha duplo longior, flavus. Limbi lacinie flavæ; fuprema major concava, ovata, obtufa, pallide flava, apice cxrulea: Laterales inferiores lanceolatæ, convolutæ, flavæ, ultimo apice cæruleo: infima brevior, parum a reliquis feparata, extra laterales collocata: Omnes bafi linea duplici purpurea in ore tubi. Affinis Ixis bulbiferæ, refpectu fpatharum.

I 7. G. ANCEPs: polyftachyus fcapo ancipiti, fpathis crilpis.

Scapus ramofus, anceps, dentatus, fpithamæus, glaber. Latera acuta \& dentes purpurafcentes. Rami fimplices, alterni, ancipites, dentati. Folia femiamplexicaulia, obverfa, curvata, enfiformia, nervofo-ftriata. Folia fpathacea latere inferiore crifpato-dentata, ramis brevio$\mathrm{ra}$, digitalia, glabra.

Flores alterni.

Spatba exterior fere duplo major, obtufa, apice purpurea, comprefla, ftriata, margine crifpo-dentata ut in folia, ungvicularis.

Corolle tubus filiformis, fenfim ampliatus, fpatha multo longior, pallide cæruleus; limbi lacinice cærulefcentes. 
IS. G. Junceus: polyftachyus floribus fecundis, foliis lanceolatis.

Scapus fæpius ramofus, flexuofus, erectus, palmaris: ramis teretibus, ftriatis, divaricatis.

Folia 4-6, ovato-cblonga, fubundulata, glabra, fcapo breviora.

Flores 4-7, fecundi, erecti, cærulefcentes.

Bractece breviffimæ, tubo corollæ multo breviores.

19. G. Setifolius: polyftachyus foliis lineari-fetaceis. Scapus polyftachyus, rarifime fimplex, flexuofoereetus, glaber, palmaris: ramis teretibus, erectis.

Folia circiter tria, lineari-fetacea, fenfim brevio$\mathrm{ra}$, infimo longiffimo fcapum xquante.

Elores alterni, albi, ringentes, tubo fpathis vix longiore.

20.G. Marginatus: polyftachyus fpica longiffima, floribus alternis cernufs, foliis enfiformibus multinerviis: marginatis.

Scapus fimplex \& polyftachyus, fublignofus, foliis vaginatus, teres, glaber, ftrictus, craffitie fere digiti, pedalis usque 4-pedalis.

Folia enfiformia, vaginantia, fcapo breviora, femipollicem lata, in medio \& margine vena craffa flavefcente marginata, venisque elevatis minoribus flavefcentibus lineata, glabra, erecta; inferiora longiora, pedalia \& ultra; fuperiora breviora, fpichamia, adpreffa. Flores magni, cernui. 


\section{De Gládiolo.}

Spica floribus alternis, digitalis usque pedalis, rachide flexuofa.

Variat a) floribus albis.

$\beta$ ) $-\ldots$ dilute rubris.

v) - - - fangvineis.

d) - - - purpureis.

Dintingvitur facile a ceteris Gladiolis: fcapo longo, craflo, erecto, ftricto; fpica florum longiffima, fubramofa, pedali \& ultra; foliis margine incraflato.

21. G. Augustus: polyftachyus foribus fecundis, fpathis acutis, foliis enfiformibus.

Scapus fimplex vel fubramofus, vaginatus, teres, elevato-ftriatus, glaber, flexuofo-erectus, pedalis.

Folia vaginantia vaginis longis, enfiformia, elevato-ftriata friis albis, integra, glabra, fcapo breviora, fuperiora fenfim minora. Flores fecundi, adfcendentes, fpica longa fimplici vel duabus palmaribus.

Rachis angulata, flexuofa, torta, glabra.

Spatba longitudine tubi corolli, ramis breviores, virides, pollicares.

Limbi corolla lacinia fæpius undulatæ. 22. G. Longiflorus: polyftachyus tubo corollæ longiffimo, fpathis obtufis foliisque enfiformibus, "glabris.

Scapus teres, fimplex \& polyftachyus, erectus, glaber, pedalis \& ultra.

Folia 3-4, enfiformia, nervofa, glabra, fcapo breviora.

$$
\text { C } 2 \text { Flo- }
$$


Flores alterni, albo-incarnati, plurimi, approximati. Brakte a membranacex, ftriatz, brevifima.

Tubus corolle pollicaris usque bipollicaris, apice ampliatus, curvus, erectus.

Facies Ixıe, fed tubus curvus \& fitus limbi feparat. 23. G. Tubiflorus : polyfachyus tubo corolla longisfimo, fpathis foliisque ellipticis plicatis hirfutis.

Radix profunda.

Scapus breviffimus, frpe vix pollicaris, foliis involutus, ramofus, hirtus.

Folia plurima, circiter 6 \& ultra, elliptica feu lineari enfiformia \& utrinque attenuata, nerrofa, fubplicata, pilofa, ereeta, fcapo longiora. Bractea oblongæ, hirfutiffimæ, apice ferruginex, pollicares.

Flores alterni, incarnati, tubo corollx fpathis multoties longiori, filiformi, apice ampliato, curvo.

Facies Ixre fed limbus corollæ Gladiolr. Affinis Antholyzis villofitate \& foliis.

24.G.Plicatus: polyftachyus floribus fecundis, fpathis foliisque enfiformibus plicatis hirfutis. Bulbus magnitudine avellanæ, fibrolus fibris longis, parum profunde infidens.

Scapus teres, villofus, fimplex vel ramofus.

$\mathbb{R}$ ami alterni, breviffimi, inferiores longiores, villof. Eolia circiter fena, margine obverfo vaginantia, enfiformia, obtula, craffiufcula, nervola nervis a latere interiori productis, plicata, villofa, mollia, erecta, apice obliqua, fcapo paulo longiora, digitalia.

Flo. 
Flores ereeti, alterni vel fapius fecundi.

Spathe villofre in rachide flexuofa.

Corolla monopetala, fubcampanulata. Tuhus fpathis longior. Limbus bilabiato-ringens, laciniis tribus inferioribus magis connexis, fuprema profundius divifa. Lacinia fuprema extra laterales proximas curvata, tota albido. violacea, latior. Laterales fuperiores paullo anguftiores, obtuix cum acumine, albido-violacex. Laterales inferiores reliquis paulo breviores, obtufæ, extus albido-violacea, intus macula magna oblonga albida, cui inclula eft figura tridentata rubro-violacea, concinente figuram fubulatam albam marginibus purpurafcentibus. Infima extra laterales proximas, obtufa cum acumine, albido-violacea, intus macula oblonga purpurea, bafi linea albida. Omnes lacinix margine crifpæ, præfertim inferne.

Antberce dorfo convexæ, cærulex, fulcatæ, albidæ; bafi fiffa; apice obiufx, fubbifidx.

Variat colore violaceo \& purpureo corollis totis Juteis, antheris violaceis \& corollis albidis; foribus paucis \& plurimis, alcernis, fecundis; fcapis breviffimis \& altioribus.

Folia fabelliformia frpe finduntur apice ut in ARECA.

Affinis AntholyzIs florefcentia, WACHENDORFIE foliis, IxIE corollis. 
25. G. Spathaceus: polyntachyus fpathis membranaceis ariftatis glabris foliis entiformibus plicatis hirfutis.

Scapus vaginatus, Ipithamæus, fuperne polyftachyus. Folia enfiformia, nervola, villofa, fcapi longicudine. Flores albidi, tubo corolla fpathis multo longiore. Spice imbricatx, digitales, plurimx.

Spathx membranacea, lape laceræ, arifatx.

Similis Gladiolo tubifloro \& plicato; fed differt fpathis,

26.G.Gramineus: polyfachyus f́apo laxo, fpicis capillaribus flexuofis, foliis enfiformibus glabris. Scapus filiformis, fubcompreffus, fulcatus, flexuofus, fcandens, laxus, glaber, polyftachyus, longiffimus.

Folia $3-4$, enfiformia, tenuia, glabra, fcapo breviora. Flores in ramis capillaribus flexuofis fparfi, minimi, albi.

Spatba obtufa cum acumine carinato, virefcens, magine membranaceo albo.

Corolla fubcampanulata: tubus breviffimus, virefcens, fpathis brevior; limbi lacinice ovatx', ariftata, concavæ, fubrquales: fuprema paulo brevior extra laterales fuperiores: infima palllo anguftior intra laterales inferiores. $\mathrm{O}$ mnes carina extus virefcente, intus linea purpurea, femiungviculares. Arift a lineam longa, cærulefcens.

Corolia decidua fitu laciniarum limbi refert GLADIOLUM, licet tubus breviffimus. 


\section{De Gladiolo.}

Capfula obcordata, retufa.

Primo intuitu gramen diceres, corolla tamen Gladioli.

\section{S. V. \\ SYNONYMA.}

G. Recurvus: Linn. Syrt. Veg. p. 77. Mant. p. 28. G. Tristis: Linn. Spec. Pl. p. 53. Synt. Veg. p. $77^{\circ}$ Gladiolus permeabilis. La Roche Difl. p. 27. t. 2. Europeis: Afiricaner.

G. Communis: Linn. Syft. Veg. p. 76. Spec. P!.p. 52. Gladiolus carneus. La Roche Difp. p. 30. t. 4. G. Mertanellus: Antbolyza Merianella. Lin. Syat. Veg. p. 77 .

G. Merianus: Am bolyza Meriana. Linn. Syft. Veg. p. 77. Spec. Pl. p. 54 .

G. Spicatus: Gladiolis fpicatus? Linn. Syft. Veg. p. 77. Spec. P1. p. 53.

Ixia alopecuroidea. Linn. Supplem. Syftem. p. 92. G. Alopecurotdes: Linn. Syft. Veg. p. 77. Spec. Pl. P.. 54 .

G. Axatus: Gladiolus flore fingulari miniato, inferioribus laciniis luteo viridibus. Breyn. Rar. p. 25. to. I2. f. 2 .

Giadiolus alatus, Linn. Syft. Veg. p.77.Spec.P1.p.53. G. ANCEPS: Ixı Fabricii. La Roche. Diff. p. 18. Glidrolus anceps. Linn. Supplem. p. 94.

G. Augustus: Breyn. Icon. t. 7. f. 2? Linn. Syf. Veg. p. 77. Spec. Pl. p. 53.

Glaculai undulatus: Linn. syft. Veg.p. 77. Mant. p. 27.

G. LON. 
G. Lokgiflonus: Ixia paniculata. La Roche. Diff. p. 26. t. I.

Ixia longiflora. Berg. Pl. Cap. p. 7.

Gladiolus longiflorus. Linn. Supplem. p. 96.

G. Plicatus: Ixia flabellifolia. La Roche Dill. p. 24 . Inia iridifolia, ibid. p. 24.

Gladiolus plicarus. Linn.Syit.Veg.p.77. Spec.Pl p.53. Europeis: Babianer.

G. Crispus, junceus: Linn. Suppl. Syf. p. 94.

G. Montanus, Marginatus, granineus: iv. p. 95. G. Flexuosus, falcatus, tudiflokus, setifolius, SPATHACEUS: ibid. p. 96.

\section{§. VI. \\ L O C US.}

Gladiolus communis habitat in Europa autrali: imbricatus in Ruffia.

biflorus in Terra Magellanica.

Ceteræ omnes fpecies in Africes autrali angulo, Caput bonæ fpei dieto, vel in ipfis montibus, vel locis arenofis depreffis, vel collibus graminofis apricis fponte crefcentes reperiuntur, ut

Montanus in ipfa planitie montis tabularis.

Crifpus in montibus Rode Sand \& Piketberg.

Triftis in collibus prope urbem, extra Cap in campis, juxta Drakenftein \& alibi.

Wat fonius ad latera montium capenfium, præcipue in Leuweftaart, juxta Conftantiam \& alibi.

Merianellus in fummo montium intar Nordhoek \& Baijfals. 
Merianus prope Valsrivier \& alibi.

Spicatus in fummis montibus Hottentots Holland.

Alopecuroides prope Cap, Swellendam, in Carro \& frpe in ipfis viis.

Alatus in Groene Kloof, Svartlandia collibus arenofis, Bockeveld alibique.

Bisolor in collibus Groene Kloof.

Anceps in Swartland \& regionibus Saldahnæbay.

Funceus in Lange Kloof.

Marginatus in fimmo Taffelberg, \& aliis altis mon-

tibus, in collibus fxpe infra montes a Cap usque ad Hauteniquas locis graminofis ea frpe copia, ut integræ colles e longinquo quafi pulcherrimo panno rubro tectx appareant.

Auguftus in Campis fteriliffimis Carro.

Longiflorus in Lange Kloof, arenofis Swartlandix \&

Helenæbay.

Tubiflorus in Swartland.

Plicatus in collibus infimis infra latus occidentale Leuwebild juxta littus, prope urbem Cap, in Swartland, Rode Sand \& alibi vulgatiffimus.

Spatbaceus in Bockland \& Hantum.

Granineus prope Cap, in Groene Kloof collibus, \& juxta Bergrivier.

$$
\begin{gathered}
\text { §. VII. } \\
\text { FLORENDI TEMPUS }
\end{gathered}
$$

Scilicer Vernale, Gladiolis iciem ac plurimis aliis Enfatis deftinatum fuit; prius tamen illæ proveniunt fpecies, quæ loca occupant depreffa, \& ferius illæ, quæ in altis montibus elevatum \& frigidius amant 
clima. Nonnullis florendi tempus breve obfervatur, dum aliis per plures menies florere conceditur. Florent Majo, Jinio, Fulio, Augufio: Watfonius, recurvus, triftis, plicatus.

Augufto, Septembri, Octobri: plicatus, merianus, alatus, bicolor, anceps, tubillorus, gramineus. OEtobri, Novembri, Decembri: gramineus, auguftus, longiflorus, fpathaceus, crifpus, junceus, alopecuroides, marginatus.

Decembri, $\mathfrak{J}_{\text {amuario: }}$ marginatus, fpicatus. Februario, Martio, Aprali: montanus, flexuofus, Merianellus.

\section{§. VIII. \\ USUS.}

Idem hujus of Generis, ac Ixiarum, fcilicet I:0 edules piures funt horum bulbi carnofi, expetiti non folum Europxis, qui hodie Africam aufralem inco. lunt \& Hottentottis, red ctiam Simiis variisque aliis animalibus, imprimis e Glirium Ordine, fodientibus. Maxime vero omnium huic ufui infervit Gladiolus plicatus, cujus bulbi a Simiis eradicati \& a tunicis purgati crudes devorantur, cocti autem a rufticis quandoque comeduntur.

2:0 Obflores magis vel minus fpeciofos, variæ fpe. cies, imprimis connmunis, triftis, alatus, augufutus, longifornis E plocatus, in Magnatum \& Eoranicorum hortis jus quafi civitatis obtinuerunt, \& adhuc inter rariores pulcherrimasque bulbofas plantos coluntur, variant coloribus atque fca. po ramofo, \& floribus multiplicatis mirifice luxuriant.

3:0. Odore grato aliquot fefe commendant fpecies, ut præ aliis triffis \& recurvus, qui vefperi florentes odo. rem fpargunt, ille fvaveolentem, hic caryophyllo. rum aromaticorum debilem. 


\section{DISSER.TATIO \\ BOTANICO-MEDICA}

$\mathrm{DE}$

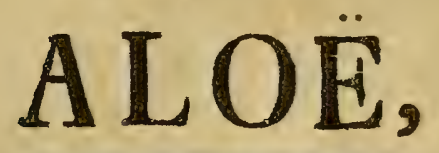

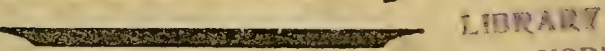

NEW YORK

\section{QUAM ,}

UGAL

ADPROB. EXPER. FACULT. MED. UPSAL.

\section{PRÆSIDE}

\section{CAROL.P.THUNBERG,} Med. Doct. Prof. Med. ét Botan. Reg. et Ord., Acad. Ceasar. N. C. Reg. Scient. Holmiens., Societ. Scient. Ups. Patr. Holmiens. Berol. N. Scrut. Lund. Harlem. Amstel, et Nidrosiens. Membro; nec non Acad. Monsp. et Batavin. Corresp.

9

$$
\text { PRO GRADU DOCTORIS }
$$

PUBLICO EXAMINI'SUBJICIT

\section{ANDREAS HESSELIUS,}

Stip. Victorintanus: V.Gothus.

IN AUDIT. GUST. MAJ. D. I. JUNII ANNO MDCCLXXXV. HORIS A. ET P. M. SOLITIS.

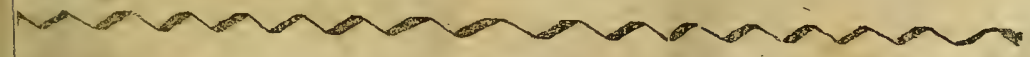

PSALIAE, APUD JOH. EDMAN, DIRECT.ET REG. ACAD. TYPOGR. 

DIEEETATIO DCTANCO - WEDICA

\section{$\mathrm{DE}$ \\ A LO \\ 5. I.}

Htjam antiquiffimis Medicis notum \& frpe ufita2. tum fuit illud remedium, quod hodie non raro in variis morbofis affectibus a Practicis Noftris præfcribitur, \& fub nomine ALOËS in Pharmacopoliis venit. Plurimæ vero, quæ hocce fuppeditare folent plantr recentioribus feculis primum innotuerunt Botanophilis.

Hlorefcentia fua CORONARISS plantis adnumeratur ALOËS genus; foliis autem fuis admodum crasfis \& fuccofis, magnam cum Succulentis plantis affinitatem prodit, atque a proximis Hexandrix \& Monogynix Generibus facile dignolcitur filamentis (non corollæ fed) receptaculo infirtis.

\section{§. H. \\ CHARACTER GENERICUS.}

CALYX nullus.

Corolla monopetala, oblonga, fexpartita: Tubus gibbus; Limbus patens.

Stamina. Filamenta fex, receptaculo inferta, filiformia, longitudine corollæ vel ultra. Antberce oblongx, incumbentes.

Prstill. Germen fuperum, obtufum, fexfulcatum, glabrum. 
Stylus filiformis, erectus, filamentis paulo brevior.

Stigma obtufum.

PERIC. Capjula oblonga, obtufa, fexfulcata, glabra, trivalvis, trilocularis.

Sernina plura, angulata.

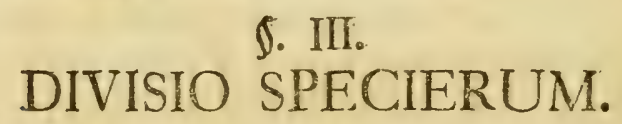

dichotoma. I. A. ramis dichotomis, foliis enfiformibus ferratis.

Spicata. 2. A. caulefcens foliis planis enfiformibus dentatis, floribus fpicatis campanu. latis horizontalibus.

perfoliata. 3. A. caulef́cens foliis enfiformibus dentatis erectis, floribus racemofis reflexis cylindricis.

picta. 4. A. caulecens foliis enfiformibus dentatis pietis pacentibus, floribus racemofis refexis cylindricis.

finuata. 5. A. caulefcens foliis enfiformibus finuato-ferratis reflexis, floribus racemofis erectis cylindricis.

bumilis. 6. A. acaulis foliis trigonis fubulatis aculeatis, Horibus racemofis reflexis cylindricis.

aracbnoides. 7. A. acaulis foliis trigonis cufpidatis ciliatis, floribus fublpicatis erectis cylindricis.

pumila. 8. A. acaulis foliis trigonis cufpidatis papil: 
pillofis, floribus racemofis cernuis cylindricis.

difticha. 9. A. acaulis foliis enfiformibus acutis papillofis diftichis, floribus racemofis reflexis clavatis.

maculata.10. A. acaulis foliis linguæformibus glabris piEtis, floribus racemofis cernuis curvatis. lingva. I I. A. fubacaulis foliis lingvæformibus denticulatis glabris, floribus racemofis ereetis cylindricis.

voriegata. I2. A. fubacaulis foliis trifariis pictis canaliculatis: angulis cartilagineis, floribus racemofis cylindricis.

vifcofa. I3. A. fubcaulefcens foliis imbricatis trifariis ovatis, floribus racemofis cernuis cy.lindricis.

Spiralis. 14. A. fubcaulefcens foliis imbricatis octofariis ovatis, foribus racemofis recurvis. retufa. I5.A. acaulis foliis quinquefariis deltoideis.

\section{IV. \\ DESCRIPTIO SPECIERUM.}

Radix omnibus perennis, ftolonifera.

Coulis vel nullus vel ex bafi foliorum formatus, teres, frpiffime fimplex, raro ramofus.

Folia fucculenta, amplexicaulia, aliis lavia, aliis pieta, aliis papillofa, varie difpofita.

Scapus vel pedunculus bracteatus, erectus, fæpe fimplex, raro ramofus.

Crefiznt omnes in promontorio bonæ fpei, nonnullæ etjam aliis locis, femper tamen calidioribus.

$$
\text { A } 2
$$

I. A. 


\section{Differtatio Botanzico. Medica.}

\section{ז. ALOË DICHOTOMA.}

Incolis: Kookerboom.

Aloë dichotoma. I Linn. Supplem. Plant. p. 206.

Crefcit in fronte montis Bockland.

Floret Augufto, Septembri.

Irusacus teres, erectus, ftridtifimus, cinereus, glà ber, laviffinus, fuperne dichotome ramofus, biorgyalis, craffitie femoris, inanis. $R$ a $n$ i dichotomi, creati, pedales \& ultra, apice foliofi. Roli a perfoliata, enfiformia, denciculata, fubus convexa, hupra plana, parenti-erefa, glabra, carnofa, pedalia, fummis fenfim minoribus.

\section{ALOË SPICATA.}

Alö̈ fpicata. Linn. Suppl. Plant. p. 205.

Crefent in Capieis bone fpei interioribus regionibus. Floret Auguito.

Cautis teres, apice foliofus tri vel quadri-pedalis, crnsfitie brachit.

Folia fubverticilata, comola, pina, baî lata, fenfin atcontan, conoliculata, actita, dentata den. tibus remotis, patentia, bipedali.

Elares fpicat, denffime approumati, horizontaltere patentes; fpica pedalis, fenfim fiorens.

Bracten fub fingulo flore folitaria, ovata, acuta, lata, membranacea, alba friis tribus viridibus, curalla paulo brevior.

Cornlla campanulata, fubhexapetala: Lacinise tres interiores, invicem non connatæ, latiores, ovatæ, obtula, albæ carina linea triplici vio ridi, unguiculares; tres exteriores bafi cinm 
interioribus connatæ, anguftiores, ceterum fimiles, minus concavæ.

Filamenta linearia, fenfin parum attenuata, bafi alba, fuperne flavefcentia, inæqualia, ereEa , corolla fesquilongiora.

Anther ovatx, incumbentes; fulva.

Sivlus fexuofus, ereetus, longitudine fere ftaminum. Stigma fimplex, obtufufculum.

Eapfula ovata, obtufa, fubtrigona, inflexa; hinc carinata lateribus planis quadriftriata; inde convexa fulco medio, glabra. Diffepimentum duplicatum.

Corolla repletx funt fucco melleo purpurafcente.

$$
\text { 3. ALOE PEREOLIATA. }
$$

Aloë perfoliata; Linn. Spec. Plant. p. $45 \%$, 458 varietates a. $\beta . \gamma . \delta, \varepsilon . \zeta . x$.

Crefcit in Italia, Sicilia, Barbados, Socotera \& promontorio bonæ ipei, ibique in Carro, trans Svellendam, ad latera montium, infar exercitus copiofifime.

Flores Julio, Augurto, Septembri, Octobri. Coulis erectus, raro Aexuofus, inæqualis, orgyalis. Folia inferiora emortua; fuperiora amplexicaulia, enfformia, acuta, fupra concava, fubus convexa, valde carnofa, integra, marginibus laceralibus \& dorío verfus apicem dentata aculeis cartilagineis, ere\&o - patentia, fpithamea, pedalia \& ultra. Flores racemofi, remotiufculi, reflexi。

Raceinzes pedalis.

Redicell filiformi-teretes, flexuofi, glabri, reflexi, uniflori, pollicares, internodiis longiores. 
Corolla ad bafin fere fexpartita, cylindrica, pollicaris. Lacmua bafi gibbofx, lineari - oblonge, obtufx, concavæ, conniventes; tres interiores invicem non connatæ, albæ carina fangvinea; tres exteriores bafi connatæ cum interioribus, totæ fangvineæ. Omnes carinæ fub apice virefcunt.

Filannenta bafi anguftata, fupra bafin parum dilatata, apice filiformia, erecta, alba, inæqualia, corollam fubæquantia.

Anthere ovatæ, didymæ, fangvinex.

Germen fexftriatum.

Stylus ereetus, glaber, flavefcens, longitudine ftaminum. Strgnna fimplex, obtufufculum, albidum.

Capfula oblonga, fenfim parum fuperne anguftior, fexftriata, obtufa, oblique truncata, glabra. 4. ALOË PICTA.

Aloë perfoliata . . . $\lambda_{0}$. . v. Linn. Sp. Pl. p. 458. Caulis flexuofo-ereetus, fpithameus vel pau!o ultra. Folis enfiformia, plana, patentia, dentata, fæpius facciata maculis interruptis pedalia.

$$
\text { 5. ALOE SINUATA. }
$$

Aloë perfoliata. $\xi$. Linn. Sp. Plant. p. 458.

Aluë Barbadenfis mitior, late virens \& fplendens. Dill. Hort. Elch. p. 23. t. 19. f. $2+$.

Caulis fpithameus, flexuofo-erectus, inaqualis. Folia enfiforma, verfus apicem valde attenuata, finuato-ferrata, reflexa, plana, pedalia \& ultra.

$$
\text { 6. ALO } \ddot{E} \text { HUMILIS. }
$$

Aloë perfoliata o. humilis. Linn. Sp. pl. p. 458. 
Folia radicalia, plurima aggregata, trigona, fubulata, margine \& pagina undique aculeata, incurva, digitalia vel paulo ultra.

Scapus flexuofo-erectus, fquamis tectus, bipedalis. Flores racemofi, cernui, fenfim florentes.

Corolla cylindrica, fangvinea: ore æquali, virefcente. Obl. flores ante anthefin ereeti, fub florefcentia nutantes, abfoluta florefcentia iterum ereeti.

\section{ALÖ̈ ARACHNOIDES.}

Aloë pumila. $\delta$. Arachnoides Linn. Sp. Pl. p. 460. Crefcit in Carro juxta Svartkops Zoutpan. Floret Decembri.

Folia radicalia, plurima aggregata, oblonga, trigona, acuminata, margine \& dorfo verfus apicem ciliata ciliis lanceolatis, albis, cartilagineis, inermibus; pallida venis viridibus, pollicaria \& ultra.

$$
\text { 8. ALÖ̈ PUMILA. }
$$

Aloë pumila. $\alpha$. B. $\gamma$ margartiferia Linn. Sp. Pl. p. 460. Folia radicalia, plurima aggregata, caulem vix formantia, valde carnofa, oblonga, trigona, feta pellucida acuminata, undique albo-papillofa, erecto-patencia, digitalia.

Scapus angulatus, flexuolo-erectus, fimplex vel ramolus. Flores racemofi, cernui, bractea minuta fub fingulo pedicello.

Aloè difticha B. Linn. Sp. Plant. p. 459.

Folia vix ullum caulem formantia, fed imbricata, diAticha, linguxformia, acuta, fupra concava, 
fubtus convexa, marginibus planata, undique albo-papillofa, erecto-patentia, fpithamea. Io. ALÖ̈ MACULATA.

Crefcit in Hautniquas montibus.

Floret Augunto \& fequentibus menfibus. Culta fxpe invenitur in urbe capitis' bonæ fpei. Folig radicalia, lingvæformia, trigona; pagina interior concavo-plana, cxterior confexa; dorfum planum, unguem latum; fenfim attenuata, glabra, ereeta, fpithamea, pollicem lata.

Flores racemofi, penduli pedunculis refiexis. Corolla fubcylindrica, bafi craftior, medio recurvata, apice angulata angulis viridibus, fubincarna. ta, ungvicularis. Lacinzice tres exteriores ad curvaturam usque divifx, craffiores; interiores tenuiores, invicem liberæ, fed cum exterioribus interne longitudinaliee connatæ. Anthere ovatx, dorfo affixæ, didymæ, flavæ. Stignza obtufum, plumolum. Varietas a) maculis magnis, oblongis, confuentibus, albis.

B) Maculis minutis, albis. I . ALOË LINGVA.

Aloë Linguæformis Linn. Suppl. Pl. p. 206. Crefcit in fummis montibus ad Roodefand prope Wa. terfall.

\section{Floret Septembri.}

Folic radicalia, vix ullum caulem formantia, fed imbricata, difticha, linguæformia, lævia, apice rotundata, margine tenuiffime denticulata, patenti-erecta, fpithamea. 
Flores racemofi, erecti.

Corolla ad medium fexpartita, cylindrica, fubdigitalis; Lacinice tres exteriores craffores, fanguinex, a bafi ad medium cohærentes, vix feparandæ fine laceratione; tres interiores liberæ, albidæ margine tenui, dorfali carina craffiore, fub apice virefcentes.

Stylus trigonus, ftaminibus longior. Stigma fimplex, parum incraffatum.

Capfula ovata, obtufa, glabra, fexpartita, diflepimento duplicato.

\section{ALÖ̈ VARIEGATA.}

Aloë Variegata. Linn. Sp. Pl. p. 459.

Folia radicalia, imbricata, oblique trifariam exftantia, oblonga, trigona feu fupra valde canaliculata, fubtus carinata, marginibus albo-cartilagineis \& papillolo-denticulatis, undique fáciis albis variegata, erecto - patentia, palmaria.

Corolla incarnata ore fexfido: laciniis tribus interioribus alternis patulis.

\section{ALOE VISCOSA.}

Caulis totus foliis tectus, palmaris.

Folia trifariam exftantia, imbricata, ovata, acuta, fupra canaliculato-concava, fubtus verfus apicem compreffo-carinata, integra, patentia, pollicaria.

\section{ALOE SPIRALIS.}

Canlis totus tectus foliis, debilis, cernuus, fpithameus. 
Folia imbricata, fex vel octofariam exfantia, ovata, [acuta, fubtus valde convexa carina longitudinali, fupra convexiufcula, integra, lævia, ereCto-patentia, pollicaria.

\section{ALOË RETUSA.}

Folia radicalia, aggregata, quinquefariam exftantia, valde carnofa, deltoidea feu fupra bafi concava, apice triquetro plano convexiulcula; fubtus convexo - trigona; apice feta terminata; integra, glabra, viridia venis pallidis, pollicaria.

Flores numquam vidimus. Facies hujus a ceteris Aloës Speciebus multum aliena obvenit; Neque fuccus hujus amarus eft, fic ut poitus crasfulam fore conjiceremus.

\section{9. $\mathrm{V}$. \\ USUS.}

¿. Ároé Drchotomá. Hottentotti truncum mediocriter craffum excavant indeque thecam pro telis fuis venenatis fervandis conficiunt.

2. Aloë Sinuata. Sepes vivas ex hac conficiune Africani.

3. Aloë Spicata. Succus Aloës hepaticus purus \& optimus ex hac Specie obtinetur.

4. Aloê Perfoliata. Ex hac Specie maxima copia gummi-refinæ Aloës paratur, quam hodie ut plurimum e Promontorio bonæ fpei Africes ad- 


\section{de Aloé.}

ferunt Naves ex India orientali domum rever. tentes, cujusque hiftoriam \& præparandi modum videre licet in Actis Societatis Phyfiographicæ Lundinenfis, P. I. pag. I I 2. Eft vero hæc Gummi - Refina infpiflatus fuccus Aloës : brunnea, femipellucida, acris, amara, naufeota, calore mollelcens, frigore fragilis infar colophonii, vario ului medico inferviens.

Pro diverfa puritate potius, quam quidem fua origine, triplicem imprimis floës Speciem in Pharmacopoliis noftris introductam invenimus, fcilicet focotrinam, bepaticarn \& Caballinnmm. Socotrina ex infula Socotera antiquitus allata, flavefcenti-brunnea ad purpureum accedit \& in pulverem redacta fere aurea evadit.

Hepatica ex infula Barbados plerumque plus vel minus pura ad nos allata, Socotrinæ paulo obfcurior, magisque amara \& naufeofa depre. henditur.

Caballina ceteris vilior \& odore magis ingrata, equis fcopo purgandi relinquenda.

\section{QUALITAS.}

Sapore hæc gummi-refina amara, acris \& naufeofa eft.

odor aliquantum ingratus Myrrhæ odorem quo. dammodo refert.

Gumninofa pars Aloës præ refinofa femper abundat, licet in diverfis Aloës fpeciebus proportio has inter B. 2

mul- 
multum differre obfervetur, majorem enin qquan. titatem gummi continet Aloë focotrina, quam hepatica, \& hæc minorem, quam cabullina, fic ut ex Aloës caballinæ $3 x i j$, refinæ $3 i i$, ex Socotrinæ anatica portione Biij \& ex hepatica fere $\mathfrak{a}^{\mathrm{iv}}$ extractæ fuerint.

\section{VIS.}

Yim fuam ftimulantem facile prodit Aloë, fi dofi majori, fcopo fortiter purgandi, datur, \& quidem adeo, ut non modo inteftinum rectum vehementer irritet, fed etjam fedes frepe cruentas cauffare valeat. Minori dofi vias primas ftimulo fuo optime evacuat \& tenaciores humores e corpore eliminat.

Calidazz femper purgans exhibet Aloës fuccus, circulationem fanguinis accelerans; corporibus itaque calidis \& plethoricis, macilencis \& febricitantibus noxium; frigidis vero \& phlegmaticis præ aliis proficuum. Vis jurgans præcipue confitit in parte gummofa; Socotrinam ergo, gummi magis foetam, purgandi fcopo, hepaticam vero ad menftrua pellenda commendat Cel. LEwIs. Singulari vi pollet omnis Aloë, menftrua \& hæmorrhoides non modo pellendi, fed etjam Pletboram partialem formandi. Stahliani itaque, qui plurimos morbos chronicos ab hæmorrhoidibus fuppreffis derivari contenderunt, Aloëtica imprimis magni fecerunt pharmaca. 
Balfanica Virtus maxime in refina confiftit, adeoque dum corpora demortua magnatum cum myrrha $\&$ aliis aromatibus contra putredinem in fequentia fecula confervanda fint, hepatica præ ceteris huic fcopo infervire videtur.

Ut reliqua amara, Aloë quoque aliquatenus Stomacbi$c a$ \& Antbelmintica eft. Interne data non mo. do vermes e corpore exterminat; fed \& externe, emplaftri forma, umbilico applicata repellendo a Vermibus fymptomata orta tollit. Antifepticann fuam vim exferit in Carie \& ulceribus fordidis, quorum fanationem depurando \& abstergendo tinctura Aloës optime promovere valet.

Medlcus UJus in fequentibus morbis præcipue obtiner, filicet in

I. Ob/itpatione Alvi, ubi continuatus ufus, parva dofi, fanguinem diffolvit. (Lewis Mat. M. p. 32). Alvum minori dofi non fubito aperit, fed fenfim referat \& apertam tenet diutius; obftructis itaque fenibus commendandus, ni aliud malum id vetet. In Co. lica, cum Obftipatione pertinaci, quæ Nautas in Indiis non raro excruciat, Celeb. D. Præfes Tinctura Aloës, parciori fed fxpius reperia dofi cum fucceffu ufus fuit.

2. IEiero, tanquam bilis fuccedaneum \& obftudtiones referans.

3. Hernorrboidlbus pari modo atque Menftruis pellendis, parciori fcilicet dof, a gr. $x-x i j$ temel vel bis de die fumta. 
Conducit itaque Aloës ufus in ulceribus \& carie, ictero, obftipatione alvi, hæmorrhoidibus cæcis, Dyfmenorrhcea \& aliis morbis, qui hifce origines fuas debent, ut inappetentia, indigertione, colica, cardialgia, epilepfia, ceteris.

Noxius autem illis, qui hæmorrhagiis!'fanguineis, hæmoptyfi, Phthifi 1. Plethora partiali laborant; nec non Gravidis ob metum abortus, hypochondriacis, macilentis, febricitantibus, atque in temperie ficca \& biliofa.

Composita Medicamina, quibus ingreditur Aloë, plu. rima quidem habemus; ea vero omnia erumerare pagina vetat. De illorum igitur ufu, quæ Pharmacopoea Svecica continentur, pauca tantum adferemus.

1. BalJamum Traumaticum in vulneribus utile.

2. Elixir Aloes Saponaceum, cujus gtt. L- LX propinantur in obftructionibus vifcerum, IEtero, anore. xia, chlorofi, cachexia \& menfium a debilitate defeEtu.

3. Elixir Aloeticum in obftructione menfum a fpasmis ad get. XXX-XL. femel vel bis de die dandum. 4. Extractum Aloes Aquofum, in debilitate ventriculi \& contra Vermes a gr. X-XVI. proficuum.

5. Extractum Colocyntbidis compofitum, ad gr. X usque $\mathrm{XV}$ commendandum, in obftructionibus \& ad pellendos vermes.

6. Pilule Aloetica in morbis chronicis fcopo laxandi ad gr. iij - vj præecribi folent.

7. Pilula ex Elaterio a fcr. jad fcr.ij, ob vim fuam drafticam, in Hydrope fine febri fumi poffunt.

8. Pilule polycbrefte ad menftrua a debilitate obftructa, referanda, dofi fcrup. 官 conducere valent. 


\section{DISSERTATIO MEDICA \\ $\mathrm{DE}$ \\ $M E D I C I N A$ \\ AF R I C A N OR UM.}

QUAM,

VEN. EXPER. FACULT. MED. UPSAL.

\section{PR坐SIDE}

\section{CAROL.P. THUNBERG,}

Med. Doct. Prof. Med. et Botan. Reg. et Ord., Acad. Casar. N. C: Reg. Scient. Holmiens, Societ. Scient. Ups. Patr. Holmiens. Berol. N. Cur, Lund. Harlem. Amstel, et Nidrosiens. Membro; nec non Acad, Monsp. it Batavin. Corresp.

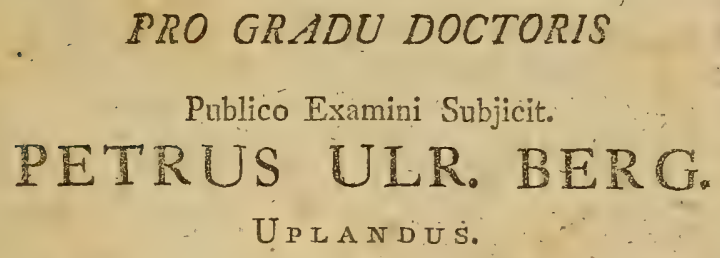

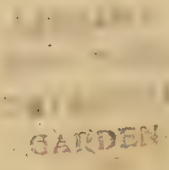
ALUMNUS REGIUS.

IN AUDIT, CUST. MAJ. D. IV. JUNII ARNO MDCCLXXXV. Horis A ET P. M. Souttis:

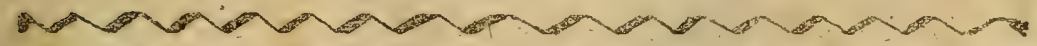
UPSALI首, APUD JOM. EDMAE, DURENT, ET REEG. ACAD. TYPOGR 


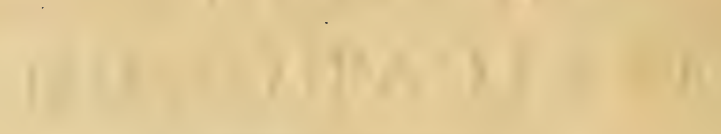




\section{DISSERTATIO MEDICA \\ DE \\ MEDICINA AFRICANORUM.}

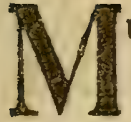

ulta remedia antiquitus in Pharmacopolia noltra introducta \& veteribus multum fæpe decantata jam dudum eviluerunt \& oblivioni tradita funt. Multa quoque alia medicamina, qva proxime elapfis fe. culis pringum innotuerunt, jam in officinas Pharmacevticas illata quotidie a Practicis cum fructu præf cribuntur illis, qui atrocibus excruciantur morbis. Horum quidem numerum, qui certe exiguus non eft, fufficere facile crederes, H. L. ad omnes tollendos humani generis cruciatus; fed cum omnibus gentibus non xque opportuna fefe offerat occafio, hæc libi acquirendi medicamenta, neceffe fuit, ut variæ Nationes aliis uterentur medelis, ad quas facilior illis, vel earum in patria, vel in confi. niis, aditus pater. Sic utuntur Ceiloneníes Ligno fuo calubrino, radice Lopes Mulallabari, Periploca indica ad vomitum excitandum \& Plumbagine ceilanicn Vefica. torii loco Cingalli, Senega \& Lobelia fipbilitica Americani, radice $N i n f i$ Sinenfes \& Japonenfes, atque aliis alii.

Variæ etjam in ufu funt tam apud Indianos quam Africanos remediorum fpecies, quæ adhuc ad cognitionem Europæorum non pervenerunt, quales non paucas fub fuis itineribus in nuper dictis regionibus obfervavit Celeber. Dominus Præfes. Ex hifce remediis ea, quæ Africa auftralis Incolæ imprimis in ufus fuos convertunt, eligere mihi contigit; illa igitur fuccincte defcripta fpecimine medico inaugurali publici juris facere conftitui, ea tamen fpe, ut Tibi, B. L. conamina mea non fore difplicitura. 


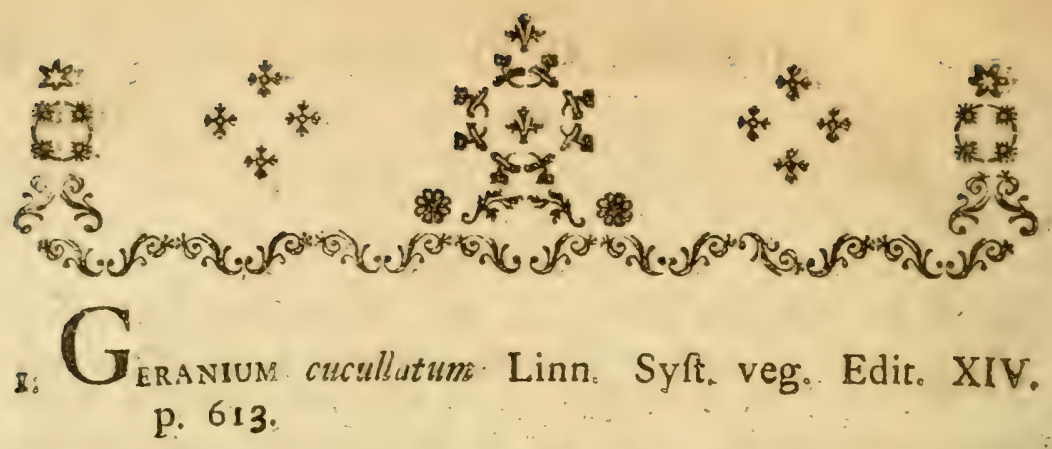

Crefcit locis montofis prope \& extra Cap, in promon. torio bonæ ípei.

Malve plerumque herbam, ob vires cum. Malva conve. nientes; Incola appellant.

Herba imprimis folia parum odora \& emollienria funt atque in facculis. emollientibus ad refolven. dum \& emolliendum adhibentur.

2. Geranium trifte Linn, Syft, veget. Edit. XIV. po.6r5a.

Grefcit in collibus \& campis fabulofis inter Cap \& Dra. kenttein in Prom. bon. fpei.

Ridis hujus rubra aditringens eft \& ficcata inque pula verem redacta fapius illis præcribitur,. qui Di. arrhoea \& Dyfenteria laborant. Leviter adftrin. git \& cum fructu adhibetur, poft Laxans ad e... vacuandam faburram \& acrimoniam daturi.

3. Bryonia aficana Linn. Sylt. veg. p. 870.

Crefcit in collibus montium prope Cap \& alibi. Davids sortel dicitur ab Europæis. Incolis.

Radix porofa valde naufeofa guftanti obvennit \& im... primis a Belgis in ufum vocatur, in Lue ve: nerea \& morbis exanthematicis.

Decoctums diureticum, quandoque catharticum \&: eme. ticum.. 


\section{DE MEDICINA AFR CANORUM.}

4. Hemanthus cocciseus Linn. Syft. veg. XIV p. $3^{16 .}$

Crefcit ubique in dunis Capenfibus vulgatifimus.

Bulbus in Promontorio b. Spei Scilla montana appellatus, albus, fibrofus \& fatis magnus locis altis ficciaribus ozcurrit.

Acris \& vifcidus vim exferit incidentem \& diureticam inftar Scillæ maritimæ, ideoque ex illo acetum \& oxymel fcilliticum paratum in Afthmate \& $\mathrm{Hy}$. drope aliisque mortis propinatur.

5. Asclepias undulata Linn. Syft. veg. XIV. p. 25.8.

Crefcit in collibus prope Paradys, in Camenafie \& alibi in Africes angulo maxime auftrali.

B.tier woortel radicem amaram \& acrem nominare folent Hollandi, atque ob vim ejus diureticam utplurimuın decoćtum Hydropicis bibendum commendant; Eundem in firiem laude etjam extollitur Afclepiadis crifpe radix.

6. Resolventia multa Africa profert; excellunt vero herbæ fequentes, ut Ocyni fpecies; Selago corym. boja, quæ tota fvaveolens; Lontana africana, crispa \& Jalvifolia; Salvis aurea, africana, paniculata; Gevanium ciliatum E moschatum; Tnnaceta non nulla; Ofteofpermum fpinofum atque Mentbe varı fragrantiflimæ \& Camphoræ odore præditæ.

7. Graveolentia varia, \& illa quidem repellentia ex. hibet Africa auftralis medicamina ut Meliantbus major, Eriocepbalus feu milde Rosmarin dictus, foliis odore Tanaceti; Diosma betulina, unifora \& pulcbella, quæ Hottentottis Bukku dicitur. 
Folia horum inter lapides in pulverem redigunt Hottentotti eoque corpus pinguedine ovina prius inun. ctum adfpergunt, unde odor eorum fortis \& non adfvetis ingratus.

8. Arctopus ecbinatus Linn. Syft. veget. XIV. p. 920.

Crefcit in collibus prope Cap vulgatifimus, infra latus orientale montium tabularis \& Diaboli.

Sapore radix ingrara decolto mundificante fre adhibetur, inprimis in Gonorrhcea.

9. Lobelia pinifolia Linn. Syft. veg. XIV. p. 800.

Crefcit in montium lateribus prope Cap \& alibi vulgaris. Radix refinofa fanguinem mundificandi vi pollet, rarius tamen ufurpatur.

30. Ricrnus communis Linn. Syft, veg. XIV p. 865, irs omni fere villa extra Cap cultus.

Seminibus vi draftica dotatis raro heic loci, fortiter pur: gandi cauffa, utuntur Incolæ, oleum vero ex illis expreffum \& leniter alvum ducens inter 0 . prima remedia domeftica numeratur, \& fape parvis, fed iteratis dofibus, fumitur.

I1. Adianthum aethiopicum Linn. Syft. veg. p. 940.

Vroume Hnar dictum, vulgatifimum crefcit in montium. lateribus \& folfis circum urbem Cap.

In fo/ss montium fatis communis filix cum Adiantbo capillo veneris qualitate, viribus \& ufu omnino con. venit, nec non in tuffi, raucedine \& alis morbis pectoris, fub forma decocti \& ryrupi pro. pinatur. 


\section{DE MEDICINA AFRIC ANORUM.}

32. ERrocephalus. Sub Gnophalii berbe titulo apud Belgas in ufu eft herba diuretica, in Hydropis variis fpeciebus laudata.

13. Mesembryanthema varia fucculenta falfum præbent fuccum, qvem ufu diætetico ad fitim reftingvendiam Hotrencotti ori admovent; Incolæ vero ex Europæa gente ad leviter adfringendum in Aph. tis \& externe in Combufionibus ufurpare folent. Succus vero fructuum Mefembr. edulis inserne in Dyfenteria propinatur.

14. Polygonum barbatum Linn. Syft. veg. XIV p. 377.

Crefcit prope Cap \& alibi in omnibus foltis.

Herba juxra follas in aquis crefcens, acris, ad cedema. ta pedum quandoque tollenda adhibetur.

15. Lycoperdon carminomale Linn. Syt, veg. XIV. pa 98I.

Crefcit fungus hic oblongus in acervis argillaceis formicarum, in promontorio bonæ fpei.

pulvis ater ad curanda ulcera cancrofa commendatur.

16. Osmites campborina Linn. Syft. veg XIV p. 783.

Crefcit juxta rivos infra montes prope Drakenfein \& infra latus orientale montis rabularis.

Bellis herba \& folia appellarur ab Incolis hac planta fvaveolens.

$D_{i s}$ incidens, nervina \& fortiter refolvens; fpiritus ejus, fpiritus Bellidis vocatus, eam ob cauffam fummo. pere commendatur in tuff, raucedine, \& morbis pectoris aliis, licet nimis calidus Nobis obveniat. 
17. PROTEA mellifera \& fpeciofa Linn. Syft, veg. p. 139 \& 14 .

Succus in capitulis florum copiofe collectus, ab infectis filtratione purificatus, \& leni igne infpiffatus $u$ fum mellis præeltat in morbis pectoris, raucedine, tuffi, ceteris.

Is. ProteA grandifloza Linn. Syft. veg. XIV p. I4I.

Cortex arboris adfringens ad fiftendas diarrhoeas utilis judicatur.

I9. Oxals cerma Linn. Syft. veg. XIV p. 433.

Copiofe crefcir locis cultis hæe herba in Cap. b. Spei, \& ex fuccu sicetofille fal conficiunt Pharmacopoei.

20. Crotalaria perfoliata Linn. Sylt. veg. XIV p. 6ir.-

Crefcit in interioribus Cap. b. rpei regionibus.

Follown decoctum fortiter diurefin promovere creditur \& cum fuccellu contra Hydropes prafcribi dicitur.

2. TEstudinum fonguinem ficcatum magni faciunt ruftci Africani in morfura ferpentum \& aliis vene. natis vulneribus; Sangvinem itaque infpiffarum in theca fervant fecumque plurimi femper circum ferunt.

22. Fagara capenfis, arbuícula in fylvis interiorum regionum capitis bonæ fpei crefcens.

Hane fub nomine milde Cardnanom feu Cardamomi fyl. veftris Incole norunt \& baccas aromaticas aliquatenus ingrati faporis, in Colica flatulenta \& Paralyfi adhibere fciunt.

23. ADO. 


\section{DE MEDICINA AFRICANORUM.}

23. Adonis veficatoria Linn, Sylt. veg. XIV p. $; 15$. Africanis: Brardblad ob vim urenrem:

Crefcit in montibus prope Cap, juxta Conftantiam, trans Svellendam, alibi:

Acerrimse \& rubefacientis plante folia in Rheumatifmo, If chiade \& variis aliis a frigoris \& caloris viciffitudinibus ortis morbis, veficatorii inftar, contufa \& externe impofita quotidie fere corporis artubus adplicantur.

24. A soë linguaformis Linn. Syft. veg: XIV p: 337. optimam \& purifimam ex omnibus Aloës fpeciebus gummi-refinam ftillar; qua in interioribus Promontorii b. Ipei regionibus non nulli Incolæ uti fciunt.

25. Solans varia, imprimis Solanum bonx Jpei dictum.

Crefcit prope fylvam Effebofch \& alibi; colitur in ur: bis hortis.

Bacce in ungventis qvandoque adhibentur, \& foliz in prolapfu vaginæ atque Uteri.

Succus herbæ in ungventis ad depuranda \& confolidanda ulcera, tota die adhibetur ab Africanis Incolis.

26. Atria varia, odore forti alliaceo, in Africa Auftrali contra Hecticam, Vermes, Suppurationes Incolis in ufu funt.

27. Tulbagia alliacea \& cepacea Linn: Syft, veg. p. 316. Africe auftralis Incolis, milde knofflook.

Crefcit in campis depreffis inter oceani littus \& feriem montium proximam alibique, femper locis arenofis: 
8 DISSERT. MEDICA DE MEDIC. AFRICANORUM.

Radix bulbofa, tunicata, fibrofa, magnitudine pyri mediocris, odore gaudet allsaceo, naufeofo, tortifrmo, diu permanente, et ad Phthifin curandam proficur prædicatur.

Tulbagia cepacea cum antecedente qualitate \& viribus omnino convenit.

28. Caroxylon falfola, Linnæi Salsola apbylla Syft. veg. p. 264. Africanis Camabofcb in locis frepe fteri. liffimis crefcit.

Sal Sodce e cineribus hujus confectum cum pinguedine ovina faponem Africanorum conftituit, non raro tam ufu oeconomico, quam medico celebrem.

29. Piper capenfe Linn, Syft, veget. ed. XIV p. 74.

Africanis Startpeeper \& Bofcbpeeper audit.

Crefcit in fylvis Hauteniquas, Grootvaders Bofch \& aliis fylvis prope rivos.

Fructus fpiritu vini maceratos, ftonachica ponidere vi non vane credunt Incolæ. 
D. D.

DISSERTATIO BOTANICA

DE

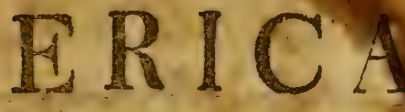

\section{(10nol}

QUAM

CONS. EXPER. FACULT. MED. UPSAL,

\section{PR $\Subset S I D E$}

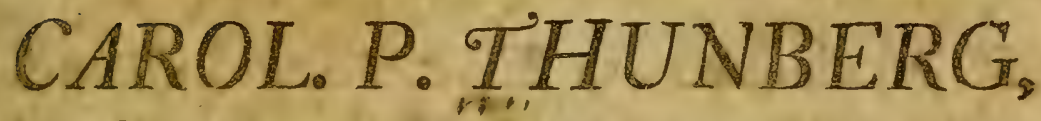
Med. Doct. Prof, Med, et Botan. Reg. it Ord., Acad。 Casar. N. C. Reg. Scient. Holmiens, Societ. Scient. Ups. Patr. Holmens. Berol. N. Scrut, Lund. Harlem. Amstel. et Nidrosiens. Membro; nec iron Acad. Monsfoet Batavin. Corresp.

PUBLICO EXAMINI SUBJICIT,

\section{JACOBUS BERNHARDUS STRUVE,} VESTRO-GOTHUS.

IN AUDIT. GUST. MAJ. D. JUNII ANNO MDCCLXXXY. HORIS A. M. SoLITIS.

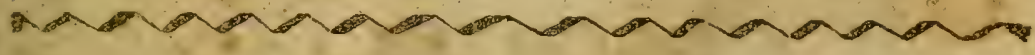
TTPSALIE, APUD JOI. EDMAN, DIRECT. \& REG. ACAD.TYP, 


\title{
S:R R:Æ M:TIS \\ A RCH I A T R O,
}

EQUIT. AURAT. DE STELLA POLARI, REGII COLLEGII MEDICI PRESIDI,

\author{
A T Q UE
}

Acad. Imper. Nat, Curios, Reg. Societ, Scient. Up'.

Nidros, Medic. Paris, ac Reg. Acad. Holmens. MEMBRO,

NOBILISSIMO ET EXPERIENTISSIMO DOMINO DOCTORI ABRAHAMO BECK 
DISSERTATIO BOTANICA

\section{DE

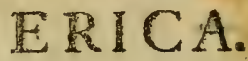

6. 1.

Trer amplifima Plantarum Genera prolixum ERIC 2 Genus jure numeratur, centum fere diftinetis fpeciebus, facili negotio minime dignofcendis, conftans. Blæriis \& Andromedis, nec non quibusdam Azaleis adeo affines funt ERICAE, ut fæpe vix nifi ftaminum numero quatuor hæc genera diftinguantur. Non itaque mirum, Blæriam pufillan, quæ ftaminibus quatuor, octo \& novem variare folet, ad ERICAS fuilfe relatam; atque ERICAS dabceinm, bryantbam \& glutinofan Andromedis fuiffe adfcripras.

Primæ, quæ innotuerunt fpecies, Europææ fuerunt; deinde una vel altera ex Africa citeriori allata fuit; plurimas vero ex Africæ promontorio auftrali, non multis abhinc annis, Varii transmiferunt Botanici.

Europæarum ERICARUM fpecies, quæ Antiquis Botanicis notæ fuerunt, quarumque feculo decimo fexto vel decimo feptimo, in fcriptis Eorum, mentio injiciur, fequentes inprimis funt, fcilicet cilioris, mediterranea, multiflora, berbacea, purpurafcens, arborea, tetralix, vulgaris, Jcoparia, cinerea, virefcens.

Ex Auftrali Africa, plurimas licet alente fpecies, nulla innotuit ante adventum in Promontorium bonæ fpei HERMANNI \& OLDENLANDI, verfus finem exeuntis fæculi. Viginti fex fpecies enumerantur quidem in Catalogo HERMANNI, fed ex diagnofticis notis omnium brevifimis, quænam hæ fuerint, dici non femper A

certo 
certo poteft. Nonnullas fpecies africanas defripferunt etian PLUKENETIUS, PETIVERIUS, RAJUS \& SE. $\mathrm{BA}$; at fine nominibus trivialibus ab aliis facile intelligendis.

Polt reformationem, dum clarior Botanice lux exorta fuir, numerofx Ericarum fpecies longe accuratius fcientiæ amatoribus innotmerunt. In Speciebus Linnæi Plantarum, qua 1753 prodierunt, fequentes cnumerantur fpecies: uulgaris, umbellata, berbacen, (herbacca \& calnea), cinerea, Jcoparia, virejcens (viridipurpurea), tetraiix, arboren (arborea \& caffra), purpura/coris (pallido purpurea), ciliaris, trifiora, curvifura, capitata (capitata \& bruniades) multiflora, pilulifera, coccinea, corifolin, abietina, gmobalodes, Plukenetii; quæ quidem in cditione Ejusdem Libri tertia 176.t auctæ funt ERICIS: dalacia, temifolia, imbricata, fpumena, tubifora, cerintboide, balica. caba, urceolnir (pentaphylla), planifulia, perjoluta (paniculata), pubelcente (pubefcente \& parviflora), empetri olia, plyfode, calycina. $\mathrm{Ex}$ his umiellatam milit LOEFLING, copenfes omnes communicavit diriffmorum Hermanni \& Oldenlandi Herbariorum Pofefror NIC. LAUR. BUR. MANNUS.

Mantiffa Linnæana prima, quæ 1767 prælum reliquir, quinque novas fpecies, fcilicer ramentacean, nigritam, arlicularem, fuftigiatam \& virgatam (abfinthoidem) defcribir; \& Planta BERGII Capenfes, guæ eodem anno prodierunt, adhuc defcriptas ad priores novas ad. dunt glutinofan, conzofan (rransparcntem), lutenm, zuncofnu (Ferream), Petiverii (Plukenerii).

Mantifa altera Linnæi edita fuit $177 \mathrm{r}$, novas continens fequentes: depreffam, mediterraneam, vagantem, vifcariam, regerminantem, melantberam, culicam, baccantem, bryantban, mammofam; duas a Prof. BERGIO communicaras dentatans (denticulatam) \& Borgisinm; unamque nempe au- 
frolem a Lib. Barone Dn. Ciaud. ALSTRO̊MER, fum. mo Hiftoriæ Naturalis Patrono \& fapienti Cultore. Disfertatio de Erica, quam 1790 fub Prælidio D. Archiatris a Linné edidit D:r Dahigren, quirquaginta octo itaque fpecies hujus generis, fupra enumeiatas, (præter mudifloranz) in tabula fyftematica continet.

Poftea Celeb. 1):no Præíidi, ad adventum fum 1772 in Caput bone fpei, fequentes contigit indagare: Maffo. ni, ocfopbyllan (fnfcicularem), retortan, "Thuhbergii, Sparrmanzi, paiferina, cernum, fpicatams (fefilifloram), bispidan ( hispidulam), tetragonam, gramdifloran, leucantheram \& Monfonianam, que omnes in Linnæi Supple. mento Plantarum 1781 inferræ exfart.

Hifce jam addere licet bractentan, fucutam, axillarenn, tottann, petiolatam, cephbalotenn, pulcbellam, vefititan, pineam, cylindi icam, glandulojan, ventricofane, racemofinn, obliquam, bicolorem, formolan, biriam, floridonn, inflitam, rubentem, incoriatim. Quas omnes defcriptas mitiori Tua B. L. cenfuræ \& examini fubjectas volumus.

\section{§. II. \\ CHARACTER GENERICUS.}

casyx. Periantbium tetraphyllum: foliola oblonga, perfsfrentia

Corolla monopetala, quadrifida.

stam, Filinnenta octo, receptaculo inferta. Antberce apice bifidæ, pertufæ.

IIST. Germen fuperum, fubrotundum.

Stylus filiformis, erectus, ftaminibus longior.

Stigma obtufum, tetragonum, guadrifidum vel peltatum.

persc. Capfula fubrotunda, calyce minor, tecta, quadrivalvis, quadrilocularis.

Semina numcrofa, minima.

A 2

Pe. 
Periantbium omnibus tetraphyllum, licet ob bracteas quandoque coloratas videatur effe polyphyllum. La. cinive autem perfiftentes five corolla breviores, five $x$ quales, five longiores; lanceolatæ vel ovaræ; obtufx vel acutr; adpreffre vel patentes vel reflexx; integra vel ciliatæ; nudæe vel pilofr vel tomentofer; virides vel coloratæ.

Corolla univerfaliter monopetala apice in quatuor lacinias finditur; figura vero valde variare perfpicitur. Globofa dicitur, qua globi formam tener, ore minuto laciniisque vix patentibus. Ovata, quæ magis oblonga ore contracto. Campamulata ore aperto \& hiante inftar campanæ. Cylindrica, cujus longitudo æqualis latitudinem multoties exfuperat. Ventrico/a, qux valde oblonga, fed fimul medio incraffata. Nonnullis præterea fpeciebus corolla calyce longior, aliis æqualis, aliis brevior; in nonnullis villofa, in aliis glabra, in aliis vifcida; in nonnullis grofla, in aliis minuta, fæpiffime purpurea, rarius lutea, alba vel cœrulefcens.

Staminum numerus in hoc genere, licet ampliffimo, minime variar, fed femper conttans eft.

Filamenta receptaculo, nec corollæ monopetalæ inferta; funt vero vel brevisfima, vel capillaria, corolla tamen femper breviora.

Antherce plerumque oblongæ, interdum lineares \& bifidæ, triplicem generatim fervant ftructuram; vel e-

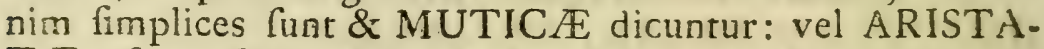
$T \&$, feu inferne fetis duabus fubulatis, divaricatis, lævibus auctæ; vel etiam CRIS'TAT duabus dentato-ferratis notatæ. Præterea aut intra corollam reconduntur \& INCLUSE audiunt, aut extra corollæ aperturam prominent atque EXSERT $\not E$ appellan- 


\section{de Evica.}

tur. Antherr vero inclufx \& exfertæ non femper fpecies certo diftingumt, cum in frutice non bene adhuc florente inclufæ fint, in floribus vero adultis exfertæ invenian. rur. Color harum utplurimum purpureus vel niger eft, rariffime luteus vel albus.

Germen plerisque glabrum, paucis hirfutum.

Stylus corolla brevior INCLUSUS dicitur, longior EXSERTUS.

Stigma utplurimum ftylo crallus, capitatum, quadrilobum vel peitatum.

\section{§. III. \\ DIVISIO SPECIERUM. \\ * MUTIC在。 \\ a. foliis alternis:}

daboecia. 1. E. mutica foliis alternis fubtus tomentofis. b. foliis oppofitis:

tenuifolia. 2. E. mutica foliis oppolitis lanceolatis glabris, floribus ternis, calyce colorato.

c. foliis ternis:

brateata. 3. E. mutica foliis ternis lanceolatis glabris, floribus umbellaris, bracteis periolaris coloratis obvallatis.

Tbusbergii. 4. E. mutica foliis ternis linearibus glabris, floribus umbellatis, corollæ tubo globofo, limbo campanularo.

tetragona. 5. E. mutica foliis ternis lanceolatis ciliatis, floribus racemofis fecundis tetragonis.

ambellata. 6. E. nutica folis rernis trigonis ciliatis, floribus umbeliatis cam panularis, caule erecto.

petiolat . 7. E. murica foliis ternis lanceolaris glabris, floribus umbellatis campanulatis, caule decumbente.

A 3 bry. 
bryatba. 8. E. muica follis ternis ovatis oilintis, fioribus paniculatis, caule decumbente.

fucato. 9. E. mutica foliis ternis lanccolatis glabris floribus raccmolis fecundis gloliofis, $\mathrm{ra}$. mis glabris.

axillaris. Io. E. mutica foliis ternis trigonis glabris, foribus racemofis globofis, ramis tamentofis.

imbiricata. ir. E. muica foliis rernis oblongis ferratis, floribus umbellatis, bracteis imbrica. tis, antheris exfertis.

melantbero. 12. E. mutica foliis ternis trigonis glabris, fioribus umbellatis, bracteis ovaris laxis, antheris inclufis.

leacontbera,13. E. mutica foliis ternis trigonis glabris, floribus umbellatis, antheris exlertis albis.

Spunosa. I4. E. muica foliis cornis trigonis glabris, floribus capitatis, bractcis imbricatis.

capitnta. 15. E. mutica foliis tcrnis ovatis hirfuti, fro: ribus umbellatis, calycibus lanatis.

pasferinc. 16. E. mutica foliis ternis ovatis glabris, flo. ribus fubfolitariis, calycibus terrentofis. toita. 17. E. mutica foliis ternis oblongis hilpidis, floribus ternis, calycibus ciliatis.

virgatn. 18. E. mutica folis ternis oblongis fcabris, foribus ternis globofrs, calycibus integris, ftylo exferto.

ciliaris. 19. E. mutica foliis ternis ovaris ciliatis, floribus axillaribus campanulatis, calycibus ciliatis.

bifpida. 20. E. mutica foliis ternis ovatis integris, flo. ribus umbellatis globolis, calycibus integris. 
Petiverit. 21. E. mutica folis ternis linearibus glabris, floribus terminalibus folitariis cylindricis, bracteis imbricatis.

Plukentii. 22. E. mutica folis ternis linearibus giabris, for: bus racemofis cylindricis, bracteis remotis. d. foliis yuaternis pluribusve:

sepbalotes. 23. E. mutica folis renis lanceolatis, floribus verticillato - capitatis clavatis.

fulcbella. 24. E. mutica folis fenis lanccolatis, floribus axillaribus tubulofo- campanulatis.

reftita. 25 . E. mutica folis fenis linearibus fecundis, floribus axillaribus clavatis villofis.

piner. 25. E. mutica folis fenis lineari-lanceolatis, flo. ribus verticillatis clavatis glabris.

coccines. 27. E. mutica foliis fenis lanceolatis, floribus racemofis clavatis villofis.

grandiflora.28. E. mutica foliis quaternis linearibus glabris, floribus racemofis clavatis glabris.

cylindrica. 29. E. mutica foliis quaternis trigonis glabris, foribus terminalibus cylindricis glabris. survifura. 30. E. mutica foliis quarernis trigonis glabris, floribus terminalibus folitaris curvatis clavatis glabris.

tubifora. 31. E. mutica foliis quaternis trigonis ciliatis, floribus terminalibus folitariis curvatis clavatis hirfutis.

glandulofa. 32. E. mutica foliis quaternis linearibus glan. dulofo-pilofis, floribus clavatis glabris, calycibus hifpidis.

cerintboides. 33 . E. mutica foliis quaternis oblongis ciliato. ferratis, floribus cylindricis villofis, calycibus ferratis.

Sparmanzi. 34. E. mutica foliis quaternis oblongis ciliatoferratis, floribus campanulatis calycibusque frigofis.

Mas- 
Mafont. 35. E. mica folis juaternis oblongis ferratis villolis, floribus cylindricis vilcofis. ventricofa. 36. E. mutica foliis yuaternis trigonis ciliatis, floribus ventricolis glabris.

fofrigiata. 37. E. mutica folis quaternis rigonis glabris, floribus capitatis, calycibus integris.

comofa. 38. E. mutica folits quaternis trigonis glabris, foribus cepiratis, calycibus ciliatis.

dentata. 39. E. murica foliis quaternis trigonis glabris, floribus capitatis, calycibus rerratis.

vifceria. 40. E. mutica folis quaternis trigonis glabris, floribus racemolis campanularis, calyce rudi ciliato.

inediterronea.41.E. mutica foliis quaternis linearibus glabris, floribus racemofis campanulatis, calyce colorato integro lanceolato.

multiflorn. 42. E. mutica foliis quinis linearibus glabris, floribus racemofis fubcampanulatis, calyce colorato integro ovato.

berbacea. 43. E. mutica foliis quaternis linearibus glabris, floribus racemofis fecundis.

furpurafcens. $44 \mathrm{E}$. mutica folis quaternis quinisque gla. bris, floribus fparfis campanulatis, caule decumbente.

vagars. 45. E. mutica foliis quaternis quinisque glabris, foribus fparfis campanularis, caule crecto.

cubica. 46. E. murica foliis quinis trigonis incurvis glabris, floribus umbellatis globolis, calyce colorato carinato.

racemoja. 47. E. mutica foliis quaternis lanceolatis villofis, floribus racemofis glcbofis, calycibus tomentofis. 


\section{**ARISTAT E.}

\section{a. foliis oppofitis:}

giutinofa. 48. E. ariftata folis oppofitis fparfisque linearibus ciliato - glandulofis.

luter.

49. E. ariftata foliis oppofitis lineari-trigonis glabris.

\section{b. foliis temis :}

deprefsa. 50. E. ariftata foliis ternis oblongis glabris, floribus fubracemolis, caule decumbente. balicacaba. 5 I. E. ariftata foliis ternis lanceolatis glabris, floribus folitariis, caule decumbente.

Monfoniana 52. E, ariftata foliis ternis ovatis glabris, floribus folitariis, caule erecto.

nigrita. 53. E. ariftata foliis ternis oblongis glabris, floribus ternis, bracteis acutis imbricatis. regerminans.54. E. ariftata foliis ternis linearibus glabris, floribus racemofis, caule eręto.

urceolaris. 55. E. ariftata foliis ternis lanceolatis fubtus tomentofis, floribus fubracemofis villofis.

birta. 56. E. ariftata foliis ternis linearibus hifpidis, floribus umbellatis, calyce fcabro rudi. bicolor. 57. E. ariftata foliis ternis ovatis fcabris, flo. ribus ternis cernuis glabris, calyce villofo colorato.

articularis. 58. E ariftata foliis ternis ovatis glabris, floribus racemofis, caule erecto.

givefcens. 59. $\mathrm{E}$ ariftata foliis ternis lanceolatis glabris, floribus racemofis fecundis.

planifolia. 60. E. ariftata foliis ternis ovatis ciliatis, floribus axillaribus, caule decumbente.

jubefcens. 6r. E. ariftata foliis ternis quaternisque line?ribus fcabris, floribus umbellatis villofs. 


\section{c. foliis quaternis pluribusve:}

perfoluta. 62. E. ariftata foliis ternis quaternisque trigonis glabris, floribus umbellaris, calyce ciliato.

arborea. 63. E. ariftata foliis quaternis lanceolatis ciliatis, floribus racemolis.

florida. 64. E. ariftata foliis quaternis lanceolatis hirfutis, floribus umbellatis, calyce villofo reflexo.

pilulifera. 65. E. ariftata foliis quaternis linearibus ciliatis, floribus umbellaris, calyce naviculari apice ciliato glabro.

tetralix. 66. E. ariftata foliis quaternis oblongis ciliatis fubrus tomentofis, floribus umbellatis, calyce ciliato tomentofo.

inflata. 67. E. ariftata foliis quaternis linearibus gla. bris, floribus umbellatis ventricofis, calyce fubulato glabro.

abietina. 68. E. ariftara foliis quaternis lanceolatisglabris, floribus racemofis cylindricis, calyce ovato ferrato.

mammofa. 69. E. ariftata foliis fenis lanceolatis glabris, floribus umbellatis, calyce fubulato glabro. empetrifolia. 70. E. ariftata foliis fenis oblongis ciliatis, floribus verticillatis, calyce ciliato.

spicata. 7r. E. ariftata foliis fenis lanceolatis glabris, floribus verticillatis, calyce periolato integro.

octopkylla. 72. E. ariftata foliis odtonis linearibus truncatis fquarrofis, floribus umbellatis.

*** CRISTAT E.

a. foliis fparfis:

oblinun. 73. E. criftata foliis oblique fparfis linearibus truncatis glabris. 


\section{b. foliis oppofitis :}

vulgaris. 74. E. criftata foliis oppofitis fagittatis.

\section{c. foliis ternis:}

gmapbalodes.75. E. criftata foliis ternis ovatis integris glabris, floribus ternis glabris, calyce bra. cteisque navicularibus coloratis.

mucofa. 76. E. criftata folis ternis ovatis ferratis gla. bris, floribus umbellatis vifcofis, caJyceo vato colorato.

corifolia. 77. E. criftata foliis ternis lanceolatis integris glabris, Horibus umbellatis glabris, ca. lyce naviculari inflato.

calycina. 78. E. criftata foliis ternis ovatis integris gla. bris, floribus umbellatis glabris, calyce naviculari truncato cufpidato.

triflora. 79. E. criftata foliis ternis fubulatis glabris, floribus fubternis, calyce ovato æquante, caule hifpido.

Scoparia. 80. E. criftata foliis ternis linearibus integris glabris, floribus umbellatis, calyce ovato brevi, caule hifpido.

Bergiana. 81. E. criftata foliis ternis lanceolatis fcabris, florbus fubternis, calyce reflexo ciliato. formofa. 82. E. criftata foliis ternis ovatis integris, glabris, floribus umbellatis fulcatis, calyce patenti integro.

rubens. 83. E. criftata foliis ternis linearibus integris glabris, floribus umbellatis globofis, calyce lanceolato brevi, ramis glabris.

incarnata. 84. E. criftata foliis ternis ovatis integris glabris, foribus umbellatis ovatis, calyce integro, ramis villofis.

cinerea. 85 . E. criftata folis ternis lanceolatis integris B 2 gla- 
glabris, floribus umbellatis ovatis, calyce ferrulato, ramis villofis.

aufralis. 86. E. criftata foliis ternis linearibus ferrulatis glabris, floribus terminali-fubfeffilibus, bracteis imbricatis.

\section{d. foliis quaternis:}

ramentacea. 87. E. criftata foliis quaternis trigonis integris, floribus umbellatis, calyce lanceolato brevi.

baccans. 88. E. criftata foliis quaternis linearibus ferrulatis, floribus umbellatis, calyce ovato æquante.

phyfodes. 89. E. criftata foliis quaternis linearibus, floribus umbellatis vifcofis, calyce ovato brevi.

cermua. 90. E. criftata foliis quaternis ovatis ciliatis, floribus capitatis, calyce ciliato.

retorta. 91. E. criftata foliis quaternis ovatis ferrulatis fqvarrofis, floribus umbellatis vifcofis.

\section{S. IV.}

\section{DESCRIPTIO SPECIERUM.}

Radix omnibus perennis.

Caulis fruticofus, omnium maxime teres, interdum fle. xuofus, erectus frepius, raro decumbens, ramuloftis. Folia rariffime alterna, raro etiam oppofita, plerisque verticillata, terna, quaterna, quina, fena, octona; atque hæc linearia, lanceolata vel ovata; adprefla, erecta vel parentia; imbricata vel remota; glabra, lævia, fcabra, pilofa vel hifpida; integra, ciliata, vel ferrata. 
Bractea in pedunculis communiter tres, raro plures, quarum duæ oppofitæ, rudes vel coloratæ, foliis fimiles vel calyciformes.

Flores plerisque fpeciebus copiofi, paucis folitarii ; feffiles umbellati, fafciculati, racemofi ; fecundi, erecti, vel nutantes.

I. E. Daboecta. Cantis erectus, fpithameus.

Rami alterni, panci, pilofi, divaricato-patentes.

Folia alterna, fubfeffilia, inferiora ovata; fuperio. ra lanceolata, acuta, integra; fupra viridia, glabra, fulco longitudinali, rarisfime pilofa; fubtus albotomentofa, margine revoluto; erecto - patentia, unguicularia.

Flores racemofi, corollis oblongo-campanulatis, truncatis, cernuis.

Antberce muticæ.

2. E. Tenuigolia. Caulis totus glaber, erectus, fpithameus. Rami \& Rumuli filiformes \& capillares, erecti.

Folic oppoifta, lanceolata, glabra, fubtus convexa fulco tenui, adpreffa.

Floves terminales, umbellati, terni, toti cum calyce \& bracteis fangvineis.

Calycis foliola corollam æquantia, carinata. Antberce muticæ ftylusque inclulus.

3. E. Bracteata. Caulis erectus, glaber, pedalis. Rami inferne pauci, alterni; fuperne aggregati, fubverticillati, faftigiati.

Folia terna, lanceolata, acuta, integra, glabra, fupra concava, fubtus convexa fulco longitudinali, adpreffa, internodiis parum longiora.

Flores terminales, umbellati, rubri, bracteis obvallati. Bractece petiolatæ, ovatæ, acuminatæ, carinatx, glabrx; exteriores margine, interiores totæ fanguineæ. Antbere muticæ ftylusque inclufus. 
4. E. Thunbergir. Caulis brunneus, glaber, erectus, res: quipedalis.

Rami alterni, conferti, cauli fimiles.

Folia terna, linearia, acuta, integra, glabra, fu. pra plana, fubens convexa fulco longicudinali, adprefia, longitudine internodiorum.

Flores umbellati, fpeciofi, bicolores.

Pedunculi fanguinei, glabri, unguiculares.

Bractex dux, alrernx, lanceolatx, integrx, Havæ.

Calycis foliola ovata, acuminata, integra, concava, flava.

Corolla dilure fanguinea; tubus globofus, calyce paulo brevior; Limbus campanulatus: laciniis ova. tis, acutis.

Antbere muticæ ftylusque inclufus.

5. E. Tetragona. Caulis totus glaber, erectus, bipedalis.

Rami verticillati, erecti, inferiores longiores, fuperiores breviores, raro ramulofi.

Folia terna, lanceolato-trigona, tenuiffime ciliata, imbricata, unguicularia.

Flores racemofi, fecundi, horizontales, lutei.

Pedunculi breviffimi bracteis foliis fimilibus.

Calycis foliola folis fimilia, adpreffa, corolla du. plo breviora.

Corolla oblonga, acuta, terragona oris laciniis reflexis. Antberce mutica ftylusque inclufus.

Differt ab E, lutea. $\alpha$ ) corolla terragona.

B) calyce lanceolato, ciliato,

$\gamma$ ) antheris muticis.

d) foliis ternis.

6. E. UMBELLATA. Frutex glaber totus, erefus. Rami \& Ramuli fparfi, filiformes, erecto-patentes. Folia terna, lineari-trigona, obrufa, fubtus fulcata, tenuifime ciliata, imbricata. Flores in ramulis umbellati, erecti. 
Pedunculi capiltares, corolla longiores.

Calycis foliola foliis fimilia, brevifima, adpreffa.

Corolla campanulata, ccerulefcens.

Antberce muticæ, fubexfertæ, purpurafcentes.'

7. E. Petiolata. Caulis teres, flexuofus, decumbens, rigidus, glaber.

Rami fparfi, oppofiti \& terni, erectiufculi, inflexi, flexuofi, ramulofi, fuperne tomentofi.

Folia terna, lanceolata, fupra plana, fubtus fulcata a marginibus revolutis, integra, glabra, patentia. Petioli femiteretes, longitudine foliorum, interno. dia aquantes, adpreffi, pallidi.

Flores in ramulis terminales, umbellati, fubterni. Pedunculi breviffimi, tomentofi.

Bractece lanceolatæ, juxta bafin calycis fitæ.

Calycis foliola ovata, acuta, integra, glabra, concava, fub apice carinata, adprefra, corollæ longitudine.

Corolla campanulata, pallida, glabra. Antberc muticæ, fubexfertæ, purpureæ.

Stylus longitudine ftaminum, filiformis ftigmate obtufo. 8. E. Bryantha. Coulis decumbens, tenellus: ramis brevibus, pollicaribus.

Folia terna, ovata, obtufa, ciliata, dorfo fulcata, imbricata, patentia.

Flores paniculati.

Pedunculi filiformes, erectiufculi, pollicares.

Pedicelli fubumbellati.

Bractece duæ, alternæ, remotæ in pedunculo. Antbere mutica.

9. E. Fucata. Rami alterni, glabri.

Folia terna, lineari - lanceolata, glabra, fupra pla. na, fubtus carinata, margine revoluta, erecto - paten. tia, internodiis duplo longiora, unguicularia. 
Flores racemoli, recundi, globoli, albo-vircintes. Antbere muticx ftylusque inclufus.

Parictas a) fricta: ramis erectis.

B) diffufa: ramis inflexis.

10. E. Axillaris. Cumlis ercctus, glaber, pedalis \& ultra. Rami frequentes, fparfi, oppofitiqus, crecti, to. mentofi, ramulofi.

Folia terna, lineari-trigona, acuta, glabra, fubus fulco tenuilimo, erecta, internodiis paulo longiora.

Flores in axillis foliorum folitarii, pedunculati, globofi, minuti.

Aatbere mutice fiylusque inclufus.

च. E. Imbricata. Caulis erectus, glaber, pecialis \& ultra. Rami alterni, fuperne pubercentes, crecti.

Ramuli oppofiri, brevilfimi, foliofi.

Folia terna, oblonga, obtula, fupra piana, fubius fulcata, margine ferrulata, glabra, imbricnta.

Flores in ramulis terminales, torni, breviffme pedunculati, minuti, albi.

Calyx albus, imbricatus bracteis albis, carinatis. Anthere muticæ, exfertæ, purpurex.

Stylus exfertus, Hore duplo longior.

I2. E. Melanthera. Caulis teres, brunneus, flexuolus, erectus, totus glaber, pedalis.

Rami fparfi \& fubverticillati, flexuofi, erecti, vir. gati.

Ramuli filiformes, confimiles.

Folia terna, lineari-lanceolata, fubrus convexa ful. co longitudinali, lævia, giabra, erecta apice patulo, frequentifima, lineam longa.

Flores in ramulis terminales, bini vel terni, umbellati, incarnati.

Bractece calyciformes, incarnatx, laxe.

Calycis foliola ovata, acuta, frave rubentia, corolla breviora. 
Corolla campanulata.

Antberce muricæ, inclufæ, purpurea.

Siyhus ftaminibus longior, fubexfertus.

13. E. Leucantuera. Caulis erectus, glaber, pedalis \& ultra.

Rami fubterni, pubefcentes, ereati, virgati.

Ramuli fparfi, frequentifrmi, filiformes \& capillares, pubefcentes, erecti, foliofi.

Folia terna, trigona, obtufa, adprefia, glabra, fub. tus: fulco tenuiffimo.

Flores in ramulis terminales, bini \& terni, brevis. fime peànculati, erecti, albi, calyce pallidiores. Antbere muticæ, exfertæ, albæ.

14. E. Spumosa. Caulis erectus, teres, punctis elevatis fcaber, fulcus, pedalis vel ultra.

Rami dichotomi \& trichotomi, divaricato-erecti, cauli fimiles.

Ranuli filiformes, fparfi, ramis fimiles, foliofi. Folia terna, trigona, fubtus fulcata, glabra, fexfariam imbricata, lineam longa.

Flores terminales, bini ternique, albo purpurafcen. tes, globoli.

Antberce muticæ, inclufæ.

Stylus exfertus.

Singularis floribus tribus in capitulum congeftis.

I5. E. Capitata. Caulis raro erectus, fæpius decumbens, glaber, flexuofus, filiformis.

Rani filiformes, flexuof, villofi.

Rammli capillares; frequentes, romentofi.

Folia terna, ovata, patentia, pilis longis hirta.

Flores in extremis ramulis terminales, pedunculati, folitarii, bini vel terni, calycibus totis denfifime albo - lanatis.

Antberce muticæ, єxfertæ, purpureæ. 
Stylus exfertus, antheris paulo longior.

16. E. Passerine. Caulis erectus, teres, inferne glaber, fupra tomentofus, bipedalis.

Rami Cparfi \& fubverticillati, breves, erecti, albo. tomentofi.

Ramuli brevilfimi.

Folia terna, ovata, obtufa, fupra plana, incurvata, fubtus fulcata, glabra, adprefra, internodiis bre. viora, lineam vix longa.

Petioli breviffimi, tomentofi.

Floves in ramulis lateralibus terminales, folitarii \& bini, pedunculati, erecti.

Pedunculi teretes, albo-tomentofi, unguiculares.

Calycis foliola bafi cohærentia, ovata, albo - tomentofa, corolla duplo breviora.

Corolla campanulata, rubra.

Antbere muticx ftylusque inclufus.

17. E. Totra. Caulis fruticofus, inferne nudus, erectus, pedalis \& ultra.

Rami dichotomi \& trichotomi, divaricati, erccti, hifpidi.

Razinuli ramis fimiles, fuperne frequentes.

Folia terna, oblonga, patenti-reflexa, hifpida, lineam longa.

Flores in ultimis ramulis terminales, folitarii, bi. ni vel terni, breviffme pedunculati, cernui, albidi.

Calycis foliola ovata, ciliata, albida, corolla breviora.

Bractere ad bafin calycis ovatæ, albæ, calyciformes.

Antberce muticx ftylusque inclufus.

18. E. Virgata. Caulis erectus, totus hirtus, pedalis.

Ramz fparfi \& fubterni, filiformes, virgati, vel paniculati, erecti, hifpidi, frequentes, digitales. 


\section{De Erica.}

Ramuli fuboppofiti, frequentisfimi, brevisfimi.

Folia terna, oblonga, fupra plana, fubtus convexa, fulcata, pilofa, fcabra, patentia, linean longa. Flores in ramulis terminales, terni.

Calycis foliola ovata, interra, corolla duplo breviora.

Corolla globofa, pallida.

Antbere murica, inclufx.

Stylis exfertus figmate peltato.

Varint $\alpha$ ) Caule virgato, ramis folisque valde hisfutis \& fcabris.

B) Canle virgato ramisque hirfutis; foliis rugofis, villofis, patulis.

y) Caule paniculato, ramulis brevisfimis folisque parum fabris \& hirfutis.

d) Canle paniculato, ramulis longioribus faftigiatis foliisque parum fcabris, giabris.

99. E. Crumaris. Caulis decumbenti-erectus, bafi glaber, fupra villofus, bipedalis.

Runi \& Ramuli fparfi \& terni, filiformes, divaricato - patentes \& reflexi, villofi.

Folin terna, ovata, acuta, ciliata margine reflexo, fupra viridia, fubtus glauca, parentia, frequentia, lineam longa.

Flores racemofi \& verticillato terni, cernui.

Calycis foliola foliis fimilia, reflexa, ciliata, corolla duplo breviora.

Corollis oblonga, campanulata, alba.

Antbere muticæ, inclufa, purpurcæ.

Stylus exfertus, corolla duplo fere longior.

20. E. Hispida. Caulis erectus, totus villolo-hifpidus, bipedalis.

Rami \& Ramuli fparfi, bini ternique, bafi divaricati, erecti, valde hifpidi; ultimi ramuli alterni, bre. vilimi. 
Folia terna, ovata, acuta, integra margine reflexo, glabra, raro fubciliata, erecta, patentia, lineam longa.

Flores in ultimis ramulis terminales, raro folitarii vel bini, fepe tres vel plures, umbellati, creati.

Calycis foliola lanceolata, glabra, crecta, albida.

Cornlla globofa, minuta, albicia, glabra.

Antherce muticæ, inclufe.

Stylus exfertus ftiomate peltato.

Similis valde: E. Planifolive; fed differt :

a) Caule fruticoro, erecto.

b) Antheris muticis.

ximatis.

c) Foliis vix ciliatis, revolutis, magis appro.

d) Corollis globofis, glabris.

2i. E. Petrverir. Caulis flexuolo-erectus, glaber, pedalis vel ultra.

Rami Cparfi, frequentes, fimplices, trpe fecundi, breviffimi.

Folin terna, linearia, glabra, bafi ciliata, recurva vel erecta, unguicularia.

Flores in apicibus ramulorum Colitarii, recurvi.

Bractee tres, calyciformes, (unde calyx heptaphyllus) ovate, acutie, pallidæe, glabrie, imbricate.

Calycis foliola ovata, acuta, concava, dorfo ca. rinata, inteorra, pallida, glabra.

Corolla cylindrica, curvata, glabra, pollicaris, lutea.

Filamenta capillaria, longitudine corollæ.

Antberce muticæ, lineares, exfertie, unguiculares, attenuatæ in filamenta.

Stylus exfertus, ftaminibus paulo longior, ftigma. te parum incrafato. 


\section{Variat: $\alpha$ ) foliis fquarrofis longioribus. \\ B) foliis erectis brevioribus.}

22. E. Plukenetir, Frutex totus glaber, erectus, pedalis. Rami dichotomi \& trichoromi, teretes, a cafu foliorum nodulofo-fcabri, flexuofi, ereeti, ramulis fimilibus fanigiaris.

Folin terna, lineari-trigona, acuta, integra, gla= bra, incurva, unguicularia.

Flores in ramulis inter tolia racemofi, cernui.

Pedunculi recurvati, bracteis remotis.

Calycis foliola ovara, acuta, carinata, integra, virefcentia, glabra, lineam longa.

Corolla cylindrica, curvata, purpurea, glabra.

Antibere mutice, lineares, exfertæ, purpurex, pollicares.

Stylus exfertus, longitudine ftaminum ftigmate pa. rum incraffato.

23. E. Cephalotes. Frutex glaber, punctato-fcaber, erectus, pedalis.

Rami verticillati, divaricato erecti, cauli fimiles, fubfaftigiati, raro ramulofi, pubefcentes.

Folia fena, lanceolata, glabra, patentia, apice incurvata, approximata, fupra plana, fubtus conve. $\mathrm{xa}$, unguicularia.

Floves in apicibus verticillato-capitati, purpurei, glabri.

Corolla clavato - cylindrica, obtula, unguicularis.

Anthere muricæ, inclufæ.

Stylus exfertus.

Differt r:o ab emtetrifolin, cui fimilis:

\&) foliis lavibus, non fulcatis.

B) corollis minoribus.

$2: 0$ ab E pulcbella:

๙) floribus feffilibus, villofis.

B) foliis latioribus.

C $324, \mathrm{E}$. 
24. E. Purcielca. Frutex torus glaber, erectus, pedalis. Rami verticillati, fubfimplices, erecto-patentes, longi.

Lolia fena, obligue verticillata, lineari-lanccolata, integra, glabra, incurva, fupra plana, fubrus convexiufcula fulco tenuifimo, erecto-patcria, internodis multoties longiora, unguculara.

Flores in ramis laterales, breviter pedunculati, fubdiftichi, fpeciofi, horizontales.

Bractere foliacere in pedunculo.

Caljcis foliola lincari-lanceolata, fubus inlcata, adprefia, viridia, coro:la triplo breviora.

Corolla tubulofo-campanulata, apice dilatata, tcnuiflime villofa, crafla, purpurea, unguicularis: ore obtufo, laciniisque reflexis.

Antberce muticæ, inclufæ.

Stylus exfertus ftigmate capitato.

Differt ab E. Cocinen antheris inclutis; corolla clavata. 25. E. Vestita. Cuntis erectus, cinereo-fufcus, glaber, pedalis.

Rami verticillati, erecto-parentes, ramuis fimilibus.

Folia fena, obliqua, ntenuata in periolos capilla. res femiunguiculares, lincaria, acuta, integra, glabra, fupra concava, fubius convexa absque finlco, bafi imbricara, fublecunda, apice patenti-recurva, fubpollicaria.

Flores in ramulis mediis fubverticillati, breviter pedunculati, erecti.

Calycis foliola bafi lata, dein lineari-fubulata, viridia, glabra, corolla triplo breviora.

Corolla clavata, cuịvata, villofa, obtufa, alba, pollicaris,

Antberce muricæ, fubexfertx, purpurex.

Stylus exfertus figmate fufco. 
26. E. Pinea. Frutex totus glaber, cinereo-fufcus, ere. ctus, plus quam pedalis.

Rami verticillati, erecto-patentes, raro ramulofi, cauli fimiles.

Folia fena, lineari-lanceolata, glabra, fupra plana, fubtus convexa fulco longitudinali, erecto-incurvata, unguicularia.

Flores in mediis ramis \& ramulis fubverticillati, brevilfime pedunculati, erecti.

Calycis foliola bafi latiora, dein lineari-fubulata, glabra, corolla triplo breviora.

Corolla clavata, curvata, alba, glabra, obtufa, pollicaris.

Antbere muticæ, minutæ, purpureæ, fubinclufa. Stylus vix exfertus.

Differt ab E. Veftita: foliis lanceolatis fulcatis, corollis glabris.

27. E. Coccinea. Frutcx glaber, erectus, pedalis.

Rami verticillati, bafi divaricati, flexuofo erecti, fubfaftigiati.

Folia fena, lanceolata, acuta, glabra, fupra plana, fubtus convexa fulco longitudinali, incurvata, patentia, femiunguicularia.

Flores in fummitate ràmorum racemofi, fubverticillati.

Pedunculi breviffimi.

Calycis fo'iola ovata, acuminata, villofa, corolla quadruplo breviora.

Corolla clavata, incurvata, fanguinea, pubefcens. Antberce muticæ, fubexfertæ.

Stylus exfertus.

Variat foliis renis, feptem, \& octo. 
23. E. Grandrlora. Caulis fufcus, erectus; punctuto: fcaber, pedalis \& ultra.

Rami alterai \& verticillati, crocti, cauli fimiles, frmplices.

Toli, quaterna, linearia, acuta, integra, glabra, fupra plana, fubrus convera fulco longitudinali, incurvata, patentia; fumma recta, erecta; uiguiculavia. Flores racemoli in apice ramorum, erecti.

Calycis foliola ovata, acuminata, corolla multoties breviora.

Corolla ciavara, curvaca, glabra, coccinco, polli caris.

Antbere muticie ftylusque exfertus.

Simillima E. Coccinere, a qua vix differt, nifi folıis quaternis \& corollis glabris.

29. E. Crumorica. Fratur glaber tolus, fexuofo-ere. ctus, bipedalis.

Trmi \& tmmuli trichotoni ô chinotoni, cauli fimiles.

Folia ramulorm quaterna, trigona, fupra plana, fubtus convara fulco longitudinali, nitida, imbricata, lineam longa.

Flores in vlnimis ramulis terminales, fubfolitarii, erecti.

Cillycis foliola carinata, fubulata, glabra, corolla triplo breviora.

Corolla cylindrica, alba, glabra, remipollicaris. Anthere mutice ftylusqua inclufus.

30. E. Cunviflora. Comlis crectus, rylaber vel fupine villofus, bipedalis.

Rami fubverticillati, erecti, ramulofi ramulis brevillimis, frequentifimis, fpartis.

Folin quaterna, trigona, feu fupra plana, fubtus convexo-trigona fulco tenuifino, glabra, imbricata, lineam longa.

Flo. 
Flores terminales in ramulis, cernui, racemum quafi formantes longum, fubfecundi vel diftichi.

Calycis foliola ovata, acuminata, glabra, corolla quadruplo breviora.

Corolla cylindrica, fubclavata, obtufa, fanguinea, glabra, pollicaris.

Antberce muticæ, inclufa.

Stylus fubexfertus.

31. E. Tubiflora. Calulis flexuofus, erectus, cinereus, fuperne tomentofus, bipedalis.

Rami fparfi, filiformes, frequentes, tomentofi, virgari.

Folia quaterna, trigona, feu fupra plana, fubtus convexa fulco longitudinali, fubciliata, imbricata, lineam longa.

Flores in ramulis terminales, quafi racemum formantes, fecundi.

Calycis foliola oblonga, acuta, brevifima.

Corolla clavata, curvata, villofa, pollicaris.

Antberce muticæ ftylusque fubex fertus.

32. E. Glandulosa. Folia quaterna, linearia, obtufa, fupra plana, fubtus profunde fulcata, pilis glandulofis hifpida, imbricata, lineam longa.

Calycis foliola ovata, brevifima, pilis glandulofocapitatis vifcidis hifpida.

Corolla cylindrico-clavata, fanguinea, glabra, pollicaris.

Antberce muticæ, inclufa.

Stylus exfertus ftigmate capitato.

Differt facile a congeneribus pilis glandulofo-capitatis \& vilcidis.

33. E. Cerinthoides. Caulis cinereus, erectus, bipedalis. Romi dichotomi \& trichotomi, divaricati, bafierecti, raro ramulofi, ramis faftigiatis fimilibus.

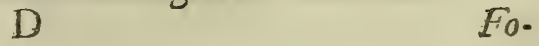


Folia quaterna, ovata, acuta, ciliato- ferrata, flipra plana, fubtus convexa fulco longitudinali, im. bricata, lineam longa.

Flores terminales, umbellati, erecti.

Pedunculi hifpidi, breves.

Calycis foliola lanceolata, ciliato-hifpida, adpres. $\mathrm{fa}$, corolla triplo breviora.

Corolla cylindrica, inflata, truncata, pilofo. hifpida, femipollicaris.

Antberce muricæ, tetragonæ, inclufæ.

Stylus exfertus.

Pariat: $\alpha$ ) corollis rubris, pilofis.

B) corollis rubris, ftrigofis.

$\gamma)$ corollis albis, cryftallinis.

34. E. Sparrmanni. Cinulis erectus, cinereus, pedalis et ultra.

Rnmi verticillati, elongati, eredri.

Ramuli oppofiti \& fparfi, frequentes, brevifimi.

Folia quaterna, oblonga, ciliato-ferrata ciliis luteis, fupra plana, fubtus a marginibus revolutis fulcata, imbricata, ultra lineam longa.

Flores in ramulis terminales, umbellati, fubquaterni.

Calycis foliola oblonga, flavef́centia, fetis flavis longis hifpida.

Corolla campanulata, fetis longioribus flavefcentibus valde ftrigofa, unguicularis.

Antbere mutice, jnclufæ.

Styius exfertus ftigmate peltato.

Valde fimilis E. Cerintboidi, a qua differre videtur:

๙) foliis longioribus.

B) corollis paucioribus, brevioribus.

$\%$ ) fetis ftrigofis, flores totos obtegentibus. 35. $\mathrm{E}$. 
35. E. Massoni. Coulis teres, brunneus, erectus, pedalis. Rami verticillato-terni, inæquales, erecti, foliis toti tecti.

Folia quaterna, oblonga, ferrata, ciliata, villola, 〔cabra, fupra plana, fubtus fulcata, octofariam imbricata.

Flores terminales, umbellati, plurimi, fpeciofi.

Pedunculi brevifimi, pilofi, fubnutantes.

Calycis foliola linearia, hirfuta, adpreffa, corolla multories breviora.

Corolla cylindrica, purpurea, unguicularis, vifcofa: ore acutiufculo, parum aperto.

Filamesta pallida, longitudine tubi.

Antbere muticæ, minutæ, purpureæ, inclufæ.

Stylus fubexfertus.

36. E. Ventricosa. Caulis erectus, glaber, parum ramofus, fpithamæus.

Runni alterni, in fummitate frequentes, fubvillo. fi, erefti.

Folia quaterna, lineari-trigona, acuta, ciliata, fubtus tenuiffme fulcata, patentia, unguicularia.

Flores in ramis terminales, umbellati, erecti.

Pedunculi villofi, unguiculares.

Calycis foliola lineari-trigona, glabra, adpreffa, corolla dimidio breviora.

Corolla ventricofa, groffa, albo-purpurafcens, glabra, fubpellucida: ore quadrifido laciniisque reflexis Antberce mutice, inclufre.

37. E. Fastigiata. Caulis brevifimus, ramofus, vel caules plures radicales, fubfimplices, faftigiati, cinerei, glabri, palmares vel paulo ultra.

Rami \& Ramuli terni, flexuofi, faftigiati.

Folia quaterna, trigona, glabra, imbricata, lineam longa.

Flores terminales, capitati, erecti. 
Calycis foliola oblonga, acuta, margine membranacea, integra, carinata, glabra.

Corolla oblonga, fubcylindrica, bafi inflata, glabra, extus pallide fanguinea, intus alba; laciniis ovatis, reflexis.

Antherce mutica ftylusque inclufus.

38. E. Comosa. Fruticulus torus glaber, erectus, pedalis \& ultra.

Rami \& Ramuli dichotomi, trichotomi \& verticillati, fuperiores filiformes, flexuofi, erecti, virgati. Folia quaterna, trigona, fupra plana, fubtus fulcata, glabra, imbricata, lineam longa.

Flores in ramulis rerminales, per ramulos quafi fpicam comofam denfam digitalem formantes.

Calycis foliola lanceolata, margine fcariofa, cilia. ta, glabra, corolla duplo breviora.

Corolla, Antberce \& Stylus ut in E. Faftiginta.

Valde affuis \& fimilis E. Fuftiginte, differt tamen;

๙) foliis fubtus manifefte fulcatis.

B) floribus non faftigiatis, fed racemum fpicatum formantes, licet in ramulis capitati.

$\gamma)$ calycibus ciliatis.

39. E. Dentata. Carlis flexuofus, erectus, palmaris, totus glaber.

Rawi pauci in fummitate caulis, breves, erecti.

Folia quaterna, trigona, glabra, imbricata.

Flores in apice ramorum capitati, fubterni.

Bradtere naviculares, ciliato-ferratæ, calyciformes, pallidæ carina viridi, longitudine calycis.

Calycis foliola ovata, acuta, lacero-ciliata, inflato - concava, pallida, glabra, corolla duplo breviora. Corolla fubcylindrica, purpurea, laciniis oblongis reflexis. 
Antbere muticæ ftylusque inclufus. 40. E. Viscaria. Caulis flexuofo-erectus, bipedalis vel ultra.

Rami \& romuli verticillati, terni, quaterni \& plures, inferne villof, fuperne albo-tomentofi, virgati.

Folia quaterna, trigona, acuta, fupra plana, fubtus convexa fulco longitudinali, glabra, imbricata apice incurvo, femiunguicularia.

Filores racemofi in medio ramulorum, comofi, patentes, fanguinei.

Pedunculi tomentoli, unguiculares: bracteis tribus, lineari-lanceolatis, pallidis.

Calycis foliola navicularia, viridia, glabra, ciliata, corolla dimidio breviora.

Corolla campanulata, glabra, magnitudine pifi minoris.

Antberce muticæ, inclufæ.

Stylus raro exfertus, fapius inclufus.

4r. E. Meditrranea. Frutex glaber totus, erectus.

Rami \& ramuli verticillati \& fparfi, patentes, virgati. Folia quaterna, linearia, acuta, glabra, fubtus fulcata, patentia, fubunguicularia.

Flores racemofi, comofi, patentes.

Pedunculi capillares bracteis in medio minimis.

Calycis foliola lanceolata, integra, concava, glabra, incarnata, corolla dimidio breviora.

Corolla campanulata, obtufa, fanguinea, glabra. Antbere mutice, fubexfertæ.

Stylus longior, exfertus ftigmate vix incraffato.

Dariat foliis ternis \& quaternis.

42. E. Multiflora. Frutex totus glaber, bafi decumbens, dein erectus, flexuofus, punctato-fcaber, pedalis \& ultra.

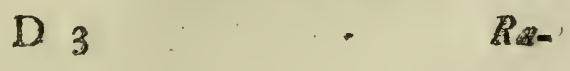


Rami verticillati, cauli frmiles, ramulor.

Folia quina, linearia, glabra, fubtus fulcata, curvata, patentia, ungicularia.

Flores racemofi, comofi, cermi, fenfim florentes.

Pedunculi capillares, purpurei : bracteis minuris infra medium.

Calycis foliola ovata, integra, colorata, glabra, corolla, triplo breviora.

Corolla campanulata, albo-fanguinea, glabra.

Antbere mutice, cxierte, purpurea.

Stylus exicrtus, longitudine ftaminum.

Affun E. Mediterranece; differt aurem:

\%) foliis quinis, minus patentibus.

B) ramis flexuofis, fcabris.

$\gamma)$ foribus minoribus, cernuis.

d) antheris magis exfertis.

Variat foliis quacernis \& quinis.

43. E. Herbacea. Frutex pulillus, glabor; ramis fiexuo. fis, erectis, iterum ramulolis.

Folia quaterna, linearia, fupra plana, fubtus convexa, carinata, glabra, erecto-patentia, femiunguicularia.

Flores racemoi, fecundi, cernui, albidi.

Bractea prope calycem minutx, pallidx.

Criycis foliola lanceolara, concava, glabra, corolJam æquantia.

\section{Antbere muticæ.}

44. E. Purpurascens. Caulis decumbens.

Folia terna, quaterna, fumma quina.

Flores dilute purpurei, fparfi.

Corolla campanulata, fubcylindrica.

Calycis foliola fubulata.

Antbere muticæ, profunde bifidæ, exfertæ.

Stylus exfertus. 
45. E. Vagans. Caulis fcaber, erectus, ramis ultimís albidis divaricatis.

Folia quaterna, raro quina, linearia, obtufiufcula, lævia, glabra, carinata fubius fulco longitudinali. Flnres fparfi, folitarii, laterales, pedunculati. Calycis foliola lancevlata, colorata, breviora. Corolla campanulata.

Antberæ muticæ, biparticæ ftylusque exfertus.

46. E. 'Cubica. Frutex totus glaber, brunneus, erectus, pedalis.

Rami \& ramuli trichotomi, filiformes, flexuofi, laxi, erecti, fubfarigiari.

Folia quaterna, fxpe quina, trigono-fubulata, patentia, incurvata, glabra, internodiis parum longiora, femilineam longa.

Flores in apicibus ramulorum umbellati, plurimi, cernui.

Pedunculi angulati, fcabridi, purpurei.

Culycis foliola ovara, acuta, carinata, purpurea, glabra, corolla paulo breviora.

Corolla globofo-campanulata, purpurea.

Antherce muticx, inclufe.

Stylus exfertus, corolla duplo longior, purpure. us: Aigmate fusfco, parum incraffato.

Singularis foliis incurvatis.

4\%. E. Racemosa. Caulis erectus, pedalis \& ultra.

Rami verticillati \& elongati, divaricato- erecti, pubefcentes.

Rnnuli verticillati, breves, per intervalla fparfi, villofi.

Folia quaterna, lanceolata, obtufa; fupra plana, læviufcula; lubtus fulcata, hifpida; patentia, lineam longa. 
Flores in ramulis racemoli, fubnutantes, incarnari. Racemi fubdiftichi, pollicares usque digitales.

Pedunculi capillares, villoli, cernui, corolla longitudine.

Calycis foliola ovata, obtura, incano-tomentofa, adpreffa, breviffima.

Corolla fubglobola ore patulo, obtufo. Antbere muticie, exferræ, brunnex.

Stylus exfertus, Ataminibus longior ftigmate capitato.

Differt I. ab E. purpurafcente : canle erecto.

2 - vagante: foliis pilofis.

3 - mediterranea: foliis pilofis corollaque glo. bofa.

4 - birta: Horibus racemofis.

48. E. Glutinosa. Catis erectus, palmaris usque fpithameus, torus vifcolus.

Rami Pparfi, filiformes, hirfuti, erecto-patentes, virgati.

Folia fparfa oppofitaque, linearia, obtufa, fupra plana, fubtus convexa, hirfura, pilis glandulofis ciliata, patentia, approximata, femiunguicularia.

Flores terminales, racemofo-fubumbellati, erecti.

Pedunculi filiformes, pilis glandulofis hirti, foliis duplo longiores.

Bractee fupra medium pedunculi minimæ.

Calycis foliola ovara, acuta, glabra, concava, viridia, corolla triplo breviora.

Corolla ovato oblonga, pubefcens, purpurafcens o. re obrufo laciniisque reflexis.

Antberce ariftatæ, inclufæ.

Stylus fubexfertus ftigmate capitato.

Florum multa millia aperuit \& ofto ftamina conftanter numeravit Exp. D. Præfes. 


\section{de Erica.}

49. E. Lutea, Frutex totus glaber, caule rufercente, erecto, bipedali.

1. Rami fparfi, erecto-patentes, virgati.

Ramuli fparfi, filiformes, frequentifimi, virgati, breves.

Folia oppofita, lineari-trigona, obtura, fubtus fulcata, imbricata, lineam longa.

Flores in ultimis ramulis folicarii, bini vel terni, erecti.

Bractece lineares, obtufæ, concavæ, pallidæ.

Caljeis foliola ovata, acuminata, fub apice carinata, adprefia, concava, corolla duplo breviora.

Corolla ovata, attenuata, femiunguicularis: ore ante florefcentiam acuto, dein obrufo lacinisque re. flexis.

Antbere ariftatæ ftylusque inclufus,

Farint corollis, calycibus \& bracteis luteis \& albis, adeo ut luter \& albens revera non fint, nifi varietares.

Tota recta floribus nitidis, aureis vel argenteis, omnium pulcherrima.

go. Depressa. Fruticulus vix palmaris, fufcus, flexuofus, fcaber; decumbens.

Rami lparfi, deprefi, fimiles cauli, ramulofi.

Folia terna, oblonga, obtufa, fupra concava, fubtus trigono - convexa fulco longitudinali, glabra, imbricata, vix femiunguicularia.

Flores racemofi vel terminales, albi.

Bractece lineares, concavæ, pallidx.

Colycis foliola oblonga, acuta, corollam æquantia. Corolla campanulata, lineam longa.

Antbere ariftate ftylusque inclufus.

Vix dici pofunt antheræe criftata.

5. E. Halicacaba. Caulis glaber, fcaber, fulcus, fle. xuofus, decumbens, ftrictus, fpithamaus. 
Rami alterni, divaricati, cauli fimiles. Ramuli tomentofi, ramis fimiles.

Folia terna, lanceolata, acuta, glabra, fupra plana, fubtus convexa fulco tenui, patentia, unguicularia.

Flores terminales, folitarii, pedunculati.

Pedunculus tomentofus, reflexus, ungुuicularis.

Bractere ovatæ, acutæ, approximatæ, calyce multoties minores.

Calycis foliola ovata, acuta, carinata, integra, adpreffa, glabra, pallida, duas lineas longa.

Corolla ovata, inflata, acuta, pallide incarnata: laciniis rectis, acutis, conniventibus.

Antbere ariftatæe ftylusque inclufus.

Corolla ex omnibus Ericis maxima.

52. E. Monsoniana. Caulis erectus, pubefcens, aphyllus, bipedalis.

Rami fparfi, frequentes, patentes, foliis tedt, breviffimi, fimplices.

Folia terna, ovata, obtufa, fubtus convexa fulco longitudinali, fupra plana, integra, imbricata, gla. bra, vix lineam longa.

Flores in ramis terminales, folitarii, nutantes, albi.

Pedunculus pubefcens, reflexus, femiunguicularis.

Bractex ovatx, carinatæ, acutæ, albæ, calyce paulo breviores, in medio pedunculo fitæ.

Calycis foliola ovata, acuta, concava, carinata, alba, glabra, corolla fere triplo breviora.

Corolla ovato-oblonga, fenfim parum attenuata, inflata, pollicaris ore quadrifido: lacinice obtufre, breviffimæ.

Antberce oblongr, apice fiffæ, inclufa, bafi bicornes, cornibus fimplicibus.

Stylus filiformis, longitudine corollæ, inclufus fti. gmate capitato. 
Sinilis quidem E. balicacabs; differt vero.

I: o foliis ovatis, nec linearibus.

2:0 corollis minus profunde partitis \& minus inflatis.

3:0 floribus copiofifimis.

4:0 caule erecto.

33. E. Nigrita. Caulis brunneus, erectus, pedalis \& ultra. Rami \& Ramuli fparfi \& verticillati, flexuofoerecti, virgati, cinereo-tomentofi.

Folis terna, lineari-ovata, obtufa, margine tenuiffime fcabra, fupra plana, fubtus convexa fulco tenui longitudinali, nirida, bafi adpreffa, a medio patenti-recurvata, lineam longa.

Floves terminales, terni, pedunculati, erecti.

Bractex oblongæ, acutæ, carinatæ, albæ, calyci approximatæ, imbricatæ calyciformes.

Calycis foliola ovata, acuta, carinata, tenuifime margine fcabrida, alba, glabra, corollam fubæquan. tia.

Corolla campanulata, albida.

Antberce ariftatæ, purpureæ ftylusque inclufus.

54. E. Regerminaris. Frutex totus glaber, erectus, rufefcens, bipedalis.

Rami verticillati, longi, fimplices, erefti.

Folia terna, linearia, acuminata, integra, glabra, patentia, internodiis longiora, unguicularia.

Floves in ramis fupremis racemofi, fecundi, cernui. Pedunculi purpurei, reflexi.

Bractere infra medium pedunculi minutæ, coloratæ.

Calycis foliola lanceolata, carinata, rufefcentia, glabra, adpreffa, breviflima.

Corolla ovato-cylindrica: ore aperto, obtufo; rufefcens, glabra.

Antberce ariftatæ. 
55. E. Urceolaris, Canlis flexuofo-erectus, cinereus, bipedalis.

Rami oppofiti \& terni, cinerco - villofi, virgati. Ramuli filiformes, fparfi, frequentes, virgati.

Folia terna, lineari-lanceolata, fupra convexoplana; fubcus fulcaca a marginibus revolutis, tomen. tofo-albida; erecto-patentia, fubcurvara, unguicularia

Flores fubracemofo umbellati, incarnati, toti hirfuti petiolis, calyce, corolla.

Calycis foliola lanceolata, corolla duplo breviora. Corolla oblonga, fubcampanulata, lineam longa. Antberce ariftata ftylusque inclufus.

Variat floribus valde hirlitis \& pilofis, rubris \& incarnato -albidis.

56. E. Hirta. Coulis Hexuofo - ercetus, glaber, pedalis. Rami \& Ramuli fparfi, virgati.

Folia terna, linearia, acuta, fupra plana, fubtus fulcata a marginibus revolutis., fcabra, ciliata, im. bricato patentia, fubunguicularia.

Floves terminales, umbellati, incarnati.

Calycis foliola lanceolara, fcabra, ciliata, adpreffá, corolla duplo breviora.

Corolla ovato - globofa, fubvillofa.

Antbeve ariftatie ftylusque inclufus.

5\%. E. Bicolor. Caulis flexuofo-erectus, cinereo-fubto. mentofus, fpithamæus vel paulo ultra.

Rami vel fimplices, vel ramulofi, frequentes, cau.

li fimiles, virgati.

Folia terna, ovata, obtufa, fcabra, tenuilfime villofa, fubtus fulcata a marginibus revolutis, imbricata, lineam dimidiam longa.

Flores in ramis \& ramulis terminales, fxpius ter. ni, nutantes, glabri, fanguinei, per fruticem copiofi. 
Calycis foliola ovata, tenuilfime villora, adpreffa, rubentia, corolla duplo breviora.

Corolla campanulata, glabra.

Antberce ariftatæ, fubexfertæ, atro - purpureæ.

Stylus fanguineus, curvatus, exfertus, corolla duplo longior, Afgmate capitato.

58. E. Articularis. Camlis fulcus, flexuolo-erectus, infers ne glaber, pedalis.

Rami \& Ramuli verticillati, faltigiati, flexuofi, patentes, tenuisfime villofi.

Folis terna, ovata, glabra, fupra concava, fubtus convexa fulco longitudinali, adprefra, internodiorum longritudine ramos quafi articulatos formantia, lineam longa.

Floves racemofi, diftichi, cernui.

Racemus pollicaris vel digitalis, comofus.

Pedunculi capillares, purpurei, tenuilfme villofi, cernui, longitudine foliorum.

Bracter minutæ, purpureæ.

Calycis foliola ovata, intus concava, extus carinata, fufco-purpurea, ciliata, glabra, corolla dimidio breviora.

Corolla campanulata, glabra, fanguinea.

Antberce ariftate ftylusque inclufus.

Antheræ in hac fpecie fingulares, cum connatæ videantur cum filamento, fic ut potius filamentum, quam antheræ, ariftatum dicendum.

59. E. Virescens. Folin terna quaternaque, lanceolata, glabra.

Flores racemofi, fecundi.

Corolla campanulata, purpurea.

Antberce ariftatæ, inclufa.

stylus inclufus. 
60. E. Planigolia. Canlis, Rami \& Ramuli trichotomi, filiformes \& capillares, decumbentes, flexuofi, glabri vel tenuiffme fcabri.

Folia terna, rarius quaterna, axillis aliis foliolis frpe onufta, ovata, acuta, tenuiffime fubciliata, margine parum revoluta, parentia, lineam dimidiam longa, internodiis breviora.

Filores verfus apices racemofi, cernui.

Pedunculi capillares, foliis longiores.

Calycis foliola ovata, fcabra, breviora.

Corolla campanulata, purpurafcens.

Antberce ariftatæ, inclufie.

Stylus exfertus, corolla duplo longior, ftigmate parum capitato.

Pariat r:o caule fcabro \& glabro.

2:0 foliis acutis \& pilo capitato terminatis.

6r. E. Pubescens. Caulis cinereus, hifpidus, flexuofus, erectus, bipedalis \& ultra.

Rami fparfi, raro verticillati, cauli fimiles. Ramuli filiformes \& capillares, breves, virgati. Folin terna \& quaterna, fæpe quaterna in ramis \& terna in ramulis, raro quaterna omnia, linearia, obtufa, fcabra, villofa, incurva, fubtus fulcata, patentia, lineam longa.

Flores in ramulis terminales, umbellati, bini, terni vel plures, copiofi, fanguinei, hirfuti.

Pedunculi capillares, bracteati.

Calycis foliola lanceolata, rufefcentia, pilofa, breviffima.

Corolle ovata, obtufa, villora.

Antbere ariftaræ ftylusque inclufus.

Dorint valde hæc fpecies Ericæ, caule, ramis, foliis, \& floribus. Præcipuæ vero varietates funt fequen. tes: 
I:o pilofa foliis ternis corollisque tenuisfime pilofis.

2:0 bi/pida foliis ternis, hifpidis.

3:0 villofa foliis quaternis, fcabris, ramisque verticillatis.

4:0 parviflora foliis ramorum quaternis, ramulorum ternis hifpidis; corollis minutis.

Villofa eadem eft, licet differe videatur foliis quaternis, fcabris, longioribus; caule ramisque verticil. latis, magis glabris; corollis magis cylindricis \& floribus conglomeratis.

62. E. Persoluta. Frutex totus cinereo-tomentolus, idque magis in ramis \& ramulis, flexuofo-erectus, fpithamrus vel paulo ultra.

Rami fparfi, oppofiti \& terni, cauli fimiles.

Ramuli filiformes, frequentes, breves, virgati.

Folia in nonnullis, fed raro terna; in nonnul. lis, at rarius \& terna \& quaterna; in plurimis quaterna, linearia, obtufa, fupra plana, fubtus convexa fulco longitudinali, rarius integra, frpius te. nuiffime ciliata, glabra, imbricata, vix lineam longa.

Flores in ramulis umbellati, fapiffime terni, per ramos quafi racemofi, copiofi, incarnati, minuti, cernui.

Bractere pallidæ, fubciliatæ.

Calycis foliola ovata, acuta, fubcarinata, tenuiffime ciliata, corolla duplo breviora.

Corolla campanulata finu laciniarum pertufo.

Anthere ariftatæ, inclufx, purpurex.

Stylus paulo longior ftaminibus, fæpius inclufus. Darint valde hæc fpecies polymorpha, fic ut exinde plures fpecies conftimerint Auctores:

1:0 foliis ternis \& quarernis, integris \& ciliatis, 
2:0 Corollis majoribus \& minoribus, carr. panulatis vel magis globofis.

3:0 antheris ftylisque inclufis or exfertis.

63. E. Arborea. Cnulis infra brunneus, fupra cinereotomentofus, flcxuofus, erectus, orgyalis. Rnmi fubverticillaci, hifpici, virgati.

Ramuli fparfi, filiformes, hifpidi, virgati, frequentes.

Folin rarius terna, fepilime quaterna, lauceola.. ta, ciliata, glabra, patentia, internodiis longiora, lineam longa.

Flores in apicibus ramulorum racemofi, crinui. Calycis foliola lanceolata, fpinofo-acuta, glabra, breviora.

Corolla campanulata, purpurea, glabra.

Antberce ariftatx, inclufx.

Stylits exfertus, fanguineus: higmate capitato, purpureo.

64. E. Florida. Canlis teres, purpurcus, fuperne villofus, fexuofus, erectus, pectalis \& ultra.

Rnmi fparfi, laxi, cauli fimiles, virgati, fubfimplices.

Folia quatcrna, lanccolata, hiriuta, fubtus fulcata, curvata, patenti-crefa, femiunguicularia.

Floves terminales, umbellati, cernui, quatuor \& ultra,

Pedunculi capillares, fanguinei.

Calycis toliola linearia, obtufa, hirfuta, reflexa, foliis duplo breviora.

Corolla globofa, pallide fanguinea, infata, glabia. Antberce ariftatæ ftylusque inclufus.

6g. E. Pilulifera. Frutex totus glaber, purpureus, erectus, pedalis \& ultra,

Rami \& Ramuli trichotomi, erecto-patentes, fub. faftigiati.

$F_{0}$. 
Folia quaterna, oblique verticillata, tria fitu zequalia quarto inferiore, linearia, obtufa, fupra plana, fubtus convexa fulco longitudinali profundo, inferiora glabra, fuprema tenuiffme ciliata, in petiolos pallidiores attenuata, imbricata, femiunguicularia.

Flores terminales, umbeliati, quatuor usque decem, cernui.

Pedunculi fanguinei, foliis longiores.

Calycis foliola navicularia, acuta, pallide fanguinea, glabra, apice ciliata, adpreffa, corolla paulo breviora.

Corolla campanulata, fanguinea, glabra.

Antbere ariftate ftylusque inclufus.

66. E. Tetradix. Fruticulus palmaris vel fpithamæus, cinereo-romentofus, bafi decumbens, flexuofo-erectus,

Rami \& Ramuli fparfi, breves, virgati.

Folia quaterna, oblonga, acuta, ciliata, fubtus fulcata a marginibus revolutis, albo-tomentofa, patentia, lineam longa.

Flores terminales, umbellati, circiter decem, cernui.

Pedunculi albo-tomentofi, foliis longiores.

Calycis foliola lanceolata, albo-tomentofa, apics pulcherrime ciliata.

Corolla ovata, fubcampanulaca, albida, glabra.

Antberce ariftatæ, incluææ.

Stylus fubexfertus, ftigmate capitato.

67. E. Inflata. Frutex totus glaber, nodulofus, erectus, pedalis.

Rami verticillati, cauli frmiles, longi, erecti, fub: fimplices.

Folia quaterna, linearia, acuta, integra, fupra plana, fubtus convexa fulco omnium tenuiffimo, curvata, patenti-erecta, glabra, unguicularia.

Flores umbellati, cernui. 
Pedunculi fanguinei, villofi, pollicares.

Bractex fupra medium pedunculi lineares, fan. guineæ.

Calycis foliola lineari-fubulata, integra, glabra, patenti-erecta, fanguinea, corolla quadruplo bre. viora.

Corolla ventricola, inflata, obtufa, pallide fanguinea, glabra, fubpollicaris.

Antbere ariftatx fylusque inclufus.

68. E. Abietina. Caulis cinereus, fcaber, erectus, peda. lis \& ultra.

Rami \& Ramuli fubverticillati, eredto-patentes.

Foliz quaterna, lanceolato - fubulata, fubtus fulcata, glabra, imbricata, unguicularia.

Flores in apicibus ramorum racemofi, nutantes.

Pedunculi fanguinei, villof, longitudine foliorum. Bractece infra medium pedunculi, ovatæ, acutæ, ciliatæ, carinatæ, pallidæ.

Calycis foliola lato-ovata, acuta, carinata, tenuisfime fubciliata, glabra, fanguinea.

Corolla cylindrica, infra a picem fubventricola, parum curvata, obtufa, glabra, fanguinea, femipollicaris.

Antberce ariftatæ ftylusque inclufus.

69. E. Mammosa. Caulis cinereo-fufcus, flexuofus, erectus.

Rami fubtrichotomi, fcabri, flexuof, iterum trichotome ramulofi ramulis fubfaftigiatis.

Folin fena, lanceolata, fupra plana, fubtus convexa fulco longitudinali, integra, glabra, curvata, patenria, fubunguicularia.

Flores terminales, umbellati, plures.

Pedunculi villofi, erecti, foliis longiores. 
Calycis foliola lineari-fubulata, glabra, corolla duplo breviora.

Corolla oblonga, fubcampanulata, oblique truncata, glabra, incarnata, unguicularis.

Antbere ariftatre ftylusque inclufus.

Differt ab E, abietina $\mathrm{I}$ : o calyce lineari.

2:0 corollis magis inflatis.

3:0 floribus umbellatis.

4:0 foliis fenis.

70. E. Empetriforia. Caulis fufcus, fcaber, pedalis.

Rami verticillati, cauli fimiles, flexuofo-erecti.

Ramuli trichotomi \& dichotomi, fimiles ramis.

Folia fena, oblonga, obtufa, incurvata, fupra trigono-plana, fubtus fulcata, fcabra imprimis fubtus, tenuiffime ciliata, imbricata, lineam longa.

Petioli imprimis ciliati.

Flores in mediis ramulis \& in apicibus aggregati, verticillati.

Calycis foliola lanceolata, ciliata, fanguinea.

Corolla ovato-campanulata, inferne hirta, fanguinea.

Antbere ariftatæ, inclufæ.

Stylus purpureus, curvatus, corolla duplo longior, exfertus 1tigmate capitato.

71. E. Spicata. Coulis craffus, rigidus, fufco-purpureus, fcaber, flexuofo-erectus, fpirhameus usque pedalis.

Rami \& Ramuli alterni vel fubverticillati, cauli fimiles, erecto-patentes, apice incurvi, virgati.

Folia fena, lanceolata, integra, glabra, fubtus ful. cata, patentia, incurvato-imbricata, fubunguicularia.

Flores in apicibus ramorum inter folia breviora verticillato-fpicati, cernui, plurimi.

Spica crafra, pollicaris usque digitalis. 


\section{Dipertatio Botanica}

Bracter calyci approximatc, bafi attonuato-fub. petiolatæ, dein oblongx, acuta, integræ, tenuiflimæ, incarnatæ.

Calycis foliola fpathulata, feu bafi attenuata, api. ce ovata, concava, margine fcariofa, integra, co. rolla multoties breviora.

Corolla clavata, curvata, obtuSa, giabra, alba, fubpollicaris.

Antbere ariftatæ, inclufr.

Stylus purpureus: ftigmate exferto, flavefcentc.

72. E. Octophyla. Frutex torus glaber: caule cinereo, erecto; pedalis.

Rami dichotomi, pauci, fimplices, longi.

Folia octona, linearia, truncata, integra, glabra, patenti-recurvata, imbricata, difticha, unguicularia. Petioli pallidi, lineam longi.

Flores ramos terminantes, umbellati, plurimi, e. recti, fpeciofi, vifcoli.

Calycis foliola lanceolata, glabra, adpreffa, corolla multoties breviora.

Corolla cylindrico-clavata, glabra, purpurea, pollicaris: laciniis erectis.

Anthere ariftatæ, inclufa.

Stylus capillaris, purpurafcens, crectus, ftigmate capitato.

73. E. Oblicua. Caulis filiformis, laxus, brunneus, fuperne fcaber, totus glaber, erectus, pedalis.

Romi dichoromi, fimplices, cauli fimiles, fubfantigiati.

Folia fparfa oblique circum ramos, linearia, truncata, glabra, attenuata in petiolos, bafi imbricata, apice patenti-recurvata, fubdifticha, femiunguicularia.

Flores terminales, umbellati, plurimi, vifcofi, fub. erecti. 
Pedunculi capillares, purpurei, folis triplo lon. giores.

Bractee tres; folitaria in medio, paulo fuperius duæ oppofitæ; minimæ, patentes.

Calycis foliola linearia; obtufa patentia, breviffma.

Corolla globofa; cre acuminato, contracto; purpurea.

Antbere criftatr ftylusque inclufus.

Folia verfus apices ramorum circum ramos oblique ita fparfa funt, ut minime verticillata dici polfint, ce. terum valde fimilia foliis E. Octoploylle.

7. E. Vuigaris. Fruticulus toius teres, glaber, brunneus, flexuofo-erectus, palmaris, pedalis \& ultra.

Rami fparfi \& verticillati, divaricato-patentes, virgati.

Ramuli oppofiti, brevifimi, follis toti tecti, internodiis breviores, erecto-parentes, unguiculares vel ultra

Folia oppofita, felfilia, fayitiata, trigona, obtufa, tenuifime ciliata, fubtus fulcata, glabra, fuprema villofa, quadrifariam imbricata, lineam dimidiam longa.

Flores racemofi, fubfecundi, cernui.

Pedunculi cernui, foliorum longitudine.

Calycis foliola ovata, acuta, carinata, tenuisfime ciliata, adpreffa, corolla multo breviora.

Corolla campanulata, nitens quafi polita.

Antherce criftatæ, inclufa.

Stylus exfertus, corolla duplo longior, ftigmate capitato.

75. E. Gnaphalodes. Fruticulus totus glaber, fufco-ci。 nereus, erectus, fpithamæus.

Rami \& Ramuli dichotomi \& trichotomi, filiformes, erecto-patentes, faltigiati. 
Folia terna, ovata, integra, glabra, fupra plana, fubtus convexa fulco longitudinali, adpreffa, longitudine internodiorum, ramulos quafi articulatos formantia, lineam dimidiam longa.

Flores in ultimis ramulis terminales, fubterni, purpurei.

Bractece calyci approximatre, naviculares, purpurer, tenuifrime ciliata.

Calycis foliola navicularia, adpretra, purpurea, corollæ longitudine.

Corolla campanulara, glabra.

Antberce criftatæ ftylusque inclufus.

76. E. Mucosa. Frutex totus glaber, flexuofo-erectus, tener, pedalis.

Romi fubverticillati, filiformes, ereiti, virgari, ramuloli.

Folia terna, ovata, obtula, margine ferrato-fcabra, fupra plana, fubtus convexa fulco longitudinali, glabra, imbricata, lineam dimidiam longa.

Flores terminales, umbellati, terni vel plures, vifcofi, cernui.

Pedunculi purpurci, breviffimi, bracteis purpureis.

Calycis foliola ovata, concava, apice incrallatocarinara, purpurea, corolla paulo breviora.

Corolla globola, pallide purpurea.

Antbere criftatix ftylusque inclufus.

77. Corifolia. Fmuticulus totus "glaber, fufio-cinereus, flexuolo-erectus, palmaris usque pedalis.

Rami \& Ramuli verticillari, fubfaftigiati.

Folin terna, lanceolata, fupra plana, fubtus convexa fulco longitudinali, margine integra vel ciliata, imbricata, internodiis paulo longiora, lineam longa.

Flores terminales, umbellati, plures. 
Bractece lanceolatæ, albo-purpureæ apice fufco.

Calycis foliola navicularia: apice compreffo, fufco; inflata, integra, glabra, pallide purpurea, corolla fere longiora.

Corolla oblonga, inflata, glabra, pallide purpurea: ore contracto, acuro, fufco.

Anthere criftate ftylusque inclufus.

78. E. Calycina. Cinulis craffus, teres, nodulofus, cinereo-fufcus, erectus, pedalis.

Rami trichotomi, cauli fimiles, cinereo-tomentofi, erecto-patentes, virgati, ramulofi ramis fimilibus.

Folia terna, ovata, acuta, integra, glabra, fupra concava, fubtus convexa fulco longitudinali, imbricata, lineam dimidiam longa.

Flores terminales, umbellati, terni, cernui.

Pedunculi breviffimi, hirti.

Bractea calyciformes, naviculares, calyci appro. ximatæ, erecto-patentes, glabræ, albæ.

Calycis foliola lato-ovata, obtufa cum acumine, intus concava, extus carinata imprimis apice, integra, glabra, erecta, corolla duplo breviora.

Corolla campanulata, glabra, alba.

Antherce criftatæ, purpureæ, ad bafin usque bifidæ, Atylusque inclufus.

Germen tomentofum, lobatum.

Valde fimilis E. nigritce refpectu florum; differt vero fequentibus notis.

I:0 foliis ovatis imbricatis.

2:0 calycibus magis obtufis \& latis.

3:0 antheris criftatis.

79. E. Triflora. Ciulis brunneus, inferne glaber, fuperne hifpiclus, erectus, pedalis, 
Rami dichotomi, inferne brunnei \& glabri, fu. perne cinereo-hirfuri, erecti, faltigiati.

Rumuli per ramos undicue fparfi, filiformes, frequentes, hirti, virgati.

Folin terna, lineari-fubulata, integra, glabra, fupra plana, fubtus convexa fulco tenuifimo, incurvata, erecto - patentia, fubunguicularia.

Flores in ramulis terminales, folitarii, bini vel terni, pedunculati, cernui.

Pedunculi cernui, cinereo-tomentoli, brevifimi.

Bractece calyciformes, lanceolatx, glabre, albec.

Calycis foliola lato-ovata, acuminata, concava, carinata, margine membranacea, integra, erectopatentia, glabra, alba, corollam requantia.

Corolla globofo-fubcampanulata, glabra, alba, magnitudine piperis.

Antberce criftatio fylusque inclufus.

80. E. Scoparia. Fintex totus cinereo-tomentolus, hifpidus, erectus.

Rami fparfi, virgati, ramulof.

Folia terna, linearia, acuta, integra, glabra, fupra plana, fubtus fulcara a marginibus revolutis, patentia, femiunguicularia \& ultra.

Flores in ultimis ramulis terminales, umbellati, terni.

Pedunculi vix longitudine foliorum.

Calycis foliola ovata, acuta, adpreffa, corolla duplo breviora.

Corolla campanulata.

Antbere criftatæ, inclufæ.

Stylus exfertus ftigmate capitato.

81. E. Bergiana. Caulis erectus, rufefcens, cinereo-hirfutus, pedalis vel ultra, totus tectus ramis \& ramulis virgatis, florentibus. 
Folic terra, lanceolata, fcabra, pilora, fubtus cule cata, imbricata, lineam longa.

Flores in ultimis ramulis terminales, umbellati, fub. rerni.

Calycis foliola ovata, acuminata, ciliata, reflexa, corolla dupio breviora.

Pedunculus hirtus brafteis filiformibus, albis, mi. nutis.

Corolla campanulata, glabra, purpurea, finu laci. niarum excavato.

Antbere crintatæ ftylusque inclufus.

Pulcbervina, tota tecta floribus fpeciofis.

82. E. Formosa. Cualis glaber, erectus, pedalis.

Ramu pauci, filiformes, fparfi, Aexuofi, cinereo. villof, erecto-patentes, faftigiati.

Ramuli fparfi, capillares, breves, virgati.

Folia terna, ovata, obtura, glabra, fupra plana, fubtus convexa fulco longitudinali, patentia, lineam dimidiam longa.

Flowes in ramulis terminales, umbellati, bini, terni, raro plures, cernui.

Pedunculus folis longior, pallidus.

Mrackee ovatx, pallidie, calyci approximatæ.

Calycis foliola ovata, acuta, concava, integra, patenti-reflexa, pallida, corolla triplo breviora.

Corolla globofa, fulcata, glabra, albida, laciniis reflexis.

Antbere criftatæ, purpureæ ftylusque inclufus.

83. E. Rubens. Frutex totus glaber, purpurafcens, flexuofo-erectus, fpithamæus.

Rami \& Ramuli trichotomi, filiformes, erecto-patentes, faftigiati.

Folia terna, linearia, acuta, integra, glabra, fuG 
pra plana, fubtus convexa fulco longitudinali, adprefia, internodiorum longitudinem vix xquantia, lineam longa.

Flores terminales, umbellati, purpurei.

Pedunculi capillares, laxi, purpurei, pollicares, Bractice lineares, rufefcentes, in medio peduncu. lo fitæ.

Calycis foliola lanceolara, adprefra, fupra plana, fubtus convexa fulco longitudinali, viridi purpurafcentia, breviffima.

Corolla globofa, fanguinea, magnitudine piperis. Antbere criftate ftylusque inclufus.

84. E. Incarnata. Coulis cinereus, totus tenuiffime villo. fus, erectus, pedalis \& ultra.

Romi \& Ranuli trichotomi \& verticillati, fexto. fi, erecti, virgati.

Folia terna, ovata, obtufa, integra, glabra, fupra concavo-plana, fubrus convexa fulco longirudinali, adprefra, longitudine internodiorum, lineam dimidiam longa.

Flores in ramulis terminales, umbellati, folitarii, ter. ni vel plures.

Pedunculi purpurei, foliis duplo longiores.

Bractere lanceolater, concave, virefcentes.

Calycis foliola lanceolata, integra, glabra, adprefia, purpurea, corolla quadruplo breviora.

Corrlla oblonga, campanulata, aiba, femiunguicularis. Anthere crifiaræ, inclufæ.

Sty'us longitudine corollæe, vix exfertus ftigmate obtufo.

Differt ab E. rubente: 1. corolla globofa.

2. pedunculis longioribus.

manums $\int a$, cui valde fimilis:

r. antheris criftatis.

2. folits ternis. 
85. E. Crnerea. Cailis cinereo-hirfutus, flexuofo-ereftus, pedalis \& ultra.

Rami alterni \& rerni, longi, divaricato-eredi.

Ramuli fuboppofiri, erecti, internodiis breviores.

Folia terna, lanceolata, acuta, fubtus fulcata, glabra, imbricata, lineam longa.

Flores in ramulis terminales, folitarii, bini vel plures, cernui, violacei.

Pcdunculi foliorum longitudine, reflexi, violacei. Calycis foliola lanceolata, tenuifrime ciliata, glabra, corolla duplo breviora.

Cornlla ovata, glabra, ore contractiore.

Anthere criftatæ ftylusque inclufus.

86. E. Australis. Caulis cinereus, erectus, rigidus.

Folia terna, linearia, obtufa, glabra, margine fcabra, parentia.

Flores terminales, bini vel terni, fubfeffiles.

Calycis foliola rudia, acuta, carinata, bracteis fimilibus, imbricatis.

Corolla cylindrica, fubclavara, obtura, calyce triplo longior.

An beve criftatx, inclufice

Stylus exfercus itigmate capitato.

87. E. Ramentacea. Frutex totus glaber, fufcus, eredtus, Spirbamæus:

Rami inferne dichoromi, fuperne verticillati, di. varicato - patentes, ramulofi.

Folia quaterna, linearia, acuta, integra, glabra, fupra plana, fubtus convexa fulco tenuiffimo, patentia.

Flores terminales, umbellati, umbellis confertis.

Pedunculi capillares, incraffati, purpurei.

Calycis foliola fubulata, glabra, brevilfima.

Corolla globofa, purpureo violacea : ore coneracto. Antbera criftaræ ftylusque inclufus. 
88. E. Baccans. Frutex totus glaber, erectus, pedalis. Rumi fubverticillati \& fparfi, faftigiati, erecto pa. tentes, ramulofi.

Folia quaterna, linearia, obufufcula, margine fiabra, fupra plana, fubus convera filco longirudirali, imbricata, incurvata, glabra, lineam longa.

Floses terminales, umbellati, nutantes.

Pedunculi incarnati, cernui.

Bractec obovato-oblorga, acuræ, concavæ, carinatæ, incarnatæ.

Calycis foliola ovata, acuta, carinata, coricava, incarnata, corollam fubxquantia.

Corolla globofa, fanguinea', glabra, magnitudine pifi.

Antherce criftatx flylusgue inclufus.

89. E. Physodrs. Frutex torus glaber, ercetus, rigidus, cinereus; bipedalis.

Rami terni \& dichotomi, crecti, viruat, ramulofi.

Folin quaterna, linearia, obiufa, margine fcabrida, glabra, fupra plana, fubtus convexa fulco lon. gitudinali, curvata, imbricato-patentia, femiunguicularia.

Flores terminales, umbellati, fubterni, cernui, vifcidi, magnitudine pifi.

Calycis foliola ovata, adprefia, pallida, brevifima. Corolli ovara, cryftallina, alba.

Anthore criftate ftylusçue inclufus.

30. E. CeRnua. Fratex torus glaber, branneus, ereans, pectalis.

Romi Sparfi \& terni, filiformes, flexuofi, erecti, ramulofi.

Folia quaterna, ovara, obtura, ciliata, fupra plana, fubtus convexa, fulcata, imbricata.

Elores terminales, capitati, cernui. 
Bractee calyciformes, ovatæ, acutæ, clliatx, con: cavæ, incarnatæ.

Cnlycis foliola fimilia bracteis, fed latiora.

Corolln ovato-globofa, incarnata, glabra.

Ambers criftatix ftylusque inclufus.

9.. E. Retorta. Frutex totus glaber, fcaber, fufcus, ere. ctus, pedalis vel ultra.

Rami verticillati, filiformes, flexuofi, erecti, fubfaftigiati, ramulofi.

Folia quaterna, ovata, acura, feta terminali ariftata, margine tenuiffime ferrulata, glabra, fubtus convexiufcula fulco tenui, fquarrofa, lineam longa.

Flores terminales, umbellari, plures, eredi.

Calycis foliola lanceolata, ariftata, adprefra, gla. bra, purpurafcentia, corolla triplo breviora.

Curolla bali inflata, apice atrenuata, cryfallina, alba, glabra, vifcofa, pollicaris: laciniis ovatis, reflexis:

Anthere villofo-crittatæ, incluæx, minutæ, fila. mentis longis, albis inferta.

Stylus ftaminibus tongior, fubexferus,

$$
\begin{gathered}
\text { f. V. } \\
\text { SYNONYMA. }
\end{gathered}
$$

E. Daboecia. Linn. Spec. Plant. p. sog.

Andromeda Daboecis Linn. Syft. Veget. XIV.p. 406. E. Terrumolia, Linn. Spec. Plant, p. 507. Berg. Plant. Capenf p. 116.

E. Thunbergir. Montin Act. nov. Upfal. Vol. 2. p. 290. t. 9. fig. 2. Ling. Supplem. Syítem. p. 220.

E. Tetragona. Linn. Suppl. Sylt. p. 223. Syft. Veg. XIV, p, 370 .

E. Umbillata. Linn, Spec, Pl. p. soi. Sylt. Veg. XiV. p. 362 . 
E. Bryantha. Bryanthus. Gmelin. Sibir. 4. 1) 133. t. 57. fin. 3.

Amiromediz bryantha. Lirn. Mant. p. 238. Ejusd. Syit. Veg: XIV. p. 406.

E. IMricata. Linn. Sp. Plant. p. 503. SyR. Veg. XIV. p. 369 .

Enca quinqunngularis Bergii Pl. Cap. p. I17.

E. Metanthera. Linn, Mant. p. 232. Sylt. Veg. XiV.

$$
\text { p. } 367 \text {. }
$$

E. Ieucanthera. Linn. Suppl. Sytt. p. 223 .

E. Spumosa, Linn. Spec. Plant. p. so8. Syte. Veg. XIV. p. 367 . Berg. Plant, Cap. p. 103.

Errca farriofa. Berg. Pl. Cap. p. 102.

E. Caputata. Linn. Spec. Plant. p. 504. Sylt. Veg. XIV. p. 367. Berg. Plant. Cap. p. 94.

Erica brminades Linn. Sp. Pl. p. 504. Syft. Ven. XIV. p. 369 .

E. Passerine. Montin. Act. Nov. Upfal. Vol. 2. p. 289.

t. 9. fig. 1. Linn. Suppl. Syft. p. 221.

E. Virgata. Berg. Pl. Cap. p. 97.

Erica abfintboides, Linn. Aant. p. 66.

E. Cilmaris, Linn. Spec. Pl. p. 503. Syt. Veg. XIV. p. 368 .

E. Hispida. Erica hifpidula. Linn. Suppl. Sylt. p. 222.

E. Petrverir. Linn. Mant. p. 235 . Syft. Veg. XIV. p.369. Erica Plukenetii. Berg. Pl Cap. p. 91.

E. Plukenetir. Linn. Sp. Pl. p. 504. Sylt. Veg. XIV. p. 369.

E. Coccinea. Linn. Sp. Pl. p. 505. Syft. Veg. XIV. p. 368.

E. Grandiflora. Linn. Suppl, p. 223. Syt, Veg. XIV. p. 370 .

E. 
E. Curviflora. Linn. Spec. Pl. p. 505. Syft. Veg. XIV. p. 368 .

E. Tubiflora. Linn. Spec. Pl. p. 505. Syft. Veg. XIV. p. 368 .

E. Cerinthoides. Linn Sp. Pl. p. 505. Syft. Veg. XIV. p. 368. Berg. P1. Cap. p. 104.

E. Sparmanni. Linn. Adt. Holmenf, 1778. p. 24. t. 2. Suppl. p. 2 I 9.

E. Massoni. Linn. Suppl. Syft. p. 221.

E. Fastigiata. Linn. Mant. p. 66. Syft. Veg.X IV. p. 368.

E. Comosa. Linn. Mant. p. 234. Syft. Veg. XIV. p. 369.

Erica transparens Berg. Pl. Cap. p. ICg.

E. Dentata. Erica denticulata. Linn. Mant. p. 229. Syft. Veg. XIV. p. 368.

E. Viscaria. Linn. Mant. p. 23 r. Syft. Veg. XIV.p. 369. E. Mediterkanea. Linn. Mant. p. 229. Syit. Veg. XIV. p. 370 .

E. Multiflora, Linn. Sp. Pl. p. 503. Syft. Veg. XiV. p. 370.

E. Herbacea, Linn. Sp. Pl. p. 501. Syft. Veg. XiV. p. 370.

Evica carnea Linn. Sp. Pl. p. 504. Mant. p. 373. E. Purpurascens. Linn. Sp. Pl. p. 503. Syft. Veg. XIV. p. 370.

E. VAGANS Linn. Mant. p. 230.

E. Cubica. Linn. Mant. p. 233. Syft. Veg. XIV. p. 368. E. Glútinós. Berg. Pl. Cap. p. 99.

Andromeda curoferoides. Linn. Mant. p. 239. Syft, Veg. XIV. p. 406.

F. Lutea. Berg. Pl. Cap. p. Irs. Linn. Mant, p. 234. Erica albens. Linn. Mant. p. $23 \mathrm{i}$. 
Li. Depressa, Linn. Mant. p. 230.

E. Halmacaba, Linn. Sp. Pl. p. 507. Syft, Veg. XiY. p. 364.

E. Monsonina. Linn. Suppl. Sylt. p. 223 .

E. Nigrita. Linn. Mant. p. 65. Sylt. Veg. XIV. p. 364. Erica lavicina, Berg. Pl. Cap. p. 94.

E. Regerminans. Linn. Mant. p. 232, Sylt. Veg. XIV. p. $36 \%$.

E. Unceolaris, Berg. Pl. Cap. p. $10 \%$.

Evica pentapbylla. Linn. Sp. Pl. p. sos.

E. Articularis. Linn. Mant. p. 65. Sylt. Veg. XIV. p. 366.

E. Virescens. Esica viridipurpurer. Linn. Sp. Pl. p. $\$ 02$. Syft. Veg. XIV. p. 364 .

E. Planifolia. Linn. Sp. Plant. P. 508, Sylt. Veg. XIV. p. 302. Berg. Pl, Cap. p. 100.

E. Pubescens. Linn. Sp. Pl. p. 506. Synt. Veg. XIV. p. 365. Burg. Pl. Cap. 121.

Evica farvifora. Linn. Sp. Pl. p. 506. Mant. p. 374. E. Cafrra. Linn. Sp. Pl. p. 502. Syft. Veg. XIV.p.365. E Persoluta. Linn. Mant, p.230.

Evica paniculata. Linn. Sp. Pl. p. 508.

Evica milleflora. Berg. Pl. Cap. p. 96.

Erica fubdivaricata. Berg. Pl. Cap. p. II4.

E. Arborea. Linn. Sp. Pl. p. 503. Syt. Veg. XIV.p. 365. E. Pilulifera. Linn. Sp. Pl. p. 507. Syft. Veg. XIV. p. 364.

Evica mudicaulis. Berg. Pl. Cap. p. I I3.

E. Tetralix. Linn. Spec. Pl. p. 502. Syft. Veg. XIV.p. 365. 
E. Ametria Linn. Sp. Pl. p. 506 . Syf. Veg. XIV. p. 365.

Evica verticillata. Berg. Pl. Cap. p. 99.

E. Mammosa. Linn. Mant. p. 23ł. Sytt. Veg. XIV. p. 365.

E. Empetrifolia. Linn. Sp. Pl, p. 507. Syft. Veg. XIV. p. 366. Berg, Pl. Cap. p. 120.

1.. Spicata. Erica feffilifora. Linn. Suppl. p. 222.

E. Octophylla, Erica fufcicularis, Linn. Supl. p. 219.

E. Vulgaris. Linn. Sp. Pl. p. 50r. Syft. Veg. XIV. p. 363 .

E. Gnaphalodes. Linn. Sp. Pl. p. 501. Sylt. Veg. XlV. p. 366. Berg. Pl. Cap. II

E. Mucosa. Linn. Mant. p. 232.

Evica ferrea. Berg. Pl. Cap. p. II2.

E. Corifolia. Linn. Sp. Pl. p. 507. Syft. Veg. XIV. p. 366. Berg. Pl. Cap. p. 108.

E. Calycina. Linn. Sp. Pl. p. \$07. Syft. Veg. XIV. p. 366.

Erica vespertina. Linn. Suppl. p. 22 r.

E. Triflora. Linn. Sp. Pl. p. 508. Veg. XIV. p. 366.

E. Bergiana, Linn. Mant. p. 239.

F. Scoparia, Linn. Sp. Pl. p. 502. Syft. Veg. XIV. p. 364.

E. Centrate. Linn, Sp. Pl. p. jor, Syft, Veg. XIV: p. 366. 
E. Australis, Linn. Mint. p. 231 . Syft. Veg. XIV. p. 366.

E. Ramentacea, Linn. Mant. p. 65. Syft. Veg. XIV. p. 365.

Evica multusnliellifera. Berg. Pl. Cap. p. 110.

Evica pilulifera. ibid. p. In

Evica granulata. Linn. Mant. p. 234. Ejusd. Syft. Veg. XIV. p. 369.

E. Baccans. Linn. Mant, p. 233. Sylt. Veg. XIV. p. 366.

E. Physcdes. Linn. Sp. Pl. p 506. Syft. Veg. XIV. p. 366. Berg. Pl Cap. p. ror.

E. Cernua. Montin. Act. Nov. Upral. Vol. 2. p. 292. t. 9. f. 3. Linn. Suppl. p. 222.

E. RetortA. Montin. Act. Stockholm. 1774. p. 297. tab. 7. Linn. Supl. Syt. p. 220.

\section{§. VI. \\ L OCUS.}

\section{Europece.}

Dulgaris crefcit in Europa campis ferilibus, in fylvis; in Svecia frequens.

totralix in Europæe borealis \& Sycciæ imprimis paludibus cefpitofis.

umbelluta, virefens, ciliuris, ouftralis in Iufitania. mediterranen in Aufriae alpibus; daboccin in Hiber. nia; cinerea in Europa media \& oriente; fcoparia in Bar. baria, Hifpania, Monfpelii ; multiflora in Anglia, Nar. bonenf Gallia, oriente; berbacen in Pannonix, Helvetix, 
Baldi, Tridentini arenofis; bryantba in Sibiria; nvores in Europa aufrali \& Africa; vagans Tolofa \& in Africa. Fucato in hortis europæis cum alis colitur.

$$
\text { Capenses }
$$

Vel campos amant vel loca alta montora, non vero unquam fylvas;

imbricata, baccans, gnapbalndes, Plukenetii crefcunt infra montes in collibus prope urbem Cap.

melontber in campis fabulofis extra urbem.

petiolata, luter, calycina, in fummitate montis ta. bularis; Spumofa, bifpida, pbyfodes glutinofa in planitie monis Tabularis; Petiverii, plasifolia in collibus montium \& in fummitate montis tabularis;

cerintboides in collibus infra Taffelberg \& Stenberg, vulgaris. B. in montibus Lange Kloof; viffaria in collibus infra Taffelberg latere orientali; deprefs in lateribus rupium pone planitiem in fummitate montis tabularis; balicacaba in rupibus praruptis verfus fummitatem montis tabularis, latere occidentali; pubefcens in collibus intra Taffelberg; villofa in fummitate montis; perfoluta in collibus infra Tafrelberg, in campis arenofis extra urbem \& alibi vulgaris.

Arborea in Capire bonæ rpei \& Europa Auftrali; ciliaris in Capite bonæ fpei \& Lufitania.

Stenberg:

corifolia in campo fabulofo intra Faffelberg \& migrita, triflora in fummitate montis Diaboli. virgata in monte tabulari, \& in dunis inter Cap. atque Bay falfo; $\delta$ in Capite bonæ fpei \& infula Mauritii. 
crecine inter Cap \& Bay falfo, inque collitus in. fra 'Thtrelberog latere orientali; pilulefora, empotrifolin in montibus inter Cap \& Bay fallo.

much inter Cap \& Bay falfo; fpicata in montibus inter Nordhoek \& Bayfals.

te Kloof.

comolis in fummitate montis Tabularis, \& in Plat.

Birginna in Roode Sands Kloof.

chivifira, tubijom ad lacera rivorum prope Dralienfein, Roode fand \& alibi.

arceolaris in montibus Rode Sand prope rivos infra Winterhoek \& prope l'uspas Rivier.

bicolor in montibus Franfche Hoek.

Faftigiata in Platte Kloof, Franfche Hoek \& mon. tibus Hottentots Holland; bratteuta in montibus Platte kloof. Mafjoni, Monfoniana, obliqua, octopbylla, retorta in montibus Hotrentots Holland; bivta in Pardeberg; Sparmamni in montibus Lange Kloof; Thunbergii, cermua in Koude Bo. ckeveld.

\section{VII.}

\section{FLORENDI TEMPUS.}

Mijo, Fumio, Futio Horent: meldnthira, cosci. nea, vifcaria, pilulifera, nigrita, perílura.

Fulio, Augulto, Settembri: imbricata, virgata, hirpida, pubefcens, baccans, triflora, calycina, hirta, perfoluta.

Septembri, Octobri, Noventhri: Thunbergii, tetrago. 
na, leucanthera, curviflora, tubiflora, urceolaris, gna. phalodes, cernua.

Novembri, Decembri, Fanuario: bracteata, cerinthoides $B$, Sparrmanni, faftigiata, comola, Monfoniana, retorta, Bergiana.

Fanuario, Februario, Martio: periolata, fpumofa, Plukenetii, pulchella, Mafroni, halicacaba, bicolor, pubefcens : villola, octophylla, obliqua.

Martio, Aprili, Mnjo: Periverii, cerinthoides a, glutinofa, lutea, deprefla, perfoluta, empetrifolia, fpicata, phyfodes, corifolia.

\section{§. VIII. \\ US.US.}

Evice in genere floribus fuis pulcherrimis \& on mnium copiofifimis oculos fpectatorum jucundifimo modo delectant, ita ut, licet difficillime transplantari fe finant, varix tamen in Hortos Botanophilorum, fummo cum ftudio, cura \& fumtibus, introductæ fint.

Species plurimæ majores, in Promontorio bonæ fpei, ubi fumma penuria ligni laborant incolie, ad focum alendum adhibentur, cui etiam ufui in Bahufia Svecia Erica vulgaris infervit.

E foribus Ericarum mellifuis Apes magnam mellis copiam ubique colligunt.

Efcam quoque Ericeta, imprimis Europæa, variis animalibus porrigunt, ut Ovibus, Leporibus, Tetraonibus \& Infectis pluribus, 
Differtatio Botanica de Evica.

\section{TABUL $\mathbb{E}$}

Differtationi appenf $:$

Tab, r. ERICA monfoniana.

obliqua.

ventricofia.

2. ERICA inflata.

Plukenetii. $\beta$.

birta.

3. ERICA mafjoni. octopbylla. formofa.

4. ERICA tetragonzi. pulcbella.

Spicata.

5. ERICA pubefcens: villora, triflorn.

6. ERICA petiolata. depref $\int$ a. florida. 



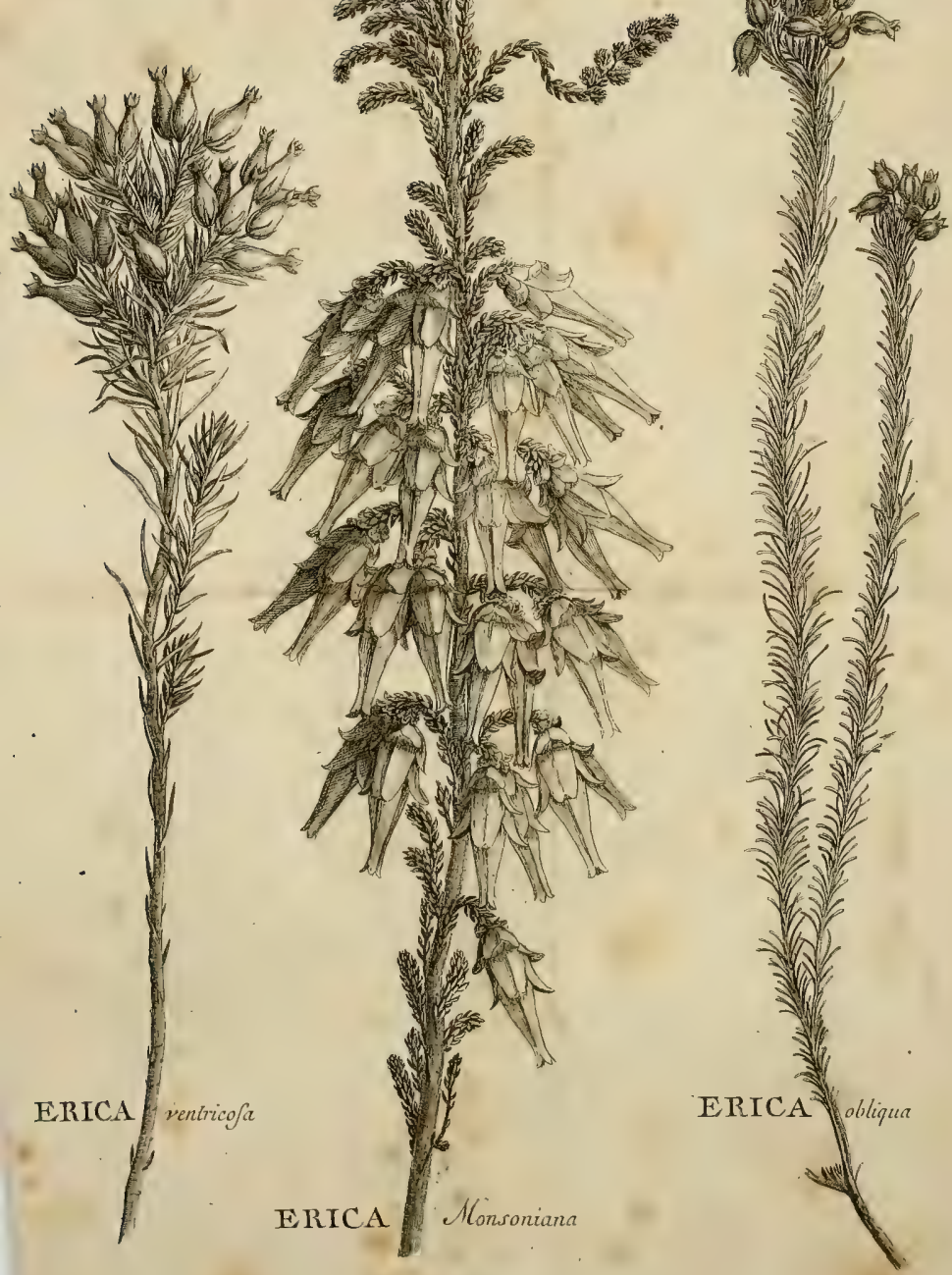



Tab. II.

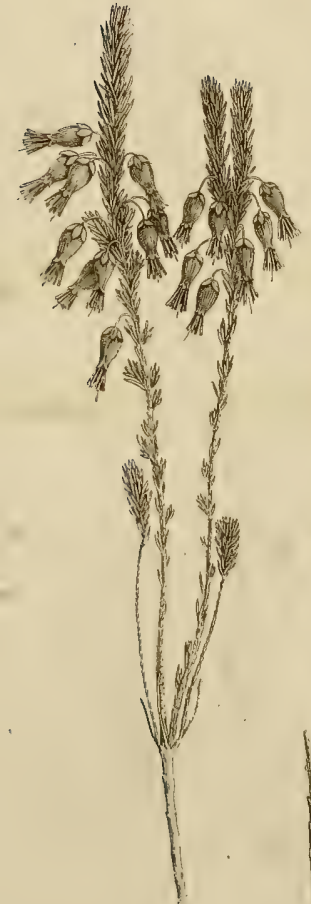

Eili ICA Tlukenetii:

3.
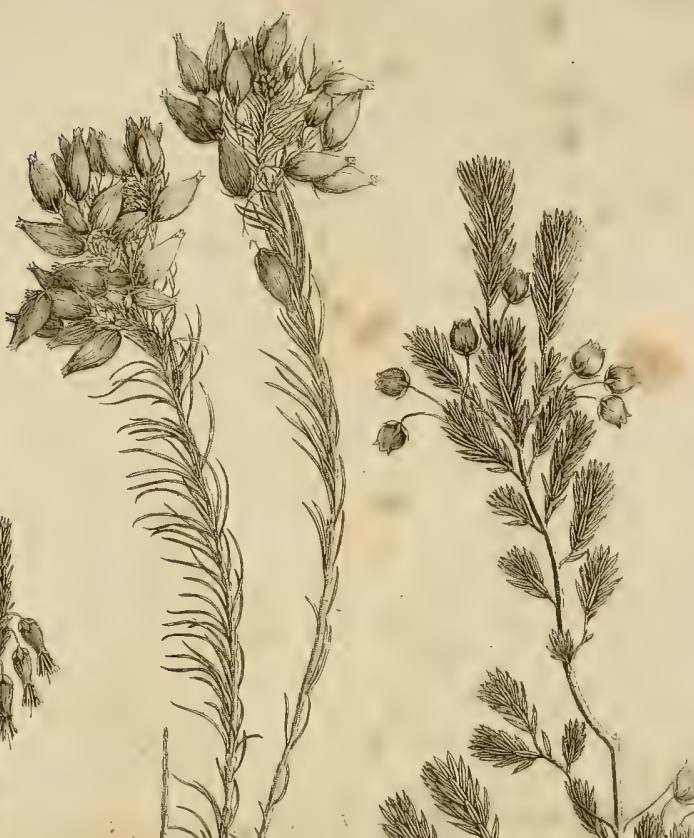



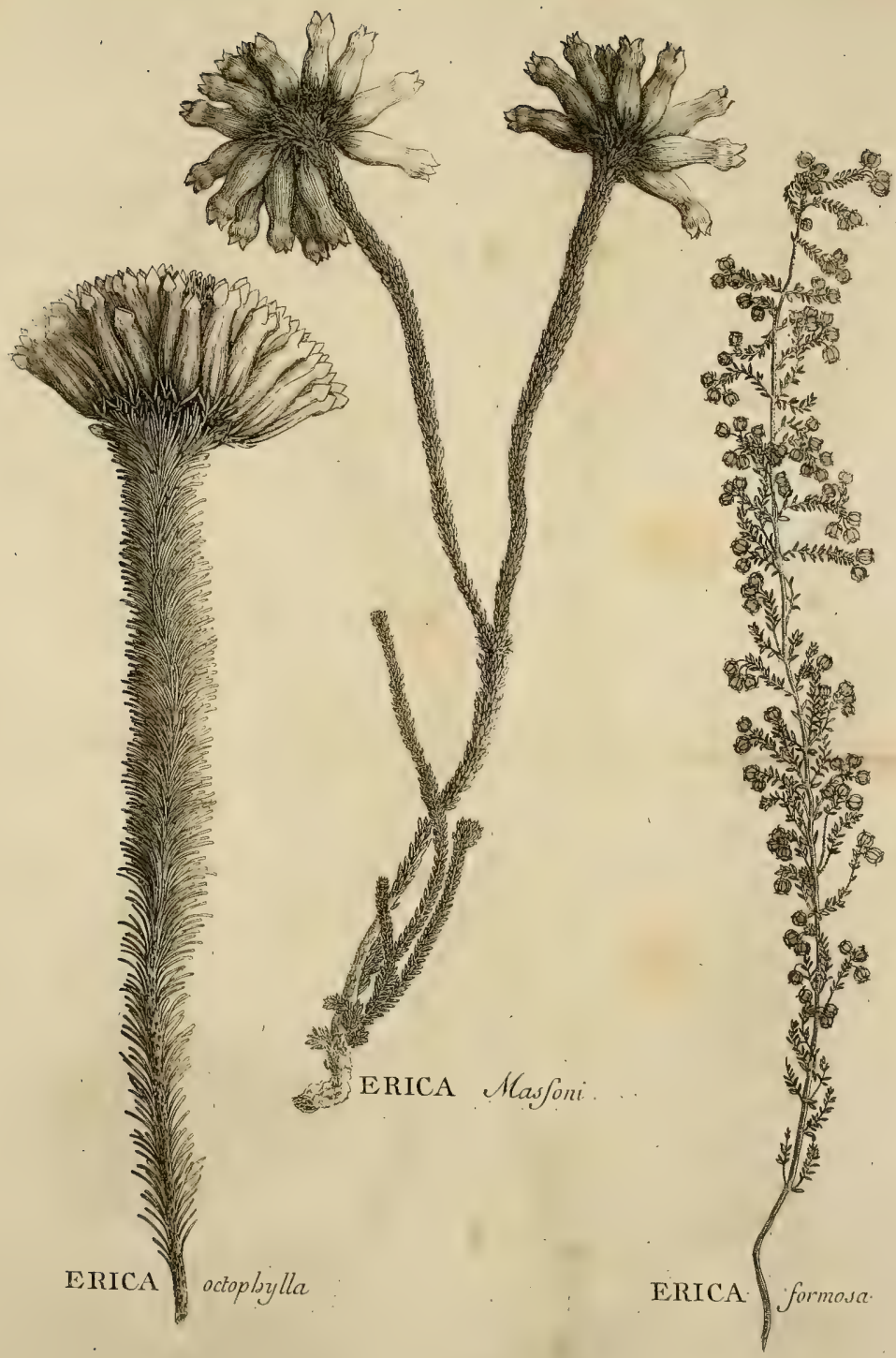




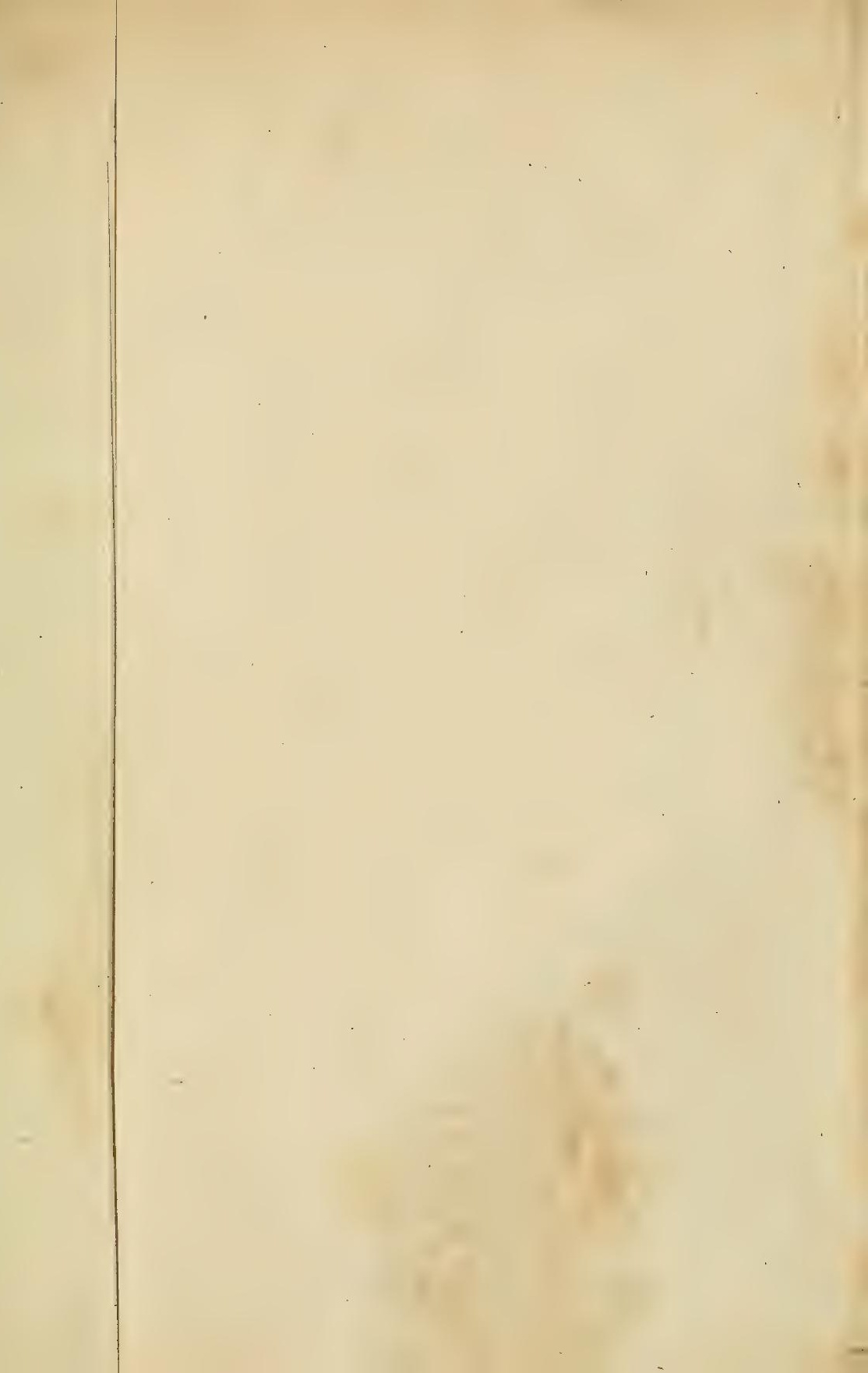




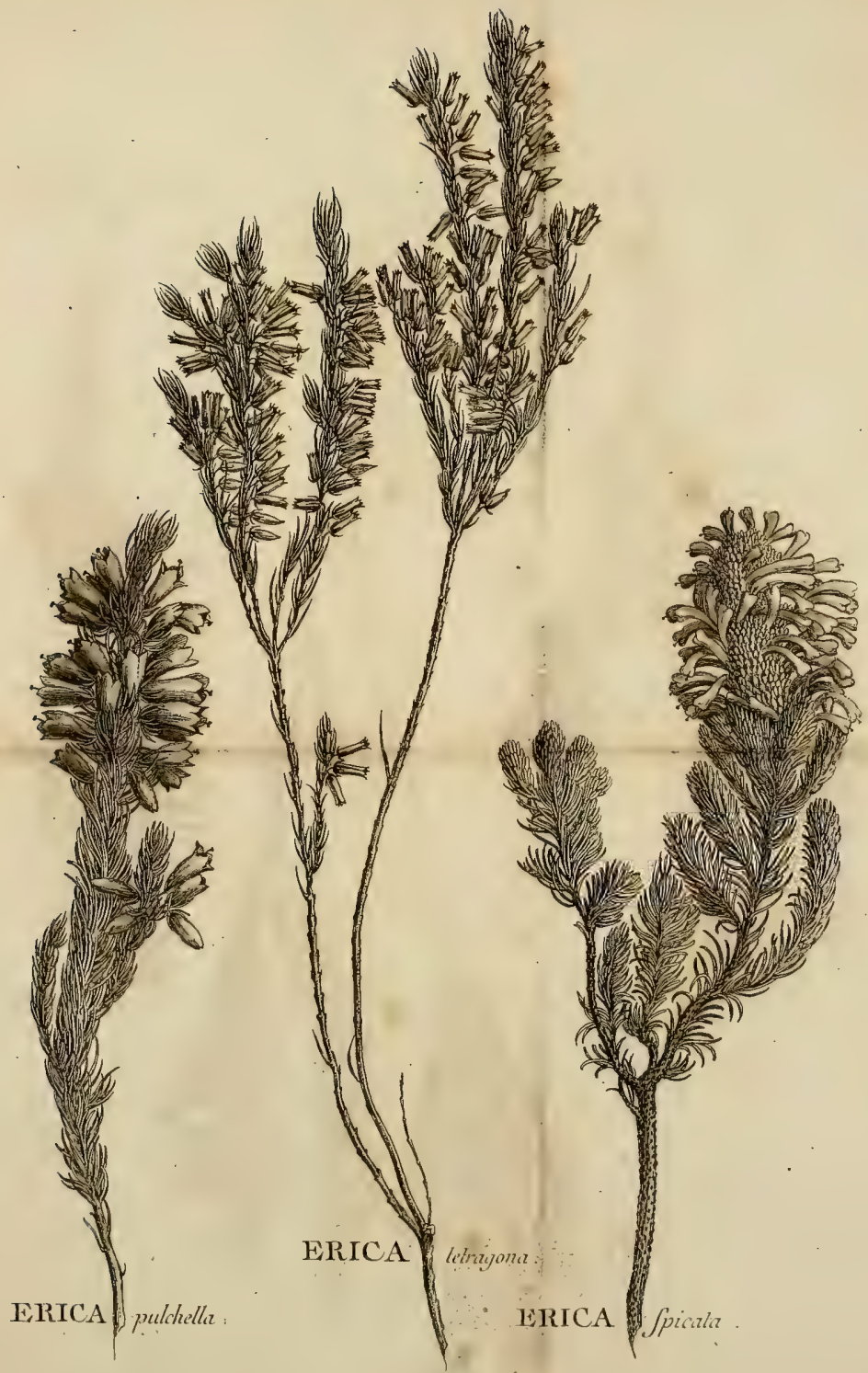




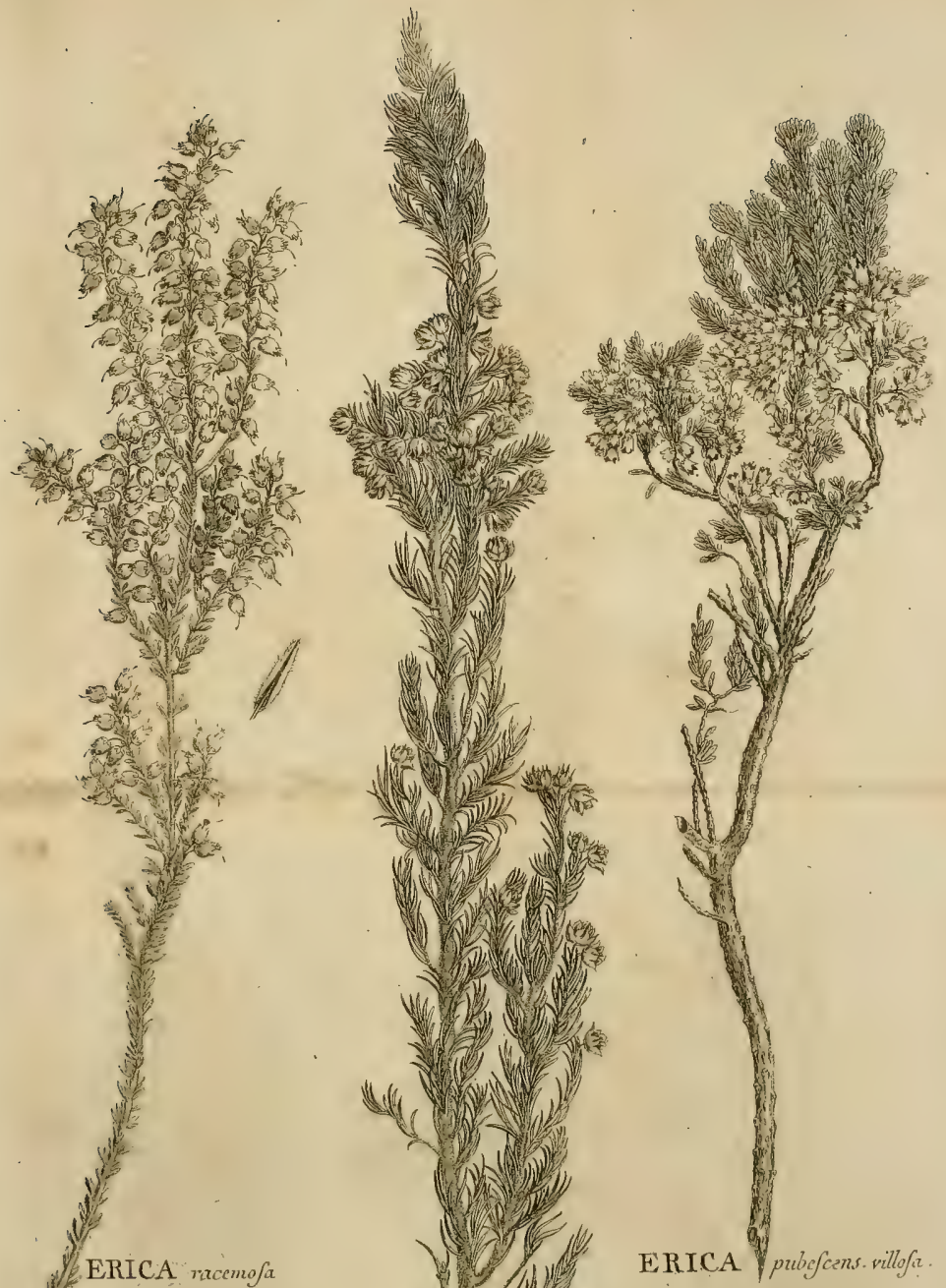

ERICA racenofa
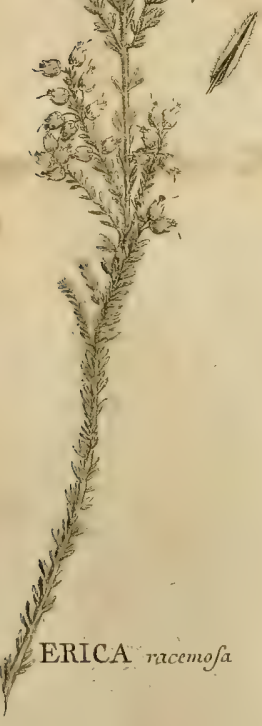

ERICA triftora

ERICA pubefens-villofa 


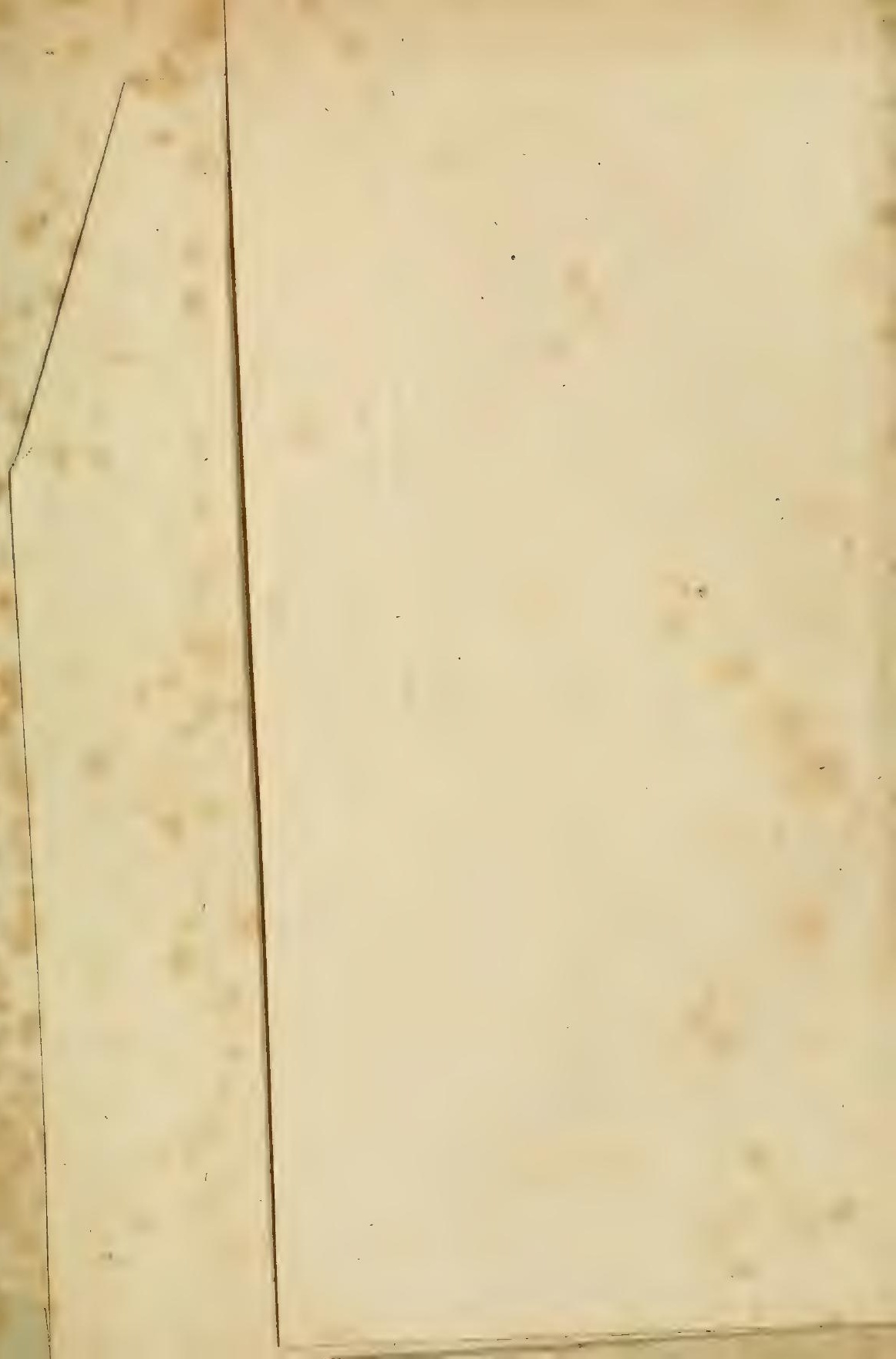


Tab.VI.

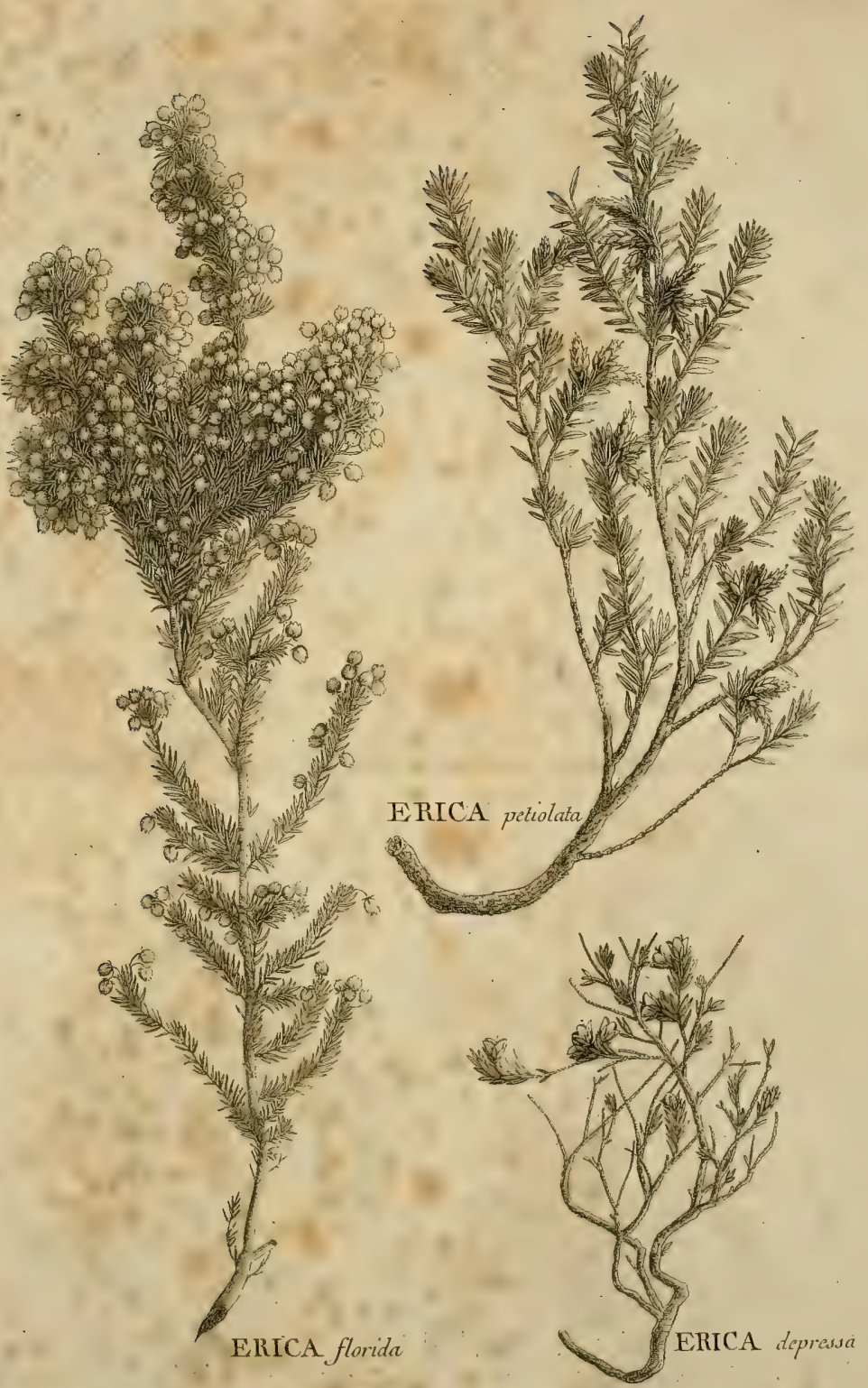




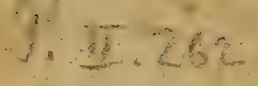

\section{D.}

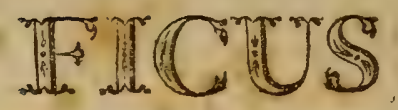

GENUS,

\section{DISSERTATIONE BOTANICA,} CONS. EXPER. FACULTAT. MED. UPSAL.

\section{PR屃SIDE}

\section{CAROL.P.IHUNBERG,}

Equite Aurat. Reg. Ord. de Vasa,

Medic. Doct. Profess. Med. et Eotan. Reg. et Ord., Acad. Casar. Nat. Curios. Reg. Scient. Holmiens. Societ. Sctent. Upsal. Patr. Holm. Berol. Nat. Scrut. Lund. Harlem. Amsteld. Zeland. Nidrosiens. Medic. Edimburg. et Nat. Studios. Ibid. Membro; nec non Acad. Monspeliens. Agricult. Paris., et BATAYIN. CORIESPONDENTE.

\section{PUBLICO EXAMINI SUBJICIT,}

Elias Gedner, Сhristophori Fil.

FJERDHUN DRENSIS.

IN AUDIT. GUST. MAJ.D. XXI DECERB. ANNO MDCCLXXXVI. Horis A. MI. Soltits.

\section{U P S A L I $\mathbb{E}$,}

APUD DIRECT. JOH, EDMAN. 



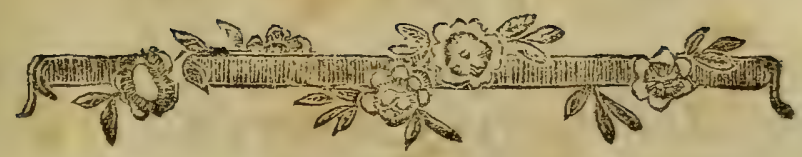

§. I. Drodii Anno iq4, fub præfidio Dn. Árch. \&
Eqv. à LINNE, de Ficu, Differtatio longe elegantiffima, qux Ficus fpecies 22 ab AuEtoribus commemoratas enumerat, Ficusque caricœ proprietates, vires \& ufus fufius aefcribit.

Cum vero eo tempore adeo parum notæ harum plerxque effent fpecies, in remotiffmis calidioribusque regionibus Indiz crefcentes, ut in Specierum Plant. Edit. fecunda Anno 1764, non nifi \& fpecies determinari potuerint, poftque id tempus, opera indefeftorum Peregrinatorum plures melius indagatx fuerint, fic ut in ultima Editione Syftematis Vege. tabilis Anno 1784, e I7 fpeciebus ibi exceptis, If numerare liceat diftinetas; non inutilem nos Botanicis praftaturos operam credidimus, fi Omnes huc usque notas Ficuun fpecies defcriptas fifteremus.

Dignofcitur Frcus, licer qua fingularem fuam florefcentiam valde variare deprehendatur, Flore incompleto, Staninibus tribus, Pifrlllo unico, feninio bus andis, imprimis vero Receptaculo clauso, interne fiores recipiente ataue frublun fornsonte. 


\section{*ist ) $4(2$ \\ §. II. \\ CHARACTER GENERIS:}

RECEPTACULCMI fubrotundum, carnofum, claufum, interna fuperficie undique teetum fioribus.

CALYX. Periantbium 3-vel 5-partitum: la. cinice xquales, Janceolatx, acutæ, erectx.

Cororla nulla.

STAMr.

Filamenta tria, fetacea, longitudine calycis.

Pist.

Gernom ovale, magnitudine calycis. Stylus fubulatus, inflexus, lateri gुerminis infertus.

Stigmata duo, acuminata, reflexa, inzequalia.

PerícARP. Sentent nedum, fubrctundum, compreffum.

In ficu flores vaide varjantes reperiuntio:

In alis namque (Hermaphrodiai) Rullimentum piftilli caducum, intortum; in alis onncs fores abortientes; in whis fertles; in aliis iterum mixti; fic ut \& mafulini (Caprifucus) \& Feminini (Ficus) \& Androgyni (Erinofyce) \& fmul máculi atque feminei intra idem receptaculum inveniantur.

\section{§. III. \\ DIVISIO SPECIERUM. \\ * folits indivifis. \\ a. folits intersis.}

Sycomorus: fol. cordatis fubrocundis fubcus tomen. tofis.

nym- 
क्रु6 ) $5(1)$

mymphoides : fol. cordatis ovatis glabris fubtus glaucis. religiofa: fol. cordatis ovatis cufpidatis glabris, fruetibus feffilibus.

afpera: fol. cordatis oblongis fubundulatis feabris. bengalenfis: fol. fubcordatis ovatis obtufis glabris coriaceis, caule arboreo erecto.

cordata:

fol. fubcordatis ovatis acutis glabris co. riaceis, caule fruticofo ereeto.

fipulata: fol. oblique cordatis obtufis glabris, caule decumbente fquamofo.

falcata: fol. oblongis falcatis glabris, caule filiformi radicante.

punctuta: fol. oblongis emarginatis glabris fubtus punctatis, caule flexuofo radicante. punila : fol. ovate-oblongis obturis glabris fubtus reticulatis, caule decumbente, fruetibus pedunculatis.

erecta: fol. oblongis actutis glabris fubtus reticulatis, caule decumbente ramis erectis, fructibus pedunculatis.

trigona: fol. ovatis obturis glabris, caule ereeto, fruetibus umbilico triangulari.

pertufa: fol. oblongis culpidatis glabris, fructibus globolis umbilicatis petiolatis.

nitidn: fol. ellipticis acutis glabris, fruetibus retufo-úmbilicatis fefflibus.

benjamina: fol. ellipticis obtufs glabris, fruEibus acutis feffilibus.

rflexa: fo! ellipticis obufis glabris, ramis recurvis, fructibus globofis fefrilibus. A. 3

$r a \cdot$ 


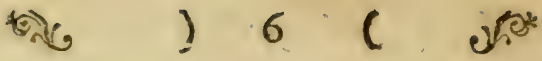

racemofa: fol. elliptico-oblongis acutis glabris fub. tus pallidis, ramis erectis, fructibus pedunculatis.

retufa: fol. obovatis oblongis obtufis, ramis angulatis, fructibus feffilibus.

drupacea: fol. obovatis culpidatis glabris, fructibus ovatis rugofis feffilibus.

indica: fol. oblongis cufpidatis glabris, caule arboreo, ramis reflexis radicantibus, fructibus aggregatis pedunculatis.

b. foliis ingulatis.

reticulata: fol. ellipticis fubangulatis cufpidatis glabris fubtus reticulatis, fruetibns globofis folitariis petiolatis.

finuata: ifol. ellipticis finuato-dentatis culpidatis glabris, fruetibus globofis aggrega. tis petiolatis.

c. foliis Serratis.

capenfis: fol. ovatis acutis glabris ferratis, frueti. bus pedunculatis glabris.

bifpida: fol. oblongis culpidatis pilofis ferratis, fruetibus hifpidis pedunculatis. *** foliis divifis.

beteropbyla: fol. indivifis \& incifis oblongis acutis fabris, fruetibus ovatis fabris petiolatis.

Carica: fol. fubtrilobis fubtus fcabris, fructibus lrevibus pyriformibus umbilicatis.

toxica: fol. cordatis finuatis fubtus albo-tomentofis, fructibus tomentofis. 


\section{*) $7(4)$ \\ §. VI.}

\section{DESCRIPTIONES SPECIERUM,}

Radices omnium perennes funt, frigoris intenfioris impatientes.

Caules frutefcunt \& in nonnullis arborei evadunt, omnes lactefcentes.

Rami femper alterni uti \& ramuli.

Folia alterna \& petiolata.

Fructus vel feffiles vel pedunculati; globofi vel turbinati.

I. Sycomorus. Folia cordata, fubrotunda, integra.

Fructus feffiles.

2. NyMPHordes. Folia cordata, ovata, acuta, integra, fupra viridia, fubtus glauca, palmaria usque pedalia.

Fetioli compreffi, glabri, fpithamæi \& ultra.

3. Religiosa. Arbor mediocris, tota glabra.

Rami angulati, flexuolo - erecti.

Folia cordata, ovata, culpidata, finuata, integra, parallelo-nervofa, glabra, raro fubtus glau. ca, bipollicaria usque fpithamæa. Culpis fæpe digitalis.

Petioli angulati, ftriati, digitales.

Fructus in ramulis fparfi, feffiles, folitarii vel aggregati, glabri, magnitudine pifi.

4. ASPERA. Rami fubcompreffi, flexuofi, Atriati, glabri.

Folia cordata, oblonga, bafi latiora, apicem verfus attenuata, cufpidata, dentato-fubundulata, glabra, afpera, patentia, fpithamæa. 


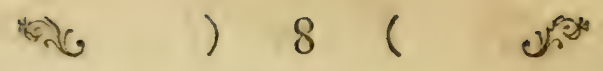

Petioli femipollicares.

Fructus globoli, magnitudine fere pruni.

5. Bengalensis. Calihs truticolus, teres, ercetus,

totus glaber, orgyalis,

Rami cauli fimiles.

Folla ovata, integra, fubundulata, coriacea, glabra, nervola, palmaria.

Petiolus femiceres, femipollicaris.

6. Cordata. kratex mediocris, tolus glaber.

Rami teretes, fubrugofi, cinerei, erecto-patentes, ramuloíi.

Folit verfus apices ramorum \& ramulorum approximata, obfolete cordata, ovata, acuta, integra, venofa venis reticulatis, patentia, fesquipollicaria.

Petiolus teres, ungvicularis.

Fruculus feffiles, verfus apices ramorum \& ra. mulorum in axillis foliorum approximati, globofi, magnizudine pifi.

7. Stupulata. Caulis lignofus, filiformis, decumbens, rufefcens, glàber.

Rami fliformes, decumbentes, inflexi, ftipulati, rufefcentes.

Stapulce fparlæ, Inbulatx, patentes, rufefcentes. Folir breviffime petiolata, oblique cordata, ovata, obtufa, integra, fupra læte viridia, fubtus pallidiora, reticulata, ungvicularia vel femipollicaria.

Petzoli vix lineam dimidiam longi.

8. Falcata. Caules filiformes, decumbentes, radicantes, flexuofi, brunnei. 


\section{$\Rightarrow$ ) $9(20$}

Rami filiformes, fimplices, cauli fimiles.

Fola oblique inferta latere altero anguftiore, oblonga, falcata, obtúa, tenuiffime nervofa, integra, glabra, f́upra viridia, fubtus pallida, ungvicularia.

Petiolus breviffimus.

9. Punctata. Caules parafiticus, longe fcandens, flexuofus, teres, rugofus, brunnevs, craffitie vix calami fcriptorii.

Rami flexuofi, læves, brunnei.

Ramuli breviffimi.

Folia oblonga, obtufa, obfolete emarginata, integra margine parum reflexo, glabra, fupra lævia, fubtus impreffo-punctata, patentia \& reflexa, ungvicularia usque pollicaria.

Petioli breviffimi.

Fructus obovati, magnitudine fere caricx. ro. Pumila. Caulis decumbens, repens, radicans, teres, rimofus, cinereus, glaber.

Rami pauci, cauli fimiles.

Folis ovata, obtufiufcula, integra, coriacea; fupra lævia, viridia; fubtus pallidiora, reticulata; glabra, pollicaria usque bipollicaria.

Petioli femiteretes, ungviculares.

Fructus petiolati, ovati, glabri, magnitudine pruni.

Pedunculi Atriati, reflexi, ungviculares. I. Erecta. Caulis debilis, parum decumbens, teres, rimofo-ftriatus, cincero - ferrugineus, glaber. 


\section{स्नु, $)$ io $\sqrt{3}$}

Rami alterni val fubumbellaio-aggregati, ereEi , cauli fimiles.

Folia obovata, itringlie parmm âtenuata, acura, integre, glabra, forra viridia; fubtus cinerea, reticulata: pacentia, poilicaria usque digitalia.

Petiole fubtrigoni, fulcati, femipollicares.

Fractus in ramulis foerfi, pedurculati, eredi, fubglobofi, magnitudine avellanx.

Differt a Ficu pumila:

1: Folnis majoribus, minus reticulatis, tennioribus.

2: Fructibus minoribus, ducioribus, edulibus.

12. Trigons. Arbor fuperne foliofa.

Rnmii teretes, rugofi, comentofi.

Ramuli brevifini.

Felı: ovata, acuta, integra, glabra, patentia, fubpalmaria.

Petiolus ungvicularis.

Fructus in ramis alterni, pedunculati, globofi, magnitudine pifi majoris. Umbilicus triangularis. Pedunculi brevifimi, uniflori.

13. Pertisa. Arúfiula.

Rami frriati, patentes.

Folia ovato-oblonga, fubcufpidara, inregra, arallelo-nervola, glabra, digitalia.

Petiolas teres, fulcatus, ungvicularis.

Fracius racemofi, globofi, pifo minores. Umbilicus teres.

Peduaculi fruetu breviores, refexi.

14. Nitma. Carilis totus glaber.

Rami Ariato-rugof, eredto-patentes. 


\section{象 ) II (}

Folan elliptico-ovata, acuta, integra, parallelo. nervofa, glabra patentia, pollicaria usque palmaria. Petioli femiteretes, vix ungviculares.

Fructus in apicibus ramulorum feffiles, globofi, returi, magnitudine piri.

15. Beniamina. Arbor mediocris, tota glabra.

Rami frriato - rugofi, flexuofi, erecto-patentes. Folia ovata, acuta, integra, glabra, parallelonervofa, patentia, digitalia.

Petioli fubtrigoni, vix ungviculares.

Fricitus fparti in ramulis, feffiles, globofi.

I6. ReFleXa. Ramiftriato-rugofi, reflexi, cinerei, glabri. Folia elliptico-obovata, obtula, integra, parellelo-nervofa, glabra, digitalia.

Petioli cinerei, folio dimidio breviores.

Fractus in ramis fparfi aggregatique, feffiles, globofi, glabri, pifi magnitudine.

17. RACEMOSA. Rambi teretes, læves, ferruginei, erecti. Ramuli fparfi, breves.

Futia oblonga, acuta, integra, nervola, glabra, fupra viridia, fubtus pallida, pollicaria usque tripollicaria \& ultra.

Petioli teretes, fulcati, femipollicares \& pollicares. Fructus racemofi, globofi, magnitudine fere pruni. 18. Retusa. Rami angulati.

Folia obovato - oblonga, obtúa. Fructus fefinles.

19. Drupacea. Rami teretes, fulcati, glabri.

Folia fparfa, obovata, acuminata, coriacea, integra, nervofa, glabra, fupra viridia, fubtns cinerea, palmaria. 


\section{*) $) 12(10$}

Petioli femiteretes, crafi, ungviculares.

Fructus verfus apices ramorum feffiles, ovati, rugofi, glabri, magnitudine pruni.

20. Indica. Artor maxima, vaftiffima, tota glabra.

Rami recurvi, inferiores radicantes, cinerei.

Folia oblonga, acuminata cufpide obtufa, integra, obfolete undulata, parallelo-nervora, fupra viridia, fubtus pallidiora, fpithamæa.

Petroli femiteretes, cinerei, digitales.

Fructus aggregati hinc inde in ramulis, pedunculati, globofi, magnirudine avellanx.

21. Reticulata. Rami teretes, rugofi, purpurei, glabri, ereeti.

Ramnulv fimiles.

Folia obovata, inferne attenuata, cufpidata, fubangulata, dentata margine reflexo, glabra, nervolo-reticulata, fupra viridia, fubtus pallida, patentia, palmaria.

Petzoli femiteretes, crafi, vix ungviculares.

Fructus axillares, pedunculati, globofi, glabri, pifo majores.

Pedunculus lineam longus.

22. Sinuata. Rami teretes, ftriati, cinerei, glabri, ereeti. Ramuli fimiles.

Folia obovata, cufpidata, fuperne dentato-angulata margine relexo, inferne integra, fupra viridia, fubtus pallida, nervofa, reciculata, glabra, patentia, palmaria.

Petiole femiteretes, fulcati, ungुviculares.

fructus in ramulis parfi \& aggregati, feffiles, glo- 


\section{ज्नेद ) 13 ( एै}

globofi, nodulofi, glabri, piperis vix magnitudine. 23. Capensis. Arbor excelfa, vafta, glabra.

Rami patentes.

Folia ovato - oblonga, acuta, finuato - dentata, glabra, fupra viridia, fubtus pallidiora, nervofa, patentia, digitalia.

Pedunculi femiteretes, pollicares.

Fructus fparti, pedunculati, turbinati, glabri, magnitudine avellanæ \& ultra.

24. Hispida. Rami teretes, ftriati, cinerei, glabri.

Folia oblonga, cufpidata, ferrata, fupra viridia, fubtus virentia, utrinque fcabra nervis pilofis, fubfpithamæa.

Petioli fulcati, pollicares.

Fructus axillares, racemofi, turbinati, villofohifpidi, magnitudine pruni.

Pedunczali hifpidi, ungviculares.

25. Heterophylla. Caulis fruticofus, ereetus, totus. fcaber.

Rami teretes, flexuofi, elongati, parum ramulofi.

Folia oblonga, cufpidata, indivifa \& finuata, dentata margine reflexo, fupra viridia, fubtus pallida, utrinque lcabra, nervofa, erecto-patentia, digitalia.

Petioli femiteretes, ungviculares.

Fistus axillares, pedunculati, ovati, obtufi, hifpidi, magnitudine avellanæ.

Peduncula petiolis breviores.

26. Carica. Arbufrala vix orgyalis, crafficie ad fummum brachii, cinerea, rimofa, fabra, ligno porofo, fpongiofo.

$\mathrm{B}_{3}$

Ra: 
(2) 14 (

Rami clabri, puntis albis oblongis notati, creEti, flexuofi retroflexique.

Sithule bina, oppofitx, fefliles, ovatx, acutæ, ferruginex, caducx.

Folia annua vel perennia, cordata, ovata, in. divila triloba \& quinqueloba finubus rotundatis, ferrato-dentata, fupra viridia, fubtus pallida, utrinque f́cabra, patentia, palmaria \& f fithamæa.

Petroli tereres, fulcati, fubpollicares.

Fructus axillares, folitarii, pedunculati, turbinati, magnitudine pyri.

Pedunculr toreces, brevifimi.

27. Toxica. Frutex mediocris.

Rami teretes, glabri, ferruginei.

Folic cordata, ovata, acuta, finuato-angulata, incilo-lobata, denticulata; fupra viridia, villola; fubtus albo-tomentola; fpithamxa \& ultra.

Petioli teretes, Priati, fubtomentofi, palmares.

Frućtus petiolati, ovati, tomentofi, magnitudine prani.

Pedunculus craffus, tomentofus, ungvicularis.

\section{§. V. \\ SYNONYMA.}

F. fycomorus. Ficus fycomorus: Linn. Syft. Veg. xIV. p. 92 r. F.nymphoides. Ficus nymphrifolia:Linn.Syt.Veg.xiv.p.92I. F. religiofa. Ficus religiofa: Linn. Syft. Veg. xIv. p. 921. F.bengalenfis. Ficus Bengalenfis: Linn. Sy凡. Veg. xIV. p. 92 r. F. cordata. Tab. Difl. Noftr.

F.pumila. Ficus pumila: Linn. Syft, Veg, xiv. p. 922. Ficus pumila: æ. Thunb. Flor. Tapon. p. 33. Frponzenflus: Mame tfuta, five Teika Katfu- 
है ) 15 ( )

ra, vulgo Inu Itabu. Kæmpf. Amæn, exor. fafc. v. p. 803. fig. p. 804.

F.eveEta. Ficus pumila: Linn. Sytt. Veg. XIv. p. 922. Ficus pumila B: Thunb. Flor. Japon. p. 33. Itabu. Kæmpf. Amœn, exot. fafc. v. p. 803 . F. trignona. Ficus trigona: Linn. Syft. Veg. xiv. p. 922. F. pertufa. Ficus pertufa: Linn. Syft. Veg.x!v, p. 922. Rhed.Hort.Mal. T.3.Tab. 56 ? F.nitida. Jtti-are-alou. Rhed. Hort. Mal. 3. p.69.t. 55. F. benjamina. Ficus benjamina: Linn, Syft. Veg. zısv. p. $92 \mathrm{r}$. Ficus microcarpa:Linn. Syft. Veg.xIV.p.922. Rheed. Hort.Mal.'T. I, t. 26.

F.racemofa. Ficus racemofa. Linn. Syft. Veg. xiv. p. 922. Teregam.Rhed.Hort.Mal.3 p.79.t.60.

F. retufa. F. indica. F. bipidde.

F. beterophylla. Ficus heterophylla: Linn.Syft.Veg.xiv.p.922. V'wll Teregam. Rheed, Hort. Mal. Tom. 3.p. 83. tab. 62 .

F. Carica. Fictus carica: Linn. Syft. Veg. xiv. p. $92 \%$.

F.toxica. Fichs toxicaria. Linn.Syft, Veg. xiv. p. 922.

\section{§. VI. \\ LOCUS.}

Crefcunt Ficus fpecies fponte vel in calidioribus zo. næ torridæ regionibus vel in terris illis, qua intrat vel paulo extra tropicos fite funt; fic inveniuntur crefcentes:

In Egypro: Sycomorus.

In America meridionali: nymphaides, trigona, pertufa, hilpida.

In India Orientali : religiofa, bengalenfis, falcata, punctata, benjamina, reflexa, racemofa, drupacea, indi- 


\section{"न्नु ) $16:(\mathrm{e}$}

ca, reticulata, finuata, hifpida, hoterophylla, cari. ca, toxica.

In Infulis Japonicis: ftipulata, pumila, erceta.

In Infula Tanna maris aufralis: afpera. Prof. Forfter.

In Europa auftrali: carica.

In Capite bonæ Ipei Africes: corciata, capenfis.

\section{§. VII. \\ CULTURA.}

Coluntur paucæ, quod mireris, fpecies, quxe facillisne omnium abrupris ttipiribus propagari \& multiplicari pofunt. Quæ maxime colitur, ob fructus edules, fpecies, eft carica; ceteræ in hortis botanicis cultæ, funt ni. rida, bengalenfis, nymphoides.

\section{§. VIII. \\ USUS.}

x. Ligni, utpote minus robulti \& compacti, ufus valde exiguus eft.

2. Humor vero laeteus, quem omnis pars arboris ftillat, acris eft, naufeofus \& lac coagulandi vi præditus; fuccus hicce externe corrodit, cofmerici inttar mundificat, odontalgiam a carie mirigat \& venenatorum Animalium morfuris mederur; interne Tr:a ftipitum fudorem urinamque pellens Hydropicis interdum prod. eft \& immaturus fructus, noxio adhuc fratens lacte, tormina, colicam, diarrhceam excitare folet.

3. Fructus maturi plerarumque fpecierum, inprimis vero carice, non palato modo grati, fed maxime falubres facile digeruntur, optime nutriunt, brevi pingve. faciunt, hepatis imprimis molem augent, edulcorant, emolliunt, lubricant, urinam pellunt, alvumque leviter ducunt; in morbis itaque Pectoris, Nephritide, Stranguria, Obftiparione, Colica aliisque proficui at. que non parum ufitati. 

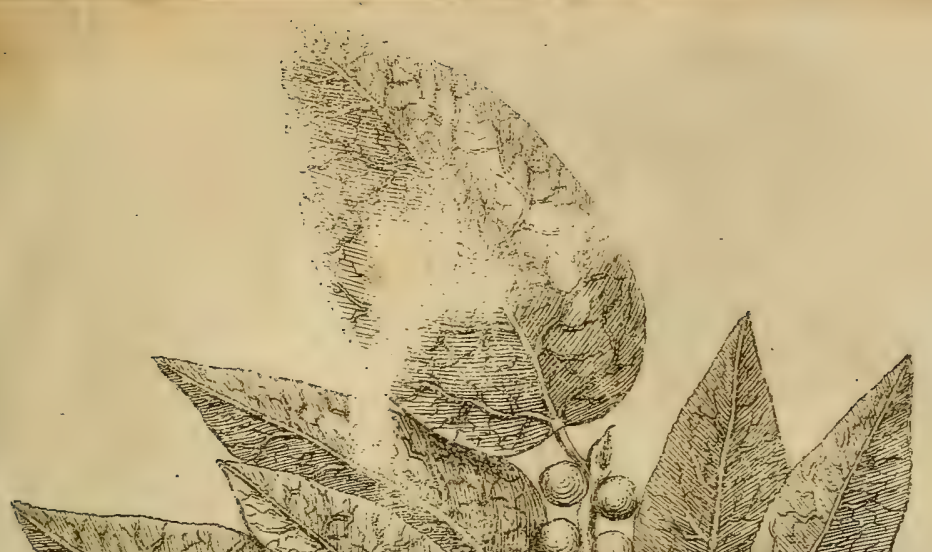

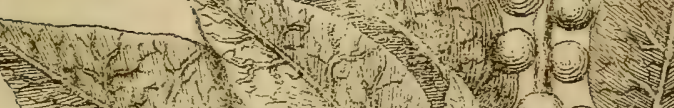
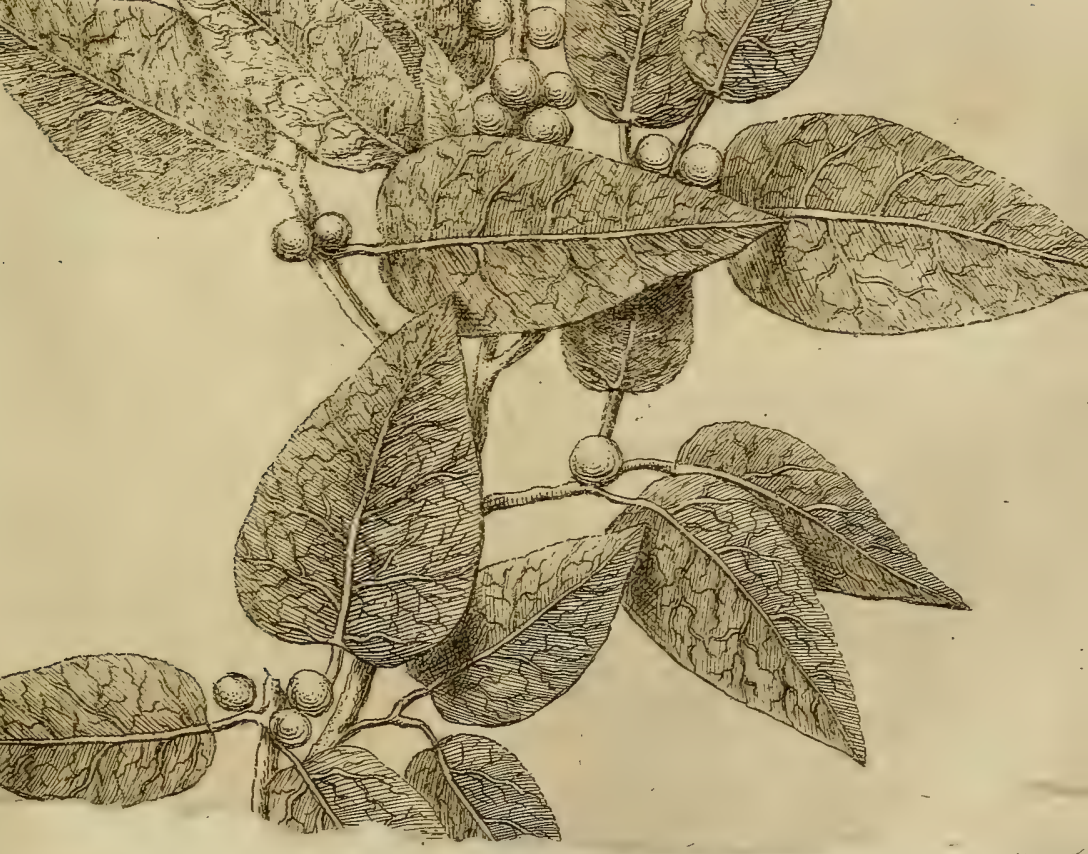

$\mathrm{N}$

TINONOL 
*h, 151 ( ) 
Ohole
D. D.

\section{DISSERTATIO BOTANICA}

$\mathrm{DE}$

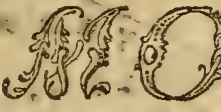

3. is
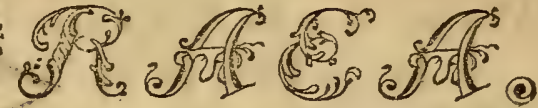

QUAM

CONSENSU EXP. FAC, MED. UPSAL.

PR FESIDE
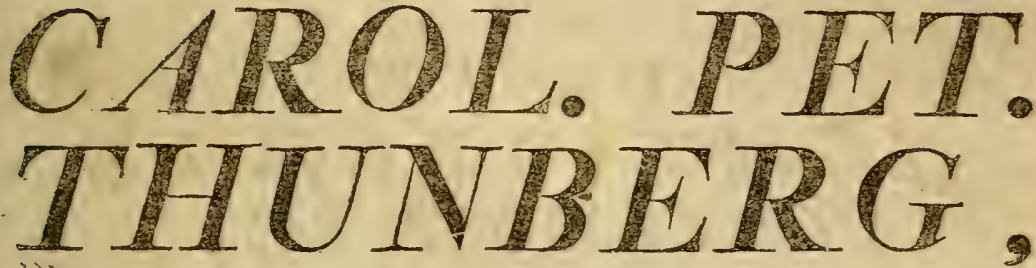

Equite Aurat. Reg. Ord, de Vasa,

Medic, Doct. Profess. Med, et Botan, Reg. et Ord., Acad. Carsar. Nat. Curios, Reg. Scient. Holmiens, Societ, Scient, Upsat, Patr. Holm. Berol, Nat. Scrut. Lund. Harlem. Amsteld. Zeland, Nidrosiens. Medic. Edimeurg. et Nat. Studios. Ibid. Membro; Nec non Acad. Monsteilens. A gricuit. Paris. Florewtin.et Batavin, Ind.

Or. CORRESTOND.

PUBLICE EXAMINANDAM SISTIT ZACHARIAS COLLIANDER, * STIPEND, REG. SMOLANDUS.

'IN AUDIT. GIST. MAJ. D. VIII. DEC. MDCCIXXXVIJ. H. A. $M . S$.

U P S A I IE,

LITTERIS DIRECTOR. JOHAN. EDMAN. 


\title{
MONSIEUR
}

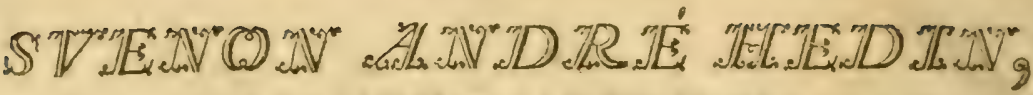
DOCTEUR EN ME'DECINE,

ASSESSEUR au Coll. Royal de la Médec. à Stockholm, Premier Médecin de la Cour, Membre de la Societé de la Médecine à Copenhague;

$\&$

à

\section{MONSIEUR}

g) IE A

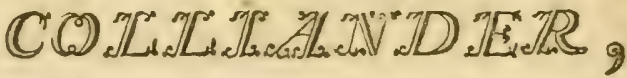

Maitre en Philosophie et Docteur en Médecine,

Lecteur au College Royal à Wexió,

Médecin de la Province de Cronoberg, MON très honoré OnCle;

\author{
DEDIÉE \\ PAR \\ VOTRES
}

très bamble drè̀s obéisfant

Serviteur

ZACHARIE COLLIANDER. 
DE

\section{MOR}

\section{§. I.}

nter nova illa Plantarum Genera, quæ poft reforma. tam hoc feculo Botanicen, a Botanicis recepta fuerunt, Moremam, a Joman. Moreo, Asfesfore \& Medicinz apud Fahlunenfes Doctore celebri \& experientisfimo, fuum matuatam nomen, is Speciebus Plantarum ill. LinNer primum commemorari, duplicique conftare fpecie diverfá, juncea fcilicet \& vegeta, perfpicimus. Utramque vero hanc fpeciem Mor licet, esfe poftea animadvertir Linswus, filius, atque in Supplemenco fuo Plantarum non modo fub triviali nomine iviopetala comprehenfit, fed etiam, quæ ad Ireos Genus, ob petala tria majora barbata, potius referatur, reEte omnino dignam declaravit. In Disfertatione itaque de Iride Celeb. Præfidis Iris plumaria appellata fuit. Cum vero plantarum individua, certe non pauca, cum lridibus fumma affinitate juncta, ab illis autem fufficienter diftincta, precipue opera Celeb. Præfidis \& imprimis in Promontorio Africes auftrali, detecta fuerunt, quæ cum celeb. fuo Antecesfore, juniore LinNæo, in Supplemento Syftematis edendo occupato, communicavit; hæc ad Morex Genus, quafi de novo condendum, jure merito. que fuerunt relata.

Defcriptione pulcherrimi hujus Generis gratiam apud B. L. me initurum fore, eo magis mihi perfvafus 
fum, quo certo certius fciam, Genus hocce non modo inf? fficienter ante esfe defcriptum, fed etiam adeo plurimis fuis fruatificationis partibus ludere, ut non facilis fit illa opera, qua eruantur genuinæ illæ notæ, quibus ab aliis generibus rite nofcatur, \& fpecies veræ eidem recte jungantur.

Ut enim fub hoc Genere fpecies comprehenfre fuerunt, quæ ad alia genera amandari debuerunt; fic etiam deprehenfx funt aliorum Generum plantx, quas ad Moraas referre coacti fuerunt Botanici recentiores. Ad Ireos itaque Genus pertinent fpecies fupra nominatæ, Morea juncea \& vegeta atque fugax, \& ait MoreAs reduci debent Iria gladiata, africana, flexunfa atque chinenfis, Fer. earia undulata, Sifyrincbium palmifoliun \& bermudiana.

Corolla in hoc genere, uti \& in Iridibus copersiluus, fubhexapetala fre occurrit, infima bafi aliquando vix perfpicue connata, fic ut dubius hæreat Examinator attentus, utrum potius monoperala, an hexapetala falutari debeat. Cum vero accurariori examini fubjectre plurimæ fpecies corolla bafi coalita infructæ inveniantur, Moræ⿸厂s æque ac IRIDIBus corollam potius monopetalam fexpartizam adfcribendam esfe judicamus.

Filamenta ftaminum, numero femper tria, in multis, fcilicet melaleuca, filiformi, fpatbacea, carulea, aliis, Ceparata funs; in a!iis vero, precipue collina, undulata, bergnudia$n a$ in cylindrum connata Monadelpha deprehenduntur, ut quoque in Iridibus non paucis, Ixiis aliisque Generibus, aufralem Africam incolentibus.

Nulla vero fructificarionis pars adeo varie ludere obfervatur, ac quidem ftigma Piftilli, quod in carulea, fpirali \& africana fimplex; in bermudiana bifidum; in polyantbo, Jputbacea, compresfa, palmifolia, filiformi trifidum; 


\section{De Moraa.}

in undulata, melaleuca tripartito-multifidum; in collina trifido-cucullatum; in flexuofa fexfidum; fic ut in hoc, licet in plurimis ad numerum ternarium proxime accedat, nulla certa characteriftica nota quærenda fit.

Dignofcenda igitur erit Morea a Triandriæ Mo. nogyniæ Bulbofarum plantarum Generibus, imprimis ab Iridibus fequenti charactere esfentiali:

Corolla monopetala, fexpartita, incquali: laciniis erectis. Stigmatibus tribus.

\section{S. II. \\ CHARACTER GENERICUS.}

cAl. Spatba duplex, exterior major; utraque convoluta, lanceolata, glabra, erecta.

CORolita fubmonopetala, campanulata, inæqualis: lacinie tres majores, obovatæ, obtufæ; tres minores, breviores vel anguttiores, oblongæ, obtufæ.

stam. Filamenta tria, fæpe libera, rarius in cylindrum connata.

Antbere lineares vel ovatæ.

PIsT. Germen inferum.

Stylus filiformis, erectus, corolla brevior.

Stigma varium, fimplex, bipartitum, trifidum fxpius, fexfidum, tripartito-multifidum, rarius trifido-cucullatum.

peric. Capfula oblonga, glabra, trigona, trivalvis, trilocularis.

Semina plurima, giabra,

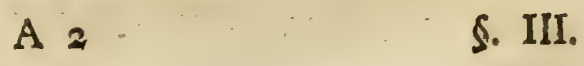




\section{§. III. \\ DIVISIO SPECIERUM.}

* Scapo ancipiti:

melaleuca. I. M. rcapo ancipiri, foliis fubfalcaris, flore fubfolitario.

fpiralis. 2. M. fcapo compreslo articularo, foliis erectis, floribus alternis fubfecundis.

africana. 3. M. Ccapo ancipiti, folis diftichis, floribus capitatis, fpathis membranaceis laceris. pufilla. 4. M. rcapo ancipiti, foliis diftichis, flore fubfolitario.

bermudiana. 5. M. fcapo ancipiti, foliis diftichis, floribus capitato-umbellatis, fpathis membranaceis. palmifolia. 6. M. Icapo ancipiti, foliis enfiformibus nervolis, floribus fpicaris.

ixioides. \%. M. fcapo compresfo, folis diftichis nervo: fis, florum umbellis pedunculatis.

gladiata. 8. M. fcapo foliisque compresfis, fpica laterali folitaria involucro duplo breviore.

apbylla. 9. M. rcapo foliisque compresfis, fpica laterali folitaria involucro multories breviore. filiformis. 10. M. fcapo foliisque compresfis fubfliformibus, flore folitario terminali.

* * Scupo tereti:

spatbacen. 1I. M. Ccapo foliisque teretibus dependentibus, fpicis lateralibus aggregatis.

fexuofa. I2, M. fcapo tereti articulato, folio reflexo fubundulato nervofo.

collinu. I3. M. fcapo tereti, folio dependente, lacinis corollæ fubæçualibus.

polyantbos. 4. M. fcapo tereti, foliis flexuofo-erectis, laciniis sorollæ ahernis minoribus. 
comlen. $\quad$ 5. M. fcapo tereti, foliis diftichis, florum ca. pitulis alternis, fpathis membranaceis integris.

ambellata. I6. M. fcapo tereti friato, florum fpicis umbellato-paniculatis, involucris diphyllis longifimis.

crifpa. I7. M. fcapo tereti articulato, folio convoluto crifpo reflexo.

iridioides. I8. M. fcapo tereti, foliis diftichis linearibus, flore fubfolitario terminali.

cbinenfis. Ig. M. fcapo tereti, foliis diftichis enfiformibus, floribus umbellatis.

pavonia. 20. M. fcapo tereti, foliis diftichis, fore folitario, corolla laciniis aiternis haftatis. undulatn. 2r. M. fcapo ramofifimo, foliis vaginantibus carnofis, corolla crifpa.

\section{§. IV.}

\section{DESCRIPTIONES SPECIERUM.}

\section{Radix carnora, fibrofa; vel bulbofa.}

Scapus frpisfime fimplex, rarius ramofus; anceps vel teres ; glaber, erectus.

Folis linearia, lineari-lanceolata vel enfiformia, dilticha fæpius, integra, głabra.

3. M. Milaleuca: fcapo ancipiti, foliis fubfalcatis, flore fubfolitario.

Radix carnofa, fibrofa.

Scapus fimplex, anceps, articulatus, erectus, glaber, pedalis vel bipedalis.

Folia radicalia plura, difticha, lineari-enfiformia, erecta, ftriata, glabra, fcapo triplo breviora, fub. falcata, duas lineas lata $j_{i}$ fcapi fpathacea, juxta A. 3 artis 
articulos alcerna, fenfim breviora; inferiora tripol licaria, fuperiora pollicaria.

Flores terminales, folitarii, vel duo; raro tres, umbellati, pedunculati, erecti.

Pedunculi breves, inæquales, glabri, craffi.

Spatbe binæ infra pedunculos, oppofitæ, lance. olatæ, concavæ, glabræ, virides, apice membrana. ceæ, erectæ, unguiculares.

Corolla fubmonopetala, inæqualis, ad bafin fere fexpartite, patens, facile fatifcens: Lacinive tres majores, obovatæ, obtufæ, fubemarginatæ, concavæ, bafi albæ, verfus apicem cæruleæ, pollicares; tres minores, ceteris mulco breviores \& angultiores, ovatæ, obtufr, concavæ, bafi albæ, a medio ad apicem atræ.

Fillamenta tria, fubulata, alba, erecta, brevisfima. Antiserc lineares, flavæ, lineam longa.

Stylus filiformis, erectus, albus.

Stigma multipartitum, cærulefcens.

2. M. Surratis: fcapo compresfo articulato, foliis erectis, floribus alternis fubfecundis.

Scapus anceps, ftriatus, glaber, articulatus, erectus, pedalis vel paullo ulrra.

Folia nadicalia linearia, acuta, ftriata, erecta, fcapo vix breviora; jcapi alterna, fpathæformia. Flores alterni, fubfecundi, laterales.

Spatór brunneæ, concavæ, acuminatæ, fubbifloræ, longitudine corollæ.

Corolla fubhexaperala, albido-cærulea, nocte \& poft florefcentiam fpiraliter convoluta. Lacinice $x$ quales, campanulato - patentes, ovatæ, obtufæ, pollicares, extus albo-virefcentes, intus albæ; inferne crasfe, intus bafi macula cordata purpurea. 


\section{De Moran.}

Filaneersta tria, corolla breviora, filiformia, alba. Antberce oblongæ, fulcatæ, croceæ, erectæ. Siylus filitormis, ftaminibus longior, albus. Stigna fimplex, truncatum, villofum, violaceum. 3. M. Africana: fcapo ancipiri, foliis diftichis, floribus capitatis, fparhis membranaceis laceris. Radix fibrofa.

Scapus fimplex vel ramofus fæpius, anceps, articulatus, g!aber, erectus, digitalis usque fpithamæus.

Folia radicalia difticha, lineari - enfiformia, ftriata, erecta, fcapo breviora; fcapi Spathæeformia.

Flores terminales, capitati, cærulei.

Spatbe binæ, oppofiræ, concavæ, bafi \& dorfo fufcæ, apice \& margine membranacer, albæ, multipartito-Jaceræ.

Stigna fimplex.

4. M. Pusilas: fcapo ancipiti, foliis diftichis, flore fub. folitario.

Radix fibrofa.

Scapus fimplex, erectus, anceps, uniflorus vel biflorus, palmaris.

Folia radicalia, difticha, lineari-lanceolata, fubfalcata, ftriata, glabra, fcapo breviora.

Spatbe naviculares, integræ, longitudine floris.

Corolla fubhexapetala, cærulea, poft florefcentiam fpiraliter convoluta: Lasinice alternæ anguftiores.

5. M. Bermudiana: fiapo ancipici, foliis diftichis, floribus capitato-umbellatis, fpathis membranaceis.

Scaptus anceps, fimplex, fxpius ramofus, glaber, fpithamæus.

Rami divaricati, fcapo fimiles, apice geniculati.

Foliz bafi \& circa genicula plura, amplexicaulia, lineari - enfiformia, ftriata, glabra, erecta, longitudine ramorum. 
Flores in ramis terminales, umbcliti.

Picianculi rerercs, glabri, unisori, unguiculares.

Spaibe folitis fimiles, integræ.

Corolla fubmonoperala, ad bain fere fexpartita: Lacinixe oblongre, obrufa, cufpidace, cærulex, bafi luteæ.

Fzlamenta tota in cylindrum comnata, alba, corolla dimidio breviora.

Antbere trigonæ, luteæ, eredæ.

Stylus filiformis, intra cylindrum filamentorum.

Stigmn clavarum, apice bifidum, laciniis erectis, fubulatis.

Obf. Corollam quadripartitam femel inveni.

6. M. Palmifolia: fcapo ancipiti, foliis entiformibus nervofis, floribus fpicatis.

Defcripta eft in Linn. Mantisf. p. 122.

9. M. Ixrordes: fcapo compresfo, foliis diftichis nervofis, florum umbellis peduncularis.

Radix fibrola.

Senfus compresfus, apice ramofus, friatus, glaber, eredtus, bipedalis \& ultra.

Folia radicalia plurima, difticha, linearia, apice attenuata, friata, glabra, erecta, longitudine fere fcapi; in fcrpo unum vel pauca, fimilia.

Floves in ramulis terminales, umbellati, minuri, albi, circiter tres vel quattuor.

Spatbe lanceolatæ, pedunculis breviores.

Pedunculi capillares, pollicares.

8. M. Gladiata: feapo foliisque compresfis, fpica laterali folitaria involucro duplo breviore.

Scapus fimplex, compresfus, glaber, rigidus, tenuislime ftriatus, enodis, erectus, tripedalis vel ultra.

Folia fcapo fimilia, radicalia, linearia, rigidula, 
giabra, pauca, erecta; friata. integra, fcapo tenuiora, ejusdem longitudine.

Spice capitatæ, terminales, floribus alternis, pedunculatis.

Pedunculus hirtus, uniflorus.

Spathe plures, imbricaræ, inæquales, naviculares, friatæ, apice compresfæ, glabræ, exima duplo longior.

Corolla flava, patens, fubhexapetala.

Stignata tria, fimplicia, patentia, recta.

9. M. Aphylra : fcapo foliisque compresfis, fpica laterali folitaria involucro multoties breviore.

Scapus aphyllus, compresfus, enodis, ftriatus, glaber, eredus, pedalis \& ultra.

Capitula fupra medum in fcapo lateralia floribús luteis.

Involucrum e fcapo continuatum, capitulo florum decies longius, curvatum.

Io. M. Filfformis: fcapo foliisque compresis fubfiliformibus, flore folitario terminali.

Scapus fubfiliformis, compresfus, enodis, fimplex, erectus, friatus, glaber, pedalis.

Folin radicalia, filiformia, compresfa, Atriata, flexuofo-erecta, fcapo breviora, duo vel tria.

Flos folitarius, terminalis.

lrvolicruot extinum flore duplo brevius.

Spatbe alterna, glabræ.

Corolla fubhexapetala, infima bafi connata, lutea. Lacinice patentes, alternæ anguftiores.

Filamenta tria, corolla breviora, lutea.

Stylus filamentis brevior, erectus, flavus.

Stiguzata tria, filiformia, patentia, lurea.

II. M. Spathacea : fcapo foliisque teretibus dependentibus, fpicis lateralibus aggregatis. 
Scapus teres, friacus, glaber, enodis, eredus, femiorgyalis.

Folis radicalia, teretia, friata, primum eresta, dein dependentia, fcapo longiora.

Florun capitula fubterminalia e fpicis aggregatis lateralibus, involucro brevioribus.

Spatbe glumacex, acuræ.

Corolla fubhexapetala, vix bafi connata: Lacinice æquales, fed alternæ cuplo anguftiores, patentes, oblongæ, obtufa, medio vena Elevata, unguiculaIes, flavi.

Filanzenta tria, fubulata, corolla multo breviora. Anthere globofx, fulcatr, incurve, flave.

Stylus filiformis, filamentis brevior.

Stigmota tria, erecto-patentia, obtufa, flava, filamentis longiora.

32. M. Flexuosa : fcapo rereti articulaio, folio reflexo fubundulato nervofo.

Radix bulbofa.

Scapus teres, articulatus, fimplex \& ramofus, ftriatus, erectus, glaber, pedalis \& ultra.

Folinn radicale unum, raro duo, lineare, friatum, reflexum, fcapo brevius; ramea fimilia.

Flores alterni in fcapi rachide flexuofa.

Spatbe oblongæ, apice acutæ, laceræ.

Corolla fubhexapetala : Lacinice bafi vix connatx, fubæquales, ovatæ, obtufæ cum acumine, concavæ, linea longitudinali elevata, patentes, unguiculares, fupra, flavæ, fubtus tres alternæ virefcentes.

Filamentr tria, fubulara, erecta, flava.

Antbere lineares, incurva, flavæ.

Stylus fimplex.

Stigmaia fub fena, filiformia, erecto-patentia, obtu$f a$, duobus femper approximatis, flava, filamentis paullo longiora.

13. M. 
13. M. Collina: rapo tereti, folio dependente, laciniis coroilæe fubrqualibus.

Radix bulbofa, fibrola, ovata, friata.

Scapus ramofus, erectus, multiflorus, glaber, pedalis.

Rani alterni, compresfi, Ppathis involuti, glabri, uniflori, bipollicares, ex eodem centro circirer tres, inæcuales.

Folium unicum, enfiforme, fcapo duplo longius, inferne vaginans, integerrimum, ftriatum, glabrum, concaviufculum, dependens.

Flores terminales, in ramis folitarii.

Spatba bivalvis, pedunculos vaginans, lanceolata, longe acuminata, concava, friata, glabra, viridis, pollicaris; valvulæe fubæquales.

Corolla fubhexapetala, erecta: Lacinie oblongx, obtufæ, fubæquales, parentes, carneæ vel flavæ, extus linea nigra; inferne crasfores, bafi connatæ, incarnate vel viridi - Alavefcentes, anguftatæ: tribus exterioribus bafi fovea neetarifera.

Filanzenta tria, tota connata in cylindrum, corolla dimidio breviora.

Antberc lineares, emarginatæ, intus planæ, ex. tus trifulcatæ, flavæ: dente utrinque unico.

Germen inferum, ovatum, trifulcum, glabrum.

Stylus trigonus, trifulcatus, faminibus paullo longior, fuperne incraslatus, flavefcens.

Stigmata tria, trigona, fubclavata, cucullato-bilabiata: labio exteriore truncato, emarginato, interiore bipartito; laciniis acutis, brevibus, inflexis.

Capfiule oblonga, trifulcata, fenfim crasfior, glabra, trivalvis, rrilocularis, pollicaris.

Obf. I. Variat flore flavo \& aurantiaco.

2. Differt a reliquis Moreis: corolla fubregulari B :2 $\&$ 
\& xquali Ixix; ftigmatibus bilabiatis, laciniis co. rollæ exterioribus fovea nectarifera.

3. Convenit cum Ividibus: ftigmatibus bilabiatis, labio interiori bipartita.

4. Scapus uniarticularus, ad medium usque folio veftitus videtur esfe fimplex, cum plurimi pedunculi cum floribus latent intra fpathas imbricatas, fenfimque florent; fed vere eft ramolus, ramis dichoromo-alternis, qui apice iterum dividuntur in duos, tres vel quaruor ramulos vel potius pedun. culos inæquales, quorum unus vel duo fimul florem aperiunt, interdum plures.

I4. M. Polyanthos: fcapo tereti, foliis fiexuolo-erectis, laciniis corollæ alternis minoribus.

Scapus teres, articulatus, paniculatus, erectus: pedalis.

Rami \& ramuli filiformes, erecti, geniculati.

Foliunz radicule lineare, ftriatum, ereetum, curvatum, fcapo longius; ramea fimilia.

Flores in ulimis ramulis capillaribus folitarii, bini, tres.

Coroll fubhexapetala, cærulea, fubregularis: $L n$ imia ovata, obrufæ, patentes, tres alternæ paullo anguftiores \& breviores, inferne linea flava, extus viridi.

Anthere lineares, flavæ.

Stigmate tria, vix bilabiata, fed bifida.

35. M. Chrulea: fcapo tereti, folis diftichis, florum caa pitulis alternis, fpathis membranaceis integris.

Scapus teres, fimplex, Atriatus, glaber, erectus; bipedalis.

Folia radicalia plurima, difticha, linearia, ftriata, glabra, erecta, fcapo breviora.

Flores laterales, alterni, fpicato-capitati, plurimi. Capi- 
Capitula pedunculata, pedunculis teretibus ungui. cularibus.

Spatbe univerfales naviculares, acuminata, longitudine capituli; partiales ovatæ, integræ, margine membranaceæ.

Corolla fubhexapetala, cærulea. Lacinia ovatæ, obtufr, concavæ, venolæ, erecto-patentes, glabiæ; alternx paullo anguftiores.

Filamenta corollæ bafi inferta, fubulata, brevis. fima, cærulea.

Antbere oblongæ, obtufæ, bafi bifidæ, extus fulcatæ, intus læves, lateralite: infertæ, flavæ, longitudine fere corollæ.

Germen inferum, triangulare, glabrum.

Stylus filiformis, longitudine ftaminum, corolla brevior, fubulatus, cæruleus.

Stigma fimplex, obtufum, trigonum.

Capfula oblonga, trigona, fenfim inferne attenuata, glabra, trivalvis, trilocularis.

36. M. Umbellata: fcapo tereti, florum rpicis umbellatopaniculatis, involucris binis longisfimis.

Scrpus teres, friatus, glaber, erectus, fimplex, pedalis.

Flores terminales, umbellato - paniculati.

Involucra duo fub umbella, linearia, ftriata; alterum brevius, acuminatum, umbella paullo longius; alterum lineare, rélexum, longitudine fcapi.

Flores in apicibus folitarii, bini vel tres, pedun. culati, carulei.

37. M. CRIPA: Ccapo tereti articulato, folio reflexo unz dulato crifpo.

Scopus fimplex, teres, fpithamæus.

Folums radicale, folitarium, lineare, convolutun, hinc inde margine crifpum, longitudine fcapi.

B 3

Flo. 
Flores terminales, pedunculati, pauci, cærulei. 18. M. IRidroides: fcapo tereti, foliis diftichis linearibus, flore fublolitario terminali.

Radix fibrofa.

Scapus teres, vix compresfus, articulatus, glaber, fimplex vel parum ramofus, ercctus, pedalis vel ultra.

Folia radicalia, plura, dificha, linęaria, nervofa, glabra, apice acuminata, erecta, fcapo paulio breviora.

Flores terminales, raro plures, fape folitarii.

19. M. Chinensis: fcapo tereti, foliis diftichis enfiformibus, floribus umbellatis.

Panicula florum trichoroma. floribus umbellatis. Ulteriorem defcriptionem videre licet in Thunb.

Flor. Japonica p. 34.

20. M. Pavonia: Rcapo tereti, folis diftichis, flore folitario corollæ laciniis alternis haftatis.

Defcriptio occurrit in Linn. Suppl. Syft. p. 407.

21. M. Undizata : fcapo ramolifimo, foliis vaginantibus carnolis, corolla crifpa.

Radix bulbofa. Bulbus folidus, carnofus, orbicu. latus, depresfus, læris, fibrillofus, magnitudine rapæ minoris. Bulbi fæpe tres vel plures moniliformi-articulati, approximati.

Scapus ramofus, totus foliis fpathæformibus tectus, reres, glaber, carnofus, fublignolus, erectus, pedalis vel bipedalis.

Rami alterni, diftichi, inferiores longiores, firperiores fenfim breviores, virgati, iterum ramulofi. Folium radicale unicum, vel pauca, obverfo margine vaginans, lineare, carnofum, utrinque medio linea elevata carinatum, integrum, friatum, glabrum, longitudine fcapi, duas lineas latum, erecto-patens; Rnmea inferiora, ramorum bafin amplexantia, difticha, vagina laca margine obverfo 
vaginantia, tandem compresfa, obtufa, Atriata, glabra, carnola, radicali fimilia, patentia, fpithamæa vel palmaria. Romulorun \& fuprema fpathacea, convoluro-vaginantia vagina lata, difticha, approximata, imbricata, ultimo apice compresfa, ftriata, glabra, carnofa, infata, pollicaria vel paullo ultra. Murgines vaginarum foliorum omnium tenues, membranacei, albi. Vagine pol. licem latæ.

Flores in ultimis ramulis bini, pedunculati, intra folia Spathacea reconditi, fenfim florentes.

Pedunculi trigoni, glabri, brevisfimi.

Spatba fimplex; foliacea.

Covolla fubhexapetala, inæqualis, bafi connata: Laciniæ patentes, apice reflexæ, ovatæ, acuminatæ, obtufæ, linea fupra elevata, fubtus fulco longitudinali, margine omni cartilagineo crifpæ, unguem latæ; tres alternæ paullo anguitiores.

Color fubtus pallide flavus nigredine pellucente; fupra triftis feu ex purpureo-fulcus, inferne purpureis transverfis fafciis lineisque. Margo pulcherrime crifpus; fubolivaceus.

Corolle laciniæ pollicares, carnofo-fragiles, fatifcentes.

Filamenta tria, ultra medium in cylindrum purpureo-maculatum connata; apice linearia, marginata, patentia, ftigmatibus fubjecta, longitudine dimidia corolla.

Antherce ovatx, compresfa, incumbentes, fubcordatæ, fubtus fufcæ, fupra fulvæ.

Stylus filiformis, albus, cylindro ftaminum involutus, ejusdemque longitudine.

Stigmata tria, bifida fere ad bafin: laciniæ linea. res, 
res, patentes, filiformi-mulrifidæ, purpurex filis apice favefcentibus, divaricatæ, lineam longæ.

Capfula oblonga, trigona angulis obrufis, glabra, trifulca, trivalvis, trilocularis.

Semina plurima, ovata, glabra.

Obr. Convenzit cum Gulaxizs ftigmatibus filiformimultipartitis.

Intima Sparha tenuifima \& pellucida eft.

Corolle facile decidunt \& difficile ficcantur.

Voriat petalis fupra albis purpureo-variegatis \& punctatis.

\section{§. $\mathrm{V}$. \\ SYNONYMA.'}

melalencr. Moræa lugens Linn. Supplem. Syft. Veger. p. 99. Syft. Veg. XIV. p. 23. Tab. Disfert. I.

spiralis. Linn. Supplem. p. 99. Syft. Vegct. XIV. p. 93. africann. Ixia africana Linn. Spec. Elant, p. 5r. Moræa africana Linn. Syft. Veget. XIV. p, 93.

bermudiana. Sifyrinchium bermudiana. Linn. Spec. Plant. p. Î́53. Syft. Veget. XIV. p. 820.

palnifolia. Sifyrinchium palmifolium. Linn. Spec. Plant. p. I352. Ejusd. Syft. Veget. XIV. p. 820.

gladiata. Ixia gladiata. Linn. Supplem. p. 93. Syftem. Veg. p. 93.

apbylla. Linn. Supplem. p. 99. Syftem. Veg. p. 93. Vid. Tab. Disfert. noftr. 2.

fliformis. Linn. Supplem. p. I00. Syftem. Veger, p. 93. Tab. Disfert. I.

Spatbacea. Linn. Supplem. p. 99. Syftem. Veget. XIV. p. 92. Tab. Disf. I.

flexuofa. Ixia longifolia. Jacq. Hort. Vol.3. t. 90. Moræa flexuofa. Linn. Suppl. p. 100. Syft. Veg. XIV. p. 93 . 


\section{De Morcen.}

polynitbos. Linn. Supplem. p. 99. Syft. Veg. XIV. p. 92. cerulea. Gladiolus capitatus. Vid. Disfert. noftr. Tab. I. Linn. Spec. Plant. p: 53.

ividioides. Linn. Syft. Veget. XIV. p. 93. Mant. p. 28. cbirzenfis. Ixia chinenfis. Linn. Spec. Plant. p. 52. Moræa chinenfis. Thunb. Flor. Japon. p. 34. Linn. Syft. Veg. XIV. p. 93.

pnomia. Ferraria pavonia. Linn. Syft. Veg. XIV. p. 820. undulatø. Ferraria undulata, Linn. Spec. Plant, p. 1353. Syft. Veget. XIV. p. 820.

\section{§. VI. \\ FLORENDI TEMPUS}

Africanarum fpecierum, quas collegit Cel. Dom: Præles, heic tantum indicare licet; floret nempe melalenca: Septembri, Octobri. Spiralis: Augufto.

africana: Augufto \& fequentibus menfibus, in montibus fæe in Menfem Martii.

Germudiana: Decembri.

gladiata: Junio.

Spatbacea: Julio \& requentibus menfibus communiter; fed per torum fere annum florem unum vel alterum aperit.

fexunfa: OAtobri, Novembri, Decembri, Januario. collina: Junio \& fequentibus menfibus.

carulen: Augufto, Septembri, Octobri, Novembri. umbellata \& undulata: Auguito, Seprembri.

\section{§. VII. \\ LOCUS}

Ubi fpote crefcunt, varius eft; occurrunt nempe Morsex $f$ pecies in omnibus mundi parcibus, imprimis 
vero multæ Auftralem Africam inhabitare deprcher. duntur. Crefcunt palmifolia in Brafilia.

ixivides in Nov. Zelandia. D. Pi. Forster. iridioides in Oriente, Conftantinopoli. cbinerz/2s in China \& Japonia.

pavmaia in Mexico.

Reliquæ omnes fpecies in capite Lonæ fpei, fcilicet: melalenca in campo infra Pariberg larere occidencali intcr frutices, in fummis lateribus Pardeberg, inque arenofis prope Ribek Cafteel.

africann in collibus prope Cap, in campis arenofis extra urbem, prope Confantiam \& alibi fape in fum. mis montibus.

bernudiana in montibus inter Hottentots Hollands Kloof \& Hourhoek, Tefte Linnæo in virginia \& Bermudis. gladiata infra latus orientale \& occidentale Taffelberg, rarior.

Spatlacea in collibus infra Taffelberg \& Duyvelsberg co. piofisfime atque alibi, tædiofifima ambulantibus, quorum pedes folia dependentia irretiunt, ur facile cadant.

flexuofa: prope Bergrivier, vier en twintig Rivieren, Olyfants rivier, a Roode Sand usque ad Hauteniquas, ubique vulgaris.

collina: prope Cap, extra urbem copiofilime \& alibi vulgaris.

cervlea : in montibus inter Hauteniquas \& Langekloof; in collibus circum Cap rarior. polyantbos: in regione Korè rivier. sumbellata: juxta Pickerberg. crifpa: in Roggeveld. undulata: in littore prope Leuweftaart extra urbem, ex: tra Groote Battery \& prope Bergrivier. 


\section{§. VIII. \\ USUS}

harum in vita communi non eft mullus; etenim

I:O efculentam fefe præbet M. flexuofa, cujus bulbi cocti comeduntur ab incolis Europæis æque ac ab Hottentottis.

2:0 In Europæis Hortis introductæ \& cultæ fuerunt va. rix fpecies ob fpeciofos fuos flores, ut bermudiana. ividioides, cbinenfis, flexuofa, undulata.

3:0 Horant diei, horologii inftar, monftrant plures, imprimis $\mathbb{M}$. undulata, quæ circa horam quartam ve. fpertinam, decedente fole, flores fuos claudit \& iterum hora nona matutina aperit.

4:0 Speciofe valde funt corulea, chrnerzis, iridioides, alix. EE 5:0 Singulares maxime atque admiratione fumma dignæ perplures hujus generis fpecies, e. gr.

a. M. melalenca floribus fuis, partim albis, para tim atris.

b. Spiralis, corollam uti plures congeneres fuam fpiraliter involvens.

c. wndulata quæ

๙. tota carnofa, glabra \& diaphana eft.

B. cujus corollæ margo denfisfime uti \& pulo cerrime crifpus.

$\gamma$. cujus corølla colore \& crifpatura refert araneam majorem.

$\delta$ ' cujus odor debilis \& ingratus.

\&. cujus corollæ triftis \& cadaverofus color mufcas, ut fibi infideant, allicit, inftar Stapeliæ。 


\section{EXPLICATIO TABULARUM.}

\section{Tab. I. MOR EA Jpatbacen. filiformis. melaúeuca.}

2. MORAEA apbylla. cerulea.

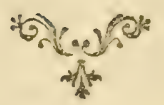


$\therefore$

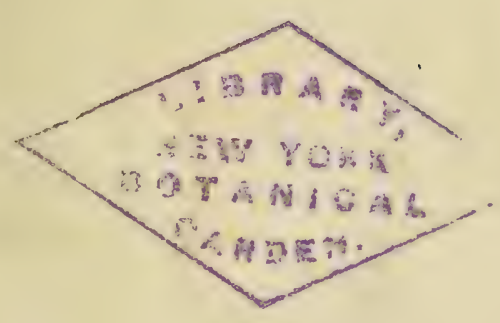


TAB. I.
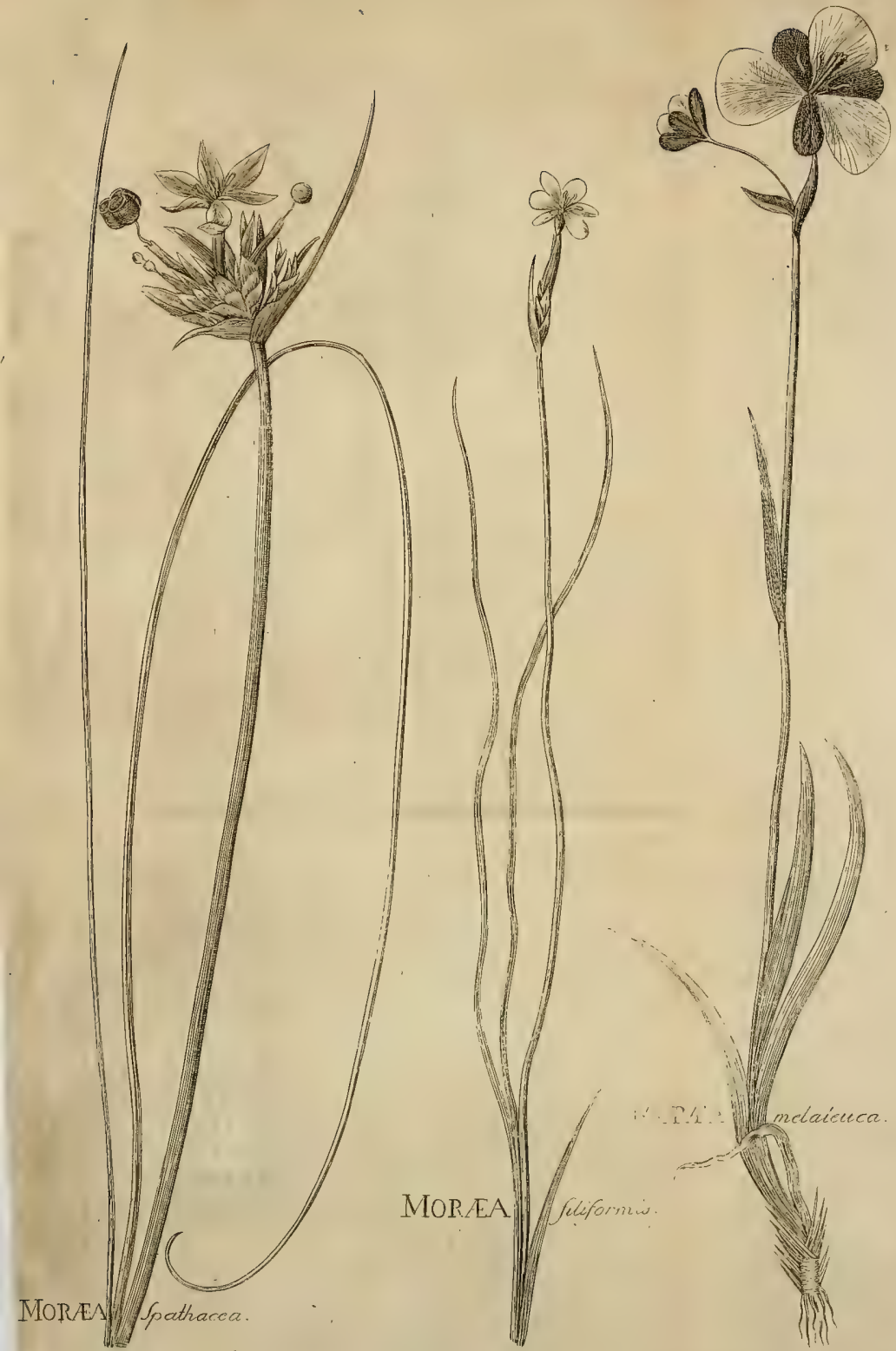

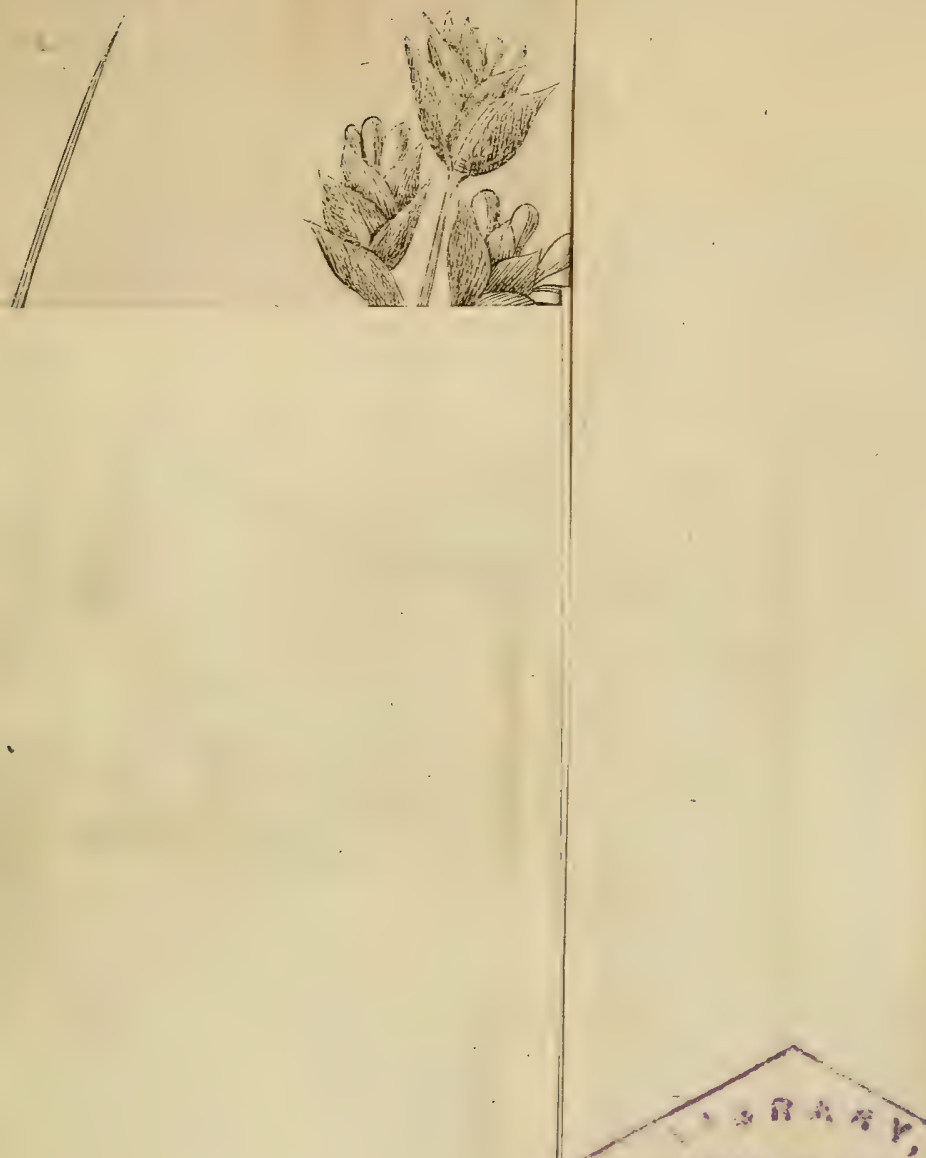

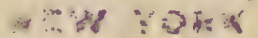

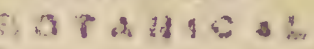




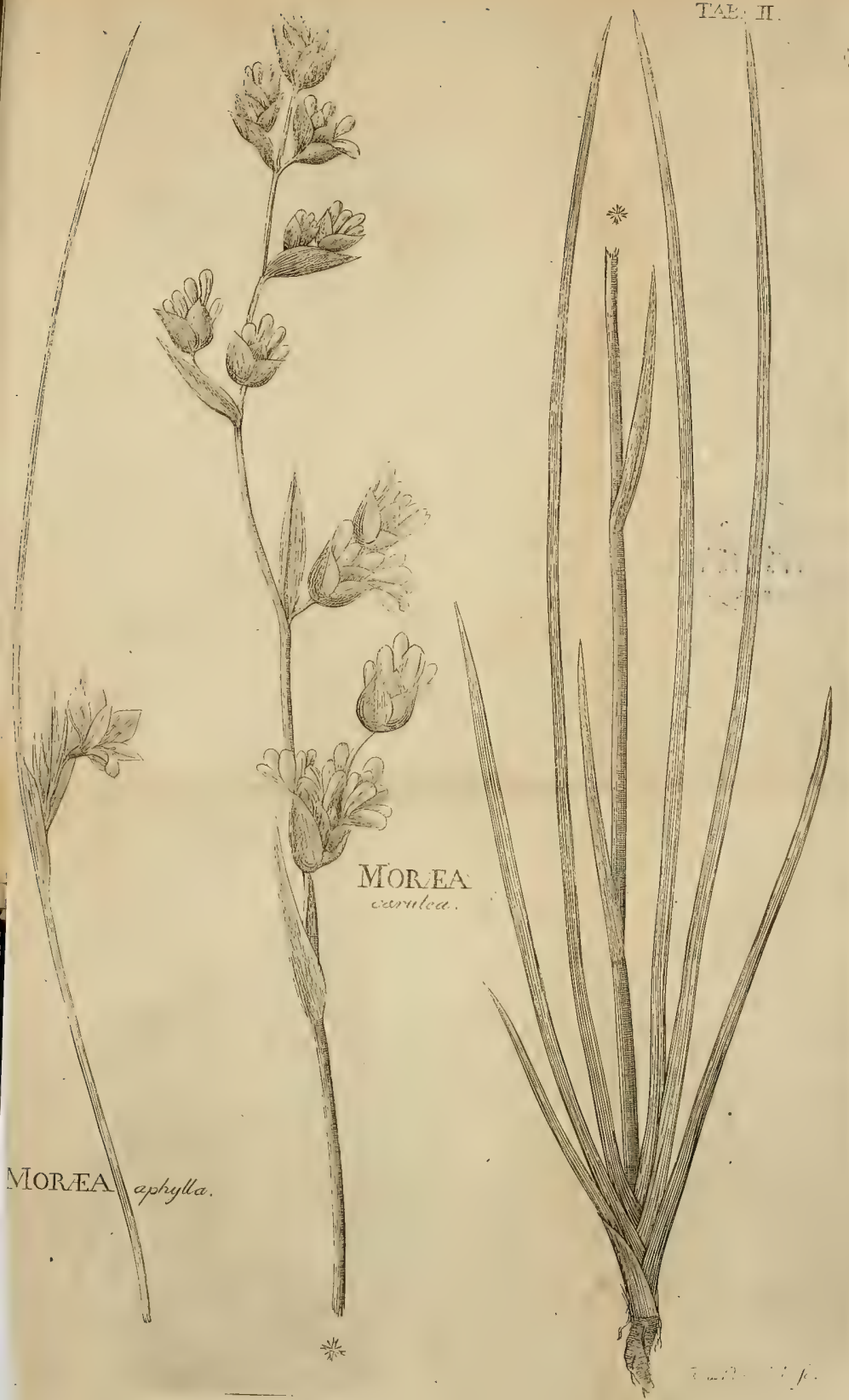




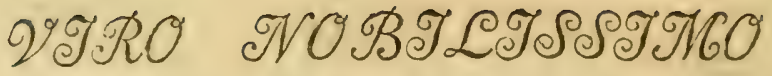

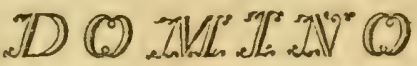

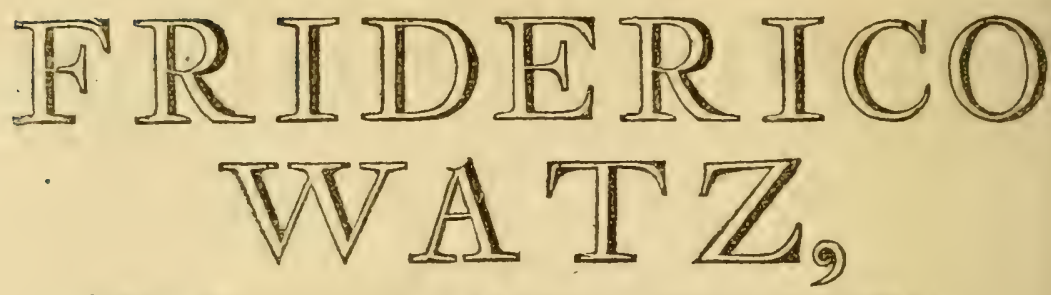

- REI METALLICE PATRONO SPECTATISSINO,

\section{PATRONO ETERNUM COLENDO}

Opusculum hocce Academicum ob magna in se colla. lata beneficia, in tesferam gratce anime dicatum, vom luit, debuit 


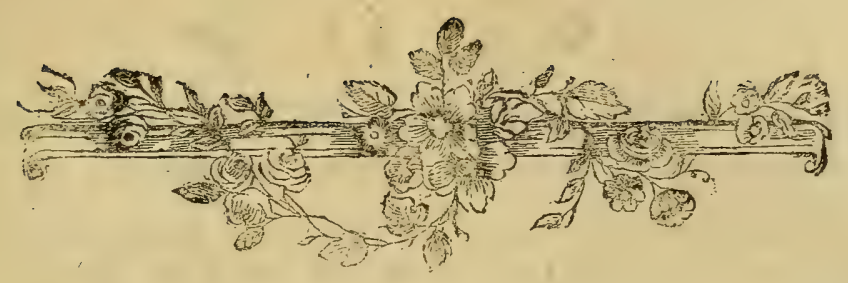

S. 1. GTramina, vim roburque Regni vegetabilis con
ftituentia, plerisque animalibus phytophagis dulia, ubique in hocce terraqueo Globo fpargere, disfeminare ac multiplicare Summo omnium rerum Creatori placuit; hac, cetera inter vegetabilia, licet magis abjecta \& minus fuperba, tamen non parum utilia, omnium funt vulgatisfima, \& Plebsjorum inftar, longe lateque diftributa, ac, ob floris partes minutas, difficile non minus examinanda quam dignofcenda. Hæc, inter qux vix ullam reperies fpeciem venenatam, in regionibus calidioribus \& ficcioribus rarius quidem, at in frigidioribus denfifime tegunt \& virore fuo perenni exornant habitabilis noftri tel. luris fuperficiem, tegmenque virefcens non minus oculis noftris amcenum efficiunt, quam teneriores plantas alias $a b$ externis frigoris injuriis defendunt.

Sunt vero gramina vel perennia; vel annua, teneriora, quotannis forentia, femina ferentia ac fingulis annis disfeminanda. Qur minora femina ferunt, Mammalibus \& avibus plerumque efcam prabent, dum illa, quæ majoribus fuperbiunt f́cicis ac femini. 


\section{औ $) 4$}

bus, a Principe Animalium colliguntur, coluntur \& in varios ulus, Cerealia dieta, vertuntur.

Conftituunt Gramina ordinem naturalem, facile $\mathrm{ab}$ aliis diftinetisfimum, variis criteriis fcilicet:

Culuno fimplici, rarius ramolo, inani, articulato, raro frutefcente.

Foliis fimplicibus, vaginantibus, alternis, plerumque integris.

Floribus rarisfime coloratis, glumis valvulisque membranaceis, fæpisfime hermaphrodicis, quandoque monoicis \& dioicis, nec non interdum polygamis.

Staminzibus utplurimum tribus, raro fex, rarius uno vel duobus.

Seminzbus nudis, rarisfime angiofpermis.

In hosce ordine naturali culmi \& folia Bettiis edulia funt, virore fuo perenni fuperficiem telluris exornant, domibus obtegendis, mattas funibusque conficiendis, inferviunt, nec non igni alendo materian prabent. Semina farinofa \& glutinofa eximie nutriunt, homini imprimis in efcam cedunt, \& in hunc finem fere ubique coluntur.

\section{S. II.}

Restronis genus, gramina inter, hoc primum feculo, nec multis abhinc annis detectum fuit in $\mathrm{Ca}$ pite bonæ Ipei Africes, ejusque fpecies fenfim multiplicatæ fuerunt. ELEGIA quidem proprium ante conftituit genus; portea vero huc relata fuit, fub no- 


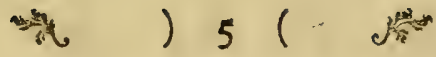

mine Refizonis Elegia; cum vero Calyx Elegix valde differat a Calyce Reftionis, confultius nos duximus, illud graminis genus iterum reftituere atque fub Elegix nomine diftinetum confervare. Aliud, \& quidem novum graminis genus, Reftioni proximum, ac quafi medium inter Reftionem \& Elegiam, WiLdENowIA dietum ab hocce noftro diffingvit Calyx polyphyllus, corolla 6 -petala \& fruetus drupaceus. Recentiori quidem åvo Reftionis genus accuratius fuit defcriptum, ab Ill. LinNeO, BERGIO \& imprimis a RotTBóLlio, additis iconibus optimis; cum vero plurimas adhuc novas fpecies in promontorio bonæ fpei collegerit, illisque Mufæum Academiæ ditaverit Celeb. D. Præfes, operam operatam me non facturum credidi, fi, \& ante notas \& hucusque incognitas in unum collectas, magis in ufum Tuum, B. L. illuftratas defcriptasque ederem.

\section{S. III.}

\section{CHARACTER GENERICUS.}

Flores dioici, collecti intra frobilum.

Strobilus ovatus vel oblongus, multiflorus.

CaL. 6-glumis compresfus, fubæqualis, raro valde inæqualis, glaber, uniflorus. Glumx exteriores obverfæ, naviculares; interiores lanceolatæ, tenuiores.

Corolla nulla, nifi glumæ tres interiores.

Stam. Filamienta tria.

Antbere oblongz. 


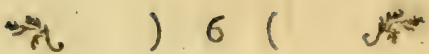

Pist. Germen fuperum.

Stylus I plerumque, rarius duplex, rarisfime triplex.

Stigma raro fimplex, fxpisfime duo, rariffme tria, plumola.

Peric. Semen obfcurum.

Affinis nimis Schœno, led femper dioicus \& habitu diverfo.

Variant nonnihil partes fruEtificationis ut CALYX, qui compresfus \& fubrqualis in cermus, umbellato, arifato, fpicigero of, erecto fi, acuminato $\delta$, parvifloro of, argenteo of, verticillari, digitato, dichotomo, triticee, virgato, paniculato, thannochorto; compresfus \& inæqualis in imbricato, fcariofo, spicigero $?$, tetragono.

STYLUs, qui unicus in R. imbricato, trifloro, Spicigero, arifato, Jcariofo; duplex in verticillari, tri. ticeo; triplex in verticillari.

Præterea nonnullæ fpecies variant CaLYCE æquali \& inæquali, in diverfo $\int e x u$, ut fpicigerus $\delta$ \& $?$. Stylis \& Stigmatibus duobus vel tribus ut werticillaris.

$$
\text { §. IV. }
$$

DIVISIO SPECIERUM.

* culmo fimplici.

a culmo aphyllo.

imbricatus. I. R. culmo fimplici aphyllo, fpica oblonga compresfa. 
औ ) $7($ )

vaginatzis. 2.R. culmo fimplici aphyllo, fpicis alter nis erettis, fquamis acuminatis.

ariftatus. 3.R. culmo fimplici aphylio, fpicis terminalibus obovatis erectis, fquamis ariftatis.

cernutis. 4. R. culmo fimplici aphyllo, fpicis turbinatis pendulis, fquamis obtufis cum acumine.

ambellatus. 5. R. culmo fimplici aphyllo, fpicis um-。 bellatis ovatis, fquamis oblongis obtufis.

fpicigerus. 6. R. culmo fimplici aphyllo, fpicis oblongis hexagonis, fquamis lanceolatis apice patulis.

tétorusn. 7. R. cuimo fimplici aphyllo, fpicis racemofis fubfecundis, fquamis furcis nitidis.

acuininatus. 8.R. culmo fimplici aphyllo, panicula erecta, fquamis ariftatis.

parviflorus. 9. R. culmo fimplici aphyllo, panicula erecta, fquamis rotundacis membra naceis.

erectus. IO. R. culmo fimplici aphyllo, panicula erecta involucrata, fpathis imbricatis Ianceolatis.

argenteus, II. R. culmo fimplici aphyllo, panicula ereeta, fquamis lanceolatis feariofis. b. culmo foliofo.

fcariofus. I2. R. culmo fimplici foliofo, fpicarunt fquamis lanceolatis fcariofis. 


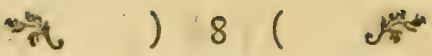

thamnocbortus. I3. R. culmo fimplici foliofo, panicula patenti, fquamis lanceolatis margine fcariofis.

fruticofus. r4. R. culino fimplici foliofo, panicula compolita, fquamis f́cariotis laceris.

fimplex. 15. R. culmo fimplici fubfoliofo, fpicis a!ternis fubagregatis, fquamis ovatis. triflorus. I6. R. culmo timpli it foliofo, fpicis alternis fesfilibus.

** culmo ramefo.

a culmo aphyllo.

tetragonus. I7. R. culmo ramisque tetragonis, Ipicis alternis.

triticeus. I8. R. culmo dichotomo aphyllo ereeto, ramis teretibus, fpicis alternis.

glomeratus.19.R. culmo dichocomo aphyllo lavi, panicula glomerata.

incurvatus. 20.R. culmo dichotomo aphyllo Atricto, fpicis imbricato aggregatis.

digitatus. 2I. R. culmo dichoromo aphyllo, ramis teretibus, fpicis ternis oblongis.

verticillaris 22.R. ramis verticillatis, panicula compofita.

b. culmo foliofo.

Scopr. 23. R. culmo dichotomo foliofo, ramis compresfis, paniculæ lpicis glomeratis. virgatus. 24. R. culmo dichotomo foliolo, ramis compre fis, fpicis paniculatis pendulis. pariculatur.25. R. culmo dichotomo foliofo, ramis com. 


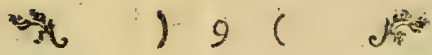

paniculatus.25. R. culmo dichotomo folio?o, ramis compresfis, , picis fesfilibus alternis ereckis. dicbotomus. 26 . R. culmo dichotomo foliofo decumben. te, ramis teretibus, fpicis folitariis alternisque.

\section{§. $\mathrm{V}$. \\ DESCRIPTIO SPECIERUM.}

Radix perennis.

Culmus fimplex vel ramolus, frpe dichotomus, aphyllus vel foliofus; femper articulatus, vaginacus ftipulis membranaceis; teres, rarius femiteres, rarisfime angulatus,

Rami frepins dichotomi, rarius verticillati。

Folis letacea, dichotome ramofa.

I. R. Imbricatus: Culmus teres, fimplex, aphyllus, articulatus, erectus, bipedalis \& ultra.

Fola nulla; fed fipula juxia articulos convolutx, vaginantes.

Spica fimplex, terminalis, ovato-oblonga, compresfa, brunnea, glabra, ereßa, pollicaris.

squanu imbricatx apice patulo, oblongx, acutæ, concavæ, glabræ, imprimis verfus apio cem brunnex.

Caly $x$ compresfus, inæqualis, 6-glumis: glet. mæ duæ anteriores naviculares, obveræ, ma. jores; quatuor inceriores lanceolati.

Stylus unicus.

Stigmata duo, clavata, plumola.

Facile dignofcitur fpica terninali folitaria. 


\section{एक $10($ )}

2. R. Vagnantus: Culmus \& Stipule omnino ut in

R. imbricato.

Spice alternæ, fubfesfiles in rachide flexuo. fa, oblonga, erestx, tres vel quatuor.

Squans imbricate apice patulo, concavx,

- ovatæ, acuminatx, glabrx, brunnex, margine membranaceo pallidiore lacero.

Spicas ante explicationem florum tantum, nec flores vidi.

Aliqua hujus fimilitudo quidem eft cum Reftione diltachyo D. Retroóllir; at revera diftinctus, ob fpicas plures \& fquamas fpicarum lato-ovatas, concavas, acuminatas, læves, laceras.

3. R. Aristatus: Culmus ut in R. cernuo.

Spice terminales, erectr; folitarix vel dua approximatæ, turbinatæ, usque quinque, oblongx.

Squamce denle imbricatæ, ovatæ, concavæ, fetaceo - ariftatæ, glabræ, brunnex.

Calyx 6.glumis: glumæ xquales, obovatæ feu inferne attenuatæ, acutæ, ferruginex, ung. viculares.

Filamenta capillaria, alba, longitudine corollæ. Antherce lineares fulcz, flavo-ftriatx.

fo Stylus unicus, brevis.

Stigmate duo, plumofa, patentia.

4. R. Cennurs: Culmus fimplex, filiformis, articulatus, glaber, erectus, bipedalis \& ultra.

Folia nulla; fed in articulis vaginæ oblongx, obtufie. 


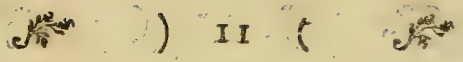

Spicce tres, quatuor vel quinque, pedun. culatæ, turbinatæ, obtufæ, cernuæ, magnitu. dine pifi.

Peaunculi capillares.

Strobili Squame imbricata, rotundatx, obtufr cum acumine, brumner, glabræ.

Calyx fubrqualis, compreffus, 6 .glumis: glumæ lanceolatæ, acutæ, glabræ.

Filamenta tria, brevifima.

Antbers lineares, flavi.

Flores femineos non vidi.

5. R. Umbellatus: Culmus ut in R. cernuo, bipeda. lis \& ultra.

Spice tres vel plures, umbellatæ umbella fimplici vel compofita, obovatæ, obtulæ, patentes, pifo majores.

Pedunculi capillares.

Squame fexfariam imbricatæ, concavæ, oblongæ, obtulæ, brunnęæ margine pallidiore, glabra.

Calyx \& Stamina omnino ut in R. cernuo.

Differt a $\mathbb{R}$. cernuo, cui valde fimilis.

I: Spicis pluribus, umbellatis, ovatis.

2:0 Sqvamis fpicarum oblongis, obtufis.

6. R. Spicigerus: Culmus fimplex, teres, fruticefcers, aphyllus, articulatus, glaber, ereetus, bipedalis \& ultra.

Folia nulla; fed in fingulo articulo ftipula vaginans, pollicaris.

d. Sprce umbellatx a medio fere culmo ad a. $\mathrm{B} 2$

picem, 


\section{) $12 \mathrm{C}$}

picon; unbellæ fubpaniculatæ, patenti cernu$\mathfrak{x}$, plurinx, oblongx, fubcylindrica, hexagonæ, erectæ, fubpollicares.

Squance fexfariam imbricatæ, apice patulo, lanceolatæ, acuminatæ, concavæ, fubcarinatæ, brunnex, glabræ.

Peduraculi trigoni, glabri, lati, flexi.

Caly» compresfus, inæqualis: glumæ binæ majores, obverfx, naviculares, ovato-lanceolatæ, fquamis breviores; quatuor interiores ovatæ, minores.

Obf. Spica hujus fpeciei inftar amenti oblongi eft: Mas 1picis paniculatis, effufis, minoribus. Fernina fpicis racemofis majoribus.

Stylus unicus.

Stigna fimplex, plumofum.

Filamenta brevisfima.

Antbere oblongx, longitudine calycis.

?. Spica a medio culmo ad apicem racemofre, erectx, oblongæ, obtufæ, breves, glabræ, fubhexagonæ, craffitie fere digiti, ungviculares usque pollicares.

Squalhe fexfariam imbricatæ, lato-Ianceolatæ apice acuto patulo, concavæ, fubcarinatæ, brunneæ, glabræ.

Pedunculi trigoni, Aricti, glabri.

Calyx inæqualis, compresfus, concavus, 6 glumis: glumæ duæ exteriores naviculares, obverfæ, majores; interiores quatuor lanceolate, minores. 


\section{- ) $13($ )}

7. R. TECTORUM: Culmi e radice plures, fimplices, aphylli, filiformes, fubcompresfi, glabri, laves, erecti, articulati, tripedales vel ultra.

Vagine articulorum nigræ, acutæ, glabræ, decidux.

Spice fubpaniculatæ, adpreffæ, plurimæ in fummitate culmi.

Spicule pedicellatæ, glomeratæ, fubfecundæ, trigonæ, acutæ.

Squame trifariam imbricatx, concavx, ovato-lanceolatæ, acutæ, nitidæ, exteriores nigræ, interiores brunnex.

8. R, Acuminatus: Culmus ut in plurimis præedentibus.

Spicx fubpaniculatx, erectx, ovatx, braEteatx.

Pedunculi ex articulo fingulo tres vel plures inæquales.

Bractece fub fingulo flore ovatx, acumina: to - ariftatæ, glabræ, brunnex.

Calyx 6-glumis, xqualis: glumæ concavæ, ovatæ, obtufx, glabræ, minimæ.

Filamenta brevisfima.

Anthere ovatx, fulcx.

Feminam non vidi.

9. R. Parviflorus: Culmus ut in præcedentibus plurimis.

Panicula terminales, aggregatæ.

$$
\text { B } 3
$$




\section{些 ) $14(2)$}

Spice ovatx, obtulix, ereetx, ftrobilifurmes; fquamæ rotundatæ, concavæ, margine membranaceæ.

Calyx 6-glumis, fubæqualis: glumæ ob. longr, interiores albidæ, exteriores brunnex, minimæ.

Filamenta brevisfima.

Antberce ovatx, exlertæ, didymæ, ferruginex, flavo - Atriatæ.

Feminam non vidi.

IO. R. Erectus: Culmils ut in R. cernuo \& plurimis præcedentibus.

Panicula alternæ, tres vel quatuor, erectx, effulæ.

Bractea in bafi finguli pedunculi \& pedicelli compresfa, lanceolata, convoluta, acuta; glabra, parva.

c. Calyx 6-glumis: glumæ xquales, lanceola. latæ, glabræ.

Filismeata breviffima.

Antbere oblongx.

Ferminleos flores non vidi.

a I. R. Argenteus: Culmus ut in plurimis præcedentibus.

Spice racemofo-paniculatx, feu e gemmis racemi plures inæquales, fpiculis fubfeffilibus, ovatis, erectis, ftrobiliformibus.

Sjuame imbricatæ, totæ fcariofx, argenteonitentes, lanceolatæ, acuminatæ.

A. Cslyx 6 -glumis, æqualis: glumæ lanceolatæ, acuminatæ, concavæ, glabræ. 


\section{紋 ) $15($ 弮}

Feninam non vidi.

12. R. SCARIOSUS: Culmus teres, fimplex, tenuifime villofus, foliofus, fruticefcens, ereetus, pedalis \& ultra.

Folia e vaginis plura, dichotome ramofa; laciniæ paniculatæ, filiformi-capillacex, ftipulate ftipulis laceris argenteis.

Flortum fpicx in mare paniculatx, effufe, oblongx; in femina racemofx \& fubfeffiles, ovata.

Sqvame imbricatæ, lanceolatx, totæ fcariofx carina obfcuriore, argentex, ungviculares.

Calyx compresfus, inæqualis, $6 \cdot$ glumis: glumix duæ exteriores majores, naviculares, compreffx, obverfi, acutx, margine membranacex; interiores quatuor lanceolatæ. obf. Calyx feminini floris duplo latior. Stylys unicus.

Stigma fimplex, plumofum.

3. R. Thamnochortus: Culmus bafi decumbens, radicans, fquamatus, culmos plures edens teretes, glabros, ereetos, foliofos, pedales \& ultra。 Folia per culmum totum fparfa, e vaginis alterna, dichotome ramofa laciniis fubulatis, ftipulata ftipulis argenteis, patentia.

Panicuia terminalis, patens in mare (in femina (picx racemofx videntur) e (picis ovatis, ferrugineis.

Squame imbricatx, lanceolatæ, acuminatæ, ferruginex margine argenteo fcariofo, glabræ. 


\section{औ) $16($ )}

5. Calyx 6-glumis, parum compresfus, fubxqualis: glumx lanceolatx; exteriores dux paulo longiores, obverla.

9. Calyx compresfus, latior.

I4. R. Fruticosus: Culinus bafi fquamolus, teres, vaginatus, fruticefcens, glaber, erectus, fimplex feu fuperne paniculatus, tripedalis \& ultra.

Vagine alternæ, fetaceo - acuminatæ, lacera, fulcx.

Folia heic, ut in R. thamnochorto, fed ma. gis protraeta \& elongata.

Flores a medio culmo ad apicem paniculati. Pedun:uli communes compreffi, glabri, inxquales.

Bractece fingुulos flores veftientes acuminatx, fcariolx, laceræ.

Flores explicatos non vidi, fic ut partes fru. Etificati nis examinare non licuerit

Differt a R. thamnochorto, quod ftrobilus heic nullus.

I5. R. Simplex: Culmi e radice plurimi, filiformes, articulati, fimplices, tenuiffime ftriati, erecti, bipedales.

Foliola in culmo rariffima, Pparla.

Spice alternæ, folitariæ \& aggregatæ, bieviter pedunculatæ.

Squalna ovatæ, concavæ, fub apice carinatæ, acuminatæ, glabræ.

16. R. 'TRIFLoRus: culini e radice cæípitofa plures, filiformes, lati glabri, fimplices, ereeti, peda. les \& paulo ultra. 


\section{y.) $17($ 器}

Folia plurima radicalia, pauciora in culmo, filiformia vel capillaria, articulata, vaginata, dichotome fed rariffime divifa, ereeta, culmum fubæquantia.

Spice terminales, feffiles, alternæ, plerumque tres, rarius plures, ovatæ.

Squanc imbricatæ, acutæ, brunnex margine membranaceo.

Flores non vidi.

Diveríus cerce a R. fimplici Forfteri.

I7. R. Tetragonus: Culimzls fruticefcens, tetragonus angulis acutis, aphyllus, glaber, erectus, bipedalis \& ultra.

Rami alterni, pauci, floriferi, aphylli, eredt. Tagine articulorum oblonga, acutz, membranacex.

Spica in ramis \& ramulis alternæ, feffiles vel terminales, ovatæ, acutæ.

Squame imbricatæ, ovatæ, acutæ, glabræ, brunnex, margine pallidiore.

Calyx 6-glumis: glume lanceolatx, exteriores duæ obverfæ, majores lanceolatæ, carina ciliatæ; interiores tenuiffimæ, minores.

Filanenta breviffima.

Anthere oblongx.

18. R. Triticeus: Calvizs trichotomus \& dichntomus, erefus teres, glaber, papilofus punctis albis parum fcabris, bipedalis \& ultra.

Rami fliformes, culno fimiles.

Vagince ramificationum ovatx, obtufx cum acumine, fufce. . C C Spice 


\section{") ) 18 (}

Spice alterna, circiter quinque, ovatx. Squanhe imbricatx, oyatr, concavæ, acutæ, uniforæ, glabræ.

Calyx fubrqualis, 6-glumis: glumæ exteriores parum majores obverfx, lanceolatx; in. teriores paulo anguftiores, albidæ.

Siyli ano, Cerecei, villofi, longitudine calycis. Filowenta tria, copillaria, albida, longit.calycis. Antbere oblongx, didymæ.

19. R. Glomeratus: Culmus teres, lavis, dichotomus, ereetus, pedalis \& ultra.

Ranni fimiles.

Flores terminales, paniculati fpicis glomeratis. Squame ovate, acuminatx, flavelcentes, flufco-irrorate, glabræ.

Flo-es non vidi.

20. R. Incurvatus: Culmuls teres, frutefoens, dichotomus, feriatus, glaber, bipedalis \& ulera. Rami alcerni, fimiles, recurvi.

Vaginze ovatx, acuminatæ.

Spice in ultimis ramis aggregate, fefiles, imbricatz.

Syunise ovate, acuminatr, glabræ.

Flores non vidi。

2I. R. Digitatus: Culmizs dichotomus, eregters, glaber, pedalis \& ultra.

Rawii compreffi, geniculati, dichotomi, glabri, faftigiati.

Vaginia ramificationum lanceolatx, glabra.

Spice circiter tres, terminales, oblongr, ferruginex, ungviculares. 


\section{यै ). $19($ )}

Squarn e laxe imbricatæ, fubinflato-concavæ, ovatæ.

¿. Calyx nullus nifi fquamulx minutiffm $x$, tenuiffimæ, albidx intra fquamam fingulam fpicx. Filamenta tria, brevia.

Antherce ovate.

22. R. Verticillaris: Cqinilzs frutefcens, teres, articulatus, lavis, glaber, creeus, craffitie calami, orgyalis.

Ram verticillati, plurimi, filiformes fimplices \& dichotomi articulati, glabri, ereeti, internodiis pluries longiores.

Fola nulla, fed vaginx fub verticillis \& in arciculis, felfiles, ovaræ, coriacex, glabræ, decidux, fenfim minores in ramis.

Panicula compofita, patens, fpicis in ultimis ramificationibus flexuofis feffilibus ovatis minutis.

Squama ovatx. obtufx, margine membranaceæ, glabræ, ferruginex.

Calyx 6 -glumis, xqualis: glumæ lanceolatx. Filomenta tria, brevifima.

Antberce ovatx.

Styli duo, \& tres. Stigmata duo vel tria villofa, fetacea.

23. R. Scopa: Culmus ut in R. paniculato.

Rami terminati in folia fetacea, fufci.

Folia in ramis fparfa eosque terminantia, comprefla, fetacea, erecta, fufca, faftigiata.

Flores in ramulis paniculatis glomerati.

Squance ovatz, concave, acuminato-arifta- 


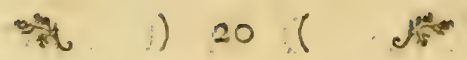

tæ, Aivefcentes, fufco irroratæ, imbricatæ, interiores fenfim minores.

Partes jonis \& frubifrationis non vidi.

24. R. Virgatus: Culwizs frutelcens, glaber, eredus, trichotomus \& dichotomus, bipedalis, \& u'tra.

Ram compreffi vel femiteretes, dichotomi, terminati in folia, erecti, faftigiati.

Vagince ramorum \& ramulorum oblonga, acuminate.

Fo! a in ultimis ramulis, filiformi fetncea,

Flomm fpica paniculata panicula patenti, acutæ.

Squnme imbricatx, ovatx, obtufx, brun. nex, glabrx, laceræ.

Calyx 6 -glumis: glume exteriores obverfa, lanceolatx, parum majores; inceriores quatuor tenuifimx, pellucidix.

Filamenta brevirima.

Anthere ovata, brunnex, lnteo-ftriatx.

25. R. Paviculares: Culmas ue in R. Virgato.

Rrmi dichotomi, compreffi feu femiteretcs, virgato - paniculati, glabri.

Folia in ramis dichotome ramola, fetacea, curvata, vaginis membranaceis bafi cincta.

Spice in ramorum apicibus dichotomis fes. files \& alternx, ovatx, ereetx.

Squaza imbricatx, ovatx, vir acutr, concavæ ferrugineæ margine albo membranaceo. 1. Calyx 6-glumis: glumæ ut in R. Virgato. Differt a $R$. virgato: foliis capillaceis curvatis. Spicis fefilibus alcernis erectis, Jquamis obtufis. 26. $R$. 


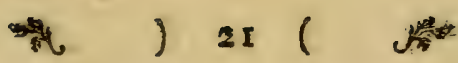

26. R. Dichotomus: Culmus teres, decumbens, Alexuofo-erectus, glaber, papillofus, dichotomus. Rami filiformes, dichotomi, fubfaltigiati, papillofi, culmo fimiles.

Vagine ramificationum ovatæ, acutæ.

Folia in ramis parfa, dichotome ramofa, filiformi - fubulata, curvata.

Spica in apicibus ramulorum alternæ, folitarix usque quinque, oblongx, glabræ, erectx.

Squarica imbricatx, oblongx, acutx, concavx. $\hat{\imath}$. Calyx 6-glumis: glumæ Iubæquales, lanceolatx; exteriores duæ obverfx, parum majores; interiores tenuiores.

Filamenta tria, calyce breviora.

Antberce ovatx, fulcx.

Variat: Culmo magis vel minus decumbente, Ramis filiformibus vel capillaribus. Spicis folitariis vel pluribus alternis.

\section{§. VI. \\ SYNONYMA.}

2. cernutus. Linn. Syft. Veg. XIV. p. 882.

ectorzm. Chondropetalum deuftum. Rottb. p. Iо. tab. 3. fig. 2. Reftio tectorum. Linn. Supl, Syft. p. 425. Syft. Veg. XIX. p. 882.

cuminatus. Chondropetalum nudum. Rottb. Gram. p. II. tab. 3. fig. 32 .

cariofus. Thamnochortus fruticolus. Berg. Plank. capenf. p. 353. tab. 5. f. 8. bamnocbortus. Reftio dichotomus. Rottb.Gram. p. 2. tab. i. fig. I. $\hat{\delta}^{\circ}, \mathrm{C}_{3}$ 


\section{* $)=2($}

trifloris. Rottb. Gram. p. 3. tab. 2. fig. 2. \$. triticeus. Rottb. Gram. p. 7. tab. 3. fig. I. verticillaris. Linn. Sylt. Veg. XIV. p. $88 \mathrm{r}$. virgatus. Rottb. Gram. p. 5. tab. I. fig. 2. 2 . paniculatus. Rottb. Gram. p. 4. tab. 2. fig. 3. Linn. Syft. Veg. XIV. p. $88 \mathrm{I}$.

sicbotomas. Schœnus capenfis. Linn. Spec. Pl. p. 64. Reftio dichotomus. Linn. Syft. Veg. XIV.p. 88 I. Reftio vimineus. Rottb. Gram.p. 4. tab.2. fig. r. Incolis Europæis: Beefem riet. Lat. gramen fcopx. §. VII.

Omnes in promontorio bonæ fpei, (unica fpecie, R. fimplici, excepta, a Pr. Forstero inventa in nova Zelandia), crefcunt fpecies Reftionis, vulgatiffimæ in dunis, imprimis copiofe in campo illo arenofo vaftisfi. mo, qui littora maris a proxima ferie montium transverfa difcernit. Nonnullæe quoque fumma ca. cumina montium inhabitare amant. Sic crefcit

cerrinus

feariofus

dicboromzus

triticeus tectortinn $\}$

\}

in collibus \& lateribus montis Taffelberg.

dìisiatutus in montibus Hote. Holland.

verticillaris juxta margines rivulorum infra winterhel: in Roode fand, in Arraquas Krloof \& alibi.

$$
\text { U. VIII. }
$$

Arenofa loca tegunt plurimæ $f_{\text {pecies }}$ frutefcentes \& ani. malibus refugia conciliant.

R. tectorum domibus obregendis optime infervit, a vehe. mentiffinis regionis ventibus \& procellis non movendus, Culmi rigidi, frutefcentes Pecoribus non appetuntur, 



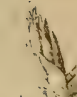

(1) (4)

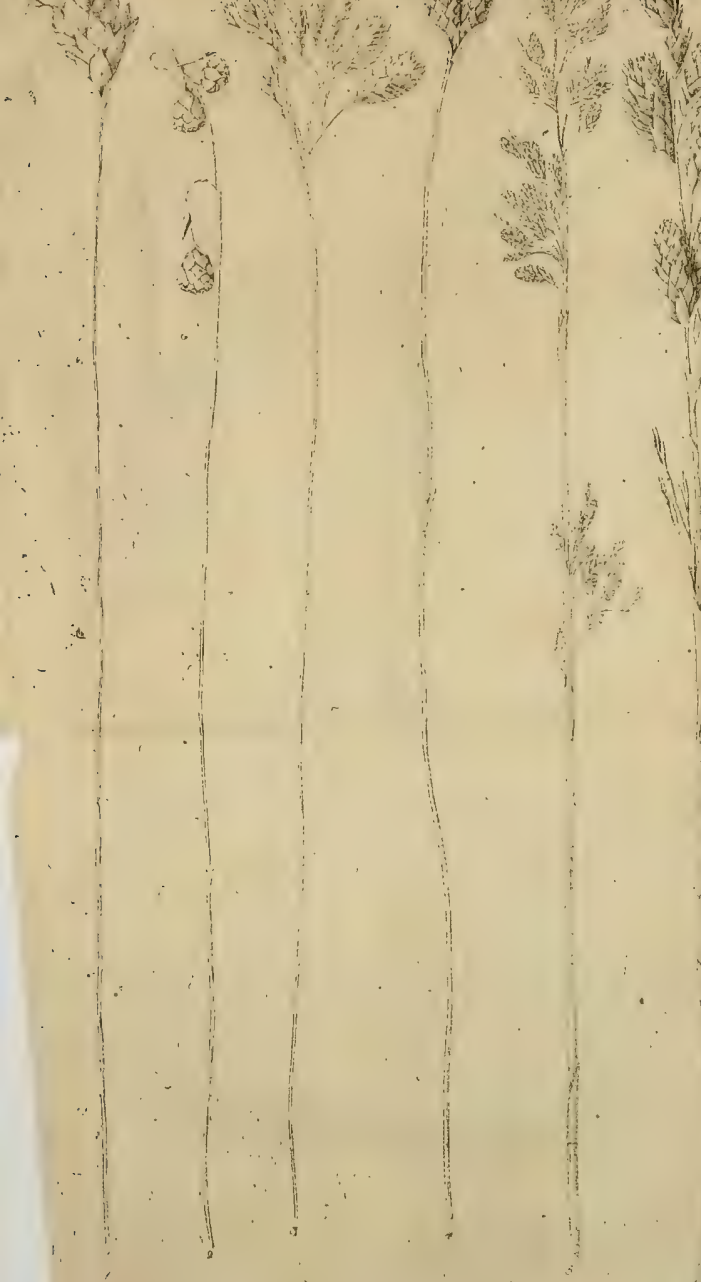

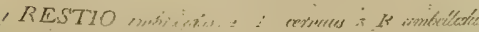

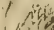

5.

this

$1+2$

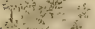

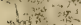

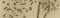

14

it

. $\mathrm{x} \cdots$

if

xis

is:

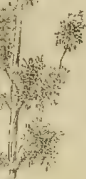

if $\quad+1$

i) $-\sqrt{1}$

a

(P) : il

, iv) $\mathrm{Nil}$

1) 11 in

$11 \%$

win,$\cdots$

(f)

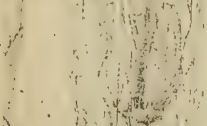

$\therefore \cdot 1+x^{3}$

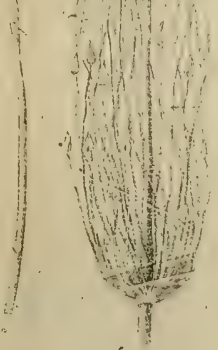

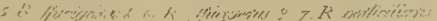





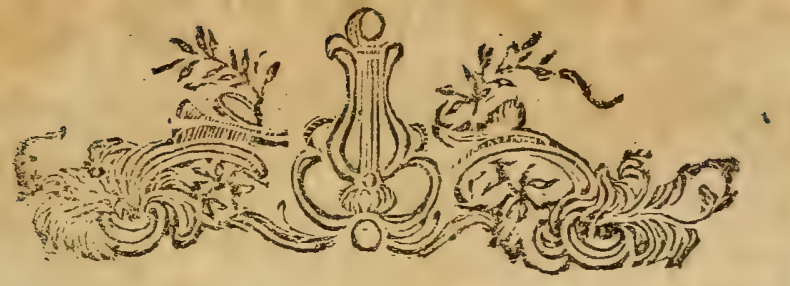

\section{5. $x$.}

enena, qux corpus humanum vel vehementer corrodendo deftruunt, vel fxpe ocisfime fcintilam vitalem exfingvunt, plura occurrunt in tribus naturæ regnis. Ex regno lapideo talia funt arfenicum, varia præparata mercurialia \& antimonialia, atque acida fortiora mineralia. In regno animali, tremenda velocitate, venenum ferpentum fangvine vivo nixtum, fymptomata lethalia excitare folet. Uti vegetabilia inter, plura reperiuntur falutaria remedia, ta \& longe plura obveniunt periculofa venena, quorum alia corrofiva inflammant, alia fangvinem \& humores corripiunt \& corrumpunt, alia fyftema nervo. um turbant, arque mora plus vel minus protracta andem mortem inferunt, ut Curara ad fumen Orenoque, Voorara prope fluvium amazonum, Cejûrum, Rkus \& plura alia.

Hæc inter venena, \& quidem fortiora, numecandum omnino eft illud venenum Indicum, quod ex 


\section{$w_{0} \quad(2)$}

ignota hactenus arbore Boa upas fumma adhibita prudencia defumitur, \& de cujus viribus atque ufu varia tam vera, quam fuperftitiofa $\&$ incredibilia, rque antiquitus ac nuper nobis fuerunt relata. De Hocce veneno teftatur Rumphins, fe non invenisfe aliud horribilius vel deteftabilius ab ullo productum vegetabili. Et addit quod hoc ven=num, quo gloriantur ipfi Indi, olim longe magis timuerint milites Belgarum, quam quidem tormenta bellica. Vide Rumph. Herb. ams. T. 2. p. 263.

\section{\$. 2.}

Arbor hac venenata, Botanicorum hucusque examini fefe fubduxit, vero tamen fimile riobis videtur, e jusdem esfe ordinis naturalis cum Ceftro ejusque cognatis, fi non omnino Ceftri generis *) ac ejusdem esfe generis arborem illam, quæ eodem nomine donata crefcit in Java *) \& pluribus aliis Indize calidioris orientalis locis.

Belgis indiam orientalem incolentibus dicitur Gifi boom vel Macasfarfche Giftboom \& nonnullis Spatteriboom. Rum.

*) Ejusmodi fpacies Cestri crefcit in Capire bonæ Spai, tam venenare inciolis, ut dum hujus fucclim cum vene. no Colubrino Hotrentorti mifcent, ambo hæc venena jundta longe vehementius aganr, quam quodque eorum feparatim: ex narrarione Celeb. D. Præe.

*) Bohon Repas appellatur quidem in Veckn/kriften for Lekkure ocb Naiurforkare Tol. s, p, 2 10, fed Celeb. D. Prefes fibi perfvader, rectius dicendam esfe Bon upas; Bon enim fignificat arborem \& upas venenum. 


\section{की}

Rumpbio: Arbor ioxicaria in Herb. amb. T. 2 p. 263. tab. 87 .

Macasfarienfibus \& Celebenfitus: Joo, \& dum duas diftingvunt diverfas arbores, foeminam Ipeciatim appellant Paccarre Sama Fang, atque marem $U$ pas radja.

Malaijenfibus: Cajo upas feu Boa upas, fœminam fpeciatim Maccan Cavul, atque marem Djato matti. Malaccenfibus: Lupo Matta Fu.

Duæ fpecies defcribuntur a Rumphio quarum alteram feminam, alteram marem appellat, an vere diftinctx fint, a brevi ejus defcriptione determinari non poteft.

Arbor eft caudice crasfo, ramisque patentibus; cortice rugofo, rimolo, cinereo-fusco; ligno albo-flavefcenti, folido nigrisque maculis variegato.

Folia fparfa. fubfesfilia, oblonga, acuta, integra, parallelo-nervofa, fupra rugofa, fubtus lanuginofa, duas pollices lata, fpithamæa.

Flores \& Fructus ignoti.

Altera arbor, mas dicta defcribitur, trunco altiori, coma anguftiori, foliis minoribus, \& mollibus ceterum omnino fimilis.

\section{\$, 3.}

Crescir venenatisfima arbor in variis Indix orien. talis calidioris locis, præcipue infulis: Java, Sumatra, Borneo, Baleija \& Macasfaria prope Miarus juxta Sudijon, atque proprie in Celebi juxta Toradios. Amat deferta loca \& nudos montes, e longinquo facile dig- 


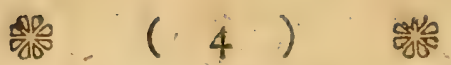

nofcenda eo, quod nullæ alix illi adftent arbores, quodque terra ipfa fuppofita fterilis fit, atque ficut exuifta.

\section{4 .}

Succus arboris, cui omnis deleteria vis inet, brunneo-ater, in refinam exficcatur. que in mare fic dißto femper eft durior magisque nigra, fere inftar picis, ac ignis calore liquefcit.

Collectio fucci refinofi fumma fier prudentia, ne vitx incurrat periculum eum collecturus. Sollicite igitur linteis obvelanda funt caput, manus \& pedes, ur defendetur tocum corpus non minus ab halitu alboris quam Atillicidio ejus. Nemo tam prope hanc arborem accedere audet, ut fuccum ejus manibus abripiat; ut itaque fuccus excipiatur, longæ arundines Bambu, fuperius acuminatx infar haftæ jaculatorix, fumma vi oblique cortici trunci intruduntur, ut in illis exfillet fuccus fangvineus, qui brevi poft condenfatur \& indurefcit, obfcure rufescens vel nigricans. Quo propius radicem arbor vulneratur, eo efficacius venenum. Interdum plures, usque viginti ejusmodi arundines arbori infixa relinquantur per tres vel quatvor dies, ut fuccus in cavo earum colligatur \& concrefcat. Supremus articulus arundinum tunc repletur fucco, reliqua pars amputatur.

Succus adhuc recens in baculos vel globulos efformatur \& in arundinum cavis fervatur, dein loco mediocriter calido linteoque fre decies obvoluto confervantur hi globuli, omni feptimana optime de- 


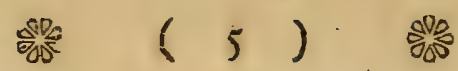

tergendi ac mundandi, ne mucore obducantur, vel exhalando nimium fua de virtute perdant, quæ intra annum mitigatur, intra paucos annos fxpe omnino perit.

\section{S. 5 .}

Maxime horrenda eft hujus arboris vis venenata. Ex bulitu arboris mox perfentiuntur omnes artus quafi congelati nec non !pasmodice affecti. Nemo igitur ad arborem accedere audet, nifi yeftimentis bene obvolutis prius brachiis, pedibus, humeris \& capite. Si quis capite denudato fub hac arbore ftare tentat, capillorum profuvium inde patitur, \& ex ftillicidio arboris in corpus depluente, magnopere intumefcit, quod etjam fit ex arbore Rhois toxicodendri. Aer circa hanc arborem adeo eft infeetus, ut aves ipfus ramis infidentes, mortui decidant; cuncta iraque animalia, qux haliru ejus tacta perirent, follicite hanc arborem evitant, inmo aves illam facile non transvolant. Asfeverat Rumphius, ramos decerptos in magna arundine Bambu tam efficaces ac caufticos fibi fuisfe transmisfos, ut fi manus arundini imponerentur, mox ticillarent, eodem fere modo, quo artus congelati, fi foveantur. Pro certo quoque venditacur, fub hac arbore nullas plantas, frutices, vel gramina crefcere in tota ejus peripheria, immo ne quidem ad lapidis jactum, terramque fub illa fterilem, fuscam \& quafi exuftam esfe.

Halitus igitur arboris vivi imprimis \& fuccus recens maxima pollet vi toxica quæ fuccesfu temoo. is fenfim magis magisque debilitatur tandemque perit. 


\section{की}

Feminæ venenum longe infirmius eft, nec facile fua fponte lethale, quam ob rem ad capturam ferarum plerumque adhiberi folet, nec ad inficienda teia bellica, nifi altero fortiori mixtum, dum utriusque vires attgeri creduntur.

Venenum telis illinitum in corpore vulnerato per omnina, fefe mox diffundit, ita ut vehernentem excitet xitum fimulque gravem vertiginem, cui frpe mors fubfequitur *) Tela venenata duos per annos vires confervant, licet interdum intra unius vel paucarum menfum fpatium vim fuam amittunt. Prudentia quoque oblervata toxicum hocce innocue traetari poteft, modo vivum non tangat fangvinem, immo Celebis incolx illud pro remedio interno ex teftimonio Celeb. Rumphii ingerere audent. "*).

Vires toxici explorantur certo quodam experimento, fcilicet contunditur radix Lampujang dicta feu

Amo-

*) Ex arbore venenata Javx fymptomata fuerunt fe. quentia: poft. 5 min. ab inflicto vulnere rremor artumm fubfultu tendinum conjunctus, intra 16 minut. mors furnma cum anxietate. Corpus demortuorum contaminatum poft aliquot horas obfervabatur maculis perechialibus, facies tumida ac plumbea, oculorum albuginea Hava.

**) Hoc qvidem repugnat narrationi de hujus vene. nivi ribus communicata in Veckolkriften for Lákare ocb $\mathrm{Na}$. tuirforfkare $\mathrm{Vol} 5$, p. 226, cum vero hæc narratio omnium aliorum narrationibus fit contraria, dubiam illam re. fpicere licebit \& ab ulterius inftituendis experimentis confirmandam. 


\section{䠰 (7)}

Amomum Zerumbet, donec mucilaginofa fit, poftea exprimitur \& transcolatur fuccus per linteum, cum parva aqux portione infunditur venenique portiuncula mifcetur. E fubita, fub hac nixtura, ebullitione fuborta ejusque vehementia, de viribus judicium ferune periti. Hac fermentatio adeo erit fæpe vehemens, ut in medio magna formetur fovea, fundusque vafis in confpedtum veniat. Operatio hæcce nulli nocere dicitur, nifi quod tantum ardorem internum percipiat experimentator; vires enim venenum inspisfa. tum non adeo vehementes halitu fuo excercet, nifi adtingat fangvinem fuccoque Zerumbet acutum in actionem deducitur.

Venenum hocce deleterium intra dimidium horæ, immo fape intra quadrantem horæ, infert mortem, prægresfo motu convulfivo ac delirio, fic ut raro antidota in auxilium vocari posfint. Macasfarienfium Reges, veneni deleteriam vim exploraturi, plura inftituerunt experimenta in morte damnatos, ut fcirent, an ulla a morte redemtio, fed fruftra tentarunt: telis veneno hoc infectis pollicem manus vel pedis vulnerarunt, articulum affeetum mox amputarunt abs. que ullo felici fuccesfu.

Auetor narrationis de Iavanica arbore venenata asleverat etjam fontes hocce veneno infici posfe lethalesque reddi, \& multos hoc Belgas in ultimo abillis cum Javanis gefto bello interiisfe. Sed de huius fide fufpendere judicium confultum erit, donec certius fit exploratum, an fuccus arboris fit gummi-refi- 


\section{कै: (8) :}

na, adeoque portionem qvanảam aqua dislolvi posfe. Experimenta vero tam ab Auctore ipto facta, quam alix circumftantix evincunt, fuccum non esfe mere gummofum, quia (piritu Arrak folvatur.

$$
\text { S. } 6 .
$$

Ujus fortisfimi veneni ad puniendos morte dam. natos nec non ad inficienda tela bellica apud varias nationes Indicas obtinet quidem inprimis. fed quod maxime mirum occurrit. toxicum hoc crudum. nec commixtum, falubre habetur antiảotum tam externe quam interne ufitatum contra letus venenacorum pifcium ac fcolopendrarum, fi emplaftri forma vulneri applicetur; tefte Rumphio, citius dolorem fedat, venenumque melius extrahit quam aliud remedium. Si quis ulcerationibus fcabieque laborans, pilulam refinæ cum Mufæ fruktus carne commixtæ asfumat, om. ni inteftinorum impuritate liberari dicitur, ut videre licet Rumph. Herb. Amb. T. 2 p. 269. Venenum quoque debilius f́ilicet ea ratione prxparari potent, qua fera animalia, præcipue Cervi, enecari posfunt, illorumque caro absque ulla noxa comedi.

\section{\$. 7 .}

Belgx incolis illis Indicis, qui veneno $U$ pas rela fua inficere folent, bella gerentes; varias excogitarunt cautelas, quibus evitare posfent lethifera illa vulnera, qux olim faltem omnem medelam refpuere credebantur. Veftimenta igitur induxerunt admodum ampla \& laxa, vel e corio Hispanico, vel e velo lintea. 


\section{解 $(9)$ कृ}

rio, quæ tela non facile perforarent, $\&$ ante milites impetum facientes, velum pice obductum fufpendebatur, in quo per rimam fclopeta ignivoma emitti, tela vero Indianorum penetrare non posfent.

Succesfu temporis píura antidota Indicorum populorum, facra diu refugia, detecta fuerunt, fcilicet.

1:o Radicis toxicaria, feu Crini Alatici bulbi mafticati fuccus degluétus vulnerique applicatus, unde vomitus fuboritur vehemens, quo venenum expellitur.

2:0 Ad fortem exftingvendum xitum vulneri intillatur fuccus e Melopepone, cuju's quoque portiuncula eft comedenda.

3:0 Cortex Ficus racemole, aliarumque Ficuum, matticatus ac contritus vulnerique applicatus.

Item Tenues rufæ fibræ feu radices tenues $V a$ ringe anguftifolie (Ficus cujusdam) partim propinatæ, partim applicatæ).

4:0 Cortex albi Saijang de ftipite rafus nec non vulneri impofitus.

5:0 Petioli \& radices Momordice charantice con. tritæ \& vulneri impofitæ.

6:0 Radices e Cajo Radja.

7:0 Certisfimum omnium antidotum Macasfarienfium eft lactescens arbor Pule Seu Rite illis dicta, cujus petioli vulneri applicati omne venenum exfugere dicuntur, uti etiam frufta parva telorum marinorum.

8:0 Radix Mungos feu Opbiorbize interne \& ex- 


\section{$\log _{0}^{50}$ ( 10$)$}

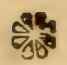

terne ufitata, omnium fine dubio optimum antido. sum refpiciendum erit.

Ex allatis itaque patet, plurima ufitata remedia esfe acria vel refrigerantia, adeoque curam ec esfe dirigendam, ut ftatim vulnus fcarificetur, illique ad venenum extrahendum applicentur fomenta acria ex allio, veficatoria \& ejusmodi alia; utque interne emetica ac emollientia ut oleofa, lac decoetaque mucilaginofa exhibeantur; ut dixta fit tenius \& refrigerans. Quoniam venenum quolibet anno revivifcere dicitur vulnerato ${ }^{*}$ ) etjam eo tempore abftineat ab ufu Zerumbetis atque omnibus aliis calefacientibus, ne recidivam incurrat, haud raro lethalem.

\section{8 .}

Nullum licet fit dubium, fummopere venenatam esfe arborem Indicam, quæ Boa Upas vocatur; variæ tamen fuperftitiof $x$ fidemque minime merentes de illa disperguntur, ab incolis aftutis ignarisque Muhammedanis Sacerdotibus narrationes: ad Jpatium 10 v. 12 miliarium ab arbore non crescent $u$ l. la arbor, frutex, berba, vel gramen. Forfan hujus fterilitatis causfa eft quærenda vel in ipfo folo lapidofo ${ }^{* *}$ ) vel in judicio ignari peregrinatoris. In Africa

*) Ejusmodi exempla in Africa auftrali obfervavit Celeb. D. Præés,

**) In Java folum defcribitur arenofum, brunneum nec non adeo lapidofum, ut fere imposíbile fit ambulare in illa regione, qux venenatie arboris eft natale domi. cilium. 


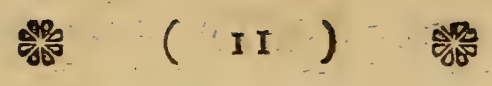

frica enim campi plurium dierum itineris fterilisfimi \& quafi exufti haud rari funt. Ad punienda peccata a Deo productam esfe banc arborem fvafu Propheta Mabomet, fancte credunt Muhammedani, fidem adhuc minorem meretur. In circumferentia 15 usque 18 miliarium nec bomo, nec aliud quodcunque animale vivum, nec piscis in aquis obfervatur, quod ecjam eft incredibile, dum latitudo Javæ confideretur. In Africæ ficcisfimis defertis per plures menfes, quibus pluviæ vel roris ne minima quidem guttula cadit, peregrinator attentus nullum detegere vale animalculum, licet per quatvor plerumque alias menfes pluviales, plura animalia fera \& ad pecora pafcenda ipfi Europæx gentis incolæ aridas has vaftasque regiones vifitent. Arbor in Java crefcens habitat in valle quadam, circumdata montibus altis vaftisque filvis. Omnia loca Javæ depresfa, imprimis aquofa, ut mihi asferuit Celeb. D. Præfes, va. poribus a firio ardente excitatis ventibusque raro disfipatis aerem nimis quantum infectum habent, corpora incolarum ad putredinem disponunt \& multitudinem eorun fæpe ocisfime ad fepulcrum trahunc.

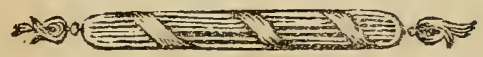





\section{DE}

\section{(Sho.s)}

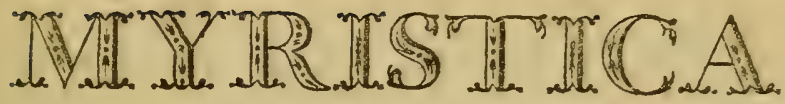

CONSENSU EXP. FAC. MED. UPSAL.

\section{PR ESIDE}
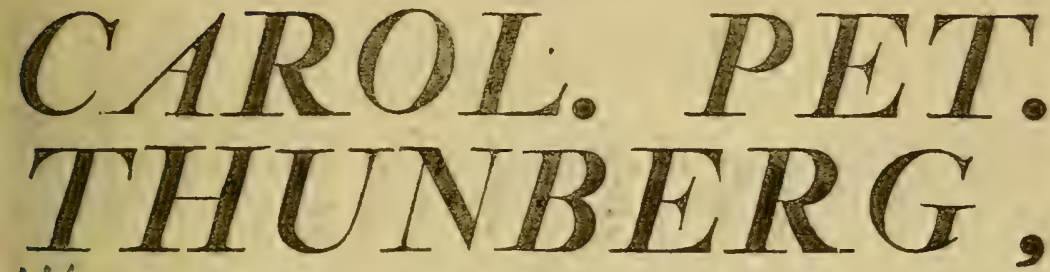

Equite Aurat. Reg, Ord, de Vasa,

Medic. Doct. Frofess, Med. et Botan. Reg. et Ord, Acad. Cesar. Nat, Curios, Reg, Scient, Londinens. Holmiens, Societ, Scient, Upsat. Patr. Holm. Berol. Nat. Scrut, Lundens, Harlem. Amsterd. Zeland. Nidrosiens. Haiens. Nat. Scrut. Medic. Edimuurg. et Nat. Studios. Ibid. Memero; nec non acad.'Scient. Paris. Monspeliens. Agricult. Paris, Florentin. et Batayin, Ind, Or, Correspond.

\section{PRO GRADU DOCTORIS,}

DISSER IT

(unt) 7 .

(n..., 1

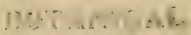
GลRD EIR

\section{FRIDERICUS VILHELM. RADLOFF,}

STOCKHOIMIENSIS.

IN AUDIT. GUST. MAJ. D. XXVIII. MAJI MDCCIXXXVIII. B. A. ET P. M. S.

$==-2)^{2}(\epsilon=9)^{2}(\epsilon=\Longrightarrow 9)^{2}(\epsilon-9)^{2}(\epsilon=0$

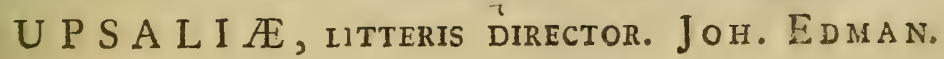





\section{$\mathrm{DE}$}

\section{MYRISTICA MOSCHATA.}

\section{§. I.}

DESCRIPTIO BOTANICA.

YRISTICA morchata: foliis lanceolatis, fruetu glabro. ARBOR magnitudine Pyri vel ultra; cortice lævi, fufco-cinereo.

RAMI patentes, ultimi capillares glabri.

FOLIA lanceolata, acuminata, integra, alterna, parum nervofa, glabra, fupra viridia, fubtus pallida, digitalia.

ELORES in ultimis ramulis, pedunculati, fparfi, folitarii, monoici.

cat. Perianthium I-phyllum, trifidum, glabrum:

Laciniæ ovatae, erectæ, breves.

corolta nulla.

sTAM. Filamentum unicum, filiforme, calyce brevius. Anthera fub apice filamenti, perforata, ftriata.

PIST: Germen fuperum.

Stylus craffis, didymus, brevis.

Stigmata duo, acuta, brevia.

PERIC, Drupa ovata, umbilicata, glabra, unilocularis, ia teraliter dehifcens, in pedunculis reflexis pendula. Caro pallide virefcens, tandem pallida, adftringens. Nux maci reticulata aurantiaca cincta, rugofa. Nucleus rugofus.

Hæc vera eft Myriftica, cujus nuces in Europam venales feruntur; alia vero exftat fpecies, in Irdia non nunquam ufitara, fpecie a priori diverfa, fcilicet: 


\section{ชै (4) कुष}

Mrristica romentofa: foliis ovatis, fructu tomentofo. ARBOR minus ampla \& ramofa, ramis ramulisque magis crasfis.

folra lato-oblonga, obtufiufcula, crafa, nervofa, fupra viridia, fubtus pallida, parum tomentofa, palmaria usque pedalia.

FLORES ad bafin ramulorum, pedunculati, folitarii; pedunculis brevibus, craffis, tomentofis. ERucrus drupa oblonga, obtufisfima, fubtomentofa. Figuras harum \& Defcriptiones exhibet Rumphius in Herbario Amboinenfi Vol. 2 tab. 4 \& 5 \& Celeb. Dn. Præes in Actis Holmenf. 1782. p. 46. tab. I. Pacala Buronget kitjil reliquæque fpecies a Rumphio tab. $6,7,8$, \& 9 defcripte, an veræ fint fpecies Myrifticæ, certo non audemus asfeverare, dum partes 'fructificationis ut plurimum adhuc incognitz fint. Indicis Nationibus pluribus M. mofchata dicitur Pala, M. tomentofa Pala Lacki; licet in diverfis infulis diverfæaliæ harum fint denominationes.

\section{§. II. \\ Locus \& Cultura.}

Crefcit fponte Myriftica in Moluccanis infulis \& hodie præcipue culta in Banda tribusque parvis ejus Provinciæ infulis, fcilicer Neijra, Lontoir \& Pulo Aij. In Neijra præ ceteris Nuces proveniunt optimæ, \& in Pulo Aij maximæ atque pulcherrimæ arbores. Omnibus in aliis Moluccanæ Archipelagi infulis, ex pecta cum Regibus, conventione, arbores omnes, Myrifticas ferentes, eradicatæ funt. a) Loca imprimis montofa amant pretiofæ hæ \& raræ arbores, qux non parum lucri, elapfis proxime duobus

a) Indefesfus \& illuftris Peregrimator Dom. Sonnernt in Nova Guinea Myrifticas crofcere otfervavit. Sine dubio etiam aliis in infulis extremi 


\section{\% (5) \%}

bus feculis, Belgis attulerunt. Aliarum arborum umbram Myrifticæ requirunt, ne nimis a frio urentur \& præcipue amant a ventis marinis eorumque falfis exhalationi. bus defendi. Anno quinto vel fexto fructus ferre incipiunt, octavo autem vel nono uberrimam dudum relinquunt mesfem.

Sponte propagatur arbor per Columbas, nuces integras deglutientes, quarum maci tantum \& pulpa nutriuntur, cetera 'Turdi inftar reddentes.

Drupas nondum apertas Belgæ hodie ferunt pullulantesque arbufculas pro lubitu transplantant. Gerunt vero per fervos omnem curam tam plantationis arborum, quam collectionis fructuum, indigenis bellicofis initio feculi decimi feptimi omnino devictis \& eradicatis.

\section{§. III. \\ Collectio.}

Toto quidem anno fructus edit Myriftica, cum ferfim floreat fructusque maturet, ter tamen in anno matu. ræ colliguntur nuces. Maturitatis fignum eft, quod fructus exterior pellicula leviter rufum præbeat colorem atque hinc inde findatur.

Maxima collectio fit fub finem Julii vel Augufti, dum Fructus copiofisfimi funt, licet Macis tenerior; Novembri fecunda fit, tertia Martio vel initio Aprilis, dum optimi fructus colliguntur \& crasfisfima ex illis macis obtinetur. Sub collectione Incolæ ipfas arbores confcendunt, nuces adducentes longis hamis celerique atractione avulfas in terram projiciunt.
A 3
Col-

Oceani hoc Aroms invenitur. Cultura Myrifticarum a Gallis, infulis eo* rum africanis tentata ex fenrentia illis ron fucceffit; in Cayenne autem hodie late crefcere relationes perhibent. Vide Acta Parifinn. 


\section{触 (6)}

Collectx nuces a fervis cultro aperiuntur? pars ca:nola tollitur \& in filvis relicta acervatim putreficit. Depuratas fic nuces domum reportant \& cultello macim abradunt, quæ qquantum fieri poteft fervatur. Macis per aliquor dies certis quibusdam quadratis exfruetis locis, ubi color kermefinus in obfcure rubantem randemque croceum mutetur, fole exficatur. fublara maci, per tres dies Incola nuces ad folem ficcant, fingula vefpera illins in aedes ducentes, ne pruina lædantur.

Nonnumquam quoque in adibus, per menfis fpatium, fumo exficcantur. Nuces aurem ficcatæ fuftibus pulfanrur, vel etiam faxo quodam contunduntur, donec puta. mina confringantur.

Nuclei feleeti in tres cumulantur acervos. Primo maximi \& optimi, in Europam transferendi b); altero viliores in Indiis confumendi; inque tertio minores \& vilis. fimi, e quibus tantum olenm elicitur. Hoc facto, nuclei lanci imponuntur \& a mercatore, qui illos emit intra octiduum aqua calcis infunduntur, ut a putredine infectis. que conferventur.

Macis eriam, poftquam optime fuerit ficcata, pon. deranda eft ac in facculis fervanda, prius autem aqua marina adfperdenda, ne fragilis nimis in parvula fruftra frangatur. Pedibus macis, tam firmitur ac fieri unquam poteft, impingitur, in fingulo facco ad libras usque I 6 I, $\&$

h) Nuces, qux in Ettropam vehuntur 250000 Libr. efficinnt; In India vero 100000 Libr. nucum \& 10000 libr. macis confumuntur. Europei 100000 Libr. macis utuntur. Lucrum tamen, quod Belgx qurftuofa hac ex mercatura reportant, hodie valde imminutum esfe nos edocet Dominus Rayunl in Hiftoire des etablifemens des Furopens dans Les deux Indes. 


\section{爱 $(7)$ 器}

\& hoc modo facco adhuc fuper indueto \& litteris finisque confignato, navibus in Belgium ttansmittitur.

E nucibus molchatis, in Indiis duplex genus olei preparatur, i Europam transvehendum, fcilicet vel expresfum vel deftillatum. Ex hisce tamen rarius in Europam venit oleum deftillatum, quod pellucidum eft ac vires habet aromaticas ipfius nucis. Oleum expreslum e vilioribus nucibus presfura elicitur. Nuces in fartagine rorrefactæ contunduntur, denuo calefiunt \& in faccis e rextura Calappi (Cocoes nuciferæ) pilofa confectis, inter duas afferculas aretisfime comprimuntur, donec Oleum profluat, butyri recentis inftar liquefacti, craffum, quod in quadratis receptaculis exceptum condenfatur.

E Maci contufa \& calefacta quoque oleum, fanguinei coloris, femper molle, faporis pinguis \& amaricantis, absque notabili calore exprimitur, guod tamen in Europa ufu medico raro obvenit. E $17_{4}^{\frac{r}{2}}$ Libr. macis $\frac{1}{2}$ Libr. olei obtinetur.

Virides nec omnino adhuc maturæ drupæ in India faccharo condire folent Belgr. Prudenter tum arbore decerptæ aqua ebulliuntur, ftilis perforantur \& per octo vel decem dies in recenti aqua fenfim renovanda macerantur, donec omnis ablata fit acerbitas; Dein in facchari folutione, quæ per octo dies, omni die effundenda, calefacienda denuoque nucibus affundenda erit, coquuntur \& in lagenis vitreis optime claufis fervantur. Muria quandoque infunduntur nuces, tantum a plebejis adhibitæ.

Tinctura fpirituofa, lutefcens, olida \& fapida evadit.

$$
\begin{gathered}
\text { S. IV. } \\
\text { Vires S. Qualitates. }
\end{gathered}
$$

Myriftica cum arbor fit fucco fanguineo difluens \& quam maxime aromatica, atque e fructibus immaturis lac, ficca- 


\section{8ूर $(8)$ \%}

tum calci hatid disfimile exftillat, non mirum, $a b$ omni fupicione venenatæ \& noxiæ indolis liberari non polle, licet prudenter fruetus ufitati tam diætetice quam medice profuerint. Docuerunt triftia exempla, halitum arboris \& fructum non modo nocuife, fed eriam exftinxire, qui illi fe imprudenter \& diutius expofuerunt. Memorat Rimnploius de binis militibus, fub arbore Myriftica pernoctantibus, quod altero die experreeti, vertiginofi fuerint \& fomnolenti. Alii quirique vel rex nuces edentes inde delirio corepti funt. De alio quodam narrat, quod in lecto mortuus fuerit inventus, ante cujus lectum collocatæ erant nuces, e quibus tamen comedisfe fupicabatur atque a nimia copia in fatalem fomnum incidisfe. vid. Rumph. Herb. Amb. T. 2. p. $2 \mathrm{r}, 22$.

E nimia dofi nucum opresfio pectoris, difficilis re. fpiratio, intenfa fits, Gephalalgia, Vertigo immo letha. lis Apoplexia oritur. Nocet vero in primis ufus horum fructuum, qui alvo taría \& obftipata, Hæmorrhoidibus \& morbis foporofis laborant, vires enim fopientes habent ac temulentiam, delirium \& apoplexiam excitare valent.

\section{§. V. \\ Ujus.}

Pretiofum aroma nucis mofchatæ ad noftram cognitionem Arabes, antiquitus ejus commercium àgentes, deduxerunt \& ejus primam mentionem Avicenna, maximum medii ævi decus \& inter Muhamedanos medicus præftantisfimus fecit.

Ad cibos condiendos non minus nuces quam macis conducunt. Proficuæ nuces in primis ftomacho debili habentur \& profluviis tam fanguineis, quam ferolis, prudenter modo ufurpatæ medentur.

In Diarrhcea \& Dyfenteria, nux tofta cum hauftu vini rubri vel alio vehiculo, adhibita frepisfime votis re- 


\section{0 $(9)$ 默}

ipondet. Nuci quoque Opium addere Arabes fvevere. In Naufea, Vomicu \& Tusfi gravidarum nux molcata a variis c) Medicis practicis commendatur.

Semimaturas asfatas cum fructibus Mufx, caute tamen, in profluviis fanguineis \& ferofis comeftas fuiffe affeverat nobis Rumphius.

Torrefacta autem, ex præfcripto Londinenfium, nux myriftica in hisce cafibus caput minus movebit. Febres intermittentes cum alumine junctum hoc pharmacum fæpe fiftit; fed heic prudentia erit adhibenda, ne graviora inde mala fequentur.

Externus nucis mofcharæ ejusque oleorum ufus, periculi non adeo plenus eft, ac quidem internus. Oleum expresfum membris illinitur in India orientali æque in Beriberi ac in Paralyfi. In Europa oleum propinatum fuit interne ad fcrupulum dimidium, externe vero umbilico illinitum utile habetur ad fiftenda tormina \& evacuationes primárum viarum nimias; ac temporibus inunctum, fomni provocandi ergo. Ufu quoque externo oleum expreffum varia præparata officinalia, Emplaftra fcilicet ftomachalia, Unguenta nervina \& Tincturas nervinas, ad do. lores \& fpásmos fedandos, ingredirur.

Oleum effentiale \& Tinctura ftomacho debili inferviunt. Saccharo conditi fruetus cum aliis tragematibus fub finem menf vel poft meridiem cum potu Theæ, in frufta minuta confcisí, comeduntur \& ventriculo robur addint.

c) Hoffman, Lewis, 


\section{照 (}

Arboris lignum, faltem in India orientali, ad poftes sedium ufurpatum, neque in oeconomia fuo caret ufu, uti neque Fructus e Myriftica tomentofa, licet viliores \& virtute debiliores fuerint.

\section{Tantum;}

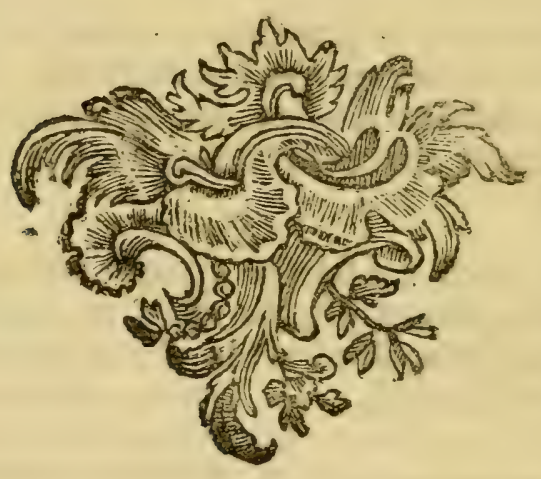




\section{DISSERTATIO MEDICA INAUGURALIS}

DE

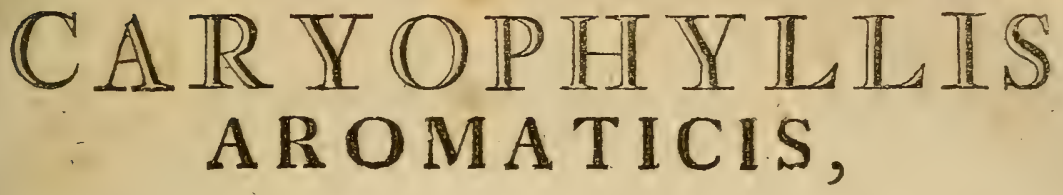

QUAM,

VENIA EXP. FAC. MED. UPSAL.

PR ESIDE
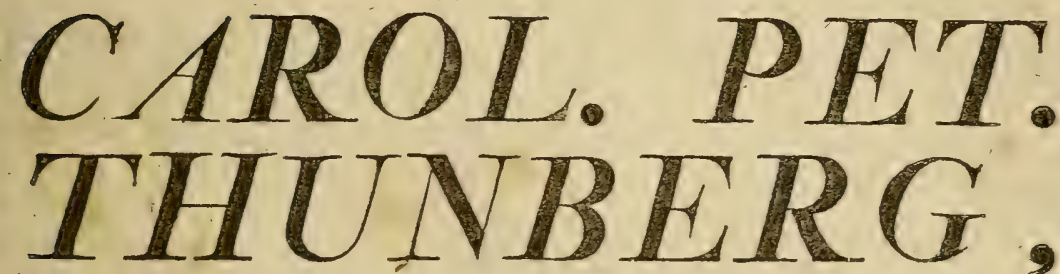

Equite Aurat. Reg. Orn. de Vasa,

Medic. Doct. Frofess, Med, et Botan. Keg. et Orto, Acad, Ceresar。 Nat. Curios. Reg. Scient. Londinens. Holmiens, Srciet, Scient. Ufsal, Patr. Holm. Berol. Nat. Scrut. lundens. Harlem. Amsteid. Zeland, Nidrosiens. Haíens. Nat. Scrut. Medic. Edimuurg. et Nat. Studios. Ibid;

Membro; nec non acad. Scient. Paris. Monspriliens. Agricult, Paris. Florentin.et Batavin. Ind. Or. Correspond.

$$
\text { PRO GRADU. }
$$

PUBLICE VENTILANDAM OFFERT HERMAN. RUD. HAST, MEDIC. PROVINC. OSTROBOTHN.

IN AUDIT. GUST. MAJ. D. XII JUN. MDCCIXXXVIII.

UPSALIE, IITTERIS DIRECTOR, JOH. EDAAN. 



\section{$\mathrm{DE}$}

\section{CARYOPHYLLIS AROMATICIS。}

\section{§. $\Upsilon_{0}$ \\ DESCRIPTIO.}

HUGENIA caryopbyllata: foliis integris, panicula trichotoma, decompofita.

Arbor elegans, magnitudine Pruni Cerafi, trunco recto; cortice glabro; ligno duro, cinereo, gravi.

Rami virgati, erecti, ramulofi.

Folra oppofita; decusfata, petiolata, elliptica, integra; fupra viridia, nitida; fubtus pallidiora; parallelo-nervofa, digitalia.

Frorum panicula decompofita, trichotoma.

CALYX. Periantbium 4-partitum: lacinice ovatæ, obtufæ, inflexæ, perfiftentes.

Corolla tetrapetala, caduca: Petala ovata, obtufa, concava, calyce paulo longiora.

Stam. Filamenta plurima, corollæ bafi inferta, filiformia, corolla longiora cumque illa caduca.

Antherce globofæ, minutæ.

Pist. Germen inferum, annulo nectareo cinctum.

Stylus unicus, fimplex, perfiftens.

Stignzata quatuor, cruciformia.

Peric. Drupa oblonga, initio clavata, dein ovata, calyce coronata. Nux ovato-oblonga. 


\section{छิ० ) 2( \\ 6. II. \\ SYNONYMA.}

Caryophyllus aromaticus. Linn. Gener. Plantar. p. 270. Spec. Plant. p. 235. Syft. Veger. XIV. p. 496.

Caryophyllus aromaticus. Houtuyn. Natuurl. Hift. Part. 2. Vol. 3. p. 44. Tab. 12. fig. 1.

Caryophyllus. Rumph. Herbar. Amboin. Tom, 2. pag. I. Tab. 1, 2, 3. Sonnerat Voyage au Nouv. Guinèe p. 196. Tab. 119.

Indianorum denominationes variis in regionibus variæ funt: Amboinenfibus: Bugulawan \& Bongulawan.

Ternatenfibus: Bohotawa \& Boa Lawa.

Tidorenfibus: Gomode.

Javanis: Chamka \& Chamke.

Malaccenfibus: Tjancke \& Tfiencke.

Chinenfibus: Thenghio.

A forma clavata, apud Europæos plerumque denominati fuerunt Caryophylli.

Belgis: Nagelen, kruydnagelen, Moernagelen \& Garioffelen.

Portugallis: Cravi.

Hifpanis: Clavo.

Anglis: Cloves:

Italis: Giroffeli.

Svecis: Neglikor, krydneglickor, moderneglikor.

\section{§. III. \\ LOCUS.}

Crefcir fponte Eugenia caryophyllata tantum in Infulis moluccanis \& precipue in infula illa, dicta Mackian. Hinc in plures alias infulas calidioris Indiæ translatæ \& plantatæ fuerunt arbores juniores, \& in nonnul- 


\section{解) $3($ )}

lis adhuc, præprimis vero in Amboina fumma cura \& indefesfo ftudio coluntur. Paulo ante Lufitanorum in Inciias orientales adventum Incolæ Ceramæ, dictæ Hua. mohel, anthophyllos maiuros, clam e Mackian fubductos terræ commiferunt fuæ atque plantas vivas obrinuerunt, licet hunc honorem dubium illis reddere facere tentent Combellenfes, qui etjam vetuftisfimas hujus fructus arbores Belgis oftendere potuerunt, \& quibus plures jam in Amboina vigentes arbores. fuas debent origines.

Ante Belgarum in Indiis adventum eorumque felicirer in his terris gefta bella, præter nuper dictas infulas, nullæ aliæ Caryophyllos produxerunt; hodie vero in parva infula Amboina \& tribus ipfi vicinis parvulis, Oma, Honimoa \& Nusfalaura folummodo cultura eorum inftituitur, poftquam in cereris fingulis hujus Archipelagi infulis, tam aftute, quam prudenti confilio a Belgis omnes arbores caryophylliferæ devaftatæ fuerunt \& fenfim excrefcentes achuc quotannis ferro \& igne devaftantur. Recentiori ævo etjam in Nova Guinea Caryo. phylli detecti fuerunt \& a Gallis A:0 1770 fructus \& plan. tæ, æque ac Myrifticæ, ex infula quadam Moluccana Guebu, in infulas Ifle de France, Bourbon \& Seichelles transplantatæ fuerunt a). Hinc poftea Caryophylli propagati fuerunt in infula Cayenne, ubi hodie læte cre. fcunt \& florent.

\section{§. IV. \\ CULTURA.}

Antiquisfimis temporibus Sinenfes, infulas Molucca. nas frequentantes, primum commercium caryophyllorum egerunt, eorumque ufum per Lufitanos cum reliqua Europa communicarunt. Poftguam vero Anno 1652 ex A 2 pa-

a) A\&t, Parifo 3772, P. I. p. 56. 


\section{) $4($ 舵}

1) Ra cim Rege Ternarenfi conventione, omnes arboles in Molucis infulis deftruetæ funt, horum fructum Monopolium habuerunt Hollandi foli, \& fummopere illo dicati, fumma cura arbores caryophyllos ferturas colendas curarunt in infula Amboina, ut \& fecurius illas defendere, cuftodire \& fructus ipfos commodius colligere posfent cultura prettantiores factos. Arbores enim adcommodato folo collocatæ nón modo magis florent, nec tam in altum excrefcentes ramis luxuriant, fed etjam fortius acquirunt aroma \& collectionem fructus longe commodiorem reddunt. Inter juniores Eugenias caryophyllaras arbores aliæ plantandæ erunt, ut umbra fua tenellas adhuc a firio ardente defendant: hæ vero fenfim minuendæ \& tandem omnino tollendæ, ut adultiores arbores lerius foreant fructusque magis aromaticas obtineant. E feminibus excrefcentes arbores potisfimum mediocres funt plantanda, licet non fine multo labore \& periculo fuccedar hic labor, quo rami fe magis in larum diffundant \& copioficres frućtus producant. Celebris Valentyn narrar An. 16;6 a Dn. Vlamming circa 120,000 arborum in Ambuina, 60,000 in Uliasfer, 30,000 in Leirimor \& 30,000 in Hiru fuisfe plantatab). Anno nono, decimo vel duodecimo primos aperire folent ílores arbores arte cultæ, quolibet anno fructuum 400 vel 500 Libras ferences, tertio vero quolibet vel quarto anno copiofiorem adhuc relinguentes fructuum fegetem. Durat deinde arbor ad 50, 100 ufque I30 annum, tuncque mesfem fructum ad ioo Libras adaugere valex.

Sponte fua arbor caryophyllifera a quadruplici fpecie avium pleramque propagatur, fcilicet alba quadam, \& viridi Columbæ fpecie, Bucero \& Cafuario, qua omnes in fui almenrum maturorum fructuum exteriorem mollem fubftantiam vertuni ac femina in fylvis disfeminant.

6) Defeript, Ind. or. Vol. 3. p. 195, 197 


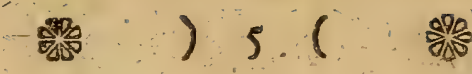 \\ §. $\mathrm{V}$. \\ FLORESCENTIA.}

Flores menfe Junio provenire incipiunt \& Augu. fto florent, poft aliquot menfes fructus maturantes. In. itio flores virides fenfim flavefcunt tandemque rubefcunt; Deinde fub maturatione fenfim intumefcit Pericarpium, crasfefcit, finditir, nucleum maturat, \& nomen Matris feu Anthophylli acquirit.

\section{VI. \\ COLLECTIO.}

Collectio caryophyllorum fiet, dum flores in $\mathrm{pa}$. niculis rufefcere incipiunt, proximaque folia plurima (an Bracteæ?) decidunt. Sub arboribus tunc terra fcopis purgata, quidam arbores prudenter confcendentes paniculas proximiores \& remotiores bacculis hamatis adductas manibus diffringunt atque fructus decerptos vel in corbis excipiunt vel in terram projiciunt. Sic decerpti Caryophylli aromatici vel aqua fervida vel non immerfi, tigillisque impofiti fumo per aliquot dies imprægnantur, ut rufum induant colorem; deinde potisfimum foli expofiti exficcantur, colorem extus atrorubentem, intus vero rufum fervantes. Síccati a pedunculis \& aliis partibus bene depurantur arque lanci imponuntur. Vera mesfis ab Octobri peragitur ufque in Decembrim. Ex narratione Rumphii, colligebantur anno 1692 in Amboina 3,700 Baharan feu 2,035,000 Libras. Optimi Caryofhylli funt pingues, acres feu calidi, \& qui presfi humidum pingue digitis affricant.

$$
\begin{aligned}
& \text { §. VII. } \\
& \text { VIRES. }
\end{aligned}
$$

Gravem fpargunt Caryophylli odorem, \& quidem fub tempore florefcentize adeo fortem, ut feryentibus 


\section{$8 \%) 6(20 \%$}

menfibus Octobris \& Novembris cephalalgiam in fylvis ambulantibus excitent, \& fi quis in camera, ubi asfervantur collecti, dormiat, capitis dolorem vehementem cum naufea contrahar. Capiri itaque valde gravis eft odor, licet alias non fit ingratus. Sapor eorum acris \& calidus eft cum levi amariciei miftura. Vires fumme ca. lefacientes, tonicæ, ftomachicæ, fralagogæ \& emmenagoge uti ipfum fingulare aroma omnibus quidem partibus arboris infident, imprimis vero petiolis \& calycibus florentibus, fic ut Anthophylii feu fructus maturi viribus minus calidis \& debilioribus gaudeant \& aromate longe fint inferiores. Caryophylli, natura fua calidisfimi, avide humidum attrahunt, uti \& de tpeciebus Piperis notum eft; Aqua infufrone odoras partes avidius tamen abripit, quam fpiritus vini, non vero item fapidas, quæ potius fpirituofis eruuntur c). Deftillatione itaque cum aqua copiam olei esfentialis præbent, licet diverfa copia, majori plerumque recentes. O!eum deftillatum, quod ex India orientali in Europam adfertur, plerumque mixtum in. venitur cum dimidia portione olei alius cujusdam peregrini, expresfi \& infipidi, ufui tantum externo inferviens. Hocce oleum tenue \& lape fanguineum, longe ab eo itaque eft diverfum, guod ex lege artis in Europa deftillarnr. Deftilatio namque in Indiis, absque ulla rectificatione, faltem antiquirus, \& æneis alembicis inftituta, oleum fubminiftravit aduftum \& adeo acre, ut inflammationem excitaverit ; oleis vero Calappæ, rofarum vel olivarum dilurum externe adhibitum fuit. Oleum hodie in Batavia frepe deftillatur, non tantum a Caryophyllis oprimis, fed erjam illis, quæ frum aliquem \& corruptionem contraxerunt, tuncque acerrimum eft fapore, cali-

c) Aromn femel deperdirum facile ah aliis, cum quibus mifcuntur, gà fe trahunt, licet debiliores \& pallidiores fiant. 


\section{ซึ: $) 7($ )}

calidisfimum, coloris brunnei \& nonnihil fpisfum. An. thophylli aptisfimi habentur ad oleum exurendum, tefte Rumphio, licet debiliores fint. Tinctura fpirituola furca, rufefcens, parum odora, faporis vero calidi etjam in officinis locum obtinuit.

Sacchari fyrupo quoque condiuntur Caryophylli aromatici in Indiis, \& ad varias infulas ibi, rarius vero in Europam circumferuntur.

\section{§. VIII. \\ US.US}

Caryophyllorum varius eft, alius vero in Indiis, alius in Europa, alius etjam diætericus, alius Medicus. Generatim autem in Indiis parcior eft, in Europa copiofior, tam medicus, quam ceconomicus.

Indi caryophyllos adhibent, \& in parva modo quantitate, ad quædam unguenta, quæ componunt ad corpora fua fricanda, dum illa calefacere velint $d$ ). Item Tabaco fuo mifcent pro fuffimigio $e$ ). Et oleum Caryophyllorum deftillatum, aliis expresfis oleis mitigatum in Beriberi ad membra paralytica inungenda adhibent. Quin \& ejusmodi olei gtt. 7,8 in Colica flatulenta propinare audent $f$ ). Apud Europæos ufus diæteticus crebrior videtur, quam medicus. Adhibentur nimirum caryophylli ad condiendas carnes ferinas, quibus transfiguntur; erjam Cafeo in gratum faporem \& robur ftomachi; item variis fructibus acetario deftinatis, ut Prunis, Cerafis, Cucumeribus alisque acero fervandis, nee non confectionibus fructuum faccharatis, ut juglandum immaturarum, \& tinct-

d) Rumph, Herb, Amb. Tom, 2. p. 8 .

e) Ibid. ( f) Ibid. 


\section{) $8($ \%}

rincturis variis fpirituofis $g$ ), adduntur Coryophylli, $2 x$ cibis ut condimenta, in morbis a muco, debilitate ventriculi, aliis.

Medice ufitati caryophylli languenti ftomacho \& in naulea inferviunt; Mafticati falivam proliciunt. Compofitis variis adduntur ut Electuar. Diafaryrii, Spiritui Maftichino, Esfentiæ abfinthii compofitæ, Emplaftro de crufta panis, Electuario Gingivali, Balfamo Caryophyllorum, Apoplectico \& vitæ Hoffmanni, reliquis.

Anchophyllorum medicus ufus a multis retro temporibus viguit apud Javanos, Malaijos \& Chinenles, uti quoque hodie apud Japonenfes \& Europæos.

Oleum deftillatum, in carie osfium utile, in odontalgia denti dolenti gosfypio inditum dolorem læpe fedat; externe in Paralyfi cum aliis oleis mixtum, in colica flatulenta \& diarrhoea abdomini inunctum proficuum laudatur.

g) Murraij Mat. Med, Vol, 3. p. 338.

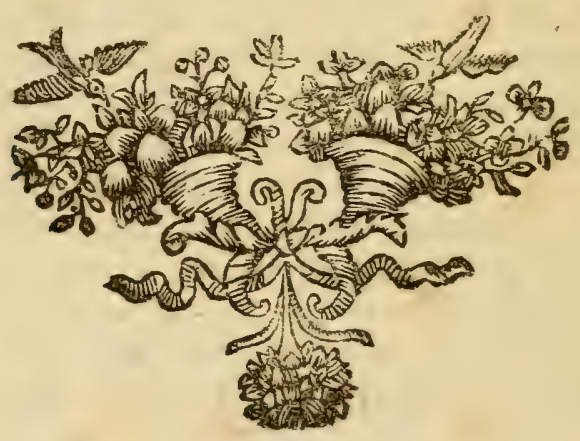


VENIA EXPER. FACULT, MEDICR,

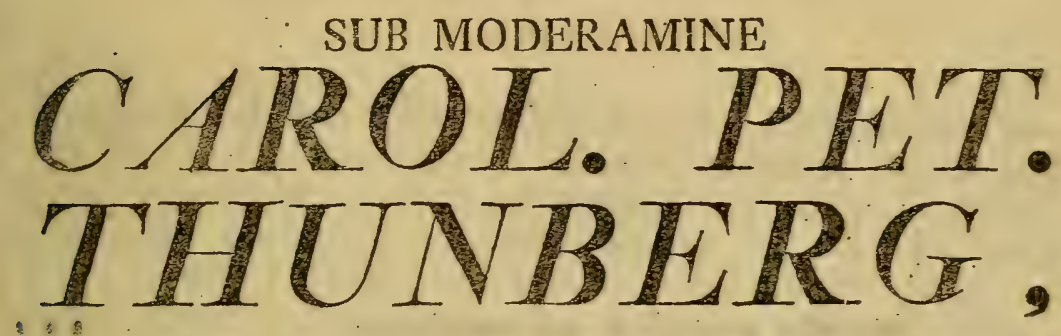

Equitis Aurat. Rgg Ord. de Vasa,

Medic. Doct. Frofess, Med. et Botan, Reg. et Ord., Acad. C.esar, Naz. Curios, Reg. Scient, Londinens. Holmiens, Societ, Scient, Upsal. Patr. Holm. Berol. Nat. Scrut. lundens. Harlem. Amsterd. Zeland, Nidrosiens. Haiens. Nat. Scrut. Medic. Edimburg. et Nat. Studios. Irid.

Membri; nec non Acad. Scient. Paris. Monspeliens. Agricult. Pakis. Florentin. et Batavin: Ind, Or. Correspono.

PRO GRADU MEDICO,

DISS E R I T

\section{JOHANNES GUSTAVUS HALLMAN,} REG. COLL. MED. MEMBR. ET MEDICUS PAUPERUM HOLM1IE, STOCKHOLMIENSIS.

IN AUDIT. GUST. MAJ. D. XXIV. MAJI MDCCLXXXVIII. H. A. ET P. M. S.

U P S L I E, IITTERIS DIRECTOR. JOH. EDMAN. 


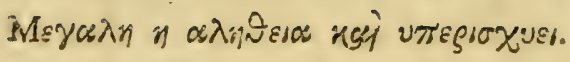

III. ESDR. IV. 4I. 


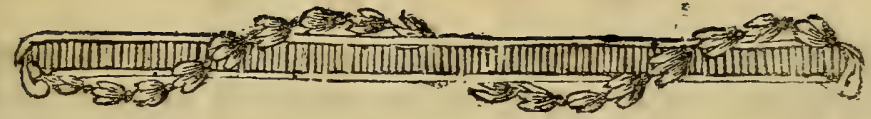

\section{§. I.}

vo hebetior Medico cuique nafus eft, eo utique minus experimentorum fallaciam olfaciet, verum nubem, ut dicunt, pro Junone amplecterur, nugas quascunque aniles ore garrulo incaute repetet \& cramben femel arque iterum recoctam propinabit, quo fcilicet ipfum rapuerit fcribendi prurigo, delatus hofpes. Hæc forfitan, vel huic non valde ablimilis, ratio in causfa eft, cur in Medicinam irrepferint obfervationes tor, partim dubiæ, partim minus fidæ, partim etiam prorfus fallaces \& tot medicamenta, incerti vel nullius ufus, jam incongruenti, jam quoque ridicula, pro lubitu fere, adpellatione falutata, in tabulas Medicorum relata fint, Ut enim de his nihil dicam, qui in Mufeorum receffu Morborum Hifto. rias conflant \& pro veris venditant, vel de illis, qui etiam veriffimas ita referunt explicantque, ut prejudicatis opinionibus faveant, alia eft etiamnum deterior, nec minus vituperanda, caterva Medicorum, qui, nec experientix nec fanioris judicii face illuminati \& fempiterna ponentes tirocinia, nil oculis ufurpant nifi novitates \& miracula, quas deinde, laboriofa cafuum fimilium ferie intextas \& quovis eruditionis peregrinæe apparatu ornatas, narrant mirabundi; quin \& eo usque interdum procedunt im. prudentix, ut, fi fcribendi materiem negaverit obfervationum penuria \& imaginatio torpens, occafionem quamcunque, qualem fcilicet fubminiftraverit fors iniqua, lati 


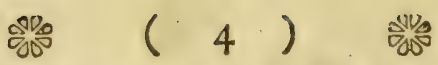

arripiant, \&, dum plures obfervationes inter fe comparare aequentit nec adcuratioris examinis remoram facile patiuntur, vel ex unico tantummocio Cafu morborun naturam atque curationes dijudicent \& methodum illam, quam obtulit fors vel tvaferunt prefumræ opiniones vel demum commendavit Auctor dilectus \& qua felici ftipara fuir fucceflu, optimam omniumque preftantisfimam irrevocabili conditione \& quali ex tripode pronuncient. Quemadmodum enim ifte ratiocinandi modus a recta illa arque faris phana Philofophorum via, qua ad inveftigandum \& indagandum verum tutillime icur, valde abhorret, ita etiam Rem Medicam, guxe fi quodnam habct, uti certe fummum habet, decoris, id omne a peripicuitare, fide atque certicudine mutuabit, mirum in modum perplexam reddidit atque incertam. Ab eo enim tempore, quo pravalere incepit ifte feribendi furor va. næque gloriæe cupido, eo usque increvit acervts Obfervationum Medicarum, ut jam mole laborent fua \& non tantum tironem, wifi caure eas habere mox didicerit, facile perterreant, verum etiam doctiffimi cujusque fagacitatem exercant eludantque. Quo quidem factum eft, ut Medicina inde a tempore fummi Hippocratis, qui non nifi nudas, eas vero utilisfimas retulit obfervariones, fi vel infignes, tamen vix tantos, quantos ceteræ fcientiæ, quæ Practicre dicuntur, fecerit progresfus. Nec fperare licet futurum effe, ut umquam ad culmen certitudinis, culture atque dignitatis prius perveniat, quam ab immenfis illis opinionum commentis fuerit repurgata \& experimenta rite inftituere \& convenienter naturæ atque fanæ rationi, juxta Leges, quas detexit recentiorum Phyfiologorum indefesfa opera, explicare didicerint Artis Salutaris Cultores.

NE vero quis hæc de Clarorum Virorum conaminibus, non temere calumninandis, nimis acriter dicta exi. 


\section{糙 $(5)$}

ftimet, Leetorem benevolum monitum volumus, quod tantum abfit, ut Cenfores vel Obtrectatores agere prageftiamus, "út potius, fi vel non prorfus coeca, tamen haud levi veneratione profequamur eos, qui in illuftranda $\mathrm{Ar}$. te Medica operan quandam collocant \& gloriam eorum eiudere religioni ducamus, verum dum in eo fuimus, ut de ufu Moxæ vel, quod idem fere eft, de vi ignis in corpus animalium atque ejus ad curandos morbos ufu disfereremus, nobis fingula perlegentibus tanta fefe obrulit de hoc argumento opinionum diverfitas, ut abs nobis impetrare non potnerimus; quominus faltem profiteremur, id valde fingulare nobis adparuisfe, quum res ipfa, uci fuidem nobis videtur, admodum fimplex eit atque pla. na. Nec facile erit didu, cur tor a:que tam fingulares ig. ni adtribuerint virtutes etmque, quod adhuc magis a ve. rolimili aber, fpecifica quadam, ut vocabulo illo fatis barbaro utamur, in quitusdam morbis gaudere vi crediderint, dum ignis, ut poft hæc cemonftrabitur, nihil aliud eft, quam ftimulus isque omnium fimplicifimus.

Ne vero quis fortasfis nobis vitio vertar, quod in deplorando Medicinæ itatu nimis multis verbis fimus commorari, ad ea quæ in hac Opella tractabuntur, de Ignis, fcilicet, \& Moxa in Medicina rationali ufu, jam revertimur. Prius vero quam ad explicandas opiniones noftras nos accingimus, Lectorem Benevolum etiam atque etiam rogatum volumus, ne ea quæ proferre nobiscum propofuimus, fi a receptis opinionibus aliquantum difcefferint, male interpretetur vel nobis, ceu otiofis novitatum machinatoribus, omnes diras imprecetur, verum æquo animo fin. gula penfiret, nosque ea prolequatur benevolentia, quam nos veri amore atque ftudio, quibus ducimur, meruifie fufpicamur vel fi noftra dicendi ratio rudior atque inculta palato, cui callum obduxit longa cibi delicatioris confvetudo, minus grata effet atque accepta.

$$
\text { A } 3
$$




\section{8ू. $\quad(6)$}

\section{§. II.}

BARBARE gentes fere omnes, uti itinerum defcriptiones abunde loquuntur, ignem, tam ornamenti gratia, quam a.1 precavendos \& debellandos morbos vario modo corpori admovent, nec apud politiores fua caret laude atque celebritate. Longe tamen frequentisfimus ejus eft ufus apud Nationes, quæ regiones trans Gangen fitas incolunt, Sinenfes inprimis \& Japonenfes. Hi peculiari prorfus ra. tione adultiones inftituunt, quæ a remotisfimis inde rem. poribus inter cos invaluit, quxque deinde, non tantum ad vicinas gentes transmigravit, verum eriam ab Euro pæ Medicis fuit recepta. Materiem, qua ad inurendum licuntur, Moxam appellant. Hanc ex Avtemifle vulgaris foliis teneris, initio mentis Junii collectis, per inultum tempus in aëre libero fulpenfs atque exficcatis, dein ve. ro piftillo quodam in ftupæ rudioris mollitiem contufis atque a fibris durioribus \& recrementis quibuscunque pro. be purgatis, parant. Quo quidem artificio lanugo obtinetur infignis teneritatis, ignique concipiendo aptifima, qui etiam admisfus lentius \& deflagratione minus confpicua ferpit, usque dum torum in favillam abear. Lanuginis Artemifix loco alii panno gosfypino vel junci medulla oleo Sefami imbuta vel, ut inter Europæ Medicos confvevit, ipfa Gosfypii lana utuntur. Ipfa vero uftio hac fere ratione inftituitur: Stupæ artemifinlis portio digitis aptatur in conum tres, \& quod excurrit, digitos altum toridemque fere ad bafin latum, quem dein. de in ima parte, quo cuti adhreat, Caliva madefactum loco inurendo imponunt \&. fátigium, virgula quadam ardenti, quam Japonenfes Senko vocant, accendunr. Turundam tum lente depafcit ignis, quo fub prinum gratus calor, dein vero dolor fenfim ingravefcens fentitur, us. que dum ad cutem pervenerit xltus, jam eo intolerabi- 


\section{袖 $(7)$}

lior, quo gravius a contactu ipfius ignis adficiuntur partes fubjectæ. Hicce adurendi modus id inprimis fecum commodi habet, quod illo, qui ferro candenti fir, minus fit terribilis, nec tamen minori fe commendet utili. tate atque efficacia.

DE eligendis locis adurendis non parum foliciti funt Japonenfes \& Sinenfs, eaque probe noffe faftigium doctrinæ pyrofophicæ cenfetur, quapropter etiam illa in tabulis impreffis exponunt. Ea vero loca ejusmodi potiffimum funt, per quæ, ut fatis' quidem fimpliciter etiam noftro tempore fibi perfvadent nonnulli, materia peccans, ut dicitur, a parte adfecta avocata, extrahi poffe creditur. Hinc uti nec fexui, nec xtati, nec habirui corporis ulli, ita etjam nulli fere parti parcunt. Omnium vero freguentifime dorfum idque prope fpinam adurunt, unde illud feedis cicatricibus obfitum quam frpiffime habent hæ Nationes, idque eo minus mirum eft, quum numerus Moxarum nulla artis regula, verum ægri fortitudine fola definiatur. Tendines tamen, nervos arque venas, quas vifi vel tactu explorant, follicite evitant, ut etiam fuadet Cersus, nec pluviofa vel humida \& $x$ ftuofa aut gelida tempeftate uftiones infituunt, verum diem ficcum, ferenum atque modice calentem eligunt. Ulcera ab aduftione orta diligenter inlpiciunt Chirurgi, Tenfafí dikti, quia loca adurenda palpantur qua fi ficca adparuerinr, id malum atque naturæ debilis indicium fcire admodum judicant \& tum cepas contufas fuperimponunt, ut promovearur fuppuratio, fin minus tamen oleo ftignata quotidie inungere non omittunt, ut puris effluvium citius adveniat. Quum manca admodum fit atque confura harum gentium, tam rerum naturalium in genere, quam inprimis corporis humani cognitio, nec valde ditis medicamentorum Syllabus, omniam fere remediorum locum tenent aduftiones, quamobrem 


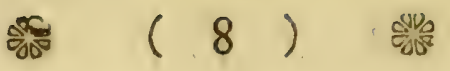

enumeratione morborum, in quibus eas adhibent, ram. quam redio plena \&, his precterum rcmportisus, quibus utiliatem ignis acgua lance ponderare didicimus, inurili fuperfedemus. Id tamen obfervare convenit, nuod ufticnes tam ad præcavencios morbos infticuantur, unde criam fingulis fere lemeftribus corporis quendam locum, tamen turundis minoribus atque rarioribus, inuri curant calida. rum regionum incolce, quam ad proficgandas varias infermitates, tum vero infigniores arque fiequanin:es funt. In Arthritide ejusque progenie Podagra, lfihiacie \& capitis adfectionibus chronicis variis, longe celebratifimus eft Moxæ ufus \& præterea in omni morbo, in quo, ut ajunt \& perfime ajunt, vapor quidam detentus continui folntionem, dolores \& actionis lafionem parit.

Hec de Moxae apud Sinenfes \& Japonenfes ufu diEta funto. Quce vero de his propolita funt, tam ex Kempfero arque aliis, qui Indiam vificarunt haulimus, quam ex ore Illuft. Pricfidis, cui longa apud Indos commoratio bellam admodum, nec utique ncglectam, prabuit occafionem in mores eorum arque confvetudines inquirendi.

Ав ео inde tempore, quo primum innotuit ifte Sinenfibus atque Japonenfibus familiaris adurendi modus, ranta fe commendavit commoditate, ut ceteris omnibus, qui ferro candente vel alio quovis modo, vifu quidem quam actu terribiliores, antiquitus fiebant, palmam facile præe. riperet. Hinc apud Gallos, fvadente inprimis Celeb. Pouteau, Anglos, Germanos \& eriam in his regionibus increbuit Moxæ ufus, licet absque difcrimine, ut Indire populi, eam non adhibeant Medici noftrates \& loco ftupæ artemifialis lanam gosfypinam vel fpongiarn præpa. ratam fumant.

§. III. 


\section{歌}

\section{$(9)$}

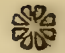

\section{§. iII.}

Quinam fint effectus ignis corporis cuidam parti ad. moti, jam explicari jubet inftituti ratio. Heic autem, \& quidem femper, quum de modo, quo corpus noftrum ad. ficiunt res externæ, fermo eft, probe caveri oportet, ne nos fugiat magna illa, quæ materiam viventem inter \& mortuam intercedıt, differentia; qux quidem admonitio fupervacua effet, nifi Medicos in hoc vitium valde pronos animadverteremus. Ad id enim non fitis adcurate attendunt, quod materia vivens non prius ad leges mortuæ revertatur vel eadem ratione qua hæc adficiatur, aquam vita penitus fuerit orbata. Hinc ea quæ de vi ig. nis nexum corporum folvendi, quo particulæ elementares tandem remanebunt, loquuntur, licet ubi de materia mortua fermo eft, fatis bel!e fe habeant, vix tamen in explicandos effectus, quos corpori vivo admotus extrcer, quadrabunt. Qui enim rem, de qua jam agitur, attentius fuerit rimatus, facile perfpiciet, calorem \& ejus collectam vim, quæ ignis vocatur, nihil omnino aliud face. re, quam folida viva ad agendum invitare vel agentibus calcar addere, ficuti, \& quidem inverfa ratione, a. ctionem eorum minuit, quod huic e diametro oppofi. tum eft frigus; verum ambo, ille nimis urgendo, hoc nimis infringendo agendi poteftatem, earn usquequaque jugulare poffunt. Calor vero, quo corpori noftro opus eft, duplex obfervatur: Alter internus, vitæ fons vel faltem fomes cenfendus, intra corpus ignoto negotio paratur vel fovetur, gradu vix variat nifi in fuperficie \& extremis artubus, calore externo, exercitatione, aëre puro \& ftimulis quibuscumque egregie refocillatur, cer.; Externzs alter, immenfum quantum gradu differre poteft absque ullo detrimento, prout fcilicet calor internus victu, cultu vel motu fuerit fuftentatus. Hic vel materiæ, jam mi- 


\section{$\omega_{00}(10)$ (10)}

nus, jam quoque magis, illo imbut $x$, vel etiam ardentes, in ufus medicos varios vocantur, eo inprimis confilio ut promovearur folidorun actio. Qum vero cuti admovetur ignis, id primum gratum elt, deinde injucundum, tum acerbum, poftremo intolerabile. In loco autem quem adgreditur hac fere obfervantur: Primum rurget, nam majorem humorun copiam ad cutem adpellunt vafa incitara; deinde ruber, quoniam plus fangrinis rtibri, quem jam transmitunt vala minora fortius agentia, illuc defertur; porro epidermis in bullas furgit, quum major fluidi portio adveniat, quam quæ per cuticulæ oftia facile exfudare poreft; tum, \& quidem continuata uftione, a nimio ftimulo fenfim jugulantur folida; poftea omncs :las mutationes, quas materiam quamcumque mortuam ad. moto igne fubire notifimum eft, experiuntur, avolat nimirum aqua, confumitur pingve, nexus foivisur; tandem sihil nifi carbo vel crufta atra remaner. $H æ$ in parte adufta apparitiones, quarum jam plures jam pauciores, pro vehementia caloris \& duratione adplicationis adeffe, vix quod moneatur neceffe eft, evidenter adnodum 0 itendunt, igrnem eadem ratione qua omnes res irritanes, Coida viva tantummodo ftimulare, unde oritur infammatio, nec prius vim corpora quxcumque in particulas quibus efficiuntur folvendi exercere, quam fublata eft vis vitæ, qux ut nulli fere materiæe communis five mortuæ legi pareamus, fola efficir \& adverfus injurias optimum priefictum eft. Præter vero hæc quæ in loco adufto fiunt, fimul torum corpus adficitur, idque eo gravius, quo major vel diuturnior fuerit uftio, eague, qua fimulum quendam corpori moleftiam adtuliffe indicant fymptomata in confpectum prodeunt.

Hecce effectuum ignis corpori admuti, qua nulla fimplicior, explicatio vehementer nobis arridet, nec illam, upote valde fundatam \& experientix atque fanæ 
rationi confentaneam, facile infirmabunt hi, qui, nulla o. mnino vite habita ratione, juxta leges Mechanicas, Phyficas \& Chemicas, varia illa, qua in corpore animali fe offerunt phrenomena, irrito tentamine explicare conantur.

§. IV.

Ex iis, quæ in fuperiori $\S$. de effeetu ignis corpori admoti propofuimus, liquidisfime conftare arbitramur, quibus in morbis commendandus fit atque utilis. Eum quoque Medicorum filii jam temporis varios in fines adhibent, quorum præcipui hi funt: I:mo, ut ftimulo fuo actionem folidorum inertium excitet vel torpentium inciter. Hine \& quidem ubi inertia reperiuntur folida, ut in paralyfi quacumque, valde prolunt aduftiones, is inprimis in locis, ubi ex capite vel medulla fpinali prodeune nervi parten adfectam adituri, inftituiæ. Eas fummo cum emolumenco in paralyfi artuum inferiorum adhibuic Cel. Рот \& in veficie Cel. Pouteau, ut alia exempla fatis frequentia taceamus. Unicum tamen adferre liceat. Eeftate anni praterlapfi acidulas Medevienfis adiit mulier quædam, quid valerent aque minerales ejus loci ad tollendem paralyfin lingur, qua laborabat, quæque, nifi valde fallimur, a febre mali moris ortum ducebar, tentatura. Aquam quidem per tcmpus forphi, verum quum hre nihil omnino proficeret, moyam pone fingulam aurem adplicari curavit Cel. Afresfor WÄhrn ejus Joci Medicus Experientiflimus, quo factum eft, ut aitero ab adutione die iterum loqui in. ciperet, tandemque liberrimum lingva ufum recuperaret. Aec vi fua irriandi minus valet ignis ad inciandam actionem folitorum torpentium. Hinc ad emendandam fuppurationem ulcerum maligniorum non parum juvat, quod jam pridem affeveravit Cel. FAvre \& experimen. tum in Nofocomio Academico nuperrime inftintum confirmavir. In oedemate guoque crum diuturniori, ubi $B \stackrel{2}{2}$ 


\section{\% (12)}

langvet abCorbentium vis, illam egregie incitant fimulanria quxcumque \& ignis caute adhibitus. Nec aliud magis ad rem facit, ut reforbeatur lympha inter ligamentorum laminas effufa in genum fungis \& illa inprimis fpecie, qure Anglis White Swelling audit, quam cauteria ab utroque la. tere genu admota. Etiam in iis tumoribus, qui in Pelte vel poft febres malignas metaftatice, ur dicitur, oriuntur, aduftione uti non alienum eft, quo fcilicet promoveatur fuppuratio lentius ingruens \& ne in gangrænam, quod facillime accidit, abeant. Id vero quantum ficri poteft cirislime eft faciendum, fin minus vel ferum vel fupervacuum id auxilium erit. Nec quoque uftiones in ca fpecie gangrænæ, quam febres peflimæ causfantur, prorfus inutiles facile judicabit, qui illam, ut quidem eft, a defeetu virium ortam exiftimaverit. z:do, ut vice perfungatur flimulorum quibus antea adfverum fuit corpus, qui vero jam caufa quadam fuerunt fublati. Hinc fi eruptiones quædam cutis, vel tumor extremi artus, atchritide laborantibus familiaris, vel ulcus vetuftum vel alius quidam morbus externus opinione citius difparterit \& gra ves inde ortæ fuerint turbæ, tum, nifi fuccesferint irritantia leniora, uftio fatis tuto atque valenter fir, vel in loco prius adfecto, vel qua commodifime fieri poteft. 3:tio, ut vi fua fimulanti fortiori tollat effectum ftimulorum debiliorum, qui dolores vel motus inordinatos mufculorum vel demum alias calamitates gignunt. Quomodo fiat hoc, quod quidem fieri nemo negabit, difficillimum eft dictu. Interim tamen huic ufui præ ceteris infervit ignis. In Rheumatifmo iraque \& prifertim illo qui chronicus dicitur \& fine febre eft, nec non in aliis ejusdem naturæ corporis affectionibus, ufus aduftionum vehementer laudatur \& præftantiffimus eft. Eas quoque in pulmonum morbis, fpafmis varii generis, capitis atque dentium doloribus, epilepfia, amentia vel, verbo, in omni infirmitatum genere, in quo dolo. 


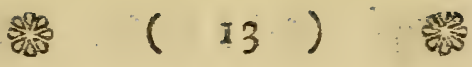

dolores vel motus inordinati vexant \& quos a fimulo quo. dam intus latenti ortos esfe adeft fufpicio, profuiffe, pasfim loquuntur Medicorum obfervationes. q:to, ut reprimantur carnes luxuriantes, ut citius decidant offum emor. tuorum particulæ, ut excitetur fuppustio tumores cyfticos devaftatura atque fanatura, cet., uftiones, antiquitus inprimis, fixpius fuerunt adhibitæ, quod quidem Chirurgorum cuique notisfimum eft. Jam temporis autem id auxilium iis, quæ leniora funt nec minus promta, poftponunt, qui Chirurgiam rationalem profitentur.

Hac de ufu ignis genuino dixife fuffaciat, quæ vero de vi ejus revellente, derivante, humores noxios allicien. te, roborante \& qua funt reliqua, antiquitus fabricatre etiamnum narrantur fabellæ, hæ noftra refutatione non indigent, easque tanquam incongruentes, obfcuras \& a fimplici illa atque plana, qua facultates medicamentorum atque agendi modum denoteri decet, adpellatione nimis alienas, ad Agyrtarum \& Empiricorum caftra volumus relegatas, his enim homunculis forfan expediet dietione intricata atque eruditionis fpeciem præ fe ferente vulgo bardo arque canora quæcumque avide inhianti fucum feciffe. Sic tandem evenier, quod tarde inceptum dolemus, ut Medicina, ab enormi illa locutionum truncarum farragine liberata, ex derifu emergat vigearque.

\section{§. V.}

EGRos ex Gangræna illa, quam in febribus mali moris interdum oriri \& cui ignem opponi polfe fupra monuimus, convaluisfe novum non eft aue inauditum, id quod natura vel per fe vel medicamentis fuffulta præftitit; moxa quoque parti adfectæ admota profuisfe vel fuppuratio falucaris polt ejus ufum orta effe paffim legitur. Ne vero quis facile credat huic femper fidendum effe, \& ut dilucidius adpareat quam vana evadat, quæ in illa ponitur fpes, nbi 


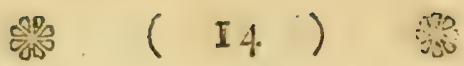

vires valde fraeta funt, Cafum quendam nobifcum Leri. gna communicatum adferre placet.

Franciscus Peauné, Vir Juvenis 25 Annorum, vilcere fatis ampio cruris finiftri laborans, d. ro Ottobris anni I $78+$ ir Wofocomium quod Lugduni Gallorum elt, defertur, curre Chirurgi tum temporis primarii Celeb. Desaussor commishus, qui, ulcere rite deligato, diata lauriori vinique generofions portiuncula fubinde fumet, viribus admodum fractis fuccurrere fuduit. Verum dis ab admis. fione f:to, qui 14 Octobris erat, febri Nosocomiali, putridam credunt, quac autumnali inprimis ternpore frequens tum grasfabatur, corripitur. Mox in lockm cubiculi, nam valde amplum eft, oftis oppofitum, uI purum magis fxpiusque renovatum hauriret aërem, translatus fuic; nec varia illa Varireque denominationis medicamina, yur ad compefcenda vel expellenda inquinamenta, quibus humores in his prafertim febribus laborare dicuntur, conducunt, uri mos eft illius gentis, in ufum vocare neglexit Chirurgus expertus. His atque ejusmodi aliis tempus terebatu, ingravefcente interim malo, eo funeftiorem exitum portendens, quo magisdecrefcebant vires, jam pridem fractx, nunc vero per liberiorem evacuantium ufum fere penitus confumer. Hec longum abfuic fumma debilitatis evidentius fignum. Quarto enim fe. bris die de dolore vehementiori cruris adficti queri incepit, quod \& infignitur turgidum lividumque erar levara. que deligatione ulcus, fi vel non prorfus ficcum, tamen parvam admodum faniei tenuioris copiam funders \& maculis nigrefcentibus undiquaque adfperfum adparmit. Fis jam rite penfitatis gangræin adventantis infautique eventus haud ambiguis ominibus, quominus ad corticem kinkina vinum. que confurerer, non amplius dubitavit Chirurgus laudatus nec irritantia illa calidaque, qux ut excietur inflammatio mortum a vivo feparatura apprime conveniunt topi$\mathrm{ca}$, cruri admovere \& refrigerata chm calidis mutare omifir. 


\section{然 ( 15$)$ 然}

Qum vero eo usque vim vitalem amiferant folida, ut vel Aimulum non fentirent, vel fi vel fentirent, inde robux non conciperent, nec interna illa nec externa medicamen. ta quidquam profuerunt, fed gangrana, febre ne ad minimum quidem imminuta, progredi perrexit, jamque feptimo febris die genu aliquantum fuperaverat, dum Moxam, cujus celebris eft in illo Nofocomio ufus, adhibere fecum conftiruit, co fcilicet confilio, ur folida fortiori ftimulo follicitata, tantam, quanta ad fuppurationem opus fuit, recuperarent agendi vim. Hinc cyindros a Goslypio contortos, tot nempe, quot ut totus ambitus femoris adureretur opus fuit, digiti transverfi a limite gangræna diftantia \& quidem parti fanæ admoveri accendique curavit. Verum etiam hac in inutionibus non temere pofita fpes evanuit, \& tantum abfuit, ut hæ corruprioni impedimenio esfent, ut potius ftimulo fuo, quem ferre non pomerunt folida infrma, reliquum vitæ exringverent arque adeo progreffui gangrenæ calcar adderent. Nec profperior fuit fuccefus inuftionum, quæ altero die paullo. que altius irrito conamine fuerunt inftiture, nam nec ha, nec medicamenta illa fimulantia atque roborantia, Coricem puta \& vinum, quæ copia fatis grandi fumebantur, vin vitæ fopitam \& fere extinctam excitare valuerunt, fed decimo febris die, quo jam ingvem fere attigerat gangræna, in noctem vergente moriebatur mifer, prægres= fis omnibus, qux mortem non dubio omine præfagiunt fignis. 



\section{融 \\ A P P E $\left.N D D I X^{*}\right)$}

Gangranam in varias easque multiplices fpecies, pro diverfiate causo fartum, difpefcere operæ pretium duxere Scriptores Medici, inde utilitatem quandam in Praxin redundaturam fibi perfvadentes. An ex voto fuccesferit labor ifte, nec probe fcimus, nec fi vel fciremus, profiteri e re ducimus; interim tamen fimplex magis, nec, uti quidem nobis videtur, minus congruens fefe offert Gangrxnæ divifio, quam Praxi adcommodatiorem fine duhio invenient etian hi, guibus forfitan difplicehit novitas rei. Omnium primo monere convenit, quod Gangræna nihil aliud fis quam ejusmodi partis cujusdam ftatus in quo, fufpenfa vel abolita folidorum vita, vel, ut alii loquantur, nervofi illius faris ignoti liquidi fecretione atque vi, circumvehi ibidem nequeunt humores, unde tann illa quarn hi, ad leges materix mortux jamjam reverfuri aut jamjam reverfi, mutationes chemicas experiuntu: five in patredinem fenfm abeunt, idque tanto citius, quanto major materiz animalifaræ, fit venia verbo, ineft ad hanc proclivitas. Ejusmodi vero partis cujusdam fatus vario modo inducitur: I:mo Ex eo, quod humorum ad partem quandam aditus vel ex illa reditus vafortum ligatura, comprestione, ruptura vel alio quodam modo fint intercepti. Hujus Gangrænæe exemplo fit illa, qux poft operationem Anevrismatis \& inprinis Arteria Poplitex interdum oritur. 2:太o Ex eo, quod ipfa vits fons iive officina aut quæe ex illa prodemnt propagines infigniores causfa quadam, externa fit vel interna, ita ladantus, ut munere fuo, quod in ciendis motibus quos necesfarios judicaverit anima $\&$ hanc rerum extra le pofitarum confciam reddendo confiftit, vei prorfus non vel non fatis perfungi queant. Hinc adfectiones animæ \& illx inprimis qux, deprimune, læfiones medullæ fpinalis, nervorum majorum presfus, lacerationes, ahfifiones, cet, Gangrana ortun dedisfe obfervatum eft. 3:tio $\mathrm{Er}$ eo, quod vires torius corporis adeo fint fracte, ut circumngi requeant humores, unde etium in extremis artubus, ubi tan vis a tergo minor eft, quam vafa debiliora, omnium frequentifime obfervatur, quæ ab hac causfa oritur, Gangrxns. Hujus autem dux Species funt; oltera lentius incedit, ito nempe, ut primum venæ, deinde arterix, tum abforbentia loci remotisfini vita priventur, q̨uo fit ut, abforprione poft ces: fantem adpofitionem durante, exarefcat pars adfeeta. Sicca vocatur Gangrana hacce, quiz in fenibus pralertion \& in is, qui fub annon: carita-

te

*) Q:tum tempus simis feftinavet, qua fequnutur in Differtatinue ipfa omittere fumus concti, ne vero onnaino defiderarentur a appendicis forma addere consultum duximus. 
ic incongruenti vel, quod idem fere eft, parum nutrienti cibo aluntur, obvia elt; cirationi gradu fertur altern, tum enim folida fimul, atque uno quali icru, vita orbari videntur, forfan ob nervos a contagii vi vehemen. rer lacesfitos. Hujus nature credimus Gangrenam qur extremitates, prxferiun inferiores, fub decurfu febris mali moris interdum adgreditur. Tum sutem non femper in illo partis loco qui remoriffinus eft, verum in illo qui morbo quodam vel alis quademumcumque ratione antea ceteris debilior factus eft, ut ex cofu allato videri poseft, incipit. 4:to Ex eo, quod lolida jam dudum valde labefis cara a fimulo vel etiam minimo quod fupereft vitæ amitrant. Huic coufre adribuimus Gangrænam, que in Scorbuticis atque Cachecticis, quos lene valere perperam dicunt, a levislima vulneratione, quxque in his, qui febre, vel alio merbo graviori laborans poft diuturniorem in dorfo decubitum fuper nares vel os facrum oritur. 5:to Ex. eo, qund, antebac falva vegetaque, folidortm organifario vehementiori ftimulo vel vi quadam prorlus deftrustur, quod quidem ec focilius fit quo fitu vel conformatione fuerint debiliora. Hoc modo oritur gangrxna in combuftionibus, pernionibus, contufionibus, hernia incarcerata, cet。

Hzc divifio Praxi ut qux maxime adcommodara videtur \& indicatio. nes curatoriz, uti quidem femper dum a causfis proximis proceditur, quafi sna fponte fe offerunt. Primum atque Sectunlum genus vix curam admittuft, nifi compresfio in causfa fuerit, qure turn fubito tollenda eff. Nec alienum erit fomentationiłns lenioribus uti, ut ad reforbendum id giuod effufum eft inftigenur vala; forfan etiom proderunt cucurbirula cruentr parti admore, inprimis f recentior cofus fuerit. Verum in illo Gangranx genere quod tertio loco pofuimus \& quidem in prima ejus Specie, quæ lentius procedit \& in qua adhuc vigent abforhantin, cibi pleniores \& potiones fpirituof $x$ conveniunt, quo fimul ea Medicanenta qua actionem languentem incitare valent, Opium, puta, Vinum atgue Corticem Peruviaıum, copiolius danda, nec parti adfeeta en Medicamina quæ calore atque oleo quodam effentiali ftimulant fuperimponere omittendum; in fecun. do vern Specie, in qua finguli vaforum ordines fimul torpere inveniunfur \& fucci gaftrici fecretio deficit, minus idoneum eft cibos dare, nam hos agre concoquerer ventriculus, unde, \& quidem haud absque damno, coacefcerent vel computrefcerent, verum es Aimulantia, qua in priori Specie commendavimus, valde profimt, fimul qunque en quæ ad curan aem febrem prafcribuntur probe obfervanda funt, nec folfitan abs re erit folidis partis adfecte calcar addere, quo eam concipiant agendi vin, qux ur exciterur atque foreatur inflammatio mortum a vivo feporaturo efficiet, qnod quidem fomentationibus calidis atque irritantibus, vel exinm sduftioue, outime peragitur. In gunso genere abomni injura externa pro- 


\section{龆}

be cavendum, valetudini totius corporis cibo inprimis, nam porum juvant medicamenta, eoque optimi fucci, ä̈re ficco arque puriffimo, exercitatione modica, cet. confulendum, vel $f i$ febris quoque fuerit, tæe per ens rationes, quas proponunt leges artis, fuhmovendo eft \& portes jarr adffetre idoneis cataplafmatibus deligandx, ut fcilicet tollatur gangræna imminens vel fuppuratinne evellatur mostuum. Verum in quinto, rotione huic prorfus contraria curam fufcipere convenit. Nam quum in illo vigorem fuum, illsfum retineant folida, imminuenda potius eft, quam promovenda, inflammatio qua tam a violentio quam a ftimulo partis emortux oriretur, quod vena feetione, laxantibus atque potionibus acidulis fatis commode fir. Omnia vero irritantia, tam externa, quam inprimis interna, probe fugienda, nec aliud quam quod leniter emollit parti, quam gangræna minatur vel corripuit, fuperimponendum.

Quod vero inflammatio quo vehementior en rarius in Gangrænam abeat tanto minus erit mirum, quum fummo folidorum vigore opus fit ut exciretur infanmatio ncutior, ejusmodi vero folidorum, natus illi, quem Gangranæ opportunum diximus, e diametro oppofitus eft. Nec utique explicarn difficilius eft, cur interdun a leviffima causfa, vel mox, vel prrsgresfa inflammatione qualicumque, adveniat gangræna, nam tum debilis aden evofit folidorum virtus, ut ftimulos, qui alio vel vegeriori obtinente corpotis habitu, infammationem five majorem actionem exciraret, jam omnem agendi vim tollat, eaden fere ratione qua chorda, cui refiliendi poteftas ineft, hac falva a vi admora in fortiorem morum cietur, illa vero imminuta vel fublata ab endem vi rumpitur. Qne cum ita fint, non poffumus, quin omni cansfarum gangranæ explicationi ab humorum quodam vitio petitæ, ut nullo argumento firmatæ, rep̧ulfam demus; *3

nee

*) Qunm comperqum babecmus genuinan $\tau$ yु bumores fignificationem non omnibus Jatis cognitom elfe, forfan expediez declarnlfe, qund nos do optimi quique vocahulo illo huмores eos znntzmmodo fuccos nutricios ntque reliqgis pnrtihus homogeneos, qui a folidis vivis intro corpus circunferuntur, neutigunm vero fimul illos, qui fecreti vel excreti vel effufi vel nlio quodemumcsmsque modo extra vita circulum pofiti ad linne non amplins refpiciunt, como plestanur. Hi estim, endem ratione qua alice res exierne vario niodo morbis anfam dare polfunt. Heic quoque loci smoneri oportet, quod per нuмoruna MORBOS, nAn ipfnm humorum mutatam conditionem, verum morbos quos ex illa proficifci crediderunt, inzellexerint ejus Theoria Auctores. Oum vero contra bumorum morbos, confentientibus yotione ntque experientia, pugnamas, id non its explicatum volumus ac fi omnem bumnrum snutationem plante ries gnremws, guod guidem nsmo contra onnem probshilitntem temere facies. We- 
anc nobis valde piacet illud Sydenhamo atque alis familiare lequendi genus, quo Febrem conamen naturx noxium expellendi dicunt, nan fi vel noxium adeffet, quod quidem admotum fuisfe quam adefe libentius concedimus, tamen que jude in functionibus nriuntur mutationes vi legis cujusdam initæ funt, nec eas conamen appallare Philnlophi eft aut magis congruens, ac of fermentationem \& lapfun lapidis conamina notura, in illa sërem fixtsın emittendi, in hoc vero centrum petendt, dicercs. Cumnes quoque ittr locutiones, qux atu nullam aut non faris claram habent f1. gnificationem, in Scientiis Prgeticis fummo ftudic fuçiendx funt.

Verum huic argumento diutius infiftere vetat, qu:e visium, tempoxis atque impenfarum prudentisfimo cuique habenda ef́, ratio. Si vero tevisfuna hacse, qua fatis incomra effe ingenue fatemur, non protus dis. plicuerint, forfan olim erit ut opfortuniorern nancifcamtil occafiunem o. piniones noftras fufus explicandi atque arçumentis majoris thomenti fir. mandi. Iu inrerim, B. L., hac accipito \& nns xqui bonique conlulito.

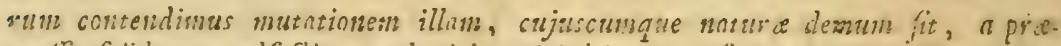
orelf. folidorum adfectione vel vitio orivi do non uifi per ens rationes, ciuce

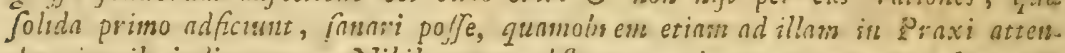
dere inutils judicamus. Nibil tamen obfot, quominus nos quaque vebeanentes Acrinonurum extituemus defenfores, nifi quod ne ullo quidem toleralibli

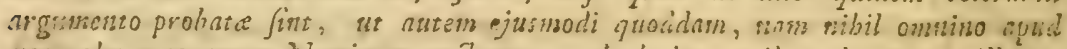

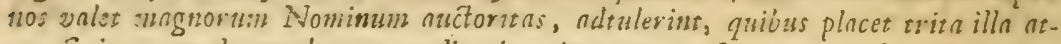
que fatis commoda norborum explicaito, in eorum cnftra, qui stobis eft candor stque veri itadium, trois ibimus latibs

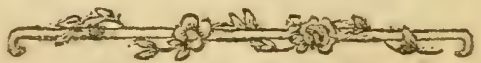


$\checkmark$ 
1 

Thunberg, Karl Pete/[Dissertationes Acad

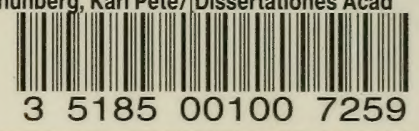


